\title{
Las Competencias
}

y su relación con ......

\section{La Eestión}

La Investigación

La Decencia

El Desanplle lirefiesional

Coordinadores

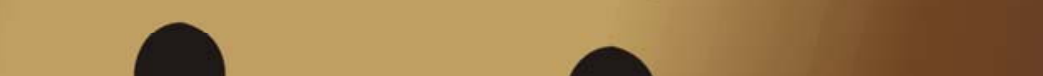

Adla Jaik Dipp

Sergio Gerardo Malaga Villegas 


\title{
LAS COMPETENCIAS Y SU RELACIÓN CON.....
}

\author{
La Gestión \\ La Investigación \\ La Docencia
}

El Desarmollo Protesional

\author{
Adla Jaik Dipp \\ INSTITUTO POLITÉCNICO NACIONAL CIIDIR DURANGO \\ INSTITUTO UNIVERSITARIO ANGLO ESPAÑOL \\ ReDIE
}

Sergio Gerardo Malaga Villegas

UNIVERSIDAD PEDAGÓGICA VERACRUZANA

ReDIE 
Primera edición mayo de 2014

Editado en México

ISBN: 978-607-9063-22-1

Editor: Red Durango de Investigadores Educativos A. C.

Coeditores: Instituto Politécnico Nacional CIIDIR Durango Instituto Universitario Anglo Español

Este libro no puede ser impreso, ni reproducido total o parcialmente por ningún otro medio sin la autorización por escrito de los editores

Diseño de Portada: M. C. Roberto Villanueva Gutiérrez 


\section{PRÓLOGO}

Actualmente las competencias siguen siendo un término polémico a nivel mundial; hay varias formas de concebirlas, desde versiones reduccionistas y conductistas hasta concepciones constructivistas y humanísticas. Esta situación provoca el atractivo de escribir y leer sobre esta temática.

Por otro lado, la globalización genera fuerte influencia en las políticas educativas de los países por parte de organismos internacionales como la Organización de las Naciones Unidas para la Educación, la Ciencia y la Cultura (UNESCO por sus siglas en inglés), la Organización para la Cooperación y el Desarrollo Económico (OCDE) y el Banco Mundial, donde se menciona el desarrollo de competencias en los estudiantes como elemento imprescindible. A nivel nacional, como ejemplo, está la Dirección General de Educación Superior Tecnológica de la Secretaría de Educación Pública, donde enuncia su "Modelo Educativo para el siglo XXI: Formación y Desarrollo de Competencias Profesionales". En el modelo educativo de la educación media superior de México se menciona que "Nuestra tarea común es asegurar que existan las condiciones y los ambientes para que todos los alumnos desarrollen las competencias para la vida y el trabajo que demanda el entorno contemporáneo."

De esta forma, independientemente de las concepciones que se construyan sobre el término competencias, es un hecho ineludible el uso de este constructo en la educación, en cualquiera de las dimensiones de estudio del sistema educativo, que giran en torno a las políticas educativas, la gestión institucional, los modelos educativos y académicos, la docencia, la investigación y la difusión.

Así, el presente libro no deja pasar de lado la necesidad de difundir investigaciones y reflexiones en torno a las competencias en el ámbito educativo. En este tomo se suman investigadores de diversas instituciones, donde, de forma certera, los Coordinadores de la obra, Dra. Adla Jaik Dipp y M. E. Sergio Gerardo Malaga Villegas, han incluido cuatro ejes temáticos en los que inciden las competencias, a saber, Gestión, Docencia, Investigación y Desarrollo Profesional. 
El tratado inicia con un autor invitado, Horacio Ademar Ferreyra, quien expresa su postura en relación a las competencias en el nivel básico, bajo su trabajo titulado: "Capacidades prioritarias en la educación general básica", donde discute sobre el desarrollo y adquisición de un listado de capacidades imprescindibles que deberán de desarrollar los estudiantes del nivel básico, las cuales se pueden reagrupar en: lectura y escritura, resolución de problemas, trabajo con otros y pensamiento crítico.

En la dimensión de la gestión se incluye la investigación "Medida de gestión directiva para educación media superior" de José Ángel Vera Noriega, Luis Enrique Fierros Dávila y Martha Olivia Peña Ramos, quienes indagan acerca de las características psicométricas para evaluar la gestión directiva de instituciones del nivel medio superior de estado de Sonora. Para lo cual elaboran un cuestionario que se agrupa en varias áreas: Comunicación efectiva y habilidades interpersonales, Condiciones de trabajo y clima organizacional, Gestión y planeación directiva y enfoque en el cliente. El instrumento se aplicó a una muestra de doscientos sesenta y cinco directivos de educación media superior. Entre los resultados sobresalientes se observa que, en general, los directivos no determinan la elección de profesores, actividades curriculares, presupuesto o infraestructura, sino que lo determina la oficina central del Estado; en este marco de condiciones los directores perciben que no existen condiciones óptimas para llevar a cabo un modelo de enseñanza basado en competencias

En la misma dimensión de la gestión, Esperanza Lozoya Meza, lleva a cabo un estudio denominado: "Las competencias genéricas: un modelo de gestión educativa para formar docentes-investigadores con enfoque humanista", donde la autora expone una serie rica en elementos que intervienen en el enfoque humanístico para la gestión educativa por competencias, con lo cual se generan lineamientos para implementar competencias genéricas en el ambiente educativo.

La investigación como dimensión institucional, en la presente obra tiene un peso importante, ya que es la que cuenta con más investigaciones en este tratado, las cuales inciden tanto en la identificación de posicionamientos sobre las competencias, como en la preocupación por el desarrollo de competencias investigativas en estudiantes de posgrado.

La revisión bibliográfica investigativa que realiza Sergio Gerardo Malaga Villegas, titulada "Las competencias: corpus de conocimiento, debates y significaciones", le permite identificar un cuerpo de conocimientos que integra distintos debates y posicionamientos acerca de las competencias. El análisis lo establece a partir de las investigaciones que sobre competencias son reportadas en los estados del conocimiento 1992-2002, del Consejo Mexicano de Investigación 
Educativa (COMIE) y los libros editados por la Red Durango de Investigadores Educativos A. C. (REDIE), entre los resultados más importante destaca que las competencias tienden a significarse en procesos operativos para el logro de finalidades pedagógicas, epistemológicas y axiológicas en la praxis del ser humano, específicamente en espacios escolarizados de formación.

En referencia al desarrollo de competencias investigativas, uno de los trabajos presentados es el titulado "Competencias investigativas en maestrantes en docencia universitaria desde su cosmovisión contextual" de Magaly Amarista, quien identifica cuáles son las competencias investigativas que debe desarrollar el estudiante de posgrado para realizar su trabajo de tesis. Encontrándose que, durante el desarrollo del trabajo, se puso en evidencia que presentan deficiencias, sobre todo para el análisis, redacción y producción escrita, habilidades consideradas de gran relevancia en la elaboración del trabajo de investigación. Asimismo, se identifica la necesidad del apoyo por parte del profesor, asesor o tutor, como guía del proceso investigativo del estudiante.

En la misma dirección se localiza la investigación de Adla Jaik Dipp, titulada "Desarrollo de competencias investigativas en dos grupos de posgrado en educación", donde indaga acerca del nivel de dominio de las competencias investigativas que desarrollan los alumnos de dos posgrados en educación, un grupo de maestría y otro de doctorado. A ambos grupos, durante un año se les aplica, al inicio a mediados y al final de los cursos, un instrumento compuesto por sesenta y un preguntas que se distribuyen en cinco ejes de análisis, de acuerdo al desarrollo de las investigaciones: Planteamiento del Problema, Marco teórico, Marco metodológico, Resultados, Competencias Genéricas. Entre los resultados relevantes se menciona que los alumnos se perciben con un nivel medio de dominio de las competencias investigativas. En relación al número de aplicación, la tercera aplicación del instrumento se ve más favorecida, marcando diferencias significativas en todas las dimensiones, salvo en la denominada Resultados.

Argelia Hernández Cortés en su investigación denominada "Procesos de formación para la escritura de un texto: competencias y estrategias", pretende mostrar cómo son adquiridas las competencias para la construcción de un escrito y la difusión del mismo. Esta actividad la realiza a través de entrevistas a cinco académicos que han publicado diferentes escritos, ya sea en forma física o electrónica. Para el estudio se incluyen tres ejes de análisis: Perfil sociocultural, Cultura académica y Proyecto de vida. Respecto al perfil sociocultural, se identifica que la técnica para escribir es personal, así como las competencias con que cuentan para realizar un escrito. En relación a la cultura académica, se observa que la formación académica sí determina 
la forma de escribir. El proyecto de vida se concreta a identificar qué persiguen al seguir escribiendo.

Para el desarrollo de competencias investigativas Angélica Quiroga Garza, con su trabajo denominado "Vínculo solidario: aprendizaje-servicio y competencia investigativa en estudiantes de psicología", verifica la pertinencia de incorporar el enfoque aprendizaje-servicio, encontrando que, con la implementación de la propuesta, se muestran buenos resultados en primera instancia. Sin embargo, la autora menciona que se pretende continuar mejorando el modelo a manera de garantizar una formación integral con impacto tanto en el beneficio social inmediato como en el desarrollo de los diversos componentes de la competencia investigativa de los estudiantes que, sin duda, permeará su actuar académico, profesional y personal.

En relación a la dimensión de la docencia se insertan cuatro estudios, dos de ellos dedicados al ambiente de aprendizaje, la evaluación y una estrategia de enseñanza, los otros dos enfocados a la formación de docentes.

El trabajo de Ma. de los Ángeles Huerta Alvarado, "La enseñanza, el aprendizaje y la evaluación de competencias en el aula", es un escrito en donde se discute la forma en que se puede entender la enseñanza, el aprendizaje y la evaluación de las competencias académicas en el ámbito escolar. A partir de la discusión se concluye que tomar la decisión de realizar el trabajo educativo basado en competencias supone adquirir un compromiso del centro escolar que permita abordar la complejidad de adoptar ciertas medidas organizativas y funcionales, imprescindibles para su desarrollo.

Mientras que el estudio titulado "El trabajo centrado en el estudiante como medio para desarrollar competencias matemáticas" de Luz María Gómez Ávila y Juan Manuel Juárez Velázquez, es un estudio que llevan a cabo con cien estudiantes, donde la mitad de ellos toman clases de forma tradicional y a la otra mitad se les adicionan clases extra que tienen que ver con trabajo centrado en el estudiante. El propósito es que los estudiantes desarrollen las competencias matemáticas de comunicación, matematización, representación, razonamiento y argumento, pensamiento estratégico, y uso de lenguaje simbólico y operaciones. Concluyéndose que los estudiantes se desempeñan mejor si se les brindan cantidades adecuadas de tiempo y trabajo, para desarrollar las competencias requeridas.

En relación a los docentes, José Antonio Fernández Lozano, en su estudio "La formación docente en el enfoque por competencias en la educación básica", realiza una entrevista de tipo no estructurada, abierta, dirigida al director de la institución en estudio, para indagar acerca de las 
siguientes interrogantes: ¿Cómo saber si la política educativa es la correcta? ¿Cómo saber si la propuesta de reforma es correcta? ¿Cuál será la propuesta de reforma a la Escuela Normal? EI proceso se lleva a cabo a través de un análisis FODA (fortalezas, oportunidades, debilidades y amenazas), encontrando la necesidad urgente de innovar en los procesos de la práctica educativa, a través de la modificación curricular. Asimismo, identifica que, para cubrir el perfil de egreso del estudiante normalista, ante un nuevo plan de estudios para la educación básica enfocado a la formación por competencias, se debe buscar la capacitación y la actualización permanente.

Por su parte, Edith J. Cisneros-Cohernour, Yazbeth Alejandra López Mézquita y Pedro J. Canto Herrera, llevan a cabo un estudio denominado "Las competencias y su relación con el docente de matemáticas de secundaria" donde pretenden determinar si existen diferencias significativas entre las competencias de los docentes participantes antes y después de tomar un programa de actualización en relación con sus años de experiencia docente. Participaron en el estudio quince profesores de matemáticas de secundaria y se menciona que la recolección de datos involucró observaciones, auto-evaluación docente y pruebas de dominio de contenido. Los resultados arrojan que sí existe diferencia significativa en las competencias de los docentes antes y después de participar en el programa. Sin embargo, no se encontraron diferencias significativas en los puntajes de los docentes en relación con sus años de experiencia docente.

El área correspondiente a las competencias y su relación con el desarrollo profesional, en la obra cobra importancia relevante en cuanto a la formación técnica y profesional, ya que del ámbito empresarial es de donde surge el concepto de competencia.

La investigación de Luis Fernando Hernández Jácquez, titulada "El nivel de desempeño de competencias profesionales en relación con la autoeficacia", pretende describir el nivel de autoeficacia presente en los estudiantes, el nivel de desempeño que han alcanzado respecto a las competencias profesionales definidas en el currículo e indagar acerca de la relación entre ambas variables. Entendida la autoeficacia como los juicios que cada individuo hace acerca de sus capacidades para llevar a cabo una tarea, en el estudio se encontró que la autoeficacia académica percibida por los estudiantes es media, lo que significa que en lo general no muestran una gran seguridad para poder desempeñar sus labores académicas, sin embargo, el nivel de desempeño alcanzado por la mayoría de los estudiantes es notable. Por otro lado, entre mayor es el nivel de autoeficacia percibida, mayor es el nivel de desempeño alcanzado de la competencia. 
María Elena Martínez Tapia en su investigación denominada "Competencias de desarrollo profesional en los cursos de salud comunitaria", indaga acerca de si el método aprendizajeservicio, permite el desarrollo de los siguientes elementos de desarrollo personal: actitud ante nuevas experiencias, actitud ante el cambio, confianza para asumir riesgos, actitud ante la autoridad. La actividad se lleva a cabo durante los cursos de salud comunitaria en el primer y segundo semestre de la carrera de medicina, observando que el método propuesto favorece el desarrollo de los elementos de desarrollo personal en los estudiantes.

"Autoconocimiento y elemento de calidad en la educación superior: estudios de egresados" de Judith Francisca Silvia Avelino Huerta, José Gaspar Rodolfo Cortés Riveroll y Jaime Meneses Guerra, es un trabajo que tiene como objetivo saber cómo se realiza la inserción laboral de los egresados de la Facultad de Medicina de la Benemérita Universidad Autónoma de Puebla. A partir de las respuestas de egresados, se identifican los problemas que están enfrentando al insertarse al mercado laboral, lo que conduce a un análisis de pertinencia del programa educativo de medicina, que permita implementar estrategias para mejorar la formación integral de los estudiantes. Asimismo, se identifica la satisfacción que tiene los egresados sobre su formación y la institución que los formó.

Dra. Patricia Camarena Gallardo Profesora e investigadora del Instituto Politécnico Nacional, México 


\section{CONTENIDO}

INTRODUCCIÓN

Sergio Gerardo Malaga Villegas

AUTOR INVITADO

CAPACIDADES PRIORITARIAS EN LA EDUCACIÓN GENERAL BÁSICA.

Horacio Ademar Ferreyra

UNA MIRADA A LAS COMPETENCIAS

Capitulo 1

16

LAS COMPETENCIAS: CORPUS DE CONOCIMIENTO, DEBATES Y SIGNIFICACIONES

Sergio Gerardo Malaga Villegas

\section{LAS COMPETENCIAS Y SU RELACIÓN CON LA GESTIÓN}

Capitulo 243

LAS COMPETENCIAS GENÉRICAS: UN MODELO DE GESTIÓN EDUCATIVA PARA FORMAR

DOCENTES-INVESTIGADORES CON ENFOQUE HUMANISTA

Esperanza Lozoya Meza

MEDIDA DE GESTIÓN DIRECTIVA PARA EDUCACIÓN MEDIA SUPERIOR

Capitulo 3

72

José Ángel Vera Noriega

Luis Enrique Fierros Dávila

Martha Olivia Peña Ramos

\section{LAS COMPETENCIAS Y SU RELACIÓN CON LA INVESTIGACIÓN}

Capitulo 492

COMPETENCIAS INVESTIGATIVAS EN MAESTRANTES EN DOCENCIA UNIVERSITARIA DESDE

SU COSMOVISIÓN CONTEXTUAL

Magaly Amarista

Capitulo 5120

VÍNCULO SOLIDARIO: APRENDIZAJE-SERVICIO Y COMPETENCIA INVESTIGATIVA EN

ESTUDIANTES DE PSICOLOGÍA

Angélica Quiroga Garza

Capitulo 6144

PROCESOS DE FORMACIÓN PARA LA ESCRITURA DE UN TEXTO:

COMPETENCIAS Y ESTRATEGIAS

Argelia Hernández Cortés

Capitulo 7169

DESARROLLO DE COMPETENCIAS INVESTIGATIVAS EN DOS GRUPOS DE POSGRADO EN EDUCACIÓN

Adla Jaik Dipp 


\section{LAS COMPETENCIAS Y SU RELACIÓN CON LA DOCENCIA}

Capitulo 8197

LA ENSEÑANZA, EL APRENDIZAJE Y LA EVALUACIÓN DE COMPETENCIAS EN EL AULA

Ma. de los Ángeles Huerta Alvarado

Capitulo 9231

EL TRABAJO CENTRADO EN EL ESTUDIANTE COMO MEDIO PARA DESARROLLAR

COMPETENCIAS MATEMÁTICAS

Luz María Gómez Ávila

Juan Manuel Juárez Velázquez

Capitulo $10 \quad 257$

LA FORMACIÓN DOCENTE EN EL ENFOQUE POR COMPETENCIAS EN LA EDUCACIÓN

BÁSICA

José Antonio Fernández Lozano

Capitulo 11282

LAS COMPETENCIAS Y SU RELACIÓN CON EL DOCENTE DE MATEMÁTICAS DE SECUNDARIA

Edith J. Cisneros-Cohernour

Yazbeth Alejandra López Mézquita

Pedro J. Canto Herrera

\section{LAS COMPETENCIAS Y SU RELACIÓN CON EL DESARROLLO PROFESIONAL}

Capitulo 12306

EL NIVEL DE DESEMPEÑO DE COMPETENCIAS PROFESIONALES EN RELACIÓN CON LA

AUTOEFICACIA

Luis Fernando Hernández Jácquez

Capitulo 13

328

COMPETENCIAS DE DESARROLLO PROFESIONAL EN LOS CURSOS DE SALUD COMUNITARIA María Elena Martínez Tapia

Capitulo $14 \quad 345$

ESTUDIOS DE EGRESADOS: ESTRATEGIA DE MEJORA A LA CALIDAD DE LA EDUCACIÓN SUPERIOR

Judith Francisca Silvia Avelino Huerta

José Gaspar Rodolfo Cortés Riveroll

Jaime Meneses Guerra.

ACERCA DE LOS COORDINADORES

VALUADORES DE LAS PROPUESTAS 


\section{INTRODUCCIÓN}

La Red Durango de Investigadores Educativos (ReDIE) tiene entre sus objetivos difundir la investigación, atendiendo a los principios de multidisciplinariedad e inclusión en distintas áreas y niveles educativos. Uno de sus programas editoriales, ya institucionalizado, alude a la publicación electrónica de dos libros al año, coordinados por miembros de la Red e integrados a partir de la emisión de convocatorias a la comunidad de investigadores nacionales e internacionales.

El primer libro electrónico que surgió de este Programa editorial lleva por título Competencias y Educación. Miradas múltiples de una relación, dicho material, coordinado por la Dra. Adla Jaik Dipp y el Dr. Arturo Barraza Macías, tenía por finalidad integrar diversas conceptualizaciones, niveles de concreción, desarrollos, estrategias y elementos necesarios que abrieran el debate y la reflexión profunda respecto a las comunicaciones en el área de competencias.

Lo nuevo, como categoría social, representa una forma de mirar, repensar, analizar y criticar lo ya dado aristotélicamente hablando; en tal sentido, como enfoque relativamente reciente en las políticas educativas latinoamericanas, las competencias se erigen como una nueva posibilidad de formar a los individuos que se encuentran inmersos en el ámbito educativo formal.

Así, después de tres años de ese primer ejercicio, se decide convocar nuevamente el tema de competencias; dado el resultado de la dictaminación de los artículos, esta obra se intitula Las competencias y su relación con la Gestión, la Investigación, la Docencia y el Desarrollo profesional.

La decisión de enunciar los campos en los que el concepto competencias se disemina, responde precisamente a que se trata de un concepto que tiene constantes rejuegos, con una capacidad específica de sustentabilidad que le permite anidarse y proliferar de forma policromática. 
De ahí que emerjan condiciones de posibilidad para pensar en otra categoría social con la que implícitamente se topará el lector a lo largo del libro, me refiero a la de relación. Dicha categoría no es pensada como algo vertical que responde a una sola dirección, finalidad y propósito; por el contrario, los aportes que aquí se integran, son trastocados desde enfoques teóricos, convencionales e innovadores pero con matices que resultan de la formación de los investigadores, sus intereses y los resultados mismos.

En tal sentido la multiplicidad de miradas representa, en este nuevo libro, una propiedad multicultural que hace posible que las aportaciones, metodologías, análisis y conclusiones de cada autor, aporten referentes situados.

En suma, este material al que se allegan, proporciona elementos para que los lectores fortalezcan, construyan, reconstruyan y deconstruyan aquellos conocimientos que poseen acerca de las competencias.

Es importante destacar que estas experiencias de investigación respecto a dicho enfoque son precisamente eso, en ningún momento tienen la pretensión de universalizar el campo de las competencias; son ante todo, una expresión del quehacer de los investigadores, siempre con sentido ético.

Sergio Gerardo Malaga Villegas

Profesor del área de posgrado Universidad Pedagógica Veracruzana. 


\title{
CAPACIDADES PRIORITARIAS EN LA EDUCACIÓN GENERAL BÁSICA
}

\section{PRIORITY CAPACITIES IN GENERAL BASIC EDUCATION}

\author{
Horacio Ademar Ferreyra \\ Universidad Católica de Córdoba - Facultad de Educación y Unidad Asociada / CONICET / \\ Universidad Nacional de Villa María de Argentina \\ hferreyra@coopmorteros.com.ar
}

\section{Resumen}

En el presente texto se presenta el abordaje del tema del desarrollo y adquisición de las capacidades en el marco de las competencias - en la educación general básica en la República Argentina - en el contexto no americano en las últimas décadas de transformación poniendo énfasis en el siglo XXI. Se identifican aquellas capacidades que se consideran imprescindibles y que la escuela no puede dejar de abordar en estos tiempos, como son las vinculadas a la oralidad, lectura y escritura, resolución de problemas, trabajo con otros y pensamiento crítico desde las distintas asignaturas, materias o espacios curriculares para mejorar los aprendizajes.

Palabras claves: curriculum, aprendizajes, capacidades, capacidades prioritarias.

\begin{abstract}
In the present text the approach to the topic of development and acquisition of capacities within the framework of competences - in general basic education in the Argentine Republic in the Latin-American context during the last decades of transformation with the emphasis on XXI Century is presented. Those capacities that are considered indispensable, and that the school must deal with, such as speaking, reading and writing, problem solving, peer work and critical thinking are identified in each subject to improve learning.
\end{abstract}

Key words: curriculum, learning, capacities, priority capacities.

\section{Introducción}

La década de los años '90 acarreó un conjunto de modificaciones sobre el propio Estado argentino. Entre ellas, puede subrayarse un debilitamiento de su responsabilidad para garantizar los derechos educativos de los ciudadanos, al mismo tiempo que se generan reformas y transformaciones educativas estructurales en casi 
todas las jurisdicciones. En el territorio latinoamericano, la descentralización educativa aparece como una de las estrategias que más eco ha tenido, si lo que se tiene en cuenta es la cantidad de países que la implementaron (por ejemplo, Argentina, Bolivia, Brasil, Chile, Perú, Colombia, México, El Salvador y Nicaragua, entre otros), siempre con la promesa de mejorar la calidad (eficiencia, eficacia, pertinencia, relevancia, equidad e impacto) de la educación. Sin embargo, estas promesas permanecen parcialmente cumplidas o aún inconclusas.

La referida descentralización acentuó aún más la desintegración y fragmentación socioeducativa de todos los niveles (Educación Inicial, Primaria y Secundaria) en las distintas provincias, generando marcadas divergencias entre ellas y también en el interior de cada una de las jurisdicciones, percibiéndose en algunos casos efectos de índole regresiva en relación con la retención de la matrícula y la calidad de los aprendizajes y la enseñanza. El escenario queda entonces signado por un sistema que presenta una gran disparidad en la oferta educativa de las diferentes jurisdicciones, características y prácticas diversas, como así también la convivencia de diversos modelos institucionales.

En este contexto, resultaba imprescindible renovar la unidad del sistema educativo, coincidir en las formas de leer y entender la realidad socioeducativa y discutir estrategias de gobernabilidad y participación, teniendo como eje el afianzamiento de un sistema educativo complejo en un escenario controvertido. Es por esto que el Gobierno Nacional, en la figura del Ministerio de Educación, junto con las provincias, en el seno del Consejo Federal de Cultura y Educación (CFCE), asume el desafío de desarrollar una política educativa que tienda a dar unidad al sistema actual.

En este marco se definen los denominados "Núcleos de Aprendizajes Prioritarios" (NAP) con la intencionalidad de afianzar la política curricular con un criterio de Justicia Social. La preocupación es poder garantizar a los niños, jóvenes y adultos aprendizajes equivalentes en su paso por la escuela.

El Consejo define a estos NAP como "una base común y equivalente de aprendizajes para todos los niños y jóvenes" que contribuyan a reducir las brechas existentes. 
En este sentido, son la expresión de un acuerdo político de alcance nacional, sobre aquellos aprendizajes fundamentales que todos los estudiantes del país realizarán, a lo largo de su trayectoria escolar.

En la Resolución 214/04 del CFCE (se anexa), se establece que el Ministerio Nacional deberá desarrollar acciones a fin de promover la calidad educativa y alcanzar logros equivalentes, a partir de heterogeneidades locales, provinciales y regionales. Esto requiere de directivos, docentes e instituciones escolares inteligentes, sensibles y emprendedoras con capacidad para reflexionar sobre lo que enseñan, cómo lo enseñan y a quiénes le enseñan para lograr más y mejores aprendizajes entre todos y para todos. Pero la responsabilidad no es sólo de la base del sistema, sino que desde el Estado esto significa garantizar condiciones pedagógicas para que pueda llevarse a cabo, respondiendo de esta manera a los problemas de la inclusión escolar.

\section{Pensar un currículum diferente para los nuevos escenarios educativos}

Como bien señala el Consejo Federal de Cultura y Educación, la identificación de prioridades no produce por sí sola la mejora en la calidad de los aprendizajes de los alumnos. Se necesitan nuevas miradas sobre el hecho educativo y sobre los sujetos de la educación y una clara recuperación de la centralidad de la enseñanza.

La educación de hoy ya no es la de los "saberes acabados", la escuela ya no es aquella que satisfacía lo que la sociedad le exigía enseñando dichos saberes. Hoy la educación que demandamos es aquella que forme en contenidos socialmente válidos -conceptos, procedimientos, prácticas culturales, actitudes, valores, disposiciones- a partir de la adquisición y desarrollo de capacidades fundamentales para saber, hacer, ser y emprender.

Para ello es necesario transformar el sistema educativo y pasar de un "saber academicista" a un saber significativo, integral y relevante. En consecuencia, no alcanza con un currículum que sólo dé respuestas al qué enseñar; es imprescindible discutir y plasmar en la acción el para qué y el cómo enseñar. En este marco, proyectar un currículum basado en capacidades educativas prioritarias es pensar en "un saber 
hacer, con ciencia y con conciencia".

Desde la perspectiva que orienta este artículo, capacidad implica una cualidad o conjunto de cualidades de las personas, cuyo desarrollo y adquisición les permite enfrentar la realidad en condiciones más favorables. Esta perspectiva trasciende la concepción de las capacidades sólo como estrategias cognitivas, pues las entiende también asociadas a procesos socio-afectivos, que garantizan la formación integral de los sujetos, se manifiestan a través de un contenido o conjunto de ellos y constituyen, en este sentido, una base desde la cual se siguen procesando, incorporando y produciendo nuevos conocimientos.

Otro de los rasgos característicos de las capacidades es su complejidad, en cuanto entrañan una serie de operaciones o procesos interiores de distinto grado de interrelación mutua. Por otra parte, su posesión habilita a los sujetos a usarlas en variadas situaciones, es decir, no se ajustan a un patrón único de actuación, sino que posibilitan un manejo contextualizado.

Teniendo en cuenta las consideraciones precedentes, aparecen como fundamentales, entre otras, las siguientes capacidades:

- La apropiación de la oralidad, la lectura y la escritura para la efectiva inclusión, permanencia y participación en los distintos ámbitos de la cultura letrada.

- La comprensión, interpretación y explicación de hechos y fenómenos sociales y naturales empleando conceptos, teorías y modelos.

- El abordaje, análisis y resolución de problemas con progresiva autonomía.

- El desarrollo de estrategias de búsqueda, selección, análisis y comunicación de información proveniente de distintas fuentes.

- El pensamiento crítico y creativo.

- El trabajo con otros para relacionarse e interactuar.

- El desarrollo de habilidades para la expresión y comprensión en otras lenguas.

- El uso reflexivo y crítico de las tecnologías de la información y la comunicación.

- Actuación responsable y comprometida en el cuidado y mejora del ambiente (natural y social). 
- El desarrollo de la sensibilidad estética y la apreciación de las distintas manifestaciones de la cultura.

- El desarrollo de habilidades para participación crítica, reflexiva, solidaria, ética y democrática.

Un eje fuerte del debate en este campo es la relación entre capacidades y contenidos conceptuales. Al respecto, un documento del Ministerio de Educación de Argentina y otras organizaciones (2010) aporta una postura:

Las capacidades no pueden ser desarrolladas en el vacío. La red de contenidos conceptuales disciplinares se debe constituir en el marco de referencia sobre el cual trabajar en relación con el desarrollo de capacidades. Esto no debe interpretarse como algo secuencial en el sentido de disponer primero de la red de contenidos para luego desarrollar capacidades, sino que se tratará de un trabajo interrelacionado. La intención del trabajo por capacidades no implica desentenderse de la enseñanza de contenidos conceptuales, sino más bien revisar la organización, la secuencia y la importancia relativa que le atribuimos a los distintos conceptos disciplinares (Argentina, Ministerio de Educación y otros, 2010a, pp. 18-19).

Por otra parte, existe discusión acerca de si corresponde hablar de construcción o de desarrollo de capacidades. Al respecto, consideramos que el segundo término es más apropiado que el de construcción, el cual supone actividades que son planificadas y ejecutadas de acuerdo con un proyecto minucioso y acabado, dirigido exclusivamente desde "fuera" de la persona del estudiante.

Entendemos que el desarrollo de capacidades no puede "realizarse" exclusivamente desde afuera, obedeciendo sólo a propósitos y planes previos del docente, sino que los mejores resultados implican la definición de objetivos y estrategias basados en intereses mutuos -del docente y del estudiante- y en colaboración, así como una ejecución de planes flexibles.

Más allá de las controversias, lo cierto es que asegurar aprendizajes personalmente significativos y socialmente relevantes fortaleciendo capacidades, se vuelve un imperativo si la educación pretende dar respuesta a los retos propios de la 
complejidad de la vida cotidiana, social, política -regional, nacional y mundial- $y$, al mismo tiempo, conciliar esta ineludible responsabilidad social con la de generar condiciones para que los estudiantes puedan construir un proyecto personal de vida (Ferreyra \& Peretti, 2006).

En este contexto, pensar la acción educativa con eje en aprendizajes relevantes y capacidades fundamentales implica potenciar la función de desarrollo de cultura y de humanidad que es inherente a la educación. Se trata, así, de pensar un proyecto que imagina, que construye la posibilidad de conciliar el presente y el futuro, lo personal y lo colectivo, los intereses individuales y los sociales; un proyecto que permita a los estudiantes pensar y actuar de una manera constructiva, ocuparse de su propio crecimiento, vincularse con otros y generar cambios en sus contextos (UNICEF, 2006).

Todo esto conduce, inmediatamente, a advertir la necesidad e importancia de un trabajo conjunto (del sistema educativo y de los diferentes sectores sociales) y continuo (durante toda la vida), para suscitar el efecto multiplicador que es propio de los procesos de adquisición y desarrollo de capacidades: una acción transformadora que se manifiesta en los sujetos y que, desde ellos y con ellos, se proyecta a los grupos, las organizaciones, las comunidades, la sociedad toda.

Si el desarrollo de capacidades se orienta a garantizar a todos los estudiantes su formación como personas críticas, creativas, capaces de generar permanentemente nuevos conocimientos y de disponer de ellos para actuar en diferentes contextos, se constituye en una vía privilegiada para la mejora de la calidad humana de los sujetos, para la democratización de la educación bajo el principio de igualdad de oportunidades, para dar respuesta a los problemas presentes y futuros con visión transformadora. Para ello, es necesario que la educación responda a los principios de calidad (eficiencia, eficacia, pertinencia, relevancia) y equidad).

Un proceso formativo de calidad con equidad es aquel que asegura a los sujetos la apropiación de los bienes de la cultura y les permite construir un conjunto de saberes que los habilita para intervenir creativamente en su contexto, producir y aportar. Se trata, entonces, de promover aprendizajes relevantes y significativos desde el punto de vista de las exigencias sociales y de desarrollo personal y que -a la vez- consideren las 
características y necesidades de cada persona, mediatizadas por el contexto social y cultural en que vive.

\section{Las capacidades prioritarias: su sentido en la escuela y en las aulas}

Pensar propuestas pedagógicas centradas en el desarrollo de capacidades prioritarias implica interrogarnos acerca de cuáles son aquellos aprendizajes que las Instituciones Educativas no pueden dejar de potenciar porque los estudiantes no van a poder aprenderlos en otros ámbitos.

Se consideran capacidades prioritarias a aquellas que más y mejor favorecen el desarrollo del potencial de aprendizaje de cada estudiante, entendiendo como tal la capacidad o posibilidad de aprender que tiene cada persona, en función de la interacción con el contexto.

La adquisición de estas capacidades se debe realizar en forma gradual y progresiva en los distintos niveles, ciclos y modalidades del sistema educativo. Se trata de un proceso que se inicia en los primeros tramos de la escolaridad obligatoria Educación Inicial y Primaria-, se continúa en Secundaria con su desarrollo y fortalecimiento hasta llegar al Nivel Superior, etapa de profundización.

Esto no significa que priorizar el aprendizaje de unas capacidades sobre otras lleve a un recorte arbitrario del currículum, sino que por el contrario es la oportunidad de aprender a jerarquizar de manera diferente lo que se enseña. Por lo tanto, no son las aquí expuestas las únicas que se deben abordar en los jardines de infantes, escuelas, centros o institutos, pero sí son aquellas que todos los estudiantes tienen que alcanzar ya que son consideradas básicas para todos los que transitan la educación obligatoria.

Las capacidades prioritarias se caracterizan por un alto grado de complejidad; se desarrollan de manera conectiva y procuran el máximo despliegue de las potencialidades de los estudiantes. En este sentido, cada área de conocimiento o disciplina - desde su particularidad, naturaleza y finalidades formativas- contribuye a la adquisición, desarrollo y fortalecimiento de las capacidades prioritarias ya que los logros se alcanzan al operar con los diferentes contenidos involucrados en los aprendizajes 
esperados, cada uno de los cuales deja su impronta sobre ese desarrollo, y lo enriquece.

Por su contribución a la ampliación de la posibilidades expresivas, comunicativas, cognitivas y sociales de los estudiantes, priorizamos en esta presentación la oralidad, la lectura y la escritura; la resolución de problemas; el pensamiento crítico y el trabajo con otros.

Entendemos que estas capacidades no son las únicas, pero sí las que consideramos prioritarias porque:

- Están estrechamente relacionadas con las grandes intencionalidades formativas del currículum de los diferentes niveles del sistema educativo y se vinculan directamente con los aprendizajes prioritarios;

- Tienen "incidencia directa, relevante y positiva en los itinerarios escolares de los alumnos" (Argentina, Ministerio de Educación y otros, 2010, p. 55);

- Son aquellas que todos los estudiantes tienen que desarrollar pues se trata de las necesarias para que puedan conocer, comprender, interpretar y participar en el mejoramiento de su calidad de vida y, por ende, la de su comunidad de pertenencia, tomando decisiones fundamentadas que les permitan continuar aprendiendo más allá de la escolaridad, dentro de un proceso de educación permanente (Ferreyra \& Peretti, 2008).

Para poder cumplir, entonces, con las funciones formativas de los diferentes niveles educativos, la institución escolar trabaja para el desarrollo y adquisición de aquellas capacidades que deberían potenciarse para que todos los estudiantes se apropien de los aprendizajes considerados prioritarios.

Si bien para su descripción las abordaremos por separado, es fundamental tener presente que, en las prácticas, aparecen fuertemente vinculadas.

Por otra parte, insistimos en la necesidad de que sea revisada la tendencia a pensar que cierta y determinada capacidad es privativa de ciertas disciplinas o áreas curriculares específicas. Muy por el contrario, el carácter integral e integrador de las capacidades hace que éstas atraviesen de manera horizontal y vertical el currículum de los distintos niveles y modalidades del sistema educativo y deban y puedan ser 
abordadas en todos los espacios curriculares para el logro de más y mejores aprendizajes para todos.

\section{Oralidad, lectura y escritura.}

La enseñanza de la oralidad, la lectura y la escritura, entendidas como acciones mediadas por la sociedad y la cultura y que involucran, además, dimensiones cognitivas y metacognitivas de las cuales los estudiantes deben apropiarse, constituye una prioridad de la escolaridad obligatoria. Esta capacidad compleja supone el abordaje de las actividades lingüísticas claves -hablar, escuchar, leer y escribir- en el marco de las diferentes prácticas sociales de lenguaje que las contextualizan y les dan sentido.

El desarrollo de esta capacidad -incumbencia de todas las áreas y disciplinas curriculares- se vincula plenamente con los objetivos de la política educativa por cuanto garantiza a todos los estudiantes el acceso a las condiciones para "tomar la palabra", es decir, poder expresar lo que se siente, se piensa, se sabe y se necesita, lo cual allana el camino a la inclusión social plena.

\section{Abordaje, análisis y resolución de problemas.}

Un problema puede definirse como toda situación nueva que un individuo o un grupo desea modificar y de la cual se conoce el punto de partida y a dónde se desea llegar, pero se desconoce un procedimiento directo para lograrlo (Pozo, et al., 1995). Si en la escuela se pretende tomar un rol activo en el desarrollo de la capacidad de resolución de problemas, deberán darse a los estudiantes oportunidades frecuentes y variadas de enfrentarse a situaciones desafiantes, con base en los contenidos de las distintas áreas curriculares. Pero para ello es necesario percibir las implicaciones de las diferentes aproximaciones que realizan los estudiantes; analizar con ellos si son fructíferas o no y qué podrían hacer en lugar de eso; decidir cuándo intervenir, qué sugerencias ayudarán sin restar autonomía. Corresponde, finalmente, que el docente supere la propia ansiedad por tener que trabajar sin saber todas las respuestas posibles. 


\section{Pensamiento crítico.}

En el contexto actual, reviste una gran importancia el fortalecimiento de la capacidad del ciudadano para conmoverse, para discriminar, para pensar y actuar. Se trata de formar ciudadanos críticos capaces de dirigir su visión, de observar, de situarse en el mundo, de desnaturalizarlo, de interpretarlo y comprenderlo y, así, poner en práctica ideas originales e innovadoras que contribuyan a crear un nuevo orden social. El pensamiento crítico cuestiona las creencias infundadas, los prejuicios, y trata de sustituirlos por ideas argumentalmente sostenidas. En este sentido, aprender a pensar de manera crítica y creativa es aprender a ser sujeto; es aprender a construir la propia subjetividad; es valorarse como ser capaz de producir significados e interpretar el mundo; es atreverse a pensar, a hacer y a ser.

\section{Trabajo con otros.}

El valor de la educación reside, hoy más que nunca, en su potencial para contribuir a la construcción de un mundo para todos. Esto sólo será posible en la medida en que la escuela ofrezca a los estudiantes experiencias en las que el aprender a ser, a saber y a hacer se plantee como una empresa colectiva, basada en el saber convivir. La capacidad de trabajo en colaboración supone reconocer la alteridad y aceptar al otro en tanto otro diferente. Receptar las ideas de los demás y exponer las propias implica aprender con otros y de otros. Elaborar acuerdos, establecer conclusiones, solucionar conflictos y sostener consensos son algunas de las habilidades que se pueden desarrollar a partir del trabajo con otros.

La escuela y el aula constituyen uno de los primeros ámbitos en donde se aprende (o no) a valorar el trabajo conjunto y estas experiencias tendrán su impronta en la futura vida laboral y/o profesional de los estudiantes. Los problemas son resueltos por el equipo, y quienes intervienen en él desarrollan las habilidades de liderazgo, comunicación, confianza, toma de decisiones, solución de conflictos y responsabilidad por los resultados. 


\section{Reflexiones finales}

Dado el carácter general de los NAP definidos en el nivel nacional -para el caso argentino-, es clave que cada provincia los analice y enriquezca a partir de su realidad, e identifique las capacidades consideradas prioritarias. Corresponderá luego a cada institución, en el trabajo conjunto de los actores que en ella conviven, especificar cuáles serán las estrategias para que tales capacidades sean abordadas integrando los NAP al contexto educativo actual y que éstos no se conviertan en conocimientos vacíos de fundamentos de los cuales los estudiantes deben apropiarse sin sentido y significado.

Avanzar en un desarrollo pedagógico de esta naturaleza demanda una relectura de los marcos curriculares vigentes desde una perspectiva reflexiva de la práctica docente y desde la lógica del trabajo de gestión institucional. Supone dar la posibilidad a los actores involucrados -tanto docentes como estudiantes- de enfrentar diferentes contextos y situaciones, promoviendo su participación e involucramiento críticos, en pos de hacer efectivo el derecho a una educación de calidad.

Poner en marcha este nuevo proyecto curricular y pedagógico supone un cambio en la cultura de la institución escolar y de los docentes, para convertir a la escuela y al aula en verdaderas comunidades de aprendizaje. Implica que los estudiantes se apropien de saberes cuya consecución no es responsabilidad exclusiva del accionar de un área, disciplina o espacio curricular determinado, sino que requiere de estrategias de enseñanza convergentes y sostenidas a lo largo del tiempo, que generen nexos y conexiones entre distintos campos del saber y del hacer, en experiencias de aprendizaje auténticas y situadas.

Como sociedad y como colectivo educador deberemos asumir la responsabilidad de generar situaciones que conviertan a los estudiantes en protagonistas de experiencias educativas que les aseguren aprendizajes vinculados no sólo con conocimientos puntuales, de corta duración, sino aprendizajes significativos, funcionales, innovadores, que les permitan transformar y transformarse. 


\section{Referencias}

Argentina. Ministerio de Educación. Consejo Federal de Cultura y Educación (2004). Reducir desigualdades y recuperar la centralidad de los aprendizajes. Anexo Resolución 2014/04. Buenos Aires: Autor.

Argentina. Ministerio de Educación; UNICEF. Oficina Argentina; Organización de los Estados Iberoamericanos OEl. Regional Buenos Aires; Asociación Civil Educación para Todos (2010). El desarrollo de capacidades en la Escuela Secundaria. Un marco teórico. Buenos Aires: UNICEF. Oficina Argentina Recuperado el 12 de febrero de 2013, de http://www.unicef.org/argentina/spanish/Cuaderno 1.pdf

Ferreyra, H. \& Peretti, G. (comp.) (2006). Diseño y gestión de una Educación Auténtica. Buenos Aires: Novedades Educativas.

Ferreyra H. (2010). Política y curriculum en la República Argentina. La construcción de núcleos de aprendizajes y la propuesta de definición de competencias para mejorar la educación. Revista Palabra Educativa. Red de Postgrado en Educación. Enero-Junio No 1, pp 9-14.

Ferreyra, H., Peretti, G. \& Vidales, S. (2012). Hacia un proyecto curricular y pedagógico centrado en la adquisición y desarrollo de capacidades. En Ferreyra H. y Vidales S. (comp). Hacia la innovación en Educación Secundaria. Reconstruir sentidos desde los saberes y experiencias. Córdoba, Argentina: Comunicarte.

Gobierno de Córdoba. Ministerio de Educación. Secretaría de Educación. Subsecretaría de Promoción de Igualdad y Calidad Educativa (2011). Encuadre General de la Educación Secundaria 2011-2015. Córdoba, Argentina: Autor.

Organización de Estados Iberoamericanos -OEl- (2009). Metas Educativas 2021. La educación que queremos para la generación de los bicentenarios. Madrid: Autor. 2009. Recuperado el 12 de febrero de 2014, de http://www.oei.es/metas2021/libro.htm

Pozo, J. I., Postigo, Y. \& Gómez Crespo, M. A. (1995). Aprendizaje de estrategias para la solución de problemas en Ciencias. En Alambique- Didáctica de las Ciencias Experimentales, (5), Barcelona, España.

UNESCO (2000). Documentos de referencia para la Educación para Todos. Recuperado de http://www.unesco.org/new/es/education/themes/leading-the-internationalagenda/efareport/background-papers/

UNESCO (2007). Educación de calidad para todos. Un asunto de derechos humanos. Documento de discusión sobre políticas educativas en el marco de la II Reunión Intergubernamental del Proyecto Regional de Educación para América Latina y el Caribe. Oficina Regional de Educación para América Latina y el Caribe (OREALC/UNESCO). Buenos Aires. Recuperado de http://unesdoc.unesco.org/images/0015/001502/150272s.pdf

UNICEF (2006). Desarrollo de capacidades para el ejercicio de la ciudadanía. Buenos Aires: Autor. 


\title{
LAS COMPETENCIAS: CORPUS DE CONOCIMIENTO, DEBATES Y SIGNIFICACIONES.
}

\section{THE COMPETENCES: A CORPUS OF KNOWLEDGE, DEBATES AND MEANINGS.}

\author{
Sergio Gerardo Malaga Villegas \\ Universidad Pedagógica Veracruzana \\ gmalvil.33@gmail.com
}

\begin{abstract}
Resumen
Este artículo es el producto de una investigación de tipo cualitativa; el referente empírico, integrado por libros, capítulos de libros y ponencias presentadas en congresos de investigación educativa que mostraban avances o resultados finales de investigaciones, se ubicó en bases de datos asociadas con el significante competencias, sus giros discursivos y tendencias en educación formal y no formal en México. El resultado es un cuerpo de conocimientos que integra distintos debates y posicionamientos acerca de las competencias. Este ejercicio permitió realizar por un lado, una revisión genealógica acerca de las competencias como significante polisémico y por el otro, el trazo de nuevas rutas respecto a futuras investigaciones en esta área de conocimiento.
\end{abstract}

Palabras clave: Investigación, Cualitativa, Estado de conocimiento, Significante.

\begin{abstract}
This article is the result of a qualitative research; the empirical referent includes books, chapters of books and papers of educational research conferences, which are in progress or concluded, is situate in databases of formal education or informal in Mexico. The result is a body of knowledge, which integrates debates and positions about the competences. This exercise allows a genealogical review about the competences as polysemic signifier, and the same time, to trace new routes to future research in this knowledge area.
\end{abstract}

Key words: Research, Qualitative, State of knowledge, Signifier.

\section{Introducción}

Las competencias, como significante en plenitud, permiten la articulación de distintas significaciones que las posicionan en distintos momentos históricos, contextos de operatividad y finalidades en su aplicación, esta noción se anota en plural debido a que 
en este estudio se comprende como un significante, en sentido saussuriano, que asume diferentes rostros de acuerdo al lugar desde el cual se enuncia, es decir, responde a una cierta multirreferencialidad y a sus multiterritorios.

En el caso mexicano, se trata de un significante aspiracional y esperanzador que intenta cumplir con un ideal educativo del Estado; que se suscribe a estándares internacionales específicos para el aprendizaje permanente de los estudiantes en edad escolar (educación básica, educación media superior y superior) y en modalidades diversas para la formación, actualización y capacitación profesional de forma no escolarizada. Acepta múltiples significaciones dependiendo de los sujetos enunciantes, el territorio de enunciación y la arena de tensión en la que se encuentre. Con la noción territorio no se pretende hablar de un espacio limítrofe, por el contrario se piensa en momentos o espacios simbólicos diversificados, así, es posible identificar significaciones institucionales, académicas, políticas, sociales, económicas, pedagógicas, intencionadas, etc.

Para dar cuenta del conocimiento producido en esta área, el presente artículo se organiza en cuatro momentos. En primer lugar se exponen los antecedentes, mismos que brindan un panorama de partida de la investigación en curso. En segundo lugar se establece la delimitación temática y las precisiones de orden metodológico que dan rostro al reporte de investigación. En tercer lugar se describen los hallazgos del estudio, para ello se hace uso de tablas que intentan facilitar la comprensión de lo encontrado, comenzando por los hallazgos en libros, capítulos de libros y ponencias presentadas en congresos. Se cierra este ejercicio con una articulación de tendencias, ausencias y necesidades que permitirán fortalecer esta área del conocimiento en futuros trabajos.

\section{Antecedentes}

Los antecedentes de esta investigación se sitúan a partir de la revisión de los estados de conocimiento que se encuentran en la colección: La investigación educativa en México 1992 - 2002, misma que edita el Consejo Mexicano de Investigación Educativa (COMIE) y que organiza en 12 áreas temáticas. En tabla 1 se sistematiza la cantidad de 
investigaciones encontradas por área y nivel educativo en el que se aborda el desarrollo de las competencias.

Tabla 1.

Distribución de la producción de trabajos, de 1992 a 2002, acerca de las competencias por nivel educativo y área temática.

\begin{tabular}{|c|c|c|c|c|c|}
\hline Áreas temáticas & $\begin{array}{l}\text { Educación } \\
\text { Básica }\end{array}$ & $\begin{array}{l}\text { Educación } \\
\text { Media } \\
\text { Superior }\end{array}$ & $\begin{array}{l}\text { Educación } \\
\text { Superior }\end{array}$ & $\begin{array}{c}\text { Educación } \\
\text { no formal y } \\
\text { empleabilidad }\end{array}$ & Total \\
\hline $\begin{array}{l}\text { 1. El campo de la investigación } \\
\text { educativa. }\end{array}$ & 2 & 1 & 4 & - & 7 \\
\hline $\begin{array}{l}\text { 2. Acciones, actores y prácticas } \\
\text { educativas. }\end{array}$ & - & - & 2 & - & 2 \\
\hline $\begin{array}{l}\text { 3. Educación, derechos sociales } \\
\text { y equidad (Tomo I, II y III). }\end{array}$ & 3 & - & - & 2 & 5 \\
\hline $\begin{array}{l}\text { 4. Aprendizaje y desarrollo. } \\
\text { 5. La investigación curricular en }\end{array}$ & - & - & 1 & - & 1 \\
\hline $\begin{array}{l}\text { México: la década de los } \\
\text { noventas. }\end{array}$ & - & - & 6 & 5 & 11 \\
\hline $\begin{array}{l}\text { 6. Educación, trabajo, ciencia y } \\
\text { tecnología. }\end{array}$ & - & - & 4 & 2 & 6 \\
\hline $\begin{array}{l}\text { 7. Saberes científicos, } \\
\text { humanísticos y tecnológicos } \\
\text { (Tomo I y II). }\end{array}$ & 4 & - & - & - & 4 \\
\hline $\begin{array}{l}\text { 8. Sujetos, actos y procesos de } \\
\text { formación (Tomo I y II). }\end{array}$ & - & - & 2 & - & 2 \\
\hline 9. Políticas educativas. & - & 1 & - & - & 1 \\
\hline $\begin{array}{l}\text { 10. Historiografía de la } \\
\text { educación. }\end{array}$ & - & - & - & - & 0 \\
\hline $\begin{array}{l}\text { 11. Filosofía, teoría y campo de } \\
\text { la educación: Perspectivas } \\
\text { nacionales y regionales. }\end{array}$ & - & - & 1 & - & 1 \\
\hline $\begin{array}{l}\text { 12. Corporeidad, movimiento y } \\
\text { educación física (Tomo I y II). }\end{array}$ & - & - & 2 & - & 2 \\
\hline Total & 9 & 2 & 22 & 9 & 42 \\
\hline
\end{tabular}

De acuerdo a lo expuesto en la tabla es posible reconocer, respecto a las competencias, que las investigaciones desarrolladas en la década 1992-2002 se ubican en dos ámbitos centrales, uno en la educación formal y otro en la no formal; en tal sentido, es en los niveles de educación primaria y licenciatura (universidades y escuelas normales) en los que se presenta mayor número de aportes. 
Respecto a la educación informal, en el campo de la capacitación para el trabajo, es donde se hacen mayores aportaciones respecto a estudios de seguimiento y evaluación.

Cabe decir que en los estados del conocimiento del COMIE, el área temática en la que se encuentra un mayor número de investigaciones acerca de las competencias es la de Investigación curricular en México, los aportes se centran en dos ámbitos, el primero en propuestas de desarrollos e innovaciones curriculares y el segundo, en la identificación de las ventajas de la capacitación y formación laboral.

En el primer ámbito emergen propuestas de modelos institucionales curriculares en la universidad (Crocker, 1997; Gómez, 1997; Lluch, 1998; Herrera, 1999; Guerrero y Peña, 2001) y de educación normal para la formación docente (Díaz \& Rigo, 2000). En el segundo ámbito destacan trabajos relacionados con la capacitación (Jiménez, 1999), formación y perfeccionamiento a partir de un currículo con enfoque basado en competencias (Bunk, 1994), en ellos interesa reconocer de qué manera inciden esos procesos de capacitación en la formación continua de los profesionales, empleados, etc.; asimismo, se reconocen contribuciones asociadas a la certificación de los saberes desde la formación en competencias (Marin, 1991; Barrón, 2000; Rojas, 2000).

En esta área destaca la categoría "currículo", la cual condensa una multiplicidad de significaciones y es posible entenderse como una “... configuración, sistema y estructura discursiva social, educativa, política, económica y ética... relacional y precaria porque no se trata de una estructura estable que defina de una vez y para siempre el acto educativo" (Malaga, 2013, p. 7), es decir, lo condiciona (temporalmente), de acuerdo a las necesidades del contexto educativo en el que se desarrolle cualquier diseño curricular; esta tarea “... no es solo asunto teórico, metodológico o técnico; es ante todo, un compromiso social para repensar cómo comunicar saberes entre sujetos que se reconocen en un espacio común" (Orozco, como se citó en De alba, 2006, p. 1).

Por otro lado, se encuentra el área temática El campo de investigación educativa, misma que integra investigaciones en educación básica, media superior y superior. Destaca un seguimiento a la implementación de competencias básicas en educación 
primaria (Vera, Peña y Domínguez, 1999; Vera y Camargo, 2000) para reconocer los niveles de desarrollo en los alumnos. También se encuentra una propuesta propedéutica de bachillerato (Canales, 1997) en la que se pretende desarrollar competencias básicas en los estudiantes para que su tránsito en este nivel educativo sea próspero.

De igual forma, en educación superior se integran trabajos de distintas disciplinas, en las que se piensa a las competencias como una serie de herramientas cognitivas y procedimentales que los docentes en formación deben fortalecer para mejorar su práctica profesional (Bazdresch, 1998); como parte de la formación de los psicólogos para favorecer habilidades en su formación (Irigoyen, 1999); como competencias integrales en educación universitaria (Castellanos 2000; Reynaga, 2000) y como estudio comparativo respecto a competencias ambientales (Corral, Obregón, Frías, Piña \& Obregón, 1994).

En esta área se identifica a la categoría "competencias básicas", misma que se comprende como un conjunto de elementos y herramientas que los sujetos inmersos en los distintos niveles y disciplinas de la educación formal deben desarrollar y fortalecer; estas competencias son de orden genérico y se piensa como aquéllas que permitirán que los estudiantes se desarrollen de forma óptima en la disciplina que estudien.

Cabe decir que las áreas temáticas del COMIE: Aprendizaje y desarrollo, Políticas educativas y Filosofía, teoría y campo de la educación: perspectivas nacionales y regionales, se encontró escasamente un aporte de investigación, mientras que en el área Historiografía de la educación no hubo aporte alguno relacionado con las competencias.

Lo anterior permite validar los resultados de esta investigación debido a que el cuerpo de conocimientos que se expone en el apartado de hallazgos, es un referente metainvestigativo para la elaboración de futuros estados de conocimientos y al mismo tiempo, brinda elementos para reconstruir las estructuras, los procesos y características del tema de estudio. 


\section{Claves de la investigación}

\section{Delimitación temática.}

Desde la producción internacional, se ubica a las competencias en el ámbito educativo formal; así, se refieren a ellas como organizadores del currículum y una forma de trasladar la vida real al aula (Jonnaert, Barrette, Masciotra \& Yaya, 2006); como elementos integradores entre el saber y el hacer (Aguerrondo, 2009), lo cual se complementa con la idea de competencias básicas (UNESCO, 2012) como un dispositivo, es decir, como un conjunto heterogéneo de discursos, prácticas, instituciones, decisiones reglamentarias y medidas administrativas (Foucault, 1982); representa un colador de formación (ideológica) de los sujetos (productivos) capaces de insertarse en el mundo laboral para el logro de una vida activa y prospera. Además, las competencias representan la orientación fundamental de diversos proyectos internacionales de educación como el Proyecto Tuning o el Alfa Tuning en Latinoamerica (Tobón, 2006).

En este informe se aborda como objeto de estudio a las significaciones de las competencias, de ahí que se haya decidido buscar, sistematizar y analizar materiales que abordaran explícitamente algún aspecto o dimensión de ellas; por ejemplo su conceptualización, diseño, implementación, seguimiento o exposición de resultados desde una investigación situada, con esta noción se hace referencia a que la investigación se haya desarrollado en un contexto específico y desde espacios educativos formales (preescolar, primaria, secundaria, bachillerato, licenciatura y posgrado), así como en espacios educativos no formales y que reporte resultados de dicho ejercicio.

En este trabajo no interesa discutir cuáles de las significaciones atribuidas a las competencias es la correcta, por el contrario resulta de suma importancia conocer cuáles han sido las significaciones de este significante en las investigaciones que aquí se señalan para reconocer las tendencias investigativas posteriores a la década de 1992-2002, en qué áreas se encuentran los aportaciones y cuáles son los debates a su 
alrededor. Se parte del supuesto que durante el último sexenio en México (2006-2012) se realizaron mayores producciones de investigaciones acerca de las competencias debido a que dicho significante se instaló de forma contundente en los planes de estudio de educación básica, media superior y superior.

\section{Pregunta guía.}

En este reporte de investigación interesa conocer ¿Cuáles son las actuales tendencias y debates reflejados en las investigaciones realizadas desde el campo de las competencias en el periodo de 2006 a 2012 y cuáles las semejanzas y diferencias que se identifican con lo sistematizado en la década 1992-2002?

\section{Objetivo.}

Realizar un breve ejercicio exploratorio respecto a las investigaciones generadas desde el campo de las competencias durante la década 2006 a 2012 para identificar sus tendencias y debates respecto a la década 1992-2002.

\section{Búsqueda y selección de materiales}

La revisión de los materiales se organizó a partir de ubicar investigaciones que tuvieran a las competencias como eje problematizador, temático o comparativo en educación formal o informal; otro criterio de selección fue que dichos materiales se encontraran en internet y se pudieran descargar para su sistematización. Inicialmente se pensaba reportar el resultado de la sistematización de libros, capítulos de libros, artículos y ponencias presentadas en congresos de investigación educativa; sin embargo, por la magnitud de los resultados se decidió, al ser un breve ejercicio exploratorio, dar cuenta de lo que comunicaban libros, capítulos de libros y ponencias, debido a que la sistematización de los artículos fue la más extensa y por tanto será objeto de otro artículo. 
Para el caso de los libros y capítulos de libros, se exploró en la base de datos de la Red Durango de Investigadores Educativos A.C. (ReDIE), así como otras que pudieran aportar elementos de análisis; mientras que para las ponencias se accedió principalmente a las memorias electrónicas del COMIE, mismas que están en el sitio electrónico de dicha organización. Una dificultad encontrada es que este tipo de búsquedas permite que se ubiquen libros $u$ otros materiales, que si bien representan un gran aporte para el estudio metainvestigativo, no fue posible descargarlos debido a políticas de privacidad. Además, muchos de los materiales encontrados no fueron considerados para integrar este cuerpo de conocimientos debido a que no cumplían con las características solicitadas para esta investigación.

\section{Tratamiento y análisis de la información}

Esta revisión no se considera exhaustiva debido a que no se tuvo acceso a otros materiales como tesis y otras bases de datos institucionales; se trata en todo momento de un ejercicio exploratorio, con enfoque cualitativo, para identificar las tendencias en el campo de las competencias. Para la organización de la información se hizo uso de tablas, con lo encontrado se establecieron puntos nodales (Laclau, 2004) de significación para comunicar los resultados de esta investigación.

De los referentes empíricos interesaba analizar "las perspectivas de significado de los actores específicos en los acontecimientos específicos" (Erickson, 1989, en Wittrock, 1989, p. 200); así, aunque se encontraron en repetidas ocasiones discusiones teóricas, que si bien aportan elementos para repensar a las competencias, no permiten identificar de qué forma se pensaba a las competencias desde un contexto específico.

\section{Hallazgos en la empiricidad} encontrado en el referente empírico, por cada uno de ellos (libros, capítulos de libros y ponencias presentadas en congresos de investigación educativa) se muestra una tabla 
que concentra la información cuantitativa y además se enlista una serie de consideraciones que explican qué se encontró en cada uno.

\section{Libros.}

A partir del acceso en línea, únicamente fue posible analizar dos libros, mismos que fueron editados por la ReDIE y que si bien representan un referente mínimo para dar cuenta de las tendencias a nivel nacional, también comunican información respecto a la forma en la que se piensan las competencias, debido a que contienen contribuciones de cualquier parte del País. En la tabla 2 aparecen los resultados:

Tabla 2.

Libros que fueron posibles descargarse del acceso en línea.

\begin{tabular}{cl}
\hline Año de publicación & \multicolumn{1}{c}{ Título } \\
\hline 2011 & $\begin{array}{l}\text { Jaik Dipp, A. y Barraza, A. (2011). Competencias y educación. Miradas múltiples } \\
\text { de una relación. }\end{array}$ \\
2012 & $\begin{array}{l}\text { Tobón, S. y Jaik Dipp, A. (2012). Experiencias de aplicación de las competencias } \\
\text { en la educación y el mundo organizacional. }\end{array}$ \\
\hline
\end{tabular}

A continuación se expresan los resultados de la sistematización de estos referentes.

Consideraciones:

1. El contenido de ambos libros se integra mayormente por capítulos teóricos y analíticos-reflexivos. En menor medida se registran artículos derivados de investigaciones que presentan resultados de las mismas.

2. El libro que coordinan Jaik Dipp y Barraza (2011), está integrado en cuatro apartados, cada uno se enfoca a un sector específico de aplicabilidad y tiene relación estrecha con los sujetos educativos, por ejemplo alumnos, docentes, directivos e investigadores. Los capítulos que en el libro aparecen fueron generados desde los estados de Coahuila, Durango, Jalisco, México, Sonora y Tlaxcala. 
3. El libro que coordinan Tobón, S. y Jaik Dipp, A. (2012), integra artículos cuyos países de procedencia son Colombia, Cuba, España, Perú y México, de este último hay aportaciones de estados como Baja California, Chihuahua, Coahuila, Guanajuato, Nuevo León, Quintana Roo, San Luis Potosí, Sonora y Yucatán.

4. Las competencias son abordadas desde un sentido formativo y de aplicabilidad en educación formal y no formal.

Por su parte la tabla 3 concentra la cantidad de artículos publicados entre ambos libros.

Tabla 3.

Artículos publicados por las instituciones participantes en los libros de competencias.

\begin{tabular}{lc}
\hline Instituciones en las que se generaron las publicaciones & Cantidad \\
\hline Universidad Autónoma de Coahuila (Facultad de contaduría y & 5 \\
administración, Facultad de medicina). & 4 \\
Universidad Pedagógica de Durango. & 3 \\
Instituto CIFE. & 3 \\
Secretaría de Educación del Estado de Durango. & 2 \\
Instituto Politécnico Nacional (Culhuacán). & 2 \\
Instituto Universitario Anglo Español. & 2 \\
Universidad Autónoma de Chihuahua (Facultad de Medicina). & 1 \\
Escuela Normal del Estado de México. & 1 \\
Instituto Tecnológico de Sonora. & 1 \\
Secretaría de Educación de Jalisco. & 1 \\
Universidad Anáhuac México-norte. & 1 \\
Universidad Autónoma de Baja California (Ciencias Veterinarias). & 1 \\
Universidad Autónoma de Tlaxcala. & 1 \\
Universidad Autónoma de Yucatán (Escuela Preparatoria). & 1 \\
Universidad complutense de Madrid. & 1 \\
Universidad de Antioquía. & 1 \\
Universidad de Holguín, Cuba. & 1 \\
Universidad de Medellín Colombia. & 1 \\
Universidad de Monterrey. & 1 \\
Universidad de Quintana Roo. & 1 \\
Universidad de Sonora. & 1 \\
Universidad Nacional de Perú. & 1 \\
Universidad Pedagógica Nacional (unidad 241). & 1 \\
Universidad Politécnica de Celaya. & 1 \\
Universidad Tecnológica de San Luis Potosí. & 39 \\
Total & 1 \\
\hline
\end{tabular}


De manera general, los artículos son generados por Institutos Politécnicos, Universidades autónomas y pedagógicas de los estados, así como por los países participantes; en menor medida, una escuela normal realizó un aporte a esta área.

\section{Capítulos de libros.}

De los 39 capítulos que integran los libros citados en el apartado anterior (Jaik Dipp y Barraza, 2011; Tobón y Jaik Dipp, 2012), únicamente 12 comunican resultados de investigaciones respecto a las competencias.

Se integraron además 2 capítulos que se encuentran en un libro coordinado por Lozano y González (2012), cabe decir que la temática general de este libro no fue la de competencias, por tanto no se incluyó en el listado de libros sistematizados.

En educación formal, los niveles educativos en los que se encuentran mayores aportes es en licenciatura (universidad y educación normal) y posgrado, apareciendo con menores aportes en educación media superior y nulas aportaciones en educación básica. En la tabla 4 aparece la lista de universidades desde las que se generaron mayores aportes.

Tabla 4.

Universidades con más contribuciones de investigaciones acerca de las competencias.

\begin{tabular}{lc}
\hline Institución desde la que se generó el estudio & Cantidad \\
\hline Universidad Autónoma de Coahuila (Facultad de contaduría y administración). & 2 \\
Universidad Autónoma de Chihuahua (Facultad de Medicina). & 2 \\
Instituto Tecnológico de Sonora. & 2 \\
Instituto Universitario Anglo Español. & 2 \\
Escuela Normal No. 3 del Estado de México. & 1 \\
Universidad Anáhuac México-norte. & 1 \\
Universidad Autónoma de Baja California. & 1 \\
Universidad Autónoma de Tlaxcala. & 1 \\
Universidad Pedagógica Nacional (unidad 241). & 1 \\
Universidad de Quintana Roo. & 1 \\
\hline
\end{tabular}


De acuerdo a la tabla anterior, fue posible identificar que el abordaje de las competencias está mayormente nutrido en la elaboración de textos académicos; la formación de investigadores; las propuestas y aplicación de diseños curriculares; y mejora de la docencia en las disciplinas de lengua y literatura, investigación, salud y docencia. En la tabla 5 aparecen las nociones que condensan estos aportes:

Tabla 5.

Nociones que condensan las significaciones de las competencias.

\begin{tabular}{l|l}
\hline \multicolumn{2}{c}{ Puntos nodales } \\
\hline \multicolumn{1}{c}{ Educación media superior } & \multicolumn{1}{c}{ Educación superior } \\
\hline Calidad educativa. & Competencias docentes. \\
Estrategias de enseñanza. & Mejora Profesión académica. \\
Prácticas educativas. & Prácticas profesionales. \\
Capacitación y formación. & Formación de investigadores. \\
Educación para la competitividad. & Innovación y reflexión. \\
\hline
\end{tabular}

En este rubro, algunas consideraciones son:

1. En educación media superior, se hace continua alusión a las estrategias de enseñanza y las prácticas educativas que los docentes deben cambiar para contribuir a la calidad educativa (Cruz Martínez, 2011) de tal manera que las competencias, desde estos estudios, se reconocen como herramientas esperanzadoras para el logro de un fin educativo.

2. En educación superior, desarrollados principalmente a nivel licenciatura y posgrado en universidades, y mínimamente en educación normal. Se ponen en la mesa de los debates a la resignificación de las prácticas profesionales (Campos, 2011); el desempeño profesional (López González, et al., 2012); las propuestas de diseño curricular (Bejarle, Salcedo, Castañeda \& Beltrán, 2012; Medina, Molina, Guerrero \& Armenteros, 2012); el seguimiento al currículo por competencias (Parra, et al., 2012); la evaluación de competencias en licenciatura (Armenteros, Guerrero, Medina, Molina \& Villanueva, 2012); la evaluación de competencias en posgrado (Guerrero, Armenteros, Medina \& Molina, 2012); las competencias para la producción del conocimiento (Perales, Macías \& Macías, 
2011); las competencias para la inclusión (Armenta, 2012); y las competencias para las actitudes matemáticas (Pimienta \& Medina, 2012; Vargas \& Cristóbal, 2012).

De manera general, se hace evidente una urgencia en la mejora de las prácticas profesionales por parte de los docentes a través de la reflexión e innovación. Nuevamente las competencias son vistas como un instrumento que permitirá la mejora de las prácticas profesionales, el logro de las metas educativas, la llave para acceder a nuevas posibilidades de aprendizaje y en última instancia de empleabilidad de los sujetos.

\section{Ponencias en congresos.}

Estos referentes se obtuvieron básicamente de la base de datos del COMIE, en sus memorias electrónicas (IX, X y XI Congreso Nacional de Investigación Educativa-CNIE, 2007, 2009 y 2011 respectivamente).

Inicialmente se tenían 78 ponencias que abordaban a las competencias; sin embargo, no todas esas ponencias eran el resultado de alguna investigación y como en todo proceso de exclusión se descartaron algunas.

La tabla 6 muestra el proceso de sistematización inicial y final por área y años de publicación.

Las ponencias que no fueron seleccionadas no es que carecieran de calidad, por el contrario no fueron elegidas debido a que no cubrían con el requisito de ser el resultado de una investigación acerca de las competencias y en sus resultados no se demostraba discusión en torno a ellas. 
Tabla 6.

Selección de ponencias analizadas.

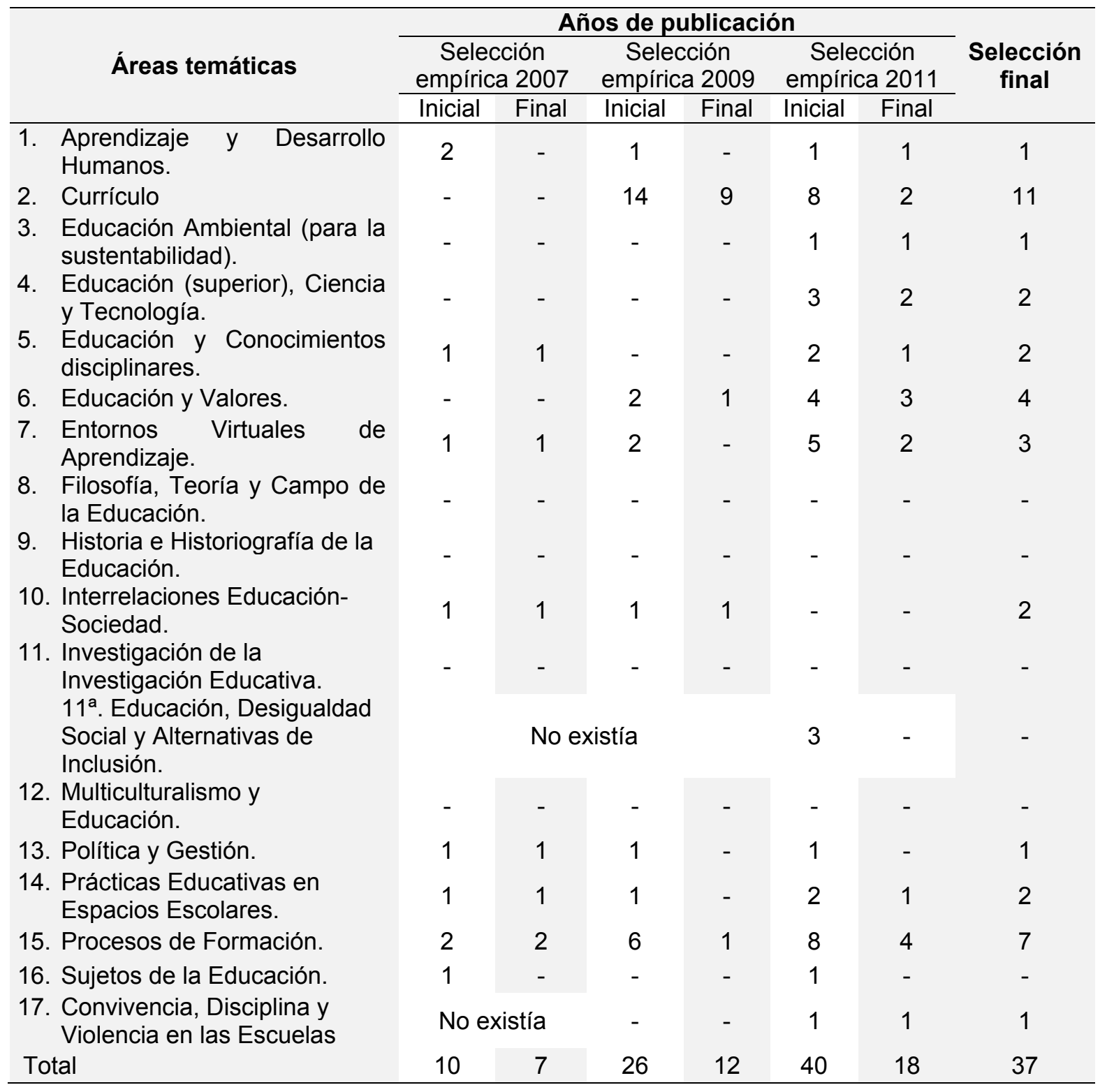

\section{Consideraciones:}

1. De la década 1992-2002 al periodo objetivo 2006-2012, en el caso del COMIE, se realizaron algunos cambios en relación a las áreas temáticas:

a) El área Educación ambiental se renombró como Educación ambiental para la sustentabilidad. 
b) El área Educación, trabajo, ciencia y tecnología, se renombró como Educación Superior, Ciencia y Tecnología.

c) Hasta 2009 se implementó el área Convivencia, disciplina y violencia en las escuelas y en 2011 se integró el área temática Educación, desigualdad social y alternativas de inclusión, lo cual podría explicarse debido a las nuevas condiciones sociales que se presentaban en la sociedad mexicana.

2. El área temática con mayores producciones en el campo de las competencias fue Currículo, seguida por Procesos de formación. Las áreas en las que no se encontraron aportes fueron Filosofía, teoría y campo de la educación; Historiografía e historiografía de la educación; Investigación de la investigación educativa; Multiculturalismo y educación.

3. Se encontró mayor número de producciones en educación superior, específicamente en nivel licenciatura (en universidades y educación normal); le siguen aquéllas que se desarrollan en bachillerato y escasamente, en educación básica.

4. Los reportes/informes de investigación que se reflejan en las memorias de las ponencias del COMIE, giran en torno a cuatro temas centrales: a) currículo, b) docencia y práctica profesional, c) intervenciones en el aula y c) formación no escolarizada.

a) En currículo se encuentran contribuciones relacionados con el diseño curricular en bachillerato (Andrade, 2011) y de una especialidad en género (González \& Rojas, 2009); se realizan acercamientos a la evaluación del diseño curricular (López, Pérez \& Gonzalo, 2009), así como la evaluación de las competencias mediante el uso de las Tecnologías de la Información y la Comunicación-TIC (Barroso \& Gómez, 2007; Esquivias, Gasca \& Martínez, 2009; Castillo \& Marín, 2011).

b) En formación y desempeño profesional se encuentran trabajos relacionados con la administración escolar en educación básica (Peniche, 2007); la mejora de la gestión escolar en educación básica (Cárdenas, 2011); el desarrollo de la práctica profesional en áreas como la pedagogía (Cruz, 2009); la formación 
inicial y su especialización en inglés (Aquino \& García, 2011), en matemáticas (Ávalos, 2011) y el uso de recursos tecnológicos (Leal \& Garza, 2011). De igual forma aquéllos relacionados con el logro de competencias investigativas en posgrado (Jaik Dipp \& Ortega, 2011; Guajardo, 2011); en formadores de educación básica (Loya, 2011); para la planificación del desempeño profesional en el área de odontología (Martínez, Mcdonal \& García, 2009); para la valoración de planes de estudio de secundaria (Velázquez, Torres \& Barona, 2011); así como para la evaluación del desempeño profesional (Gómez, Tablas \& López, 2009).

c) Respecto a intervenciones en el aula se presentan estudios relacionados con el desarrollo y empleo de las competencias en educación primaria (Toscano \& Paniagua, 2007; Pineda, 2009); con estudiantes de telesecundaria (Cortés Garavito, 2007); competencias éticas profesionales (Ibarra, Escalante \& Fonseca, 2011) y emocionales en bachillerato (Ruelas, 2011). En educación superior se encontraron trabajos generados desde la oferta educativa de distintas universidades, específicamente en áreas como ciencias agropecuarias (Medina, 2007), ingeniería (Rodríguez, Lara \& Cerpa, 2007; Vargas, 2011), alimentos (Juárez, 2009), psicología (Torres, 2009); de formación ética en educación tecnológica (Ortega \& Terrazas, 2011) y finalmente en educación normal a través de experiencias de ciencias (Vázquez, Barzola \& Pérez, 2011), matemáticas (García \& Benítez, 2011) y formación en valores cívicos (Medina, Cordero \& González, 2011).

d) En educación no formal, se presentaron trabajos referentes al mercado laboral y capacitación para el trabajo (Gaspar, 2007), en odontología (Sánchez, Moreno \& Herrera, 2009) y en la industria (Rodríguez, 2009).

Finalmente, las categorías más recurrentes en relación a los estudios de las competencias se suscriben a dos ámbitos, por un lado, tiene una función adjetivante, in situ dependiendo de las condiciones específicas de su aplicabilidad, nivel educativo o espacio de formación. $Y$ por otro lado, una función esperanzadora en términos de lo que se espera que logre en los sujetos a los que interpele. 


\section{Lo transitado y las nuevas rutas}

Sin duda, las competencias tienen un carácter abierto, inestable y contingente, mismo que está en continua tensión a partir del contexto en el que se desarrolla, la intención de los informantes, el sentido que le impregna cada investigador, las finalidades de las investigaciones, los objetivos y las preguntas que aperturan nuevas discusiones.

\section{Ausencias, tendencias y recomendaciones.}

A partir de los resultados encontrados se identifican, no en sentido cartesiano, sino en uno de prospectiva indefinida, tres aspectos centrales en los estudios de las competencias, mismos que se exponen a continuación:

1. Tendencias:

a) Las investigaciones acerca de las competencias, en su mayoría, continúan formando parte de una perspectiva de desarrollo social que se inscribe primeramente en una meta educacional desde las recomendaciones internacionales y la política educativa nacional.

b) Son recurrentes los diseños, seguimientos y evaluaciones curriculares, los cuales pasan a suplir los enfoques "tradicionales" aún existentes, como es el caso de las universidades, los tecnológicos y la educación normal.

c) El mayor número de investigaciones se situaron en las áreas de Ciencias sociales (pedagogía, psicología, docencia, ambiental); en medicina (odontología); alimentos y el sector Industrial (ingeniería).

d) Hay un fuerte arraigo hacia el desarrollo de investigaciones cualitativas, destacando los diseños cuasi-experimentales, los registros etnográficos, la investigación acción, la investigación acción-participativa, el análisis de contenido, los estudios de caso y análisis documentales. Las técnicas de acopio de información más recurridas fueron la encuesta, el cuestionario y la entrevista (estructurada, semi-estructurada y cerrada). 
e) En menor medida se encontraron investigaciones cuyo enfoque fue el cuantitativo, destacando los diseños descriptivos, las pruebas $T$ y Análisis de la Varianza (ANOVA) en grupos experimentales.

\section{Ausencias:}

a) A través de este estudio exploratorio-cualitativo, se reconoce que existen grandes ausencias de investigaciones en educación básica; se da por sentado que los docentes de educación básica/investigadores en esa área, realizan intervenciones en sus contextos escolares, lo cual permite pensar que si bien existe producción respecto a las competencias en básica, dicha producción no aparece sistematizada en bases de datos debido a que el informe de su intervención educativa o experiencias, no cumple con los requerimientos que se solicitan para la dictaminación de artículos, ponencias, capítulos de libros, etc.

b) Hay ausencia de trabajos en las áreas temáticas Filosofía, teoría y campo de la educación; Historiografía e historiografía de la educación; Investigación de la investigación educativa; Multiculturalismo y educación. Ello representa un área de oportunidad para los interesados en el área de competencias.

3. Recomendaciones:

a) Hacen falta esfuerzos metainvestigativos para realizar mapeos relacionados con las investigaciones respecto a las competencias, los cuales en un determinado periodo, serán de utilidad para enriquecer el área temática Investigación de la investigación educativa.

b) Es necesario fortalecer la formación en investigación de quienes realizan investigación, a fin de que la comunicación de resultados sean eficaces y permitan circular sus hallazgos. 


\section{A manera de cierre}

De manera general, este estado de conocimiento, como ejercicio exploratorio, representa un modesto aporte metainvestigativo en relación a las tendencias y debates del campo de las competencias. A continuación se exponen algunas ideas finales:

1. Como significante, las competencias operan como un punto nodal que condensa una multiplicidad de significaciones, las cuáles no son estables sino contingentes y se amoldan de acuerdo a las exigencias del medio en el que se pretendan desarrollar y los intereses de los investigadores.

2. Las competencias tienden a significarse en procesos operativos/utilitaristas para el logro de finalidades pedagógicas, epistemológicas y axiológicas en la praxis del ser humano, específicamente en espacios escolarizados de formación.

3. Las competencias se comprenden como dispositivos que movilizan y activan la organización de la urdimbre escolar; como respuesta pedagógica; nivel de dominio; principio orientador; como un medio para lograr una formación integral en los ciudadanos;

4. Las competencias se discuten desde planteamientos teóricos, conductistas, funcionalistas, constructivistas, utilitarios y metodológicos. Se hacen visibles las posibilidades de una educación que permita el desarrollo humano, social y profesional de los sujetos escolares desde ámbitos académicos formales y laborales, con la finalidad de que esos sujetos se inserten a un determinado mercado laboral de manera eficaz y eficiente.

5. Las competencias no tienen una significación cerrada y única, se conforman por una multiplicidad de significaciones que se deconstruyen y reconstruyen a partir de los contextos políticos, educativos y socio-económicos en los que se inserte cualquier investigación.

6. De manera general, no existe un acuerdo en cuanto a la definición de las competencias, por el contrario las rutas de acción se diversifican en el orden de lo necesario, lo pertinente y lo deseable; ello enriquece el debate. 
7. Las nuevas rutas que se proponen desde este estudio es la posibilidad de desarrollar investigaciones relacionadas con el ámbito del multiculturalismo y educación en todos los niveles educativos, ya sea como estudios longitudinales, comparativos, análisis de contenido o aplicabilidad.

Sin duda este trabajo es inacabado y puede seguirse enriqueciendo desde diferentes perspectivas de análisis. El reto principal en este tipo de investigaciones es, durante la sistematización, enfrentarse a la multiplicidad de metodologías utilizadas en durante su diseño.

\section{Referencias}

Aguerrondo, I. (2009). Conocimiento complejo y competencias educativas, Ginebra. BIE/UNESCO: Oficina internacional de educación.

Álvarez, L. (1994). La educación basada en competencias: implicaciones, retos y perspectivas. En Didac, México: UIA Santa Fe.

Andrade, R. A. (2011). El proceso de diseño curricular con enfoque de competencias. El caso del bachillerato general de la Universidad de Guadalajara. En Memorias del XI Congreso Mexicano de Investigación Educativa, México: COMIE.

Aquino, M. D. \& García, G. (2011) Trayectorias y competencias profesionales: quiebres impuestos por el contexto institucional y el entorno global. En Memorias del XI Congreso Mexicano de Investigación Educativa, México: COMIE.

Armenta, A. (2012). Educación especial: inclusión y competencias para la vida. En Tobón, S. y Jaik Dipp, A. (coords.) Experiencias de aplicación de las competencias en la educación y el mundo organizacional, (pp. 433-445), México: Red Durango de Investigadores Educativos A.C.

Armenteros, M., Guerrero, L., Medina, M., Molina, V. \& Villanueva, Y. (2012) Evaluación de las competencias de investigación a nivel de licenciatura. Experiencias en las carreras de contaduría y administración. En Tobón, S. y Jaik Dipp, A. (coords.) Experiencias de aplicación de las competencias en la educación y el mundo organizacional, (pp. 265287), México: Red Durango de Investigadores Educativos A.C.

Avalos, A. (2011). El desarrollo de competencias indiciales en el último año de la formación inicial de profesores de matemáticas: el caso del tratamiento del error. En Memorias del XI Congreso Mexicano de Investigación Educativa, México: COMIE.

Barrera, M. (1997). Educación y competitividad: principales propuestas de los organismos internacionales. El caso de la capacitación en competencias en México. Tesis de licenciatura en relaciones internacionales, México: UNAM.

Barrón, C. (2000). La educación basada en competencias en el marco de los procesos de globalización. En Valle, M. A. (coord.) Formación en competencias y certificación profesional, (pp. 17-44) col. Pensamiento universitario, México: CESU-UNAM.

Barroso, C. \& Gómez, R. A. (2007). La incidencia de las TICS en el fortalecimiento de competencias para participar con éxito en un programa académico (reporte final de 
investigación). En Memorias del IX Congreso Mexicano de Investigación Educativa, Yucatán: COMIE.

Bazdresch, M. (1998). Las competencias en la formación de docentes. Educar, nueva época (2), Guadalajara.

Bejarle, E. G., Salcedo, H., Castañeda, M. C. \& Beltrán, J. (2012). Lengua y literatura de Hispanoamérica: una propuesta de diseño curricular. En Tobón, S. y Jaik Dipp, A. (coords.) Experiencias de aplicación de las competencias en la educación y el mundo organizacional, (pp. 125-138), México: Red Durango de Investigadores Educativos A.C.

Bunk, G. (1994). La transmisión de las competencias en la formación y perfeccionamiento profesionales de la RFA. En Revista Europea Formación Profesional, Alemania: CEDEFOP, pp. 8-13.

Campos, M. (2011) La reflexión: un camino hacia la resignificación de las prácticas profesionales de los académicos de la Escuela Normal No. 3. de Nezahualcóyotl. En Jaik Dipp, A. y Barraza, A. (coords.) Competencias y educación. Miradas múltiples de una relación, (pp. 180-194), México: Red Durango de Investigadores Educativos A.C.

Canales, M. A. (1997). El bachillerato propedéutico en el Estado de México. Una educación orientada por competencias básicas. En Investigación educativa 1993 - 1995. Instituciones, sistemas educativos, procesos curriculares y de gestión. Tomo I: Curriculum, evaluación y planeación educativa, (pp. 224-231). México: COMIE/CESU, ENEP Iztacala-UNAM.

Cárdenas, V. G. (2011). Competencias docentes: solución de conflictos y gestión del clima escolar en profesores de Educación Básica. En Memorias del XI Congreso Mexicano de Investigación Educativa, México: COMIE.

Castellanos, A. R. (2000). Desarrollo curricular por competencias profesionales integrales. En Educar, Secretaría de Educación de Jalisco.

Castillo, M. I. \& Marín, R. (2011). Identificación de competencias docentes en ambientes virtuales de aprendizaje: una aproximación desde la perspectiva del profesor. En Memorias del XI Congreso Mexicano de Investigación Educativa, México: COMIE.

CONOCER (1999). Experiencia piloto "Lucha unida", sociedad de solidaridad social ubicada en El Trapiche, Santa Cruz, Zimatlán, Oaxaca. En Experiencias piloto para la aplicación de la formación en alternancia y la emergencia de competencia laboral en microempresas rurales, (pp. 119-177), México: SAGAR-CIMO-INCA-RURAL

Corral, V., Obregón, F. J., Frias, M., Piña, J. A. \& Obregón, M. E. (1994). Educación ecológica: comparación de competencias pro-ambientales entre estudiantes universitarios mexicanos y estadounidenses. En Revista Latinoamericana de Psicología, 3 (26), 415430.

Cortés, M. (2007). El desarrollo de competencias a través del componente de formación para el trabajo en las TVC. En Memorias del IX Congreso Mexicano de Investigación Educativa, Yucatán: COMIE.

Crocker, F. (1997). Construcción de diseños curriculares por competencias profesionales en educación superior en la etapa de la globalización. El caso de la licenciatura en nutrición de la Universidad de Guadalajara. En Innovación curricular en las instituciones de educación superior, (pp. 183-190) México: ANUIES-UAS.

Cruz, B. (2009). Las competencias en la formación y práctica profesional del pedagogo. Un estudio exploratorio de su campo laboral. En Memorias del X Congreso Mexicano de Investigación Educativa, Veracruz: COMIE.

Cruz Martínez, A. (2011). Las competencias básicas y la construcción de textos académicos y científicos en la educación superior. Caso del posgrado de la Universidad Pedagógica 
Nacional. En Jaik Dipp, A. y Barraza, A. (coords.) Competencias y educación. Miradas múltiples de una relación, (pp. 26-49). México: Red Durango de Investigadores Educativos A. C.

De Alba, A. (2006). ¿Filosofía política del currículum? En Anales de la educación común, 2 (4).

Delgado, M. A. (1990). Influencia de un entrenamiento docente durante las prácticas docentes sobre algunas de las competencias del profesor de educación física. Universidad de Granada.

Díaz, F. \& Rigo, M. A. (2000). Formación docente y educación basada en competencias. En Valle, M. A. (coord.) Formación en competencias y certificación profesional, (pp. 76-104) col. Pensamiento Universitario, México: CESU-UNAM.

Erickson, F. (1989). Métodos cualitativos de investigación sobre la enseñanza. En Wittrock, C. La Investigación de la enseñanza, II. Barcelona, Paidós.

Esquivias, M. T., Gasca, M. A. \& Martínez, M. E. (2009). Competencias del docente virtual universitario y a distancia: sistemas de evaluación por rúbricas. En Memorias del $X$ Congreso Mexicano de Investigación Educativa, Veracruz: COMIE.

Flores, F. (2001). Competencias didácticas de los maestros en formación. En Memoria electrónica del VI Congreso Nacional de Investigación Educativa, México: COMIE/Colima.

Foucault, M. (1982). El discurso del poder. México: Ed. Folios.

García, M. L. \& Benítez, A. A. (2011). Desarrollo de competencias matemáticas a través de resolución de problemas y utilizando una herramienta computacional. En Memorias del XI Congreso Mexicano de Investigación Educativa, México: COMIE.

Gaspar, H. (2007) Dinámica de las competencias laborales en México. Una metodología de medición para un análisis macrosocial. En Memorias del IX Congreso Mexicano de Investigación Educativa, Yucatán: COMIE.

Gómez, H. (1996). Inicios del pensamiento proporcional. Un estudio en la escuela primaria sobre competencias al resolver situaciones de cambio. Tesis de maestría en Ciencias, México: Departamento de Matemática Educativa-CINVESTAV-IPN.

Gómez, R. A. (1997). Modelo institucional de educación basado en competencias. En Innovación curricular en las instituciones de educación superior, (pp. 135-140) México: ANUIES-UAS

Gómez, R. G., Tablas, V., \& López, M. A. (2009). La evaluación con rúbricas en el desempeño por competencias profesionales. En Memorias del $X$ Congreso Mexicano de Investigación Educativa, Veracruz: COMIE.

González, M. (2003). La formación del profesor de educación física en el modelo curricular para competencias profesionales integradas (un camino por recorrer). En Educar (26) (3), 2130, Jalisco.

González, R. M. \& Rojas, P. (2009). Diseño y validación de un programa de formación por competencias en género y educación. En Memorias del X Congreso Mexicano de Investigación Educativa, Veracruz: COMIE.

Guajardo, E. N. (2011). Rasgos y competencias en ética profesional: un estudio a profesores de educación básica en el posgrado de educación de la UIA Puebla. En Memorias del XI Congreso Mexicano de Investigación Educativa, México: COMIE.

Guerrero, G. M. y Peña, C. M. (2001). Las competencias: un currículum en construcción. Estudio de caso. En Memorias electrónicas del VI Congreso Nacional de Investigación Educativa, México: COMIE/Universidad de Colima.

Guerrero, L. A., Armenteros, M., Medina, M., \& Molina, V. (2012). Evaluación de competencias para la investigación en postgrado. Experiencias en la universidad autónoma de 
Coahuila. En Tobón, S. y Jaik Dipp, A. (coords.) Experiencias de aplicación de las competencias en la educación y el mundo organizacional, (pp. 288-308), México: Red Durango de Investigadores Educativos A.C.

Hernández, H. A. (1999). La educación media superior: hacia una educación basada en competencias. En Pedroza, R., Cortés, L., Gómez, T., et. al. (coords.) (1999). La educación media superior en México. Realidad y perspectiva, (pp. 19-64), México: UAEM.

Herrera, A. (1999). Las competencias académicas en educación superior: la opinión de los expertos. En Memorias electrónicas del $V$ Congreso Nacional de Investigación Educativa, México: COMIE-UAA.

Ibarra, L. M., Escalante, A. E., \& Fonseca, C. D. (2011). Valores en las competencias de los estudiantes de educación media superior. En Memorias del XI Congreso Mexicano de Investigación Educativa, México: COMIE.

Irigoyen, J. J. \& Jiménez, M. Y. (1999). Educación: habilidades y competencias. En Bazan (comp.) Aportes conceptuales y metodológicos en psicología aplicada, (pp. 150-164), Sonora: Instituto Tecnológico Superior de Sonora.

Jaik Dipp, A. \& Barraza, A. (2011). Competencias y educación. Miradas múltiples de una relación. México: Instituto Universitario Anglo Español A.C./Red Durango de Investigadores Educativos A.C.

Jaik Dipp, A. \& Ortega, E. (2011). Nivel de dominio de las competencias investigativas de los alumnos de posgrado. En Memorias del XI Congreso Mexicano de Investigación Educativa, México: COMIE.

Jaik Dipp, A. \& Reza, F. (2012). Competencias investigativas de estudiantes técnicos de educación superior. En Lozano, J. y González, O. (Coords.) Tomo seis: La evaluación Educativa. Experiencias de investigación: Puntos de encuentro con el campo de la educación, (pp. 76-90), México: Red Durango de Investigadores Educativos A. C.

Jiménez, E. N. (1996). De una lectura del error a una interpretación de los saberes de los niños: un estudio en la escuela primaria sobre competencias al resolver situaciones de cambio. Tesis de maestría en Ciencias. México: Departamento de Matemática EducativaCINVESTAV-IPN.

Jiménez, M. A. (1999). Propuesta de un programa en capacitación basada en competencias laborales para el nivel operativo en una empresa de servicios, en la ciudad de México, Tesis, México, D.F.

Jonnaert, P., Barrette, J., Masciotra, D., \& Yaya, M. (2006). Revisión de la competencia como organizadora de los programas de formación: hacia un desempeño competente, Ginebra. BIE/UNESCO: Oficina internacional de educación.

Juárez, N. (2009). Las competencias del área de alimentos en el instituto tecnológico del altiplano de Tlaxcala. En Memorias del $X$ Congreso Mexicano de Investigación Educativa, Veracruz: COMIE.

Laclau, E. (2004). Hegemonía y estrategia socialista. Buenos Aires: Fondo de Cultura Económica.

Leal, S. A. \& Garza, M. E. (2011). Las competencias didácticas de las estudiantes normalistas y el uso de los recursos educativos abiertos (REA) en su trabajo docente. En Memorias del XI Congreso Mexicano de Investigación Educativa, México: COMIE.

Lluch, E. (1998). Introducción a la educación basada en competencias. En educación (53), 81104.

López, A. Pérez, I. \& Gonzalo, M. (2009). Evaluación del desarrollo curricular por competencias profesionales integradas del centro universitario de ciencias de la salud. Universidad de 
Guadalajara. En Memorias del X Congreso Mexicano de Investigación Educativa, Veracruz: COMIE.

López González, J., et al. (2012). La administración educativa del currículo por competencias y sus implicaciones en el desempeño profesional de los médicos internos de pregrado. En Tobón, S. y Jaik Dipp, A. (coords.) Experiencias de aplicación de las competencias en la educación y el mundo organizacional, (pp. 97-118), México: Red Durango de Investigadores Educativos A.C.

Loya, H. (2011). Referencial de competencias de los formadores de profesores de educación básica. En Memorias del XI Congreso Mexicano de Investigación Educativa, México: COMIE.

Malaga, S. G. (2013). Encuentros y dislocaciones con el APD. Grupos focales en una escuela normal particular del estado de Veracruz. En Memorias electrónicas del XII Congreso Nacional de Investigación Educativa, Guanajuato: COMIE.

Marín, D. E. (1991). La certificación de los saberes profesionales en la carrera de ingeniería civil. En Valle, M. A. (coord.). Formación en competencias y certificación profesional, (pp. 173-198) col. Pensamiento Universitario, México: CESU-UNAM.

Martínez, A. R., Mcdonal, R. S. \& García, J. (2009). Plan de estudios por competencias profesionales: una experiencia de planeación. En Memorias del X Congreso Mexicano de Investigación Educativa, Veracruz: COMIE.

Medina, M. (2007). Perfil de egreso en ciencias agropecuarias basado en competencias profesionales como pertinencia educativa. En Memorias del IX Congreso Mexicano de Investigación Educativa, Yucatán: COMIE.

Medina, G., Cordero, M. \& González, M. P. (2011). Análisis del desarrollo de competencias éticas de alumnos del tecnológico de Monterrey. En Memorias del XI Congreso Mexicano de Investigación Educativa, México: COMIE.

Medina, M., Molina, V. Guerrero, L. \& Armenteros, M (2012). Modelo de formación basado en competencias, diseño, implantación y evaluación. Experiencias en la universidad autónoma de Coahuila. En Tobón, S. y Jaik, A. (coords.) Experiencias de aplicación de las competencias en la educación y el mundo organizacional, (pp. 181-200), México: Red Durango de Investigadores Educativos A.C.

Mendoza, E. (2001). El modelo de educación basada en competencias y la educación tecnológica en México: un análisis de un caso, centro de estudios tecnológicos industrial y de servicios núm. 153, Tesis, México.

Mertens, L. \& Wilde, R. (1996). Una visión del enfoque de capacitación basado en competencias laborales. México: UAM.

Muñoz, E. (1996). Pensamiento relacional en una etapa de transición. Un estudio en la escuela primaria sobre competencias al resolver situaciones de cambio. Tesis de maestría en Ciencias. México: Departamento de Matemática Educativa-CINVESTAV-IPN.

Nájera, F. (1997). Fomento de competencias mediante un programa basado en estrategias cognitivas para el desarrollo creativo en futuros docentes. En Memorias electrónicas del IV Congreso Nacional de Investigación Educativa, México: COMIE-Universidad Autónoma de Yucatán.

Organización de las Naciones Unidas para le Educación, la Ciencia y la Cultura (UNESCO) (2012). Los jóvenes y las competencias: Trabajar con la educación. Informe de seguimiento de la Educación para Todos en el Mundo, Francia.

Orozco, B. (2000). De lo profesional a la formación en competencias: giros conceptuales en la noción formación universitaria. En Valle, M. A. (Coord.) Formación en competencias y 
certificación profesional, (pp. 45-75) col. Pensamiento Universitario, México: CESUUNAM.

Ortega, F. \& Terrazas, V. (2011). Estrategias didácticas asociadas al aprendizaje basado en competencias en una institución de educación superior. En Memorias del XI Congreso Mexicano de Investigación Educativa, México: COMIE.

Parra, H., et al. (2012). Seguimiento a la reforma curricular por competencias de la facultad de medicina. En Tobón, S. y Jaik, A. (coords.) Experiencias de aplicación de las competencias en la educación y el mundo organizacional, (pp. 244-264), México: Red Durango de Investigadores Educativos A.C.

Peniche, R. (2007). Determinando competencias y necesidades de desarrollo profesional de administradores escolares en el oriente del estado de Yucatán. En Memorias del IX Congreso Mexicano de Investigación Educativa, Yucatán: COMIE.

Perales, R. C., Macías, M. P. \& Macías, A. (2011). Competencias del investigador educativo en la producción del conocimiento desde su cultura experiencial. En Jaik Dipp, A. y Barraza, A. (coords.) Competencias y educación. Miradas múltiples de una relación, (pp. 180194), México: Red Durango de Investigadores Educativos A.C.

Pimienta, J. H. \& Medina, L. (2012). Aprendizaje y actitudes de los estudiantes hacia las matemáticas. Una intervención educativa en Educación Superior. En Tobón, S. y Jaik, A. (coords.) Experiencias de aplicación de las competencias en la educación y el mundo organizacional, (pp. 443-468), México: Red Durango de Investigadores Educativos A.C.

Pineda, I. (2009). Competencias para el desarrollo del trabajo docente en la escuela primaria Ignacio Pineda Pineda. En Memorias del X Congreso Mexicano de Investigación Educativa, Veracruz: COMIE.

Reynaga, S. (2001). Competencias educativas-integrales. Didac, (37), México: Universidad Iberoamericana.

Rojas, I. (2000). La educación basada en normas de competencia (EBNC) como un modelo de formación profesional en México. En Valle, M. A. (coord.) Formación en competencias y certificación profesional, (pp. 45-75) col. Pensamiento Universitario, México: CESUUNAM.

Ruiz, E. (2000). Desarrollo de competencias para la innovación tecnológica. El reto de las instituciones de educación superior en la formación de ingenieros, México: IISUNAM/Plaza y Valdez.

Sánchez, C. L., Moreno, W. \& Herrera, A. (2009). Competencias profesionales y su vinculación con el mercado laboral en la formación del odontólogo de la facultad de estudios superiores Zaragoza, UNAM. En Memorias del X Congreso Mexicano de Investigación Educativa, Veracruz: COMIE.

Sañudo, L. E. (1999). Competencias formativas. En anexo del Proyecto curricular de la Maestría en Educación con intervención en la práctica educativa. Guadalajara.

Sañudo, L. E. (2000). Un objeto de investigación en proceso de confrontación. En Sinéctica, (17), Tlaquepaque.

Soria, G. (2001). La planificación por competencias: una opción para conferir sentido y utilidad al aprendizaje escolar. En Memorias del Segundo Encuentro Iberoamericano de Colectivos Escolares que Hacen Investigación desde la escuela, (pp. 87-92), México: UPN.

Tinoco, M. (2001). Educación basada en competencias en el ámbito de educación superior. En Didac. México: Universidad Iberoamericana.

Tobón, S. (2006). Aspectos básicos de la formación basada en competencias. Talca: proyecto Mesesup. Bogotá: ECOE. 
Tobón, S. \& Jaik Dipp, A. (2012). Experiencias de aplicación de las competencias en la educación y el mundo organizacional. México: Instituto CIFE/ReDIE-CIIDIR-IPN, Unidad Durango-IUNAES.

Torres, L. C. (2009) Funciones y competencias en psicólogos de educación especial. En Memorias del X Congreso Mexicano de Investigación Educativa, Veracruz: COMIE.

Toscano, U. \& Paniagua, M. (2007). Desarrollo de competencias cognitivas en el aula: dos abordajes que lo intencionan. En Memorias del IX Congreso Mexicano de Investigación Educativa, Yucatán: COMIE.

Valdés, J. A., Vera, J. A. \& Siqueiros, J. P. (2012). Competencias científicas de estudiantes de posgrado en ciencias naturales e ingenierías. En Lozano, J. y González, O. (Coords.) Tomo seis: La evaluación Educativa. Experiencias de investigación: Puntos de encuentro con el campo de la educación, (pp. 64-75), México: Red Durango de Investigadores Educativos A. C.

Valenzuela, M. (1999). Una alternativa para la equidad de género en preescolar. En género e Educacao. Cadernos Sempreviva, Textos para a acao Feminista, 40-54.

Vargas, C. R. (2011). Competencias profesionales del ingeniero en la sociedad del conocimiento En Memorias del XI Congreso Mexicano de Investigación Educativa, México: COMIE.

Vargas, V. \& Cristóbal, C. (2012). Competencias matemáticas y el uso de herramientas tecnológicas en el nivel superior. En Tobón, S. y Jaik Dipp, A. (coords.) Experiencias de aplicación de las competencias en la educación y el mundo organizacional, (pp. 387403), México: Red Durango de Investigadores Educativos A.C.

Vázquez, E., Barzola, A. \& Pérez, A. (2011). El jardín botánico como recurso para el desarrollo de competencias docentes. En Memorias del XI Congreso Mexicano de Investigación Educativa, México: COMIE.

Velázquez, A., Torres, S. A. \& Barona, C. (2011). La visión de los profesores sobre la reforma por competencias en la educación secundaria del estado de Morelos. En Memorias del XI Congreso Mexicano de Investigación Educativa, México: COMIE.

Vera, J. A. \& Camargo, P. (2000). Evaluación de una política pública sobre las competencias básicas de niños y niñas de escuelas primarias rurales del sur del estado de Sonora. En Ramos (comp.) Investigaciones educativas en Sonora, Vol. 2, (pp. 66-95), Sonora: Red de investigación educativa/Dirección General de Investigación Educativa.

Vera, J. A., Peña, R. \& Domínguez, S. E. (1999). Nivel de entrada de competencias básicas en niños escolares de zona urbana marginada. En Ramos (comp.) Investigaciones educativas en Sonora, Vol. 2, (pp. 66-95), Sonora: Red de investigación educativa/Dirección General de Investigación Educativa.

Yurén, M. T. (1997). Democracia radical, eticidad y educación. En Aleph, 2 (1), Oaxaca, 5-12. 


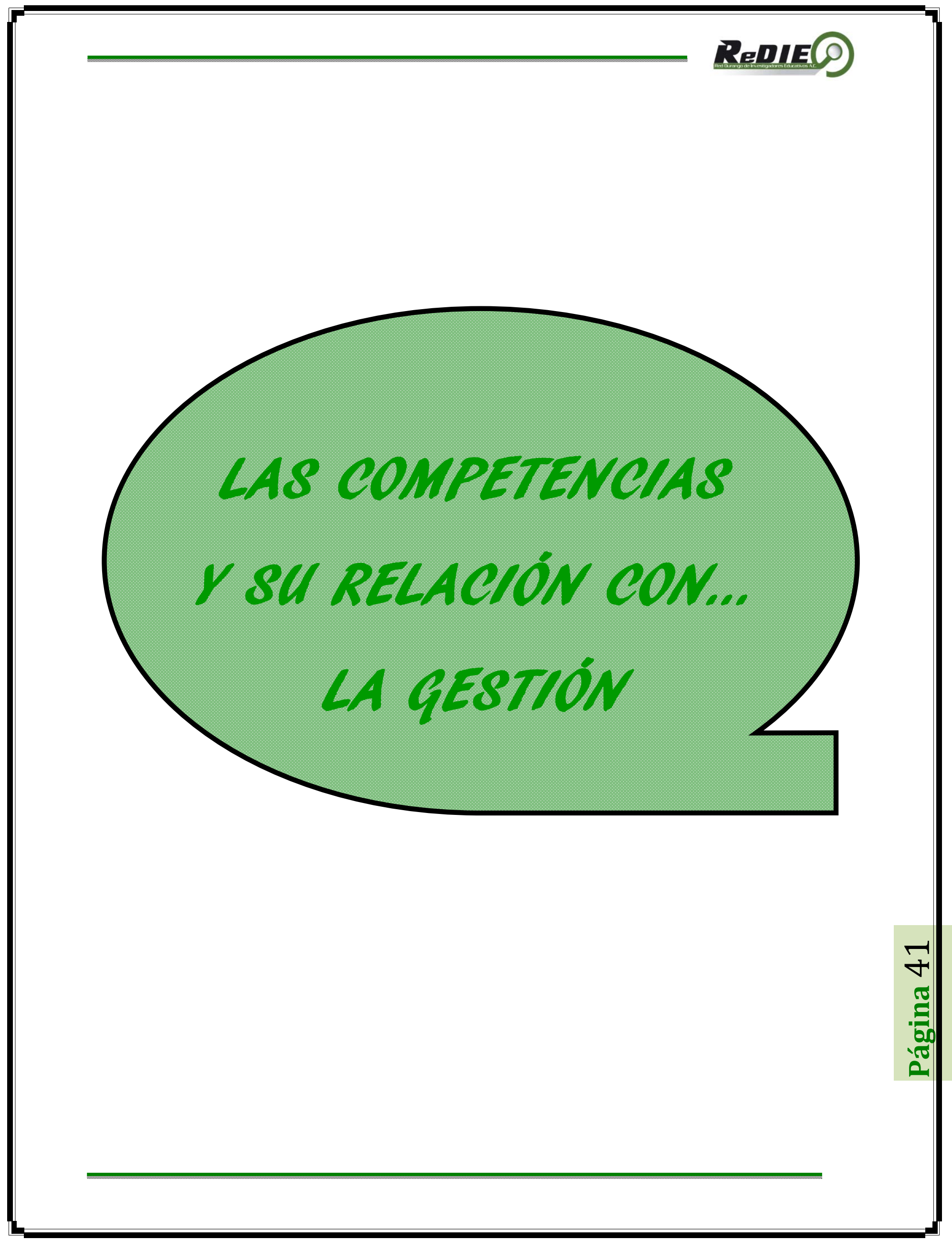




\title{
LAS COMPETENCIAS GENÉRICAS: UN MODELO DE GESTIÓN EDUCATIVA PARA FORMAR DOCENTES-INVESTIGADORES CON ENFOQUE HUMANISTA
}

\author{
GENERIC COMPETENCES: A MODEL OF EDUCATIONAL \\ MANAGEMENT TO FORM PROFESSORS BASED HUMANIST
}

\author{
Esperanza Lozoya Meza \\ Centro de Investigaciones Económicas Administrativas y Sociales (CIECAS) \\ Instituto Politécnico Nacional \\ perylozoya@gmail.com
}

\begin{abstract}
Resumen
La propuesta Modelo de Gestión Educativa que aquí se presenta es de (transición/proceso), porque los resultados en el proceso de formación, no van a aparecer inmediatamente, se van desarrollando poco a poco. Su contenido pretende ser un material de apoyo para que el docente, independientemente de su profesión, cuente con marcos de referencia en el campo de la educación ya sean contextuales o teóricos, con el objetivo de que adquieran con esto, herramientas para implementar las competencias genéricas en el salón de clases. Esta propuesta, viene a complementar algunos Modelo Educativos que se tienen actualmente en las diversas Instituciones Educativas del país. Es un modelo de "proceso y de toma de conciencia para el desarrollo del ser humano integral" en las áreas biológica, psicológica, social y trascendental, con aprendizaje significativo y apoyado por el enfoque humanista.
\end{abstract}

Palabras Clave: (Modelo de gestión educativa; toma de conciencia; área biopsicosocial-trascendental).

\begin{abstract}
The Model of Educational Management proposal presented here is (transition / process), has the results in the training process, they will not appear immediately, they develop gradually. Its content is intended to be a supporting material for teachers, regardless of their profession, expect frameworks in the field of education either contextual or theoretical, in order to acquire this, tools for implementing generic skills in the classroom. This proposal complements some Educational Model that is currently in various educational institutions of the country. It is a model of "process and awareness for the comprehensive development of human beings" in the biological, psychological, social and transcendental, with significant learning and supported by the humanistic approach areas.
\end{abstract}

Key words: Model of educational management; awareness; biopsychosocial-transcendental area. 


\section{Contexto Internacional y Nacional}

Se considera que el docente debe tener un marco de referencia sobre cuál es el rumbo que tiene la educación en nuestro país a nivel internacional y nacional, como por ejemplo, la UNESCO menciona que la educación deberá transformarse para atender a las necesidades sociales y fomentar la solidaridad y la igualdad en la perspectiva de la educación a lo largo de la vida y señala que se deben formar ciudadanos que participen activamente en la sociedad, promover, generar y difundir conocimientos por medio de la investigación para que con ello se contribuya a proteger y consolidar los valores de la sociedad.

Más adelante se señalan las políticas de gestión educativa (globalización, sociedad del conocimiento, multi y transdisciplinar). Es decir hoy en día un objeto de estudio se debe analizar desde diferentes enfoques, no sólo desde la disciplina, sino multidisciplinariamente. Más adelante señala en uno de sus objetivos que la educación es un derecho humano y un bien público social. Los Estados tienen el deber fundamental de garantizar este derecho. Los Estados, las sociedades nacionales y las comunidades académicas deben ser quienes definan los principios básicos en los cuales se fundamenta la formación de los ciudadanos y ciudadanas, velando por que ella sea pertinente y de calidad.

El Programa Sectorial de Educación 2007-2012, dice que El México del nuevo milenio demanda que el Sistema Educativo Nacional forme a sus futuros ciudadanos como personas, como seres humanos conscientes, libres, con identidad, razón y dignidad, con derechos y deberes, creadores de valores y de ideales. En la escuela, los alumnos han de encontrar las condiciones adecuadas para el desarrollo pleno de sus capacidades y potencialidades; de su razón y de su sensibilidad artística, de su cuerpo y de su mente; de su formación valoral y social; de su conciencia ciudadana y ecológica.

Desde luego es necesario que los docentes (sobre todo los de nuevo ingreso) conozcan la misión, la visión, el origen y desarrollo de la Institución donde colaboran ¿Quiénes fueron los precursores? ¿Cómo está estructurada y organizada? ¿Cuáles son 
los centros, escuelas y unidades que la conforman?, entre otros. Esto con la intención de que se identifique plenamente con su Institución.

Afortunadamente los mexicanos, contamos con instituciones educativas públicas que nos dan la oportunidad de seguirnos superando todos los días, lo que tiene que hacer el docente, es detectar las áreas de su interés para continuar su formación integral, no sólo de actualización profesional, sino de formación como docente. Esta formación la puede ir adquiriendo ya sea a través de cursos, talleres, seminarios, coloquios, o bien con Diplomados, Maestrías, Doctorados y Postdoctorados.

Otro aspecto relevante es la "formación para la investigación". Esta es conceptualizada como un quehacer académico consistente en promover y facilitar, preferentemente de manera sistemática, el acceso a los conocimientos y el desarrollo de las habilidades, hábitos y actitudes que demanda la realización de la práctica denominada investigación en donde el docente, en una primera instancia, se vuelve investigador de su propia práctica educativa, ya que tendrá que investigar cuáles son los avances de la asignatura que imparte, cuáles son los marcos teóricos con los que se puede apoyar para desarrollar el proceso enseñanza-aprendizaje, tomando en consideración que no todos los alumnos aprenden de la misma manera.

Es importante ir desarrollándose como docente-investigador, siempre y cuando le interese profundizar sobre los grandes problemas educativos que tenemos a nivel nacional, para ello existe un Consejo Mexicano de Investigadores Educativos (COMIE), que organizan cada 2 años congresos, éstos dan cuenta cómo está la investigación educativa a nivel nacional a través de sus resultados presentados en los estados del conocimiento, entendido como un análisis sistemático y la valoración del conocimiento y de la producción generada en torno a un campo de investigación durante un periodo determinado. Permite identificar los objetos bajo estudio y sus referentes conceptuales, las principales perspectivas teóricas-metodológicas, tendencias y temas abordados, el tipo de producción generada, los problemas de investigación y ausencias, así como su impacto y condiciones de producción.

Haciendo esta actividad, se enriquece, en primer lugar a sí mismo, en segundo lugar se enriquece el trabajo que desarrolla en el aula, beneficiando con esto a los educandos y en tercer lugar beneficia el entorno en el cual se desenvuelve pues toma 
más conciencia de su Ser y de su hacer en un campo que tiene muchas líneas de investigación.

\section{La Gestión Educativa Centrada en la Persona}

Para algunos estudiosos del tema, la gestión se concibe como el conjunto de servicios que prestan las personas, dentro de las organizaciones. Esto significa que la gestión adquiere una especificidad, en tanto que tiene mucha importancia la labor humana.

Pero en el caso de la gestión educativa, el peso recae en las competencias profesionales humanas, que en este caso el docente lleva a cabo en el salón de clases, pero a la vez necesita tener competencias profesionales, porque no es un ente aislado, sino que forma parte de una comunidad que tiene su propia misión, visión institucional, por eso también es necesario que tenga este tipo de competencias.

Por "competencia profesional" se puede entender de acuerdo con De Lella (1999), un dominio de conocimientos, habilidades y técnicas articuladas desde la conciencia del sentido y de las consecuencias de la propia práctica.

Carlos Topete (2007), señala, que las -competencias profesionales son- "una mezcla de habilidades, capacidades, actitudes, rasgos de personalidad, que se encuentran más o menos relacionados con la actividad profesional". Lo que resulta evidente hoy día, es que la formación de competencias, es un imperativo para las instituciones educativas.

En el caso de las Instituciones de Educación Superior, se requiere llevar a cabo procesos de formación de competencias no sólo escolares, sino ante todo, competencias profesionales y yo añadiría competencias humanistas. Sólo así se podrá contrarrestar "el divorcio" entre lo que se aprende en los sistemas de educación formal y lo que demanda el mercado laboral y por supuesto el deseo interno de cada ser humano. Estas capacidades están compuestas "por tres dimensiones:

1. El saber o componente conceptual de la competencia

2. El saber hacer o dominio de procesos y tecnologías

3. El ser o valores y actitudes vinculadas con el comportamiento social y el desarrollo ético" 
De estas tres dimensiones, Topete considera que se derivan otros saberes, como lo menciona Braslavsky y Acosta (2004), el saber actuar con pertinencia, saber movilizar saberes y conocimientos en un contexto profesional, saber integrar 0 combinar saberes múltiples y heterogéneos, saber transferir, saber comprometerse, saber aprender y aprender a aprender.

Asimismo se plantea un cuestionamiento esencial: ¿Pueden definirse a las competencias en abstracto o debieran depender del contexto en el que se ejercen? Su respuesta a esta interrogante plantea que la selección de las competencias y su definición, dependen del contexto educativo y cultural.

A partir de esta visión integradora de las distintas perspectivas acerca de las competencias profesionales para la gestión educativa, Elizabeth Iturbe (2009) plantea las finalidades primordiales que a su consideración debe perseguir la formación en competencias de gestión educativa.

$>$ El desarrollo del saber (nivel conceptual)

$>$ El desarrollo del saber hacer (nivel fáctico) y

$>$ El desarrollo del ser (nivel ontológico).

Además añade una cuarta finalidad, que la considera la más importante:

$>$ El desarrollo del aprender a convivir (nivel humanístico)

Estas cuatro finalidades se relacionan también directamente con el informe Delors (1996) y esta cuarta finalidad representa la principal "asignatura pendiente" que tenemos que aprender para poder considerarnos cabalmente como humanidad, aunque yo añado también la del desarrollo del Ser humano.

Aquí es justo donde empata mi propuesta de Modelo de Gestión Educativa con enfoque humanista, porque se considera que se trata de un desarrollo de aprendizaje personal continuo de las competencias en gestión educativa.

Estas competencias, ayudan para que se pueda generar un aprendizaje organizacional que pueda tornar a las instituciones educativas en organizaciones inteligentes, con trabajo colaborativo, para que se puedan formar redes del conocimiento, entre otras. Por ello es vital que los procesos de formación en gestión educativa, se enfoquen a la formación de competencias, tomando en consideración desde luego el desarrollo del ser humano integral. 
Fernando Villarán (2010) plantea que ha coordinado proyectos para la Organización Internacional del Trabajo (OIT) de la UNESCO, señalan que las competencias profesionales esenciales para la gestión son, entre otras:

> Tener vocación por la innovación, el cambio y la mejora continua

$>$ Resolver problemas, buscando permanentemente soluciones creativas

Actuar en función de los valores, comprometiendo las voluntades de las personas para la creación de una cultura organizacional propia y apropiada

> Tener capacidad de comunicación fluida y empática

> Poseer iniciativa y capacidad para tomar decisiones en situaciones normales 0 de riesgo y asumir permanentemente nuevos desafíos

> Desarrollar métodos de trabajo sistemáticos, organizar las funciones y procesos de la organización, planteándose metas de crecimiento

Estas son otras competencias profesionales, pero son de "formación para la gestión", incluyen el conocimiento de la gestión estratégica, así como una serie de habilidades y capacidades situacionales que se tornan en competencias al interactuar entre sí para enfrentar sinérgicamente los desafíos de la educación.

El eje que vincula la sinergia de la interacción de las competencias, está constituido por la gestión estratégica, el liderazgo, el trabajo en equipo y la participación y demanda educativa. Estas competencias constituyen un eje motor que permite vincular las demás competencias: anticipación, resolución de problemas, delegación y negociación. Esta interacción sinérgica favorece la gestión educativa estratégica para enfrentar los desafíos de la educación en el siglo XXI.

Desde luego, hay que tomar en cuenta que estas competencias planteadas de manera general, deben entrar en acción en un contexto cultural, educativo, social, político y económico determinado en cada país. A continuación y para complementar este enfoque, se presenta el esquema "Gestión Estratégica" con las competencias profesionales para la gestión educativa propuesta (desde hace varios años pero que todavía se consideran de actualidad) por el IIPE-UNESCO Buenos Aires en sus 10 Módulos de Gestión Educativa y son las siguientes: 


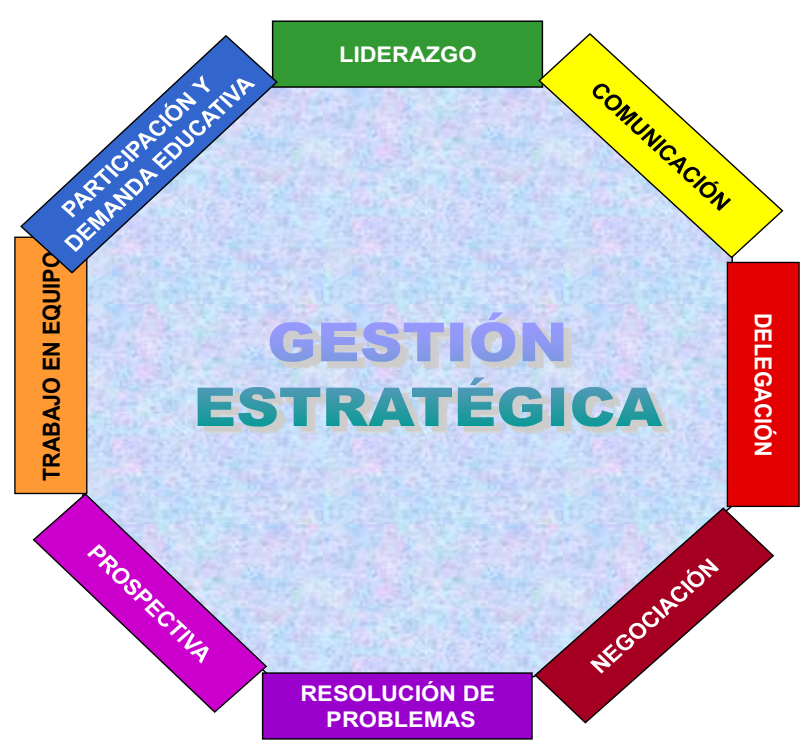

Figura 1. Gestión Estratégica.

Fuente: Elaboración propia a partir del documento Diez módulos destinados a los responsables de los procesos de transformación educativa, (2000) IIPE-UNESCO, Buenos Aires.

Sintetizando se considera que las "capacidades de gestión educativa" que requiere un docente en formación son las siguientes:

1) Conocer la situación socio-histórica, cultural e institucional del lugar donde se desarrolla inicialmente, pero podrá investigar otros sistemas educativos si es que le interese incursionar en la investigación de la gestión educativa.

2) Un docente deberá conocer las diferentes técnicas y metodologías disponibles de la gestión educativa que se hace en el salón de clases, o bien, para hacer investigación educativa apoyada en la gestión y administración de los servicios educativos en el que colabora u otros de su interés. Así como poseer criterio para seleccionar los adecuados procesos de toma de decisiones.

3) La actual complejidad de la administración y gestión de los sistemas exige el conocimiento y uso pertinente de nuevas modalidades para la investigación y de los recursos de la tecnología que permita mejorar los conocimientos del campo sobre el que actúan en investigaciones cuantitativas y cualitativas que puedan aportar al conocimiento del campo. 
4) Poseer la capacidad de articular los datos de la realidad para poder construir las problemáticas educativas que deberán ser abordadas por los docentes interesados a partir de la gestión educativa, es otro campo abierto a la exploración.

5) Conocer la especificidad del sector educativo es obligación del docente, para que pueda evaluar la pertinencia de las propuestas construidas desde lógicas provenientes de otras áreas de la administración pública pertinentes para la organización de sectores de la actividad social diferentes del educativo.

6) Capacidad para analizar las políticas educativas y evaluar sus resultados a la luz de los objetivos planteados y del conjunto de los valores que orientan la acción, es también una necesidad obligada por parte del docente en su planeación educativa.

7) Tener la capacidad de identificar las peculiaridades de diferentes actores $y / o$ instituciones y construir propuestas de investigaciones educativas desde la perspectiva organizacional y/o pedagógica en relación con sus necesidades específicas y demandas, para promover una gestión flexible que sea capaz de atender la diversidad, para poder lograr la equidad.

Estas son algunas de las "capacidades o competencias" para la gestión educativa que se considera que son importantes, no sólo para los docentes, sino también para los funcionarios responsables del sector educativo comprometidos con la gestión educativa.

Las capacidades o competencias vinculadas a la investigación, antes señaladas, deben desarrollarse inicialmente a lo largo de los procesos para la formación en gestión, ya que permiten reunir conocimientos especializados, así como habilidades para ser aplicadas en investigaciones educativas realizadas por los profesores de su propia práctica educativa.

Es decir, para la formación de los docentes-investigadores es importante tomar en consideración las competencias relacionadas con actitudes y hábitos, así como con habilidades de percepción, habilidades instrumentales, de pensamiento, de construcción conceptual metodológica y social del conocimiento, entre otras.

Recordemos que el objeto de la gestión educativa es la formación de seres humanos integrales y por ello, en el ámbito de la educación, el contexto interno, o al 
menos parte del contexto interno (alumnos-docentes) tienden a mezclarse conceptualmente con los fines de la organización.

\section{Educación por competencias}

En México se ha venido haciendo énfasis en que los procesos de formación docente se lleven a cabo para desarrollar planes y programas de estudio bajo el enfoque por competencias.

Es por ello que en los últimos tiempos se ha procurado que la formación de los profesores vaya acorde con el desarrollo de los enfoques de formación basados en competencias, de acuerdo a la propuesta presentada por la Reforma Integral de la Educación Media Superior (RIEMS) a través del Sistema Nacional de Bachillerato (2008), entre sus planteamientos se encuentran las competencias siguientes:

Tabla 1.

Competencias en el Sistema Nacional de Bachillerato

\begin{tabular}{|c|c|c|}
\hline \multicolumn{2}{|c|}{ COWPETENCJAS } & OBJEூJVOS \\
\hline \multicolumn{2}{|c|}{ GENÉRICAS } & $\begin{array}{l}\text { Son competencias clave, por su importancia y } \\
\text { aplicaciones diversas a lo largo de la vida. Son } \\
\text { transversales y transferibles (todas las disciplinas). }\end{array}$ \\
\hline \multirow[t]{3}{*}{ Disciplinares } & \multirow{3}{*}{$\begin{array}{l}\text { Básicas } \\
\text { Extendidas }\end{array}$} & $\begin{array}{l}\text { Integran conocimientos, habilidades y actitudes y } \\
\text { se construyen desde la lógica de las disciplinas del } \\
\text { saber. Dan sustento a la formación de los estudiantes. }\end{array}$ \\
\hline & & $\begin{array}{l}\text { Son las competencias disciplinares que deben } \\
\text { desarrollar todos los estudiantes del bachillerato. } \\
\text { Representan la base común. }\end{array}$ \\
\hline & & $\begin{array}{l}\text { Dan especificidad al Modelo Educativo de los } \\
\text { distintos subsistemas de la EMS. Son de mayor } \\
\text { profundidad, (no son compartidas). Propedéuticas }\end{array}$ \\
\hline \multirow[t]{3}{*}{ Profesionales } & \multirow{3}{*}{$\begin{array}{l}\text { Básicas } \\
\text { Extendidas }\end{array}$} & $\begin{array}{l}\text { Se refieren a un campo del quehacer laboral. } \\
\text { Definen la capacidad productiva en cuanto a } \\
\text { conocimientos, habilidades y actitudes. }\end{array}$ \\
\hline & & $\begin{array}{l}\text { Proporcionan a los jóvenes formación elemental para } \\
\text { incorporarse al mercado de trabajo. }\end{array}$ \\
\hline & & $\begin{array}{l}\text { Preparan a los jóvenes con una calificación de nivel } \\
\text { teórico para incorporarse al ejercicio profesional. }\end{array}$ \\
\hline
\end{tabular}

Fuente: SEP/ Reforma integral de la Educación Media Superior en México (2008). 
En este apartado se hará énfasis en "Las competencias genéricas que son aquellas que permiten a los bachilleres desarrollarse como personas, y desenvolverse exitosamente en la sociedad y el mundo que les tocará vivir.

Estas competencias son transversales; no se restringen a un campo específico del saber ni del quehacer profesional y su desarrollo no se limita a un campo disciplinar, asignatura o módulo de estudios. La transversalidad se entiende como la pertinencia y exigencia de su desarrollo en todos los campos en los que se organiza el plan de estudios" (RIEMS, 2008) y son las siguientes:

Tabla 2.

Competencias Genéricas

\begin{tabular}{|c|c|c|}
\hline ALUMNOS & DOCENTES & DIRECTIVOS \\
\hline $\begin{array}{l}\text { 1. Se autodetermina } \\
\text { y cuida de sí }\end{array}$ & $\begin{array}{l}\text { 1. Organiza su formación continua a lo largo de su } \\
\text { trayectoria profesional. }\end{array}$ & $\begin{array}{l}\text { 1. Organiza su formación continua a lo largo } \\
\text { de su trayectoria profesional e impulsa la } \\
\text { del personal a su cargo. }\end{array}$ \\
\hline $\begin{array}{l}\text { 2. Se expresa y se } \\
\text { comunica }\end{array}$ & $\begin{array}{l}\text { 2. Domina y estructura los saberes para facilitar } \\
\text { experiencias de aprendizaje significativo. }\end{array}$ & $\begin{array}{l}\text { 2. Diseña, coordina y evalúa la } \\
\text { implementación de estrategias para la } \\
\text { mejora de la escuela, en el marco del } \\
\text { Sistema Nacional de Bachillerato. }\end{array}$ \\
\hline $\begin{array}{l}\text { 3. Piensa critica y } \\
\text { reflexivamente }\end{array}$ & $\begin{array}{l}\text { 3. Planifica los procesos de enseñanza y de } \\
\text { aprendizaje atendiendo al enfoque por } \\
\text { competencias, y los ubica en contextos } \\
\text { disciplinares, curriculares y sociales amplios. }\end{array}$ & $\begin{array}{l}\text { 3. Apoya a los docentes en la planeación e } \\
\text { implementación de procesos de E-A por } \\
\text { competencias. }\end{array}$ \\
\hline $\begin{array}{l}\text { 4. Aprende de forma } \\
\text { autónoma }\end{array}$ & $\begin{array}{l}\text { 4. Lleva a la práctica procesos de enseñanza y de } \\
\text { aprendizaje de manera efectiva, creativa e } \\
\text { innovadora a su contexto institucional. }\end{array}$ & $\begin{array}{l}\text { 4. Propicia un ambiente escolar conducente } \\
\text { al aprendizaje y al desarrollo sano e } \\
\text { integral de los estudiantes. }\end{array}$ \\
\hline $\begin{array}{l}\text { 5. Trabaja en forma } \\
\text { colaborativa }\end{array}$ & $\begin{array}{l}\text { 5. Evalúa los procesos de enseñanza y de } \\
\text { aprendizaje con un enfoque formativo. }\end{array}$ & $\begin{array}{l}\text { 5. Ejerce el liderazgo del plantel, mediante la } \\
\text { administración creativa y eficiente de sus } \\
\text { recursos. }\end{array}$ \\
\hline \multirow{3}{*}{$\begin{array}{l}\text { 6. Participa con } \\
\text { responsabilidad en } \\
\text { la sociedad }\end{array}$} & $\begin{array}{l}\text { 6. Construye ambientes para el aprendizaje } \\
\text { autónomo y colaborativo. }\end{array}$ & \multirow{3}{*}{$\begin{array}{l}\text { 6. Establece vínculos entre la escuela y su } \\
\text { entorno. }\end{array}$} \\
\hline & $\begin{array}{l}\text { 7. Contribuye a la generación de un ambiente que } \\
\text { facilite el desarrollo sano e integral de los } \\
\text { estudiantes. }\end{array}$ & \\
\hline & $\begin{array}{l}\text { 8. Participa en los proyectos de mejora continua de } \\
\text { su escuela y apoya la gestión institucional. }\end{array}$ & \\
\hline
\end{tabular}

Fuente: Elaboración propia apoyada en los documento de la SEP / RIEMS / SNB (2008). 


\section{Enfoque Humanista}

La propuesta que se hace para desarrollar las competencias genéricas, es tomar en cuenta el "enfoque humanista", entendido como una corriente de la Psicología y una filosofía de la vida que sitúa al hombre, la humanidad, la naturaleza y el universo como un TODO armónico, coherente y perfecto.

Se apoya en la Psicología humanista que concibe a la persona como una totalidad, con una visión integradora en las distintas áreas (intelectual, emocional, corporal y trascendental) en las que se interrelacionan factores físicos, emocionales, ideológicos o trascendentales formando el ser real, integral, no una suma de partes. Algunos de sus teóricos son:

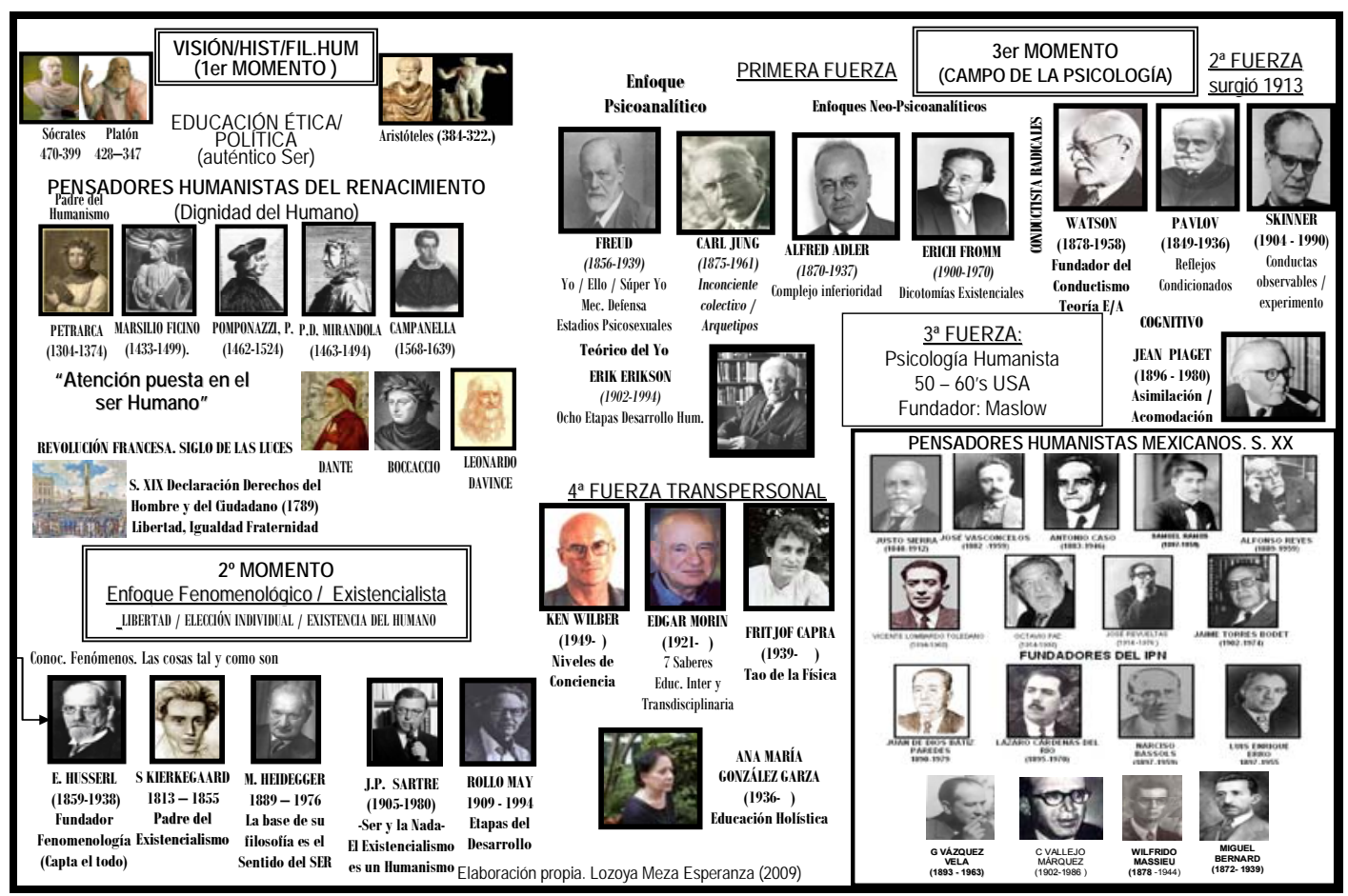

Figura 2. Enfoque Humanista para la Formación de Docentes-Investigadores (Marco Teórico).

Fuente: Elaboración propia (2009), apoyada en los planteamientos de los teóricos del enfoque humanista.

\section{Concepto de Educación, desde el Enfoque Humanista}

Se entiende como un proceso de formación y transformación, en el que los elementos del proceso educativo participan, interactúan y convergen en el aprendizaje significativo 
para el engrandecimiento y perfeccionamiento del ser, integrando la evolución de la transformación interna que conlleva al cambio basado en experiencias significativas de naturaleza dialéctica y la evolución de los agentes de cambio siendo éstos al mismo tiempo, sujetos de cambio.

Desde esta perspectiva, el tradicionalmente llamado maestro, se convierte en un promotor cuya labor será favorecer el proceso enseñanza-aprendizaje de manera significativa, aportando estrategias didácticas para este fin y el alumno es un sujeto orientado a la búsqueda de sus potencialidades y realización de las mismas desde su responsabilidad individual y el ejercicio de su libertad.

Las experiencias significativas que aporta la planta docente (facilitadores), generará un aprendizaje definitivo de un conjunto sistemático de contenidos, experiencias y aprendizajes implícitos en cada asignatura, siendo un proceso lento, gradual y complejo que despega desde el sincretismo inicial, pasando por un enfoque analítico e integrador, hasta la consolidación y la acomodación de todos los elementos de la disciplina para su aplicación a los campos disciplinares.

Por lo tanto, y a partir de esta definición, la educación es el medio que permite al ser humano llegar a satisfacer las necesidades bio-psico-sociales, culturales y trascendentales (o meta necesidades) a través de una praxis educativa que comprende: objetivos, métodos, planes, programas y sistemas de evaluación que responden de manera distinta a los diversos tipos de educación que se conocen: La educación formal, a distancia y la educación continua o permanente.

Así como a las aplicaciones específicas que de éstas se desprenden y que son, entre otras: la educación física, sexual, moral, trascendental, artística, profesional, vocacional, social, entre otras.

La educación vista como un proceso, es un camino que conlleva tanto los aspectos socio-culturales como los axiológicos, elementos que acompañan a toda persona a lo largo de su existencia (González, 1995).

El camino que desde la perspectiva humanista es el más apropiado para facilitar el proceso de educación es el de la relación interpersonal comprometida, que se expresa a través del diálogo abierto, del compartir con autenticidad, congruencia en las 
experiencias, conocimientos, significados personales, y de la confianza y el respeto que toda persona le merece, por el simple hecho de ser humano.

Parafraseando a Carl Rogers (1996), la educación que incluye la exploración y transmisión de valores, es en el encuentro yo-tú, que se descubre que el otro -los otrosson parte de nosotros mismos, y es en donde se realizan los valores cobrando un significado único y pleno. Ir al encuentro, dice el autor, implica valentía y apertura.

Apertura para poder abrazar y hacer nuestro lo que se encuentra fuera de nosotros como algo que se nos opone, y valentía para liberamos de las cadenas del egocentrismo y el deseo de control y de dominio que no impide llegar a ser lo que somos en esencia. Convertirse en un medio para promover en las personas el crecimiento es un trabajo muy importante, el educador no debe descuidar su material de trabajo. La materia prima de su labor educativa y formativa es el ser humano por lo que es responsabilidad tratar de concientizar a las personas sobre su desarrollo y estimularlo a lograr su propia realización.

Tal responsabilidad forma parte de la ética profesional que comprende los principios, los valores, las responsabilidades, las actitudes, la capacitación, las experiencias y metas que todo promotor de procesos grupales o individuales debe poseer.

El ser humano se desarrolla, se forma y humaniza no por un moldeamiento exterior, sino como enriquecimiento que se produce desde el interior mismo del sujeto, con un despliegue libre y expresivo de la propia esencia que se va forjando desde el interior en el cultivo de la razón y la sensibilidad, en contacto con la cultura propia y universal, la filosofía, las ciencias, el arte y el lenguaje.

Carl Rogers (1996) afirma que la Psicología Humanista revoluciona todos los métodos habituales de la ciencia. Apoyándose en la idea de que los fenómenos humanos como la vivencia no pueden ser medidos, abstraídos o reproducidos estadísticamente, se aclara el rechazo tanto a la rigidez del método científico como la predictibilidad del individuo.

Desde una visión holística del hombre, el ser humano es considerado como unidad integral, capaz de conocerse, de ser consciente de sí mismo, de las situaciones y condiciones que lo influyen y al mismo tiempo de influir sobre las mismas. Esta 
conciencia le permite la libertad precisamente como libertad de elección en relación a su propio ser y a su quehacer en el mundo.

La Filosofía Humanista está basada en los siguientes supuestos básicos:

$>$ Cada persona posee una naturaleza interna, de base esencialmente biológica, que es hasta cierto punto natural, intrínseco, innato y en cierto sentido, inmutable, o por lo menos, inmutante.

> La naturaleza interior de cada persona es parte privada de sí y en parte común a la especie.

$>$ Es posible estudiar científicamente esta naturaleza interna y descubrir cómo es (no inventar, sino descubrir)

> Esta naturaleza interna, en la medida en que nos es conocida hasta el momento, no parece ser intrínseca, primordial o necesariamente perversa. Las necesidades básicas (vida, inmunidad y seguridad, pertenencia, afecto, respeto y autorrespeto, autorrealización). Las emociones humanas básicas y las potencialidades humanas básicas son -según todas las apariencias- neutrales, premorales o positivamente constructivas.

$>E$ El ansia de destrucción, sadismo, crueldad, la malicia, etc., parecen hasta ahora no ser de naturaleza intrínseca, sino más bien reacciones violentas contra la frustración de nuestras necesidades intrínsecas, emociones y potencialidades. Así, se puede decir que la ira, el miedo, la pereza y la ignorancia no son malos en sí mismos; aunque en algunos casos pueden llevar al mal comportamiento. La naturaleza humana no es ni mucho menos tan mala como se creía.

> La intensa vocación de que el hombre tiene una naturaleza propia, un esqueleto de estructura psicológica, que puede ser tratado y examinado analógicamente a su estructura física; que tiene capacidades, necesidades y tendencias, de origen genético, algunas de las cuales son características de toda especie humana, sin importar las barreras culturales y otras que son exclusivas del individuo

> La salud total y el desarrollo normal consisten en actualizar esa naturaleza, en realizar estas potencialidades, en crecer hacia la madurez siguiendo las líneas tenues, oscuras, apenas visibles de esta naturaleza esencial, desde dentro más que desde fuera. 
$>$ El ser humano está destinado a un sano respeto propio y a su crecimiento humano personal y social. Esto no significa que en el camino de la vida no existan frustraciones, corajes, justa indignación; no obstante el camino del sufrimiento -no masoquista- y el conflicto llevan al desarrollo $y$ perfeccionamiento.

Y considerando las ya mencionadas con anterioridad:

> El mundo tiene un orden natural que se da en la libertad, desde la cual el ser humano es libre, responsable, consciente, digno de confianza, se autorregula y posee un poder de trascendencia (Sartre; Maslow; Goldstein).

> Las personas buscan su seguridad personal y asumen riesgos, con éstas polaridades promueven su crecimiento (Maslow).

> La relación en comunidades promueve el desarrollo del individuo, si no existe una relación Yo- Tú, no es posible (Buber).

> La comunicación, es el instrumento privilegiado para contactar con el mundo y consigo mismo, para comprender al mundo y para la comprensión del ser.

$>$ La tarea principal del ser humano es convertirse en sí mismo, llegar a ser lo que realmente es (Rogers).

$>$ Estar en-el-mundo, es una característica existencial del ser humano. (representante: Heiddegger).

> El mundo no es concebible sin el hombre (Kierkegaard).

> La naturaleza humana es profundamente positiva, cualquier elección que realiza un individuo expresa su búsqueda de desarrollo total y autorrealización (Rogers; Maslow).

$>$ Todo conocimiento es de importancia relativa, el dogmatismo y absolutismo obstaculizan al conocimiento mismo (De Chardin).

> El ser humano es innatamente constructivo, se autorrealiza constantemente, busca satisfacer sus necesidades, mantiene su existencia.

> La enfermedad mental es vista como una opción desesperada del organismo por mantener su existencia; y la salud, el estado natural del ser humano (Lafarga)

> Es la filosofía humanista la que se sugiere como marco teórico de referencia en la Propuesta de Modelo de Gestión Educativa (transición) para formar docentes- 
investigadores (de su propia práctica educativa) con este enfoque, tratando de responder con el compromiso de formar y formarnos con valores que generen ética profesional y personal, en bien de nosotros mismos y de nuestra sociedad.

\section{Enfoque de Enseñanza-Aprendizaje.}

Considerando que la educación se concibe como un proceso dinámico de aprendizaje significativo, en el cual la participación activa y comprometida del estudiante es un elemento indispensable, el alumno es acompañado por el maestro, quién deja de ser el centro de enseñanza - aprendizaje y se convierte en facilitador que se preocupa por estimular y promover la habilidad para aprender a aprender, lo que implica la apertura a la experiencia. Esta apertura motiva al estudiante a investigar, conocer, descubrir, expresarse, experimentar, dialogar, sentir, comunicarse, escuchar, razonar, relacionarse y responsabilizarse por su propio proceso y existencia.

La aportación del aprendizaje es retomada del discurso de Ausubel (2005) a la psicología cognitiva el cual consiste en la concepción de que el aprendizaje debe ser una actividad significativa para la persona que aprende y dicha significatividad está directamente relacionada con la existencia de las vinculaciones entre el conocimiento nuevo y el que posee ya el alumno.

Por lo tanto resulta básico que el docente no sólo conozca las representaciones que poseen los alumnos sobre lo que se les va a enseñar, sino también, analizar el proceso de interacción entre el conocimiento nuevo y el que ya poseen. La transmisión del conocimiento por parte del profesor puede ser un modo adecuado y eficaz de producir aprendizaje siempre y cuando tenga en cuenta la capacidad de comprensión de los educandos y como ya se mencionó, su experiencia previa en el área del conocimiento que se aborda.

En esta misma línea, el papel del promotor o facilitador es estimular, acompañar, comunicar y facilitar el aprendizaje, además de compartir, relacionarse, comprender, experimentar, empatizar y responsabilizarse también de su existencia y su proceso personal. 
Esto supone que el facilitador desarrolle ciertas habilidades que le permitan convertirse en un facilitador del aprendizaje significativo y en un promotor del desarrollo integral del potencial humano.

Dentro del contexto de la educación humanista en general y de la educación centrada en el alumno, en particular se pueden rescatar algunos de los postulados centrales que dan forma a la Teoría de Rogers:

1. No podemos enseñar a otra persona directamente, sólo podemos facilitar su aprendizaje.

2. Sólo se puede aprender significativamente lo que es percibido como enriquecedor del propio yo, que mantiene la imagen de estima que cada uno tiene de sí mismo.

3. Una atmósfera amenazante genera una experiencia de miedo y un aprendizaje rígido e inflexible. En cambio una atmósfera aceptante y estimulante genera una experiencia placentera y un aprendizaje flexible y abierto.

4. Un ambiente educativo es más eficaz para promover un aprendizaje integral si se reducen las amenazas a la imagen que el estudiante tiene de sí mismo y se facilita y estimula la captación.

En la política de la educación centrada en el alumno, quienes ejercen el poder o control son los alumnos mismos, es decir, es en el grupo en donde el estudiante se encuentra en el proceso de ejercer el control responsable sobre la dirección de su propio aprendizaje y de su propia vida. El facilitador sólo mantiene el control sobre sí mismo.

De esta manera se genera un nuevo concepto del aprendizaje, conocido como aprendizaje significativo, que es aplicable a cualquier nivel de docencia, desde el preescolar hasta el de la educación superior, incluyendo la formación docente.

Se observan en él algunas otras características:

1. Posee una cualidad de compromiso personal. El sujeto pone en juego tanto sus aspectos afectivos como cognitivos.

2. Se auto inicia. Aunque el incentivo o la motivación se originen afuera, el significado del logro, la captación, el descubrimiento o la comprensión surgen del interior de la persona. 
3. Es penetrante. Diferente de la conducta, de las actitudes, de la personalidad del que aprende.

4. El mismo alumno la evalúa. Determina si responde a su necesidad, si le lleva hacia lo que él quiere saber.

5. Su esencia es el significado. Este se constituye dentro de la experiencia global del alumno.

Como se podrá pensar hasta este momento, el ser facilitador del aprendizaje significativo desde el marco de la educación humanista implica una serie de características personales en el que se aventura en tan singular tarea.

\section{Características del Facilitador con Enfoque Humanista: (Rogers, 1996).}

Autenticidad: es la actitud en la que el facilitador interactúa con sus alumnos sin máscaras ni fachadas, consciente de sus experiencias, de sus sentimientos, capaz de vivir éstos libremente y de comunicarlos cuando esto resulte facilitador del desarrollo.

Comprensión empática: se refiere a la capacidad de vivenciar "desde dentro" las reacciones del estudiante; es "sentir con", "sentir como si". Cuando el maestro es sensible a los sentimientos del alumno y a cómo experimenta éste el proceso del aprendizaje. Significa simplemente comprenderlo sin juzgarlo ni evaluarlo; comprenderlo a partir de su propio marco de referencia interno y no a partir de la crítica del maestro.

Aprecio: significa valorar al alumno, considerar sus sentimientos opiniones, su persona toda. Es preocuparse por él pero no de manera posesiva.

Aceptación: es considerar genuinamente al otro, como una persona independiente con derechos y responsabilidades propias, con aciertos y errores, con aspectos que agradan a unos y a otros no. La aceptación a la que se refiere Rogers no considera el estar de acuerdo con todas las conductas o actitudes del alumno, pero si, desde un respeto auténtico, expresar genuinamente lo que el docente piensa y siente.

Confianza: implica poseer la auténtica y profunda convicción de que el alumno es digno de creer en él. Esta confiabilidad se la otorga el simple hecho de "ser humano", al igual que la capacidad para el desarrollo de las potencialidades que este carácter le 
confiere. Claro está que la medida de tal confianza la conferirá la propia capacidad del docente, porque no se trata de una técnica y no se puede fingir que se confía cuando no es así.

La siguiente tabla compara el modelo educativo tradicional y el centrado en el estudiante, véase de qué trata:

Tabla 3.

Educación Convencional vs. Educación Centrada en el Estudiante.

\begin{tabular}{|c|c|}
\hline EDUCACIÓN CONVENCIONAL & $\begin{array}{c}\text { EDUCACIÓN CENTRADA EN EL } \\
\text { ESTUDIANTE }\end{array}$ \\
\hline $\begin{array}{l}\text { El profesor es el poseedor de los } \\
\text { conocimientos mientras que el alumno es } \\
\text { quien los recibe }\end{array}$ & $\begin{array}{l}\text { Precondición: una persona preparada con seguridad } \\
\text { en sí misma y en su relación con los demás, podrá } \\
\text { confiar en la capacidad de otras personas para } \\
\text { aprender por si mismas }\end{array}$ \\
\hline $\begin{array}{l}\text { La clase, o algún medio de instrucción } \\
\text { verbal, es la forma principal de colocar los } \\
\text { conocimientos en quien los recibe. El } \\
\text { examen indica hasta qué punto los recibió }\end{array}$ & $\begin{array}{l}\text { La persona facilitadora comparte con los demás - } \\
\text { estudiantes y miembros de la comunidad- la } \\
\text { responsabilidad del proceso de aprendizaje }\end{array}$ \\
\hline $\begin{array}{l}\text { El profesor posee el poder, impone la } \\
\text { disciplina y es el estudiante quien obedece. }\end{array}$ & $\begin{array}{l}\text { El facilitador proporciona los recursos de aprendizaje: } \\
\text { sus recursos propios y de su propia experiencia, libros, } \\
\text { material didáctico o experiencias de la comunidad }\end{array}$ \\
\hline $\begin{array}{l}\text { La práctica adoptada en la clase se basa } \\
\text { en la autoridad. }\end{array}$ & $\begin{array}{l}\text { El estudiante desarrolla su propio programa de } \\
\text { aprendizaje, ya sea solo o en colaboración con los } \\
\text { otros }\end{array}$ \\
\hline El grado de confianza es mínimo & $\begin{array}{l}\text { Se ofrece un clima de confianza que facilita el } \\
\text { aprendizaje }\end{array}$ \\
\hline $\begin{array}{l}\text { A la democracia y a sus valores se les trata } \\
\text { con desdén. }\end{array}$ & $\begin{array}{l}\text { La disciplina necesaria para que el estudiante alcance } \\
\text { sus metas, es la autodisciplina }\end{array}$ \\
\hline \multirow{2}{*}{$\begin{array}{l}\text { En el sistema educativo apenas hay sitio } \\
\text { para el intelecto, no para la persona como } \\
\text { un todo }\end{array}$} & $\begin{array}{l}\text { El aprendizaje en este clima promotor del crecimiento, } \\
\text { en comparación con los sistemas tradicionales, tiende } \\
\text { a ser más profundo, a desarrollarse a un ritmo más } \\
\text { reflexivo y a ser más abarcador en la vida y en el } \\
\text { comportamiento del estudiante }\end{array}$ \\
\hline & $\begin{array}{l}\text { La persona aprende que es el principal evaluador de la } \\
\text { extensión e importancia del aprendizaje. Si bien la } \\
\text { relación con los otros puede enriquecer su } \\
\text { autoevaluación. }\end{array}$ \\
\hline
\end{tabular}

Fuente: Material de apoyo del Colegio de Especialidades Psicoterapéuticas COPSI (2009) 
En la tabla anterior, se puede abstraer que las condiciones que ofrece el facilitador para el aprendizaje son principalmente actitudinales; el facilitador debe de creer en la capacidad de los estudiantes, respetar su dignidad e integridad, promover con actividades motivantes al aprendizaje, crear la atmósfera adecuada de confianza, evitar el autoritarismo, la coerción al igual que la humillación y comparación con otras personas. El facilitador es un observador de tres pistas puesto que observa su comportamiento, el de sus estudiantes y el de la relación.

Otro modelo interesante de considerar es el de Winne y Marx, (1987) quienes sustentan que el estudiante y el profesor son los principales responsables de los efectos reales de la vida en el aula; las variaciones en los efectos del aprendizaje son función de las actividades mediadoras empleadas por los alumnos en el proceso de aprendizaje.

El comportamiento del profesor no causa directamente el aprendizaje, influye en los resultados en la medida en que activa en el alumno respuestas de procesamiento de información. Ante una misma experiencia de aprendizaje distintos alumnos pueden activar distintos procesos cognitivos y afectivos, provocando, por lo mismo, resultados de aprendizaje muy distintos.

Por todo lo anterior, se piensa que es importante tomar en consideración el enfoque humanista en la educación integral, para promover el desarrollo de las potencialidades y facultades físicas, intelectuales, psicológicas, sociales, trascendentales del ser humano desde una perspectiva holística, es decir, integral.

Por tal razón, la psicología humanista ha comprendido con claridad que uno de los componentes fundamentales del desarrollo y la integridad funcional de la persona es la adquisición o formación de un sistema de valores personales al cual está íntimamente ligado el funcionamiento cabal de la personalidad (C. Rogers, 1983), la auto actualización (Maslow, 1968), el sentido de identidad (Erickson, 1969) y el sentido de vida (Frankl, 1979), entre otros.

Cabe mencionar que el Aprendizaje Significativo es la piedra angular de la educación centrada en la persona. Este aprendizaje consiste en asimilar uno mismo lo aprendido, hacerla propio tal como se hace con el alimento que se ingiere, se digiere y 
se asimila. Cuando el aprendizaje tiene significado para la persona, se integra a ella, por lo tanto, no se olvida y puede aplicarse prácticamente en la vida diaria.

Este tipo de aprendizaje siempre implica un contenido afectivo, ya que el ser humano es una unidad indivisible que debe funcionar en forma integral (González, 2008).

Los objetivos del aprendizaje significativo propuesto en el enfoque centrado en la persona son:

1. Ayudar al individuo a convertirse en persona capaz de tener iniciativas propias y de ser responsable de sus acciones.

2. Facilitar la independencia y autonomía de la persona. Que ésta desarrolle la capacidad de elegir, tomar decisiones y de autodirigirse inteligentemente.

3. Que la persona aprenda a aprender.

4. Que los individuos aprendan a buscar nuevas soluciones a los problemas de su vida diaria, utilizando sus experiencias en forma libre y creadora.

5. Que las personas sean capaces de adaptarse flexible e inteligentemente a situaciones y problemas nuevos.

6. Que los individuos aprendan a vivir en armonía y colaboren con los demás en forma eficaz.

7. Que las personas desarrollen un juicio crítico que les permita evaluar objetivamente las contribuciones de los demás.

8. Que todos trabajen no con el fin de lograr la aprobación de los demás, sino en términos de sus propios objetivos socializados.

De acuerdo con la hipótesis de Carl Rogers (1996) de que no se aprende significativamente más que aquellas cosas que la persona percibe como vinculadas a su propia supervivencia y desarrollo, la primera condición básica para que se dé el aprendizaje es que la persona esté en contacto real con los intereses, las inquietudes y los problemas importantes de su existencia, de tal forma que perciba todo aquello que resuelva su problema existencial.

Cuando el aprendizaje está vinculado a la vida y los intereses de la persona, ésta participa, opina y aplica a su vida diaria lo que aprende. "El aprendizaje significativo o 
trascendente se produce con mayor facilidad cuando el individuo se enfrenta a situaciones problemáticas" (Rogers, 1997, p. 72).

La segunda condición básica para que se dé el aprendizaje significativo, tiene que ver con la autenticidad, aceptación positiva incondicional y comprensión empática. La educación integral se da siempre y cuando en el salón de clases se tome en consideración trabajar con los dos hemisferios del cerebro, ya que esto permite tener equilibrado el organismo desde la parte lógica matemática y la parte de la creatividad. Se mencionan distintas maneras en que el ser humano percibe y conoce al mundo que lo rodea, desde las áreas:

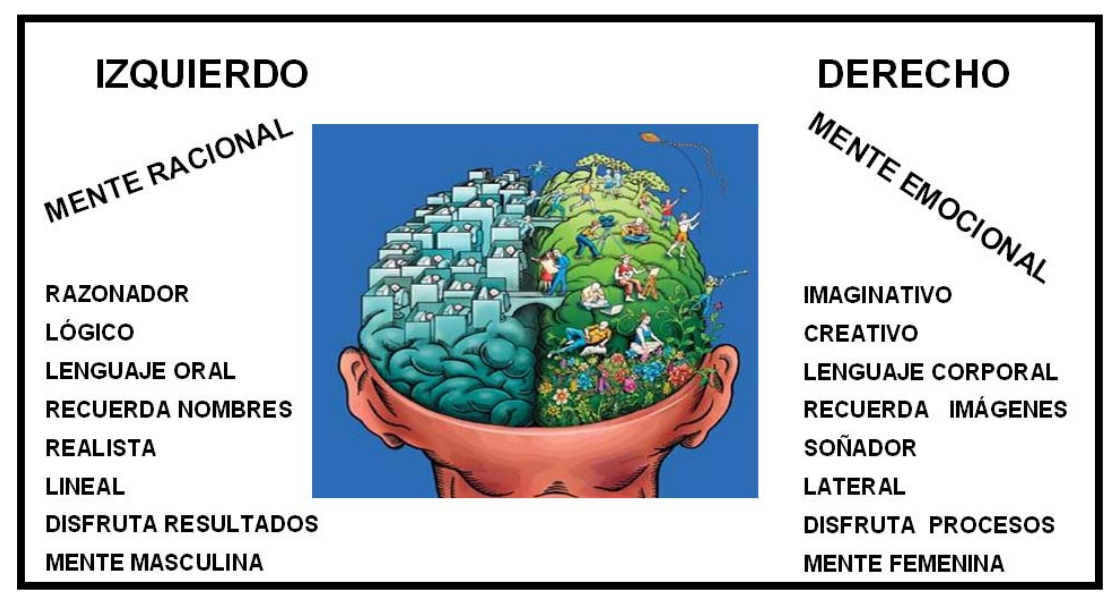

Figura 3. Hemisferios Cerebrales.

Fuente: Lozoya Meza Elaboración propia, apoyada en los planteamientos de Howard Gardner (1993).

a) Cognitiva o intelectual, que involucra la acción del hemisferio cerebral izquierdo.

b) Intuitiva o creativa, que corresponde a las funciones del hemisferio derecho.

c) Integral o significativa, que abarca a la totalidad de la persona al unir y armonizar la acción de ambos hemisferios cerebrales.

El comportamiento en el aula de los alumnos variará en función del modo de pensamiento que prefieran. Un hemisferio no es más importante que el otro, un modo de pensamiento no es mejor que el otro, para poder realizar cualquier tarea, por simple que parezca, se necesita usar los dos hemisferios. Cuanto más complicada sea la tarea más importante será utilizar todos los modos de pensamiento y no uno sólo. Sin embargo nuestra cultura y nuestro sistema escolar no son neutros. 
Al igual que con los sistemas de representación, nuestro sistema escolar privilegia el hemisferio lógico sobre el hemisferio holístico. Una vez, desde el punto de vista del profesor lo que nos debería de interesar es organizar el trabajo en el aula de tal forma que las actividades potencien la utilización de ambos modos de pensamiento (Waisburd, 2008).

Tabla 4.

Estilos de aprendizaje

\begin{tabular}{|c|c|}
\hline ALUMNO HEMISFERIO LÓGICO & ALUMNO HEMISFERIO HOLÍSTICO \\
\hline $\begin{array}{l}\checkmark \text { Visualiza símbolos abstractos (letras, } \\
\text { números) y no tiene problemas para } \\
\text { comprender conceptos abstractos. } \\
\text { Verbaliza sus ideas. } \\
\checkmark \quad \text { Aprende de la parte al todo y absorbe } \\
\text { rápidamente los detalles, hechos y reglas. } \\
\checkmark \quad \text { Analiza la información paso a paso. } \\
\checkmark \quad \text { Quiere entender los componentes uno por } \\
\text { uno. } \\
\checkmark \quad \text { Les gustan las cosas bien organizadas y } \\
\text { no se pierden por las ramas. } \\
\checkmark \quad \text { Se siente incómodo con las actividades } \\
\text { abiertas y poco estructuradas. } \\
\checkmark \quad \text { Le preocupa el resultado final. Le gusta } \\
\text { comprobar los ejercicios y le parece } \\
\text { importante no equivocarse. } \\
\checkmark \text { Lee el libro antes de ir a ver la película. }\end{array}$ & $\begin{array}{l}\checkmark \quad \text { Visualiza imágenes de objetos concretos pero no } \\
\text { símbolos abstractos como letras o números. } \\
\checkmark \quad \text { Piensa en imágenes, sonidos, sensaciones, pero no } \\
\text { verbaliza esos pensamientos. } \\
\checkmark \quad \text { Aprende del todo a la parte. Para entender las } \\
\text { partes necesita partir de la imagen global. } \\
\checkmark \quad \text { No analiza la información, la sintetiza. } \\
\checkmark \quad \text { Es relacional, no le preocupan las partes en sí, sino } \\
\text { saber cómo encajan y se relacionan unas partes con } \\
\text { otras. } \\
\checkmark \quad \text { Aprende mejor con actividades abiertas y poco } \\
\text { estructuradas. } \\
\checkmark \quad \text { Les preocupa más el proceso que el resultado final. } \\
\text { No le gusta comprobar los ejercicios, alcanzan el } \\
\text { resultado final por intuición. Necesita imágenes, ve la } \\
\text { película antes de leer el libro. }\end{array}$ \\
\hline
\end{tabular}

Fuente: Robles A. (2008). Estilos de aprendizaje: como organizamos la información. Instituto de Lugo, Galicia.

Sintetizando, se podría decir que el Aprendizaje Significativo con Enfoque Humanista, tiene que ver con el desarrollo de la persona en su área biológica, psicológica, social y trascendental, que es la propuesta que viene a complementar al Modelo Educativo real, con un (Modelo de Gestión Educativa de transición), para llegar al perfil ideal del egresado que se desea tener en un modelo por competencias. Algunos de sus aspectos son: 


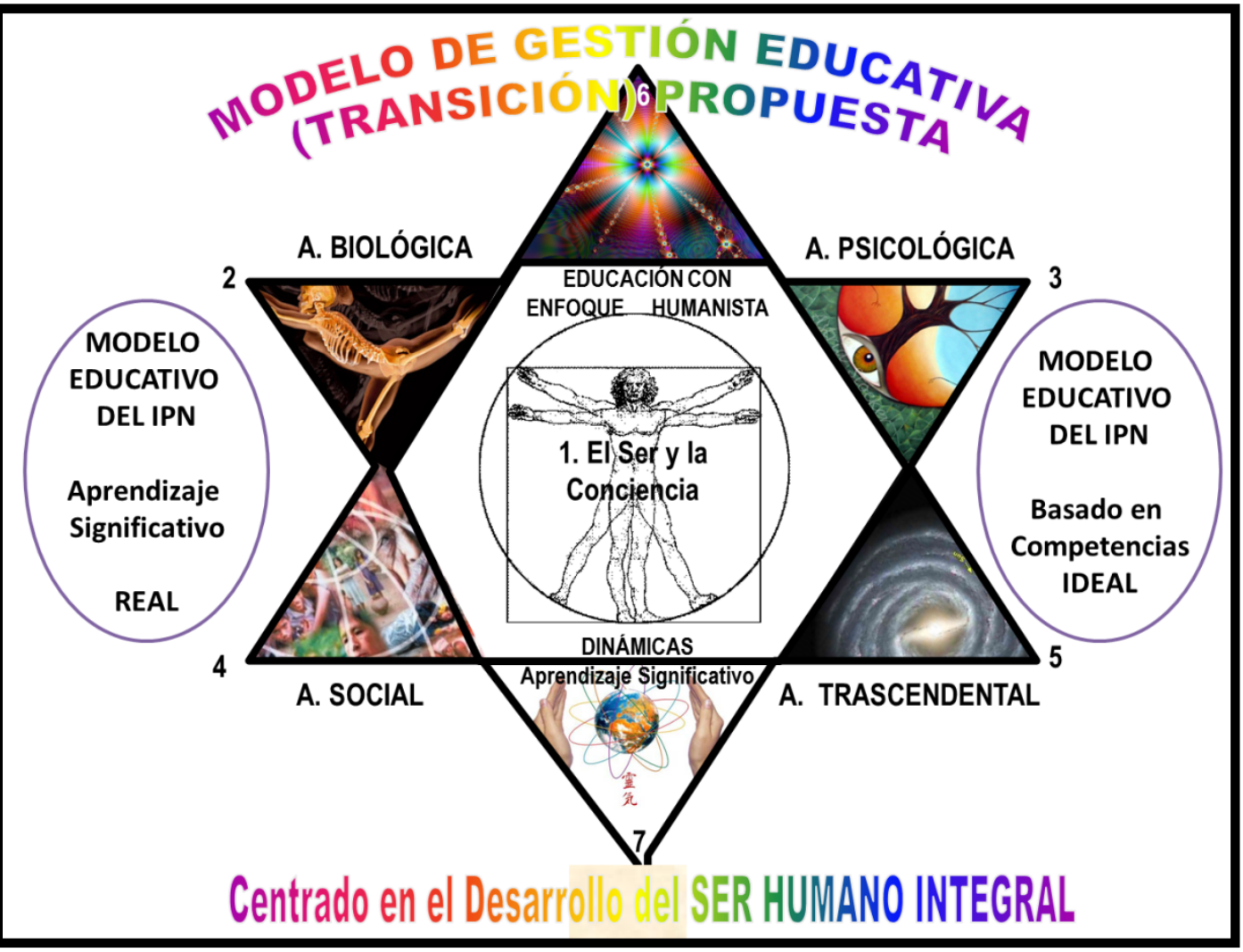

Fuente: Elaboración propia, apoyada en materiales del enfoque humanista (2010)

Este Modelo es de Transición se puede llevar a cabo en el salón de clases en todos los niveles educativos y en todas las asignaturas y desde luego se vincula con los planteamientos de las competencias genéricas y en los planteamientos que nos hace Ana María Gonzáles (2008) cuando nos dice que:

Este proceso biopsicosocial-transpersonal incluye:

a) El desarrollo físico, que se refiere a los cambios que el cuerpo sufre en su proceso de maduración (dimensión biológica).

b) El desarrollo psicológico que incluye los cambios que ocurren en la personalidad del individuo, como resultado del desarrollo de la potencia cognoscitiva y del desenvolvimiento del mundo interno afectivo-emocional (dimensión psicológica).

c) El desarrollo social en el que ocurren los cambios en la interacción e interrelación del individuo con los demás (dimensión social) y 
d) El desarrollo transpersonal, es un proceso progresivo, individual, responsable y liberador que permite a la persona ir más allá del mundo material, así como lograr una síntesis que integre a su sí mismo, las polaridades y dicotomías entre las que se encuentran: cuerpo-mente, razón-intuición, femeninomasculino, materia-espíritu, sujeto-objeto, yo-tú, nosotros-los otros, organismo-mundo y mundo-cosmos.

El resultado es llegar a una autorrealización integral, holística (Maslow) con conciencia y responsabilidad, (que se va dando en el campo educativo en el binomio maestro-alumno), misma que se verá reflejada en el comportamiento personal, interpersonal y transpersonal del Ser Humano. Pero... ¿Qué es lo que nos hace humanos? El darnos cuenta de que formamos parte de un todo, es decir que no estamos solos en el mundo. Que primero reconozcamos nuestro sí mismo, vinculando mente-cuerpo-corazón, cuando estemos listos salir del yo para ir al otro a los otros, en un encuentro del yo- tu, nos-otros. Poniéndonos en los zapatos del otro y desde ahí comportarnos con responsabilidad y siempre trabajando unidos por el bien de nuestra madre tierra y por el Universo en su conjunto.

Por esta razón se considera que esta propuesta puede ser de utilidad, como un primer acercamiento para desarrollar las Competencias Genéricas con el sustento de una educación multi y transdisciplinar con enfoque humanista, para una toma de conciencia con responsabilidad.

Cómo plantea Montseny (2002) cuando nos dice que "todos buscamos la armonía. La naturaleza verdadera y el estado natural y original del ser humano es el equilibrio. Si una persona tiene defectos de carácter, carencias en su vida, limitaciones e incapacidades, problemas, molestias o enfermedades es porque algo está pasando en su ser que le impide ese equilibrio. La desarmonía en cualquier ámbito de la vida es una señal que nos dice que algo no funciona bien, algo falla".

Una vez que la persona comprende que la identidad como ser humano se forma a través de la conducta y la identidad corporales, puede aprender a utilizar la conexión mente-cuerpo para que, trabajando, sintiendo y liberando cada estructura, órgano, parte y elemento del cuerpo, sienta, tome conciencia, se liberé y sane cada valor, facultad, 
cualidad y potencialidad de su conciencia, para que tenga un aprendizaje más pleno, más integral.

Por tanto la educación para la salud puede definirse como un proceso formativo, participativo y permanente, integrado en un marco educativo global, que permita a todos los individuos en relación a la salud, aumentar conocimientos, adquirir actitudes positivas y adoptar estilos de vida sanos, de modo que la salud debe ser considerada como un valor y una responsabilidad individual y social de la escuela y de la comunidad mexicana.

\section{Referencias}

Ausubel, D. (1978). Teoría del aprendizaje significativo. New York, Holt, Rinehart \& Winston. Ausubel, D. (2005). Psicología Educativa. Un punto de vista cognoscitivo. México, Trillas.

Braslavsky, C. \& Acosta, F. (2004). Competencias para la gestión y la política educativa. Conceptos clave y orientaciones para su enseñanza. Buenos Aires: IIPE-UNESCO.

Congresos Nacionales de Investigación Educativa. (1981, 1993, 1995, 1997, 1999, 2001, 2003, 2005 y 2007). Cuadernos, libros y Documento sobre los estados del arte vinculados a la formación de investigadores en Investigación Educativa en México.

De Lella, C. (1999). I Seminario Taller sobre Perfil del Docente y Estrategias de Formación. Modelos y tendencias de la formación docente. Organización de Estados Iberoamericanos. Para la Educación, la Ciencia y la Cultura. Lima, Perú. Recuperado de http://www.oei.es/cayetano.htm

Delors, J. (1996) La educación encierra un tesoro informe de la UNESCO de la Comisión internacional sobre la Educación para el Siglo XXI. México: Santillana.

Dirección General de Bachillerato. (2008). Reforma Integral de la Educación Media Superior. México, SEP.

Documento Rector de la Reforma Integral. (2008). Construcción de un Sistema Nacional de Bachillerato en un marco de diversidad.

González Garza, A. M. (1995). De la Sombra a la Luz. México: Jus.

Iturbe Escalona, E. M. (2007). El Método de Grupos de Enfoque como Instrumento de Diagnóstico para la Formación en Gestión. Experiencias del Programa MADE. Tesis de Maestría, Instituto Politécnico Nacional, ESCA, Santo Tomás.

Lozoya Meza, E. (2004). ¿Cómo Implementar y Evaluar las Competencias Genéricas? México: Limusa.

Lozoya Meza, E. \& Mainou y Abad, V. (2012). Gigantes de la Psicología Humanista. México: CEID Editores.

Montseney, R. (2002). Integración. Cuerpo-Mente. México: Índigo,

Robles, A. (2008). Estilos de aprendizaje. [En línea]. Lugo, Galicia. ¿Qué son los estilos de aprendizaje? Recuperado de http://www.galeon.com/aprenderaaprender/vak/queson.htm

Rogers, C. (1996). El Proceso de Convertirse en Persona. México: Paidós.

Rogers, C. \& Freiberg, J. (1997). Libertad y Creatividad en la educación. Barcelona, España: Paidós. 
Topete Barrera, C., Bustos Farías, E. \& Winfield Reyes, A. M. (2010). El papel del tutor en los desafíos para el desarrollo de competencias de gestión y liderazgo en entornos virtuales. Revista Internacional de Sistemas Computacionales y Electrónicos, México, ISSN: 16659066.

UNESCO. (1996). Instituto Internacional de Planeamiento de la Educación IIPE, Buenos Aires. Diez módulos destinados a los responsables de los procesos de transformación educativa.

Villarán, F. Coordinador, (2010.). Competencias necesarias para la creación y gestión exitosa de pequeñas y microempresas en el Perú. Documento de Trabajo.

Waisburd, J. G. (2009). Pensamiento creativo e innovación. Revista Digital Universitaria [en línea].

(12).

ISSN:

1607-6079.

Recuperado

de:

http://www.revista.unam.mx/vol.10/num12/art87/int87.htm

Winne \& Marx. (1977). Modelo mediacional integrador. 


\title{
MEDIDA DE GESTIÓN DIRECTIVA PARA EDUCACIÓN MEDIA SUPERIOR
}

\author{
MEASUREMENT OF MANAGEMENT POLICY \\ FOR HIGH SCHOOL EDUCATION
}

\author{
José Ángel Vera Noriega \\ Centro de Investigación en Alimentación y Desarrollo, A.C. \\ avera@ciad.mx \\ Luis Enrique Fierros Dávila \\ Universidad de Sonora \\ Ifierros@psicom.uson.mx \\ Martha Olivia Peña Ramos \\ Centro de Investigación en Alimentación y Desarrollo, A.C. \\ mpena@ciad.mx
}

\begin{abstract}
Resumen
El objetivo del presente estudio fue obtener las características psicométricas de un instrumento diseñado para evaluar la gestión directiva como parte del contexto en el que se desenvuelven las instituciones en el nivel medio superior de Estado de Sonora, y para ello se diseñó y elaboró un cuestionario compuesto por 40 reactivos en varias dimensiones, a saber: Datos generales, Comunicación efectiva y habilidades interpersonales, Condiciones de trabajo y clima organizacional, Gestión y planeación directiva y, Enfoque en el cliente. Los directores emitieron su percepción con respuestas tipo Likert donde el máximo es representado con el número 1 y el mínimo con el número 5. De los 651 directores en funciones se seleccionaron de manera aleatoria como muestra a 272 de ellos, utilizando la tabla elaborada por Tagliacarne (1968) para poblaciones finitas. Después de revisar cuidadosamente la base de datos se eliminaron 7 participantes por presentar información incompleta, quedando como número final 265 sujetos. Los resultados obtenidos por los análisis realizados nos indican que la medida diseñada permite contar con un conjunto de elementos de gestión directiva que es indispensable en la gerencia de la escuela y que cuentan con aceptables niveles de confiabilidad y validez de constructo.
\end{abstract}

Palabras clave: Comunicación efectiva y habilidades interpersonales, Condiciones de trabajo y clima organizacional, Gestión y planeación directiva y, Enfoque en el cliente.

\begin{abstract}
The objective of the present study was to obtain the psychometric characteristics of an instrument designed to evaluate the management as part of the context in which operate high school level institutions in the State of Sonora, and for this was designed and drew up a questionnaire consisting of 40 items in several dimensions, namely: General data, Effective communication and interpersonal skills, Conditions of work and organizational climate, Management and planning directive, and Customer focus. The directors issued his perception with answers Likert-type where the maximum is represented with the number 1 an the minimum is the number 5.651 directors were selected randomly as sample to 272 of them, using the table prepared by Tagliacarne (1968) for finite populations. After carefully reviewing the database 7 participants were eliminated to present incomplete information, leaving as the final number 265 subjects.
\end{abstract}


The results obtained by analyses indicates that designed measure allows a set of elements of management which is essential in the management of the school and have acceptable levels of reliability and construct validity.

Key words: Effective communication and interpersonal skills, working conditions and organizational climate, management and planning directive and, customer focus.

\section{Introducción}

El diseño de políticas gubernamentales y la generación de lineamientos teóricos por parte de las comunidades académicas nacionales de reconocido prestigio no son suficientes para incrementar los niveles educativos del país, pues es desde la apropiación crítica y constructiva que de ellos hagan los directores que se pueden plasmar y, por ende, generar los beneficios buscados. En este contexto, la caracterización como proceso de reflexión y análisis del proceso formativo y orientador del trabajo profesional de gestión educativa puede y debe constituirse en una herramienta indispensable para incrementar las posibilidades de alcanzar la excelencia educativa en cualquier institución.

El desarrollo de un país es medido a través de su producto interno bruto (PIB), así como el porcentaje de ocupación de la población económicamente activa (PEA), entre otros, como indicadores de desarrollo (aunque parecieran ser más de crecimiento).

Algunos analistas sobre desarrollo mencionan que este se encuentra directamente relacionado con el nivel educativo (Granados, 2005), sin embargo, si revisamos los datos que se presenta en Education at Glance (2004) no se encuentran evidencias de esto.

Entre los retos actuales tenemos la competitividad y esto no se puede materializar cuando los niveles de crecimiento del producto, el ingreso de la población, la productividad laboral, entre otros, se encuentran estancados. Si bien podemos decir que la inversión en educación en México es mayor que la de algunos países de la región, los resultados que se obtienen en las evaluaciones internacionales no reflejan esta inversión (Education at Glance, 2004). ¿Qué es lo que está fallando? Los análisis 
de la OCDE apuntan a las estructuras, el manejo de los recursos, la planeación, entre otros, se considera que los elementos mencionados son fundamentales para el avance de la educación que se tienen que considerar al momento de proponer cambios en el sistema educativo y al implementar estrategias tendientes a la consecución de las metas que se plantean.

El reto a las instituciones educativas es por tanto, propiciar una formación integral que consiga incorporar a los egresados a la era de la planetarización, aspiraciones de la educación que se han quedado en al ámbito local y que hoy en día trascienden fronteras.

Por primera vez, lo que el mercado de trabajo moderno demanda de las escuelas se acerca mucho a lo que los educadores desde siempre se han planteado como objetivo de la educación: un estudiante que sea capaz de pensar por sí mismo, analizar situaciones, resolver problemas, cooperar con otros, etcétera (IIPE, 2000).

En términos de lo que ocurre en nuestras instituciones educativas, todo parece indicar que permanecen en la posición de hacer equivalentes los conceptos de gestión educativa y administración, es decir, considerar a la escuela como si fuera una empresa donde lo importante es volverse eficiente y eficaz, sin considerar que..

.....no es posible una transformación de la calidad en la educación y una formación acorde a la mutación del contexto en curso, sin orientar todos los esfuerzos al fortalecimiento del docente para reconfigurar su protagonismo social y de esta manera situarlo a la vanguardia de las políticas de las sociedades de riesgo (Motta, 2008, p. 61).

Esto no puede lograrse implementando la noción tradicional de administración, debemos movernos al nivel de la gestión educativa, lo cual implica competencias y capacidades distintas a las de los meros administradores.

Mientras que la Administración implica un uso apropiado de los recursos existentes y mantener el funcionamiento de la organización, en la Gestión Estratégica se tiene una concepción más amplia pues implica actuar en el mundo cambiante e incierto y generar una visión de lo que se desea obtener bajo dichas circunstancias. 


\section{Para diferenciar con mayor precisión es necesario señalar que Gestión escolar}

es el conjunto de acciones relacionadas entre sí, que comprende el equipo directivo de una escuela para promover y posibilitar la consecución de la intencionalidad pedagógica en, con y para la comunidad educativa. Mientras que la gestión educativa puede entenderse como las acciones desarrolladas por los gestores que pilotean amplios espacios organizacionales. Es un saber de síntesis capaz de ligar conocimiento y acción, ética y eficacia, política y administración en procesos que tienden al mejoramiento continuo de las prácticas educativas; a la exploración y explotación de todas las posibilidades; y a la innovación permanente (Instituto Internacional de Planeamiento de la Educación (IIPE, 2000).

Tabla 1.

Competencias y capacidades básicas de un gestor.

\begin{tabular}{|l|l|}
\hline $\begin{array}{l}\text { Conocer las de } \\
\text { necesidades de otros }\end{array}$ & $\begin{array}{l}\text { Tener perspectiva de los puntos de vista de otras personas; Anticiparse a } \\
\text { las necesidades de otras personas y responder a sus preocupaciones y } \\
\text { problemas. }\end{array}$ \\
\hline Comunicación efectiva & $\begin{array}{l}\text { Expresar información a individuos o grupos considerando la audiencia y la } \\
\text { naturaleza de la información; hablar con claridad y confianza; organizar la } \\
\text { información de una manera lógica, hablar usando lenguaje convencional; } \\
\text { observar la respuesta de la audiencia y reaccionar adecuadamente a ésta. }\end{array}$ \\
\hline $\begin{array}{l}\text { Habilidades } \\
\text { interpersonales }\end{array}$ & $\begin{array}{l}\text { Relacionarse bien con los clientes, colegas y miembros del equipo; } \\
\text { mantener una actitud positiva, de apoyo y apreciación. }\end{array}$ \\
\hline Trabajo en equipo & $\begin{array}{l}\text { Demostrar compromiso con la misión y la motivación para combinar la } \\
\text { energía del equipo y la experiencia para lograr un objetivo común; entender } \\
\text { la dinámica del equipo de trabajo para conseguir los más altos niveles de } \\
\text { desempeño }\end{array}$ \\
\hline $\begin{array}{l}\text { Enfoque en el cliente } \\
\text { (interno y externo) }\end{array}$ & $\begin{array}{l}\text { Entender que esta es una orientación de la organización dirigida hacia la } \\
\text { satisfacción de las necesidades de clientes potenciales y actuales; } \\
\text { asegurar que toda la organización, y no sólo el personal de servicio de } \\
\text { primera línea coloquen a los clientes primero. }\end{array}$ \\
\hline Planeación/Organización & $\begin{array}{l}\text { Planear efectivamente lo que se debe lograr e involucrar a todos los } \\
\text { miembros relevantes; anticipar acontecimientos importantes o críticos; } \\
\text { identificar los requisitos de los recursos y asignando responsabilidad para } \\
\text { trabajos específicos, incluyendo los plazos límites y las expectativas de } \\
\text { desempeño. }\end{array}$ \\
\hline $\begin{array}{l}\text { Administración/Gestión } \\
\text { de conflictos }\end{array}$ & $\begin{array}{l}\text { Demostrar habilidad para administrar conflictos al identificar y manejar } \\
\text { estos de una forma sensible, justa y eficiente. }\end{array}$ \\
\hline Fuente: Elaboración propia a partir de: APICS The Association for Operations Management. (2009). Modelo de \\
Competencias del Administrador/Gestor.
\end{tabular}

Todo lo anterior (tabla 1) enfatiza que el rol directivo es un papel especialmente complejo, como señalan Marchesi y Martín (1998): 
El trabajo de los directores no es nada sencillo. El problema principal al que se enfrentan no es sólo que sus funciones han ido cambiando a lo largo de los últimos años sino que, además, se han ido acumulando unas sobre otras. El director debe aprender nuevas estrategias derivadas de las demandas más recientes sobre la escuela, pero tiene que continuar haciendo frente a las tareas habituales para garantizar el funcionamiento de los centros. Posiblemente lo que mejor define en la actualidad la figura del director es que se encuentra en el centro de las tensiones y conflictos que se producen en la escuela y sobre la escuela...Las tensiones más importantes que afectan al director pueden resumirse en las cuatro siguientes: entre el individuo y la organización, entre las demandas de estabilidad y de cambio, entre las funciones de gestión y de instrucción, y entre la autonomía y la rendición de cuentas.

Como lo plantea Acosta (2010), la figura de Director de una institución educativa es el de pieza central en el esquema general de gobierno y gobernabilidad. Por ello, para responder a las problemáticas académicas, burocráticas y políticas debe contar con las habilidades del gerente, del burócrata y del príncipe, "mezclando así las habilidades políticas del príncipe con las exigencias administrativas del burócrata y las actitudes gerenciales asociadas a la gestión".

Diferentes estudios sobre la administración de organizaciones educativas señalan una alta correlación entre la calidad de la enseñanza y el aprendizaje que tiene lugar en las escuelas y la calidad del liderazgo del director, y en ese mismo orden de ideas, Murphy (1990, como se citó en Peniche \& Cisneros-Cohernourm, 2013) plantea que las investigaciones realizadas acerca del papel del director en el mejoramiento de sus organizaciones educativas han encontrado sólidas evidencias de que ciertas prácticas del director tienen un impacto en la calidad de los resultados de aprendizaje de la escuela.

Lo anterior enfatiza, entonces, la formación del director es fundamental dado que es "quien tiene a su cargo no sólo las responsabilidades de gestión, dirección de la organización escolar, y de supervisión y evaluación docente, sino que es quien debe proveer oportunidades para fortalecer el liderazgo instruccional de los maestros al 
promover su crecimiento y desarrollo personal" (Checkley, 2000, como se citó en Peniche \& Cisneros-Cohernourm, 2013).

El objetivo del estudio fue obtener las características psicométricas de un instrumento diseñado para evaluar la gestión directiva como parte del contexto en el que se desenvuelven las instituciones en el nivel medio superior de Estado de Sonora.

\section{Metodología}

\section{Instrumento.}

Se diseñó y elaboró un cuestionario para evaluar algunos elementos del contexto en el que se desenvuelven los directores de preparatoria que participaron en el estudio. Es un cuestionario compuesto por 40 reactivos en varias dimensiones.

La medida está compuesta de varias dimensiones: Datos generales, nos permite identificar condiciones familiares, personales y académicas del director, obteniendo información también sobre el perfil pedagógico. Los reactivos que componen este apartado son: sexo, estado civil, cantidad de hijos, tipo y nombre de la escuela, antigüedad en la docencia, antigüedad en la institución, grado académico, área de estudios, actividades laborales externas a la institución, productividad, participación en la carrera magisterial (11 reactivos).

La dimensión Comunicación efectiva y habilidades interpersonales incluye reactivos como: reuniones con padres de familia, juntas de planeación con profesores, juntas con supervisores y autoridades de la SEC o de la propia institución, cursos de capacitación para maestros, reuniones con alumnos, gestiones para la adquisición de nuevo equipo, reuniones para elaboración de proyectos de investigación, actividades culturales, deportivas o sociales con alumnos y promoción de eventos académicos externos entre profesores del plantel. (9 reactivos).

La dimensión Condiciones de trabajo y clima organizacional es útil para obtener información sobre la evaluación que el director hace de su entorno laboral y su relación con su práctica, así como sus niveles de satisfacción. Las subescalas que componen a 
esta dimensión son: atención a la organización académica, equipamiento, aprovechamiento del alumno, asistencia y puntualidad, infraestructura y salario y desempeño y comunicación. Los reactivos que conforman este apartado son: atención al personal de biblioteca, apoyo al trabajo conjunto de profesores y alumnos, realización de eventos académicos, equipamiento de aulas, laboratorios y talleres, sobre su habilidad para coordinar equipos de trabajo, condiciones laborales en su institución, comunicación con alumnos, profesores y padres de familia, etc. (35 reactivos).

La siguiente dimensión es Gestión y planeación directiva, su objetivo es obtener información sobre la actividad sustantiva del director, la cual está conformada por cuatro subescalas: gestión administrativa, planeación, gestión docente y relación con padres de familia. Los reactivos se refieren a la gestión de recursos financieros, para mejorar la infraestructura, de actividades extracurriculares, de estudios de posgrado para sus profesores, incentivar a los profesores a que continúen sus estudios, informar a los padres sobre el desempeño de sus hijos, etc. (20 reactivos).

Finalmente, la dimensión sobre el enfoque en el cliente, compuesta por cuatro dimensiones: mejora del desempeño de los alumnos, motivación y capacitación, problemas y más problemas. Los reactivos tienen que ver la comunicación con los alumnos, comunicación entre alumnos y profesores, problemas administrativos, innovación de las TIC's, promoción de becas, etc. (11 reactivos).

El instrumento consiste en un cuestionario en el cual los directores emiten su percepción con respuestas tipo Likert donde el máximo es representado con el número 1 y el mínimo con el número 5 . Para efectos de esta investigación, las respuestas de los directores que se encuentran en el rango del 1 al 3 se consideran como percepciones de que ocurre con frecuencia, que ellos están satisfechos, que lo que hacen u ocurre es bueno, que es importante o están de acuerdo. En el caso de las respuestas que se encuentran en el rango del 4 al 5 , se considera que este grupo de directores están insatisfechos, lo que ocurre o hacen es infrecuente, es malo o nada importante, es decir, representan una percepción negativa del evento, las distintas variantes se muestran en la tabla 2: 
Tabla 2.

Distintas variantes de las opciones de respuesta utilizadas en el presente estudio.

\begin{tabular}{|c|c|c|c|c|}
\hline 1 & 2 & 3 & 4 & 5 \\
\hline Muy frecuente & Frecuente & $\begin{array}{l}\text { Medianamente } \\
\text { frecuente }\end{array}$ & Poco frecuente 2 & Nunca \\
\hline Muy buena & Buena & Regular & Mala & Muy mala \\
\hline Muy satisfecho & Satisfecho & $\begin{array}{l}\text { Ni satisfecho ni } \\
\text { insatisfecho }\end{array}$ & Poco satisfecho & $\begin{array}{l}\text { Completamente } \\
\text { insatisfecho }\end{array}$ \\
\hline Muy positiva & Positiva & Regular & Negativa & Muy negativa \\
\hline $\begin{array}{l}\text { Totalmente de } \\
\text { acuerdo }\end{array}$ & $\begin{array}{l}\text { Parcialmente de } \\
\text { acuerdo }\end{array}$ & $\begin{array}{l}\text { Ni de acuerdo ni } \\
\text { en desacuerdo }\end{array}$ & $\begin{array}{l}\text { Parcialmente en } \\
\text { desacuerdo }\end{array}$ & $\begin{array}{l}\text { Totalmente en } \\
\text { desacuerdo }\end{array}$ \\
\hline Muy importante & Importante & $\begin{array}{l}\text { Regularmente } \\
\text { importante }\end{array}$ & Poco importante & Nada importante \\
\hline
\end{tabular}

\section{Población:}

De los 651 directores en funciones (Anexo 1 del Marco jurídico del Plan estatal de desarrollo 2009-2015 para el estado de Sonora) y utilizando la tabla elaborada por Tagliacarne (1968) para poblaciones finitas con un límite de error más menos dos desviaciones estándar, con cinco por ciento de error para una probabilidad de cincuenta sobre cincuenta y un intervalo de confianza de noventa y cinco punto cinco por ciento equivalente a dos sigmas (Sierra Bravo, 1985), arrojó como tamaño de muestra a 272 directores a quienes se aplicó el cuestionario descrito con anterioridad. Después de revisar cuidadosamente la base de datos, se eliminaron 7 participantes por presentar información incompleta quedando como número final 265 sujetos .

$n=\frac{4 * p * q * N}{E^{2}(N-1)+4 * p * q}$

Cada uno de los elementos de la muestra fue elegido de manera aleatoria, además la muestra total fue ponderada de la siguiente manera: $40.66 \%$ para el segundo semestre, $31.51 \%$ para el cuarto semestre y $27.78 \%$ para el sexto semestre. De tal forma que del total de la muestra estratificada del $\mathrm{COBACH}$ el $40 \%$ corresponderá al segundo semestre, $30 \%$ al cuarto semestre y $30 \%$ al sexto. 


\section{Características de la muestra.}

La muestra utilizada quedó constituida de la siguiente manera de acuerdo a las características de quienes formaron parte de ella (tabla 3):

Tabla 3.

Características sociodemográficas de la muestra utilizada.

\begin{tabular}{llr}
\hline Sexo & Masculino & 188 \\
& Femenino & 75 \\
\hline \multirow{4}{*}{ Estado civil } & Soltero & 39 \\
& Casado & 206 \\
& Divorciado & 11 \\
& Otro & 8 \\
\hline \multirow{3}{*}{ Antigüedad en la escuela } & Menos de 1 año & 35 \\
& De 1 año a 5 años & 80 \\
& Entre 5 años - 10 años & 49 \\
& Más de 10 años. & 100 \\
\hline \multirow{3}{*}{ Antigüedad en la docencia } & Menos de 1 año & 8 \\
& De 1 año a 10 años & 69 \\
& Más de 10 años & 183 \\
\hline & Técnico & 4 \\
& Normal superior & 27 \\
Último grado obtenido & Pasante de licenciatura o ingeniería & 14 \\
& Licenciatura o ingeniería & 111 \\
& Pasante de maestría & 58 \\
& Maestría & 42 \\
\hline \multirow{3}{*}{ Antigüedad como director en la } & Candidato a doctor & 4 \\
institución & Menos de 1 año & 60 \\
& De 1 año a 10 años & 142 \\
& Más de 10 años & 59 \\
\hline Trabaja en otro nivel educativo & Si & 56 \\
\hline Realiza alguna otra actividad & No & 209 \\
remunerada que no se relacione & Si & 29 \\
con el sistema educativo & No & 222 \\
\hline
\end{tabular}

\section{Procedimiento.}

Las actividades que se desarrollaron en la aplicación de la medida fueron: En la primera etapa, antes de la aplicación: identificación del lugar físico en donde se desarrolló el proceso y recepción de material de aplicación y llenado de formatos de logística. 
Segunda etapa, durante la aplicación: el monitor se encargó de hacer la gestión para la aplicación de los exámenes en dicha institución. Se identificó y acreditó el lugar de procedencia, indicándole al director del plantel el objetivo y las dinámicas de actividades de trabajo que el equipo desarrollaría en la escuela, así mismo se solicitó el apoyo en la facilitación de condiciones para realizar las entrevistas a los directores participantes.

Una vez que los directores contestaron el instrumento de contexto, se revisó para verificar que no hubiese faltado algún reactivo por contestar. En esos casos, se solicitó que terminara de llenar, (si era posible). No hubo límite de tiempo.

\section{Resultados}

Para cada una de las dimensiones de contexto se realizó un análisis factorial de carácter exploratorio, el método de extracción utilizado fue el de componentes principales, la rotación utilizada fue varimax, suponiendo que los reactivos que obtuvieran pesos factoriales menores a 300 fueran eliminados (Kerlinger \& Lee, 2001).

Con el fin de analizar la consistencia interna de las pruebas, se efectuó un análisis de confiabilidad mediante el método de alfa de Cronbach. La alfa de Cronbach total (incluyendo los 77 reactivos) fue de .898 .

Las tablas siguientes muestran los resultados del análisis, en el que sólo se consideraron aquellos ítems que tuvieran cargas factoriales superiores a 0.350 en alguno de los factores.

Se extrajeron dos factores de la subescala de Comunicación efectiva y habilidades interpersonales (tabla 4).

Se puede observar que en Actividades y reuniones la media más alta fue 3.39 y la media más baja fue de 2.08 y en Juntas y cursos la media más alta fue de 2.70 y la media más baja fue de 1.91 . 
Tabla 4.

Pesos factoriales, media y desviación estándar para una solución ortogonal Varimax de los factores del instrumento de contexto para directores.
Media
D.E.
P. F.

II Comunicación efectiva y habilidades interpersonales (V.E. = 49.01)

\section{Actividades y reuniones}

Actividades culturales, deportivas o sociales con alumnos

$2.08 \quad .832 \quad 708$

Reuniones con alumnos

2.11

.819

.697

Promoción de eventos académicos externos entre profesores

2.86

1.002

.677

Reuniones para elaborar proyectos de investigación

3.39

1.021

.657

\section{Juntas y cursos}

Juntas con supervisores y autoridades de la SEC

$\begin{array}{lll}2.70 & 1.035 \quad .817\end{array}$

Cursos de capacitación a maestros

2.55

.886

.613

Gestiones para la adquisición de nuevo equipo

$2.41 \quad .968 \quad .611$

Juntas de planeación con profesores

$1.91 \quad .720 \quad .532$

Reuniones con padres de familia

2.24

.766

.516

D.E.= Desviación Estándar; P. F.= Peso Factorial; V.E. = Varianza explicada

La primera subescala denominada de Comunicación efectiva y habilidades interpersonales, está constituida por dos factores: Actividades y reuniones (media $=$ 2.61; desviación estándar $=.91$ ), está compuesta por 4 reactivos, la otra subescala que compone esta dimensión, denominada Juntas y reuniones (media $=2.36$; desviación estándar $=.87)$ se constituyó por 5 reactivos, con un valor en su conjunto de KMO de 0.831, una varianza explicada de 49.01 y una alfa de Cronbach de .784 .

De la subescala denominada Condiciones de trabajo y clima organizacional se extrajeron seis factores denominados: Atención a la organización académica (media $=$ 1.87; desviación estándar $=.75$ ) está compuesto por 4 reactivos, equipamiento (media = 1.87; desviación estándar $=.75$ ), aprovechamiento del alumno (media $=1.78$; desviación estándar $=.62$ ) está compuesto por tres reactivos, asistencia y puntualidad $($ media $=1.73$; desviación estándar $=.67)$, infraestructura y salario $($ media $=2.33$; desviación estándar $=.98$ ) y desempeño y comunicación (media $=1.77$; desviación estándar $=.62$ ), que en su conjunto presentan un valor de KMO de .846, una varianza explicada de 56.63 y una alfa de Cronbach de .897 (tabla 5). 
Tabla 5.

Pesos factoriales, media y desviación estándar para una solución ortogonal Varimax de los factores del instrumento de contexto para directores.

\begin{tabular}{|c|c|c|c|}
\hline & Media & D.E. & P.F. \\
\hline \multicolumn{4}{|c|}{ III Condiciones de trabajo y clima organizacional (V.E. = 56.63) } \\
\hline \multicolumn{4}{|c|}{ Atención a la organización académica } \\
\hline Atención al personal de biblioteca & 2.12 & .911 & .721 \\
\hline Apoyo al trabajo conjunto de profesores y alumnos & 1.76 & .618 & .707 \\
\hline Realización de eventos académicos & 1.90 & .704 & .706 \\
\hline Acceso a los servicios de cómputo & 1.73 & .780 & .624 \\
\hline \multicolumn{4}{|l|}{ Equipamiento } \\
\hline Equipamiento de laboratorios y talleres & 2.45 & .968 & .875 \\
\hline Equipamiento de las aulas & 2.18 & .780 & .789 \\
\hline Disposición de espacios para estudio & 2.30 & .948 & .698 \\
\hline \multicolumn{4}{|l|}{$\begin{array}{ll}\text { Aprovechamiento del alumno }\end{array}$} \\
\hline Motivación que brinda el docente para participar en su clase & 1.78 & 651 & .745 \\
\hline Atención que brindan los docentes fuera de su clase & 1.98 & .704 & .706 \\
\hline Conocimiento amplio de la materia del personal docente & 1.57 & .574 & .700 \\
\hline Su habilidad para coordinar un equipo de trabajo & 1.70 & .520 & .700 \\
\hline Vinculación de los conocimientos teóricos práctica & 2.02 & .736 & 664 \\
\hline Desempeño del personal docente en general & 1.78 & .577 & 655 \\
\hline Motivación al alumno a acceder a nuevos conocimientos & 1.73 & .559 & 649 \\
\hline Pluralidad de enfoques teóricos y metodológicos & 1.96 & .644 & 645 \\
\hline Respeto al alumno por parte del personal docente & 1.51 & .572 & 623 \\
\hline Puntualidad de la planta docente & 1.77 & .678 & .585 \\
\hline Asistencia regular a clase del personal docente & 1.70 & .676 & 569 \\
\hline Actualización de la planta docente & 1.81 & .678 & 548 \\
\hline \multicolumn{4}{|l|}{ Satisfacción } \\
\hline \multicolumn{4}{|l|}{ Infraestructura y salario } \\
\hline Cantidad de equipo de cómputo disponible & 2.39 & 1.134 & .730 \\
\hline Condiciones de la biblioteca & 2.48 & 1.118 & .713 \\
\hline Cantidad y disponibilidad de recursos financieros & 2.85 & 1.083 & 689 \\
\hline Condiciones del equipo de cómputo & 2.12 & 1.064 & 677 \\
\hline Condiciones laborales en la institución & 1.87 & .711 & .653 \\
\hline Condiciones de las aulas & 2.22 & .878 & .620 \\
\hline Apoyo de las autoridades de la institución & 1.77 & .836 & 610 \\
\hline Salario y prestaciones & 2.31 & .878 & 581 \\
\hline Condiciones de la infraestructura deportiva del plantel & 2.97 & 1.185 & .544 \\
\hline \multicolumn{4}{|l|}{ Desempeño y comunicación } \\
\hline Comunicación con los profesores del plantel & 1.50 & .552 & .799 \\
\hline Comunicación con los alumnos & 1.53 & .571 & .736 \\
\hline Comunicación entre profesores del plantel & 1.74 & .574 & .713 \\
\hline Comunicación con los padres de familia & 1.79 & .762 & .612 \\
\hline Desempeño de sus profesores en clase & 1.86 & .601 & 609 \\
\hline Desempeño de los trabajadores no académicos en el plantel & 1.85 & .648 & 593 \\
\hline Desempeño de los alumnos del plantel & 2.17 & 691 & .455 \\
\hline
\end{tabular}

D.E.= Desviación Estándar; $\quad$ P. F.= Peso Factorial; V.E. = Varianza explicada

Se puede observar que en Atención a la organización académica la media más alta fue 2.12 y la media más baja fue de 1.73; En equipamiento la media más alta fue 
2.45 y la media más baja fue de 1.73; En aprovechamiento de alumno la media más alta fue de 2.02 y la media más baja fue de 1.51; En Infraestructura y salario la media más alta fue 2.97 y la media más baja fue de 1.77 y en Desempeño y comunicación la media más alta fue de 2.17 y la media más baja fue de 1.50 .

En la subescala que corresponde a gestión y actividades directivas se formaron cuatro factores: Gestión administrativa (media $=2.32$; desviación estándar $=.98$ ), planeación $($ media $=2.24$; desviación estándar $=.86$ ), gestión docente (media $=1.95$; desviación estándar $=.91)$ y relación con padres $($ media $=1.87$; desviación estándar $=$ .75), se constituyó por 20 reactivos, presentó un valor de KOM de .709, una varianza explicada de 50.76 y una alfa de Cronbach de .848 (tabla 6).

Tabla 6.

Pesos factoriales, media y desviación estándar para una solución ortogonal Varimax de los factores del instrumento de contexto para directores.

\begin{tabular}{|c|c|c|c|}
\hline & Media & D.E. & P. F. \\
\hline \multicolumn{4}{|c|}{ VI Gestión y planeación directiva (V.E. = 50.76) } \\
\hline \multicolumn{4}{|c|}{ Gestión administrativa } \\
\hline Gestión de recursos financieros & 2.23 & .886 & .880 \\
\hline Gestión para mejorar la infraestructura & 2.08 & .889 & .849 \\
\hline Gestión para el desarrollo de actividades especiales & 2.56 & .980 & .561 \\
\hline Actividades administrativas & 1.93 & 1.061 & .470 \\
\hline Diseño e implementación de programas de vinculación & 2.77 & 1.085 & 469 \\
\hline \multicolumn{4}{|l|}{$\begin{array}{ll} & \text { Planeación } \\
\end{array}$} \\
\hline Gestión de actividades extracurriculares & 2.41 & .871 & 693 \\
\hline Planeación de actividades para cada ciclo escolar & 1.61 & 613 & 667 \\
\hline Selección de maestros & 2.71 & 1.123 & 584 \\
\hline \multicolumn{4}{|l|}{ Gestión docente } \\
\hline Gestionó apoyos para que los profesores estudien posgrados & 1.94 & 1.004 & .790 \\
\hline Los profesores reciben capacitación constante & 1.92 & .868 & .775 \\
\hline La capacitación a los profesores es favorable en su desempeño & 1.68 & .736 & 676 \\
\hline Incentiva a sus profesores a continuar sus estudios & 1.57 & .679 & .676 \\
\hline La infraestructura es adecuada al modelo de competencias & 2.27 & 1.127 & .507 \\
\hline Los padres conocen el modelo de competencias & 2.35 & 1.058 & 487 \\
\hline \multicolumn{4}{|l|}{ Relación con padres } \\
\hline Los padres se informan sobre el desempeño de sus hijos & 2.00 & .735 & 797 \\
\hline Los padres apoyan a sus hijos en sus estudios & 2.01 & .780 & 771 \\
\hline Los maestros están motivados a dar sus clases & 1.59 & 671 & .590 \\
\hline Los maestros constantemente innovan sus estrategias didácticas & 2.03 & .770 & 557 \\
\hline Los maestros tienen tiempo suficiente para preparar clase & 1.48 & .699 & .544 \\
\hline $\begin{array}{l}\text { Se ha incrementado el desempeño de los alumnos con el modelo } \\
\text { de competencias }\end{array}$ & 2.16 & .885 & .522 \\
\hline
\end{tabular}

D.E.= Desviación Estándar; P. F.= Peso Factorial; V.E. = Varianza explicada 
Se puede observar que en Gestión administrativa la media más alta fue 2.77 y la media más baja fue de 2.08 y en Juntas y cursos la media más alta fue de 2.70 y la media más baja fue de 1.93; En planeación la media más alta fue 2.71 y la media más baja fue de 1.61; En Gestión docente la media más alta fue 2.35 y la media más baja fue de 1.57 y en Relación con padres la media más alta fue 2.16 y la media más baja fue de 1.48.

En la subescala sobre el alumnado se formaron cuatro factores constituida por 13 reactivos: mejora del desempeño de los alumnos (media $=2.18$; desviación estándar $=1.18$ ), motivación y capacitación (media $=1.86$; desviación estándar $=.98$ ), problemas (media $=3.48$; desviación estándar $=1.12)$ y más problemas (media $=2.37$; desviación estándar $=1.19$ ) con un valor de KMO de .793 , una varianza explicada de 61.33 y una alfa de Cronbach de .762 (tabla 7). Se puede observar que en Mejora del desempeño de los alumnos la media más alta fue 2.24 y la media más baja fue de 2.09; En Motivación y capacitación la media más alta fue 2.24 y la media más baja fue de 1.57 y en problemas la media más alta fue de 4.16 y la media más baja fue de 2.37 .

Tabla 7.

Pesos factoriales, media y desviación estándar para una solución ortogonal Varimax de los factores del instrumento de contexto para directores.

\begin{tabular}{|c|c|c|c|}
\hline & Media & D.E. & P. F. \\
\hline \multicolumn{4}{|c|}{ VIII Enfoque centrado en el cliente (V.E. = 61.33) } \\
\hline \multicolumn{4}{|c|}{ Mejora del desempeño de los alumnos } \\
\hline Mejoramiento de la infraestructura & 2.23 & 1.199 & .762 \\
\hline Mejoramiento del acervo en bibliotecas & 2.18 & 1.193 & .757 \\
\hline Promoción de becas para alumnos de bajos recursos & 2.09 & 1.172 & .748 \\
\hline Innovación de las TIC's & 2.24 & 1.177 & .632 \\
\hline \multicolumn{4}{|c|}{ Motivación y capacitación } \\
\hline Motivación del alumnado & 1.57 & .824 & .802 \\
\hline Capacitación docente & 1.78 & 1.013 & .763 \\
\hline Modelos de enseñanza & 2.24 & 1.132 & .725 \\
\hline \multicolumn{4}{|l|}{ Problemas } \\
\hline De comunicación entre alumnos y maestros & 3.47 & 1.202 & .819 \\
\hline De comunicación entre alumnos & 3.58 & 1.056 & .619 \\
\hline Problemas administrativos & 4.16 & 1.116 & .499 \\
\hline Problemas de conocimiento & 2.74 & 1.145 & 449 \\
\hline Problemas sociales & 2.38 & 1.143 & .344 \\
\hline Problemas económicos & 2.37 & 1.251 & .309 \\
\hline
\end{tabular}


Finalmente, en la tabla 8 se resumen las características psicométricas de instrumento sobre contexto aplicado a los directores de EMS de nuestro Estado, las cuales nos permiten afirmar la confianza en la información recolectada y en el uso que le daremos en un futuro mediato.

Tabla 8.

Subescalas que constituyen a cada factor, número de reactivos que las componen, medias, desviación estándar promedio, pesos factoriales, KOM, varianza explicada y Alfa de Cronbach.

\begin{tabular}{|c|c|c|c|c|c|c|c|}
\hline & $\begin{array}{l}\text { Número } \\
\text { Reactivo }\end{array}$ & Media & D.E. & P. F. & KMO & V.E. & $\mathbf{a}$ \\
\hline \multicolumn{8}{|c|}{ Comunicación efectiva y habilidades interpersonales } \\
\hline Actividades y reuniones & 4 & 2.61 & .91 & De .65 a .70 & .831 & 49.01 & .784 . \\
\hline Juntas y cursos & 5 & 2.36 & .87 & De .51 a .81 & & & \\
\hline \multicolumn{8}{|c|}{ Condiciones de trabajo y clima organizacional } \\
\hline $\begin{array}{l}\text { Atención a la organización } \\
\text { académica }\end{array}$ & 4 & 1.87 & .75 & De .62 a .72 & .846 & 56.63 & .897 \\
\hline Equipamiento & 3 & 1.87 & .75 & De .69 a .87 & & & \\
\hline Aprovechamiento del alumno & 10 & 1.78 & .62 & De .52 a .76 & & & \\
\hline Asistencia y puntualidad & 2 & 1.73 & .67 & De .87 a .89 & & & \\
\hline Infraestructura y salario & 9 & 2.33 & .98 & De .54 a .73 & & & \\
\hline Desempeño y comunicación & 7 & 1.77 & .62 & De .45 a .79 & & & \\
\hline \multicolumn{8}{|c|}{ Gestión y planeación directiva } \\
\hline Gestión administrativa & 5 & 2.32 & .98 & De .46 a .88 & .709 & 50.76 & .848 \\
\hline Planeación & 3 & 2.24 & .86 & De .58 a .69 & & & \\
\hline Gestión docente & 6 & 1.95 & .91 & De .48 a .79 & & & \\
\hline Relación con padres & 6 & 1.87 & .75 & De .52 a .79 & & & \\
\hline \multicolumn{8}{|c|}{ Enfoque centrado en el cliente } \\
\hline $\begin{array}{l}\text { Mejora del desempeño de los } \\
\text { alumnos }\end{array}$ & 4 & 2.18 & 1.18 & De .63 a .76 & .793 & 61.33 & .762 \\
\hline Motivación y capacitación & 3 & 1.86 & .98 & De .72 a .80 & & & \\
\hline Problemas & 4 & 3.48 & 1.12 & De .44 a .79 & & & \\
\hline Más problemas & 2 & 2.37 & 1.19 & De .79 a .79 & & & \\
\hline
\end{tabular}

\section{Discusión}

En primer plano, la medida diseñada permite contar con un conjunto de elementos de gestión directiva que es indispensable en la gerencia de la escuela y que cuentan con aceptables niveles de confiabilidad y validez de constructo. Por un lado, es necesario hacer ver que las dimensiones orientadas al cliente son aquellas que presentan los valores que indican la necesidad de programas de mejora continua. Por otro lado, las escalas de comunicación efectiva y habilidades interpersonales nos hace comprender la 
falta de control institucional de presupuesto, ejercicio de poder y administración institucional que muestra la falta de capacidad directiva sobre los asuntos asociados a la posibilidad de integrar y conformar grupos de trabajo, comités y cuerpos académicos para diseñar y desarrollar planes de trabajo y planeación didáctica. Lo anterior, primero porque se requiere contar con instalaciones y recursos económicos para pagar horas e insumos a los docentes. Segundo, porque aun cuando se contara con los recursos económicos, los profesores cuentan con doble plaza o se dedican a otro trabajo remunerado.

Los datos obtenidos revelan una gestión directiva permisiva y estatutaria que promueve el cumplimiento del horario de clase, reportes a la supervisión, llenado de formatos estatales y federales pero sin manejo de un sistema local de incentivos, motivadores y promociones que le permitan al director ejercer su papel de manera autónoma y participativa. Está restringido a los recursos federales de nómina o estatales de infraestructura con grandes limitaciones en el manejo de recursos y demandas para ejercer los pocos posibles.

Recordemos que los directores a nivel EMS no tienen autoridad legítima académica sino que se trata de puestos obtenidos por escalafón y promovidos a través de antigüedad y el fuerte impulso del sindicato. No se cuenta con la experiencia necesaria para la gestión directiva y, en pocas ocasiones, son elegidos definiendo un perfil de socialización y habilidades interpersonales.

La percepción de los directivos sonorenses de educación media superior nos indica las condiciones que prevalecen en las instituciones en cuanto al desarrollo de la gestión directiva:

a) Dentro de los valores en los que se obtuvieron las menores frecuencias satisfacciones o niveles de acuerdo tenemos que los directores no tienen capacidad económica e independencia administrativa para convocar a los profesores a eventos externos y menos aún para proponer proyectos de investigación colaborativos. Esto nos plantea un escenario en el cual el director solo administra personal en el sentido más elemental del término o sea su asistencia y permanencia en el plantel (Bonnefoy, et al. 2004); 
b) El aislamiento en el cual se encuentra el director se hace patente en su percepción de la frecuencia con la cual se puede proponer y negociar con las autoridades, profesores y padres. La gestión directiva exógena no tiene mediadores en la subsecretaria de educación media y superior pues el director sin la posibilidad de negociar mejor presupuesto, docentes, infraestructura, innovaciones para la mejora está vinculado con su papel de representante de la autoridad estatal en el plantel y es esta autoridad la que solicita y adjudica recursos a cada uno de los planteles la mayoría de las veces por necesidades políticas (Fierro, 2005);

c) Consecuencia de lo anterior tenemos una percepción de insatisfacción con la disponibilidad de recursos financieros, equipo de biblioteca, cómputo e instalaciones deportivas, lo mismo con el salario que percibe el director. Tal como lo vimos en la tabla de características socio demográficas de la población el $85 \%$ de los 265 directores declararon tener una actividad adicional para obtener recursos económicos propios, ósea una tercera parte encuentra insuficiente los pagos estatales y además es interesarte ver como la ocupación de director les deja tiempo para realizar a cabo otra actividad.

Todo lo anterior nos indica las condiciones en las que se encuentran los planteles o infraestructura y la incapacidad del director para negociar buscar o promover mejores condiciones de infraestructura en la escuela preparatoria (Ulloa, et al., 2012).

Esto se refleja en la percepción de la gestión administrativa con valores entre regular y frecuente (2 a 3 ) para las actividades de búsqueda de mejora financiera, infraestructura y de rendimientos académicos y programas de vinculación.

En general, los directores no discuten, negocian o pactan la elección de profesores, actividades curriculares o extracurriculares, presupuesto o infraestructura, sino que lo determina la oficina central del Estado a la que pertenece la modalidad; en estas condiciones no resulte extraño que los directores perciban que no existen condiciones óptimas para llevar a cabo un modelo de enseñanza basado en competencias 


\section{Referencias}

Abbott, R. \& Perkins, D. (1978). Development and construct validation of a set of student rating of instruction items. Educational and Psychological Measurement, 38, 1069-1075.

Acosta, A. (2010). Príncipes, burócratas y gerentes. El gobierno de las universidades públicas en México. México: ANUIES.

Bonnefoy, C., Gamal, S., Durán, M. \& Ponce, Y. (2004). Gestión Directiva Universitaria: Un Instrumento para su Evaluación. Revista de Psicología, XIII, 2, 63-82.

Briggs, S. (2005). Changing roles and competencies of academics. Active Learning in Higher Education, 6(3), 256-268.

Chaín R (1995). Estudiantes universitarios: trayectorias escolares. Tesis doctoral Universidad Veracruzana, Universidad Autónoma de Aguas Calientes.

De la Orden Hoz, A. (1987). Formación, selección y evaluación del profesorado universitario Bordón. Revista de pedagogía, ISSN 0210-5934, № 266, 5-30.

Dunkin, M. J. \& Precians, R. P. (1992). Award-winning university teachers concepts of teaching. Higher Education, 24, 483 - 502.

Fierro, M. C. (2005). El problema de la indisciplina desde la perspectiva de la gestión directiva en escuelas públicas del nivel básico. Revista Mexicana de Investigación Educativa, 10, núm. 27, 1133-1148.

Gagné, R. \& Briggs, L. (2006). La planificación de la enseñanza: sus principios, México: Trillas.

Granados, R. (2005). Educación en México ¿Gastar más o invertir mejor? Volumen V, número 148. México. febrero de 2005. [Consultado el 24 de octubre de 2012]Disponible en http://www.observatorio.org/colaboraciones/granados.html.

IIPE Buenos Aires. Instituto Internacional de Planeamiento de la Educación. Competencias para la profesionalización de la gestión educativa. Módulo II: Gestión educativa estratégica. (2000). En: Diez módulos destinados a los responsables de los procesos de transformación educativa. Ministerio de Educación de la Nación. [Consultado el 24 de octubre de 2012]. Disponible en: http://www.iipebuenosaires.org.ar/publicaciones resultados?tid=1\&field edicion ano value $=2000$

Luna, E. (2002). La Participación de los Docentes y Estudiantes en la Evaluación de la Docencia. Universidad Autónoma de Baja California, México: Plaza y Valdez Editores.

Marchesi, A. \& Martín, E. (1998). Calidad de la enseñanza en tiempos de cambio. Madrid: Alianza.

Marsh, H. (1984). Student's evaluation of university teaching: dimensionality, reliability, validity, potential biases and utility. Journal of Educational Psychology, 76, 707-754.

Marsh, H. \& Overall, J. (1980). Validity of students evaluations of teaching effectiveness: cognitive and affective criteria. Journal of Educational Psychology, 72, 468-475.

Motta, R.D. (2008). Filosofía, complejidad y educación en la Era planetaria. UANL, Monterrey, N.L.

Newman, R. (1994). Valuing, Quality Teaching through recognition of context specific skills, The Australian Universities, Review, (37)1, 8-13.

OECD. (2009). Education at a Glance 2009. OECD INDICATORS.

Overall, J. \& Marsh, H. (1977). The relationship between students evaluations of faculty and instructional improvement. University of California. Los Angeles (ERIC Document Reproduction Service $\left.n^{0} 138165\right)$.

Peniche, R. \& Cisneros, E. (2013). Competencias profesionales de administradores escolares desde la perspectiva de los docentes, Cap. 3. En M. Navarro Rodríguez y A. Barraza Macías (Coords). Dirección, liderazgo, modelos y procesos de gestión: Claves hacia la 
transformación. México: Red Durango de Investigadores Educativos A. C. ISBN: 978607-9063-12-2.

Pérez Franco, Liliana (1997). Caracterización y seguimiento de estudiantes de la Licenciatura en sociología, generación 1995 y 1996, Reporte de Investigación, Serie 2 No. 289 de la UAM-A DCS y H. México.

Rodríguez, R. (1984). Estadísticas sobre los cursos de formación docente en el bachillerato del CCH, Cuadernos del Colegio, 25, 32-42.

SEP: Antología: la Gestión Educativa (2000).

Shulman, L. S. (1989). Paradigmas y Programas de Investigación en el estudio de la enseñanza. Una perspectiva contemporánea. En M. C. Wittrock (Ed). La investigación de la Enseñanza I, Enfoques teorías y Métodos, (pp. 9-91), Barcelona: Paidós.

Tagliacarne, G. (1968). Técnica y Práctica de las Investigaciones de Mercados. Ed Ariel.

Ulloa, J., Nail, O., Castro, A. \& Muñoz, M. (2012). Problemas de gestión asociados al liderazgo como función directiva. Estudios Pedagógicos, XXXVIII, 1, Universidad Austral de Chile Valdivia, 121-129. 


\section{ReDIED}

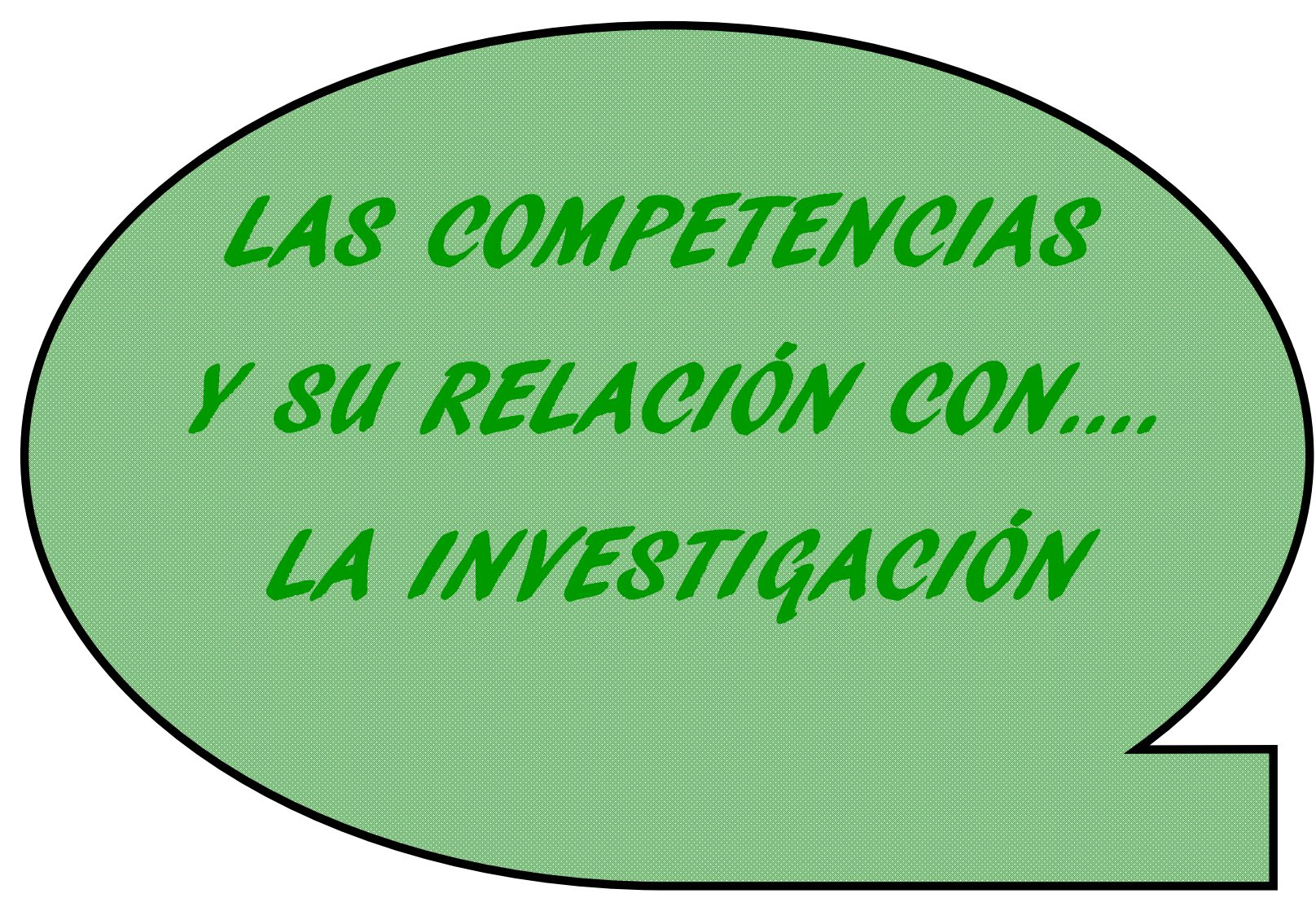




\title{
COMPETENCIAS INVESTIGATIVAS EN MAESTRANTES EN DOCENCIA UNIVERSITARIA DESDE SU COSMOVISIÓN CONTEXTUAL
}

\section{INVESTIGATIVE COMPETENCES IN UNIVERSITY TEACHING MAGISTERS FROM THEIR CONTEXTUAL WORLDVIEW}

\author{
Magaly Amarista \\ Universidad Ezequiel Zamora- Universidad Fermín Toro \\ magamarista@gmail.com
}

\begin{abstract}
Resumen
El propósito de esta investigación consistió en generar una aproximación teórica sobre competencias investigativas en la formación de los participantes del programa de la Maestría en Ciencias de la Educación, Mención Docencia Universitaria de la Universidad Fermín Toro, oficina de Enlace Barinas, desde su cosmovisión contextual. Se situó en el paradigma cualitativo-fenomenológico, con apoyo del enfoque de la hermenéutica, dentro de la modalidad de investigación de campo de carácter descriptivo e interpretativo. La fundamentación teórica se basó en el enfoque socioformativo de las competencias de Tobón, el Constructivismo y el Construccionismo Social. Para recopilar la información se utilizaron documentos, la observación directa y entrevistas semiestructuradas a cinco Informantes clave, dos docentes tutores y tres participantes de la Maestría, y así conocer de su propia voz, sus impresiones y vivencias al respecto, de modo de elaborar una descripción detallada de esa realidad y construir el sistema de categorización representativo, realizar la triangulación para su interpretación. Se comprendieron las categorías subyacentes de las competencias investigativas que le permiten desarrollar el trabajo de grado con éxito y se esbozan las consideraciones del corpus teórico que sirve como fuente de información y antecedente para la realización de futuras investigaciones en este campo.
\end{abstract}

Palabras claves: formación en investigación, trabajo de grado, educación universitaria, estudios de postgrado.

\begin{abstract}
The main purpose of this research was to generate a theoretical approach about investigative competences in the training of the participants in the Master of Science in Education, Major in University Teaching at Fermín Toro University, Barinas, from their contextual worldview. Initially the intention was to answer what investigative competences do they need to do the Master's thesis? This research was conducted in the qualitative - phenomenological paradigm, with support from the hermeneutic approach, in the form of descriptive, interpretative and field research. The theoretical foundation of the study was based on Tobon's socioformative competences approach, Social Constructivism and Social Constructionism. For data collection, direct observation, documents and interviews with five key informants, two mentor teachers and three participants of the Master program, were used. In order to establish the representative categorization system of the actors' speech and with the disclosure of the findings, the corresponding triangulation was performed for its interpretation. The emerging meanings from the existential situations of the participants in the study were revealed and the underlying categories of investigative skills that allow them to do the Master's thesis were understood. Some theoretical
\end{abstract}


considerations that served as a source of information and background to conducting future research in this field were outlined.

Key words: training in research, Master's thesis, higher education, postgraduate studies.

\section{Introducción}

La educación constituye uno de los instrumentos más poderosos para poder hacerle frente a los vertiginosos cambios que se experimentan hoy día en la llamada sociedad del conocimiento. Es por ello que se ha planteado la exigencia de un profesional competente (Informe final Proyecto Tuning America Latina, 2004-2007). Le corresponde, en consecuencia, a las instituciones educativas formar docentes que sean capaces de interpretar la realidad desde su contexto para ofrecer soluciones creadoras a los problemas que se les presentan. La producción de conocimiento es la razón de ser de la existencia de la institución universitaria a través de la investigación, en términos de reivindicar la capacidad de cuestionamiento, crítica y construcción de conocimiento en el aula de clase, en la biblioteca, en el trabajo, y en el permanente contacto con la sociedad y sus realidades.

En este contexto, el Postgrado se constituye en la última fase de la educación formal, dirigido a fortalecer y mejorar la pertinencia social, académica, política, económica y ética de los estudios que se realizan con posterioridad a la obtención del título profesional. Se hace necesario, que los estudiantes se apropien de herramientas que le permitan desarrollar su potencial en la construcción del conocimiento, mediante el aprendizaje de otros nuevos, la adquisición de habilidades, el desarrollo de determinadas actitudes, para tener la capacidad de utilizar con eficiencia en cada caso, lo que han ido adquiriendo (Checchia, 2009).

En ese sentido, la formación de estos profesionales debe propiciar las competencias necesarias para que su propio quehacer cotidiano se convierta en un auténtico proceso de investigación científica en el campo de la educación. El abordaje de las competencias no es una tarea sencilla, puesto que además de adoptar diferentes significados, las posiciones teóricas que las sustentan surgen de referentes muchas 
veces contradictorios. No obstante, coinciden en que es el resultado de los conocimientos, habilidades, capacidades y cualidades que le permite funcionar con flexibilidad, reflexivamente, con iniciativa, perseverancia, y perspectiva futura, ante las situaciones (Tobón, 2006; Pérez, 2012).

Con respecto al nivel de postgrado, se hace innegable la necesidad de la formación de los profesores universitarios, no sólo en las áreas del conocimiento de una disciplina en particular, sino en cómo abordar la docencia y sus implicaciones, mediante la investigación, con el fin de hacerle frente a los distintos desafíos que se le presentan.

En el caso venezolano, los aspectos relativos a la definición de los estudios de Postgrado están contemplados en la Normativa General de los estudios de postgrado para las Universidades e Instituciones debidamente autorizadas por el Consejo Nacional de Universidades (2001). En la misma se plantea como finalidad la de formar recursos humanos altamente especializados y promover la investigación para responder a las exigencias del desarrollo nacional (artículo 4, literal b), además la formación metodológica para la investigación y la necesidad de la elaboración, presentación, defensa y aprobación de un Trabajo de Grado (Artículos 23 y 24), el cual debe ser el resultado de un proceso analítico, crítico y constructivo que demuestre el dominio teórico y metodológico de los diseños de investigación del área en un plazo máximo de cuatro (4) años (Artículo 25).

Es pertinente señalar que la investigación, así como la formación del investigador, son un proceso acumulativo, a largo plazo, de naturaleza muy personal, que pasa por diferentes etapas, donde se necesitan destrezas y nociones metodológicas pero al mismo tiempo se requiere desarrollar aspectos motivacionales (Valarino, 2000). Resulta evidente, que la investigación es un compromiso necesario de los estudiantes, esencial para su formación humana, ya que le permite además de la realización de sus trabajos, la adquisición de nuevos conocimientos, que le servirán de ejercicio para pensar, razonar, crear, reflejar su pensamiento, su manera de ver el mundo, su forma de abordar situaciones de la vida, al plantear y resolver un problema, al hacer uso de su creatividad. No obstante debe señalarse que, si bien es cierto, que en los programas de Postgrado no sólo de las universidades nacionales, ni dentro del 
ámbito latinoamericano, sino inclusive en los países industrializados, existe un elevado número de participantes que culminan la escolaridad, no hay una proporcionalidad directa con respecto a los que elaboran y presentan su trabajo de grado (Cadenas, Rojas \& Reyes, 2004), reflejando lo que se conoce bajo la denominación de TMT (Todo Menos Tesis) o ABD (All But Dissertation) en inglés.

En ese sentido Padrón (1996), sostiene que la manera como se administran las asignaturas relacionadas con el eje de investigación, está asociada con este problema, ya que en ello se atiende específicamente la parte operativa y no se desarrollan las competencias necesarias para ejecutar los procesos de investigación.

Por su parte, Morales, Rincón y Romero (2005), hacen referencia a las deficiencias con que ingresan los estudiantes a la Universidad venezolana, así como las limitaciones con las que egresan, como un obstáculo para el desarrollo de la investigación. Señalan que en su período de formación son pocas las asignaturas que le brindan una formación conceptual, procesal y actitudinal en las prácticas investigativas, y más aún, no desarrollan competencias como investigadores, pues se parte de la idea de que ya deben saber lo que implica investigar.

Igualmente, Cabra y García (2009) en Colombia, Álvarez y Orozco (2011), en Cuba y Jaik Dipp y Ortega (2011), en México, entre otros, afirman que los estudiantes de postgrado no poseen el nivel de dominio de las competencias necesario para elaborar un trabajo de grado; son escasas, insuficientes o están en proceso de desarrollo.

De los 2104 cursos de postgrado que se ofrecen en Venezuela, 159 corresponden al nivel de Doctorado, 834 al nivel de Maestría y 1083 a las Especializaciones (OPSU-CCNPG, 2011). Con respecto a los 241 programas autorizados por área de conocimiento, 48 corresponden a Ciencias de la Educación.

Sin embargo, existen evidencias de que un gran porcentaje de los estudiantes de Postgrado en las instituciones universitarias venezolanas no presentan sus trabajos de grado de maestría en el tiempo estipulado en sus programas de formación (Morles, 2004; Cadenas, Rojas \& Reyes, 2004; Padrón, 1996), por lo que cabe preguntarse: 
¿Cuáles competencias para investigar necesitan, que le permitan desarrollar su trabajo de Grado?

En la experiencia de la autora como docente, investigadora, tutora, asesora y jurado de trabajos de grado en los programas que se ofertan en la Universidad Fermín Toro - UFT-, oficina de enlace Barinas y a pesar de que el Plan de estudios de la Maestría en Educación Superior, Mención Docencia Universitaria (Universidad Fermín Toro, 2011), cuenta con algunas asignaturas como insumo que se presume le brindan herramientas y conocimientos específicos para la elaboración de su trabajo de grado, los estudiantes evidencian muchas debilidades con respecto a las competencias necesarias para el desarrollo de su trabajo de investigación, lo que en el menor de los casos, causa retardo en el período de culminación del programa, y en el peor, les conduce al fracaso.

Existe una realidad preocupante en el sentido de que, según datos suministrados por la Coordinación de esa Maestría en la oficina de enlace Barinas (2012), son muy pocos (entre $20 \%$ y $35 \%$ ) los participantes que culminan su trabajo de grado al finalizar la escolaridad (dos años), un pequeño grupo (entre $40 \%$ y $60 \%$ ) lo hace en el tiempo adicional (dos años después), pero quedan otros (alrededor del $20 \%$ ), que pierden todo su esfuerzo, tiempo y dinero, ya que no logran realizar su trabajo de grado, situación que no se evidencia en las otras Maestrías ofrecidas en esta sede (Gerencia y Liderazgo en Educación, Educación Inicial y Gerencia Empresarial).

Para corroborar esta realidad, en un sondeo inicial de entrevistas preliminares, con dos profesores de experiencia como tutores en las distintas Maestrías de la UFT, ofrecidas en la extensión Barinas, se recogen expresiones textuales tales como:

Informante T1: “....de cada diez (10) participantes de Docencia Universitaria, puede decirse que solo tres (3) defienden a tiempo, siete (7) no lo hacen ya que presentan debilidades para investigar... no tienen las competencias.." (p. 1, L 33-40). Informante T2: "..un alto porcentaje se va quedando en el tiempo...rezagado... llegan hasta a perder su derecho al título" ( $p$ 1, L 12$20)^{\prime \prime . . . . ~ l o s ~ e s t u d i a n t e s ~ p r e s e n t a n ~ d e b i l i d a d e s ~ e n ~ c u a n t o ~ a ~ l a ~ i n v e s t i g a c i o ́ n . . . . ", ~(p . ~}$ 1, L 31-33) “....se puede decir que no tiene las competencias ” (p. 2, L 60-62). 
Es por ello que surge la inquietud por conocer ¿por qué ocurre esta situación? y se hace esta investigación con el propósito de generar una aproximación teórica sobre competencias investigativas en la formación de participantes de postgrado a nivel de Maestría en Educación Superior, Mención Docencia Universitaria, desde su cosmovisión contextual.

De allí que se plantearon los siguientes propósitos particulares:

- Analizar los fundamentos teóricos, ontológicos, epistemológicos y axiológicos en relación con las competencias investigativas en la formación de participantes de postgrado a nivel de Maestría en Docencia Universitaria.

- Develar los significados que emergen de las situaciones vivenciales sobre las competencias investigativas de los participantes de postgrado a nivel de Maestría en Docencia Universitaria.

- Comprender las categorías subyacentes de las competencias investigativas necesarias en la formación que le permitan desarrollar el trabajo de Grado a los participantes de postgrado a nivel de Maestría en Docencia Universitaria.

- Establecer los lineamientos de una aproximación teórica referente a las competencias investigativas en la formación de participantes de postgrado a nivel de Maestría en Educación Superior, Mención Docencia Universitaria de la UFT- Barinas.

\section{Consideraciones Epistemo- Metodológicas}

De acuerdo con los propósitos y supuestos planteados en esta investigación, el enfoque más adecuado para abordarla requirió de un paradigma que indague acerca de la comprensión de la experiencia tal y cómo es vivida, sentida o experimentada por los actores sociales dentro de su contexto, por lo que se considera de naturaleza cualitativa.

El estudio se desarrolló desde una perspectiva fenomenológica, con apoyo del enfoque de la hermenéutica, el cual lleva a conocer parte de la vida de los participantes de la investigación así como su propio mundo (Latorre, et. al., citado en Sandín, 2003), 
relacionados con las competencias investigativas. El trabajo se concibe además, dentro de la modalidad de investigación de carácter descriptivo e interpretativo, puesto que plantea analizar los datos reunidos, para luego descubrir qué variables están relacionadas entre sí; es decir, pretende describir con exactitud los hechos y fenómenos de una determinada realidad. Esta investigación se inscribe asimismo dentro del modalidad de estudio de caso (Stake, 1998), más concretamente en el estudio instrumental de casos, puesto que el caso particular se analiza para obtener mayor compresión sobre una temática o refinar una teoría y no la comprensión del caso en sí mismo, no llegar a generalizaciones. Adicionalmente, se apoyó en la investigación documental.

\section{Diseño General de la Investigación}

Siguiendo las etapas propuestas por Monje (2011), se planteó el plan de actividades y procedimientos del diseño de la investigación que se muestra a continuación:

Tabla 1.

Plan de actividades y procedimientos del diseño de la investigación.

\begin{tabular}{|c|c|c|}
\hline Etapa & Actividad & Procedimiento \\
\hline Preparatoria & $\begin{array}{l}\text { Elaboración de cronograma } \\
\text { de actividades. }\end{array}$ & Planificar el tiempo de las actividades. \\
\hline Reflexiva & $\begin{array}{l}\text { Exploración del contexto } \\
\text { Trabajo de campo } \\
\text { Diseño, elaboración y } \\
\text { aplicación de técnicas e } \\
\text { instrumentos } \\
\text { Recogida de los datos }\end{array}$ & $\begin{array}{l}\text { Identificar el problema } \\
\text { Clarificar supuestos } \\
\text { Describir el contexto } \\
\text { Seleccionar y contactar los informantes clave } \\
\text { Elección de la técnica adecuada para recopilar } \\
\text { información. } \\
\text { Elaborar protocolo de entrevista y registro de } \\
\text { observación } \\
\text { Aplicar técnicas e instrumentos } \\
\text { Elaboración de matriz para asentar información } \\
\text { recabada. }\end{array}$ \\
\hline Analítica & $\begin{array}{l}\text { Interpretación de los } \\
\text { hallazgos } \\
\text { Teorización }\end{array}$ & $\begin{array}{l}\text { Transcripción de entrevista para sistematizar, } \\
\text { clasificar y categorizar la información suministrada por } \\
\text { los actores claves } \\
\text { Análisis y contrastación teórica } \\
\text { Triangulación de la información que permite la } \\
\text { construcción de la aproximación teórica }\end{array}$ \\
\hline Informativa & Elaboración del informe final & Presentación de los resultados \\
\hline
\end{tabular}

Fuente: Amarista, 2013 


\section{Escenario de la Investigación e Informantes Claves.}

El escenario elegido para este estudio fue la Universidad Fermín Toro, institución de carácter privado, caracterizada por ser un organismo que no sólo imparte conocimientos a nivel superior, sino también que representa el carácter social y cultural del país y la región, orientando su proceso hacia los valores humanos. Su asiento principal está ubicado en el Municipio Palavecino, capital Cabudare del Estado Lara, Venezuela; sin embargo, se escogió la extensión ubicada en Barinas, estado Barinas, ya que por constituir el propio lugar de trabajo de la investigadora desde que se iniciaron las actividades académicas en esa sede, no existe inconveniente para la entrada y permanencia en las instalaciones. Además el conocimiento y experiencia previa sobre ese escenario permitió tener un grado de información palpable sobre el contexto.

Se utilizaron dos tipos de fuentes: primarias y secundarias. En cuanto a las primarias, se tomaron participantes del programa de Maestría y profesores- tutores, quienes pueden brindar información sobre el tema objeto de estudio. Las fuentes secundarias, la conformaron la documentación escrita tales como Leyes, Reglamentos, diseño curricular, revistas, informes, artículos, libros, entre otros. Para la obtención de la información de primera mano se utilizó una muestra intencional (Martínez Miguélez, 2000), escogiendo los informantes claves atendiendo a unos determinados criterios en donde el investigador selecciona los sujetos según su potencial y es él quien decide cual escoger (Rojas, 2010).

Respecto de los informantes Tutores, después de analizar el contexto en la institución, conversar formalmente con algunos profesores que laboran allí, hacer las revisión de las características de los profesores que imparten docencia en esta Maestría, se seleccionaron dos profesores, ya que fueron los que se acogieron a estos criterios: uno de cada sexo, licenciados en Educación, con postgrado en el área educativa, experiencia en docencia universitaria, con al menos cinco (5) años como tutores de tesis de los participantes de la Maestría en Educación Universitaria, haber dictado, la asignatura Investigación en las Ciencias Sociales y con disposición a 
participar en el estudio, quienes con visión crítica pudieron aportar concepciones que subyacen tanto en lo epistemológico y teórico, como en lo metodológico, respecto de la investigación educativa.

En el caso de los informantes Participantes, previo abordaje utilizando la observación participante durante actividades de clase, conversación formal, se sondeó por parte de la investigadora, los criterios de conocimiento, comprensión y experiencia del tema objeto de estudio, así como también se consideró la disponibilidad futura para participar como informante clave. En ese sentido se escogieron tres (3) estudiantes egresados de la Maestría en Ciencias de la Educación, mención Docencia Universitaria de la Universidad Fermín Toro, oficina de Enlace Barinas, pertenecientes a los grupos: 6, 8 y 10. Los criterios establecidos fueron: experiencia en Docencia Universitaria, con la escolaridad culminada en el tiempo estipulado (dos años), fuera del tiempo (entre 2 y 4 años), con disposición a contribuir con la investigación y con preocupación por su formación.

Técnicas e Instrumentos para recolectar y registrar la información.

La investigación cualitativa, en criterio de Bryman y Burgess (como se citó en Corbetta, 2007), no puede reducirse a técnicas específicas, sino que consiste más bien en un proceso dinámico que une problemas, teorías y métodos. En ese sentido, se habla de tres grandes categorías de técnicas para la recopilación de datos en este tipo de investigación: la observación directa, las entrevistas en profundidad y el uso de documentos, las cuales fueron usadas en este estudio.

En la fase de exploración, se utilizó la técnica de la observación participante. La misma se dirigió a registrar las actuaciones de las situaciones de interacción didáctica entre los docentes tutores y los participantes tutorados, así como sus opiniones y percepciones para percibir la realidad exterior con el fin de obtener datos que se han definido previamente como de interés para la investigación, orientada hacia un objeto de estudio (Martínez Miguélez, 2000), lo que permitió describir la realidad social, las 
percepciones y vivencias de las personas implicadas y el significado de sus acciones para contrástalas e interpretarla mediante la triangulación de la información.

Con el propósito de contrastar los hallazgos obtenidos a partir de la teoría y del análisis de contenido, se recogieron las nociones que poseen los informantes sobre esas categorías mediante la técnica de la entrevista a profesores y a participantes de la Maestría. Para complementar la información requerida para el desarrollo de la investigación, fue preciso analizar algunos documentos escritos; por lo importante de su contenido, para lo cual se hizo un arqueo bibliográfico de los más relevantes, además de una revisión somera del contenido de los materiales para encontrar aquellos aspectos concretos que se identificaban con el objeto de estudio.

El análisis de contenido permitió establecer comparaciones y hacer apreciaciones sobre el significado, concepto- y actitudes de los sujetos de estudio, por lo que se empleó con la intención de develar en los enunciados el significado subyacente en el material textual recogido tanto en la revisión documental, como en los registros de lo dicho y comunicado por los interlocutores durante la investigación. Se buscó además descubrir las intencionalidades de los sujetos participantes, las concepciones que tienen acerca de las competencias investigativas en la formación de Maestrantes en Docencia Universitaria y la manera en que construyen sentidos e interpretaciones dentro del contexto.

Con el fin de analizar la información obtenida en las entrevistas realizadas a los informantes claves, se aplicaron los lineamientos descritos por Martínez Miguélez (2009). Se desarrollaron mediante dos etapas: la descriptiva y la estructural. La primera, para lograr una representación del fenómeno en estudio que resulte lo más completa posible de modo que refleje la realidad vivida por cada sujeto, su situación, desde su cosmovisión, de la forma más auténtica. Para ello, se transcribieron las grabaciones de audio con las entrevistas realizadas, sin omitir aspectos relevantes y $\sin$ incluir elementos imaginados por la investigadora, donde se presenta la información de cada uno de los cinco (5) actores claves. Luego de comparar las transcripciones ya elaboradas con las grabaciones, le fueron facilitadas a los encuestados para confirmar 
la información suministrada por ellos y de esa manera asegurar su veracidad y fidelidad.

La segunda etapa se centró en el estudio de las descripciones para delimitar las unidades temáticas naturales, determinar el tema central que domina cada unidad temática, integrar éstas en estructuras descriptivas particulares y finalmente la integración de ellas en una general. Es decir, se realizó el proceso de categorización (Straus \& Corbin, en Martínez Miguélez, 2000), para darle sentido a lo dicho por los entrevistados, destacando los aspectos convergentes y divergentes, que resultaron en los conceptos claves, registrado en una matriz elaborada a tal efecto. Posteriormente, se compendió la información en otra matriz, con la síntesis interpretativa de las categorías y subcategorías, desde lo teleológico, ontológico y heurístico, de acuerdo con los tópicos tratados en las entrevistas, lo que llevó a la fase de teorización, por medio de la triangulación de las fuentes: Teoría, informantes claves y postura de la investigadora.

Para describir la interpretación y comprensión de lo manifestado por los informantes claves sobre competencias investigativas, se hizo necesario registrar la respuesta dada a cada pregunta planteada, para luego proceder a la extracción de los fragmentos considerados relevantes de los textos originales de la trascripción de las entrevistas, en procura de dar respuestas a las interrogantes del estudio, en relación con los objetivos formulados que orientaron la investigación, lo que permitió interpretar de manera minuciosa la dimensión subjetiva que entrañan los actores sociales involucrados en la investigación. De este modo se procedió reconstruir lo narrado vivido, expresado, pensado y sentido por los sujetos investigados, con respecto a las mismas, contrastándolo con los fundamentos epistemológicos y la experiencia observacional de la investigadora.

\section{Realidad encontrada}

A partir de lo referido por los informantes claves en las entrevistas realizadas, conjuntamente con la información producto las observaciones efectuadas en el contexto 
universitario, pudimos descifrar las manifestaciones que expresaron sobre sus experiencias vividas como tutores, unos, y tutorados otros, con respecto de las competencias investigativas en la formación de Maestrantes en Docencia Universitaria, que le permiten culminar con éxito y pertinencia social el trabajo de grado en el tiempo establecido en la Normativa de la institución. Para ello nos fundamentamos en las categorías y subcategorías que del análisis, emergieron durante el proceso de investigación.

Una vez analizados los fundamentos ontológicos, epistemológicos; y axiológicos acerca de las Competencias Investigativas, a partir de las teorías referidas, más las observaciones realizadas, se evidenció la necesidad de clarificar el concepto de competencias y en particular aquellas específicas para desarrollar la actividad investigativa. Las teorías referenciales, así como los antecedentes utilizados para el abordaje conceptual en el presente estudio, son coherentes con los fundamentos ontológicos, puesto que los autores coinciden en la necesidad de incorporar las competencias investigativas en la formación del docente universitario, a nivel de postgrado.

Para poder hacer la construcción mental alegórica planteada por los actores involucrados en el estudio y de la propia investigadora, hubo que pensar en el concepto de las Competencias Investigativas desde el enfoque de la socioformación, de modo de interpretarlo de acuerdo con las exigencias de que demanda el mundo postmoderno. Cabe resalta que se demostró la conexión del marco teórico con los principios metodológicos que se deben seguir para el desarrollo de investigación.

Desde los principios epistemológicos del enfoque cualitativo fenomenológico que permitieron desarrollar la investigación, se comprendió que las competencias investigativas en el contexto educativo constituyen todos esos conocimientos, habilidades, capacidades y cualidades que le permiten al docente la construcción del conocimiento científico acerca del proceso pedagógico en general, además del proceso de enseñanza-aprendizaje en particular, con el fin de hacerle frente de una manera eficiente a los problemas en dicho contexto, de una manera reflexiva y crítica (Sanz y Pérez, 2007; Ossa, 2008). 
En consonancia con este enfoque, se tomó en cuenta la capacidad hermenéutica o interpretativa, de manera subjetiva e intersubjetiva, de los participantes, como sujetos que viven situaciones de aprendizaje, con sus características particulares (Sandín, 2003), para generar una realidad que le permita mejorar su formación con miras a la culminación exitosa de su Maestría.

Del producto de las observaciones realizadas y su interpretación, podemos señalar que, tomando en consideración las nuevas realidades educativas y sociales que vivimos en la actualidad, el Diseño curricular del Programa de la Maestría en Docencia Universitaria, necesita actualizarse para responder al perfil del docente universitario que satisfaga tales demandas. En los contenidos sinópticos no están planteadas con claridad las competencias investigativas y las horas de asesoría resultan insuficientes para la apropiación de los conocimientos y puesta en práctica de los mismos, de allí que manifiestan la necesidad de apoyo adicional.

Con relación al significado de investigación, los participantes de la Maestría en Docencia Universitaria de la UFT-Barinas conocen el concepto, señalando elementos coincidentes con los expresados por los teóricos, que le permite al investigador la búsqueda de alternativas para dar respuesta a las diferentes situaciones o problemas que se le presenten en su práctica diaria. No obstante, muestran evidencias que no han logrado internalizar el proceso en la práctica para el desarrollo de una investigación. En efecto, los docentes tutores advierten sobre un insuficiente dominio que tienen de los conocimientos básicos sobre investigación, poca profundidad, escasa experiencia y falta de entrenamiento para el trabajo investigativo, lo que ellos plantean como desconocimiento de la actividad investigativa, una de las posibles causas de que no culminan a tiempo su trabajo de investigación.

Con respecto a las competencias investigativas, en las declaraciones de los informantes, no se evidencia una definición clara del término; a pesar de que coinciden al referirse a algunos de los aspectos que las constituyen. Las consideran como aquellos conocimientos, habilidades, destrezas, capacidades, conjuntamente con el uso de los métodos, técnicas y estrategias de investigación, que necesitan los estudiantes 
en su formación, de modo de que le garanticen realizar un trabajo de investigación de relevancia y profundidad.

Por otra parte, en lo atinente a su experiencia en investigación, los participantes manifestaron la importancia de poseer formación previa en investigación, para ingresar a la Maestría (Cadena, et al., 2004). Contrariamente a lo que se espera, el culminar el trabajo de grado de la Maestría no necesariamente es signo de que los maestrantes poseen las competencias investigativas que los convierte en investigadores. Durante el desarrollo del trabajo; se puso en evidencia que presentan deficiencias, sobre todo para el análisis, redacción y producción escrita, habilidades consideradas de gran relevancia en la elaboración del trabajo de investigación (Machado \& Montes de Oca, 2009).

Del testimonio de los actores claves, basados en sus vivencias durante el proceso, surgió como aspecto notable, la motivación e interés por la actividad investigativa. De igual manera señalaron la necesidad de que el investigador se desenvuelva en el contexto universitario para que pueda vivenciar directamente las situaciones educativas que le sirvan de insumo para plantear un problema de investigación.

\section{Aproximaciones conclusivas}

Como producto de la exégesis de los hallazgos significativos logrados en la investigación, para dar respuesta al primer objetivo, se comprendió que abordar el tema sobre las competencias investigativas, no es tarea fácil; es necesario entender en primera instancia lo polisémico del término competencia, lo que significa ser una persona competente y afrontar el ámbito investigativo.

Las competencias están asociadas a la formación en los diferentes contextos de la actividad humana. La mayoría de los autores que han estudiado el concepto de competencias coinciden en que tiene que ver con el "saber conocer", el "saber hacer", el "saber ser y el saber estar" de la persona que la posee. Es decir, la persona o estudiante se considera competente cuando realiza un conjunto de acciones en un contexto particular que responde a las exigencias del mismo. 
Es indudable, que las competencias, como una estructura compleja, deben estar conformadas además de aquellos comportamientos observables, por varias particularidades que integran los conocimientos (componente cognitivo), habilidades, técnicas y procedimientos (componente procedimental), actitudes y valores (componente actitudinal) para buscar el desempeño eficiente en el marco de un contexto específico.

Con respecto a las competencias investigativas, a pesar de ser un tópico objeto de estudio y discusión en el ámbito internacional, se puede decir que no existe claridad conceptual con respecto al término, aspecto que se corrobora en las declaraciones tanto de los tutores como los participantes de este estudio. En la mayoría de los casos, se confunde con la metodología a seguir para realizar una investigación. De esa manera, se evidencia la necesidad de su comprensión con el fin de formar profesionales con amplios conocimientos que puedan emprender proyectos y programas de investigación de problemas de relevancia social de su contexto.

Es evidente que las competencias investigativas pretenden formar profesionales con amplios conocimientos para emprender proyectos y programas de investigación de problemas de relevancia social del contexto, y el desarrollo de esas competencias propende a estructurar un pensamiento crítico, sistémico, abierto, reflexivo y creativo; sin embargo, en esta tarea en el postgrado, se han encontrado algunas debilidades, entre las que destacan: enfoque del tema o planteamiento del problema, falta de herramientas en cuanto a metodología y diseño de la investigación y pobre administración del tiempo para la ejecución (Dubs, 2005).

No es muy común encontrar referencias sobre competencias específicas para la actividad investigativa en la bibliografía especializada, a pesar de ser un tópico importante para el desarrollo de la creación de nuevos conocimientos y objeto de estudio en el contexto del debate internacional sobre las metas de la educación superior para este milenio. De igual manera, no hay una definición clara de lo que significan las competencias investigativas. Las competencias investigativas constituyen herramientas mentales que permitirán al individuo conocer mejor la realidad y ser más comprensivo frente a ella, saber cuándo y cómo actuar, así como extraer significados de experiencia 
vital que movilicen el desarrollo individual. Además, permiten generar en los estudiantes universitarios, un aprendizaje significativo de conocimientos especializados y habilidades en la investigación que les ofrecen las herramientas para que diseñen y ejecuten proyectos de investigación. Para el caso de la investigación en educación, es necesario el desarrollo de estas competencias, no sólo para el "conocer" sino para el "hacer", "actuar", "emprender" (Pérez, 2012).

Hechas las consideraciones anteriores, podemos concebir las competencias investigativas del docente universitario como un conjunto de saberes (saber/conocer), que mediante la puesta en práctica de habilidades y destrezas, (saber hacer) permiten detectar una situación del contexto educativo, problematizarla, a efecto de plantear su solución haciendo uso de todas las etapas de la metodología de investigación, de manera eficiente, crítica, reflexiva, creativa y responsable (ser/convivir).

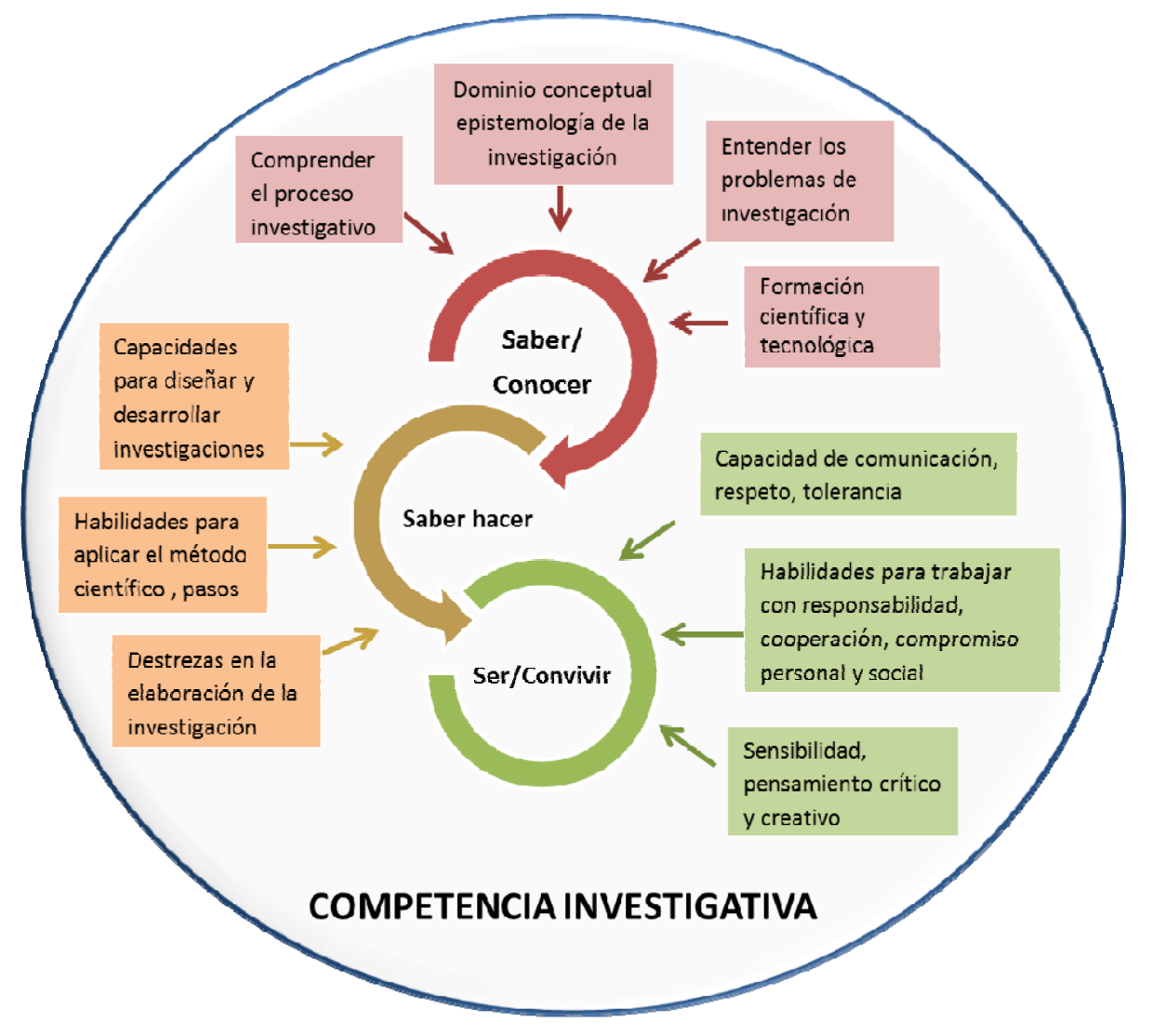

Figura 1. Competencia Investigativa desde el "saber/conocer", "saber hacer" y "ser/convivir".

Fuente: Amarista, 2013 
Cuando en investigación, nos referimos a la competencia del "saber" (conocer) hacemos mención al tipo de competencias cognitivas, que llevan a identificar un problema, búsqueda, selección y sistematización de información, comprensión, análisis, síntesis, evaluación, inducción y deducción del conocimiento; corresponde al manejo conceptual que los estudiantes tienen sobre el saber especifico y su aplicación en contextos sociales.

La competencia del "saber hacer" requiere además de conocimiento teórico, práctico o teórico práctico, afectividad, compromiso, cooperación y cumplimiento. Con esta competencia se contribuye a la formación del estudiante para hacer frente a una cantidad de situaciones y problemas, que conlleven una experiencia formativa y una praxis social. En ese sentido, es claro que deben presentarse problemas reales, en un clima de confianza y libertad que permitan potenciar el deseo de aprender para alcanzar un propósito en la vida.

La competencia del "ser", mundo ontológico actitudinal y axiológico, es necesaria en el desarrollo de actitudes primordiales para el crecimiento personal. En la actividad investigativa es importante la comprensión, la tolerancia, la cooperación, el respeto por sí mismo y por los demás, la motivación, el querer hacer, la tolerancia a las frustraciones, la disposición y confianza hacia el aprendizaje; la capacidad para superar obstáculos; la capacidad de asombro, de curiosidad, así como el reconocimiento de sus potencialidades y habilidades.

Se confirmó que, a pesar de que los participantes de la Maestría en Docencia Universitaria de la UFT-Barinas reconocen en el concepto de investigación, elementos coincidentes con lo señalados en la teoría, que le permite al investigador la búsqueda de alternativas para dar respuesta a las diferentes situaciones o problemas que se le presenten en su práctica diaria, muestran evidencias de que no han logrado internalizar el proceso en la práctica para el desarrollo de una investigación. En efecto, los docentes tutores advierten sobre un insuficiente dominio que tienen de los conocimientos básicos sobre investigación, poca profundidad, escasa experiencia y falta de entrenamiento para el trabajo investigativo. 
Por otra parte, en la revisión realizada al diseño curricular de la Maestría, se evidenció que no están planteadas con claridad las competencias investigativas que necesita adquirir el participante durante su formación. Así mismo, entre los requisitos de ingreso no se toma en consideración la formación o experiencia previa en investigación como elementos facilitadores que puedan garantizar un mayor éxito en la elaboración y culminación del trabajo de grado. Existe preocupación por la reducción del tiempo que actualmente se establece para las asesorías, considerado muy poco para que el participante pueda internalizar y desarrollar el proceso investigativo. No obstante, existe disposición de parte de los tutores en plantear alternativas que pudieran subsanar esa situación.

Con respecto al segundo objetivo, en cuanto a su experiencia de cómo aprendieron a investigar, desde la voz de cada uno de los participantes se indica la formación mediante cursos, talleres y seminarios como factor importante, además de la realización de lecturas de trabajos de investigación como modelos a seguir, pero sobre todo la necesidad de plantear una inquietud o interrogante y desarrollar en la práctica los pasos de la metodología científica.

El culminar el trabajo de grado de la Maestría, no precisamente los convierte en investigadores. Las debilidades observadas en los participantes para desarrollar el trabajo de investigación se confirman en sus declaraciones, a pesar de que manifiestan conocimiento teórico sobre lo que significa investigar y el proceso a seguir para desarrollar una investigación; sin embargo, en sus actuaciones es notorio que presentan deficiencias para el análisis, redacción y producción escrita. Todo esto pudiera considerase como un impedimento para concebir, desarrollar y culminar un trabajo de investigación con éxito, debido a la ausencia de correspondencia entre los conocimientos adquiridos previamente y los pasos a seguir para elaborar un proyecto de investigación.

Un aspecto de singular importancia que emergió del testimonio de los actores es la motivación e interés por la actividad investigativa, es decir, el participante debe estar motivado, abierto a considerar otras alternativas de mejora novedosas, que le brinde la posibilidad de ir más allá de las simples actuaciones dentro de los parámetros 
institucionales, como afirma Checchia (2009). Cabe agregar que el no estar inmerso en el contexto universitario, se consideró como una debilidad, puesto que no se tiene la oportunidad de vivenciar directamente la cotidianidad del acto educativo, con todas sus características, del cual pueden surgir las inquietudes que le ayuden a diseñar su investigación.

Es incuestionable que se necesitan capacidades, habilidades y destrezas para poder operacionalizar los pasos para desarrollar investigaciones, entre las cuales los entrevistados plantearon: la observación, selección de información relevante, registro, análisis, descripción, interpretación, comprensión lectora con actitud reflexiva, habilidades comunicativas, tanto oral como escrita, uso de herramientas estadísticas, todo ello con disciplina, orden; en otras palabras, aplicar con rigor científico los conocimientos adquiridos.

En cuanto al cuarto objetivo, como parte del proceso de interpretación dialógica entre la voz de los informantes claves para esta investigación, así como la revisión de las teorías sobre los aspectos estudiados, se presentan las siguientes consideraciones como resultado del proceso reflexivo seguido durante la investigación, para una aproximación teórica sobre las Competencias Investigativas en la formación de Maestrantes en Docencia Universitaria desde su cosmovisión contextual.

Diseño curricular $y$ el enfoque socioformativo de las competencias: $A$ las universidades le corresponde, la tarea de formar un docente, que desde su quehacer contextual, pueda enfrentar los problemas pedagógicos o técnicos, de una forma científica, contribuyendo a las transformaciones necesarias que desde la educación puedan dar respuestas a las demandas sociales. Es por ello que, en el diseño curricular se debe tomar en consideración el enfoque socioformativo de las competencias como perspectiva que apunta más allá de lo meramente cognoscitivo, es decir, asumir el compromiso para lograr la realización personal, haciendo posible la convivencia con los demás (Tobón, 2007). En otras palabras considerar el desarrollo de estas competencias, no sólo para el "conocer", sino para el "hacer" o "actuar", "ser y convivir", con referencia a los pilares de la educación. 
La investigación en la formación de Maestría en Docencia Universitaria: Se hace necesario promover la investigación de la realidad educativa, de modo que el docente reflexione sobre su práctica, para comprender su contexto, de tal manera que pueda contribuir a la construcción de una cultura investigativa y al desarrollo del conocimiento. Es allí donde los estudios de postgrado deben abocarse a la formación de profesionales capaces de transformar su realidad, al promover el desarrollo de la investigación educativa no solo en el mejoramiento de la calidad educacional sino de algunos indicadores asociados a la calidad de vida de la población (Henao, 2005).

Los estudios de postgrado, específicamente en el área de Docencia Universitaria, deben enfocar sus esfuerzos hacia el proceso de formación investigativa en los participantes, hacia la construcción de sus aprendizajes, haciendo posible la integración de conocimientos, habilidades, destrezas y actitudes para que pueda mediante la reflexión de su accionar docente contribuir a mejorar el proceso educativo. Para que el participante de la Maestría en Docencia Universitaria culmine su formación con la elaboración de un trabajo de investigación pertinente, en el tiempo reglamentario, debe apropiarse de un amplio sistema de conocimientos estructurados significativamente sobre la investigación, lo que quiere decir, que debe comenzar por el concepto de ciencia, en qué consiste la investigación científica, para qué sirve y cómo se desarrolla, para continuar con los distintos paradigmas que permiten abordar ese proceso, así como lo relativo a las normas que regulan los aspectos formales para la elaboración del informe final.

Además, debe demostrar capacidad de observación, interpretación- y análisis, que le permita desarrollar un pensamiento crítico. Tal como se ha visto, el hábito de la lectura emerge como un elemento de considerable importancia, ya que es necesario en el desarrollo de todo el proceso investigativo, para principalmente, seleccionar la información pertinente, en la bibliografía a consultar.

Estos conocimientos deben estar consolidados para poder articularlos con la puesta en práctica de una serie de acciones, es decir, aplicar esos saberes, a situaciones particulares. Se hace referencia a las herramientas cognoscitivas, técnicas, metodológicas y procedimentales necesarias para poder operacionalizar las etapas del 
proceso investigativo, entre las que se destacan: plantear un problema con todos sus componentes, desarrollar el sustentación teórica, definir el diseño de la investigación de forma rigurosa, analizar e interpretar la información recolectada que le permita llegar a las conclusiones del trabajo, haciendo uso de igual forma, de las habilidades comunicativas en la elaboración y presentación del informe final (Rivera \& Torres, 2005).

Otro aspecto que merece especial atención, se refiere a lo que se ha llamado, la manera de "ser" del investigador frente a la actividad investigativa, cuáles son sus actitudes y valores que favorecen la vocación científica. Existen otros rasgos que complementan una personalidad creadora propia del individuo con vocación científica, como la libertad, justicia, honestidad, lealtad, tolerancia, cooperación, confianza y respeto mutuo, colaboración, solidaridad, pero sobre todo el compromiso que asume con la investigación (Lara, 2009). En ese orden, se ha señalado la motivación como un rasgo importante, en otras palabras, debe sentir la necesidad para descubrir algo que no conoce, un problema o situación que lo inquieta y desea resolver, esto es lo que va a permitir que el investigador participante, se sienta involucrado e identificado con la tarea investigativa, planteándosela como un logro más de su proyecto de vida.

Como se observa en la siguiente figura, las competencias investigativas que deberían poseer los Maestrantes en Docencia Universitaria para poder culminar con éxito su trabajo de grado, no sólo se refieren a tener el dominio de los aspectos cognoscitivos sobre la investigación y la puesta en práctica de esos conocimientos en el desarrollo de la misma, cumpliendo con todas las fases del proceso; sino que además debe dar muestras de sus actitudes y valores, que favorecen la vocación científica.

Es decir, que evidencie su compromiso personal para contribuir en la solución situaciones que buscan mejorar la calidad de la educación y por ende, de la sociedad, para una mejor convivencia. Por lo cual, no sólo en las asignaturas relacionadas con la investigación, que conforman el plan de estudios deben plantearse estrategias más específicas que coadyuven en la formación de este investigador. En ese caso, propiciar situaciones que permitan reflexionar desde la experiencia, sobre la acción docente, para buscar nuevas formas de producción, creación y legitimación del conocimiento, 
involucrando al participante desde el comienzo del programa, en proyectos de investigación para plantear soluciones a necesidades o problemáticas en su contexto, utilizando las diversas tecnologías de información y comunicación; el aprendizaje por descubrimiento, el trabajo en grupo, entre otras, con la debida asesoría.

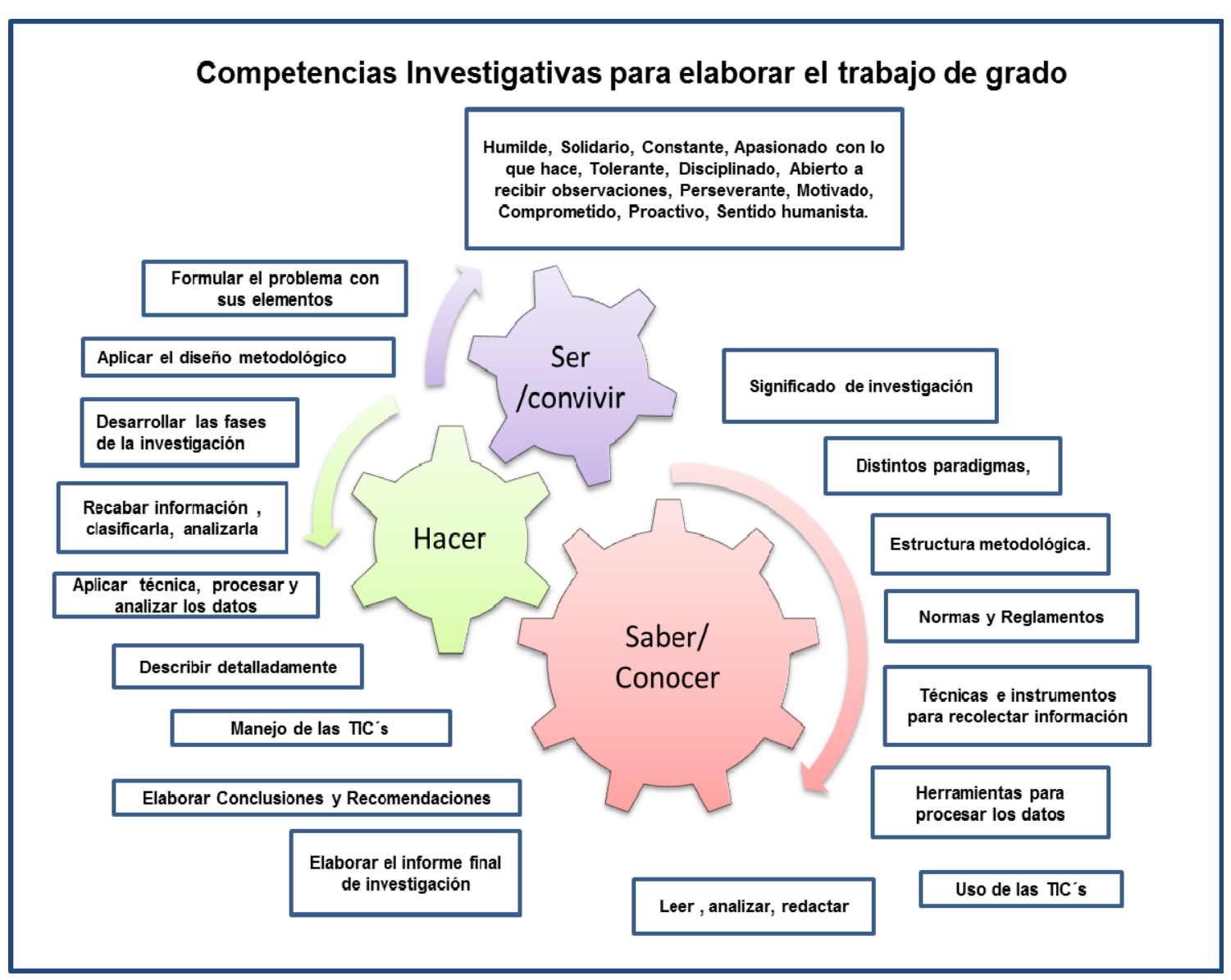

Figura 2. Competencias Investigativas que deben poseer los Maestrantes para la elaboración de su trabajo de grado.

Fuente: Amarista, 2013

\section{Reflexiones}

La investigación en la educación universitaria se convierte en el mecanismo vinculante de sus actores con la experiencia de la producción de conocimientos, sin embargo, las estrategias utilizadas en el desarrollo de las asignaturas, pareciera que no dan muestra 
que se esté cumpliendo con este fin. Se requiere de una pedagogía que aporte sentido al acto educativo, al proceso de formación investigativa que conlleve a la construcción de su aprendizaje, posibilite la integración de conocimientos, habilidades, destrezas y aptitudes que le permitan adentrarse en la investigación.

De los planteamientos hechos por los actores sociales de este trabajo se recoge la necesidad de apoyo en el profesor, asesor o tutor, como guía del proceso investigativo, en la concepción, planeamiento, desarrollo y culminación de los trabajos de investigación. Es por ello que esta persona debe, además de ser especialista en el área de conocimiento que aborda, y del proceso investigativo, mostrarse colaborador, orientador, tolerante, comprensivo, dispuesto a ofrecer la debida asesoría, más la retroalimentación, constante y adecuada a las necesidades de los tutorados.

Se recomienda realizar un estudio a nivel curricular, para adecuar los contenidos a las exigencias actuales, así como revisar las estrategias, de forma que se incorporen actividades prácticas, como proponen Machado y Montes de Oca (2009), que se conviertan en talleres o laboratorios para el aprendizaje formativo, con la asesoría acerca de los aspectos técnico-metodológicos que necesita el estudiante para desarrollarse como investigador y culminar su trabajo de grado con éxito. Además, reconsiderar el tiempo de asesorías para los Proyectos I, II y III. Igualmente, estudiar la posibilidad de agregar dentro del curso nivelatorio, alguna asignatura para cumplir con este fin, o incorporar entre los requisitos de ingreso, una propuesta de protocolo de investigación, de modo que el estudiante asuma su compromiso con la actividad investigativa desde el comienzo de la Maestría. Resultaría interesante incorporar estas modificaciones mediante el abordaje desde el enfoque por competencias, donde no sólo se haga énfasis en los aspectos de índole cognoscitivos y procedimentales, sino que también se tome en consideración aquellas aptitudes fundamentales para el crecimiento personal, que le permitan problematizar su realidad circundante y producir conocimientos que sirvan para transformar relaciones sociales (Vargas, 2010) de una manera crítica y responsable.

Como resultado de todo el proceso reflexivo hermenéutico para con la investigación, se presenta a continuación un ejemplo del planteamiento de una 
competencia investigativa, así como una representación gráfica de la interpretación de los significados que los actores sociales, conjuntamente con la realizada por la investigadora, le atribuyen a las competencias investigativas necesarias para la elaboración del trabajo de grado basados en los aportes teóricos que sustentan este estudio. En ella se concreta la importancia que revisten la incorporación de las competencias investigativas en el diseño curricular de Maestría en Docencia Universitaria, desde el "saber, hacer y ser", de modo que como resultado de la formación ese docente universitario, demuestre no sólo sus conocimientos y habilidades para conducir una investigación, sino además su compromiso personal para contribuir en la solución situaciones orientadas a mejorar la calidad de la educación en un clima de armonía para una sana convivencia.

Tabla 2

Ejemplo de Planteamiento de una Competencia Investigativa

Competencia: Elabora una investigación sobre la praxis educativa en el contexto universitario, con base en la normativa institucional, siguiendo los pasos de la investigación científica para presentarla como trabajo de Grado de Maestría en Docencia Universitaria

\begin{tabular}{|c|c|c|}
\hline \multicolumn{3}{|c|}{ Unidad de Competencia: Plantea el Problema de Investigación } \\
\hline Saber & Hacer & Ser/convivir \\
\hline $\begin{array}{l}\text { *Conocer } \\
\text { sobre la } \\
\text { temática. } \\
\text { *Definir y } \\
\text { detectar una } \\
\text { situación a } \\
\text { Investigar } \\
\text { *Identificar la } \\
\text { situación } \\
\text { problema, sus } \\
\text { causas y } \\
\text { consecuencias }\end{array}$ & $\begin{array}{l}\text { *Estructurar formalmente la idea de investigación. } \\
\text { *Delimitar el campo de investigación. } \\
\text { *Describir la situación a investigar. } \\
{ }^{*} \text { Especificar las propiedades importantes de personas, grupos, } \\
\text { comunidades o cualquier fenómeno que sea sometido a análisis. } \\
\text { *Destacar las características conocidas de la realidad, con sus } \\
\text { condiciones, regularidades, normalidad y deficiencias. } \\
{ }^{*} \text { Analizar y exponer las teorías, enfoques teóricos y antecedentes } \\
\text { que se consideren válidos para el estudio } \\
\text { *Plantear interrogantes precisas. } \\
\text { *Formular los objetivos } \\
\text { *Elaborar la Justificación }\end{array}$ & $\begin{array}{l}{ }^{*} \text { Desarrollar en } \\
\text { forma } \\
\text { comprometida las } \\
\text { fases de la } \\
\text { investigación } \\
\text { *Trabajar con } \\
\text { calidad, esfuerzo } \\
\text { y responsabilidad. } \\
\text { *Establecer } \\
\text { prioridades, } \\
\text { programar el } \\
\text { tiempo. }\end{array}$ \\
\hline
\end{tabular}

Fuente: Amarista, 2013 


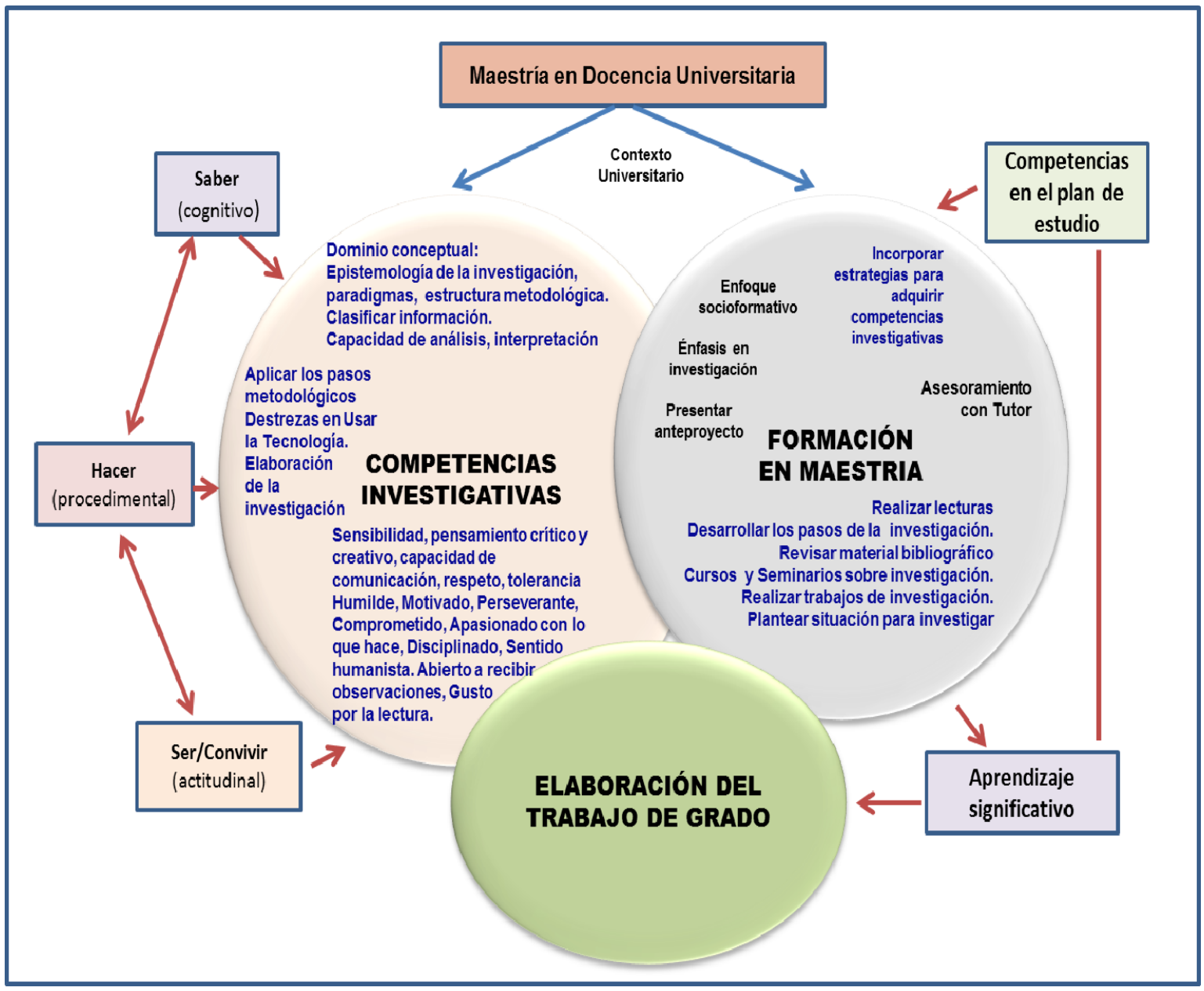

Figura 3. Competencias en la formación de Maestría en Docencia Universitaria para elaborar el trabajo de grado.

Fuente: Amarista, 2013

\section{Referencias}

Álvarez, V. \& Orozco, O. (2011). Determinación de la formación investigativa en estudiantes de carreras de Ciencias Sociales y Humanísticas de la sede universitaria municipal de Guantánamo. Cuba. Cuadernos de Educación y Desarrollo. 3 (25), Recuperado en http://www.eumed.net/rev/ced/25/avoh.htm

Cabra, F. \& García, M. (2009). La formación investigativa en la educación de postgrado. ¿Cómo cualificar la fundamentación de la investigación en ciencias sociales? Recuperado de http://javeriana.academia.edu/FABIOLACABRATORRES/Papers/542823/La_formacion_i nvestigativa_en_la_educacion_de_postgrado_Como_cualificar_la_fundamentacion_de_I a_investigacion_en_ciencias_sociales._Coautor. 
Cadenas, Y., Rojas de C., B. y Reyes, C. (2004). Competencias en el eje investigativo de los participantes de la cohorte 2000-2004 del Subprograma de Maestría en Educación Superior de la UPEL-IPB. Ponencia presentada en el Congreso Internacional de Investigación Educativa IIMEC-INIE 25 años en Pro de la Educación. Recuperada de http://74.125.155.132/scholar?q=cache:hshYvjofPqUJ:scholar.google.com/+competencia s+investigativas\&hl=es\&as_sdt=2000\&as_vis $=1$.

Checchia, B. (2009). Las competencias del docente universitario. Recuperado de http://www.fvet.uba.ar/institucional/subir/adjuntos/userfiles/COMPETENCIASDOCENTES .pdf

Consejo Consultivo Nacional de Post Grado CCNPG. OPSU-CNU. (2011). [Página web en línea]. Disponible: www.ccnpg.gob.ve

Corbetta, P. (2007). Metodología y Técnicas de Investigación Social. Madrid: McGraw Hill.

Dubs, R. (2005). Permanecer o desertar de los estudios de Postgrado: Síntesis De Modelos Teóricos. Investigación y Postgrado [online]. 20(1), (pp. 55-79). Recuperado de http://www.scielo.org.ve/scielo.php?script=sci_arttext\&pid=S1316-

00872005000100003\&Ing=es\&nrm=iso. ISSN 1316-0087.

Henao, M. (2005). El papel de la investigación en la formación universitaria. Universia. Colombia. Recuperado de http://especiales.universia.net.co/ docentes/articulos-deeducacion-superior/el-papel-de-la-investigacion-en-la-formacion-universitaria/la-actitudinvestig.html

Jaik Dipp, A. \& Ortega, E. (2011). Nivel de dominio de las competencias investigativas de los alumnos de Posgrado. Ponencia presentada en el XI Congreso Nacional de Investigación Educativa / 4. Educación Superior, Ciencia y Tecnología. Noviembre, 2011. pp. 1-10. Recuperado de http://lab.iiiepe.net/congresonacional/docs/area_04/0552.pdf.

Lara M., C. (2009). El valor de Investigar. Trabajo de Ascenso no publicado Universidad Experimental de los Llanos Occidentales “Ezequiel Zamora”. Barinas. Venezuela.

Machado, E. \& Montes de Oca, N. (2009). El desarrollo de habilidades investigativas en la educación superior: la solución de problemas profesionales. Humanidades Médicas, 9 (2) Recuperado de http:// scielo. sld.cu/scielo.php?pid=S1727$81202009000200002 \&$ script=sci_arttext.

Martínez Miguélez, M. (2000). La Investigación Cualitativa Etnográfica en educación. Manual Teórico-Práctico.3ra Reimpresión. México: Trillas.

Martínez Miguélez, M. (2009). Ciencia y Arte en la Metodología Cualitativa. 2da Ed. México: Trillas.

Monje, C. (2011). Metodología de la Investigación Cuantitativa y Cualitativa. Guía Didáctica. Universidad Surcolombiana. Recuperado de http://www.google.co.ve/url?sa=t\&rct=j\&q=\&esrc=s\&source=web\&cd=1\&ved=0CCsQFjA A\&url=http \%3A\%2F\%2Fcarmonje.wikispaces.com\%2Ffile\%2Fview\%2FMonje\%2BCarlos $\% 2 B A r t u r o \% 2 B-\% 2 B G u \% 25 C 3 \% 25 A D a \% 2$

Bdid\%25C3\%25A1ctica\%2BMetodolog\%25C3\%25ADa\%2Bde\%2Bla\%2Binvestigaci\%25 C3\%25B3n.pdf\&ei=oFIfUovnJIOm9gSq7oG4Aw\&usg=AFQjCNEIHyJnFg5cZxwAh-

YreARdISb3IA\&sig2=_0HVlegzGVJC_8Eu1PmEMg\&bvm=bv.54176721,d.eWU

Morales, O., Rincón, A. \& Römero, J. (2005). Cómo enseñar a investigar en la Universidad. La Revista Venezolana de Educación. EDUCERE. 9 (29), 217-224.

Morles, V. (2004). La Educación de Postgrado en Venezuela. Panorama y Perspectivas. Recuperado de http//www.iesalc-unesco.org.ve/.

Normativa General de los Estudios de Postgrado para las Universidades e Instituciones debidamente Autorizadas por el Consejo Nacional de Universidades. (2001). Gaceta 
Oficial de la República Bolivariana de Venezuela, 37.328 (Ordinaria), Noviembre 20, 2001.

Ossa, J. (2008) Competencias Investigativas. UNI-PLURI/VERSIDAD. 8(2) Recuperado de http://www.slideshare.net/nscinvestigacion4y5/competencias-del-investigador.

Padrón, J. (1996): Acerca de la Investigación Educativa del Nivel Doctoral (Testimonios de un Tutor), en Sánchez, J. (comp.): Investigación Educativa. Un compromiso para investigar y aprender con otros. Barquisimeto: CNU/OPSU/UNESR. (pp. 71-94). Recuperado de http://padron.entretemas.com/TestimonioDeUnTutor/Index.htm

Pérez R., M. (2012). Fortalecimiento de las competencias investigativas en el contexto de la educación superior en Colombia. Revista de investigaciones UNAD Bogotá - Colombia 1, enero-junio. Recuperado:

http://www.google.co.ve/url?sa=t\&rct=j\&q=\&esrc=s\&source=web\&cd=1\&ved=0CCwQFjA A\&url=http $\% 3 \mathrm{~A} \% 2 \mathrm{~F} \% 2 \mathrm{Fweb}$.unad.edu.co\%2Frevistainvestigaciones $\% 2 \mathrm{Fimages} \% 2 \mathrm{Frevi}$ stas $\% 2 F U N A D \% 2520$ WEB\%2520\%2520\%2520vol.11\%2520num.1\%25202012\%2F1.\% 2520Fortalecimiento\%2520de $\% 2520$ las $\% 2520$ competencias $\% 2520$ investigativas $\% 2520$ en $\% 2520$ el\%2520contexto\%2520de $\% 2520 l a \% 2520$ educaci\%25C3\%25B3n\%2520superi or\%2520en\%2520Colombia.pdf\&ei=Hgg1UqLv14S29QSv-

YDgAw\&usg=AFQjCNE_9b6BoOVnFRsxCYwhO_xOTPqUBQ\&sig2=IceHZQFTHOSdbso alK4VaA\&bvm=bv.52164340,d.eWU

Informe Final del Proyecto Tuning- América Latina- 2004-2007. Reflexiones y perspectivas de la Educación Superior en América Latina. Universidad Deusto-Universidad de Groningen, Bilbao, 2007, 427 páginas. [Libro en línea] Recuperado de http://tuning.unideusto.org/tuningal/index.php?

option=com_docman\&ltemid=191\&task=view_category\&catid=22\&order=dmdate_publis hed\&ascdesc $=$ DESC

Rivera, M. \& Torres, C. (2005). Percepción de los estudiantes universitarios de sus propias habilidades de investigación. Recuperado de www.usb.edu.mx/investigacion/cif/proyectos/

Rojas de E., B. (2010). Investigación Cualitativa fundamentos y praxis. 2da Edición. Caracas: FEDEUPEL.

Sandín E., M. (2003). Investigación cualitativa en educación. Fundamentos y tradiciones. España: McGraw Hill

Sanz, M. \& Pérez, M. (2007). Hacia la adquisición de competencias en un contexto Investigador, ponencia presentada en el $15^{\circ}$ Congreso Universitario de Innovación Educativa en las Enseñanzas Técnicas Escuela Universitaria Politécnica de Valladolid, 18, 19, 20 de julio, 2007. Recuperado de http://www.upc.edu/rima/grups/greco/recursos/aportacions-enplantilla-greco-del-membres-del-grup/upc-ice-sanz-y-perez.

Stake, R. (1998). Investigación con estudio de casos. Madrid: Morata.

Tobón, S. (2006) Aspectos básicos de la formación basada en Competencias. Recuperado de http://www.uv.mx/facpsi/proyectoaula/documents/Lectura5.pdf

Tobón, S. (2007). La formación basada en competencias en la Educación Superior: El enfoque complejo. Universidad Autónoma de Guadalajara. Curso IGLU 2008 Guadalajara, México. Recuperado de http:// www.eventos.cfie.ipn.mx/reuniones_academicas/dialogos/pdf/dfle1.pdf

Universidad Fermín Toro. (2011). Diseño Curricular Maestría en Educación Superior. Mención Docencia Universitaria. UFT.

Valarino, E. (2000). Tesis a tiempo. Síndrome TMI. [Libro en línea]. Recuperado http://books.google.co.ke/books?id=w_vA02P3obgC\&printsec=frontcover\&source=gbs_g e_summary_r\&cad $=0 \# v=$ onepage $\& q \& \bar{f}=$ false 


\section{REDIED}

Vargas, S. (2010). Las competencias investigativas como eje curricular. Cuadernos de Educación $y \quad$ Desarrollo. 2

http://www.eumed.net/rev/ced/18/svr2.htm.

(18)

Recuperado

de 


\title{
VÍNCULO SOLIDARIO: APRENDIZAJE-SERVICIO Y COMPETENCIA INVESTIGATIVA EN ESTUDIANTES DE PSICOLOGÍA
}

\section{SOLIDIARITY LINKAGE: SERVICE-LEARNING AND RESEARCH COMPETENCE IN PSYCHOLOGY STUDENT}

\author{
Angélica Quiroga Garza \\ Universidad de Monterrey \\ angelica.quiroga@udem.edu.mx
}

\begin{abstract}
Resumen
La investigación forma parte del quehacer cotidiano del psicólogo ya que por su propio objeto de estudio requiere del uso del método científico para su comprensión y análisis. En este trabajo se evalúa la pertinencia de desarrollar la competencia investigativa en estudiantes de psicología de pregrado vinculando ciencia-investigación-servicio de manera sistemática. Se conceptualiza acerca de las competencias en relación a la formación, la profesionalización, la disciplina y la investigación. Se fundamenta la vinculación investigación-servicio, base del método educativo del curso PS3105 Aplicaciones en Psicología Clínica y se comparten aspectos del diseño instruccional y su gestión en el aula virtual. Posterioremente se presentan los resultados de su ejecución en los últimos dos años y medio y los beneficios que de ello se han derivado.
\end{abstract}

Palabras clave: responsabilidad social universitaria, aprendizaje autorregulado, método científico.

\begin{abstract}
Research is part of the daily work of the psychologists due to the fact that in order to understand and analyze their object of study, they require to use the scientific method. In this paper we assess the relevance of developing research competence in undergraduate psychology students linking scienceresearch-service systematically. We conceptualize competencies in relation to higher education, professionalism, discipline, and research. We also argue about linking research- service, base of the educational method in PS3105 Applications Clinical. Psychology course. We share issues of the instructional design and the virtual classroom management. Subsequently, we present the results of the implementation in the last two and half years and the benefits they have derived from it are presented.
\end{abstract}

Key words: university social responsibility, self-regulated learning, scientific method

\section{Introducción}

El desarrollo de la competencia investigativa en cada una de las disciplinas se ha constituido como un proceso crítico en las instituciones de educación superior. La 
vinculación ciencia-investigación de manera sistemática y temprana en el pregrado, favorece el desarrollo de competencias en los estudiantes tanto investigativas como para la vida. Esto se sustenta en el manejo crítico de la información (D'Ottavio, 2001; Gayol, Tarrés, García \& D'Ottavio, 2011; Manassero, Vázquez \& Acevedo, 2004), la reflexión sobre, en y para la acción teórico-metodológica (Quiroga \& Moreno, 2012) en un ciclo autorregulatorio (Schunk \& Zimmerman, 1998), que mejora con la práctica (Zimmerman, 2008) y puede ser enseñado (Schunk, 2005) como parte de un proyecto ético de vida sólido (Tobón 2010; Tobón \& Guzmán, 2010).

En el caso del psicólogo, la investigación forma parte de su quehacer cotidiano ya que por su propio objeto de estudio, la conducta, requiere del uso del método científico para su comprensión y análisis. De esta manera, conforme el psicólogo avanza en su formación profesional, independientemente de su área de especialización o interés, se formula distintas preguntas sobre el comportamiento humano y su relación con un sinnúmero de variables ya sean intrínsecas o extrínsecas al propio individuo.

En el plan de estudios de la carrera de Psicología de la Universidad de Monterrey (UDEM) se contempla el desarrollo de competencias profesionales, entre ellas la competencia de investigación en todas sus variantes: documental, aplicada y básica. En diferentes cursos del plan de estudios del Licenciado en Psicología, los estudiantes se involucran en proyectos de investigación que les permiten llegar al Seminario de Proyectos de Investigación Psicológica, un curso en el que se realiza el diseño del protocolo de investigación de la tesis para su posterior implementación en el siguiente semestre en el curso Programa de Evaluación Final en el que se realiza el proyecto de evaluación final (PEF), requisito indispensable de titulación. El PEF consiste en el desarrollo de un proyecto especial para una institución beneficiaria. Se lleva a cabo en un escenario real, y debe además ser retador, de manera que el estudiante aplique todos los conocimientos adquiridos durante su carrera profesional y muestre un desempeño competente.

Antes de presentar los resultados del trabajo realizado a la fecha para el desarrollo de la competencia investigativa en estudiantes del curso PS3105 Aplicaciones en Psicología Clínica, a continuación se precisan algunos conceptos y se 
revisa lo que organismos e instituciones de educación superior han realizado al respecto en los últimos años.

\section{Educación superior y su responsabilidad con la formación científica}

El compromiso de las instituciones de educación superior con su vocación científica, tecnológica, humanística y social supone la búsqueda del conocimiento, no por sí mismo, sino para potenciar de manera directa o indirecta, el bienestar de la humanidad actuando como agentes de cambio social. Para lograrlo, están llamadas a garantizar que sus egresados dominen el método científico para el estudio de situaciones o fenómenos relacionados con su profesión de manera que en forma innovadora y comprometida, con base en principios de sustentabilidad y bienestar social, generen conocimiento y apliquen la inteligencia humana en la transformación de la realidad, utilizando las nuevas tecnologías de la información y de la comunicación para lograr impactos significativos de orden científico, económico, social y medioambiental.

A este respecto, en la Conferencia Mundial de Educación Superior de la Organización de las Naciones Unidas para la Educación, la Ciencia y la Cultura (UNESCO, 2009) se puntualizó la importancia de invertir en educación superior, base fundamental para el progreso de la investigación, la innovación y la creatividad y el desarrollo de sistemas de investigación más flexibles y organizados que promuevan la excelencia de la ciencia, la interdisciplinariedad y que se pongan al servicio de la sociedad. Un año después, Oppenheimer (2010) resalta la importancia de reenfocar la educación en la práctica de una estructura analítica futurística centrada en la lógica, la estructura analítica, la investigación, la comprensión y el entendimiento para promover la investigación y el desarrollo de nuevos avances. En octubre 2013, la Organización para la Cooperación y Desarrollo Económicos (OCDE) publicó los análisis de las principales tendencias en el conocimiento y la innovación en la economía global de hoy en día concluyendo que se requiere construir y conectar conocimiento, asimismo y que las instituciones de educación superior y los centros de investigación han de concentrar 
sus esfuerzos en concienciar sobre el valor de la innovación basada en evidencia, estudios de casos, métricas y el involucramiento de los usuarios finales.

\section{Formación en competencias}

La Formación en Competencias (FC) se distingue de otras propuestas de modelos educativos ya que trabajar en el desarrollo de competencias supone mucho más que pretender que el alumno alcance un saber hacer en contexto. El debate actual se centra entre posturas pragmáticas y enfoques con orientación constructivista sociocultural.

En el primer caso, las competencias sobrepasan la mera actuación, implicando además compromiso, disposición para realizar las tareas con calidad, raciocinio, comprensión y manejando una fundamentación conceptual (Tobón, Rial, Carretero y García, 2006). Además, sus atributos les confieren un carácter de formación integral debido a) la integración de la tríada conocimiento-habilidad-técnica en saberes y competencias; b) criterios de nivelación en función de las exigencias de cada área del saber, del dominio personal requerido, de la ayuda externa, de la complejidad del procesamiento cognitivo a realizar y de sus normas; centradas en el desempeño y en su contexto; c) objetividad para establecer las normas del desempeño esperado; d) su manifestación observable, el desempeño, evidencia de la actuación consciente con base en los recursos personales desarrollados de manera empírica y formal; y e) las estrategias cognitivas implicadas en al actuar en los contextos particulares y específicos (Ruiz, 2008). Se concluye entonces que la sola existencia de una capacidad no determina un desempeño exitoso; sin embargo, el desempeño da cuenta del nivel de competencia que ha logrado un individuo.

Por su parte, las competencias con base en una perspectiva socioconstructivista suponen una movilización de saberes (Moreno, 2012), elaborando vínculos entre lo conocido y lo realizado con éxito para su aplicación a nuevas situaciones en una creciente espiral (Jonnaert, 2001), integrando saberes y relacionándolos con la vida diaria (Roegiers, 2010). Todo esto refiere a una transferencia de conocimientos adquirida a través del ejercicio y una práctica reflexiva, construyendo estrategias 
originales en situaciones cada vez más complejas (Perrenoud, 2008), un saber estar ligado a saberes sobre la propia persona, los otros, las situaciones, a la forma de reaccionar y actuar en la vida (De Ketele, 2008).

\section{Competencias profesionales.}

Esta polisemia y complejidad del concepto de competencias, al trasladarlo a un modelo educativo basado en competencias profesionales -nivel oficial del currículum- podría abordarse desde dos posibles enfoques, uno orientado a objetivos y el otro al proceso, ambos buscando generar procesos formativos de calidad.

La formación basada en competencias profesionales se fundamenta en formas de saber (contenidos) y de hacer (métodos y actividades), así como el desarrollo de herramientas del pensar (capacidades y destrezas) y del perfil valoral y actitudinal encaminados al desarrollo individual y grupal progresivo tendiente a cubrir las demandas de la sociedad, de la profesión, del desarrollo disciplinar y del trabajo académico (Ruiz, 2008). Por otro lado, en el modelo de proceso, en la formación con competencias, el esquema es interactivo e integral, sin separar los medios de las finalidades, como una actividad humana, reflexiva, abierta y experiencial, ligada a ideales de transformación social, en la que la "selección de los contenidos (rigurosos, pertinentes, profundos y relacionados, significativos y comprensibles) y el modo de trabajarlos (comprensión, capacidad de establecer relaciones, argumentación, resolución de problemas, creatividad, etc.)" (Escudero, 2008, p. 16) están integrados, se influencian recíprocamente y son coherentes.

El sentido de las competencias implica entonces integrar el saber, el hacer, el pensar, el sentir y el ser como una unidad indisociable de manera consciente y planeada de tal forma que el educando pueda desarrollar su capacidad de autoaprendizaje como resultante de la práctica reflexiva. La idea central de las competencias se puede condensar como Saber hacer con sentido ético-social en diferentes situaciones. 
Goñi (2005) y Ruiz (2008) enfatizan que en pregrado es imperativo no perder de vista el perfil de egreso al definir las competencias generales a trabajar por aludir a campos de estudio extensos y las competencias específicas o disciplinares relacionadas con el objeto de estudio de las distintas materias en el currículum.

De lo anterior se desprende que la formación en competencias como opción educativa en educación superior se ha de caracterizar por una formación potenciadora de capacidades que permita a los educandos la adaptación al cambio, el desarrollo del raciocinio, la comprensión y la solución de situaciones complejas, mediante la combinación de conocimientos teóricos, prácticos, experiencias y conductas (Quiroga, 2008; Ruiz, 2008) con base en proyectos formativos de investigación dentro y fuera del aula asociado a un plan de vida ético y los procesos de emprendimiento creativo (Tobón, 2010; Tobón \& Guzmán, 2010; Tobón, Pimienta y García Fraile, 2010; Tobón et al., 2006) en busca de la solución de problemas reales o simulados, normalmente en colaboración con otros (Moreno, 2012; Quiroga, 2008; Ruiz, 2008), bajo supervisión (Peiró, 2010) y asumiendo compromiso y responsabilidad por las consecuencias de las decisiones tomadas (González, 2002).

\section{Competencias disciplinares.}

Con el Modelo Europsy, se pretende establecer un marco y unos estándares comunes en Europa, para certificar a los psicólogos que desarrollen y demuestren competencias profesionales nucleares o relacionadas con el contenido psicológico del proceso de práctica profesional y competencias facilitadoras que permiten al profesional prestar sus servicios eficazmente. Entre los requisitos para la reacreditación está la (co) autoría y/o edición de publicaciones de investigación y/o temas profesionales y presentaciones a audiencias profesionales (Peiró, 2010). En Estados Unidos, la Asociación de Psicología Americana (APA) señala que los alumnos deben desarrollar durante su entrenamiento en psicología seis conjuntos de competencias esenciales -profesionalismo, relaciones interpersonales, aplicación, ciencia, educación y sistemas- que, a su vez, anidan 16 competencias que contienen diversos componentes esenciales con descriptores de 
desarrollo y anclajes de comportamiento delineados para cada una de las tres etapas en la educación y la secuencia de entrenamiento. Asimismo, en el objetivo de aprendizaje 2 , indagación científica y pensamiento crítico, se enfatiza el desarrollo del razonamiento científico y la solución de problemas, incluyendo métodos de investigación efectivos y que hacia el final de la carrera el estudiante debe ser capaz de interpretar, diseñar y conducir estudios psicológicos básicos (Kaslow, et al., 2009).

De lo anterior se desprende que de un currículum academicista se ha pasado a un modelo en competencias sobre el saber hacer en contexto que incluye la responsabilidad ética y social en un mundo diverso que demanda respuestas a las distintas problemáticas humanas (investigación básica) así como el estudio de la aplicación de los conocimientos en diversos contextos (investigación aplicada) cuyos resultados se conformen como evidencia de las mejores prácticas con base en estrategias de intervención, revisiones sistemáticas de eficiencia, extensión del efecto, significatividad clínica y estadística, y un sólido cuerpo de evidencia teórica.

\section{Competencia investigativa.}

El desarrollo progresivo de competencias en investigación científica, particularmente ligadas al saber hacer, es un proceso multifactorial y multidimensional. La formación de la competencia investigativa en los distintos elementos que la conforman -problematización, teorización e instrumentación- requiere, por un lado, de un diseño curricular que transversalmente vaya desarrollando las actitudes y capacidades lógicas y heurísticas en las que se soporta la competencia, y por otro, durante la gestión curricular, el diseño de actividades formativas promotoras del desarrollo de los procesos psicológicos base del pensamiento científico estratégico y del espíritu investigador.

El desarrollo de la capacidad potencial para la ejecución de la una investigación requiere reflexión para la apropiación de estrategias cognitivas y metacognitivas, agudeza mental, analítica e interpretativa, conciencia actitudinal, conceptual y ética; proyección a través de la anticipación de hechos, situaciones, resultados, entre otros; y creación caracterizada esencialmente por la apertura al cambio y el compromiso con la 
innovación. Para favorecer estos procesos psicológicos en una tarea investigativa específica, el discente a través de actividades integradoras secuenciadas bien diseñadas irá recopilando evidencia de niveles de competencia cada vez más complejos y cualificados (Dusú \& Suárez, 2003).

Por su parte, Gallardo (2003) indica que puede darse un desarrollo diferenciado de los cinco componentes de la competencia investigativa: indagación (ejecución del proceso investigativo); innovación (generación, abstracción y generalización); comunicación (redacción científica y publicación de resultados); gerencia (planeación, organización, control y evaluación de proyectos); y uso de tecnología (genérica y específica de la disciplina).

La APA define dos componentes de la competencia investigativa:

1. Conocimiento y método científicos. Aplicación de métodos científicos a la práctica profesional (mentalidad científica); conocer, entender y aplicar los fundamentos científicos de la psicología y de la práctica profesional.

2. Investigación y evaluación. Aproximación científica a la generación de conocimiento y aplicación del método científico a la evaluación de prácticas, intervenciones y programas (APA, 2011).

En conclusión, los modelos pedagógicos basados en competencias y los programas que de ellos se derivan conllevan la intencionalidad de formar alumnos que demuestren su desempeño competente a través de evidencias y que reúnan criterios de excelencia. Si de competencia investigativa se trata, las evidencias y la excelencia provendrían de diversas fuentes: (1) los productos de aprendizaje entregados y retroalimentados de forma presencial o virtual; (2) el impacto social de los proyectos de investigación realizados; y (3) la divulgación de los resultados de la investigación en foros académicos y científicos.

\section{Vínculo investigación-servicio}

El modelo formativo para el desarrollo de la competencia investigativa propuesto para este programa de entrenamiento científico en psicología, se fundamenta en los 
postulados de la responsabilidad social universitaria, el aprendizaje autorregulado y la inclusión del aprendizaje-servicio.

\section{Responsabilidad Social Universitaria (RSU).}

Dado el compromiso institucional con una formación académica de excelencia y en aras de continuar los esfuerzos para lograrla, la presente estrategia para el desarrollo de la competencia investigativa se sustenta en los postulados sobre la RSU de la Organización de las Naciones Unidas para la Educación, la Ciencia y la Cultura (UNESCO, por sus siglas en inglés).

Su declaración de 1998 presentaba las directrices para que las Instituciones de Educación Superior reforzaran sus funciones de servicio a la sociedad. Para el cumplimiento efectivo de esta misión social a lo largo del tiempo se ha venido proponiendo la gestión ética y ambiental de la institución (Byrne, 2009; De la Cuesta, De la Cruz \& Rodríguez, 2010; Domínguez, 2009; Martí \& Martí, 2010; Mendivelso, 2008; Navos, 2011; Noguera, Martínez, Martí \& Martí, 2007; Savater, 1998; Vallaeys, 2008); la formación de ciudadanos responsables y solidarios (Álvarez, 2005; Gaete, 2011; Gasca-Pliego \& Olvera-García, 2011; Herrera, 2004; Martí \& Martí, 2010; Sánchez, Herrera, Zárate \& Moreno, 2007; Vallaeys, 2008); la producción y difusión de conocimientos socialmente pertinentes (Benito, 2010; Soriano, 2011; Vallaeys, 2008); la participación social en promoción de un desarrollo más humano y sostenible (Bies, Bartunek, Fort \& Zald, 2007; Domínguez, 2009; Sánchez et al., 2007; Vallaeys, 2008) y el diseño de indicadores que valoren el grado y sentido de la responsabilidad social universitaria (Martí \& Martí, 2010; Sánchez et al., 2007).

\section{Aprendizaje autorregulado.}

Zimmerman $(1998,2008)$ desde hace más de una década ha venido trabajando en el ciclo de aprendizaje y las dimensiones que lo constituyen: 
Premeditación: reflexión sobre la acción. Incluye los procesos que preparan al estudiante para el aprendizaje. Supone el análisis de la tarea (establecimiento de metas y planeación estratégica) y el involucramiento y auto-motivación (autoeficacia, expectativas sobre los resultados, interés/valor de la tarea, orientación a metas).

Actuación/Desempeño: reflexión en la acción. Consiste en procesos de autocontrol (auto-instrucción, imaginería, focalización de la atención, estrategias para realizar la tarea) y auto-observación (monitoreo metacognitivo, auto-registro) que ocurren durante el aprendizaje: actuación (lo que se hace) y desempeño (calidad con que se hace).

Auto-reflexión: reflexión para la acción. Los estudiantes deliberan a partir de auto-juicios (auto-evaluación, atribución causal) y auto-reacciones (autosatisfacción/afectividad, adaptación/defensividad) sobre los esfuerzos realizados.

En este contexto, la retroalimentación de desempeños anteriores se utiliza para hacer ajustes, lo que favorece el esfuerzo actual en el ciclo autorregulatorio (Schunk y Zimmerman, 2001). Asimismo, de acuerdo con Zimmerman (2008) la autorregulación mejora con la práctica al construir un creciente repertorio de creencias y estrategias que incrementan el aprendizaje y, además, puede ser enseñada (Schunk, 2005).

\section{Aprendizaje-Servicio (APS).}

Su principal característica es la integración del estudio académico con el servicio a la comunidad (Furco, 2002; Honnet \& Poulsen, 1989; Martí \& Martí, 2010; Tapia, 2001); es también concebido como: a) una actividad formal compleja que contribuye a desarrollar la responsabilidad cívica a través de la reflexión sobre la experiencia de servicio (Puig, Batlle, Bosch \& Palos, 2007); b) un programa de acción que brinda servicios a personas y grupos sobre el medio ambiente natural o cultural (González \& Elicegui, 2001; Halsted, 1998); c) una pedagogía vinculada a la educación experiencial en un proceso de intercambio social y educativo entre estudiantes y beneficiarios (Eyler \& Gilers, 1999; Jacoby, 1996; Stanton, 1990); d) como filosofía que lleva al estudiante a la trascendencia a través del servicio (Campus Compact, 2011; Puig, et al., 2007); e) 
como investigación vinculada al servicio, una actividad formativa solidaria (Alden \& Hunt, 2008; Quiroga, 2013).

Todo lo anterior garantizando que el alumno conozca y comprenda los retos y responsabilidades éticas que su quehacer profesional, consigo mismo y con los que lo rodean, buscando tener un impacto en su sociedad.

\section{Aplicaciones en Psicología Clínica: una experiencia}

Las actividades solidarias en la Universidad de Monterrey ocupan un lugar preponderante, tanto en su misión como en su visión al 2020, y comprometen a la comunidad udemita a actuar en consecuencia. En la carrera de Psicología desde siempre los alumnos se involucran en actividades que incluyen trabajo de campo en comunidad como parte de su formación profesional. PS3105 Aplicaciones en Psicología Clínica es un curso en línea, de nivel avanzado, cuyos objetivos se centran en:

- el campo de especialización de la Psicología Clínica y de la Salud aplicando los principios, las técnicas y los conocimientos científicos desarrollados por ésta para evaluar, diagnosticar, explicar, tratar, modificar y prevenir las anomalías o los trastornos mentales o cualquier otro comportamiento relevante para los procesos de la salud y enfermedad, en los distintos y variados contextos en que éstos puedan tener lugar;

- la prevención y la educación para la salud en las que se trabaja con los procesos y estados de salud y bienestar, tanto de los individuos como de los grupos humanos, para tratar de asegurarlos o de reinstaurarlos en caso de que se hubieran perdido.

La mayor parte de los proyectos de aplicación realizados por los estudiantes referían al desarrollo de programas preventivos en temas relacionados con la salud, psicoeducación y programas para la atención del adulto mayor, entre otros. Las instituciones beneficiarias al finalizar los proyectos evaluaban el trabajo de los estudiantes, pero estaba faltando una mayor intencionalidad solidaria desde el diseño de los cursos, el seguimiento y la evaluación final.

A partir del semestre otoño 2011 se agrega al curso la metodología educativa de 
aprendizaje-servicio con la finalidad de involucrar a los estudiantes en procesos de investigación y acción solidaria. Al tiempo que desarrollan habilidades clínicas y actúan como agentes de cambio, retoman los conocimientos y las habilidades desarrolladas en materias previas en una experiencia profesionalizante autoconstruida en la que analizan la realidad clínica, los elementos conceptuales y valorales y se adiestran para la ejecución de la práctica. En el curso se estipula que los estudiantes trabajen en modalidad de seminario en la plataforma educativa y en ese mismo espacio virtual, se habilitan herramientas que permitan la interacción colaborativa entre los estudiantes que en equipo deben realizar un proyecto de aplicación que implica 160 hs. de trabajo de campo.

\section{Proyecto de aplicación.}

Al ser la actividad principal del curso la planeación y desarrollo de un proyecto de aplicación, los estudiantes se integran en equipos de 3 a 8 personas. El trabajo colaborativo está concebido como servicio a la comunidad con vistas a desarrollar responsabilidad cívica a través de la reflexión sobre la experiencia de brindar servicios a beneficiarios.

Gestión en el aula virtual. La mayor parte de la actividad se realiza a través de la herramienta Foros que permite el acceso a foros privados, con espacios destinados a cada uno de los equipos base conformados por elección personal de los integrantes para participar a lo largo del curso. Los estudiantes firman electrónicamente en la hoja de inscripción que se habilita automáticamente en la sección Grupos del menú.

El trabajo colaborativo se realiza en el foro del Proyecto que tiene formato blog. Su estructura permite trabajar en distintos temas al mismo tiempo y la participación es permanente. Se inicia al darse de alta el participante en el equipo para empezar con la elaboración del anteproyecto hasta su presentación ejecutiva en plenario presencial abierta a la comunidad. Responde a la necesidad de propiciar un espacio en el que los estudiantes puedan compartir y discutir lecturas, así como analizar en equipo las 
dificultades que puedan surgir en la realización de las actividades. Asimismo, supone un acompañamiento grupal por parte del docente con el que se fomenta la expresión de logros y avances de los alumnos en su desarrollo profesional con vistas a contribuir a una mayor seguridad profesional y lograr una formación integral.

Las entregas de los distintos documentos electrónicos que muestren los avances y el proyecto terminado, se realiza a través de las Bandejas de Tareas, mismos que son evaluados conforme a rúbricas especialmente diseñadas para guiar la actividad, orientando a los estudiantes acerca de lo que se espera de ellos: se especifica lo que constituye la excelencia y cómo evaluar su propio desempeño y les estimula a esforzarse para realizar un producto final mejor.

La presentación de resultados es la culminación de las actividades de aplicación y permite la divulgación académica de los resultados con la finalidad de socializar los avances cognoscitivos y su autoría. Estas dos actividades se entregan también a través de las Bandejas de Tareas.

Otro aspecto a valorar lo constituyen las actividades del proyecto de auto y coevaluación y la evaluación del proyecto por parte del beneficiario. La auto y coevaluación se realiza a través de un documento electrónico en el que cada miembro del equipo evalúa el desempeño y la actitud de sus compañeros durante la realización del proyecto y lo envían a través de la Bandeja de Tareas. La Evaluación del Proyecto por el Beneficiario es otro formato al que se puede acceder desde el curso. Los miembros del equipo lo bajarán para llenar los datos correspondientes a Organización, Nombre del proyecto, Responsables del proyecto, Nombre de la persona que evalúa y su puesto dentro de la Organización. Posteriormente se lo presentarán al evaluador para que evalúe el proyecto, firme el formato y lo selle.

Por otro lado, cada estudiante entrega un reporte semanal en papel y debidamente firmado y sellado por el funcionario en la institución sede a cargo de verificar las actividades realizadas. La entrega se hace a más tardar el viernes siguiente a la semana reportada en la bandeja del profesora localizada en el Departamento de Psicología y en el formato diseñado para tal efecto disponible en Módulos de Aprendizaje > Proyecto $>$ Reporte Semanal de Actividades. 
Autogestión del conocimiento. Consiste en la búsqueda, lectura exploratoria y análisis de información relevante para su posterior organización y sistematización de manera de poder participar en las discusiones en pequeño grupo en las distintas fases del proyecto de aplicación. Como producto de estas actividades iniciales, el estudiante ha de elaborar-distintos tipos de notas acerca de la temática y las posibles alternativas de solución a la problemática específica presentada en la institución beneficiaria. Asimismo, en el blog Mi Legado, como miembro de la comunidad de aprendizaje, el estudiante comparte con el grupo en pleno, las reflexiones y las vicisitudes que en el día a día surjan en el diseño, elaboración y entrega de sus productos de aprendizaje. Con esto se pretende favorecer una red de interacciones promotora del desarrollo personal y profesional de todos los participantes.

Transformación del conocimiento grupal. La articulación de los aprendizajes construidos colaborativamente se transforman en distintos documentos electrónicos que van evidenciando los avances en cada etapa del proyecto y que dan cuenta del cumplimiento responsable de las tareas asignadas en el marco del respeto mutuo y la valoración de las aportaciones individuales para su posterior integración en la entrega de productos de aprendizaje grupal de excelente calidad. Las acciones realizadas se documentan en formato de proyecto de investigación aplicada, en tres entregas que dan cuenta del desarrollo de la competencia investigativa:

- Anteproyecto: indagación, problematización, teorización, innovación.

- Avance de resultados: recopilación y análisis de datos.

- Informe final: abstracción y comunicación.

Finalmente, a partir de auto-juicios (auto-evaluación, atribución causal) y autoreacciones (autosatisfacción/afectividad, adaptación/defensividad) sobre los esfuerzos realizados, cada estudiante con base en su experiencia por el trabajo realizado y la retroalimentación de su desempeño, ha de reflexionar y reconstruir el conocimiento adquirido en la práctica e identificar las competencias desarrolladas, las áreas de oportunidad a fortalecer. Asimismo, ha de valorar el servicio prosocial brindado a una institución beneficiaria y el impacto social de su producto/servicio. 
Dada la sistematización del programa del curso PS3105 Aplicaciones en Psicología Clínica a lo largo de cinco semestres, se considera necesario evaluar si cumple con principios de calidad en la consecusión de las metas educativas referente al desarrollo de la competencia investigativa, la pertinencia de las estrategias instruccionales, el uso medios y recursos tecnológicos y el impacto social de su implementación.

\section{Método}

Con un enfoque mixto de estudio de caso, se llevó a cabo una investigación evaluativa (Tejedor, 2000) sobre la eficacia (logro de objetivos) y eficiencia (logros en relación con los medios disponibles) del programa Aplicaciones en Psicología Clínica a partir de la inclusión de objetivos de acción solidaria con base en la metodología de aprendizajeservicio. El desarrollo del programa a lo largo de los cinco semestres comprendidos entre otoño 2011 y otoño 2013 fueron las unidades de análisis. El diseño descriptivo con temporalidad semestral secuenciada brindó información sobre la cantidad de proyectos e instituciones beneficiarias, en tanto que el diseño cualitativo, abierto y emergente, posibilitó valorar el proceso de integrar el aprendizaje-servicio en el desarrollo de la competencia investigativa en estudiantes de pregrado de la licenciatura en Psicología.

\section{Resultados}

En dos y medio años de trabajar con la triada aprendizaje-servicio-investigación, en los cinco semestres se han inscrito el curso 135 estudiantes, de los cuales 33 fueron en el semestre de otoño de 2011; en 2012, 40 se inscribieron en el semestre de primavera y 28 en el de otoño; en 2013 fueron 14 los estudiantes inscritos en el semestre de primavera y 20 en el de otoño. Del total de los estudiantes, $95 \%$ fueron mujeres, $5 \%$ hombres. 
Objetivos de acción solidaria. Durante los cinco semestres, se han desarrollado 24 proyectos: en el semestre de otoño 2011 se realizaron 6; en 2012 fueron 11 los proyectos realizados, 6 en el semestre de primavera y 5 en el de otoño; fueron 8 los proyectos ejecutados en 2013,5 en el semestre de primavera y 3 más en el de otoño. Del total de proyectos desarrollados, $10(55.5 \%)$ fueron para instituciones públicas y 8 (45.5\%) para Organizaciones de la Sociedad Civil (OSC).

Objetivos de aprendizaje. Las temáticas de las intervenciones han sido diversas. Entre ellas destacan, prevención de violencia familiar, acoso escolar, residencia en consumo de sustancias, desórdenes de alimentación. Los beneficiarios han sido usuarios de las distintas instituciones. En el caso de uno de los proyectos en los que se diseñó el contenido para la página de Psicología de una dependencia gubernamental, a la fecha lleva 626,727 visitas. Esto da cuenta de la aplicación de principios, técnicas y conocimientos científicos desarrollados en el campo de especialización de la Psicología Clínica y de la Salud, así como del trabajo preventivo y la educación para la salud para tratar de asegurar o reinstaurar los procesos y estados de salud y bienestar en caso de que se hubieran perdido.

Competencia investigativa. Los documentos de avance de la investigación aplicada de cada proyecto son entregados en tiempo y forma, así como los reportes de actividades, reflexiones personales y la auto y coevaluación. Considerando que los indicadores de la competencia pueden ser apreciados a través de la co-construcción del conocimiento y el desempeño en el escenario de intervención, a continuación se presenta datos que evidencian su desarrollo.

Trabajo colaborativo virtual. En el blog del proyecto, todos los estudiantes enviaron mensajes por lo menos tres veces durante el semestre. Las secuencias de las interacciones de los estudiantes variaron entre dos y ocho comentarios, con un promedio de tres. A continuación se muestran dos de los mensajes publicados en el blog de un equipo que diseño dos intervenciones para el manejo de estrés postraumático: un curso psicoeducativo y un taller vivencial sustentado en estrategias de afrontamiento con técnicas cognitivo-conductuales. La investigación fue de enfoque cuantitativo, diseño cuasi- experimental con grupo de comparación, de temporalidad 
transversal. A continuación se muestran dos de los siete mensajes publicados en el blog del equipo después de realizar la preprueba y preparándose para iniciar la intervención:

Asunto: Vaciado de resultados de la escala de resiliencia

Autor: $\mathrm{S} 10$

Fecha: Sábado, Marzo 17 de 2012, 11:39:21 AM

Hola equipo! Les adjunté por File Exchange la base de datos con los resultados que se obtuvieron en la Escala de Resiliencia (ER), en ella podrán observar la división entre los grupos que corresponden a los dos talleres que implementaremos. A un lado de las puntuaciones, encontrarán los colores según la interpretación de cada rango (verdealto, amarillo-moderado y rojo-bajo), así como las gráficas según las puntuaciones capturadas. En rojo, dejé al alumno que contestó todos los ítems con 7, de ahí que su puntuación sea tan alta. Por otro lado, la evaluación de los alumnos que habían quedado pendientes, se realizará el miércoles por cuestiones académicas y logística de la Preparatoria. Seguimos en contacto! Saludos.

Asunto: Vaciado de resultados de la escala de resiliencia

Autor: S8

Fecha: Sábado, Marzo 17 de 2012, 5:48:57 PM

Gracias (nombre de la alumna) por subir el archivo. Primero, en cuanto a los alumnos quienes todavía no presentan la prueba, yo misma voy a supervisar que la aplicación se realice el miércoles, con ayuda de (nombres de dos alumnas); en cuanto tenga esos resultados se los hago saber y (nombre de la alumna), si pudieras incorporarlos al archivo estaría excelente. En cuanto a nuestra primera sesión, después de mucha organización y estar hablando no sólo con la coordinadora, la fecha quedó ya para este jueves 22; agéndenlo. La hora no está confirmada, pero sería o de 2 a 4 p.m. o de 2:30 a 4:30 p.m. Eso se lo dirá ella a (nombre de la alumna) el martes, y en caso de que no, yo el miércoles les aviso por este medio. Hay mucho que preparar y revisar para este jueves, así que al menos el martes debemos de ponernos todas en contacto para ver qué hace falta; incluso para los pequeños detalles como lo que llevaremos para el receso, por ejemplo. El miércoles nada más saliendo de la Prepa les escribo cualquier 
otro detalle importante para que nuestra primera sesión, para ambos talleres, sea exitosa. Saludos

En el primer mensaje, S10 informa sobre el avance en la captura en la base de datos y explica cómo se interpretarían los puntajes de la preprueba. En el segundo mensaje, S8 realiza declaraciones que instan a la acción formulando una propuesta sobre cómo continuar con las tareas pendientes, animando al resto del equipo a participar activamente en el desarrollo de su investigación.

Evaluación externa del proyecto. Los proyectos fueron evaluados por parte de la institución beneficiaria en cuanto a la contribución del proyecto a los objetivos de la organización, innovación, alcances para la institución y los beneficiarios finales. Con cuatro opciones de respuesta (sobresaliente, satisfactorio, satisfactorio con recomendaciones, necesita mejorar), los representantes de las instituciones los evalúan mayormente como sobresaliente.

Por otro lado, los resultados de tres de las investigaciones han sido presentadas en congresos nacionales y los artículos en extenso publicados en sus memorias.

\section{Consideraciones finales}

En la formación basada en competencias se destaca la necesaria planeación de las secuencias didácticas por parte del docente de manera que paulatinamente el estudiante desarrolle competencias y autogestione su aprendizaje y en el caso, de Aplicaciones en Psicología Clínica, asegure la conexión con el mundo real que enfrente al estudiante a problemas reales y use sus experiencias personales para aplicar saberes en el diseño, ejecución y evaluación de proyectos de investigación aplicada. El juicio académico sobre lo que el alumno debe saber sobre un tema o disciplina (Irigoin, 2002; Senior, 2004) y el saber hacer requerido en el campo laboral, demanda convertir el saber en acción (Tribó, 2005), transfiriendo el saber a la práctica usando recursos y competencias propias. A este respecto, las temáticas de los proyectos, por un lado dan cuenta de la aplicación de los saberes sobre el campo de la Psicología Clínica y de la Salud. De igual forma, el diseño, la ejecución y la presentación de resultados de las 
investigaciones realizadas tanto ante las instituciones beneficiarias como a los comités dictaminadores de congresos nacionales de la disciplina, indican el buen nivel de desarrollo de la competencia investigativa que han logrado los estudiantes a lo largo de su formación y que, de acuerdo con Kaslow et al. (2009), es lo esperado hacia el final de su carrera.

Por otro lado, la participación autogestiva en el foro de discusión del proyecto favoreció, por un lado, una práctica reflexiva (Perrenoud, 2010) y el ciclo autorregulatorio (Schunk \& Zimmerman, 1998; Zimmerman, 2008), ampliando en los estudiantes el repertorio de creencias positivas sobre sí mismos y su desempeño competente en el trabajo de campo y, por otro, la co-construcción del conocimiento con base en un proceso colaborativo basado en la indagación (Garrison \& Anderson, 2003), el intercambio de ideas en la solución de problemas reales (Magnuson, 2005; Murphy, 2004; Quiroga, 2008) y la co-responsabilidad por su aprendizaje (Abedin, Daneshgar \& D’Ambra, 2010).

De particular relevancia el proceso interactivo e integral ligado a ideales de transformación social (Escudero, 2008) soportado en el aula virtual con los lineamientos (Shi, Bonk \& Magjuka, 2006; Song, 2011) y las rúbricas con los criterios de calidad y niveles de dominio de la competencia (Robinson, 2011; Tobón, 2010) disponibles durante todo el semestre en la plataforma educativa, posibilitaron mantener el foco en la tarea tanto como en la ejecución del proyecto. Sin embargo, queda pendiente diseñar estrategias dirigidas a los estudiantes cuya participación es mínima o se limita a secundar ideas y propuestas de sus compañeros y a realizar sólo las actividades que le son asignadas, que si bien cumplen con la actividad, su nivel de competencia es resolutivo, con áreas de oportunidad en autonomía para actuar con criterio propio y aplicación de estrategias con compromiso antropoético (Tobón, 2010).

En conclusión, los logros alcanzados indican que el diseño instruccional para crear el ambiente educativo virtual del curso de Aplicaciones en Psicología Clínica orientado a potenciar el desarrollo progresivo de la competencia investigativa en estudiantes de pregrado ha favorecido: 
La promoción de un proceso de enseñanza-aprendizaje en el que tanto el docente como el alumno se convierten en agentes activos, con métodos de enseñanza proactivos, para responder a los retos tanto de la disciplina como de la sociedad.

La vinculación sistemática ciencia-investigación-servicio en contextos que ponen a prueba el nivel de responsabilidad social, capacidad metodológica de búsqueda, procesamiento y utilización de la información en el planteamiento de problemas, diseño de soluciones y aplicación de técnicas adecuadas a situaciones específicas.

La contribución en la solución de los problemas psicológicos, la mejora de la calidad de vida de los individuos y la construcción de una sociedad sostenible a través del conocimiento y el espíritu de servicio.

La difusión de los avances científicos y tecnológicos bajo el principio de integridad y compromiso social.

La autorregulación que lleva al alumno a convertirse en el verdadero protagonista de su aprendizaje activo y emprendedor.

El desarrollo de la identidad del psicólogo a través de la participación activa y auto-transformadora de los estudiantes ya que por sí mismos negocian con las instituciones, discuten colaborativamente la manera de sustentar un proyecto de aplicación para finalmente dialogar entre pares sobre los resultados alcanzados.

La formación de profesionales de alto nivel, portadores de una cultura científica y humanística, capaces de resolver problemas sociales con racionalidad y objetividad.

La intención es continuar mejorando el modelo de manera de garantizar una formación integral con impacto tanto en el beneficio social inmediato como en el desarrollo de los diversos componentes de la competencia investigativa de los estudiantes que sin duda permeará su actuar académico, profesional y personal.

\section{Referencias}

Abedin, B., Daneshgar, F. \& D'Ambra, J. (Septiembre, 2010). Underlying factors of sense of community in asynchronous computer supported collaborative learning environments. Journal of Online Learning and Teaching, 6(3), 585-596. 
Alden, B. \& Hunt, A. (2008). Buena Práctica II.7. Modelo de investigación y aprendizajeservicio (Universidad de Duke, EE.UU.) En Global University Network for Innovation (GUNI). La educación superior en el mundo 3 (pp. 281-282). España: Mundi-Prensa.

Álvarez, L. A. (2005). Responsabilidad social institucional. México, DF: Universidad Iberoamericana.

APA. American Psychological Association. (2011). Competency initiatives in professional psychology. Recuperado de http://www.apa.org/ed/graduate/competency.aspx

Benito, E. (2010). Perspectivas para una formación Científico-Social en Psicología. Eureka Investigaciones en Psicología, 7(2), 61-70.

Bies, R., Bartunek, J., Fort, T. \& Zald, M. (2007). Corporations as social change agents: individual, interpersonal, institutional, and environmental dynamics. Academy of Management Review, 32(3), 788-793.

Byrne, C. C. (2009). Proactive versus defensive ethics: Re-humanizing Psychology. Peace \& Conflict, 15(2), 215-225. doi: 10.1080/10781910902849722

Campus Compact (2011). Educating citizens. Building communities. Washington, DC: Board of Directors.

De Ketele, J. M. (2008). Enfoque socio-histórico de las competencias en la enseñanza. Profesorado. Revista de Currículum y Formación de Profesorado, 12(3), 112.

De la Cuesta, M., De la Cruz, C. \& Rodríguez, J. (2010). Responsabilidad social universitaria. España: Editorial Netbiblo.

Domínguez, M. J. (2009). Responsabilidad social universitaria. Humanismo y Trabajo Social, 8, 37-67.

D’Ottavio, A. E. (2001). Ser médico. Reflexiones sobre la formación y la práctica médicas. Argentina: Editorial Homo Sapiens.

Dusú, R. M. \& Suárez, C. (2003). Capacidades, competencias y estrategias en la formación científica-investigativa. Santiago, 101, 446-450.

Escudero, J. (2008, Junio). Las competencias profesionales y la formación universitaria: posibilidades y riesgos. Red U. Revista de Docencia Universitaria, Formación centrada en competencias (II),11. Recuperado de http://www.redu.m.es/Red_U/m2

Eyler, J. \& Gilers, D. E. (1999). Where's the learning in service-learning? San Francisco: JosseyBass.

Furco, A. (2002). Is service-learning really better than community service? En A. Furco y H. B. Shelley (Eds.), Service-learning: The essence of the pedagogie. Greenwich: Information Age Publishing.

Gaete, R. (2011). La responsabilidad social universitaria como desafío para la gestión estratégica de la Educación Superior: el caso de España. Revista de Educación, 355, 109-133.

Gallardo, O. (2003). Modelo de formación por competencia para investigadores. Contexto e Educação, 18(70), 9-25.

Garrison, D. \& Anderson, T. (2003). E-learning in the 21st century. Londres: Routledge Falmer.

Gasca-Pliego, E. y Olvera-García, C. J. (2011). Construir ciudadanía desde las universidades, responsabilidad social universitaria y desafíos ante el siglo XXI. Convergencia. Revista de Ciencias Sociales, 18(56), 37-58.

Gayol, M. C., Tarrés, M. C., García, E. \& D'Ottavio, A. E. (2011). Aproximación sistemáticodiacrónica para el desarrollo progresivo de competencias investigativas del saber-hacer en el grado y el postgrado del área salud. Revista Iberoamericana de Educación, 55(1), $1-9$. 
González, A. S. \& Elicegui, P. J. (Comps.). (2001). Módulo I: Guía para emprender un proyecto de aprendizaje-servicio (4a. ed.). Argentina: Programa Nacional Escuela y Comunidad, Ministro de Educación de la Nación.

González, V. (2002). ¿Qué significa ser un profesional competente? Reflexiones desde una perspectiva psicológica. Revista Cubana de Educación Superior, XXI(1), 45- 53.

Goñi, J. M. (2005). El espacio europeo de educación superior: Un reto para la Universidad. Barcelona: Octaedro-Ice-UB.

Halsted, A. (1998). Educación redefinida: la promesa del aprendizaje servicio. En Actas I Seminario, El servicio a la comunidad como aprendizaje escolar, pp. 23-24. Buenos Aires: Ministerio de Educación de la Nación.

Herrera, G. (2004). Políticas institucionales: Responsabilidad Social Universitaria. Guatemala: Universidad Rafael Landivar, Vicerrectoría General.

Honnet, E. P. \& Poulsen, S. (1989). Principles of good practice in combining service and learning. Wingspread Special Report. Racine, Wis.: Johnson Foundation.

Irigoin, M. (2002). Mapa de competencias de la comunicación para el desarrollo y el cambio social: Conocimientos, habilidades y actitudes en acción. The CHANGE Project/Agencia de los Estados Unidos para el Desarrollo Internacional. Bellagio, Italia.

Jacoby, B. (1996). Service-learning in higher education. San Francisco: Jossey-Bass.

Kaslow, N. J., Grus, C. L., Campbell, L. F., Fouad, N. A., Hatcher, R. L. \& Rodolfa, E. R. (2009). Competency assessment toolkit for professional psychology. Training and Education in Professional Psychology. Vol 3(4, Suppl), Nov 2009, S27-S45. doi: 10.1037/a0015833

Magnuson, C. (2005). Experiential learning and the discussion board: A strategy, a rubric, and management techniques. Distance Learning, 2(2), 15-20.

Manassero, M. A., Vázquez, Á. \& Acevedo, J. A. (2004). Opiniones sobre la influencia de la ciencia en la cultura. Recuperado de la Sala de Lecturas CTS+l de la Organización de Estados Iberoamericanos para la Educación, la Ciencia y la Cultura (OEI) http://www.oei.es/salactsi/ acevedo17.htm

Martí, M. \& Martí, J. (2010). Programa iberoamericano en responsabilidad social universitaria. España: Pensamiento e Interacción social UV/ Programa RSU.

Mendivelso, N. (2008). Ciencia y ética: Matrimonio necesario para este milenio. UN Periódico, $118,7$.

Moreno, T. (2012). La evaluación de competencias en educación. Sinéctica, 39, 1-20.

Recuperado de

http://www.sinectica.iteso.mx/?seccion=articuloylang=esyid=555_la_evaluacion_de_com petencias_en_educacion

Murphy, E. (2004). Recognizing and promoting collaboration in an online asynchronous discussion. British Journal of Educational Technology, 35(4), 421-431.

Navos, O. (2011). La Responsabilidad Social Universitaria - RSU: como mecanismos de vinculación con el mundo empresario. Argentina: Universidad Abierta Interamericana.

Noguera, J., Martínez, F., Martí, M. \& Martí, M. (2007). Responsabilidad social universitaria: Acción aplicada de valoración del bienestar psicológico en personas adultas mayores institucionalizadas. Polis, Revista de la Universidad Bolivariana, 18, 1-14.

OCDE. Organización para la Cooperación y Desarrollo Económicos. (2013). OECD Science, Technology and Industry Scoreboard 2013. Innovation for Growth. doi:10.1787/sti_scoreboard-2013-en

Oppenheimer, A. (2010). ;Basta de historias! México, DF: Debate.

Peiró, J. M. (2010). Competencias para el ejercicio profesional del psicólogo. España: Consejo General de Colegios Oficiales de Psicólogos. 
Perrenoud, P. (2008, Junio). Construir las competencias, ¿es darle la espalda a los saberes? Red U. Revista de Docencia Universitaria, Formación centrada en competencias (II),11. Recuperado de http://revistas.um.es/redu/article/view/35261

Puig, J. M., Batlle, R., Bosch, C. \& Palos, J. (2007). Aprendizaje servicio. Educar para la ciudadanía. Barcelona: Octaedro.

Quiroga, A. (2013). Aprendizaje-Servicio en México: Participación solidaria en pro de la equidad de género. Revista Internacional de Educación para la Justicia Social, 2(2).

Quiroga, A. (2008, Diciembre). Un modelo colaborativo virtual: Proyectos de intervención. En el Simposio Internacional sobre Competencias. SICOM 2008. Las Competencias Científicas. Colombia: SICOM.

Quiroga, A. \& Moreno, A. (2012). Sinergia: Comunidad de aprendizaje autogestiva. En S. Tobón y A. Jaik Dipp (Coord.). Experiencias de aplicación de las competencias en la educación y el mundo organizacional (pp. 333-361). México: Red Durango de Investigadores Educativos A. C.

Robinson, J. (2011). Assessing the value of using an online discussion board for engaging students. Journal of Hospitality, Leisure, Sport and Tourism Education, 10(1), 13-22. doi: 10.3794/johlste.101.257

Roegiers, X. (2010). Una pedagogía de la integración. Competencias e integración de los conocimientos en la enseñanza. México: Fondo de Cultura Económica.

Ruiz, M. (2008). Formación basada en competencias. Monterrey, México: Universidad Regiomontana, Diplomado en Competencias.

Sánchez, C. L., Herrera, A., Zárate, L. \& Moreno, W. (2007). La Responsabilidad Social Universitaria (RSU) en el contexto del cambio de la educación superior. México, DF: Universidad Nacional Autónoma de México.

Savater, F. (1998). La dimensión ética de la empresa. Bogotá: Siglo del Hombre Editores.

Schunk, D. H. (2005). Commentary on self-regulation in school contexts. Learning and Instruction, 15(2), 173-177. doi:10.1016/j.learninstruc.2005.04.013

Schunk, D. H. \& Zimmerman, B. J. (Eds). (1998). Self-regulated learning: From teaching to selfreflective practice. Nueva York: Guilford Press.

Senior, F. A. (2005). Nuevos paradigmas para la educación en línea. Revista Cognición, 1(1), 12-27.

Shi, M., Bonk, C. J. \& Magjuka, R. J. (2006). Time management strategies for online teaching. International Journal of Instructional Technology \& Distance Learning, 3(2), 3-10.

Song, L. (2011). Understanding students' online interaction: Analysis of discussion board postings. Journal of Interactive Online Learning, 10(1), 1-14.

Soriano, O. (2011, Junio). Responsabilidad social universitaria. Trabajo presentado en el I Foro Internacional de Educación Superior: Educación Superior, Estado y Desarrollo. Honduras: Banco Centroamericano de Integración Económica.

Stanton, T. (1990). Service learning: Groping toward a definition. En J. C. Kendall et al., Combining service and learning. Raleigh: National Society for Internships and Experiential Education.

Tapia, M. N. (2001). La solidaridad como pedagogía. El aprendizaje servicio en la escuela. Buenos Aires: Ciudad Nueva.

Tejedor, F. J. (2000). El diseño y los diseños en la evaluación de programas. Revista de Investigación Educativa, 18(2), 319-339.

Tobón, S. (2010). Formación integral y competencias. Pensamiento complejo, currículo, didáctica y evaluación (3a ed.). Bogotá: Ecoe.

Tobón, S. y Guzmán, C. E. (2010). El modelo de competencias en la práctica educativa: Hacia la gestión de la calidad. Bogotá: Instituto CIFE. 
Tobón, S., Pimienta, J. \& García, J. A. (2010). Secuencias didácticas: aprendizaje y evaluación de competencias. México: Pearson.

Tobón, S., Rial, A., Carretero, M. A. \& García, J. A. (2006). Competencias, calidad y educación superior. Bogotá, Colombia: Alma Mater Magisterio.

Tribó, G. (2005). Enseñar a pensar históricamente. Barcelona: ICE Universitat de Barcelona, Horsori Editorial.

UNESCO. Organización de las Naciones Unidas para la Educación, la Ciencia y la Cultura. (2009, Julio). Conferencia Mundial de Educación Superior "Las Nuevas Dinámicas de la Educación Superior y de la Investigación para el Cambio Social y el Desarrollo". París: UNESCO.

Vallaeys, F. (2008, Septiembre). Responsabilidad social universitaria: una nueva filosofía de gestión ética e inteligente para las universidades. Revista Educación Superior y Sociedad, 13(2), 193-219. Disponible en el sitio de internet del Instituto Internacional de la UNESCO para la Educación Superior en América Latina y el Caribe (IESALC): www.iesalc.unesco.org.ve

Zimmerman, B. J. (2008). Investigating self-regulation and motivation: Historical background, methodological developments, and future prospects. American Educational Research Journal, 45(1), 166-183. doi: 10.3102/0002831207312909

Zimmerman, B. J. (1998). Developing self-fulfilling cycles of academic regulation: An analysis of exemplary instructional models. En D. H. Schunk y B. J. Zimmerman (Eds). Selfregulated learning: From teaching to self-reflective practice. Nueva York: Guilford Press.

Zimmerman, B. J. \& Schunk, D. H. (2001). Self-regulated learning and academic achievement: Theoretical perspective. Hillsdale, NJ: Erlbaum. 


\title{
PROCESOS DE FORMACIÓN PARA LA ESCRITURA DE UN TEXTO ACADÉMICO: COMPETENCIAS Y ESTRATEGIAS
}

\section{FORMATION PROCESSES FOR WRITING AN ACADEMIC TEXT: SKILLS AND STRATEGIES}

\author{
Argelia Hernández Cortés \\ UNAM, FES Aragón \\ argelishc@yahoo.com.mx
}

\begin{abstract}
Resumen
La presente investigación tiene como objetivo mostrar cómo son adquiridas las competencias, habilidades y estrategias en escritura para la construcción de un escrito y la difusión del mismo. Dichas competencias desarrollan procesos de formación que se van adquiriendo a través de una serie de mediadores tanto académicos, sociales, culturales, como individuales. En dicho reporte se incluyen tres ejes de análisis (el sociocultural, el académico y el proyecto de vida) los cuales indagan las opiniones generadas por lo sujetos de estudio, de quienes a través del análisis interpretativo se conoce cómo manejan esas competencias, que son aprehendidas como parte de la escritura en la difusión del conocimiento.
\end{abstract}

Palabras clave. Escritura académica, habilidades, construcción, difusión.

\begin{abstract}
This research aims to show how they are acquired skills, writing skills and strategies for building a writing and dissemination. These skills develop training processes that are acquired through a series of mediators both academic, social, cultural and individual. Three axes analysis (socio-cultural, academic, and life project) which investigate the views generated by the study subjects, those who through interpretive analysis is known how to handle these powers, which are seized are included in this report as part of the writing on the dissemination of knowledge.
\end{abstract}

Keywords. Academic writing, skills, construction, distribution.

\section{Introducción}

\section{La escritura en la formación.}

La escritura involucra procesos que se van adquiriendo a través de una formación, misma que articula saberes los cuales van construyendo y desarrollando capacidades 
para la aprehensión de aptitudes y habilidades para la realización de alguna tarea. Según Ferry (1999, p. 54).

La formación es entonces diferente a la enseñanza y el aprendizaje. O sea que la enseñanza y el aprendizaje pueden entrar en la formación, pueden ser soportes de la formación, pero la formación consiste en encontrar formas para cumplir ciertas tareas para ejercer un oficio, una profesión, un trabajo.

Por lo anterior, un individuo se forma por sí mismo, es quien adquiere la capacidad de desarrollarse, aprehende capacidades formativas en escritura las cuales construyen un texto.

El pensamiento es el que formula las ideas, el proceso de construcción alude al pensamiento teórico como nos refiere (Zemelman, 2005, p. 66)

...un pensamiento que ya tiene un contenido organizado y que puede ser el mismo contenido que se viene arrastrando (o puede ser un contenido diferente, pero lo fundamental es que tenga contenido) y por lo tanto, su estructura en términos de construir proposiciones es muy precisa.

Asimismo, el pensamiento incluye un proceso de formación, como señala (Ferry, 1999), el cual proporciona tres características: la primera la mediación como parte fundamental de las actividades que se realizan, por ejemplo en la lectura porque se desarrolla el proceso de adquirir habilidades para la escritura; la segunda la reflexión, cuando se asimila y se comprende el conocimiento se realiza el proceso de formación; la tercera es la realidad la relación que ejerce la formación con la ésta establece una distancia que se desprende para representarla, por lo tanto, presentarla construye formas y dicha formación se trabaja sobre representaciones.

La escritura emplea características determinadas, competencias personales desde la sensibilidad, la ética, la identidad que emana en el escrito, por ello, "desde los saberes el maestro requiere un saber pedagógico, cultural e interdisciplinario, el saber investigar y reflexionar, saber de su contexto histórico, socio-histórico, político, saber integrar y proyectarse" (Bravo, 2002, p. 1).

El representar algo es apropiarse de imágenes, figuras, construir una realidad mental para ejercer ciertas ocupaciones, como el planear un escrito, el empezar la 
construcción de ideas que generarán frases, enunciados, párrafos y textos, el incluir todos esos recursos procede a un proceso, como señala (Ferry, 1999, p. 57), "El proceso de formación es exactamente el anticipar sobre situaciones reales, y es, a favor de estas representaciones, encontrar actitudes, gestos convenientes, adecuados para impregnarse de y en esta realidad".

Para conocer cómo se escriben los textos llamados científicos se realiza la presente investigación, la cual se remite a analizar las competencias en escritura a partir de conocer las opiniones generadas en la construcción de un escrito, por medio de la entrevista y en la construcción de ejes de análisis.

\section{El objeto de estudio: razones de la investigación}

A partir de las siguientes preguntas se genera la investigación, con ellas se establece el trabajo del presente reporte: ¿por qué para algunos es importante publicar lo que investigan?, ¿qué y cómo se genera la inquietud para difundir lo que se hace?, ¿cómo se construyen, se incluyen las habilidades, estrategias y competencias para la elaboración de un escrito científico? De acuerdo a lo anterior, se explica cómo se desarrolla la investigación a partir del objeto de estudio: los informantes.

Se presenta a los sujetos de estudio, cabe destacar que son elegidos por sus trayectorias mismas que se encuentran vinculadas a diferentes áreas del conocimiento, por lo tanto existe una diversidad en cuanto a comentarios e intereses los cuales son relevantes para el reporte. Asimismo, "existe predeterminado de antemano un tema o foco de interés, hacia el que se orienta la conversación y mediante el cual hemos seleccionado a la persona objeto de la entrevista" (Galindo, 1998, p. 299).

En la investigación se analizaron a cinco sujetos de estudio quienes han publicado diferentes escritos, ya sea en forma electrónica o en papel, se usó como técnica la entrevista enfocada aplicando como instrumento una guía de entrevista. Para la investigación de los sujetos de estudio, se desarrollaron tres ejes de análisis el primero el perfil sociocultural, el segundo cultura académica y el tercero proyecto de vida. 
Tabla 1

Sujetos de estudio

\begin{tabular}{lll}
\hline Informante & Experiencia académica & Criterio de selección \\
\hline Dr. José Luis & Profesor de Carrera de Investigación en & Participa con colaboraciones \\
Martínez Marca & Economía, 26 años de docente en la FES & en diferentes universidades \\
(1) & Aragón, fue responsable del Posgrado en & tanto nacionales como \\
& Economía de la FES Aragón. & extranjeras
\end{tabular}

Mtro. Miguel Martínez Curiel

(2)

Mtra. Carmina

Flores Carranza

(3)

Dr. José Luis

Romero

Hernández

(4)

Dr. Luis Gabriel

Arango Pinto

(5)
Actualmente cursa el doctorado en Pedagogía en la FES Aragón, participa en el programa de radio el Espiral y en la columna El octavo pasajero del periódico el Metro. Actualmente profesor de la licenciatura en Comunicación y Periodismo.

Arquitecta. Profesora de asignatura de la licenciatura en Diseño Industrial. Participa en proyectos de restauración de estaciones de ferrocarril en la UNAM y como coordinadora de proyectos arquitectónicos en el sector privado.

Cuenta con cerca de 40 años en la docencia, 23 años dentro de la FES Aragón, responsable, instructor de diferentes foros académicos dentro y fuera de la FES Aragón. En su trayectoria dentro de la FES ha logrado 228 titulaciones en la carrera de Pedagogía.

Investigador, académico y docente en la UNAM, así como en la Universidad Simón Bolívar; participante, ponente y escritor de diversos proyectos de investigación.
Ha colaborado en diversas publicaciones; imparte cursos de redacción y corrección de estilo dentro del mismo posgrado en Pedagogía.

Publicó el ensayo Características constructivas y beneficios del bambú

Cuenta con diversos textos, antologías y apuntes para la carrera en Pedagogía.

Su investigación ha generado diversos textos la mayoría publicados en la red.

\section{Método a desarrollar}

El reporte se centra en el método cualitativo interpretativo, "en la perspectiva cualitativa la primacía de su interés radica en la descripción de los hechos observados para interpretarlos y comprenderlos en el contexto global en el que se producen con el fin de explicar los fenómenos" (Cook, 1997, p. 20). Por lo anterior, en el método cualitativo, la entrevista enfocada como instrumento metodológico es la utilizada, ya que muestra una perspectiva amplia del objeto de estudio que son los sujetos en cuanto a los ejes de análisis: el perfil sociocultural, la cultura académica y proyecto de vida. A partir de la entrevista, el diálogo como uso de las competencias comunicativas resulta un 
intercambio de ideas, una narración creada entre el entrevistado y el entrevistador, el mantener esa conversación interpersonal irrumpe en esos pensamientos, sentimientos que son el vehículo del proceso para el análisis de la investigación.

La investigación social trabaja con personas, los sujetos sociales que en relación con grupos son los que construyen el objeto de estudio, además estos sujetos de investigación determinan la construcción teórica y práctica de la investigación. "Hay varias formas de comparar aspectos de interior de una sociedad, comparaciones, interpretaciones explicativas como comprensivas, el momento metódico envuelto en la subjetividad, la relación con las realidades. No pueden ser medidas sino comprendidas" (Cardoso de Oliviera, como se citó en Paraizo \& Moreira, 2009, p. 3).

El interés primordial se centra en conocer los factores que determinan cómo un texto se escribe para la difusión, donde las competencias, habilidades, estrategias además de los saberes encierran la construcción de un escrito científico. Las indagaciones que se obtienen al acercarnos a la realidad de los propios autores, que trasladan su creatividad e imaginación junto con las técnicas de escritura y los procesos encierran toda una actividad que aquí se presenta.

\section{Resultados}

\section{Comentarios del Perfil Sociocultural.}

El perfil sociocultural indica las competencias, habilidades, aprendizajes previos, saberes y estrategias con lo que cuentan los informantes clave para elaborar un texto científico; lo importante es conocer cómo se han relacionado con la habilidad de escribir desde diferentes contextos sociales y cómo se han apropiado de esas competencias.

Con el perfil sociocultural el escritor aclara como han sido usados esos medios y mecanismos dentro de la sociedad, mismos que han sido soportes en el transcurso de su vida. Los bienes intelectuales para muchos son proporcionados y la adquisición es personal, el desarrollo de habilidades y capacidades se desarrollan como el "expresar nuestro pensamientos por escrito en forma coherente y clara es una habilidad difícil de 
lograr y requiere no sólo el ejercicio de la habilidad en sí,... sino aunar al proceso de producción el de reflexión como inseparables" (Pansza, 1991, p. 53).

La relación de las ideas socioculturales con los conocimientos, generan respuestas construidas que procesan contextos que definen el énfasis en las diferentes aplicaciones e implicaciones de la escritura, en medida...

...que los docentes deberían tener en cuenta no sólo los textos, sino también las maneras en las cuales ellos responden al complejo contexto discursivo, ideológico, social, cultural e institucional en el cual se presentan, tratando de centrarse en la conexión vital entre lenguaje y la vida" (Freedman, 1999, como se citó en Blanco, 2005, p. 15).

La siguiente tabla muestra la guía de entrevista que aplicamos a los sujetos del primer eje de análisis: Perfil Sociocultural.

Tabla 2

Guía de entrevista en relación al perfil sociocultural.

\begin{tabular}{ll}
\hline Eje de análisis & Preguntas \\
\hline & 1.- ¿De qué tipo fue tu formación académica? Estudiaste en escuelas públicas o \\
& privadas. \\
& 2.- ¿Recuerdas qué escribías en la escuela? \\
& 3.- Mencióname si redactar te era fácil o encontrabas obstáculos o dificultades \\
& ¿cómo cuáles? \\
PERFIL & 4.- Dime si alguna vez escribiste un diario, poesías, cuentos, canciones. \\
SOCIO & 5.- Cuéntame si alguien en particular te ha ayudado a escribir. \\
CULTURAL & 6.- ¿Utilizabas alguna estrategia o técnica para ayudarte a escribir mejor? \\
& 7.- Dime si has tomado algunos cursos de redacción, creación literaria, corrección \\
& de estilo u otro que te haya ayudado a desarrollar la escritura. \\
& 8.- ¿Recuerdas si siempre o nunca terminabas lo que empezabas a escribir?, ¿por \\
& qué sucedía? \\
& 9.- Platícame qué te motiva a escribir.
\end{tabular}

La siguiente información, presenta el análisis de acuerdo a la información recibida. Además, detallamos las respuestas enfatizando los contenidos de interés para el reporte, que son el punto de partida del mismo, como las competencias adquiridas por parte de los sujetos.

Asimismo, exponemos las cuestiones y las respuestas obtenidas, cabe mencionar que a los sujetos se les dio un número, que se expone al final de sus comentarios. 
A la cuestión, ¿si su formación proviene de escuelas públicas o privadas?, esta pregunta es determinante para conocer si la enseñanza que recibió fue centrada en un currículum oficial o si fue construido por otras actividades académicas que fortalecieron tanto las bases de la lectura como de la escritura.

La respuesta emitida por todos los sujetos fue que su educación desde el preescolar hasta el posgrado la recibieron en escuela públicas. Lo que determina que su gusto por escribir es personal, no motivado por otros factores como talleres extras de animación a la escritura y la lectura que se imparten en escuelas privadas u otro tipo de cursos recibidos durante su educación básica. Por lo tanto, "los aprendizajes de vida implican algo más que conocimientos o habilidades ésta es una noción ligada a lo afectivo o a lo moral" (Laclau 2005, como se citó en Soriano, 2009, p. 177).

En cuanto: ¿a qué escribían en su niñez y adolescencia?, las respuestas fueron las siguientes. Cuatro sujetos coinciden $(1,2,4,5)$ que les gustaba escribir desde su niñez algún tipo de escrito entre ellos destacan las fábulas, los cuentos o diarios; un sujeto contestó que no escribía nada en su niñez sino hasta apenas en el posgrado (3). Por lo tanto: "La formación es entonces completamente diferente a la enseñanza y del aprendizaje. O sea que la enseñanza y el aprendizaje pueden entrar en la formación, pueden ser soportes de la formación, pero la formación consiste en encontrar formas para cumplir ciertas tareas para ejercer un oficio, una profesión, un trabajo" (Ferry, 1999, p. 54).

A la pregunta de ¿si les era fácil escribir, o si alguien en particular les ha ayudado a desarrollar su escritura?; las respuestas fueron las siguientes.

Mencionan tres sujetos $(1,2,5)$ que les era fácil escribir, que no tenían dificultades al realizarlo y dos que fue difícil porque ya en la licenciatura nunca tuvieron alguna asignatura que los guiara en el camino de la redacción $(3,4)$.

Por lo que coincidimos, con lo siguiente el representar algo es trabajar con imágenes, figuras, construir una realidad mental para hacer ciertas tareas, como el planear un escrito, el empezar la construcción de ideas que generaran frases, enunciados, párrafos y textos, el incluir todos esos recursos. "El proceso de formación es exactamente el anticipar sobre situaciones reales, y es, a favor de estas 
representaciones, encontrar actitudes, gestos convenientes, adecuados para impregnarse de y en esta realidad" (Ferry, 1999:57).

A la consulta de ¿si alguien los ha ayudado a escribir?, contestaron tres que no, que solos lo han hecho (1, 3 5); dos que sí, que a lo largo de su vida académica y laboral han tenido quien les ayude a aclarar dudas, errores y muletillas en general (4, 2). En estas respuestas indicamos que más de la mitad de los entrevistados tienen el gusto por la escritura desde temprana edad, que es de carácter personal, porque ellos han buscado la forma de plasmar sus ideas, ya sea en una fábula, cuento u otro género. Por lo anterior, destacan que no presentaban alguna dificultad por hacerlo, desarrollaban fácil sus ideas, además que siempre han confiado en alguien para poder seguir escribiendo, las opiniones que generaban sus escritos por parte de otros siempre las recibían sin molestias o malos entendidos.

De tal forma, coincidimos con el concepto de formación desde la construcción misma que va generando el hombre en la trayectoria de vida y que es constante e interminable en la formación, formar la conciencia para el éxito ya sea tanto social, político, académico como vida. Gadamer comenta (Bravo, 2002, p. 1) "el concepto formación es el pensamiento más grande del siglo XVIII".

Las siguientes respuestas determinan ¿qué tipo de estrategias o técnicas han utilizado para desarrollar un escrito?

Sólo uno de los entrevistados mencionó que no tiene estrategias o técnicas porque su formación no le dio alguna base específica a seguir, por lo que es muy complicado desarrollar un escrito, necesita ayuda y una serie de pasos como guía para poder desarrollar algún texto (3).

Cabe destacar, el concepto de un saber que utiliza Foucault (1994, p. 306)..

....un saber es aquello de lo que se puede hablar en una práctica discursiva que así se encuentra especificada...es también un espacio en el que el sujeto puede tomar posición para hablar de los objetos de que trata en su discurso... es también el campo de coordinación y subordinación de los enunciados en que los conceptos aparecen, se definen, se aplican y se transforman. 
Asimismo, cuatro utilizan una técnica en particular para desarrollar un texto: "Sí naturalmente, primero hay que tener una idea clara y fragmentarla en partes para armar un cuerpo, que debe tener una constitución coherente, lógica, secuencial, de tal modo que los nexos, las preposiciones hilen las oraciones, los párrafos en ideas concretas que articulen un capítulo con otro, eso da consistencia y razón de ser a un cuerpo de conocimiento de otro. Creo que ha sido una tarea no fácil pero con la práctica me ha permitido desarrollar con mayor grado de profesionalismo y poder trabajar" (4).

"Yo no sé mucho de reglas, generalmente las reglas no las conozco muy bien, más bien ha sido por ver como se escriben textos, la técnica para escribir: primero leer y después revisar la ortografía, las estructuras como lo ha hecho otra gente y básicamente así lo hago" (5).

"Pienso que la mejor estrategia es la continuidad, la práctica constante, el fijarte un formato para después hacer tus propias estructuras mentales. Es muy importante hacer un plan para el desarrollo de tu escritura para que finalmente tengas mayor visión en el objetivo que persigues en el momento de escribir" (2).

"Sí tenía ideas para escribir siempre manejaba ideas, pero una estrategia definida, pues no" (2). Destaca (Foucault, 1994, p. 307) "pero no existe un saber sin una práctica discursiva definida; y toda práctica discursiva puede definirse por el saber que forma".

Por lo cual, mencionamos que el uso de competencias se remite a las prácticas cotidianas en donde se utiliza el sentido común, la experiencia orientada a desarrollar esas competencias de manera creativa en donde la adquisición de saberes se transmite por el "saber-hacer" (habilidades manuales); porque el uso de ellas depende de gran medida como se utilicen fuera de la escuela y esos saberes se transforman en conocimientos para poder realizar cualquier tarea, salir de un problema, enfrentar una situación, tomar decisiones.

Sobre la transferencia de conocimientos...

...el transfert no es automático, se adquiere por el ejercicio y una práctica reflexiva, en situaciones que propician la ocasión de movilizar los saberes, de 
extrapolarlos, de cruzarlos, de combinarlos, de construir una estrategia original a partir de recursos que no la contienen y no la dictan" (Perrenoud, 2008, p. 4).

En relación a ¿si han tomado algunos cursos de redacción, creación literaria, corrección de estilo $u$ otro que te haya ayudado a desarrollar la escritura? Tres de los entrevistados contestaron que no han tomado ninguno de los antes mencionados $(1,3$, 5). Uno dijo que sí ha cursado diferentes cursos porque son factor determinante para su desempeño laboral. "He tratado de prepararme de hecho aunque siento que muchos elementos ya los manejo, pero siempre en cada curso, en cada experiencia aprendes algo nuevo y eso es lo que me motiva a seguir tomando los cursos aunque algunos de ellos ya conozco los programas" (2).

Otro sujeto expuso que ha desarrollado algunos cursos pero personalmente, "He leído algunos cursos que ha trabajado Guillermina Baena Paz, Raúl Rojas Soriano de los básicos hasta los más, digamos sofisticados, complejos, en la SEP nos daban cursos específicamente para analistas de estructuras administrativas y creo que eso ha sido un factor determinante para que yo tenga mayor habilidad a la hora de dirigirme al público o en su defecto poderlo hacerlo de manera escrita" (4). Una de las características esenciales en la redacción científica es la claridad, cuando contamos con ella se percibe "una mente clara que abordará un problema claramente formulado y llega a unas conclusiones claramente enunciadas" (Day, 2005, p. 1).

El discurso científico se encuentra en relación con las competencias y el análisis, el nivel de la estructura es empleado en cuanto las habilidades que se tengan para desarrollar un texto en particular. Las herramientas utilizadas como cursos referentes para aprender a escribir mejor, ayudan en la manera de cómo redactamos y soportan toda la actividad en la escritura. Destacamos que:

...saber escribir no es sólo una habilidad funcional o un criterio que define cierto nivel operacional de comportamiento. Dada su relación con los poderes de la mente, la alfabetización permite trascender el entorno inmediato generando un mundo compartido de inteligibilidad más abstracto que el de las interacciones cotidianas (Pisticelli, como se citó en Cuadra, 2004, p. 15). 
A lo referente a ¿si siempre o nunca terminabas lo que empezabas a escribir?, contestaron. Cuatro dijeron que siempre terminan lo que empiezan $(3,1,2,5)$ uno concluyó que "es difícil a veces los dejo de manera inconclusa, es difícil terminar una idea, porque el tiempo es factor fundamental para poderse dedicar a ello". (4). Por lo anterior, entendemos el aprendizaje como un proceso individual en que cada uno enfrenta diversos problemas y llega a las metas que se propone por diversos caminos (Pansza, 1991, p. 7).

Destacamos que cada uno de los sujetos de estudio quiere el desarrollo personal y se enfoca en la búsqueda de dicho crecimiento, que implica una serie de procesos personales que pasa por etapas para obtener beneficios que cambian actitudes frente a cualquier tarea.

La última cuestión sobre ¿qué los motiva a escribir? respondieron. "Yo creo que más de los tecnicismos, es la necesidad como docente, veo que hay que buscar la manera de comunicarse con los alumnos que están interesados en desarrollar un proceso de investigación y que en ocasiones no encuentro el texto apropiado para poderlos orientar y sí tengo el conocimiento busco la manera de hacerlo didáctico, entonces le hago algunos escritos, elaboro apuntes y se los doy a leer y eso ayuda mucho para fundamentar lo que ellos desarrollan posteriormente" (4).

"Me motiva el gusto por la escritura. De repente siento que mis ideas quedan mejor plasmadas de manera escrita que oralmente, entonces eso me motiva a compartir determinadas cosas que yo tengo, o siento, eso me motiva a comunicarlas o compartirlas" (5).

"Aquí básicamente son dos factores, aparte de que me gusta escribir, la situación que nosotros tenemos como profesores de carrera de investigadores, es que nos evalúan anualmente y trimestralmente, entonces estamos obligados a presentar determinado número de publicaciones, estamos obligados a escribir, no sólo por parte de la universidad sino también por parte de CONACYT, esa es la situación. Entonces desde que he participado en la universidad, siempre de alguna manera he escrito" (1).

"Creo que es una búsqueda de expresar, de manifestar el interior, de querer expresar sentimientos, inquietudes, deseos a través de la escritura, sentimientos que 
atraviesas y que de alguna forma tienes necesidad de manifestarlos. Yo creo que la pasión por escribir es un elemento fundamental" (2).

"Me gustó la experiencia de publicar, de interpretar lo que quieres, lo que consideras" (3).

Como conclusión del perfil sociocultural como exponente de nuestro continuo quehacer; las respuestas anteriores manifiestan en gran medida que los diferentes sujetos de estudio adquirieron el gusto por escribir a temprana edad, que les gustaba desarrollar escritos en forma de cuentos, fábulas o diarios; además que siempre han sido motivados a seguir en el camino de la escritura, ya sea por gusto personal o por alguien más que los ha motivado y ayudado en esa inquietud por exteriorizar esas ideas escritas para que por otros sean leídos.

Por lo consiguiente, el perfil sociocultural como elemento de análisis de toda organización social y cultural involucra hábitos y valores, (Malinowski, como se citó en Puga, 1993, p. 43) donde la organización social no puede ser entendida sino como una parte de la cultura, la cual constituye otra perspectiva para analizar la sociedad, en donde cada miembro adquiere un significado. Otro elemento importante a considerar es la necesidad que tienen los sujetos por contar con estrategias que ayuden a desarrollarse en su vida tanto laboral como académica, asimismo, han tomado cursos o personalmente han buscado los elementos necesarios para empaparse de esas carencias con que dicen contar y terminarlas.

La técnica para escribir es personal como las competencias y habilidades con que se cuentan para realizar un escrito, sin embargo, podemos mencionar las siguientes: las ideas claras, coherentes, lógicas que articulen párrafos el leer, la ortografía, las estructuras, la continuidad, tener un formato, un objetivo, visión de lo que se quiere, la práctica constante, éstas son las principales características que comparten los sujetos de estudio. 


\section{Comentarios del eje Cultura Académica.}

En el punto anterior analizamos el eje del Perfil Sociocultural en donde los hábitos y valores destacan parte de nuestra personalidad social, que junto con los saberes y actitudes incluyen la perspectiva tanto social como cultural. Por lo anterior, se articula el siguiente eje La Cultura Académica parte vital como referente en nuestro quehacer estudiantil. La cultura académica que cualquier sujeto lleva consigo es considerada como instrumento, una herramienta de adquisiciones, de conocimiento, de selección, porque la cultura interpreta la realidad donde cada individuo forma su conocimiento. Por lo tanto...

...si la escuela ofrece como cultura las creaciones de un grupo humano e ignora otras empieza a crear desigualdad ante la educación, porque algunos alumnos sentirán que están en su ambiente, otros se sentirán como en un país extraño, en el que ven y oyen pero no entienden" (Estebaranz, 1996, p. 192).

De tal forma el hombre como actor social cumple en la sociedad el rol de relacionarse en todos los ámbitos de su vida, las actividades que ejerce influyen en la vida laboral, académica, social y personal. Como ser social se adquieren diferentes herramientas mismas que son utilizadas en diferentes contextos, como parte de ello, las diferentes investigaciones escritas constituyen un hecho cultural que transforma la realidad.

Tabla 3

Guía de entrevista en relación a la cultura académica

\begin{tabular}{cl}
\hline $\begin{array}{c}\text { Eje de } \\
\text { análisis }\end{array}$ & \multicolumn{1}{c}{ Preguntas } \\
\hline & 1.- Cuéntame cómo integras la investigación para desarrollar un escrito. \\
& 2.- ¿Cuándo desarrollas un escrito cómo incluyes las habilidades y a la metodología? \\
& 3.- ¿Consideras que necesitas apoyo para mejorar tu redacción?, ¿de qué tipo? \\
& 4.- Tu formación académica determina la forma de como escribes un texto, ¿por qué? \\
CULTURA & 6.- ¿Piensas que la motivación personal es factor determinante para elaborar artículos, \\
ACADÉMICA & ensayos o reseñas?, ¿por qué? \\
& 7.- Cuéntame cuánto tiempo inviertes en la realización de un texto y cómo organizas tu \\
& tiempo para desarrollar un texto. \\
& 8.- ¿Cuando escribes vas corrigiendo o lo realizas hasta el final? \\
9.- Dime si en la actualidad estás elaborando algún escrito, ¿de qué tipo?
\end{tabular}


A continuación presentamos las consideraciones que obtuvimos a las preguntas respecto a la cultura académica, esos factores que influyen como parte de la vida de los sujetos de estudio.

Las respuestas generadas a partir de la interrogación de ¿cómo integran la investigación para desarrollar un escrito?, cabe destacar, que "la formación metodológica es particularmente importante dado que procura la apropiación de las herramientas de análisis necesarias para la aprehensión de esas diferentes situaciones" (Ferry, 1997, P. 40).

Las respuestas coincidieron, los sujetos las integran conforme van trabajando su escrito, primero surgen las ideas que desarrollan, después recopilan datos y elementos enfocados en la investigación.

"Trato de seguir primero que nada lo que aprendí en la carrera, en la formación, en los libros de metodología, de cómo dicen se debe hacer la investigación y también en la práctica, trato tomar lo que me haya servido para repetirlo en la siguiente vez" (5).

Por lo anterior, cuando se compone un escrito se despiertan procesos como las habilidades cognitivas, "fruto de la interacción de diferentes procesos cognitivos, que tiene como resultado la construcción de una representación mental del significado del texto" (Woolfolk, 1999, P. 241).

Dichas habilidades se adquieren a través de procedimientos como la memoria, la actividad del pensamiento que soluciona problemas en la forma de escribir algún texto. Asimismo se realiza un esfuerzo que contiene soluciones por obtener un resultado, por lo cual la composición escrita relaciona formas de habilidades unas específicas y otras metacognitivas.

La siguiente pregunta responde al tema ¿cuándo desarrollan un escrito cómo incluyen a las habilidades y a la metodología?, las respuestas dadas nos llevan a la conclusión de que cada uno es autónomo e individual y usa diferentes estrategias como: desarrollar y sistematizar lo que quiere y cómo lo va a hacer antes de empezar a escribir; la lectura de otros autores quienes desarrollan escritos académicos los cuales les proporcionan ideas y formas de escribir. 
Otro sujeto comenta que siempre con la ayuda de alguien porque de manera individual nunca lo ha hecho (3); otro más dijo que la experiencia es factor determinante para redactar con diferentes habilidades como contar con agilidad en ideas e integrar la investigación (2).

La organización de objetos forman parte de esas unidades de coherencia que se encierran en los temas, las diferencias en la redacción fluctúan de una persona a otra como las técnicas empleadas para dicho propósito.

Por ello, "una formación discursiva será individualizada si se puede definir el sistema de formación de las diferentes estrategias que en ella se despliegan: en otros términos, si se puede mostrar cómo derivan todas ellas... de un mismo juego de relaciones" (Foucault, 1990, P. 112).

A continuación las opiniones. "Básicamente la estrategia parte de un esquema, de una idea que tengo, de ahí desarrollo un guion y posteriormente lo desarrollo, es mi guía" (1).

"Lecturas sí, siempre he dicho que el objeto de estudio lo que tu creas, lo vas construyendo no sale de la nada, sale del contexto de la realidad, de la observación, de las lecturas, entonces es poco probable que no leas antes de escribir algo. La lectura previa es fundamental y en la medida como la voy integrando es cómo voy haciendo una especie de fichas, pero no como las bibliográficas, lo que voy leyendo lo voy pasando a un archivo y después lo voy enriqueciendo, contrastando con otros autores, con otras lecturas, voy diciendo yo cosas; cuando menos siento ya el texto es amplio, siempre con un objetivo previo, una especie de planeación, por lo menos mínima. Porque no en todos los escritos digo este es mi plan o mi esquema para un ensayo, no si no simple y sencillamente tengo una estructura que no necesariamente plasmo en el papel, pero que sí la tengo en la cabeza con base en eso voy organizando la información que quiero escribir" (5).

Por lo comentado coincidimos con "el aprendizaje como la adquisición y estabilización de pautas de conductas nuevas que son consecuencia de nuestra experiencia con el medio ambiente... el aprendizaje se manifiesta a través de nuestra conducta" (Pansza, 1991, p. 15). 
De la pregunta ¿si necesitan algún tipo de apoyo para mejorar su redacción? Las respuestas emitidas fueron que todos sí necesitan algún tipo de ayuda, en general para mejorar problemas de redacción; pero destacó el comentario de un sujeto el cual contestó que no necesita ayuda, por lo siguiente:

Que tal vez de corrección de estilo sí necesite (pero fue claro al decir que su redacción la considera apta para elaborar escritos) (1).

Los restantes sujetos fueron reiterativos al decir que siempre es bueno mejorar porque hay errores, detalles en cuanto a preposiciones por ejemplo (5).

Otra persona por su parte dijo que la formación es un proceso inacabado que empieza con el nacimiento y termina con la muerte (4).

Por su parte un siguiente sujeto comentó que en definitivo sí necesita ayuda porque repite muchas palabras, se queda sin vocabulario y es reiterativo (3).

El último sujeto aclaró que siempre se debe estar abierto al intercambio de aprendizaje entre los compañeros que tienen las mismas intenciones de escribir (2).

Las respuestas anteriores nos hablan de la competencia que se obtiene por la adquisición de saberes en diferentes procesos de formación algunos son destacados más que otros, lo que implica a la competencia comunicativa que ejerce un individuo la cual se destaca en primer lugar en el lenguaje que maneja y cómo lo hace.

Destacamos el comentario de (Martín-Barbero, 2004) quien habla acerca de la competencia como "la capacidad que desde muy pequeños tienen los humanos de entender frases nuevas y de producir mensajes nuevos, inéditos".

Las respuestas dadas ¿a la motivación de influye para crear textos? todos coincidieron que sí es un gran alentador para desarrollar ideas. A continuación las opiniones: La motivación como principal generador de ideas, además el compromiso por cumplir con la misma universidad o CONACYT para desarrollarse como académico" (1). Influye para la creación de textos (3).

Un sujeto nos dice que si lo haces por obligación no lo disfrutas, entonces lo debes disfrutar dentro de nuestras actividades, y pensar en desarrollar una idea es crucial para organizarla y desarrollarla (5). 
Otro nos comentó que el impulso que fomenta el desarrollo de cualquier actividad, si no tienes motivación simple y sencillamente no puedes producir nada y sin sentido, entonces la motivación es importante no solamente para la escritura sino para el estilo de vida de las personas. El tiempo que invierten para escribir un texto varía de acuerdo a las actividades de cada sujeto y también comentan que al tipo de texto, no es lo mismo un ensayo a una nota informativa (2); otra persona dice que puede ser de un mes hasta un año (5) y otro más complementa que va de tres meses hasta seis meses por 30 cuartillas o hasta 100 (1).

La manera de ¿cómo organizan un texto?, depende de sus labores de trabajo para tres sujetos es parte de sus actividades el escribir es cotidiano, constante, le destinan el mayor tiempo posible (4), (5), (2); que escribe por las noches, domingos o días libres porque "las ideas las tienes que escribir, porque sí no se van y no regresan jamás" (4).

En este proceso, mencionamos las habilidades para desarrollar un texto, (González, 1993): Las habilidades escritas para la composición de un texto, son las habilidades de tipo mecánico, habilidades de tipo ortográficos, habilidades de producción, habilidades lingüísticas y habilidades organizativas.

Estas habilidades son las que debe poseer el escritor para iniciarse en la escritura; el componente mecánico lo entendemos como el desarrollo de la letra legible acompañada de una adecuada redacción, que en la parte de ortografía es de suma importancia, ya que implica las reglas que se deben utilizar al momento de redactar. Por lo que respecta, al proceso de producción de un ensayo inicia por la lectura de datos, la cantidad de ideas, juicios y pensamientos que queremos exponer en el texto. Las lecturas, la revisión del material deberán hacerse de una forma dialógica, concluyendo si realmente hemos entendido el contenido temático; el siguiente paso es la reflexión para reconocer los acuerdos con las ideas recogidas sobre la metodología de los documentos. Los componentes lingüísticos son caracterizados por la sintaxis adecuada de unidades sintácticas; todo ello implica la coherencia lógica, la secuencia y la organización que se le denomina la habilidad organizativa. 
La pregunta de ¿cuándo escribes vas corrigiendo o lo realizas hasta el final?, emitió las siguientes respuestas cuatro de los sujetos que sí van corrigiendo conforme escriben, van cuidando los detalles, las estructuras, conceptos y siempre al terminar hacen una revisión exhaustiva del texto $(2,1,5,3)$. Un último dice que sigue escribiendo y hasta el final corrige, porque se le van las ideas (4).

Con respecto a las respuestas generadas incluimos a la habilidad en la composición escrita porque conlleva un proceso arduo ya que los factores determinantes para la escritura de cualquier texto implican una serie de procesos como: la planificación del escrito, la generación de frases determinantes para la construcción de párrafos, la revisión del producto las veces que sea necesario. Se menciona que el transcurso no debe ser lineal, se pueden alterar los lineamientos, pero en consecuencia son los componentes que se deben seguir en la redacción de un escrito, los procesos intervienen permitiendo que la persona que escribe regule estrategias, como el componer ideas y desarrollar escritos.

Por lo tanto, se conocen como expertos a aquellas personas que utilizan las estrategias metacognitivas para autorregular la forma de la composición escrita. "la redacción de los expertos es cualitativamente distinta puesto que se vuelve autónoma respecto de una audiencia presente y pueden hablar sobre lo que van a escribir por anticipado" (Bereiter \& Scardamalia, 1983, como se citó en Pacheco, 2005, p. 1205). De acuerdo a lo anterior, el experto autorregula los procesos de escritura y la composición no le causa problemas porque la manera en que la persona experta ayuda a construir el sistema de regulación del otro, si éste aún no cuenta con los procedimientos adecuados para desarrollar las actividades de la propia autorregulación, le ayudará de manera significativa para empezar a adquirir las herramientas que le fortalecerán en la manera de autorregular esos factores que hasta el momento no han podido generarse por sí mismos.

A la pregunta ¿si en la actualidad están desarrollando algún escrito?, cuatro sujetos contestaron que sí se encuentran realizando un texto siempre con la finalidad de terminarlo y publicarlo en algún medio $(2,1,4,5)$. El quinto que no está escribiendo nada en particular (3). 
Las respuestas anteriores nos llevan a concluir que las competencias, el uso de estrategias y habilidades, son parte del sentido cognitivo del pensamiento y de la práctica en el entorno social, porque cada sujeto usa los sentidos de experiencias pasadas y presentes, las cuales se internan en el comportamiento que debe enfrentar ante una situación. Es decir, en el que se integran sus experiencias, su trayectoria cultural, o lo modos de adquirir esas disposiciones. El habitus tiene que ver con la forma en que adquirimos los saberes, las destrezas y las técnicas artísticas: la forma de adquisición se perpetúa en las formas de uso (Bourdieu, como se citó en MartínBarbero, 2004, p. 24).

Cabe destacar, que las respuestas emitidas a la mayoría de las preguntas fueron de igualdad porque consideran que la formación académica sí determina la forma de escribir, y los sujetos que estudiaron licenciaturas donde la redacción era parte de sus asignaturas ayudó a desarrollar esas competencias, habilidades y estrategias para creación y construcción de escritos.

Por otro lado, el sujeto que nunca accedió en su formación a materias relacionadas con la escritura, comentó que fue muy difícil escribir, porque no tiene la menor idea de cómo hacer un ensayo o un artículo y la falta de práctica ocasiona contar con una deficiente redacción, además nos aclara que nunca uso una metodología en particular ya que el texto que realizó fue guiado paso a paso y así fue como lo creó para su publicación (3).

Además concluimos, que todos de manera personal les gusta escribir y se motivan por realizar algún texto, porque buscan tiempo para hacerlo además existe una satisfacción al terminarlo. Al ver cualquier texto que hayan concluido y publicado en donde los lectores conocen esas ideas es un impulso a seguir haciéndolo en otros textos, además enriquece su labor académica tanto en la misma universidad como para otros sectores educativos.

Ante los sentires exponemos a (Estebaranz, 1996) quien sugiere que la escuela ofrece como cultura las creaciones de un grupo humano e ignora otras porque algunos son competentes para ciertas habilidades que incluye saberes y competencias, es cuando se empieza a crear desigualdad ante la educación, porque algunos alumnos 
sentirán que están en su ambiente porque manejan adecuadamente esos estudios que terminan en finales felices, por así decirlo, para algunos pero otros se sentirán como en un país extraño, en el que ven y oyen pero no entienden.

\section{Análisis del eje Proyecto de Vida.}

El proyecto de vida es único e irrepetible, se constituye por la unión de elementos que a través de ellos forman la integración tanto social como cultural, que se complementan relacionando los factores que engloban la formación que nos acompaña a lo largo de nuestra vida. Los proyectos personales funcionan con la ayuda de diversos sucesos que complementan y proporcionan unidad en nuestra vida, ya sea afectiva, académica, social como cultural.

Todo individuo social integra a su ser un proyecto de vida el cual es personal de acuerdo a las condiciones e intereses que desarrolla para la adquisición de la personalidad y compatibilidad con las condiciones sociales que mejor le favorezcan, el conocimiento es gradual así como la formación de saberes, por ello, "la formación como un trabajo sobre sí mismo, un trabajo de sí mismo" (Ferry, 1999, p. 98).

Tabla 4

Guía de entrevista en relación al proyecto de vida.

\begin{tabular}{ll}
\hline Eje de análisis & Preguntas \\
\hline \multirow{2}{*}{ PROYECTO } & 1.- ¿Qué meta pretendes alcanzar con la publicación de tus escritos? \\
DE VIDA & 2.- ¿Les gustaría escribir un libro, sobre qué temas? \\
& 3.- ¿Sobre la investigación qué nos dicen? \\
\hline
\end{tabular}

El proyecto de vida es determinante en lo que realizamos como función social, que prácticamente se encuentra vinculado en todo el entorno y en los sentires que se vinculan en las situaciones académicas como personales; en donde algún proyecto, lo que deseamos hacer relaciona una serie de tareas para conseguir ese fin.

A la cuestión siguiente ¿las metas que pretenden alcanzar con sus escritos?, las respuestas fueron claras porque para todos es fundamental dar a conocer sus investigaciones, el difundir esos conocimientos, esos fenómenos y construir el 
conocimiento como principal factor. La investigación que sirva para otros temas en común, la unión de todo un proceso lleva a transformar procesos y rescatar ideas.

Por consiguiente cada sujeto cuenta con un propio "estilo como una elección de formas y patrones, se adopta el punto de vista del autor o hablante que tiene una cantidad de posibilidades diferentes de lo que quiere decir" (Renkema, 1999, p. 129).

En cuanto a la pregunta de ¿qué sí les gustaría escribir algún libro?

Un sujeto (1) nos aclaró que se encuentra en proceso de publicar su tesis doctoral como libro de apoyo para alumnos tanto de licenciatura como de maestría.

Otro por su parte (5) dijo, que ha publicado en diversos medios tanto electrónicos como en papel, colaborado en textos colectivos, antologías diferentes escritos como ponencias, ensayos, artículos.

El siguiente (4) también asevera que ha escrito para diferentes publicaciones en la UNAM y colaborado con diversos escritos para la SEP.

Uno más (2) comenta que por sus actividades laborales escribe para publicar y que también ha colaborado en diversas publicaciones y libros.

Un último sujeto (3) comentó que fue su primera publicación y la hizo para una revista principalmente, pero le gustaría seguir colaborando en ella.

Por lo anterior destacamos que cuando se compone un escrito se despiertan procesos como las habilidades cognitivas, "fruto de la interacción de diferentes procesos cognitivos, que tiene como resultado la construcción de una representación mental del significado del texto" (Woolfolk, 1999, p. 241).

Dichas competencias se adquieren a través de procedimientos como la memoria, la actividad del pensamiento que soluciona problemas en la forma de escribir. Se realiza un esfuerzo en donde las reacciones para encontrar esas posibles salidas $u$ obtener un resultado, por lo tanto, la composición escrita relaciona maneras de construcción de habilidades unas específicas y otras metacognitivas. Además destacamos, que la adquisición del aprendizaje lo logramos en la adolescencia gracias a la maduración que interactúa dinámicamente como parte de la gama de intereses y va acompañado de transformaciones en nuestro pensamiento (Pansza, 1991). 
Como conclusión las opiniones emitidas, nos aclaran que en general todos los sujetos de estudio siempre buscan el crecimiento tanto profesional como personal, además de desarrollar y perfeccionar las habilidades, los saberes y las estrategias, mismas que ha generado diferentes escritos para su difusión.

Asimismo, los sujetos coincidieron en que construyen la investigación individualmente, y buscan los medios para darla a conocer. La investigación es importante porque todos los sujetos de estudio coincidieron que es esencial para el fortalecimiento de cualquier texto a desarrollar, y buscar las referencias tanto en internet, como físicamente es el principal factor para desarrollar un escrito.

En particular todos buscan seguir escribiendo, además de tiempo para hacerlo, como generar investigaciones que sean leídas tanto por académicos y alumnos, ya sea en medios electrónicos como en papel. Cabe destacar que un sujeto comentó acerca de quienes no publican "porque generalmente no les interesa, yo creo que ese es el punto" (1).

Por lo tanto, (Bourdieu, 2003, p. 72) nos dice "si existe un ámbito en el que cabría suponer que los agentes actúan de acuerdo con esas intenciones consientes y calculadas, de acuerdo con unos métodos y unos programas conscientemente elaborados, sería el ámbito científico".

\section{Consideraciones}

Las aportaciones dadas en el presente reporte permiten conocer los porqués: de lo importante del difundir las investigaciones en los medios tanto electrónicos como en papel. Nos aclara cómo utilizan los recursos para escribir un texto, cómo incluyen a las competencias, a las habilidades y estrategias en la composición escrita

De los tres ejes de análisis que utilizamos para la investigación: el Sociocultural, la Cultura Académica y el Proyecto de Vida destacamos que los sujetos de estudio los integran en sus quehaceres cotidianos, viven con ellos desarrollándolos en sus actividades diarias y ese saber se observa en lo que realizan y como lo hacen. 
La confianza de realizar lo que les gusta, es notable y se observa de manera significativa, porque la investigación integra sus vidas, generando escritos que reflejan las inquietudes de una realidad que los mueve a publicar esos pensamientos.

Asimismo, destacamos, "gracias a la escritura, hemos atravesado una nueva etapa. Esta técnica ha permitido un aumento de eficacia de la comunicación y de la organización de los grupos humanos mucho más importante que lo que hubiera permitido la simple palabra" (Lévy, 2004, p. 11).

Por lo cual concluimos, que todos integran la metacognición (Woolfolk, 1999), que consiste en la regulación y control de conocimiento en situaciones de aprendizaje o solución de problemas, refiriéndose a la participación activa en tres momentos: el antes, el durante y el después, del cual entendemos que la capacidad de conocer el propio conocimiento de pensar y reflexionar en el cómo solucionamos problemas o tareas que se pueden presentar de manera inesperada o prevista.

Destacando de manera significativa los aspectos de "la conciencia y el conocimiento que posee un individuo acerca de sus propios procesos cognitivos y las actividades cognoscitivas que son utilizadas por las personas para regular sus procesos cognitivos, a dichas actividades Brown las denominó control ejecutivo o autorregulación” (Brown, 1987, como se citó en González, 1993, p. 70).

Por lo anterior, el concepto de autorregulación describe el manejo y control que se ejerce sobre los procesos psicológicos, tanto de metas como objetivos planeados, de cualquier persona para resolver actividades o problemas. El cual incluye el planear, el monitorear, el verificar el tipo de actividad antes de resolver alguna complicación siempre confrontándolo con juicios de efectividad.

Precisamente, las herramientas como las: competencias, habilidades, y saberes que se involucran en un proceso escrito, comparten procesos como: la planificación, la generación de ideas para la construcción de párrafos, la revisión, los lineamientos y componentes de la redacción que permiten la regulación de quien escribe en las estrategias para la composición de un texto.

El concepto de formación es constante en el proceso de construcción y humanización. "El concepto de formación, desarrollado inicialmente en la ilustración, no 
es hoy día operacionalizable ni sustituible por habilidades y destrezas particulares ni por objetivos específicos de instrucción. Más bien los conocimientos, aprendizajes y habilidades son apenas medios para formarse como ser espiritual.

La formación es lo que queda, es el fin perdurable; a diferencia de los demás seres de la naturaleza, "el hombre no es lo que debe ser", como dedica Hegel, y por eso la condición de la existencia humana temporal es formarse, integrarse, convertirse en un ser espiritual capaz de romper con lo inmediato y lo particular, y ascender a la universalidad a través del trabajo y de la reflexión filosófica, partiendo de las propias raíces" (Flórez, 1979, como se citó en Bravo, 2002).

\section{Referencias}

Blanco, C. E. (2005). Sociolingüística y análisis del discurso: herramientas para la investigación en educación. Caracas. Revista de pedagogía, 26, 1-30. Recuperado de www.scielo.org.ve/scielo.php?pid=S0798...sci...

Bravo, C. (2002). El concepto de formación pedagógica: tradición y modernidad. Colombia. Revista de Ciencias Humanas, 30, 1-11. Recuperado de http://www.utp.edu.co/ chumanas/revistas/revistas/rev30/bravo.htm

Bourdieu, P. (2003). El oficio de científico. Barcelona: Anagrama.

Cook, T. \& Reinhardt, CH. S. (1997). Métodos cualitativos y cuantitativos en investigación social. Madrid: Morata.

Cuadra, Á. (2004). Paisajes virtuales. Imágenes y simulacros del hombre imaginario. Santiago de Chile. Recuperado de www.campus-oei.org/publicaciones/gratuitas.htm - 19k -

Day, R. (2005). Cómo escribir y publicar trabajos científicos. Publicación Científica y Técnica no. 598. Washington EUA: The Orys Press. Recuperado de www.uclm.es/centro/CELatinoamericanos/pdf/CEYPUTRACI.pdf -

Estebaranz, A. (1996). Didáctica e innovación curricular. España: Universidad de Sevilla.

Ferry, G. (1997). Pedagogía de la formación. Argentina: Facultad de Filosofía y Letras de la Universidad de Buenos Aires.

Foucault, M. (1970). La arqueología del saber. México: Siglo XXI.

Galindo, J. (1998). Técnicas de investigación en sociedad, cultura y comunicación. México: Pearson.

González, A. (1993). Estrategias cognitivas, metacognitivas y autorreguladoras en los procesos de comprensión y composición escrita. Tesis de Licenciatura en Psicología, Facultad de Psicología. México: UNAM

Lévy, P. (2004). Inteligencia colectiva por una antropología del ciberespacio. Washington DC: Organización panamericana de la salud. Recuperado de http://inteligenciacolectiva.bvsalud.org

Martín, J. (2003). Saberes hoy: diseminaciones, competencias y transversalidades. Revista Iberoamericana

de Educación.

Recuperado

de 
http://redalyc.uaemex.mx/redalyc/src/inicio/ArtPdfRed.jsp?iCve=80003203 ISSN $1022-$ 6508-X

Paraizo, J. \& Moreira, R. (2009) Curso: Teorías y métodos de investigación comparada: Una mirada desde la antropología. México: FES Aragón.

Pansza, M. (1991). Hábitos y técnicas de estudio. México: Gernika.

Perrenoud, P. (2008). Construir las competencias ¿es darle la espalda a los saberes? Revista de Docencia Universitaria, número monográfico II "Formación centrada en competencias

(II)",1-8 pp. Recuperado de http://www.redu.m.es/Red_U/m2

Puga, C. (1993). Hacia la sociología. México: Alhambra mexicana.

Renkema, J. (1999). Introducción a los estudios sobre el discurso. España: Gedisa.

Soriano, R. (2009). Significados e identificaciones construidas por los tesistas desde la Fes Aragón. Tesis para obtener el grado de doctora en pedagogía. Facultad de Filosofía y Letras. México: UNAM.

Woolfolk, A. (1999). Psicología educativa. México: Pearson.

Zemelman, H. (2005). Pensar teórico y pensar epistémico. Los desafíos de la historicidad en el conocimiento social. Ánthropos, (pp. 63-79), Barcelona, en coedición con el Centro de Investigaciones Humanísticas de la Universidad Autónoma de Chiapas. 


\title{
DESARROLLO DE COMPETENCIAS INVESTIGATIVAS EN DOS GRUPOS DE POSGRADO EN EDUCACIÓN
}

\author{
INVESTIGATIVE SKILLS DEVELOPMENT IN TWO GROUPS OF \\ GRADUATE EDUCATION
}

\author{
Adla Jaik Dipp \\ Instituto Politécnico Nacional CIIDIR Durango \\ Instituto Universitario Anglo Español \\ adlajaik@hotmail.com
}

\begin{abstract}
Resumen
Los objetivos de esta investigación son: a) Determinar el nivel de domino de las competencias investigativas que desarrollan los alumnos de dos posgrados en educación de una institución particular; b) Establecer si la variable Aplicación marca diferencia significativa a lo largo de los programas. El estudio se caracterizó como no experimental, descriptivo y longitudinal. Se utilizó la escala de evaluación de competencias investigativas (EECI) (Ortega Rocha y Jaik Dipp, 2010) que está compuesta por 61 ítems distribuidos en 5 dimensiones con un nivel de confiabilidad en Alpha de Cronbach de .98. La población se conformó con dos grupos de posgrado de una institución particular de la ciudad de Durango, uno de Maestría en Educación y otro de Doctorado en Ciencias de la Educación. Se efectuaron tres mediciones a lo largo de un año y se recuperaron en total 45 instrumentos contestados por los alumnos de maestría y 42 instrumentos contestados por los alumnos de doctorado, 87 en total. Entre los resultados relevantes se menciona que los alumnos se perciben con un nivel medio de dominio de las competencias investigativas; la variable aplicación, marca diferencias significativas en todas las dimensiones, salvo en la denominada Resultados.
\end{abstract}

Palabras clave: Metodología de la investigación, Investigación Científica, Estudiante de posgrado.

\begin{abstract}
The objectives of this research are: a) Determine the level of proficiency of the investigative skills developed by students from two graduate programs in education of a particular institution; b) Establish if the variable Application makes a significant difference along programs. The study was characterized as no experimental, descriptive and longitudinal. A used assessment scale investigative skills (ASIS) (Ortega Rocha y Jaik Dipp, 2010) which is composed of 61 items divided into five dimensions with a level of reliability in Cronbach Alpha .98. The population was composed by two groups of a particular graduate institution in the city of Durango, one in a Masters in Education and the other one PhD in Science Education. Three measurements were taken over a year and recovered a total of 45 instruments answered by master's students and 42 instruments answered by PhD students, 87 in total. Among the relevant results, mentioned that students with average perceived level of mastery of investigative skills, and the Application variable makes significant differences in all dimensions, except in the called Results.
\end{abstract}

Key Words: Research Methodology, Scientific Research, Graduate student. 


\section{Introducción}

La investigación se ha constituido en un factor relevante en el proceso educativo y es al nivel superior a quien se le ha delegado la función de participar en la solución de los problemas que conciernen a la sociedad, a través del desarrollo de investigación científica, ya que a través de ella se genera conocimiento, se propicia el aprendizaje para generar nuevos conocimientos, y se vincula la universidad con la sociedad. Es por esta razón, que resulta innegable la importancia de formar especialistas de alto nivel profesional con una sólida formación investigativa que les permita detectar los problemas importantes de su entorno y ser capaces de lograr transformaciones a través de respuestas acordes al desarrollo científico-técnico contemporáneo.

La ANUIES en su Estrategia de Desarrollo para el 2015, ha determinado a la investigación como un proceso fundamental de la universidad, operado a través de la organización de proyectos conjuntos de investigación con los diversos sectores económicos y sociales.

En este sentido, es necesario, incorporar la investigación al proceso pedagógico a fin de favorecer que el pensamiento científico se constituya en parte inherente de la cultura profesional y disminuir la brecha entre la formación científico investigativa y la formación cultural general (Núñez, 2007).

Particularmente la investigación educativa es ahora una vía de acceso estratégica para mejorar la calidad educativa, cada vez más la producción de conocimiento científico en el campo educacional está ocupando un lugar primordial en la resolución de problemas, en la toma de decisiones y en la construcción de teoría que dé sustento al cambio y a la transformación (Castellanos, 2005).

Llivina, Castellanos B., Castellanos D. y Sánchez (2001) afirman que la investigación educativa tiene ahora un importante papel y un eminente compromiso social, relacionado éste con la propuesta de soluciones sustentadas científicamente, que den respuesta a las problemáticas emergentes; y se convierte entonces en un elemento central de la profesionalización académica, como condición esencial para el cambio educativo. 
La producción de conocimiento a través de la investigación educativa no se concreta a una actividad metodológica, sino que es una actividad creativa, que requiere del razonamiento lógico, de la toma de decisiones, de desarrollo de estrategias para solucionar problemas y del compromiso ético con las realidades estudiantes, entre otras cosas.

Para abordar estos escenarios educativos se requiere del desarrollo de competencias investigativas en los alumnos de posgrado, que a decir de Álvarez, Orozco y Gutiérrez (2011), propician un aprendizaje significativo de conocimientos y habilidades, que les permite contar con las herramientas necesarias para diseñar y ejecutar proyectos de investigación, propiciando la utilización de sus resultados en la retroalimentación y transformación de su práctica profesional y su conducta social.

El tema del desarrollo de competencias investigativas en los estudiantes, es abordado por Sayous (2007) quien resalta la importancia de formar profesionistas comprometidos, con el propósito de generar procesos dinámicos y continuos de aprendizaje para producir y transmitir conocimientos y tecnologías, y establecer valores y actitudes que les permitan generar ideas que confluyan en cambios e innovaciones congruentes con el momento histórico.

Por su parte, Figueroa (s.f.) manifiesta que desarrollar competencias investigativas en Educación, implica vincular la teoría con la praxis investigativa, proporcionando a los alumnos herramientas cognoscitivas, técnicas, metodológicas y procedimentales que conduzcan a la observación, compresión, análisis y reflexión crítica de la realidad.

A partir de esta situación, se plantean como objetivos que guiarán esta investigación:

a) Determinar el nivel de domino de las competencias investigativas que desarrollan los alumnos de dos posgrados en educación de una institución particular;

b) Establecer si la variable Aplicación marca diferencia significativa a lo largo de los programas. 


\section{Revisión de literatura}

En relación al término competencia, Tobón (2005) expresa: "En el lenguaje cotidiano las competencias se emplean con varias significaciones y esto hace que sea un término con sentidos intercambiables y adaptables a las diferentes situaciones y contextos sociales, educativos, laborales e intenciones comunicativas de los hablantes..." (p. 43).

De forma genérica, la investigación es concebida como un proceso reflexivo, ordenado, crítico y creativo a partir del cual se analiza la producción, la transferencia y la utilización del conocimiento y particularmente en el contexto educativo, busca que la comunidad académica se interese en descubrir, manipular, explicar, comprender y categorizar el mundo, planteando hipótesis en los diferentes campos del conocimiento (Pineda, 2007).

Castellanos (2005), especifica que la competencia para la investigación educativa es la que permite a los actores involucrados en el proceso educativo, la construcción de conocimiento científico relativo al proceso pedagógico, a fin de solucionar eficientemente los problemas que se presentan en la comunidad educativa escolar.

Las competencias investigativas en educación, son aquellas que se requieren para que los educadores interpreten, argumenten y propongan a partir de la experiencia pedagógica acorde a su contexto de aula y escuela (Muñoz, 2001).

Borjas (2000) opina que la formación de competencias investigativas en educación, está relacionada con la capacidad crítica que debe tener el docente, para lograr un desempeño académico eficiente, de manera que convierta su práctica pedagógica en objeto de estudio a través de considerar a la escuela como un espacio de intercambio y confrontación de ideas.

Por su parte Ramírez y González (2008) manifiestan que para desarrollar la competencia investigativa y consolidar el trabajo científico de los estudiantes en la formación profesional pedagógica, hay que atender una serie de principios, tales como la continuidad, sistematicidad, utilidad y proyección pedagógica del trabajo científico, así como generar la vinculación entre la actividad científica estudiantil y el trabajo de investigación de los docentes. 
En la revisión de literatura se encuentran diversos trabajos, se recuperan algunos que están insertos en áreas del conocimiento específico, que han abordado este tipo de investigaciones:

En Colombia, Moreno Mosquera (2012) trabaja las competencias investigativas en los estudiantes de derecho de la Institución Universitaria de Envigado; Correa Bautista (2009) mide las competencias investigativas en docentes de fisiología vinculados a las Facultades de Medicina en Bogotá; y Castrillon Agudelo (2012) trabaja con competencias investigativas del docente universitario en enfermería en la Universidad de Antioquia.

Rojas, Vázquez y Roque (2012) reportan un trabajo realizado con egresados de la Universidad de Ciencias Médicas "Dr. Jose Assef Yara" Ciego de Ávila, en Cuba, acerca de las competencias investigativas en la construcción del talento humano dentro de las Ciencias Médicas.

En México, Jaik Dipp (2013) reporta un trabajo sobre competencias metodológicas de investigación de alumnos de posgrado en administración, derecho, psicología y trabajo social de la Universidad de Durango; Salcido, Torre y Piñón (2010), indagaron sobre el grado de formación en competencias de investigación en alumnos de posgrado en el área administrativa de la Universidad Autónoma de Chihuahua; Armenteros, Guerrero, Medina, Molina y Villanueva (2012, en Tobón y Jaik Dipp) realizan un diagnóstico para evaluar las competencias investigativas en alumnos de las carreras de Contaduría y Administración de la Universidad Autónoma de Coahuila; Jaik Dipp (2013) analiza las competencias investigativas en alumnos de los posgrados en gestión ambiental, biomedicina y biotecnología del CIIDIR IPN Durango.

Concretamente en el área educativa se tienen algunos reportes de las competencias investigativas:

En Venezuela, Aular de Durán, Marcano y Moronta (2009) trabajan las competencias investigativas de los docentes de educación básica adscritos a las Escuelas Básicas Nacionales del Municipio Escolar № 5 de la Parroquia Cecilio Acosta; Castillo (2008) trabaja las competencias investigativas desarrolladas por docentes de la Maestría en Ciencias de la Educación mención Enseñanza de la Matemática de la Universidad Nacional Experimental de Guayana; así mismo, Cadenas, Rojas y Reyes 
(s/f) reportan las competencias investigativas desarrolladas por alumnos de un Programa de Maestría en Educación Superior de la Universidad Pedagógica Experimental de Venezuela (UPEL-IPB).

González González y Álvarez Mesa (2012) reportan un trabajo realizado con docentes de la Universidad "Camilos Cienfuegos" Matanzas, Cuba, denominado: La formación de competencias profesionales del profesor: las competencias investigativas.

Jaik Dipp (2013), en México, reporta un estudio longitudinal en el que aborda las competencias investigativas de los estudiantes de un posgrado en educación de la Universidad Pedagógica de Durango; Perales Ponce, Macías Morales M. y Macías Morales, A. (2011, en Jaik Dipp y Barraza Macías), comparten el documento Competencias del investigador educativo en la producción del conocimiento, desde su cultura experiencial.

Otros hallazgos importantes en la literatura corresponden al reporte de diversas estrategias utilizadas para trabajar las competencias investigativas: Escobar Yéndez, Plasencia Asorey y Almaguer Delgado (2012) trabajan en Cuba una Estrategia pedagógica para el desarrollo de la competencia investigativa en Medicina General Integral; en México, Carrillo Flores (2012) analiza el desarrollo de competencias investigativas con apoyo del video en la Universidad Autónoma de Aguascalientes; Valdés Cuervo y Rodríguez López (2011, en Jaik Dipp y Barraza Macías) reportan estrategias de enseñanza utilizadas por docentes de educación media superior pertenecientes a los Colegios de Bachilleres de Obregón, Sonora; Gutiérrez Leyton y Torres Herrera (2012) reportan un trabajo realizado en una Universidad Privada del Noreste de México, denominado "La formación de competencias de investigación a través de los métodos cualitativos en el análisis de la narrativa audiovisual"; y finalmente, Jaik Dipp (2013) propone un acercamiento a las estrategias para formar competencias investigativas en estudiantes del nivel superior, en la ciudad de Durango.

Como se puede observar, cada vez más investigadores incursionan en el ámbito de las competencias investigativas, con el propósito general de profundizar en la comprensión de las mismas, y más recientemente, el área educativa, con la propuesta de estrategias para desarrollarlas, considerando la importancia de hacer conciencia del actuar del investigador ante una realidad dinámica que muestra a la educación como 
"motor de desarrollo" o "punta de lanza" que exige la generación de procesos de investigación que incidan de manera directa en la mejora educativa, trasformando los sujetos receptores en sujetos generadores de conocimiento, en un afán de convertir la actividad científica en la ruta estratégica para promover los cambios educativos y sociales que requiere el país.

Particularmente se hace hincapié en algunos trabajos, dada su relación con el presente estudio.

Abella Mahecha y Pachón Soler (2011) en Colombia, realizan un estudio comparativo para conocer los avances y fortalezas en la formación de estudiantes en competencias investigativas en dos programas de Maestría en educación, uno de la Universidad Javeriana y otro de la Universidad Sergio Arboleda, y así mismo, para detectar los problemas o deficiencias que estos programas tienen, a fin de hacer la recomendaciones pertinentes; a partir de los resultados de la investigación, definieron una serie de categorías con la pretensión de explicar el problema de la formación investigativa y establecer los vínculos para identificar fortalezas, debilidades, similitudes y diferencias del actual trabajo formativo y desarrollo investigativo en Educación Superior.

Aular de Durán, et al. (2009) investigan en la Universidad Pedagógica Experimental Libertador, de Venezuela, las competencias investigativas que posee el docente de educación básica a través de una metodología cuantitativa. Los resultados informan que los directivos y docentes de las escuelas básicas presentan limitaciones para el cumplimiento de su función social y pedagógica porque carecen de las competencias necesarias para abordar la realidad educativa y resolver problemas. Particularmente mencionan que los encuestados (50\%) tienen muy bajo nivel de competencias en lo relativo a la aplicación de programas estadísticos como herramientas básicas que el docente, como investigador, debe manejar, además tienen escasas competencias para producir informes escritos con interpretaciones, poca capacidad de síntesis y de análisis.

Jaik Dipp y Ortega Rocha (2011, en Jaik Dipp y Barraza Macías) determinaron el nivel de dominio de las competencias investigativas que tienen los alumnos de posgrado de la ciudad de Durango. Aplicaron un cuestionario de autopercepción 
(Ortega Rocha \& Jaik Dipp, 2010) a 200 estudiantes de posgrado; entre los resultados se destaca: un nivel de dominio medio (68\%) de las competencias investigativas; el nivel de dominio más alto se ubicó en la búsqueda de información en Internet (80\%) y el más bajo en la traducción del inglés (54\%).

Correa Bautista (2009) realizó una investigación con el propósito de determinar el nivel de desarrollo de competencias investigativas de docentes de las Facultades de Medicina en Bogotá. Entre sus resultados destaca que las competencias relacionadas con la capacidad de resolver problemas tiene un nivel de desarrollo medio; dentro de éstas los indicadores de competencias con más baja calificación son: la capacidad de interpretar datos válidos y confiables y el conocimiento apropiado para aproximarse a un problema de investigación, con un nivel medio; con un nivel calificadas como bajas, se encuentra el manejo de las fases de investigación de tipo explicativo, descriptivo y exploratorio. Las competencias relacionadas con el diseño experimental, también presenta un nivel de desarrollo medio, destacando, el conocimiento que tienen los docentes sobre el método científico y planteamiento de ideas e hipótesis, con un nivel alto; y con un nivel medio, todo lo relacionado con la selección apropiada de instrumentos para la adquisición de datos y la de capacidad de llegar a conclusiones a partir de los datos. La competencia referida al análisis de datos, también presenta un desarrollo medio, sobre todo en lo relacionado al conocimiento y capacidad para seleccionar el análisis estadístico apropiado y la capacidad para interpretar adecuadamente los resultados obtenidos. En general, la percepción de los docentes sobre el nivel de desarrollo de las competencias investigativas es de un nivel de desarrollo medio $(3,733 \pm 0,8)$.

Jaik Dipp (2013) reporta un estudio longitudinal que realizó con el objetivo de determinar a través de la autopercepción, el nivel de competencias investigativas de alumnos inscritos en tres programas de posgrado en el IPN CIIDIR Durango, a lo largo de un año. Los resultados obtenidos indican: que el nivel de dominio de competencias en promedio de las tres aplicaciones es de $73 \%$ (nivel medio); que los estudiantes se perciben con mayor dominio en lo relativo al manejo de la computadora, y con menor dominio en la construcción de hipótesis y la selección de la muestra. No se advirtió diferencia significativa en el dominio de las competencias entre las tres aplicaciones a lo 
largo de un año, se destaca que el $46 \%$ de los alumnos del Programa Doctoral se ubican entre los que se perciben con el menor dominio de la competencia investigativa, y en la variable Posgrado también se presentan diferencias significativas en todas las dimensiones, favorables para la Maestría en Biomedicina.

Con el objetivo de determinar las competencias investigativas desarrolladas por alumnos de un Programa de Maestría en Educación Superior de la Universidad Pedagógica Experimental de Venezuela (UPEL-IPB), Cadenas, Rojas y Reyes (s/f) realizaron una investigación en la que destacan como resultados relevantes que el promedio del nivel de competencia para la categoría de competente se ubica en $39 \%$ y para la de bastante competente en $36 \%$ y un $28 \%$ manifiesta tener un bajo nivel de competencia para publicar. Concluyen que en general, las dificultades en los programas de Maestría en Educación, obedecen a un inadecuado desarrollo de las competencias investigativas a través del proceso formativo, mencionando entre otras causas: la orientación de los cursos de metodología que no le proporciona las competencias investigativas; la carencia de investigadores activos; la presencia de tutores no investigadores; y la poca disponibilidad de tiempo del alumno para la elaboración de la tesis de grado.

Padrón (2008) realiza un estudio en que determina que las dificultades que se presentan en la investigación educativa, son relativos a la falta de competencias en la producción académica escrita de los alumnos, a una escasa asesoría por parte del tutor y a una deficiente conducción institucional que inhibe la formación de competencias al propiciar que la investigación sea absorbida por el curriculum.

Con el propósito de determinar las competencias investigativas de los alumnos de la Maestría en Educación: Campo práctica educativa de la Universidad Pedagógica de Durango y su relación con el plan de estudio, Jaik Dipp (2013) realiza una investigación en la que destaca como resultados relevantes: que los alumnos se perciben en promedio con un nivel de dominio medio $(57 \%)$ de las competencias investigativas, que fue de menos $(47 \%)$ a más $(69 \%)$ a lo largo de tres aplicaciones; que el nivel de dominio más bajo es manejar medidas de tendencia central y calcular correlaciones de datos (39\%), ambos pertenecientes a la dimensión de Resultados; y que se presentan diferencias significativas entre las diferentes aplicaciones efectuadas 
en los tres últimos semestres, todas ellas favorables a la tercera aplicación, es decir, en el paso por las diferentes materias de la línea metodológica incluidas en el plan de estudios, los estudiantes van adquiriendo mayor dominio de las competencias investigativas.

Con la revisión efectuada queda de manifiesto que hay un claro interés de las Instituciones por conocer y evaluar de manera cuantitativa y cualitativa las competencias investigativas tanto de los alumnos como de los docentes.

\section{Estrategia metodológica}

La presente investigación tiene un enfoque cuantitativo, se caracteriza como no experimental, descriptiva y longitudinal (Hernández, Fernández y Baptista, 2006).

La información se recogió a través de la Escala de evaluación de competencias investigativas (EECI) (Ortega Rocha y Jaik Dipp, 2010), que registra la autopercepción de los estudiantes, y que presenta un nivel de confiabilidad de .98 determinado mediante el Coeficiente de Alfa de Cronbach.

La EECl está compuesta por 61 indicadores empíricos todos ellos con un formato de respuesta de escalamiento tipo Lickert que están distribuidos en cinco dimensiones: a) Problema; b) Marco teórico; c) Marco metodológico; d) Resultados; y e) C. Genéricas.

La población estudiada se conformó por dos grupos, uno de Maestría en Educación y otro de Doctorado en Ciencias de la Educación, los dos pertenecientes a una institución particular de la ciudad de Durango. Los participantes del Programa de Maestría cursaron dos materias incluidas en el eje investigativo: Fundamentos de la investigación educativa y Metodología y práctica de la investigación educativa. Los alumnos participantes del Programa de Doctorado cursaron un módulo de metodología de la investigación y participaron en dos seminarios de investigación.

Se efectuaron tres mediciones a lo largo de un año: al inicio de los programas, al concluir la primera y segunda materia del eje investigativo en el caso de maestría, y al término del segundo seminario de investigación en el caso del doctorado. 
Se recuperaron en total 45 instrumentos contestados por los alumnos de maestría y 42 instrumentos contestados por los alumnos de doctorado, 87 en total, se eliminaron aquellos que tenían sólo una o dos mediciones durante el período de estudio.

La distribución según los datos sociodemográficos capturados fue la siguiente: el $55 \%$ pertenecen al género femenino y el $45 \%$ al masculino; en cuanto al rango de edad, el $45 \%$ tienen entre 20 y 29 años, el $31 \%$ entre 40 y 49 , el $21 \%$ están entre 30 y 39 años y el $3 \%$ tiene 50 o más años de edad; el $52 \%$ son alumnos del programa de doctorado y el $48 \%$ del Programa de Maestría.

La variable Aplicación se analizó a través del estadístico ANOVA de un sola vía, agregando la prueba de Duncan.

La regla de decisión para establecer una diferencia significativa de la variable en el nivel de competencia investigativa fue de $p<.05$. Los resultados se analizaron con el programa estadístico PASW Statistics 18.

\section{Resultados}

El nivel de dominio de las competencias metodológicas de investigación, en cada una de las dimensiones que conforman el instrumento (EECI), se muestra en la Tabla 1.

Tabla 1.

Nivel de dominio de las competencias investigativas por dimensión en los alumnos de posgrado

\begin{tabular}{l|ccccc|c}
\hline \multirow{2}{*}{ Programa/Dimensión } & \multicolumn{2}{|c|}{ Maestría } & \multicolumn{2}{c|}{ Doctorado } & Posgrado \\
\cline { 2 - 6 } & Media & S & Media & S & Media \\
\hline Problema & 2.587 & .586 & 2.747 & .489 & 2.667 \\
Marco teórico & 2.365 & .707 & 2.668 & .538 & 2.516 \\
Marco Metodológico & 2.315 & .701 & 2.670 & .561 & 2.492 \\
Resultados & 2.556 & .696 & 2.744 & .809 & 2.650 \\
C. Genéricas & 2.830 & .476 & 2.917 & .561 & 2.873 \\
\hline Totales & 2.530 & .632 & 2.749 & .592 & 2.639
\end{tabular}


El nivel de dominio, de las competencias investigativas, que reportan los alumnos de posgrado en general es de 2.64 que interpretado con los siguientes valores asignados (media entre 0 y 1 = nulo; entre 1.1 y 2 = bajo; entre 2.1 y $3=$ medio; y entre 3.1 y 4 = alto), permite afirmar que los alumnos encuestados se perciben en general con un nivel medio de dominio.

Se aprecia una diferencia entre los niveles de dominio de competencias investigativas que presentan los alumnos en cada programa, siempre mayores para el Doctorado. Se manifiestan para los dos programas, niveles más bajos de dominio en las Dimensiones Marco teórico y Marco metodológico, y más altos para la Dimensión Competencias genéricas.

Algunos estudios coinciden con estos resultados obtenidos: entre ellos el estudio de Correa Bautista (2009) quien reporta que la percepción de los docentes de las Facultades de Medicina en Bogotá, Colombia, sobre el nivel de desarrollo de las competencias investigativas, es de un nivel medio. Jaik Dipp (2013) reporta que el nivel de dominio de competencias investigativa de alumnos inscritos en tres programas de posgrado en el IPN CIIDIR Durango, es de nivel medio (2.92), así mismo reporta que la dimensión con menor dominio es la de marco metodológico (2.76). Cadenas, et al. (s/f), reportan que un 39\% de los alumnos de un Programa de Maestría en Educación Superior, en Venezuela se ubica en la categoría de "competente" en la competencia investigativa. Jaik Dipp (2013) en su investigación con alumnos del Maestría en Educación de la Universidad Pedagógica de Durango, determina que los alumnos se perciben con un nivel de dominio medio (2.28) de competencias investigativas, su mayor dominio de competencias se ubica en la Dimensión Competencias genéricas (2.48) y el menor en la Dimensión Resultados (1.96) que presenta un dominio bajo.

A fin de responder al segundo objetivo de investigación referido a establecer si la variable Aplicación marca diferencia significativa a lo largo de los Programas de posgrado, se presentan en la tabla 2 las medias calculadas, por cada una de las dimensiones que conforman la EECl para cada aplicación en los dos programas de posgrado. 
Tabla 2

Medias por aplicación

\begin{tabular}{ll|r|r|r|r}
\hline \multirow{2}{*}{ Dimensión } & \multirow{2}{*}{ Aplicación } & \multicolumn{2}{|c|}{ Maestría } & \multicolumn{2}{c}{ Doctorado } \\
\cline { 3 - 6 } & Media & \multicolumn{1}{c}{ S } & \multicolumn{1}{c}{ Media } & \multicolumn{1}{c}{ s } \\
\hline \multirow{4}{*}{ Problema } & 1a aplicación & 2.379 & .573 & 2.441 & .432 \\
& 2a aplicación & 2.385 & .454 & 2.891 & .450 \\
& 3a aplicación & 2.995 & .529 & 2.908 & .462 \\
\hline \multirow{4}{*}{ Marco teórico } & 1a aplicación & 2.057 & .661 & 2.366 & .487 \\
& 2a aplicación & 2.207 & .537 & 2.800 & .511 \\
& 3a aplicación & 2.832 & .698 & 2.840 & .512 \\
\hline \multirow{3}{*}{ Marco Metodológico } & 1a aplicación & 2.011 & .536 & 2.307 & .392 \\
& 2a aplicación & 2.148 & .614 & 2.830 & .559 \\
\multirow{3}{*}{ Resultados } & 3a aplicación & 2.787 & .718 & 2.871 & .557 \\
\hline \multirow{3}{*}{ C. Genéricas } & 1a aplicación & 2.383 & .542 & 2.558 & .830 \\
& 2a aplicación & 2.455 & .690 & 2.825 & .816 \\
& 3a aplicación & 2.830 & .797 & 2.850 & .803 \\
\hline & 1a aplicación & 2.510 & .378 & 2.600 & .580 \\
& 2a aplicación & 2.760 & .369 & 3.066 & .502 \\
& 3a aplicación & 3.219 & .398 & 3.085 & .489 \\
\hline
\end{tabular}

Se determinó la diferencia significativa entre aplicaciones para cada dimensión, en los dos programas participantes en el estudio (tabla 3).

Tabla 3

Diferencia significativa en aplicación por Dimensión/ Programa

\begin{tabular}{lrrrr}
\hline \multirow{2}{*}{ Dimensión/Programa } & \multicolumn{2}{c}{ Maestría } & \multicolumn{2}{c}{ Doctorado } \\
\cline { 2 - 5 } & F & Sig. & F & Sig. \\
\hline Problema & 6.46 & .004 & 5.225 & .009 \\
Marco teórico & 5.84 & .006 & 4.069 & .024 \\
Marco Metodológico & 6.09 & .005 & 5.725 & .006 \\
Resultados & 1.71 & .193 & .587 & .560 \\
C. Genéricas & 12.40 & .000 & 4.104 & .024
\end{tabular}

Se observa que en todas las dimensiones hay diferencia significativa entre las aplicaciones, salvo en la dimensión Resultados, en la tabla 4 se presentan los resultados obtenidos a través de la prueba de Duncan. 
Tabla 4

Prueba de Duncan en aplicación por Dimensión

\begin{tabular}{|c|c|c|c|c|c|}
\hline \multicolumn{3}{|c|}{$\begin{array}{l}\text { Maestría } \\
\text { Problema }\end{array}$} & \multicolumn{3}{|c|}{$\begin{array}{l}\text { Doctorado } \\
\text { Problema }\end{array}$} \\
\hline \multirow[t]{2}{*}{ Aplicación } & \multicolumn{2}{|c|}{ Subconjunto para alfa $=.05$} & \multirow[t]{2}{*}{ Aplicación } & \multicolumn{2}{|c|}{ Subconjunto para alfa $=.05$} \\
\hline & 1 & 2 & & 1 & 2 \\
\hline $\begin{array}{l}\text { 1a aplicación } \\
\text { 2a aplicación } \\
\text { 3a aplicación }\end{array}$ & $\begin{array}{l}2.379 \\
2.385\end{array}$ & 2.995 & $\begin{array}{l}\text { 1a aplicación } \\
\text { 2a aplicación } \\
\text { 3a aplicación }\end{array}$ & 2.441 & $\begin{array}{l}2.891 \\
2.908\end{array}$ \\
\hline \multicolumn{3}{|c|}{ Marco teórico } & \multicolumn{3}{|c|}{ Marco Teórico } \\
\hline \multirow[t]{2}{*}{ Aplicación } & \multicolumn{2}{|c|}{ Subconjunto para alfa $=.05$} & \multirow[t]{2}{*}{ Aplicación } & \multicolumn{2}{|c|}{ Subconjunto para alfa $=.05$} \\
\hline & 1 & 2 & & 1 & 2 \\
\hline $\begin{array}{l}\text { 1a aplicación } \\
\text { 2a aplicación } \\
\text { 3a aplicación }\end{array}$ & $\begin{array}{l}2.057 \\
2.207\end{array}$ & 2.832 & $\begin{array}{l}\text { 1a aplicación } \\
\text { 2a aplicación } \\
\text { 3a aplicación }\end{array}$ & 2.366 & $\begin{array}{l}2.800 \\
2.840\end{array}$ \\
\hline \multicolumn{3}{|c|}{ Marco Metodológico } & \multicolumn{3}{|c|}{ Marco Metodológico } \\
\hline \multirow[t]{2}{*}{ Aplicación } & \multicolumn{2}{|c|}{ Subconjunto para alfa $=.05$} & \multirow[t]{2}{*}{ Aplicación } & \multicolumn{2}{|c|}{ Subconjunto para alfa $=.05$} \\
\hline & 1 & 2 & & 1 & 2 \\
\hline $\begin{array}{l}\text { 1a aplicación } \\
\text { 2a aplicación } \\
\text { 3a aplicación }\end{array}$ & $\begin{array}{l}2.011 \\
2.148\end{array}$ & 2.787 & $\begin{array}{l}\text { 1a aplicación } \\
\text { 2a aplicación } \\
\text { 3a aplicación }\end{array}$ & 2.307 & $\begin{array}{l}2.830 \\
2.871\end{array}$ \\
\hline \multicolumn{3}{|c|}{ C. Genéricas } & \multicolumn{3}{|c|}{ C. Genéricas } \\
\hline \multirow[t]{2}{*}{ Aplicación } & \multicolumn{2}{|c|}{ Subconjunto para alfa $=.05$} & \multirow[t]{2}{*}{ Aplicación } & \multicolumn{2}{|c|}{ Subconjunto para alfa $=.05$} \\
\hline & 1 & 2 & & 1 & 2 \\
\hline $\begin{array}{l}\text { 1a aplicación } \\
\text { 2a aplicación } \\
\text { 3a aplicación }\end{array}$ & $\begin{array}{l}2.510 \\
2.760\end{array}$ & 3.219 & $\begin{array}{l}\text { 1a aplicación } \\
\text { 2a aplicación } \\
\text { 3a aplicación }\end{array}$ & 2.600 & $\begin{array}{l}3.066 \\
3.085\end{array}$ \\
\hline
\end{tabular}

Se observa que en el caso del Programa en Maestría en Educación, todas las diferencias son favorables para la tercera aplicación, es decir entre su ingreso al programa en que se aplicó por primera vez la EECl, y cursar la primer materia del eje investigativo, no hay diferencia en cuanto al desarrollo de las competencias investigativas de los alumnos, puede deberse a que la primer materia denominada fundamentos de la investigación educativa, son justamente eso, los fundamentos teóricos que sustentan la metodología con autores como Comte, Russell, Poper, Habermas, etc., por lo que resulta completamente teórica.

En cuanto al Programa de Doctorado en Ciencias de la Educación, se observa que todas las diferencias son favorables para la segunda y tercera aplicación, es decir entre su ingreso al programa en que se aplicó por primera vez la $E E C l$, y cursar la materia de Metodología de Investigación y participar en dos Seminarios de 
Investigación hay diferencia significativa en las dimensiones, salvo como ya se mencionó en la dimensión Resultados.

En relación a otros estudios, se observa que los datos coinciden con los reportados por estudiantes de la Maestría en Educación de la Universidad Pedagógica de Durango (Jaik Dipp, 2013) en los que su nivel de dominio de las competencias metodológicas de investigación, fue de menos a más a lo largo de tres aplicaciones, es decir, al igual que en el presente estudio, en el paso por las diferentes materias de la línea metodológica incluidas en el plan de estudios, los estudiantes van adquiriendo cierto domino de las competencias investigativas; no así en el caso del estudio realizado con programas de posgrado del IPN (Jaik Dipp, 2013) en el que no se advirtió diferencia significativa en el dominio de las competencias investigativas, entre las tres aplicaciones a lo largo de un año de estudio.

En este primer acercamiento a las diferencias entre los Programas de posgrado, se pueden observar algunas similitudes entre ellos: en todas las aplicaciones los alumnos tienen un nivel medio de competencias, salvo en la tercera aplicación para la Dimensión C. Genéricas, en las que alcanzan un nivel alto de dominio; el nivel de desarrollo va avanzando conforme transcurren los programas en todas las dimensiones; aún quedan por cursar módulos/seminarios que apoyan el desarrollo de esta competencia; las sesiones de concentración no favorecen un desarrollo significativo en la Dimensión Resultados, que incluye competencias como la construcción de gráficas, tablas y cuadros de doble entrada, el manejo e interpretación de datos estadísticos, y la identificación de resultados relevantes de la investigación. Se puede inferir que de alguna manera, las materias del eje investigativo incluidos en los programas, así como los docentes involucrados en la impartición de los contenidos, están logrando a través del tiempo, aprendizajes significativos que permiten un mayor acercamiento a las competencias investigativas. Se puede observar también que el perfil de ingreso (con relación a competencias investigativas) de los alumnos de doctorado es mejor, producto seguramente de los aprendizajes obtenidos en la realización de una tesis de maestría.

Una vez detectado que hay diferencia en las dimensiones, se procedió a un análisis más a fondo a fin de detectar en que ítems específicamente se encuentran las diferencias. Los resultados de estos análisis se muestran de forma separada por 
dimensión y por programa. Se presentan en las tablas 5, 6, 7 y 8 las diferencias encontradas en los ítems de la dimensión Problema, a través de un ANOVA, adicionando la prueba de Duncan.

Tabla 5

Significancia por ítem/Dimensión Problema/Maestría

\begin{tabular}{lcc}
\hline İems Dimensión Problema (Maestría) & F & Sig. \\
\hline Percibir situaciones deficientes en el entorno profesional susceptibles de ser investigadas & 3.61 & .037 \\
Identificar los elementos del contexto de un problema de investigación & 7.29 & .002 \\
Relacionar entre sí los factores que se encuentran en el contexto de un problema & 4.21 & .022 \\
Identificar qué es lo que se va a investigar & 5.03 & .011 \\
Describir de manera concreta el problema de investigación & 5.07 & .011 \\
Definir los objetivos específicos como parte del general y desde términos más & 5.66 & .007 \\
operacionales & & \\
Expresar por qué se desarrolla el tema de estudio & 3.64 & .035 \\
Poner límites espaciales a la investigación & 3.48 & .041 \\
Poner límites teóricos a la investigación & 6.60 & .003 \\
ldentificar las limitaciones externas a la investigación & 4.72 .015 \\
\hline
\end{tabular}

Tabla 6

Prueba de Duncan/Dimensión Problema/Maestría

\begin{tabular}{|c|c|c|c|c|c|}
\hline \multicolumn{3}{|c|}{$\begin{array}{l}\text { Percibir situaciones deficientes en el entorno } \\
\text { profesional susceptibles de ser investigadas }\end{array}$} & \multicolumn{3}{|c|}{$\begin{array}{c}\text { Identificar los elementos del contexto de un } \\
\text { problema de investigación }\end{array}$} \\
\hline \multirow[t]{2}{*}{ Aplicación } & \multicolumn{2}{|c|}{ Subconjunto para alfa $=.05$} & \multirow[t]{2}{*}{ Aplicación } & \multicolumn{2}{|c|}{ Subconjunto para alfa $=.05$} \\
\hline & 1 & 2 & & 1 & 2 \\
\hline $\begin{array}{l}\text { 1a aplicación } \\
\text { 2a aplicación } \\
\text { 3a aplicación }\end{array}$ & $\begin{array}{l}2.50 \\
2.57\end{array}$ & 3.08 & $\begin{array}{l}\text { 1a aplicación } \\
\text { 2a aplicación } \\
\text { 3a aplicación }\end{array}$ & 2.21 & $\begin{array}{l}2.79 \\
3.14\end{array}$ \\
\hline \multicolumn{3}{|c|}{$\begin{array}{l}\text { Relacionar entre sí los factores que se } \\
\text { encuentran en el contexto de un problema }\end{array}$} & \multicolumn{3}{|c|}{ Identificar qué es lo que se va a investigar } \\
\hline \multirow[t]{2}{*}{ Aplicación } & \multicolumn{2}{|c|}{ Subconjunto para alfa $=.05$} & \multirow[t]{2}{*}{ Aplicación } & \multicolumn{2}{|c|}{ Subconjunto para alfa $=.05$} \\
\hline & 1 & 2 & & 1 & 2 \\
\hline $\begin{array}{l}\text { 1a aplicación } \\
\text { 2a aplicación } \\
3 a \text { aplicación }\end{array}$ & $\begin{array}{l}2.29 \\
2.36\end{array}$ & 3.00 & $\begin{array}{l}\text { 1a aplicación } \\
\text { 2a aplicación } \\
\text { 3a aplicación }\end{array}$ & $\begin{array}{l}2.71 \\
2.71\end{array}$ & 3.36 \\
\hline \multicolumn{3}{|c|}{$\begin{array}{c}\text { Describir de manera concreta el problema de } \\
\text { investigación }\end{array}$} & \multicolumn{3}{|c|}{$\begin{array}{c}\text { Identificar en el problema las variables a } \\
\text { medir }\end{array}$} \\
\hline \multirow[t]{2}{*}{ Aplicación } & \multicolumn{2}{|c|}{ Subconjunto para alfa $=.05$} & \multirow[t]{2}{*}{ Aplicación } & \multicolumn{2}{|c|}{ Subconjunto para alfa $=.05$} \\
\hline & 1 & 2 & & 1 & 2 \\
\hline $\begin{array}{l}\text { 1a aplicación } \\
\text { 2a aplicación } \\
\text { 3a aplicación }\end{array}$ & $\begin{array}{l}2.36 \\
2.36\end{array}$ & 3.14 & $\begin{array}{l}\text { 2a aplicación } \\
\text { 1a aplicación } \\
\text { 3a aplicación }\end{array}$ & $\begin{array}{l}2.29 \\
2.36\end{array}$ & $\begin{array}{l}2.36 \\
3.00\end{array}$ \\
\hline \multicolumn{3}{|c|}{$\begin{array}{l}\text { Establecer claramente en forma de pregunta } \\
\text { lo que se desea indagar }\end{array}$} & \multicolumn{3}{|c|}{$\begin{array}{l}\text { Definir los objetivos específicos como parte del } \\
\text { general y desde términos más operacionales }\end{array}$} \\
\hline \multirow[t]{2}{*}{ Aplicación } & Subconjunto & $\mathrm{fa}=.05$ & \multirow[t]{2}{*}{ Aplicación } & \multicolumn{2}{|c|}{ Subconjunto para alfa $=.05$} \\
\hline & 1 & 2 & & 1 & 2 \\
\hline $\begin{array}{l}\text { 2a aplicación } \\
\text { 1a aplicación } \\
\text { 3a aplicación }\end{array}$ & $\begin{array}{l}2.23 \\
2.43\end{array}$ & $\begin{array}{l}2.43 \\
2.92\end{array}$ & $\begin{array}{l}\text { 2a aplicación } \\
\text { 1a aplicación } \\
\text { 3a aplicación }\end{array}$ & $\begin{array}{l}2.00 \\
2.29\end{array}$ & 2.93 \\
\hline
\end{tabular}




\begin{tabular}{|c|c|c|c|c|c|}
\hline \multicolumn{3}{|c|}{$\begin{array}{c}\text { Expresar por qué se desarrolla el tema de } \\
\text { estudio }\end{array}$} & \multicolumn{3}{|c|}{$\begin{array}{c}\text { Expresar a quiénes se beneficia con la } \\
\text { investigación }\end{array}$} \\
\hline \multirow[t]{2}{*}{ Aplicación } & \multicolumn{2}{|c|}{ Subconjunto para alfa $=.05$} & \multirow[t]{2}{*}{ Aplicación } & \multicolumn{2}{|c|}{ Subconjunto para alfa $=.05$} \\
\hline & 1 & 2 & & 1 & 2 \\
\hline 1a aplicación & 2.36 & & 2a aplicación & 2.57 & \\
\hline 2a aplicación & 2.64 & 2.64 & 1a aplicación & 2.64 & 2.64 \\
\hline 3a aplicación & & 3.07 & 3a aplicación & & 3.07 \\
\hline \multicolumn{3}{|c|}{ Poner límites espaciales a la investigación } & \multicolumn{3}{|c|}{ Poner límites teóricos a la investigación } \\
\hline \multirow[t]{2}{*}{ Aplicación } & \multicolumn{2}{|c|}{ Subconjunto para alfa $=.05$} & \multirow[t]{2}{*}{ Aplicación } & \multicolumn{2}{|c|}{ Subconjunto para alfa $=.05$} \\
\hline & 1 & 2 & & 1 & 2 \\
\hline 1a aplicación & 2.21 & & 1a aplicación & 2.00 & \\
\hline 2a aplicación & 2.21 & & 2a aplicación & 2.14 & \\
\hline 3a aplicación & & 2.79 & 3a aplicación & & 2.86 \\
\hline \multicolumn{3}{|c|}{$\begin{array}{c}\text { Identificar las limitaciones externas a la } \\
\text { investigación }\end{array}$} & & & \\
\hline \multirow[t]{2}{*}{ Aplicación } & \multicolumn{2}{|c|}{ Subconjunto para alfa $=.05$} & & & \\
\hline & 1 & 2 & & & \\
\hline 1a aplicación & 2.21 & & & & \\
\hline $\begin{array}{l}\text { 2a aplicación } \\
\text { 3a aplicación }\end{array}$ & 2.21 & & & & \\
\hline & & 2.9 & & & \\
\hline
\end{tabular}

Tabla 7

Significancia por ítem/dimensión Problema/Doctorado

\begin{tabular}{lcc}
\hline İtems Dimensión Problema (Doctorado) & F & Sig. \\
\hline Identificar los elementos del contexto de un problema de investigación & 3.27 & .048 \\
Identificar qué es lo que se va a investigar & 4.00 & .026 \\
Poner límites teóricos a la investigación & 8.73 & .001 \\
Identificar las limitaciones externas a la investigación & 3.65 & .034 \\
\hline
\end{tabular}

Tabla 8

Prueba de Duncan/Dimensión Problema/Doctorado

\begin{tabular}{|c|c|c|c|c|c|}
\hline \multicolumn{3}{|c|}{$\begin{array}{l}\text { Identificar los elementos del contexto de un } \\
\text { problema de investigación }\end{array}$} & \multicolumn{3}{|c|}{ Identificar qué es lo que se va a investigar } \\
\hline \multirow[t]{2}{*}{ Aplicación } & \multicolumn{2}{|c|}{ Subconjunto para alfa $=.05$} & \multirow[t]{2}{*}{ Aplicación } & \multicolumn{2}{|c|}{ Subconjunto para alfa $=.05$} \\
\hline & \begin{tabular}{|c|}
1 \\
\end{tabular} & 2 & & 1 & 2 \\
\hline $\begin{array}{l}\text { 1a aplicación } \\
\text { 2a aplicación } \\
\text { 3a aplicación }\end{array}$ & 2.60 & $\begin{array}{l}3.07 \\
3.13\end{array}$ & $\begin{array}{l}\text { 1a aplicación } \\
\text { 2a aplicación } \\
\text { 3a aplicación }\end{array}$ & 2.33 & $\begin{array}{l}3.00 \\
3.00\end{array}$ \\
\hline \multicolumn{3}{|c|}{ Poner límites teóricos a la investigación } & \multicolumn{3}{|c|}{$\begin{array}{c}\text { Identificar las limitaciones externas a la } \\
\text { investigación }\end{array}$} \\
\hline \multirow[t]{2}{*}{ Aplicación } & \multicolumn{2}{|c|}{ Subconjunto para alfa $=.05$} & Aplicación & \multicolumn{2}{|c|}{ Subconjunto para alfa $=.05$} \\
\hline & 1 & 2 & & 1 & 2 \\
\hline $\begin{array}{l}\text { 1a aplicación } \\
\text { 2a aplicación } \\
\text { 3a aplicación }\end{array}$ & 1.87 & $\begin{array}{l}2.60 \\
2.60\end{array}$ & $\begin{array}{l}\text { 1a aplicación } \\
\text { 2a aplicación } \\
\text { 3a aplicación }\end{array}$ & 2.13 & $\begin{array}{l}2.67 \\
2.80\end{array}$ \\
\hline
\end{tabular}


Se observa en las tablas anteriores, que en el caso de Maestría son 10 los ítems de la Dimensión Problema en los que se presenta diferencia significativa, y en el doctorado sólo son cuatro en los que se logra detectar un mayor desarrollo de competencias con el paso del tiempo; cabe mencionar que estos cuatro ítems, se presentan en los dos programas. El comportamiento en cuanto a la diferencia por aplicación, es en su mayoría similar, en relación a la dimensión completa.

Se presentan en las tablas 9, 10, 11 y 12 las diferencias encontradas en los ítems de la Dimensión Marco Teórico.

Tabla 9

Significancia por ítem/Dimensión Marco teórico/Maestría

\begin{tabular}{lcc}
\hline Items Dimensión Marco teórico (Maestría) & F & Sig. \\
\hline Relacionar los antecedentes de investigación con el trabajo de investigación que se realiza & 5.96 & .006 \\
Definir conceptos involucrados en las variables de investigación & 5.57 & .007 \\
Describir los elementos teóricos que fundamentan el proceso de investigación & 4.89 & .013 \\
Identificar la relación entre hipótesis, preguntas de investigación y objetivos & 4.02 & .026 \\
Diferenciar entre hipótesis de trabajo, nula y alternativa & 4.46 & .018 \\
Operacionalizar las variables inmersas en el objetivo e hipótesis de investigación & 6.56 & .003 \\
\hline
\end{tabular}

Tabla 10

Prueba de Duncan/ Dimensión Marco teórico/Maestría

\begin{tabular}{|c|c|c|c|c|c|}
\hline \multicolumn{3}{|c|}{$\begin{array}{c}\text { Relacionar los antecedentes de } \\
\text { investigación con el trabajo de investigación } \\
\text { que se realiza }\end{array}$} & \multicolumn{3}{|c|}{$\begin{array}{l}\text { Definir conceptos involucrados en las } \\
\text { variables de investigación }\end{array}$} \\
\hline \multirow[t]{2}{*}{ Aplicación } & \multicolumn{2}{|c|}{ Subconjunto para alfa $=.05$} & \multirow[t]{2}{*}{ Aplicación } & \multicolumn{2}{|c|}{ Subconjunto para alfa $=.05$} \\
\hline & 1 & 2 & & 1 & 2 \\
\hline $\begin{array}{l}\text { 1a aplicación } \\
\text { 2a aplicación } \\
\text { 3a aplicación }\end{array}$ & $\begin{array}{l}2.43 \\
2.50\end{array}$ & 3.21 & $\begin{array}{l}\text { 1a aplicación } \\
\text { 2a aplicación } \\
\text { 3a aplicación }\end{array}$ & $\begin{array}{l}2.21 \\
2.29\end{array}$ & 3.07 \\
\hline \multicolumn{3}{|c|}{$\begin{array}{l}\text { Describir los elementos teóricos que } \\
\text { fundamentan el proceso de investigación }\end{array}$} & \multicolumn{3}{|c|}{$\begin{array}{c}\text { Identificar la relación entre hipótesis, } \\
\text { preguntas de investigación y objetivos. }\end{array}$} \\
\hline \multirow[t]{2}{*}{ Aplicación } & \multicolumn{2}{|c|}{ Subconjunto para alfa $=.05$} & \multirow[t]{2}{*}{ Aplicación } & \multicolumn{2}{|c|}{ Subconjunto para alfa $=.05$} \\
\hline & 1 & 2 & & 1 & 2 \\
\hline $\begin{array}{l}\text { 1a aplicación } \\
\text { 2a aplicación } \\
\text { 3a aplicación } \\
\end{array}$ & $\begin{array}{l}1.93 \\
2.43\end{array}$ & $\begin{array}{r}2.43 \\
2.86 \\
\end{array}$ & $\begin{array}{l}\text { 1a aplicación } \\
\text { 2a aplicación } \\
\text { 3a aplicación } \\
\end{array}$ & $\begin{array}{l}2.07 \\
2.21\end{array}$ & 2.92 \\
\hline \multicolumn{3}{|c|}{$\begin{array}{c}\text { Diferenciar entre hipótesis de trabajo, nula y } \\
\text { alternativa }\end{array}$} & \multicolumn{3}{|c|}{$\begin{array}{l}\text { Operacionanalizar las variables inmersas en } \\
\text { el objetivo e hipótesis de investigación }\end{array}$} \\
\hline \multirow[t]{2}{*}{ Aplicación } & \multicolumn{2}{|c|}{ Subconjunto para alfa $=.05$} & \multirow[t]{2}{*}{ Aplicación } & \multicolumn{2}{|c|}{ Subconjunto para alfa $=.05$} \\
\hline & 1 & 2 & & 1 & 2 \\
\hline $\begin{array}{l}\text { 1a aplicación } \\
\text { 2a aplicación } \\
\text { 3a aplicación }\end{array}$ & $\begin{array}{l}1.79 \\
1.79\end{array}$ & 2.64 & $\begin{array}{l}\text { 1a aplicación } \\
\text { 2a aplicación } \\
\text { 3a aplicación }\end{array}$ & $\begin{array}{l}1.50 \\
1.86\end{array}$ & 2.64 \\
\hline
\end{tabular}


Tabla 11

Significancia por ítem/Dimensión Marco teórico/Doctorado

\begin{tabular}{lcc}
\hline İtems Dimensión Marco teórico (Doctorado) & F & Sig. \\
\hline Relacionar los antecedentes de investigación con el trabajo de investigación que se realiza & 4.27 & .020 \\
Describir los elementos teóricos que fundamentan el proceso de investigación & 4.25 & .021
\end{tabular}

Tabla 12

Prueba de Duncan/ Dimensión Marco teórico/Doctorado

\begin{tabular}{|c|c|c|c|c|c|}
\hline \multicolumn{3}{|c|}{$\begin{array}{c}\text { Relacionar los antecedentes de } \\
\text { investigación con el trabajo de investigación } \\
\text { que se realiza }\end{array}$} & \multicolumn{3}{|c|}{$\begin{array}{l}\text { Describir los elementos teóricos que } \\
\text { fundamentan el proceso de investigación }\end{array}$} \\
\hline \multirow[t]{2}{*}{ Aplicación } & \multicolumn{2}{|c|}{ Subconjunto para alfa $=.05$} & \multirow[t]{2}{*}{ Aplicación } & \multicolumn{2}{|c|}{ Subconjunto para alfa $=.05$} \\
\hline & 1 & 2 & & 1 & 2 \\
\hline $\begin{array}{l}\text { 1a aplicación } \\
\text { 2a aplicación } \\
\text { 3a aplicación }\end{array}$ & 2.53 & $\begin{array}{l}3.13 \\
3.20\end{array}$ & $\begin{array}{l}\text { 1a aplicación } \\
\text { 2a aplicación } \\
\text { 3a aplicación }\end{array}$ & 2.33 & $\begin{array}{l}2.87 \\
2.93\end{array}$ \\
\hline
\end{tabular}

Se observa, al igual que en las tablas anteriores, que son más los ítems (6) en los que se detecta un mayor desarrollo de competencias con el paso del tiempo en el Programa de Maestría, que en el del Doctorado (2). Los dos ítems que se significan en el Doctorado, también se presentan en Maestría y su comportamiento en general también es similar al de la dimensión completa de Marco teórico, es decir, las diferencias se presentan en la $3^{\mathrm{a}}$ aplicación en el caso de Maestría y a partir de la $2^{\mathrm{a}}$ en el caso del doctorado. Se destaca el ítem relativo a "Relacionar los antecedentes de investigación con el trabajo de investigación que se realiza", que en los dos programas llega a alcanzar un nivel alto de competencia investigativa en la autopercepción de los estudiantes.

Se presentan en las tablas 13,14, 15 y 16 las diferencias encontradas en los ítems de la dimensión Marco Metodológico.

Tabla 13

Significancia por ítem/Dimensión Marco metodológico/Maestría

\begin{tabular}{lll}
\hline İtems Dimensión Marco metodológico (Maestría) & F & Sig. \\
\hline Saber cuándo hay manipulación de variables en el proceso de investigación & 4.56 & .017 \\
Elegir el tipo de investigación experimental & 3.06 & .049 \\
Elegir entre una investigación transversal y una longitudinal & 6.24 & .004 \\
Diferenciar lo que es una muestra probabilística y una no probabilística & 5.59 & .007 \\
Elegir el método de investigación & 5.84 & .006 \\
Elegir la técnica de investigación & 8.25 & .001 \\
Aplicar un cuestionario & 4.38 & .019 \\
\hline
\end{tabular}


Tabla 14

Prueba de Duncan/ Dimensión Marco metodológico/Maestría

\begin{tabular}{|c|c|c|c|c|c|}
\hline \multicolumn{3}{|c|}{$\begin{array}{c}\text { Saber cuándo hay manipulación de variables } \\
\text { en el proceso de investigación }\end{array}$} & \multicolumn{3}{|c|}{ Elegir el tipo de investigación experimental } \\
\hline \multirow[t]{2}{*}{ Aplicación } & \multicolumn{2}{|c|}{ Subconjunto para alfa $=.05$} & \multirow[t]{2}{*}{ Aplicación } & \multicolumn{2}{|c|}{ Subconjunto para alfa $=.05$} \\
\hline & 1 & 2 & & 1 & 2 \\
\hline 1a aplicación & 1.57 & & 1a aplicación & 2.00 & \\
\hline $\begin{array}{l}\text { 2a aplicación } \\
\text { 3a aplicación }\end{array}$ & 2.07 & $\begin{array}{l}2.07 \\
2.50\end{array}$ & $\begin{array}{l}\text { 2a aplicación } \\
\text { 3a aplicación }\end{array}$ & 2.29 & $\begin{array}{l}2.29 \\
2.71\end{array}$ \\
\hline \multicolumn{3}{|c|}{$\begin{array}{c}\text { Elegir entre una investigación transversal y } \\
\text { una longitudinal }\end{array}$} & \multicolumn{3}{|c|}{$\begin{array}{c}\text { Diferenciar lo que es una muestra } \\
\text { probabilística y una no probabilística }\end{array}$} \\
\hline \multirow[t]{2}{*}{ Aplicación } & \multicolumn{2}{|c|}{ Subconjunto para alfa $=.05$} & \multirow[t]{2}{*}{ Aplicación } & \multicolumn{2}{|c|}{ Subconjunto para alfa $=.05$} \\
\hline & 1 & 2 & & 1 & 2 \\
\hline 1a aplicación & 1.50 & & 1a aplicación & 1.86 & \\
\hline 2a aplicación & 1.86 & & 2a aplicación & 1.93 & \\
\hline 3a aplicación & & 2.71 & 3a aplicación & & 2.86 \\
\hline \multicolumn{3}{|c|}{ Elegir el método de investigación } & \multicolumn{3}{|c|}{ Elegir la técnica de investigación } \\
\hline \multirow[t]{2}{*}{ Aplicación } & \multicolumn{2}{|c|}{ Subconjunto para alfa $=.05$} & \multirow[t]{2}{*}{ Aplicación } & \multicolumn{2}{|c|}{ Subconjunto para alfa $=.05$} \\
\hline & 1 & 2 & & 1 & 2 \\
\hline 1a aplicación & 1.79 & & 1a aplicación & 1.86 & \\
\hline 2a aplicación & 2.14 & & 2a aplicación & 2.14 & \\
\hline 3a aplicación & & 2.86 & 3a aplicación & & 2.93 \\
\hline \multicolumn{3}{|c|}{ Aplicar un cuestionario } & & & \\
\hline \multirow[t]{2}{*}{ Aplicación } & \multicolumn{2}{|c|}{ Subconjunto para alfa $=.05$} & & & \\
\hline & 1 & 2 & & & \\
\hline 1a aplicación & 2.50 & & & & \\
\hline 2a aplicación & 2.57 & & & & \\
\hline 3a aplicación & & 3.21 & & & \\
\hline
\end{tabular}

Tabla 15

Significancia por ítem/Dimensión Marco metodológico/Doctorado

\begin{tabular}{lcc}
\hline İtems Dimensión Marco metodológico (Doctorado) & F & Sig. \\
\hline Caracterizar los tipos de investigación en cuanto a su alcance & 3.68 & .034 \\
Saber cuándo hay manipulación de variables en el proceso de investigación & 6.65 & .003 \\
Seleccionar una muestra no probabilística & 3.24 & .049 \\
Elegir el método de investigación & 6.56 & .003 \\
Elegir la técnica de investigación & 4.39 & .019 \\
Diseñar un cuestionario & 6.43 & .004 \\
Aplicar un cuestionario & 7.30 & .002 \\
Llevar a cabo una entrevista & 8.72 & .001 \\
\hline
\end{tabular}

Tabla 16

Prueba de Duncan/ Dimensión Marco metodológico/Doctorado

\begin{tabular}{|c|c|c|c|c|c|}
\hline \multicolumn{3}{|c|}{$\begin{array}{c}\text { Caracterizar los tipos de investigación en } \\
\text { cuanto a su alcance }\end{array}$} & \multicolumn{3}{|c|}{$\begin{array}{c}\text { Saber cuándo hay manipulación de variables } \\
\text { en el proceso de investigación }\end{array}$} \\
\hline \multirow[t]{2}{*}{ Aplicación } & \multicolumn{2}{|c|}{ Subconjunto para alfa $=.05$} & \multirow[t]{2}{*}{ Aplicación } & \multicolumn{2}{|c|}{ Subconjunto para alfa $=.05$} \\
\hline & 1 & 2 & & 1 & 2 \\
\hline $\begin{array}{l}\text { 1a aplicación } \\
\text { 2a aplicación } \\
\text { 3a aplicación }\end{array}$ & 2.13 & $\begin{array}{l}2.73 \\
2.80\end{array}$ & $\begin{array}{l}\text { 1a aplicación } \\
\text { 2a aplicación } \\
\text { 3a aplicación }\end{array}$ & 1.87 & $\begin{array}{l}2.60 \\
2.67\end{array}$ \\
\hline \multicolumn{3}{|c|}{ Seleccionar una muestra no probabilística } & \multicolumn{3}{|c|}{ Elegir el método de investigación } \\
\hline Aplicación & Subconjunto & $a=.05$ & Aplicación & Subconjunto & $f a=.05$ \\
\hline
\end{tabular}




\begin{tabular}{|c|c|c|c|c|c|}
\hline & 1 & 2 & & 1 & 2 \\
\hline $\begin{array}{l}\text { 1a aplicación } \\
\text { 2a aplicación } \\
\text { 3a aplicación }\end{array}$ & 2.07 & $\begin{array}{l}2.73 \\
2.73\end{array}$ & $\begin{array}{l}\text { 1a aplicación } \\
\text { 2a aplicación } \\
\text { 3a aplicación }\end{array}$ & 2.33 & $\begin{array}{l}3.07 \\
3.07\end{array}$ \\
\hline \multicolumn{3}{|c|}{ Elegir la técnica de investigación } & \multicolumn{3}{|c|}{ Diseñar un cuestionario } \\
\hline \multirow[t]{2}{*}{ Aplicación } & \multicolumn{2}{|c|}{ Subconjunto para alfa $=.05$} & \multirow[t]{2}{*}{ Aplicación } & \multicolumn{2}{|c|}{ Subconjunto para alfa $=.05$} \\
\hline & 1 & 2 & & 1 & 2 \\
\hline $\begin{array}{l}\text { 1a aplicación } \\
\text { 2a aplicación } \\
\text { 3a aplicación }\end{array}$ & 2.53 & $\begin{array}{l}3.07 \\
3.07\end{array}$ & $\begin{array}{l}\text { 1a aplicación } \\
\text { 2a aplicación } \\
\text { 3a aplicación }\end{array}$ & 2.73 & $\begin{array}{l}3.20 \\
3.27\end{array}$ \\
\hline \multicolumn{3}{|c|}{ Aplicar un cuestionario } & \multicolumn{3}{|c|}{ Llevar a cabo una entrevista } \\
\hline \multirow[t]{2}{*}{ Aplicación } & \multicolumn{2}{|c|}{ Subconjunto para alfa $=.05$} & \multirow[t]{2}{*}{ Aplicación } & \multicolumn{2}{|c|}{ Subconjunto para alfa $=.05$} \\
\hline & 1 & 2 & & 1 & 2 \\
\hline $\begin{array}{l}\text { 1a aplicación } \\
\text { 2a aplicación } \\
\text { 3a aplicación }\end{array}$ & 2.80 & $\begin{array}{l}3.33 \\
3.40\end{array}$ & $\begin{array}{l}\text { 1a aplicación } \\
\text { 2a aplicación } \\
\text { 3a aplicación }\end{array}$ & 2.80 & $\begin{array}{l}3.40 \\
3.47\end{array}$ \\
\hline
\end{tabular}

Se observa que la Dimensión Marco Metodológico es la única en la que son más los ítems (8) en los que se detecta mayor desarrollo de competencias con el paso del tiempo en el Programa de Doctorado. Hay cuatro ítems que se presentan significativos en los dos programas y su comportamiento en general es similar al de la dimensión completa de Marco metodológico. También se destaca que ambos programas presentan el nivel más bajo percibido de toda competencia investigativa en la primera aplicación (media $=2.0$ para maestría y media $=2.3$ para doctorado), enfatizando en el caso del Doctorado, que en cinco de los ocho ítems que fueron significativos, los alumnos llegan a percibirse con un nivel alto de competencia investigativa en la Dimensión Marco metodológico. Finalmente se presentan en las tablas 17, 18, 19 y 20 las diferencias encontradas en los ítems de la Dimensión Competencias Genéricas.

Tabla 17

Significancia por ítem/Dimensión C. Genéricas/Maestría

\begin{tabular}{lrc}
\hline İems Dimensión C. Genérica (Maestría) & F & Sig. \\
\hline Comprender una idea & 10.20 & .000 \\
Realizar el análisis de un concepto & 14.53 & .000 \\
Sintetizar un concepto & 7.94 & .001 \\
Comunicarse en forma oral & 3.22 & .049 \\
Comunicarse en forma escrita & 4.15 & .023 \\
Comprender textos escritos & 5.97 & .005 \\
Producir textos escritos & 7.64 & .002 \\
Analizar información de fuentes diversas & 3.29 & .048 \\
Integrar datos de varias fuentes de información & 6.43 & .004 \\
Elaborar una referencia bibliográfica & 6.74 & .003 \\
\hline
\end{tabular}


Tabla 18

Prueba de Duncan/ Dimensión C. Genéricas/Maestría

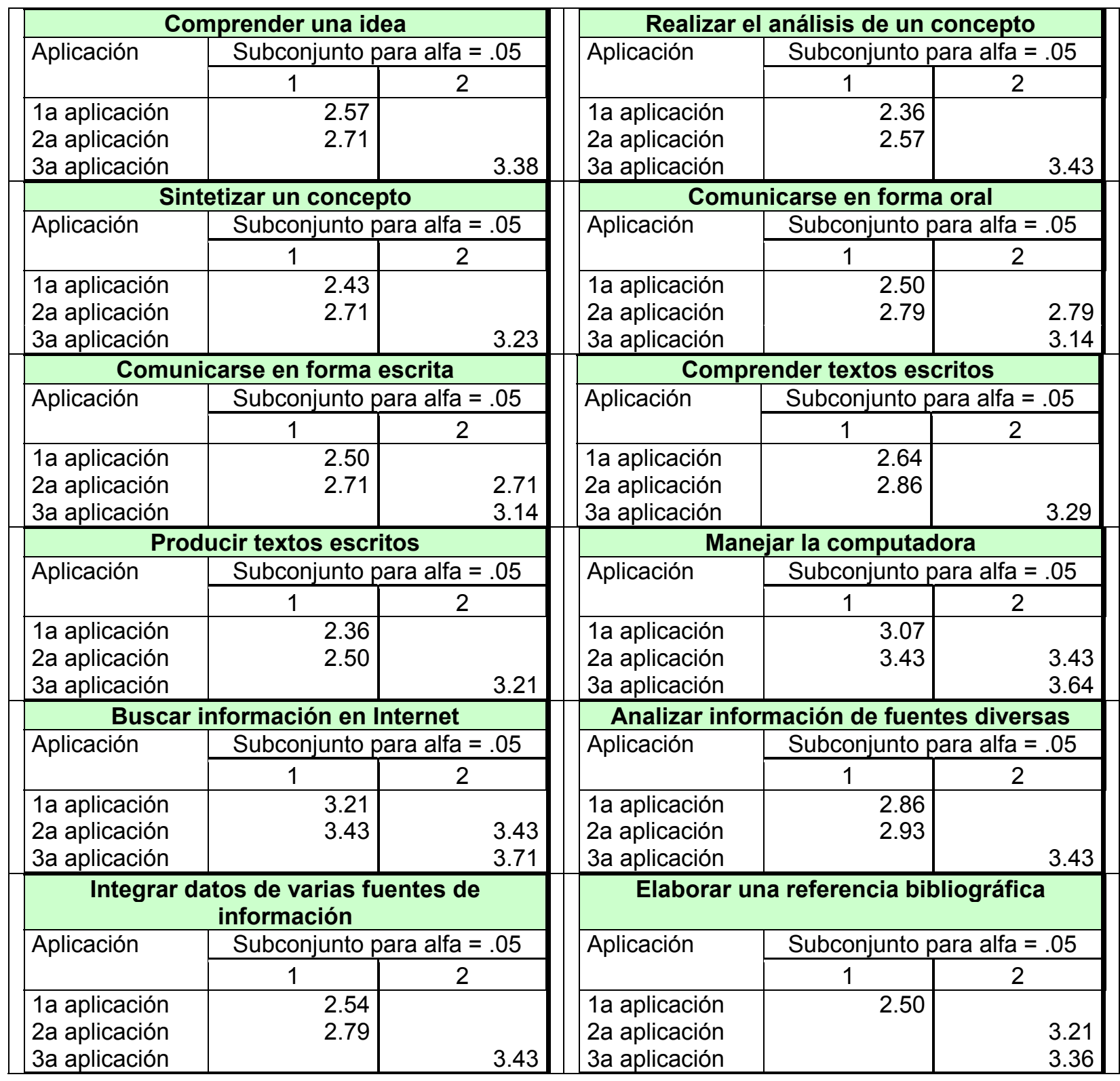

Tabla 19

Significancia por ítem/Dimensión C. Genéricas/Doctorado

\begin{tabular}{lcc}
\hline İtems Dimensión C. Genéricas (Doctorado) & F & Sig. \\
\hline Realizar el análisis de un concepto & 4.66 & .015 \\
Sintetizar un concepto & 6.00 & .005 \\
\hline
\end{tabular}


Tabla 20

Prueba de Duncan/ Dimensión C. Genéricas/Doctorado

\begin{tabular}{|c|c|c|c|c|c|}
\hline \multicolumn{3}{|c|}{ Realizar el análisis de un concepto } & \multicolumn{3}{|c|}{ Sintetizar un concepto } \\
\hline \multirow[t]{2}{*}{ Aplicación } & \multicolumn{2}{|c|}{ Subconjunto para alfa $=.05$} & \multirow[t]{2}{*}{ Aplicación } & \multicolumn{2}{|c|}{ Subconjunto para alfa $=.05$} \\
\hline & 1 & 2 & & 1 & 2 \\
\hline $\begin{array}{l}\text { 1a aplicación } \\
\text { 2a aplicación } \\
\text { 3a aplicación }\end{array}$ & 2.67 & $\begin{array}{l}3.3 \\
3.3\end{array}$ & $\begin{array}{l}\text { 1a aplicación } \\
\text { 2a aplicación } \\
\text { 3a aplicación }\end{array}$ & 2.53 & $\begin{array}{l}3.33 \\
3.33\end{array}$ \\
\hline
\end{tabular}

Las tablas anteriores muestran gran diferencia entre los programas, mientras que en la Maestría hay 12 ítems que presentan diferencia significativa, en el caso del Doctorado sólo son dos.

Se destaca que en todos los ítems mencionados los alumnos llegan a percibirse con un nivel alto de Competencias genéricas necesarias para realizar un trabajo de investigación.

En este sentido Aular de Durán, et al. (2009) en su estudio realizado en Venezuela, manifiesta que los docentes tienen escasas competencias para producir informes escritos, poca capacidad de síntesis y de análisis. Pudiera pensarse que en el nivel superior estarían desarrolladas mínimamente las competencias genéricas, pero éste y otros estudios nos revelan que no es así.

\section{Conclusiones}

Los estudiantes de posgrado que participaron en el estudio se manifiestan en promedio de las tres aplicaciones, con un nivel medio de las competencias investigativas (media = 2.639), se perciben con menor dominio en las Dimensiones Marco teórico y Marco metodológico.

Se aprecia una diferencia entre los niveles de dominio de competencias investigativas que presentan los alumnos en cada programa, siempre mayores para el Doctorado.

En todas las dimensiones hay diferencia significativa entre las aplicaciones, para los dos programas, salvo en la dimensión Resultados. 
En la Maestría en Educación, todas las diferencias son favorables para la tercera aplicación, en el Doctorado en Ciencias de la Educación, todas las diferencias son desfavorables para la primera aplicación.

El análisis efectuado para detectar específicamente en donde se encuentran las fortalezas y debilidades de los estudiantes con relación al desarrollo de las competencias investigativas, permite contar con elementos de juicio para proponer estrategias específicas de intervención a la institución educativa.

Por los resultados obtenidos, se puede concluir que las materias del eje investigativo incluidas en los programas, así como los docentes involucrados en la impartición de los contenidos, están logrando a través del tiempo, aprendizajes significativos que permiten un mayor acercamiento a las competencias investigativas.

Se recomienda continuar con esta línea y constatar si estas competencias que autoperciben los alumnos, se ven reflejadas en los trabajos de tesis de maestría y doctorado que realizan; en la percepción que tienen sus directores de tesis en cuanto a su formación investigativa; en la calidad y cantidad de sus publicaciones, etc.

\section{Referencias}

Abella Mahecha, M. \& Pachón Soler, A. (2011). Formación en competencias investigativas en educación superior estudio de caso: dos programas de maestría en educación. Tesis para optar para al título de Magíster en Educación. Facultad de Educación, Pontificia Universidad Javeriana. Bogotá, Col.

Álvarez Villar, V. M., Orozco Hechavarria, O. \& Gutiérrez Sánchez, A. (2011). La formación de competencias investigativas profesionales, una mirada desde las ciencias pedagógicas. Cuadernos de Educación y Desarrollo, Vol 3, № 24.

Armenteros, M. C., Guerrero, L., Medina, M., Molina, V. \& Villanueva, J. (2012). Evaluación de las competencias de investigación a nivel de licenciatura. Experiencias en las carreras de contaduría y administración. En S. Tobón y A. Jaik Dipp (Coords.), Experiencias de Aplicación de las competencias en la educación y el mundo organizacional (pp.265-287). Durango México: ReDIE.

Aular de Durán, J., Marcano, N. \& Moronta, M. (2009). Competencias investigativas del docente de educación básica. Laurus, 15(30), pp. 138-165.

Borjas, B. (2000). El docente como investigador. Revista Movimiento Pedagógico, 2. Maracaibo, Venezuela.

Cadenas, E., Rojas, B. y Reyes, C. (s/f). Competencias en el eje investigativo de los participantes de la cohorte 2000- 2004 del subprograma de maestría en educación superior de la UPEL-IPB. Universidad Pedagógica Experimental Libertador, Venezuela. Congreso Internacional de Investigación Educativa. 
Carrillo Flores, I. (2012). El desarrollo de competencias investigativas con apoyo del video. Revista Iberoamericana para la Investigación y el Desarrollo Educativo, 5(3).

Castellanos, B. (2005). Esquema conceptual, referencial y operacional sobre la investigación educativa. La Habana: Editorial Pueblo y Educación.

Castillo, S. (2008). Competencias investigativas desarrolladas por docentes de Matemática. Acta Scientiae, 10(2).

Castrillon Agudelo, M. C. (2012). Competencias investigativas del docente universitario en enfermería. Enfermería Universitaria ENEO-UNAM, 9(3), 9.

Correa Bautista, J. E. (2009). Medición de las competencias investigativas en docentes de fisiología: una aproximación empírica. Rev.Fac.Med. 2009; 57: 205-217.

Escobar Yéndez, N. V., Plasencia Asorey, C. \& Almaguer Delgado, A. J. (2012). Estrategia pedagógica para el desarrollo de la competencia investigativa en Medicina General Integral. Revista Congreso Universidad, I(3).

Figueroa, M. (s.f.). Aproximaciones teóricas para el desarrollo de competencias investigativas en educación superior. Doctorado en Educación de la Universidad de Los Andes, Mérida, Venezuela.

González González, M. \& Álvarez Mesa, Y. (2012). La formación de competencias profesionales del profesor: las competencias investigativas. Revista Electrónica de Desarrollo de Competencias (REDEC), 5(1).

Gutiérrez Leyton, A. E. \& Torres Herrera, M. (2012). Formación de competencias de investigación a través de los métodos cualitativos en el análisis de la narrativa audiovisual. Revista Comunicación, 10(1), pp.1397-1408.

Hernández-Sampieri, R., Fernández, C. \& Baptista, P. (2006). Metodología de la investigación. México: Mc Graw Hill.

Jaik Dipp, A. (2013). Competencias investigativas: Una mirada a la Educación Superior: México: ReDIE A.C.

Jaik Dipp, A. \& Ortega Rocha, E. (2011). El nivel de dominio de las competencias que, en metodología de la investigación, poseen los alumnos de posgrado. En A. Jaik Dipp y A. Barraza (Coords.), Competencias y Educación. Miradas múltiples de una relación (pp. 50 - 67). Durango, México: IUNAES - ReDIE A. C.

Llivina, M., Castellanos, B., Castellanos, D. \& Sánchez, M. E. (2001). Los proyectos educativos: una estrategia para transformar la escuela. Colección Proyectos, Centro de Estudios Educacionales, Universidad Pedagógica Enrique José Varona. La Habana, Cuba.

Moreno Mosquera, V. J. (2012) De la argumentación pragmadialéctica como competencia investigativa en los estudiantes de derecho de la Institución Universitaria de Envigado. Revista Ratio Juris, 7(15) pp. 123-148.

Muñoz, J. F. (2001). Competencias investigativas para profesionales que forman y enseñan: cómo desarrollarlas. Bogotá: Cooperativa Editorial Magisterio.

Núñez, J. (2007). La ciencia y la tecnología como procesos sociales. Lo que la educación científica no debe olvidar. La Habana: Editorial Félix Varela.

Ortega Rocha, E. \& Jaik Dipp, A. (2010). Escala de evaluación de competencias investigativas. Revista Electrónica Praxis Investigativa ReDIE, 2(3), 72-75.

Padrón, J. (2008). Obstáculos para la investigación orientada al desarrollo. IV Jornada de Investigación e Innovación Educativa. UCLA. Barquisimeto.

Perales Ponce, R. C, Macías Morales, M. P. \& Macías Morales, A. (2011). Competencias del investigador educativo en la producción del conocimiento desde su cultura experiencial. En A. Jaik Dipp y A. Barraza (Coords.), Competencias y Educación. Miradas múltiples de una relación (pp. 332 - 348). Durango, México: IUNAES - ReDIE A. C.

Pineda, L. (2007). ¿Cómo se entiende formar para la investigación en contextos de educación media y de Educación Superior? Revista Científica Guillermo de Ockham, 5. 
Ramírez Ramírez, I. \& González González, M. (2008). Metodología de la Investigación Educativa. Un acercamiento desde la perspectiva del maestro. Perú: Editorial San Marcos.

Rojas, M. H., Vázquez, C. L. \& Roque, M. (2012). Las competencias investigativas en la construcción del talento humano dentro de las Ciencias Médicas. MEDICIEGO, 18(2).

Salcido Ornelas, D., Torre Aranda, A. \& Piñón Arzaga, O. A. (2010). Grado de formación en competencias de investigación de los alumnos de postgrado de la Facultad de Contaduría y Administración de la UACH. Recuperado de http://www.fca.uach.mx/revista electronica/VOL.8/Ponencia\%2017-UACH.pdf

Sayous, N. (2007). La investigación científica y el aprendizaje social para la producción de conocimientos en la formación del ingeniero civil. Ingeniería, 11(2), 39-46.

Tobón, S. (2005). Formación basada en competencias. Bogotá: Eco Ediciones.

Valdés Cuervo, A. \& Rodríguez López, J. (2011). Estrategias de enseñanza utilizadas por docentes de educación media superior. En A. Jaik Dipp y A. Barraza (Coords.), Competencias y Educación. Miradas múltiples de una relación (pp. 222 - 239). Durango, México: IUNAES - ReDIE A. C. 


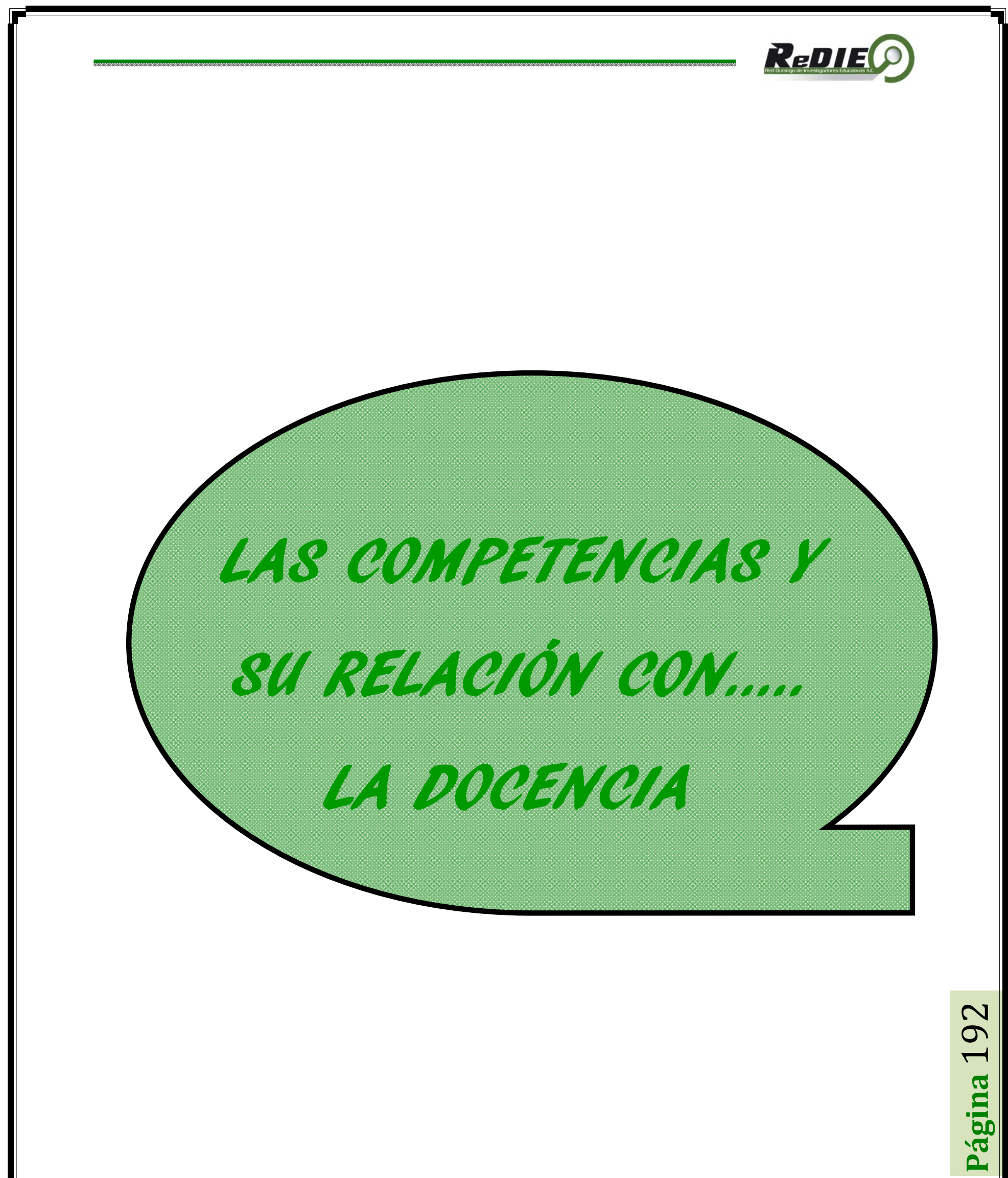




\title{
LA ENSEÑANZA, EL APRENDIZAJE Y LA EVALUACIÓN DE COMPETENCIAS EN EL AULA
}

\section{THE TEACHING, LEARNING AND ASSESSMENT OF SKILLS IN THE CLASSROOM}

\author{
Ma. de los Ángeles Huerta Alvarado \\ Universidad Pedagógica Nacional \\ mahuertaa@gmail.com
}

\section{Resumen}

En el presente trabajo se aborda la discusión del concepto de competencias, el surgimiento y desarrollo que este modelo ha tenido en el sistema educativo mexicano. Se discute la forma en que se puede entender la enseñanza, el aprendizaje y la evaluación de las competencias académicas en el ámbito escolar y se señala la importancia de integrar a las competencias docentes para su cabal comprensión. Al argumentar la relación entre las competencias académicas y las didácticas se aportan elementos para la comprensión del aprendizaje escolar de competencias académicas y la forma en que el docente puede promover la enseñanza y la evaluación por competencias.

Palabras clave: educación por competencias, aprendizaje de competencias académicas, competencias didácticas, evaluación por competencias.

\begin{abstract}
This paper deals with the discussion of the concept of competencies, the emergence and development that this model has had on the Mexican educational system. Discussed the way in which the teaching, learning and assessment of academic skills at school can be understood and referred to the importance of integrating educational competencies for their thorough understanding. To argue the relationship between academic responsibilities and the didactic provides elements for the understanding of school learning academic skills and the way in which teachers can promote the teaching and evaluation competency.
\end{abstract}

Key words: education competency, learning of academic competence, didactic competence, competency assessment.

\section{El surgimiento de la Educación basada en competencias en México}

La Educación Basada en Competencias (EBC) que se está aplicando en México desde hace 18 años, deviene del mundo del trabajo, comenzó en la educación tecnológica y se ha extendido hasta ser el fundamento y orientación de las reformas curriculares de la 
educación básica, media superior y superior. Sin embargo, a pesar del tiempo transcurrido, sigue habiendo evidencia del desconocimiento y confusión que sobre la EBC tienen los docentes, quienes son los encargados de darle vida a las propuestas curriculares, (Guzmán, 2010).

Desde la perspectiva de la EBC, el docente está comprometido con dos aspectos centrales: la promoción de los procesos de aprendizaje de sus alumnos, (que además deben ser estratégicos) y la respectiva evaluación de estos procesos. ¿Cómo acercarse a su cabal apropiación? Un punto de partida es recuperar la dimensión histórica como contexto de la dimensión pedagógica.

\section{¿De dónde surge el concepto de competencia?}

A partir de la década de los 80's los países industrializados como Gran Bretaña, Australia, Canadá, Francia y Estados Unidos de América impulsaron la formación (educación y capacitación) basada en competencias con resultados exitosos. Como cita Barrón (2002), los cambios geopolíticos experimentados afectaron la economía de diversos países, y llevaron a la incorporación de diversas tecnologías en todos los ámbitos de la vida cotidiana, afectando con ello los ámbitos cultural, político y económico en cada país.

En México, la política gubernamental desde finales de los años 80's planteó la reordenación económica bajo los dictados del Fondo Monetario Internacional (FMI). EI gobierno mexicano ofreció apoyo incondicional a la iniciativa privada y al comercio exterior por lo que se integró formalmente al Bloque de América del Norte para establecer redes de comercio internacional mediante la firma del Acuerdo General de Aranceles, Tarifas y Comercio (GATT) y, posteriormente, del Tratado Trilateral de Libre Comercio (TLC) con Estados Unidos y Canadá. También solicitó el ingreso a organismos internacionales como la Organización Mundial de Comercio (OMC), y la Organización de Países para la Cooperación y de Desarrollo Económico (OCDE). Esta globalización en la economía obligó a las empresas productivas y de servicio a revisar y modificar los procesos de producción y comercialización a fin de incrementar la productividad reduciendo los costos laborales y flexibilizando el capital humano. La 
política gubernamental mexicana concretó también acciones importantes que buscaron integrar los esfuerzos empresariales con los del sector educativo. Por ello se inició a partir de 1995, la implantación del Proyecto de Modernización de la Educación Técnica y la Capacitación (PMETyC), bajo la responsabilidad del Consejo de Normalización y Certificación de Competencia Laboral (CONOCER), con el propósito de otorgar, por primera vez, el mismo valor social al trabajo y a la educación, reconociendo las capacidades y competencias de un individuo, mediante la certificación de su competencia laboral independientemente de cómo fueron conseguidas.

Sin embargo, el sistema educativo ha mantenido históricamente distancias ideológicas y reales con el sistema productivo. La articulación ha sido muy escasa, sobre todo, como cita Hualde (2001), a partir de la inexistencia de trayectorias coherentes y escaso desarrollo de formas identitarias ligadas a la industria. Para el sector educativo el interés central ha sido principalmente asegurar el empleo para los egresados mientras que para los empleadores la demanda era la reorientación de la oferta educativa. Gradualmente se ha ido abandonando la idea de que en la escuela se adquieren los conocimientos teóricos y en el trabajo se aplican. El propio currículo escolar introduce la práctica como un aspecto cada vez más importante de los planes de estudio (Hualde, 2001).

Esto propició que los diferentes sectores productivos se abocaran fundamentalmente al abatimiento de costos, la eficiencia y la innovación tecnológica, sin afectar la calidad del producto o servicio. Todos estos aspectos condujeron a la identificación, y en su caso la promoción, de competencias clave de la organización que establecen las características distintivas de la organización.

El factor humano se erige entonces como una categoría de competitividad importante, entendida como la identificación de la capacidad de las personas para brindar aportaciones que contribuyan al alcance de los objetivos de la organización. Esta visión incluye la variable esfuerzo como elemento básico, lo cual representó un reto de reinterpretación importante.

Antes de la década de los 80's, la noción de innovación consistía básicamente en la introducción de tecnologías, que en su aplicación daba como resultado una adaptación de la organización hacia la producción. 
La premisa de este sistema era, como señala Mertens, (1997), que la suma de eficiencias en cada puesto iba a resultar en una eficiencia de flujo. Al paso del tiempo, se hizo evidente que este esquema no representaba un ahorro de costos substancial y desperdiciaba un recurso muy importante: la educación, conocimientos, creatividad e inteligencia del trabajador.

En años posteriores, este modelo se transforma y convierte en un esquema interactivo o sinérgico, donde los lineamientos y prospectiva de innovación tecnológica están marcadas y promovidas por la estructura organizativa, por la arquitectura de la organización.

Uno de los ejes vertebradores de esta arquitectura fue la definición de normas o estándares de competencia, que dotan de significado la interacción entre los subsistemas de la empresa y animan el proceso a través del despliegue práctico de conocimientos y creatividad como contenido de las tareas designadas.

Este proceso se manifestó en dos acciones principales:

1. Se estandarizaron las operaciones y se introdujo el concepto de multihabilidad en el mismo nivel de complejidad de las tareas.

2. En cuanto a las tareas periféricas relativas a la administración, coordinación y organización del trabajo, se promovió un enriquecimiento social y técnico para eliminar las actividades de poco valor agregado y mejorar el flujo productivo.

De este modo, la EBC surgió como una nueva orientación educativa para dar respuestas a la naciente sociedad de la información, en contra de procedimientos tradicionales para reducir la brecha entre la teoría y la práctica.

\section{¿Cómo se han explicado las competencias?}

A pesar del tiempo transcurrido no se ha delimitado aún un concepto unívoco que defina a las competencias. Si bien el concepto cobra auge desde el mundo del trabajo, en otras áreas de conocimiento ya se ocupaba para dar cuenta de determinados objetos de estudio. Por ejemplo, Chomsky, (1985) y Hymes, (1996) a partir de las teorías del lenguaje definen la competencia como la capacidad y disposición para el desempeño y para la interpretación. A partir de la psicología cultural se caracterizó a la 
competencia como un concepto que está en la base de la interacción de la persona con el entorno. El concepto de competencia comunicativa refería el empleo efectivo del lenguaje en situaciones específicas de comunicación. Se reconocen como construcciones sociales que requieren de la interacción con otras personas y que es el mismo contexto sociocultural lo que determina la idoneidad de las mismas.

Desde entonces, se ha propuesto que las competencias son acciones situadas que se definen en relación con determinados instrumentos mediadores: el lenguaje y otros procesos cognitivos. La Teoría de las inteligencias múltiples de Gardner (1998) ha brinda apoyo teórico a la comprensión de las competencias en su dimensión cognoscitiva, (Tobón, 2005). Por otra parte, autores como Sternberg (1997) con sus investigaciones sobre la inteligencia práctica, (capacidad de las personas para desenvolverse con inteligencia en las situaciones de la vida) y Holland, (1966-97, como se citó en Argudín, 2001) con su teoría de las necesidades, estilos de aprendizaje y potencialidades individuales aportaron elementos importantes para un entendimiento más cabal del desarrollo de las competencias.

Con base en lo anterior, se tienen elementos para entender cómo una competencia en educación, da cuenta de una convergencia de comportamientos cognitivos, sociales, afectivos y habilidades que le permiten a una persona llevar a cabo adecuadamente un papel, un desempeño, una actividad o una tarea.

Gonzi y Athanasou (1996) señalan tres conceptuaciones básicas correspondientes a tres enfoques distintos:

$>$ "Basada en la tarea" (task-based) que queda definida como diversos 'comportamientos discretos' ligados con la realización de tareas muy específicas.

> "Genérica" en la cual se aglutinan los 'atributos generales' del profesional experto, indispensables para un "desempeño efectivo". Se trata de conocimientos y habilidades de índole general que augurarían el "pensamiento crítico" y las "habilidades en comunicación" con cierto nivel de dominio para el desempeño del profesional, cualquiera que fuese el contexto. Este enfoque se encuentra muy apegado a los modelos administrativos. 
> "Relación holística o integrada" en la cual toda competencia se planea como un complejo estructurado de atributos generales (conocimientos, actitudes, valores y habilidades) requeridos para interpretar situaciones específicas y desempeñarse en ellas de manera inteligente.

Las competencias "tienen un alcance mucho más limitado que el de las destrezas de tipo profesional, pero más completo que el de los conocimientos asociados a un puesto de trabajo específico y, lo que es más importante, están concebidas para ser transferibles en virtud de su normalización y certificación”, Marsden (1994). Por ende, la competencia puede entonces entenderse como un potencial que deriva en un comportamiento integral y como la capacidad disponible en un momento determinado del desempeño del sujeto en condiciones bajo las cuales resulta relevante dicha intervención que integra saberes teóricos y prácticos con un base actitudinal, (Rojas, 2000).

Autores como Malpica, (1996) recuperan dos características fundamentales de la noción de competencia:

I. Se centra en el desempeño. Esto es importante en la medida en que se asume que la educación (y por ende, la evaluación y la capacitación), debe tener un impacto directo en las posibilidades de actuación de la gente.

II. Recupera las condiciones concretas en que dicho desempeño es relevante.

Un componente fundamental de la noción de competencia es la Unidad. La competencia tiene un sentido propio porque conforma una totalidad en la que aun cuando pueden identificarse diversos componentes, éstos por separado no constituyen la competencia. La convergencia de los elementos relevantes a una situación, es lo que constituye la competencia y le da sentido, límites y alcances, (Malpica, 1996). Otro concepto importante a recuperar para explicar la Competencia es el que se refiere a la Alternancia como recurso didáctico en la formación para el trabajo. Esta refiere una relación significativa entre el abordaje o recuperación de conocimientos teóricos y las condiciones y demandas de la situación de trabajo. De este modo la competencia se puede entender como un punto de convergencia de varios elementos que no son exclusivos de ella, p.e. la información que maneja una persona, los procesos de 
organización y análisis que aplica, las habilidades motoras y las actitudes o las formas de representación que extrae de la realidad y que al ponerse en juego favorecen el desarrollo de mayores niveles de autonomía de los individuos (Mertens, 1998).

Para la comprensión de la noción de competencia también es importante recuperar la noción de inferencia integradora ya que sin ésta la referencia al desempeño reduciría el planteamiento a un análisis conductual. Por otro lado es necesario reconocer que esta competencia no es generalizable o genérica porque la práctica es específica y “..La posibilidad de transferirla más allá de los casos particulares, como todo argumento inductivo, no produciría más que probabilidades sin garantía sólida de existencia" (Hager \& Becckett, 1996, p. 303,).

Otra noción conceptual ligada con la competencia es la "aplicación de la inteligencia práctica" la cual implica la generabilidad de las competencias en combinaciones específicas que dependen del significado y valor que tienen en cada ambiente.

Desde el enfoque de competencia laboral ésta se clasifica en tres tipos diferentes:

I. Competencias básicas que se refieren a los comportamientos elementales que deben mostrar los trabajadores y que están asociados a conocimientos de índole formativa: Comunicación:
a) Leer y escribir
b) Manejo de recursos y de tareas (de función y relación)
c) Desarrollar diversas tareas que impliquen percepciones y valoraciones éticas, conocimientos matemáticos y resolución de problemas, que impliquen una toma de conciencia del desarrollo histórico, una comprensión global, diferentes modelos de investigación y que impliquen percepciones y valoraciones estéticas.

Liderazgo:

a) Movilizar innovaciones y cambios.

b) Autogestión (integrar conocimientos):

c) Desarrollar diversas tareas que impliquen madurez en la conducta y se relacionen con los valores éticos, profundidad y amplitud en la comprensión que impliquen una 
independencia del pensamiento y que impliquen que el alumno ha aprendido a aprender.

II. Competencias genéricas que describen comportamientos asociados con desempeños comunes a diversas ocupaciones y ramas de actividad productiva, como son la capacidad de trabajar en equipo, programar, negociar y entrenar, que son comunes a una gran cantidad de ocupaciones:

1. De estimación e injerencia de los conocimientos de la disciplina y dominio de tareas y contenidos.

2. De comunicación: a) Habilidades verbales, b) Habilidades de lectura, c) Habilidades de expresión escrita, d) Habilidades de computación.

3. De pensamiento crítico: a) Evaluación, b) Análisis, c) Resolución de problemas, d) Toma de decisiones, e) Consulta.

4. De relación: a) Actitudes relacionadas con el humanismo y los valores y la ética profesional y la legalidad, b) Cultura, c) Relaciones interdisciplinares, d) Relaciones interpersonales.

5. De función: a) Administrar, b) Planificar, c) Trato con el personal y uso de recursos,

d) Responsabilidad.

6. De liderazgo: a) Colaborar, b) Creatividad, c) Planear.

7. De investigación y para la docencia.

8. Integrar conocimientos: a) Relación con otras disciplinas y b) Integrar conocimientos de otras disciplinas a la propia

III. Competencia específica que identifica comportamientos asociados con conocimientos de índole técnico, vinculados a un cierto lenguaje tecnológico y a una determinada función productiva. Los conocimientos que éstas implican se pueden dividir en generales, específicos y de la disciplina y unidos a las habilidades y a los valores, permiten que se construyan competencias.

La experiencia en la Unión Europea (UE) al respecto fue la integración de competencias clave, las cuales básicamente hablan de competencias técnicas y de desarrollo personal y humano como son: 
1. La comunicación como medio de expresión oral y escrita.

2. La formación científica y tecnológica.

3. La educación para el uso de las nuevas tecnologías.

4. La educación para el desarrollo humano personal (emociones y percepciones).

5. La cooperación y la resolución de problemas como forma emprendedora y creadora.

6. La cultura del esfuerzo con el fin de mejora de resultados.

A grandes rasgos son estas competencias básicas las que se deben desarrollar para lograr una participación con éxito en la sociedad a lo largo de la vida (Romero Torres, 2013).

Por otra parte, la construcción de competencias en los subsistemas de educación básica, media y superior se inscribe en el marco de una educación flexible y permanente, con fundamento en la teoría psico y sociocognitiva, y en un contexto institucional, cultural, social, político y económico específico.

Las competencias no son potencialidades a desarrollar sino que forman parte de la construcción personal y en relación con una comunidad específica, de acuerdo con las metas, requerimientos y expectativas cambiantes de una sociedad abierta, (Argudín, V., 2001).

En México, la introducción oficial de la EBC se llevó a cabo en 1995 cuando se estableció el Proyecto para la Modernización de la Educación Técnica y la Capacitación tuvo la potencialidad de orientar planes y programas de estudio en condiciones formales de educación como es el caso del CONALEP, el CETIS, el CBTIS y el CECATIS y también de prever formas y métodos de capacitación insertos en el contexto laboral para la autoformación de los individuos que no asisten a instituciones formales de educación o capacitación.

Por otro lado, se encuentran los trabajos desarrollados en la Subsecretaría de Educación Básica en donde, derivadas de la reforma educativa se enmarcan acciones de reformulación de materiales y programas con las que es posible reconocer una orientación hacia la organización de estrategias de enseñanza para el desarrollo de competencias generales y específicas en cada asignatura orientados por el desarrollo de competencias para la vida. Un ejemplo de ello son los programas del CONAFE en donde se ha hecho recientemente una revisión del Programa para la atención a niños 
migrantes desde una perspectiva basada en competencias, lo que ha dado lugar a una reducción de contenidos y una organización curricular diferente.

La educación basada en competencias en educación básica, (preescolar, primaria y secundaria), ha introducido reformas educativas a partir de un currículo que incluye aprendizajes esperados, estándares y competencias que permitan aprendizajes efectivos para los niños en el proceso de transición de un nivel a otro. La tendencia actual básicamente refleja el interés y el esfuerzo por sistematizar propuestas de enseñanza y aprendizaje en una óptica globalizadora que oriente los aprendizajes en un sentido innovador e integrador.

La tendencia actual en educación básica refleja el interés y el esfuerzo por sistematizar propuestas de enseñanza y aprendizaje en una óptica globalizadora que oriente los aprendizajes en un sentido innovador e integrador. A partir de la Conferencia Mundial sobre Educación para todos (Jomtiem, Tailandia, 1990), se adoptaron dos categorías centrales para conceptuar el vínculo entre sociedad y educación: Necesidad y Competencia. Esta última se reconoce precisamente como la tarea educativa que incluye al menos cuatro componentes: información, conocimiento, (en cuanto apropiación, procesamiento y ampliación de la información), habilidad y actitud o valor (Schmelkes, 1991).

El Programa educativo de la Organización para la Cooperación y Desarrollo Económicos (OCDE), durante los últimos años, ha permitido un trabajo con sus países miembros que ha permitido perfeccionar los indicadores de actuación educativa. En la publicación anual Education at a glance, ha dado cuenta de información comparativa sobre recursos humanos y financieros invertidos en educación, operación y desarrollo de los sistemas educativos y de aprendizaje, así como de las tasas de retorno de las inversiones en educación. Desde 1997 la OCDE ha participado en las mediciones de resultados educativos elaborando comparaciones internacionales que investigan sobre las competencias que son necesarias en la vida moderna.

Baste citar el estudio Adult Literacy Survey (IALS) que se avocó al análisis de la forma en que los adultos utilizaban sus habilidades de lectura para efectuar sus tareas diarias y actualmente se ha extendido a las habilidades que éstos tienen para resolver problemas, trabajar en equipo, y usar la información y la tecnología de la comunicación. 
De hecho aún antes de que en México se hiciera tanto énfasis en el trabajo curricular y escolar orientado hacia competencias, se llevó a cabo la primera aplicación del Proyecto PISA (Programme for International Student Assesment) que evaluó en estudiantes de 15 años de 28 países de la OCDE las competencias que los alumnos tienen en lectura, matemáticas y ciencias al terminar la educación obligatoria. A partir de entonces ha realizado evaluaciones cada 3 años haciendo énfasis en alguna de las 3 áreas mencionadas. Con base en los resultados derivados de la primera fase la SEP desde diversas direcciones formuló lineamientos para orientar la política educativa de los próximos años.

En el caso de educación media superior y superior, el desempeño se ha planificado buscando que el alumno desarrolle competencias y habilidades apropiadas para el perfil de egreso propuesto. Sin embargo, a pesar de que en educación superior los currícula se han venido orientando desde esta perspectiva, debe insistirse en que la lógica de los procesos de trabajo en el sector productivo es distinta a la lógica de los procesos escolares (Barrón, 2002). El reto parece ser que las instituciones de educación superior en una nueva cultura académica diseñen productos de aprendizaje, servicios y experiencias que coincidan con los parámetros de la sociedad de la información, (Herrera, 1996).

En la última década, la educación superior ha ido desarrollando una visión renovada para su planeación, congruente con las características de la sociedad de la información, por ejemplo, el desarrollo y promoción de nuevas tecnologías, que amplían las fronteras y transfiguran ya el proceso de enseñanza-aprendizaje. Algunos eventos importantes al respecto se han desarrollado reuniones importantes en Europa y América que ha buscado aprovechar las condiciones de la comunidad europea para comprometer una relación sólida en la esfera educativa, cultural y humana, reconocer la voluntad de incrementar la movilidad de los estudiantes, docentes y personal administrativo, avalando los procesos y periodos de estudios o de los diplomas y destacando la formación profesional de calidad y a lo largo de toda la vida.

En este contexto surgió en América el proyecto $6 \times 4$ UEALC que refiere al trabajo de seis profesiones (Administración, Ingeniería Electrónica, Medicina, Química, Historia y Matemáticas) en cuatro ejes (Competencias profesionales, créditos 
académicos, evaluación y acreditación y formación para la innovación y la investigación).

Por su parte, el proyecto Alfa Tuning, retomó los conceptos básicos y metodología del proyecto Tuning Educational Structure in Europe para el desarrollo de cuatro líneas de acción 1) competencias genéricas y específicas, 2) Enfoques de enseñanza, aprendizaje y evaluación, 3) Créditos académicos y 4) calidad de los programas. Actualmente participan en el proyecto Alfa Tuning América Latina: 62 universidades latinoamericanas, de los 18 países; Argentina, Bolivia, Brasil, Chile, Colombia, Costa Rica, Cuba, Ecuador, El Salvador, Guatemala, Honduras, México, Nicaragua, Panamá, Paraguay, Perú, Uruguay y Venezuela. En este contexto de formación profesional, se identifican dos conceptos importantes: Competencia Académica como un constructo pertinente dada su inserción en el ámbito cultural y Competencia profesional concebido como " ... combinación dinámica de atributos - con respecto al conocimiento y su aplicación, a las actitudes y responsabilidades - que describen los resultados del aprendizaje de un determinado programa, o cómo los estudiantes serán capaces de desenvolverse al final del proceso educativo ... “ (Comisión Europea.Tuning educational structures in Europe. Informe final. p. 280)

El proyecto Tuning en México, se ha visto como un referente de gran importancia por las universidades públicas que influyen en líneas de acción de agrupaciones académicas como la del Consorcio de Universidades Mexicanas (CUMEX), en cuyo programa de trabajo contempla la gestión de recursos para sus programas, como el de comparabilidad de programas educativos entre las universidades del consorcio y el ámbito latinoamericano y europeo.

Las principales tareas de la educación superior han estado y seguirán estando ligadas a sus funciones principales:

- Una generación con nuevos conocimientos (Función de investigación)

- La formación profesional altamente calificada (Función de docencia)

- Proporcionar servicios a la sociedad (Función social o de extensión académica)

- La crítica social (Función ética).

Para autores como Tobón, (2005) aparentemente las competencias escolares se traslapan con las del ámbito de la formación profesional o laboral. Esta postura es 
ambigua respecto a la relación entre el enfoque de las competencias y el modelo pedagógico: el enfoque de competencias puede llevarse a cabo desde cualquiera de los modelos pedagógicos existentes, o también desde una integración de ellos. En esta lógica, se pierde de vista que los debates sobre competencias no impliquen los mismos retos, ya sea que se trate de la educación escolar o de la formación profesional.

Por su parte, Perrenoud, (2004) sostiene un enfoque más amplio y comprensivo orientado por una perspectiva socioconstructivista. Según este autor, el enfoque por competencias amplía el sentido de escolaridad, lo vincula a las prácticas sociales y a la vida; lo vuelve accesible para quienes no iniciaron, desde la escuela primaria, un largo camino hacia los estudios superiores. Desde esta lógica, este enfoque podría otorgarle mayor sentido a la profesión docente y modificar la relación pedagógica, al imprimirle un significado más cooperativo y menos conflictivo. En el desarrollo de competencias, el formador debe estar junto al estudiante, acompañándolo como un asesor y estimulándolo a reflexionar, en lugar de sólo volcarse en los conocimientos y habilidades que deberán aprenderse. A partir de lo anterior, lo que puede apreciarse es que no hay propuestas curriculares "neutras" o "asépticas", todas ellas implican tomas de posturas acerca de las formas como se conciben la enseñanza y el aprendizaje que implica tomar posturas filosóficas, sociales y pedagógicas, las cuales deberán explicitarse.

El Programa educativo de la OCDE durante los últimos diez años, ha permitido el trabajo con sus países miembros para perfeccionar los indicadores de actuación educativa. Desde esta óptica, el quehacer educativo puede entenderse como la identificación de necesidades básicas que requieren de competencias básicas para satisfacerlas incorporando conocimiento y acción como unidad reconociendo su dimensión histórica social y su diversidad cultural.

\section{Competencias educativas y su enseñanza}

La discusión sobre las competencias académicas se ha articulado con la discusión de las competencias didácticas o docentes. Al descansar en el docente la responsabilidad de desarrollar la enseñanza y enfrentar, de manera pertinente, diversas situaciones en 
el aula, se confirma y muestran también, el nivel de conciencia sobre sus propias acciones y reflexiones. No es casual que haya surgido en la discusión la noción de "competencias docentes" que pueden ser definidas como la forma práctica en que se articula el conjunto de conocimientos, creencias, capacidades, habilidades, actitudes, valores y estrategias que posee un docente y que determina el modo y los resultados de sus intervenciones psicopedagógicas (DGOSEDF, 2003a).

En la Tabla 1 se comparan los indicadores formulados para identificar las competencias docentes en diferentes propuestas:

Tabla 1.

Comparación de indicadores de competencias docentes

\begin{tabular}{|c|c|c|c|}
\hline $\begin{array}{l}\text { Klemp, (1977, } \\
\text { como se citó en } \\
\text { Elliot, 1993) } \\
\text { "Partes } \\
\text { sintetizadoras en } \\
\text { conjuntos" }\end{array}$ & $\begin{array}{l}\text { Scriven, (como se } \\
\text { citó en Mateo, et. } \\
\text { Al., 2000) } \\
\text { "Contenidos en la } \\
\text { función docente" }\end{array}$ & $\begin{array}{l}\text { Ibarrola y Gallart } \\
\text { (1994) Propuesta } \\
\text { de formación } \\
\text { integral }\end{array}$ & $\begin{array}{l}\text { Dirección General de } \\
\text { Operación de Servicios } \\
\text { Educativos para el Distrito } \\
\text { Federal (DGOSEDF) }\end{array}$ \\
\hline $\begin{array}{l}\text { Habilidades } \\
\text { cognitivas }\end{array}$ & $\begin{array}{l}\text { Conocimiento de la } \\
\text { materia }\end{array}$ & Matemáticas & Saberes Pedagógicos \\
\hline Empatía & & Comunicacionales & Comunicación \\
\hline \multirow[t]{4}{*}{ Iniciativa cognitiva } & & & Interacción Social \\
\hline & & Científicas & Organización de la Enseñanza \\
\hline & $\begin{array}{l}\text { Competencias } \\
\text { evaluativas }\end{array}$ & & Intervención Psicopedagógica \\
\hline & Profesionalidad & & Desarrollo Profesional \\
\hline \multicolumn{4}{|l|}{$\begin{array}{l}\text { Relacionadas con la } \\
\text { motivación de logro }\end{array}$} \\
\hline \multirow[t]{4}{*}{$\begin{array}{l}\text { Relacionadas con la } \\
\text { motivación de poder }\end{array}$} & & $\begin{array}{l}\text { Socio históricas o } \\
\text { de conciencia de la } \\
\text { historia y una } \\
\text { profunda formación } \\
\text { ética }\end{array}$ & \\
\hline & $\begin{array}{l}\text { Competencias } \\
\text { instruccionales }\end{array}$ & Tecnológicas & \\
\hline & & Ecológicas & \\
\hline & & Críticas y creativas & \\
\hline
\end{tabular}

Fuente: elaboración propia

Como puede apreciarse, existen diversas formas de conceptualizar la competencia didáctica de un docente. Si bien pueden reconocerse situaciones específicas según el nivel educativo para el que fueron propuestas, también puede 
identificarse que si bien no corresponden en forma unívoca, la diferencia no es significativa. Lo que debe resaltarse es el interés por reconocer en el docente el principal agente educativo de la escuela, aquel que trabaja en el aula y puede conducir un trabajo articulado y sólido que atienda a los procesos de enseñanza, de aprendizaje y de evaluación. Lo cierto es que no hay propuestas curriculares "neutras" o "asépticas", todas ellas implican tomas de posturas acerca de las formas como se conciben la enseñanza y el aprendizaje que implica tomar posturas filosóficas, sociales y pedagógicas, las cuales deberán explicitarse. El proceso aún no concluye y las definiciones o redefiniciones ocurren día con día inscritas también en el orden de cada disciplina.

En general, dentro de los componentes del modelo educativo de la EBC se espera que el docente realice las siguientes funciones:

- elabore la planificación del curso que consiste en diseñar el programa, objetivos y contenidos básicamente que respondan a las competencias clave usando una metodología flexible y adaptable.

- elabore los materiales educativos teniendo en cuenta las características y requerimientos según el sentido educativo y lo que se pretenda enseñar

- realice asesoría vivencial y directa a los involucrados en el proceso educativo

- evalúe basándose en el proceso formativo y no sólo en el resultado, tomando en cuenta todos los elementos del proceso educativo, tanto la formación de sus alumnos como la actuación y los recursos utilizados, mismos que previamente estarán descritos y delimitados en la construcción de las competencias.

En el caso de educación superior, la EBC es una perspectiva que pretende dar respuesta a las necesidades individuales y sociales que plantea la actual sociedad del conocimiento.

Las competencias del profesor universitario serían de acuerdo con Fernández March, (2005) las que siguen:

1. Planificar el proceso de enseñanza-aprendizaje.

2. Seleccionar y prepara los contenidos disciplinares.

3. Ofrecer informaciones y explicaciones comprensibles y bien organizadas

(Competencia comunicativa). 
4. El manejo de las nuevas tecnologías como soporte de almacenamiento y búsqueda y tratamiento e intercambio de la información.

5. Diseñar la metodología de trabajo y organizar las actividades y tareas de aprendizaje.

6. Relacionarse con los alumnos.

7. Tutorizar.

8. Evaluar.

9. Reflexionar e Investigar sobre la enseñanza.

10. Identificarse con la institución y trabajar en equipo.

Entender la enseñanza desde la EBC implica reconocer el contexto curricular e institucional. Actualmente, los programas curriculares en México en los diferentes niveles educativos requieren que la metodología de enseñanza contribuya a la retroalimentación entre el profesor y el alumno, y atienda los supuestos que subyacen a un aprendizaje colaborativo y constructivo. Sin embargo, los maestros construyen una aproximación a la docencia que capitaliza sus propias fortalezas y métodos preferidos de enseñanza, como se muestra en la figura 1.
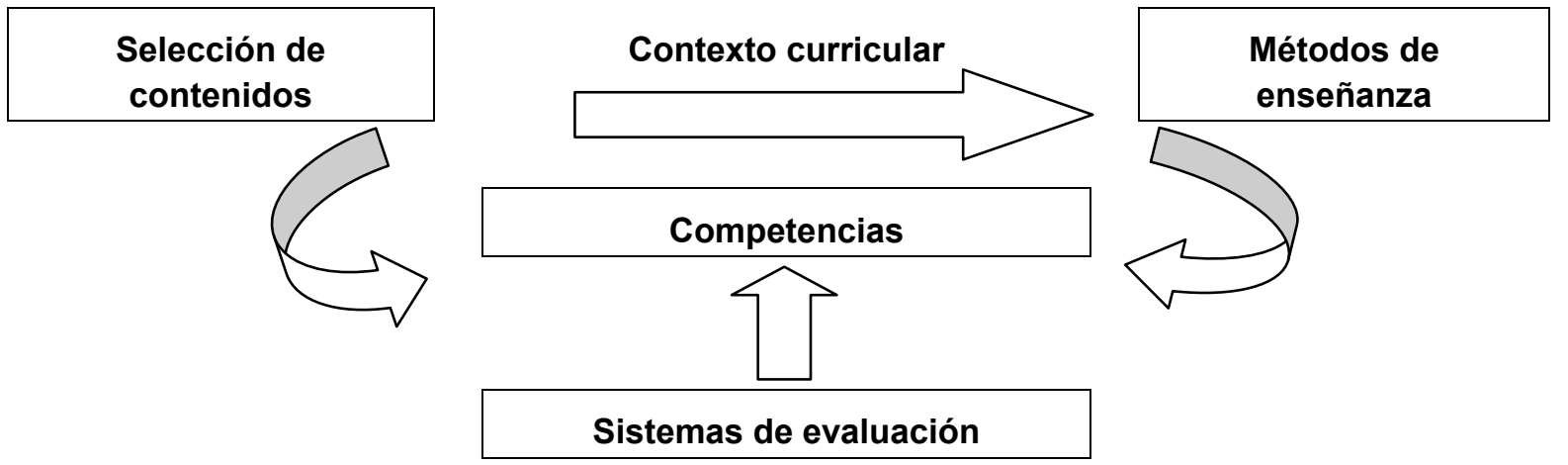

Figura 1. Contexto Institucional

En coincidencia con Moreno, $(2009,2010 a)$; la EBC promovida desde las instancias oficiales para educación básica ha sido poco consistente, a partir del momento en que se pone en marcha un ambicioso proyecto de reforma educativa sin tener un 
diagnóstico certero de las condiciones en que se trabaja en las escuelas, ni un programa de formación y actualización para maestros en servicio. El retraso en el diseño y difusión de los materiales didácticos que requiere el docente en el aula, ha propiciado que éste no opere cabalmente el cambio operado en los planes y programas de estudio de educación básica. Asimismo, subsiste una contradicción entre las formas y prácticas de enseñanza y la evaluación del aprendizaje por competencias.

\section{El aprendizaje y la evaluación de competencias}

La reflexión sobre el proceso de evaluación es un ámbito muy favorable para comprender la naturaleza de la actividad docente y educativa del aula y de la institución. Como señalan Comboni y Juárez, (2000), la evaluación condiciona de tal manera la dinámica del aula, que bien podría decirse que la hora de la verdad no es la del aprendizaje, sino la de la evaluación. Al enfocarse la actividad escolar al proceso de evaluación, se determina lo que hay que aprender, el modo de aprendizaje y el momento en que ha de efectuarse el mismo.

La evaluación se caracteriza también por su carácter instrumental. Esto lleva, por lo tanto a reconocer que la evaluación lleva necesariamente a la emisión de un juicio de valor, pero no solamente, sino también a tomar decisiones. Evaluar es comprender situaciones educativas que tienen que ver con la actuación de alumnos y docentes y cómo estos se relacionan en el proceso de alcanzar mayores logros de aprendizaje. En este sentido, evaluar los procesos de enseñanza y aprendizaje permitirá comprender las condiciones en que éste se desarrolla con la finalidad de introducir cambios y mejoras durante su ejecución. La evaluación es pues, en sí misma, un proceso continuo y un elemento, a la vez de toda actividad educativa intencional. Aplicada a la recuperación de información sobre las competencias, requiere un nuevo rol del docente en el que proponga alternativas, estimule la meta cognición, la comprensión de los procesos de pensamiento, incentive los procesos de creación e iniciativa de los alumnos e impulso a la investigación y la búsqueda propia de los significados del nuevo conocimiento o experiencia. 
En la EBC la evaluación consiste en un proceso de recolección de evidencias sobre el desempeño del estudiante con la intención de construir y emitir juicios de valor a partir de su comparación con un marco de referencia constituido por las competencias, sus unidades o elementos y los criterios de desempeño y en identificar aquellas áreas que requieren ser fortalecidas para alcanzar el nivel de desarrollo requerido, establecido en el perfil y en cada uno de los cursos del plan de estudios. Con base en el planteamiento de que las competencias son expresiones complejas de un individuo, su evaluación se lleva a cabo a partir del cumplimiento de niveles de desempeño elaborados ex profeso.

De esta manera, la evaluación basada en competencias implica, entre otros aspectos, que éstas deben ser demostradas, por lo que requieren de su definición de evidencias, así como de los criterios de desempeño que permitirán inferir el nivel de logro. Este tipo de evaluación no excluye la verificación del dominio teórico y conceptual que necesariamente sustenta la competencia. En ese sentido, se requiere una evaluación integral e integrada de conocimientos, habilidades, actitudes y valores en la acción.

Desde esta perspectiva, la evaluación cumple con dos funciones básicas, la sumativa de acreditación/certificación de los aprendizajes establecidos en el plan de estudios y la formativa, para favorecer el desarrollo y logro de dichos aprendizajes; esto es, el desarrollo de las competencias y de sus elementos. Dicho de otro modo, la función sumativa puede caracterizarse como evaluación de competencias y la evaluación formativa como evaluación para el desarrollo de competencias ya que valora los procesos que permiten retroalimentar al estudiante.

Con base en lo anterior, la evaluación basada en competencias se caracteriza por centrarse en las evidencias de los aprendizajes (definidos en parámetros y en criterios de desempeño) y por ser integral, individualizada y permanente; por lo tanto, no compara diferentes individuos ni utiliza necesariamente escalas de puntuación y se realiza, preferentemente, en situaciones similares a las de la actividad del sujeto que se evalúa.

Para ello, es importante utilizar las propias tareas de aprendizaje como evidencias, ya que permiten una evaluación del proceso de aprendizaje y no sólo 
de los resultados. Si la evaluación pretende ser integral, habrá de utilizar métodos que permitan demostrar los conocimientos, las habilidades, las actitudes y los valores en la resolución de problemas. Requiere además, seleccionar métodos y estrategias acordes para el tipo de desempeño a evaluar. Por lo anterior, es posible utilizar entrevistas, debates, observación del desempeño, proyectos, casos, problemas, exámenes y portafolios, entre otros.

La evaluación que se lleva durante el proceso educativo es de tipo formativa y sumativa, cuantitativa y cualitativa y recupera información sobre diferentes objetos de evaluación, entre otros: a) los conocimientos previos, b) la motivación, c) los materiales utilizados, d) las actividades de enseñanza y aprendizaje, e) la participación y compromiso del alumno, e) los resultados de las actividades y logros del alumno, f) la innovación y transformación de materiales realizada por los alumnos.

El concepto de evaluación está íntimamente ligado a la forma de concebir el aprendizaje como se aprecia en la tabla 2:

Tabla 2.

Conceptualización del aprendizaje en diferentes enfoques

\begin{tabular}{ll}
\hline \multicolumn{1}{c}{ ENFOQUE } & \multicolumn{1}{c}{ CONCEPTUALIZACIÓN DEL APRENDIZAJE } \\
\hline Objetivos operativos & Énfasis en resultados observables \\
$\begin{array}{l}\text { Procesos de pensamiento } \\
\text { y resolución de problemas } \\
\text { (neo conductismo) }\end{array}$ & $\begin{array}{l}\text { Resultados del aprendizaje interpretados como base de la readaptación } \\
\text { de actividades pedagógicas }\end{array}$
\end{tabular}

Procesos constructivistas de aprendizaje

Proceso reflexivo y meta cognitivo

Competencias académicas y profesionales

La práctica es una forma nueva de aprendizaje en la que el alumno es el principal protagonista de organización de su aprendizaje. La práctica docente impacta en el desarrollo de la competencia. La evaluación debe ser un proceso individual por lo que no hay comparaciones entre sujetos

Se argumenta que el enfoque de la educación y la capacitación basadas en competencias constituyen en potencia un marco coherente para el aprendizaje y desarrollo de una habilidad. No obstante, hay diferentes maneras de conceptualizar la naturaleza de la competencia. Si no se adopta la apropiada o si las normas desarrolladas no son las adecuadas, entonces no solo no se desarrollará dicho 
potencial, sino que, a mediano plazo, se perjudicará la estructura de desarrollo de habilidades, (Gonczi, Hager, \& Athanasou, 1996).

La evaluación de Competencias da cuenta de un juicio de valor con respecto a la competencia e implica la atención tanto al Educando (a partir de las evidencias de desempeño y de conocimiento); como al Docente (en términos de valorar su función en el acompañamiento y promoción del desarrollo de las competencias esperadas en los educandos). Considerando que todo aprendizaje parte de lo que un estudiante ya sabe o es capaz de hacer, es importante realizar una evaluación cualitativa de los saberes y conocimientos previos, las necesidades educativas y el contexto sociocultural que permitirá reconocer por donde reconocer y evaluar aprendizajes situados y significativos. Otro momento importante de evaluación es el que se refiere a la observación de los avances de los alumnos a fin de proporcionar los andamiajes necesarios.

Finalmente, considerando el carácter institucional que tiene la evaluación, al final de un ciclo o de un periodo de estudios, debe darse cuenta del balance constatando el grado de avance del alumno y del cumplimiento de los propósitos de enseñanza y aprendizaje. Debe distinguirse la evaluación como recuento de un proceso y la acreditación del mismo. En este sentido, se está hablando de un continuum como se muestra en la figura 2:

\section{Estado 1}

Evaluación diagnóstica

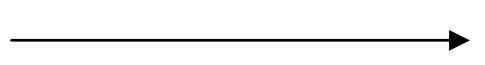

Evaluación formativa

\section{Estado 2}

Evaluación Sumativa

Figura 2. Continuum del proceso de evaluación.

Una vez reconocidos o elaborados los objetivos de todo proceso educativo, las preguntas obligadas que debe hacerse un docente son:

- ¿Qué clase de datos o información requiero para evaluar los efectos de un proceso educativo?

- ¿De qué manera recogeré la información que necesita?

- ¿Cómo interpreto las informaciones recogidas? 
Para tratar el tema de la evaluación centrada en las competencias es viable recuperar lo que Biggs (2005) denomina "alineamiento constructivo" que implica que tanto los sistemas de evaluación como los métodos se definen y estructuran según las competencias a alcanzar.

Este alineamiento con las competencias supone cambios importantes y a todos los niveles en la configuración de los sistemas de evaluación.

Estos son:

a) Aplicar evaluación auténtica, (“Authentic Assessment")

Evaluar el desarrollo de competencias implica valorar de una forma integrada todos sus componentes. Es un acto planificado, integral y pertinente a las competencias a alcanzar, a las demandas que plantea el desempeño prefijado con anterioridad. Esta evaluación es más holística que analítica al evitar presentar tareas que requieran el desempeño de una única habilidad, conocimiento o actitud.

b) Evaluación referida al criterio

En una evaluación alineada con las competencias resulta necesario ir más allá de la pura definición de estas competencias y establecer para cada una de ellas o para cada conglomerado de competencias los niveles de logro o desempeño que se consideran adecuados, así como los criterios o niveles que serán los referentes que orienten la evaluación del alumno.

c) Apoderamiento de la evaluación por parte de los alumnos

La evaluación de competencias se focaliza en el aprendizaje del alumno, requiere un papel activo y responsable por parte de éste y diluye la distinción entre lo que se puede considerar actividad de aprendizaje y actividad de evaluación. La evaluación sería una actividad imbricada en el propio aprendizaje. La autoevaluación y la coevaluación (por "pares" o "grupos") cobran importancia bajo este nuevo enfoque. Conseguimos con ello un papel activo del alumno y que se haga responsable de sus logros, se automotive, autorregule y autooriente su aprendizaje.

d) Evaluación continua y formativa 
La evaluación sumativa tiene una función certificadora que sigue siendo esencial dentro del proceso de enseñanza y aprendizaje, pero con el nuevo paradigma la evaluación debe asumir más funciones, mayor profundidad y mayor cobertura. Las actividades de evaluación sumativas y finales deben complementarse con actividades de evaluación formativas y continuas.

La evaluación por competencias es tanto cualitativa como cuantitativa. En lo cualitativo se busca determinar de forma progresiva los logros concretos que van teniendo los alumnos a medida que avanzan en el curriculum. En lo cuantitativo, los logros se relacionan con una escala numérica, para determinar de forma numérica el grado de avance. De esta manera, los números indicarán niveles de desarrollo, y tales niveles de desarrollo se corresponderán con niveles de logro cualitativos. Las matrices de evaluación de competencias son las que nos permiten evaluar a los alumnos tanto de forma cualitativa (en sus logros) como cuantitativas (niveles numéricos de avance), (Zavala, 2003)

\section{¿Cómo evaluar?}

Para evaluar las competencias, un docente debe referir un sistema de conocimientos conceptuales y de procedimiento para identificar una tarea o problema y las formas de resolverla mediante acciones eficaces.

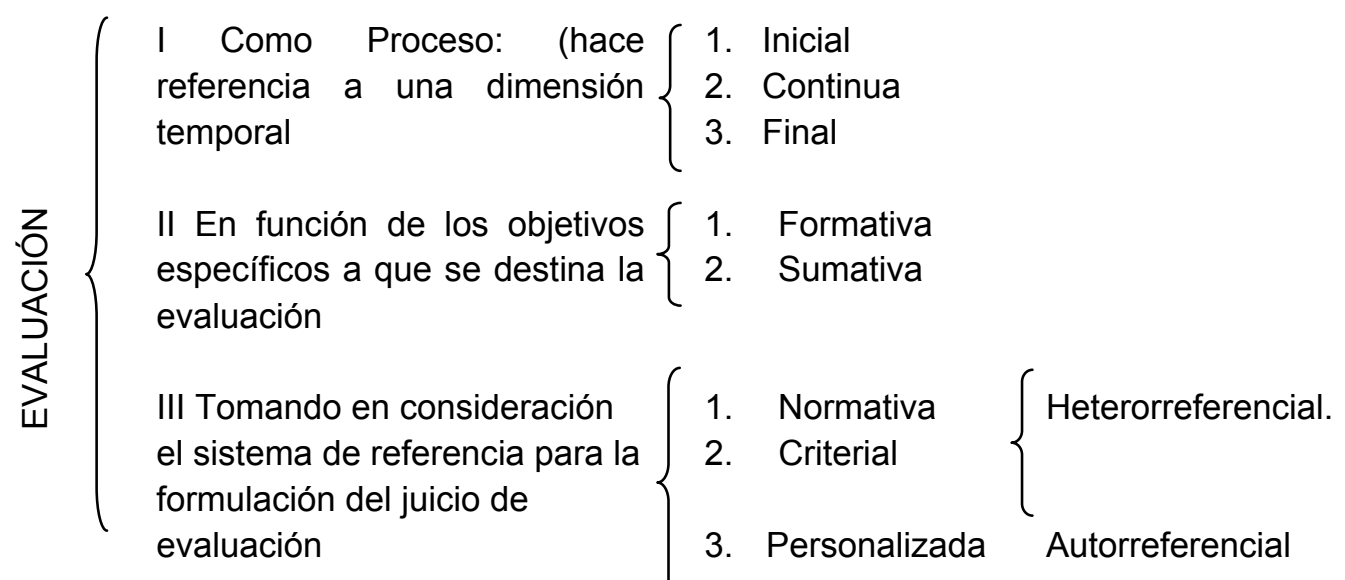

Figura 3. Clasificación de la evaluación (Huerta, 2002). 
Es decir, supone la recuperación del conocimiento y de habilidades que aunados a actitudes $\mathrm{y}$ valores permiten a sus alumnos el uso inteligente de sus saberes, habilidades y un desempeño eficiente como resultado de acciones pertinentes en un contexto específico.

De acuerdo con Comboni y Juárez (2000), los criterios pedagógicos para instrumentos de evaluación deben distinguir entre obstáculo, dificultad y logro. Un obstáculo sería una situación en la que el alumno no puede resolver el problema por sí solo.

La dificultad se manifiesta cuando el alumno requiere de un pequeño apoyo de maestro para superar un problema de perspectiva. El logro seria la manifestación del dominio de una competencia.

\section{¿Qué evaluar?}

De forma resumida podemos plantear que la evaluación por competencias tiene las siguientes características: 1) Es un proceso dinámico y multidimensional que realizan los diferentes agentes educativos implicados (docentes, estudiantes, institución y la propia sociedad). 2) Tiene en cuenta tanto el proceso como los resultados de aprendizaje. 3) Ofrece resultados de retroalimentación tanto cuantitativa como cualitativa. 4) Tiene como horizonte servir al proyecto ético de vida (necesidades y fines, etc.) de los estudiantes. 5) Reconoce las potencialidades, las inteligencias múltiples y la zona de desarrollo próximo de cada estudiante. 6) Se basa en criterios objetivos y evidencias consensuadas socialmente, reconociendo además la dimensión subjetiva que siempre hay en todo proceso de evaluación. 7) Se vincula con la mejora de la calidad de la educación ya que se trata de un instrumento que retroalimenta sobre el nivel de adquisición y dominio de las competencias y además informa sobre las acciones necesarias para superar las deficiencias en las mismas (Ruiz Iglesias, 2008).

Para entender mejor el quehacer evaluativo, en la tabla 3 se presenta un cuadro comparativo entre las características de la evaluación tradicional por objetivos y la evaluación por competencias. 
Tabla 3.

Parámetros empleados en la evaluación por objetivos y la evaluación por competencia (Huerta, 2002).

\begin{tabular}{ll}
\hline Evaluación tradicional (por objetivos) & Evaluación de competencias \\
\hline Orientado a condiciones observables & Orientado a aptitudes complejas \\
Fragmentación en áreas de aprendizaje & Integración de conocimientos, habilidades y valores \\
Tendencia a mecanizar el proceso educativo & Orientado a dinamizar el proceso educativo \\
Evaluación fragmentadora & Evaluación integradora \\
Desconoce lo que va a evaluarse & Conoce lo que va a evaluar \\
& Individual \\
\hline
\end{tabular}

Una discusión contemporánea se da en torno al objeto de evaluación al introducir los logros curriculares o aprendizajes esperados como se les conoce en educación básica. La idea inicial al implantarlos es desplazar el concepto de objetivo y de esta manera superar las limitaciones propias de un objetivo que durante mucho tiempo fue considerado como un punto de partida, de llegada y premisa general para la educación y la enseñanza. Lo cierto es que hasta ahora el objetivo no ha perdido vigencia, pero se le asignan funciones más instrumentales. Es un punto central de referencia para entender la naturaleza específica de las acciones que se han de realizar. El objetivo es el nivel de educación que se quiere alcanzar y el logro del nivel efectivamente logrado, cuando se ha alcanzado el objetivo propuesto. Véase la tabla 4:

Tabla 4.

Diferencia entre evaluación por objetivos y por Logros curriculares

EVALUACIÓN POR OBJETIVOS

Establece el nivel de educación que se quiere alcanzar

Es un punto central de referencia para entender la naturaleza específica de las acciones que se han de realizar

Demarca el resultado esperado, el qué y para qué de nuestro trabajo, el camino a seguir y los medios que se utilizarán para alcanzar estos fines

\section{EVALUACIÓN DE LOGROS CURRICULARES}

Establece el nivel efectivamente logrado, cuando se ha alcanzado el objetivo propuesto

Es esencialmente cualitativa, global y centrada en el aprendizaje quizás por su mayor grado de complejidad, por lo que va a depender más del criterio y el entendimiento del docente, que de los propios procedimientos que utilice

Requieren como mecanismo de control y de medición, indispensables para establecer una correspondencia entre los supuestos teóricos de los logros, las realidades objetivas de la actuación y el desempeño del estudiante. 
El objetivo señala el qué y para qué de nuestro trabajo, el camino a seguir y los medios que se utilizarán para alcanzar estos fines. Pero también se ha querido presentar a los objetivos como un resultado esperado. Los objetivos surgen como resultado de los procedimientos y medios pedagógicos y educativos que se determinen en cada caso para alcanzar estos logros.

Los logros curriculares en el papel se presentan como una herramienta muy importante y útil en una enseñanza y un aprendizaje concebidos como un proceso de formación permanente. Las dificultades comienzan en el momento en que el docente se deba evaluar estos logros.

Sabemos los problemas que ha tenido que enfrentar la evaluación en el momento de valorar los procesos y los resultados globales o generales. Una evaluación por logros, es esencialmente cualitativa, global y centrada en el aprendizaje quizás por su mayor grado de complejidad, por lo que va a depender más del criterio y el entendimiento del docente, que de los propios procedimientos que utilice.

No es extraño entonces que la evaluación de logros se haya constituido en quebradero de cabezas para un maestro formado en una tradición donde la enseñanza dominó sobre el aprendizaje, los resultados sobre el proceso y la calificación numérica siempre se constituyó en la medida del rendimiento y la formación.

Todos sabemos que en la investigación científica existen las denominadas variables, que no son otra cosa que las dimensiones, aspectos, rasgos o cualidades que caracterizan un fenómeno y que tiene la capacidad de asumir distintos valores. Pero como una variable tiene un grado de generalidad y de abstracción y no posee una utilidad directa en el régimen operativo de una investigación, se recurre a los indicadores cuya función principal es servir de indicios, señales, medidas o datos empíricos que permite aprehender las dimensiones de esta realidad.

Lo mismo sucede con los logros que necesitan de un conjunto de indicadores específicos que se requieren como mecanismo de control y de medición, indispensables para establecer una correspondencia entre los supuestos teóricos de los logros, las realidades objetivas de la actuación y el desempeño del estudiante. 
¿Cómo se evalúan estos logros? Ahí comienza la confusión entre los maestros, que no están muy seguros si se trata de una evaluación de rendimientos, de objetivos o una clásica evaluación de productos. Debido a la complejidad de los logros se requiere de una multiplicidad de medios que nos permitan captar todas las dimensiones cognoscitivas del proceso evaluado: evaluaciones, debates, diálogos, entrevistas, pruebas escritas, etc.

El maestro debe monitorear formal y/o informalmente los procesos de aprendizaje y recoge evidencia necesaria para emitir una evaluación sobre el logro de las metas de aprendizaje y el desarrollo conceptual a fin de saber si el estudiante logró la competencia esperada.

El carácter preestablecido y complejo de la evaluación de competencias en el aula, ha derivado hacia prácticas muy irregulares entre los docentes, ya que éstos muchas veces centran su trabajo pedagógico alrededor de los logros elaborados por los organismos oficiales y dejan por fuera todo aquello que no hace parte de ellos.

El hecho de que todo gire alrededor de los logros deja por fuera lo que algunos denominan los factores asociados, algo así como las variables extrañas que inciden en un problema pero que no han sido considerados como parte de esta relación de variables.

Muchas veces todo se concentra en los aspectos cognoscitivos de los logros y se olvida aquello que nos permita conocer más allá de la memorización o asimilación de un conocimiento. Por ejemplo, saber qué y por qué no ha aprendido, cuáles son los contenidos que no ha aprendido, que desde un punto de vista pedagógico tiene más relevancia que la misma adquisición de un conocimiento.

Algunos creen que para resolver estas limitaciones los logros debieran convertirse en verdaderas hipótesis de trabajo, donde el estudiante tenga la oportunidad de ir más allá de los estrechos límites de estos logros. Véanse a continuación algunas recomendaciones técnicas... 


\section{¿Con qué instrumentos evaluar?}

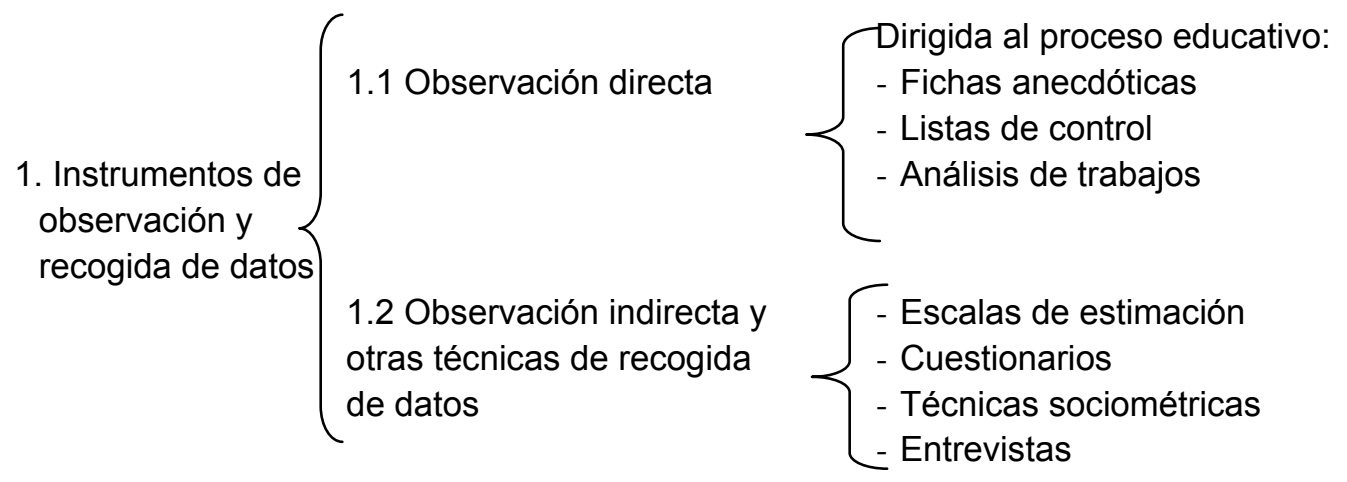

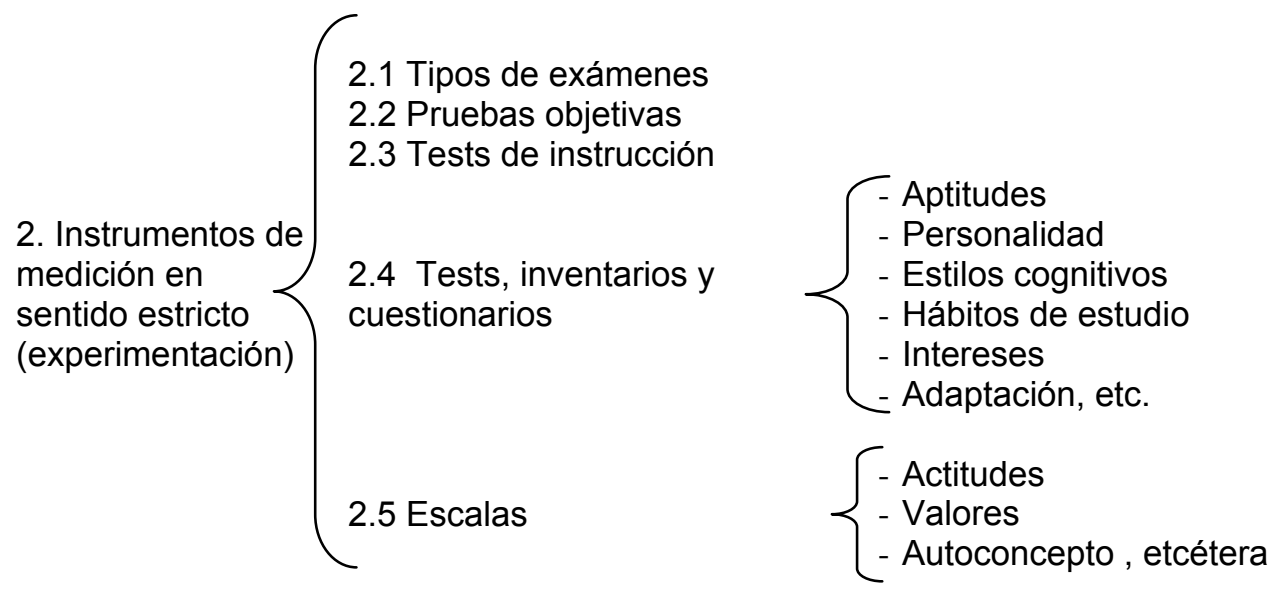

Figura 4. Instrumentos de recogida de información (García Ramos, 1989).

Cabe señalar que desde una perspectiva de evaluación de competencias, debe hacerse énfasis en el uso de instrumentos que permitan recuperar aspectos cualitativos que complementen el uso de instrumentos objetivos. Entre otros cabe mencionar los siguientes:

- El tipo de andamiaje o ayuda pedagógica que se otorga

- Adaptación al grupo social

- Participación del alumno en el grupo

- Motivación e interés

- Asumir responsabilidades

- Respeto a los demás en sus intervenciones

- Trabajo individual y colectivo

- Interactividad en el aula 
- Desarrollo del pensamiento critico

- Manifestación de nuevas actitudes y valores, hábitos de trabajo

- Diario, asamblea de aula, o debates

- Historial académico

- Portafolios o carpetas

La experiencia escolar ha flexibilizado la práctica de la evaluación, y en la actualidad numerosas instituciones educativas y docentes han adaptado o enriquecido de acuerdo a sus exigencias y necesidades educativas los indicadores de logros curriculares oficializados. Una actividad importante es la explicitación de los requerimientos de evaluación que implican definir la relación entre el objeto (lo que se quiere evaluar); el objetivo (para qué se quiere evaluar) y el parámetro de evaluación (con relación a qué se va a evaluar).

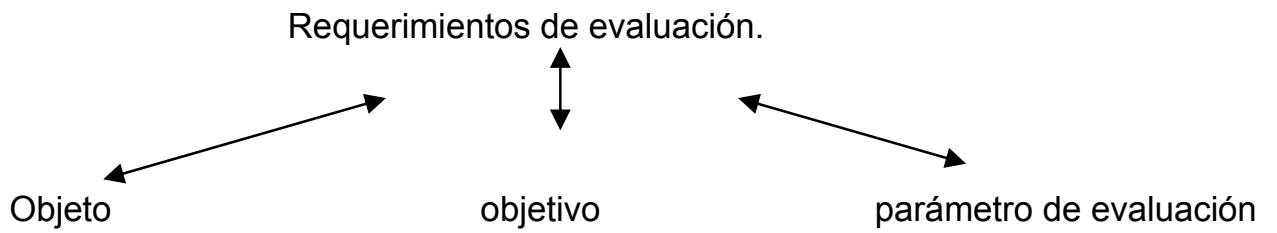

(¿Qué se quiere evaluar?) (¿Para qué se quiere evaluar?) (¿Con relación a qué se va a evaluar?).

En síntesis, la evaluación es un proceso que comprende distintas fases:

1. Planeación de la evaluación para determinar las técnicas a emplear, los aspectos que se incluirán en el proceso, la selección y construcción de instrumentos de recopilación de información.

2. Recolección de evidencias a través de la aplicación de instrumentos de evaluación.

3. Comparación de evidencias con los requerimientos. Se refiere al contraste de los resultados obtenidos con el parámetro establecido.

4. Formulación del juicio basado en la comparación. Con base en la contrastación de datos y referentes, se formulan las conclusiones de valoración.

5. Involucrar otras prácticas de evaluación 
Autoevaluación que como proceso de autocrítica genera hábitos enriquecedores de reflexión sobre la propia realidad. Puede materializarse en una parte de la calificación. Algunas de sus implicaciones son:

\begin{tabular}{l|l}
\multicolumn{1}{c|}{ Para el alumno } & \multicolumn{1}{|c}{ Para el docente } \\
\hline Reconocer avances, logros y dificultades & $\begin{array}{l}\text { Disponer de mejores elementos de juicio que le } \\
\text { permitan facilitar y reorientar el aprendizaje }\end{array}$ \\
\hline $\begin{array}{l}\text { Analizar su actuación individual y grupal } \\
\text { en el proceso educativo }\end{array}$ & $\begin{array}{l}\text { Valorar la actuación y conocer la situación de los } \\
\text { alumnos }\end{array}$ \\
\hline Desarrollar una actitud crítica y reflexiva & Valorar su propia actuación y adecuar las actividades \\
\hline $\begin{array}{l}\text { Desarrollo de metacognición y y } \\
\text { autoestima }\end{array}$ &
\end{tabular}

Coevaluación: refiere la valoración grupal entre pares y tiene las siguientes implicaciones:

\begin{tabular}{|c|c|}
\hline Para el alumno & Para el docente \\
\hline $\begin{array}{l}\text { Tomar conciencia respecto a los avances } \\
\text { y problemas individuales y grupales y de } \\
\text { las percepciones que tiene de las } \\
\text { actividades }\end{array}$ & $\begin{array}{l}\text { Valorar el desempeño personal y social de los } \\
\text { alumnos en el grupo para reorientar el proceso de } \\
\text { aprendizaje }\end{array}$ \\
\hline $\begin{array}{l}\text { Desarrollar un aserie de desempeños } \\
\text { sociales, como la convivencia, } \\
\text { solidaridad, sociabilidad, respeto mutuo, } \\
\text { etc. }\end{array}$ & \\
\hline $\begin{array}{l}\text { Asumir actitudes críticas frente a los } \\
\text { demás }\end{array}$ & \\
\hline
\end{tabular}

\section{A manera de conclusión: Algunos ideas y sugerencias}

El enfoque educativo basado en competencias constituye un marco de trabajo coherente para el desarrollo de habilidades. Sin embargo, no deben perderse de vista los siguientes aspectos:

La evaluación de Competencias da cuenta de un juicio de valor con respecto a la competencia e implica la atención tanto al educando (a partir de las evidencias de desempeño y de conocimiento); como al docente (en términos de valorar su función en el acompañamiento y promoción del desarrollo de las competencias esperadas en los educandos). La evaluación debe ser un proceso individual que no requiere de comparaciones entre sujetos. 
$>$ El aprendizaje y la evaluación de competencias en la escuela, requieren considerar a la práctica como una forma nueva de aprendizaje en donde el alumno es el principal protagonista de la organización de su aprendizaje, y el docente el promotor central que incide en los resultados que se logren en el desarrollo de dichas competencias.

$>$ No basta con enunciar habilidades o competencias, sino explicitar qué se entiende por ellas, cómo desarrollarlas y cómo evaluarlas.

> Si el problema de la evaluación de las competencias se reduce a determinar hasta qué punto los alumnos han desarrollado o logrado las competencias propuestas como resultado de la ayuda pedagógica que han recibido, es necesario diseñar procedimientos e instrumentos de evaluación que permitan captar efectivamente los progresos que realizan los alumnos en el nivel inicial de competencia, durante el transcurso de la instrucción y como resultado de la misma.

> Tomar la decisión de realizar el trabajo educativo basado en competencias supone adquirir un compromiso de centro escolar que permita abordar la complejidad de adoptar ciertas medidas organizativas y funcionales, imprescindibles para su desarrollo.

$>$ Como docentes, debemos tener presente que la evaluación puede convertirse en un instrumento indiscriminado para avalar decisiones sobre política económica más que educativa si permitimos que la evaluación de los logros curriculares y de aprendizaje responda más a las directrices y políticas acordadas por las grandes agencias y bancos internacionales, que a las necesidades más sociales, culturales y educativas de nuestro contexto.

\section{Referencias}

(1998) Estrategias de productividad, recursos humanos y competencia laboral. Industria de Autopartes en México. CONOCER, Organización Nacional del Trabajo (OIT).

(1998) La transferibilidad de las nuevas competencias en empresas innovadoras. CONOCER, Organización Internacional del Trabajo (OIT).

Argudín V. Y. (2001). Educación Basada en Competencias. Revista de Educación. Nueva Época, 16. 
Argüelles, A. (Comp.) (s/f). Competencia laboral y educación basada en normas de competencia. SEP, CNCCL, CONALEP. México: Limusa V Ed.

Barrón, T. C. (2002) La educación basada en competencias en el marco de los proceso de globalización. En M. A. Valle (Coord.) Formación profesional y certificación profesional. Pensamiento Universitario 91. Universidad Nacional Autónoma de México. Coordinación de Humanidades. Centro de Estudios sobre la Universidad. México. 2a. Ed.

Biggs, J. (2005): Calidad del aprendizaje universitario. Madrid: Narcea.

Cerda, G. H. (2003). La nueva evaluación educativa. Desempeños, logros, competencias y estándares. Colombia: Cooperativa Editorial Magisterio.

Chomsky, N. (1985). El conocimiento del lenguaje, su naturaleza, origen y uso. Ed. Alianza.

Comboni, S. \& Juárez, J. M. (2000). La evaluación educativa y de los aprendizajes. En Resignificando el espacio escolar. La innovación y la calidad educativa en una nueva práctica pedagógica.

Comisión Europea.Tuning educational structures in Europe. (2006). La contribución de las universidades al proceso de Bolonia. Informe final. Universidad Deusto. Universidad de Groningen

De Ibarrola, M. \& Gallart, M. A. (Eds.). (1994). Democracia y productividad. Desafíos de una nueva educación media en América Latina. Santiago- Buenos Aires- México: UNESCOOREALC-Red Latinoamericana de Educación y Trabajo CIID-CENEP.

De la Orden. (1982). La evaluación educativa. Documento inédito. Universidad Anáhuac.

Díaz Barriga, A. (2006), El enfoque de competencias en la educación. ¿Una alternativa o un disfraz de cambio? Perfiles Educativos, XXVIII (111), pp. 7-36. http://scielo.unam.mx/pdf/peredu/v28n111/n111a2.

Dirección General de Educación Superior para Profesionales de la Educación (DGESPE), (2012). Recuperado de http://www.dgespe.sep.gob.mx/reforma_curricular

Dirección General de Operación de Servicios Educativos para el Distrito Federal (DGOSEDF). (2003). Lineamientos para la organización y funcionamiento de los Servicios de Educación Primaria 2003 - 2004. Subsecretaría de Servicios Educativos para el Distrito Federal.

Dirección General de Operación de Servicios Educativos en el Distrito Federal. (DGOSEDF), (2003A). Coordinación Sectorial de Educación Primaria. Cuaderno de Autoevaluación de las Competencias Docentes

Elliot, J. (1990). La investigación - Acción en Educación. Madrid: Morata.

Fernández March, A. (2005). Nuevas metodologías docentes. España: Universidad Politécnica de Valencia.

Ferraro, A. (2001). En D. R Thierry. La evaluación de programas de formación profesional basada en competencias. Paedagogium, 3 (1).

Flecha, Padrós \& Puigdellívol. (2003). Comunidades de Aprendizaje: transformar la organización escolar al servicio de la comunidad. Organización y gestión educativa, 5 pp. 4-8. Bilbao: Fórum Europeo de Administradores de la Educación y CISSPRAXIS, S.A.

García, J. (2008). Las competencias básicas: ¿Un nuevo enfoque educativo? Documento circulación interna Ceneval. México.

García Ramos, J. M. (1988). Modelos exploratorios y confirmatorios en la investigación pedagógica no experimental. Revista Ciencias de la Educación. XXXIV (136). Madrid.

García Ramos, J. M. (1989). Bases pedagógicas de la evaluación. Madrid: Síntesis.

Gardner, M. (1998). Inteligencias múltiples. La teoría en la práctica. Barcelona: Paidós.

Gonczi, A., Hager, P. \& Athanasou, J. (1996). Instrumentación de la educación basada en competencias. En J. A. Argüelles (Comp.). Competencia laboral y educación basada en normas de competencia. SEP, CNCCL, CONALEP. México, Limusa Eds. 
Guzmán, J. C. Experiencias curriculares de la educación basada en competencias (EBC) en México. Entre el desconocimiento y la confusión coordinación de psicología educativa. Facultad de psicología. Recuperado de UNAM http://www.marco.edu.mx/BibliotecaDlgital/files/31\%20Experiencias $\% 20$ curriculares $\% 20$ de\%20la\%20EBC.pdf

Hager, P. \& Beckett, D. (1996). Bases filosóficas del concepto integrado de competencia. En A. Argüelles (Comp.). Competencia laboral y educación basada en normas de competencia. México: Limusa Eds.

Herrera, M. A. (1996). Formación científica y profesional: propuesta para la universidad pública de México. Perfiles Educativos 71, 42-53. México, CISE - UNAM.

Hualde, A. (2001). Aprendizaje industrial en la frontera norte de México: la articulación entre el sistema educativo y el sistema productivo maquilador. El Colegio de la Frontera Norte. México: Plaza y Valdés Ed.

Huerta, A. M. A. (2002). Bases sociales y psicopedagógicas de la evaluación de competencias. Análisis de una experiencia en el sector agrario. Tesis de doctorado. Universidad Anáhuac e Universidad Complutense de Madrid.

Hymes, D. (1996). Ethnography, Linguistics, Narrative Inequality: Toward an Understanding of Voice e Taylor \& Francis e-Library

Malpica, M. C. (1996). El punto de vista pedagógico. En Argüelles, A. Op. Cit.

Marsden, D. (1994). Cambio industrial, 'competencias' y mercados de trabajol en Centro Europeo para el desarrollo de la formación profesional. Formación profesional. Revista Europea. Las competencias: el concepto y la realidad, 1, 14-21.

Mertens, L. (1998). Competencia laboral: sistemas, surgimiento y modelos. Montevideo, Uruguay: OIT. Cinterfor.

Montero, A. (2008). ¿Son universales las competencias básicas? ESCUELA. Foro de debate. No. 3.775 (199).

Moreno, M. (2009). Didáctica. Fundamentación y práctica. México: Editorial Progreso. Recuperado de

http://redescolar.ilce.edu.mx/redescolar/biblioteca/articulos/htm/recursos_eva.htm

Perrenoud, P. (2004). Diez nuevas competencias para enseñar. Recuperado de http://www.uv.mx/dgda/files/2013/09/Philippe-Perrenoud-Diez-nuevas-competenciaspara-ensenar.pdf

Rojas Moreno, I. (2002). La EBNC como un nuevo modelo de formación profesional en México. En Valle F., M. A. (Coord.) Formación profesional y certificación profesional. Pensamiento Universitario 91. Universidad Nacional Autónoma de México. Coordinación de Humanidades. Centro de Estudios sobre la Universidad. México. 2a. Ed.

Romero Torres, N. L. ¿Y qué son las competencias? ¿Quién las construye? ¿Por qué competencias? Recuperado de http://www.quadernsdigitals.net.

Ropo, E. (1991). Diferencias en la enseñanza de docentes de inglés: expertos y principantes. En M. Carretero (Comp.) Procesos de enseñanza y aprendizaje. Aique Grupo Editor

Ruiz Iglesias, M. (2008). La evaluación de competencias. Recuperado de: http://servicios.encb.ipn.mx/tutorias/formatos/LECTURA_TUTO/LA\%20EVALUACI\%C3\% 93N\%20DE\%20COMPETENCIAS.pdf.

S/A. (2003). Dossier Educativo Num. 22. Calidad del aprovechamiento escolar en primarias y secundarias públicas de México. Revista Educación, 98.

Schmelkes, S. (1991). Necesidades básicas de los adultos en América Latina, trabajo realizado por encargo de la Oficina Regional de la UNESCO para América Latina y el Caribe.

Scriven, en Andrés J. M. (2000). Manual de la Educación. España: Ediciones Credimar.

SEP- SEMS- COSDAC. (2009). Reforma Integral del Bachillerato Normas de control escolar de planteles que integran el Sistema Nacional de Bachillerato (Documento de Trabajo). 
Sternberg, R. J. (1997). Inteligencia exitosa. Cómo una inteligencia práctica y creativa determina el éxito en la vida. Barcelona: Paidós.

Stufflebeam, D. \& Shinkfield, A. (1993). Evaluación sistemática, guía teórica y práctica. España: Paidós.

Tobón, S. (2005). Formación basada en competencias. Pensamiento complejo, diseño curricular y didáctica. Bogotá: Ecoe Ediciones.

Toledo G., J. et al. (2008). Ensayo sobre la evaluación de la educación basada en competencia. Documento interno Facultad de Medicina, UNAM, México.

Villa Sánchez, A. (2007). Capítulo I. Aprendizaje basado en competencia, en: Aprendizaje basado en competencias: una propuesta para la evaluación de las competencias genéricas. España: Universidad de Deusto.

Zavala, M. (2003). Qué es la evaluación por competencias? En Las competencias del profesorado universitario. Madrid: Narcea. 


\title{
EL TRABAJO CENTRADO EN EL ESTUDIANTE COMO MEDIO PARA DESARROLLAR COMPETENCIAS MATEMÁTICAS
}

\section{STUDENT-CENTERED WORK AS A MEANS TO DEVELOPING MATHEMATICAL COMPETENCIES}

\author{
Luz María Gómez Ávila \\ Universidad Autónoma de la Ciudad de México \\ academiacch@yahoo.com.mx \\ Juan Manuel Juárez Velázquez \\ Instituto Politécnico Nacional / \\ Instituto de Educación Media Superior \\ ijuarez2002@hotmail.com
}

\begin{abstract}
Resumen
El objetivo de esta investigación fue determinar el papel del trabajo centrado en el estudiante como un medio para desarrollar competencias matemáticas. 100 estudiantes de bachillerato participaron en este estudio, 50 de los cuales participaron en sesiones de trabajo periódicas, centradas en el estudiante, para aprender las competencias matemáticas esbozadas por Turner (2011): comunicación, matematización, representación, razonamiento y argumento, pensamiento estratégico, y uso de lenguaje simbólico y operaciones. Estas competencias fueron activadas a través de estrategias especialmente diseñadas para ayudar a los estudiantes a incrementar el uso productivo de su conocimiento matemático y para desarrollar las habilidades requeridas. Los otros 50 estudiantes asistieron a las clases regulares del curso, pero no tomaron el trabajo extra centrado en el estudiante, previamente descrito. Esta investigación mostró que aquellos estudiantes que se enfocaron directamente al desarrollo de las arriba mencionadas competencias matemáticas a través del trabajo centrado en el estudiante, pudieron realmente activar su conocimiento y habilidades más efectivamente, como se demostró en su puntuación de matemáticas (un examen estandarizado fue resuelto por los 100 sujetos, al inicio y final de este estudio pretest-postest). Adicionalmente, esos estudiantes obtuvieron mejores calificaciones al final del curso. Algunas conclusiones se extrajeron de este estudio: 1) Los estudiantes se desempeñan mejor si se les brindan cantidades adecuadas de tiempo y trabajo, para desarrollar las competencias requeridas. 2) El trabajo centrado en el estudiante es una importante herramienta de aprendizaje cuando el propósito consciente de la educación es el desarrollo de competencias. 3) El desempeño de los estudiantes no debería ser determinado mediante el uso de sólo una medida de evaluación.
\end{abstract}

Palabras clave: asesoría personalizada, atención a la diversidad, buenas prácticas, andamiajes

\begin{abstract}
The objective of this research was to determine the role of student-centered work as a means to developing mathematical competencies. 100 high school students participated in this study, 50 of which engaged in periodical student-centered work sessions, in order to learn the mathematical competencies outlined by Turner (2011): communication, mathematising, representation, reasoning and argument, strategic thinking and using symbolic language and operations. These competencies were activated
\end{abstract}


through strategies specially designed to help students to increase the productive use of their mathematical knowledge, and to develop the required skills. The other 50 students attended the regular course classes, but did not take the extra student-centered work previously described. This research showed that those students who targeted directly to the development of the above mentioned mathematical competencies through student-centered work, could actually activate their knowledge and skills more effectively, as demonstrated by their Math scores (a standardized test having been taken by all 100 subjects, at the beginning and at the end of this pretest-postest study). Also, those students obtained better grades at the end of the course. Some conclusions were drawn from this study: 1) Students perform better if they are given adequate amounts of time and work to develop the required competencies. 2) Student-centered work is an important learning tool when the perceived purpose of education is the development of competencies. 3) Students' performance should not be determined using just a single assessment measure.

Key words: personalized assessment, attention to diversity, good practice, frameworks

\section{Introducción}

El sistema de bachillerato del Instituto de Educación Media Superior del D. F. (IEMS DF) es de relativa reciente creación, habiendo comenzado sus operaciones hace poco más de diez años. La evaluación contemplada dentro de su modelo educativo tiende a poner especial énfasis en el carácter formativo de ésta. Dentro de este modelo, uno de los espacios académicos para provocar el aprendizaje, y para fomentar la evaluación formativa, es la asesoría personalizada, o en grupos pequeños, fomentando el trabajo colaborativo entre pares.

Este modelo educativo no fue formulado originalmente para abordar el desarrollo de competencias, y ha sido hasta fechas recientes que la discusión en torno a ello se ha incorporado en el trabajo colegiado. Desde sus inicios, el aprendizaje ha sido evaluado por medio de objetivos, realizándose la evaluación en términos cualitativos. Se ha detectado un área de oportunidad dentro de las asesorías, como un espacio idóneo para impulsar el desarrollo de competencias matemáticas. Por tal motivo, el objetivo primordial de esta investigación fue determinar si el trabajo personalizado, centrado en el estudiante, a través de la asesoría académica, puede contribuir positivamente al desarrollo y despliegue de competencias matemáticas.

Dicho objetivo responde a la formulación del siguiente problema: En el curriculum formal del bachillerato del IEMS, la materia de matemáticas cubre cinco 
niveles, a cursarse en los primeros cinco de seis semestres. Período tras período, consistentemente, estas materias tienden a registrar un porcentaje de alrededor de $70 \%$ de estudiantes aprobados. El curriculum formal prescribe 3 clases por semana de esta materia, es decir, 4.5 horas. Este tiempo puede resultar insuficiente para impulsar el desarrollo de competencias matemáticas. Sin embargo, existe la posibilidad de trabajar en asesorías académicas personalizadas, en las cuales sería posible enfocarse en dicho desarrollo.

La justificación para llevar a cabo esta investigación reside en que, dado el problema descrito, se hace patente la necesidad de prestar especial atención al trabajo que pueda promover el aprendizaje de competencias matemáticas, susceptibles de ser aplicadas no sólo dentro de los contextos escolarizados, sino que también se constituyan como esquemas mentales transferibles a situaciones diversas, propias de la vida cotidiana. A nivel académico, es de importancia medular que los estudiantes logren construir y activar competencias matemáticas como un medio que facilite su acceso a la educación superior, por lo cual resulta impostergable la promoción de estos aprendizajes dentro del curriculum en acción. Es a través de estrategias de enseñanzaaprendizaje como puede contribuirse a elevar los porcentajes de aprobación, reflejándose esto en el desarrollo de competencias matemáticas. Dichas estrategias pueden ser implementadas dentro del espacio académico destinado a las asesorías centradas en el estudiante, personalizadas o en grupos reducidos que privilegien el trabajo entre pares.

\section{Marco Teórico}

\section{¿Qué es una competencia?}

Atinadamente se ha señalado que el concepto de "competencia" reviste un carácter polisémico (Torres, 2009). Asimismo, se ha apuntado que la falta de una definición "precisa" representa una fuente de desacuerdo (Gimeno, 2009). Incluso, hay un reconocimiento a que la evaluación de las competencias responde más a una 
aspiración por introducir cambios benéficos en el trabajo, la planeación y los resultados de las instituciones educativas, que a un concepto y sistema claramente definidos (Álvarez, 2001). Esto contribuye a que el concepto se constituya como un campo de continuos debates y polémicas, ganando para sí tanto adeptos, como críticos.

Por parte de los primeros, Perrenoud (1998) enfatiza que la inclusión del concepto de competencia en el campo educativo ha contribuido a iluminar con nuevos "matices teóricos" la búsqueda de las características del tipo de aprendizaje que hoy se busca construir. $Y$ en torno a los segundos, mucho del rechazo hacia el término "competencias" y sus implicaciones, se halla vinculado con su génesis, con su marco originario: el ámbito empresarial. Fundamentalmente entretejidas en un árbol semántico con otros conceptos como: "habilidad", "pericia", "destreza", "indicador", "observable", "demostrable", "cuantificable", "estandarizado", las competencias, en su fuente primigenia, aludían a la necesidad de optimizar los procesos y productos del campo industrial y denotaban una fuerte carga conductista: innegablemente, la demostración de una competencia demanda un "performance", un comportamiento observable y mesurable, que, mediante una serie de indicadores, puede ser calificado por un evaluador experto; sin embargo, en unos cuantos años, esta primera acepción de "competencia", concatenada con los intereses económicos de empresas e industrias, alcanzará la centuria de edad, ya que, como lo señala Martínez (2009), data de la década de 1930, en un contexto estadounidense.

Paulatinamente, el concepto de "competencias" se fue adaptando al campo de la educación, con los ya anteriormente señalados problemas por controversias y falta de acuerdos. La vinculación de las competencias con lo laboral representa, para algunos, una realidad innegable, que comporta una tarea ineludible para los sistemas educativos de educación media superior y superior: la preparación y adaptación al mundo del trabajo. En ese sentido, lo denota Pimienta (2008, p. 25), quien reconoce el traspaso del término "competencias", desde la industria a la escuela; pero reconoce en ésta un marco para impulsar la educación para la vida, y dentro de ésta, la incorporación al ámbito laboral: "Me limito a plantear que la incorporación al campo laboral es una realidad para la que tenemos que estar preparados, de manera que debemos contribuir 
a que los estudiantes se capaciten y puedan enfrentar estos retos utilizando las competencias esenciales para la vida".

Cabe enfatizar que, vinculado o no con el campo laboral, el concepto actual de competencia ha logrado trascender ampliamente lo meramente conductual. Así, Perrenoud (1998) postula que las competencias movilizan saberes, entre los cuales se cuentan los conocimientos, las habilidades, los valores y las actitudes, para aplicarlos al encarar una diversidad de tareas. Yendo aún más lejos, Coll y Martín (2006) ahondan en la necesidad de no perder de vista que, para desarrollar las competencias, hay que identificar cuáles son los saberes fundamentales asociados a dichas competencias, coincidiendo en que dichos saberes abarcan no sólo lo procedimental, sino también lo conceptual y lo actitudinal-valoral.

Para otros autores, el concepto de "competencia" envuelve un intrincado proceso evolutivo, que ofrece múltiples posibilidades y oportunidades para la representación y la acción educativas: las competencias, hoy en día, se refieren a complejos constructos holísticos, que han de posibilitar que el individuo enfrente situaciones cambiantes, e incluso, inéditas, de las sociedades actuales, no sólo laboral-económicas, sino sociales, culturales, éticas, humanas, existenciales. Se requiere un "aprendizaje de segundo orden" (Pérez, 2009), que implique las capacidades de la persona para aprender a aprender, y para dirigir y regular su propio aprendizaje. Las consecuencias más radicales, pero factibles, de no desarrollarse como un "individuo competente", no estriban en un mero estar "desposeído" de los conocimientos escolarizados, sino el riesgo de quedar excluido productiva, social, cultural y personalmente de las sociedades presentes, altamente dinámicas e interactivas (Pérez, 2007).

Argudín (2006) hace notar que este complejo proceso evolutivo del concepto de competencia, lo ha desarraigado de su etimología original, en la antigua Grecia, que lo emparentaba con la raíz agon (preparación para competir y ganar en las Olimpiadas), arropado en una cosmovisión mitológica, y se ha estatuido como objeto de consideración de instituciones internacionales, en décadas recientes. Así, Argudín (2006, p. 12) refiere que la UNESCO, en 1999, definía la competencia como: "El conjunto de comportamientos socioafectivos y habilidades cognoscitivas, psicológicas, 
sensoriales y motoras que permiten llevar adecuadamente un desempeño, una función, una actividad o una tarea". En un intento por superar el sempiterno señalamiento que las competencias guardan con el ámbito laboral, se ha reconocido que existen "competencias para la vida". Éstas engloban no sólo los retos del desempeño profesional, sino los círculos privado, social y cultural. Por ello, atendiendo el objetivo 3 del Foro Mundial para la Educación (celebrado en Dakar, en el año 2000), que se refiere al acceso equitativo y universal a la educación para la vida, la UNESCO brindó una definición que aspira a lo omnicomprensivo:

"Las competencias para la vida (...) deberían proveer las herramientas para transformar las sociedades y ayudar a llevar a cabo una globalización con rostro humano. Se refiere a una aplicación efectiva de todas las formas de conocimiento por parte de individuos que funcionen tanto independientemente como en relación con otros, con el objetivo de ayudar a la gente a que se vean a sí mismos como los actores principales en la construcción de su propio futuro y el futuro de la sociedad" (UNESCO, 2003).

Ello contribuye a poner en claro, entonces, que si bien hay competencias expresamente desarrolladas para facilitar la integración del individuo a entornos laborales, hay otro tipo de competencias, mucho más amplias: las competencias para la vida. $Y$ de todo lo dicho anteriormente, se desprende que el período de aprendizaje en la vida de una persona, ya no puede quedar restringido a su vida escolarizada: hoy se concibe que el aprendizaje se ha de registrar a lo largo de toda la vida. No podrá ser así si el individuo no es competente en autodirigir su propio aprendizaje.

La OCDE (2005) también ha reconocido que las competencias juegan un papel de máxima importancia en la época actual, dadas las circunstancias que la modernidad crea, caracterizadas por la diversidad creciente, la interconectividad y la tecnologización, que a su vez, deben ser empleadas para evitar la disociación con tareas insoslayables, tales como: el equilibrio económico, lo ambientalmente sustentable, y la equidad social. El individuo actual precisa más que el simple dominio de unas cuantas habilidades, que antes pudieron haber sido operacional y 
estrechamente definidas por objetivos de aprendizaje, pero que hoy se revelan como insuficientes.

La definición de competencias que la OCDE (2005) proporciona, resulta relevante para México, por ser éste un país miembro de dicha organización, y que participa en las evaluaciones periódicas del PISA (Programme for International Student Assessment, por sus siglas en inglés). Esta definición postula que:

"una competencia es más que sólo conocimiento y habilidades. Involucra la capacidad de afrontar demandas complejas, al activar y movilizar recursos psicosociales (incluyendo habilidades y actitudes) en un contexto particular. Por ejemplo, la habilidad de comunicarse efectivamente es una competencia que puede poner en acción el conocimiento que un individuo tiene sobre el lenguaje, sus habilidades prácticas en tecnologías de la información, y las actitudes hacia aquéllos con quienes él/ella se está comunicando" (OCDE, 2005, p. 4).

La OCDE (2005) ha propuesto un conjunto de "competencias clave", que reúnen las siguientes condiciones:

a) Contribuyen a generar productos importantes para las personas, y también para las sociedades.

b) Facilitar la respuesta de los individuos ante contextos variados y dinámicos.

c) Ser valiosas para todos los individuos, no sólo para los académicos e investigadores.

Las competencias clave reconocidas por la OCDE (2005) son tres: i) usar herramientas de forma interactiva; ii) interactuar en grupos heterogéneos; iii) actuar de manera autónoma. Aunque cada competencia cubre un campo específico, existe correlación entre ellas. Asimismo, las competencias precisan que el individuo ejercite sus capacidades de pensamiento, reflexión, crítica y evaluación, de modo en que, lejos de ser estructuras rígidas o fórmulas inalterables, la aplicación de las competencias permita a la persona responder ante las circunstancias cambiantes, encontrando en ellas una fuente de aprendizaje. Es por esto que las competencias clave son competencias para la vida: promueven no sólo una adaptación al mundo actual, sino la participación del individuo para "moldearlo", en conjunción con el resto de la sociedad. 
Para los intereses del presente trabajo, la interacción entre las competencias clave resulta sobremanera importante; sin embargo, se reconoce que, por estar dirigido al desarrollo de la competencia en matemáticas, se inserta específicamente en la competencia que la OCDE (2005) ha denominado como 1-A: la habilidad para usar el lenguaje, los símbolos y el texto, de manera interactiva. $\mathrm{Y}$ dentro de ella, hay que destacar el desarrollo de las habilidades en matemáticas.

\section{Las competencias matemáticas.}

En concordancia con lo anterior, el PISA (en OCDE, 2005, p. 16) propone el concepto de "Alfabetismo Matemático", el cual se refiere a:

"la capacidad para identificar y comprender el papel que las matemáticas juegan en el mundo, hacer juicios bien fundados, y utilizar e integrar las matemáticas en formas que respondan a las necesidades de la vida del individuo, como un ciudadano constructivo, involucrado y participativo".

El alcanzar este alfabetismo matemático supondría un desarrollo previo de ciertas competencias en matemáticas. Algunos autores han buscado definir las competencias básicas en esta área:

- "Tener competencia matemática significa: poseer habilidad para comprender, juzgar, hacer y usar las matemáticas en una variedad de contextos intra y extra matemáticas y situaciones en las que las matemáticas juegan o pueden tener un protagonismo" (Niss, en González, 2004). Para este autor, la competencia matemática se integra a su vez, por ocho competencias matemáticas, que se clasifican en dos grupos. El primero involucra la capacidad de formular y dar respuestas dentro del campo de las matemáticas, o relacionando la situación con ellas. El segundo grupo comprende la capacidad de utilizar las herramientas y lenguaje de las matemáticas, aplicándolas a situaciones y representaciones diversas.

- "La competencia matemática consiste en la habilidad para utilizar y relacionar los números, sus operaciones básicas, los símbolos y las formas de expresión y 
razonamiento matemático, tanto para producir e interpretar distintos tipos de información, como para ampliar el conocimiento sobre aspectos cuantitativos y especiales de la realidad y para resolver problemas relacionados con la vida cotidiana y con el mundo laboral (Gutiérrez, Martínez \& Nebreda, 2008, p. 10). Comprende: finalidades, conocimientos, destrezas y actitudes.

Resulta importante señalar que una cierta competencia, puede estar conformada por un "cluster" o conglomerado de competencias. Así lo señala Gimeno (2009): dependiendo de su nivel de complejidad, habrá "megacompetencias", y también "microcompetencias".

En particular, en este trabajo, interesa la propuesta de Ross Turner (2011) acerca de que, en efecto, la competencia matemática comprende en conjunto seis competencias "individuales". Dicho autor ha formulado estas competencias en concordancia con el PISA (OCDE), por lo que están dirigidas a estudiantes de educación media o media superior, estando los sujetos de esta investigación, precisamente, insertos en esta última. Las seis competencias matemáticas propuestas por Turner (2011) son:

1) Comunicación: involucra habilidades de "entrada" y "salida". Entre las primeras se encuentran: leer, decodificar, interpretar información matemática. Las segundas incluyen: explicar, demostrar y argumentar.

2) Matematizar: habilidad para traducir un problema del "mundo real", como problema matemático, y saber interpretar la información matemática de manera contextualizada, de acuerdo con una determinada situación.

3) Representar: desarrollar y utilizar representaciones de "objetos matemáticos" o relaciones, tales como: ecuaciones, diagramas, gráficas, fórmulas, etc.

4) Razonar y argumentar: utilizar el pensamiento lógico para conducir procesos que exploren e interrelacionen los elementos de un problema, para generar inferencias. Verificar o producir una justificación.

5) Pensamiento estratégico: identificar, elegir, desarrollar y aplicar estrategias matemáticas para dar solución a problemas, de forma congruente con el contexto o la tarea planteada. 
6) Utilizar lenguaje simbólico, formal y técnico, así como operaciones: Comprender, dominar y hacer uso de las expresiones simbólicas; "usar constructos basados en definiciones, reglas y convenciones, sistemas formales" (Turner, 2011, p. 2).

Estas seis competencias individuales, señaladas por Turner (2011) son compatibles con los curricula de los cursos de matemáticas, del sistema de bachillerato del IEMS DF, en uno de cuyos planteles se desarrolló esta investigación.

\section{El docente y el trabajo con las competencias matemáticas.}

En este punto, resulta pertinente hacer dos señalamientos:

1) El concepto de competencia, si bien surgió con un énfasis en su aspecto como recurso de evaluación, ha extendido su campo de acción hasta lograr ser tomado en cuenta dentro del diseño curricular, y dentro de la implementación de éste, en lo que Gimeno (2007) ha denominado como "el curriculum en acción".

2) Este "curriculum en acción" precisa que el docente planee, diseñe e implemente estrategias de enseñanza-aprendizaje que impulsen el desarrollo de las competencias en los estudiantes. Asimismo, el docente debe disponer de herramientas de evaluación que permitan emitir una "valoración" cabal de cómo los estudiantes han activado, desplegado y aplicado dichas competencias, acercándolos esto al ya mencionado "alfabetismo en matemáticas". Esto es, la evaluación para el desarrollo de las competencias no debe centrarse únicamente en evaluar productos. Lo deseable es que ésta sea un recurso más para el aprendizaje, tal como diversos autores lo han postulado: es necesario privilegiar la evaluación formativa (Jorbá \& Sanmartí, 2009; Sanmartí, 2007; Álvarez, 2001).

Estos dos señalamientos remarcan la importancia de que todo el dispositivo educativo trabaje de manera sinérgica, si el objetivo es impulsar el desarrollo de las competencias. En concordancia con esto, Pérez (2007) ha indicado una serie de aspectos que deben cuidarse: 
- El centro escolar debe tener presente que su función fundamental no reside en la mera transmisión de información o de conocimiento. Debe autoasumirse como un impulsor del desarrollo de las competencias.

- El foco de énfasis no estriba en que los estudiantes aprendan un cúmulo de contenidos segmentados en disciplinas. La finalidad principal es que, de manera transversal, los estudiantes puedan construir esquemas de pensamiento que articulen e inerven las competencias básicas.

- Los docentes, idealmente, deberían trabajar con sujetos activos, insertos en procesos de búsqueda, estudio, experimentación, reflexión, aplicación y comunicación del conocimiento; sin embargo, debe señalarse que los estudiantes, por lo general, no reúnen estas características, y hay una tendencia a asumirse como actores pasivos en los procesos educativos. De ahí que otra tarea de los docentes incida en lo formativo, no en lo informativo.

- Los docentes necesitarán preparar entornos de aprendizaje enfocados en las tareas, actividades y estrategias dirigidas al desarrollo de las competencias. Es importante que dentro de éstas, se contemplen recursos tales como: el impulso a la cooperación entre pares; el estímulo de la metacognición; la detección del error, la corrección y la retroalimentación oportunas.

- Otorgar un papel prioritario a la evaluación formativa: diseñar situaciones y ambientes propicios para que los estudiantes pongan a prueba los conocimientos, cometan errores, reciban retroalimentación, e intenten nuevamente soluciones viables.

Si bien al estudiante se le concibe como el sujeto protagonista y activo en el desarrollo de las competencias, el docente es también un actor multifuncional, entre cuyas tareas se encuentran: la tutorización del aprendizaje, el diseño, la planeación, la organización, la motivación y el estímulo, el acompañamiento, la retroalimentación, el diagnóstico y la evaluación de los procesos de aprendizaje. Perrenoud (2013) ha señalado que pueden producirse consecuencias graves cuando el docente no ha desarrollado sus propias competencias para enseñar. El diseño, estructuración y "animación" de estrategias y actividades pedagógicas, que propicien el aprendizaje, es 
la función primordial del docente enfocado al impulso del desarrollo de las competencias. Específicamente en el área de matemáticas, es importante que el docente recurra a andamiajes y buenas prácticas que contribuyan a tomar en consideración y a implementar los puntos anteriormente recomendados por Pérez (2007).

\section{Marco contextual}

En México, la Educación Media Superior es abordada desde una variedad de estructuras organizativas tan amplia, que pueden contabilizarse alrededor de dos docenas de subsistemas. A su vez, éstos pueden agruparse en siete tipos de organismos: 1) Centralizados del Gobierno Federal; 2) Descentralizados de la Federación; 3) Descentralizados en las entidades federativas; 4) Estatales; 5) Organismos del Gobierno del D. F; 6) Autónomos; 7) Privados.

Adicionalmente, en esta amplia gama de opciones, se encuentra también la Preparatoria Abierta, el Bachillerato Semiescolarizado, e incluso, la educación a distancia. Esta diversidad de organismos, instituciones y modelos educativos, lejos de brindar fortaleza a la Educación Media Superior, ha acarreado como consecuencias, entre otras, la falta de un enfoque integrador, y con ello, la carencia de una "equivalencia" o portabilidad entre sistemas. Algunas de estas dificultades ya habían sido señaladas desde hace al menos dos lustros (Castañón \& Seco, 2000), pero esta condición prevalece en la actualidad. Dentro de esta oferta educativa, y para los propósitos de este trabajo, interesa uno de los modelos educativos más recientemente surgidos (en 2001): el del IEMS DF. Éste es un bachillerato de tipo general, propedéutico, que declara estar enfocado al desarrollo de competencias significativas para enfrentar la vida académica y personal. Los estudiantes ingresan por medio de un sorteo de números aleatorios ante Notario Público. Este procedimiento intenta no reproducir los mecanismos de selección y exclusión que privan en otros sistemas de bachillerato, tendiendo así a la práctica de una política de equidad, a través de la cual se hace accesible la oferta educativa a quienes no han encontrado opciones 
disponibles en otros bachilleratos propedéuticos. Consecuencia de esto es la gran diversidad y heterogeneidad que caracterizan a la población estudiantil en estos planteles.

El Plan de Estudios contempla seis períodos semestrales. Se ha intentado responder con flexibilidad a las características personales, familiares, económicosociales, académicas, etc. de los estudiantes. El proyecto educativo no está cimentado en ninguna corriente pedagógica particular, porque se considera que cada una de ellas ha sido producto de escenarios histórico-sociales particulares. El docente es concebido como un agente reflexivo sobre su ejercicio cotidiano, y no como un mero transmisor de conocimientos y contenidos. Recrea el saber disciplinario a través de su experiencia, diseñando mecanismos para traducirlo y potenciar los aprendizajes significativos. La atención al estudiante es personalizada, y tiende a que éste logre su "emancipación cognitiva, emocional, simbólica social y cultural". Esta atención se presenta como un acompañamiento durante toda la trayectoria escolar, caracterizado por el respeto, la responsabilidad y la comprensión de los factores que afectan el aprendizaje: antecedentes escolares, características de la comunidad y la familia de las que proviene, interés o motivación en el aprendizaje, empleo, autoconcepto, planes de vida, desempeño en el bachillerato, características del capital cultural que ha adquirido, etc. (IEMS/GDF, Proyecto Educativo, 2006).

En este sistema de bachillerato la evaluación no se efectúa por medio de calificaciones numéricas, sino que se realiza de manera cualitativa: existe una evaluación diagnóstica cada semestre, que orienta las estrategias de enseñanzaaprendizaje, y se realiza de forma continua. Hay algunos "cortes de evaluación" a lo largo de cada semestre, en los cuales se hace un registro sobre las fortalezas de los estudiantes, respecto a los objetivos declarativos, procedimentales y valorales previstos, así como sus carencias y los medios para superarlas. Se asigna una "C" para denotar que los objetivos de aprendizaje han sido alcanzados, o una "NC" si no ha sido así. No se recurre a exámenes extraordinarios, sino a períodos de trabajo personalizados denominados "módulos" o "períodos intersemestrales", en los cuales el 
estudiante trabaja muy cercanamente con el docente, incidiendo particularmente en los aspectos de aprendizaje que aún no domina.

Es importante señalar que, aunque en distintos espacios del trabajo colegiado se ha estado hablando acerca de las competencias, aún no se ha desarrollado nada "oficial" en torno al trabajo con éstas, pues la evaluación sigue centrándose en objetivos de aprendizaje "cubiertos" o "no cubiertos". Por ello, puede afirmarse que los profesores que desean impulsar el desarrollo de competencias, deben hacer uso de su libertad de cátedra, y de su iniciativa personal, para investigar sobre este tema, e implementarlo en sus labores diarias.

Específicamente para los propósitos de esta investigación, el impulso para el desarrollo de las competencias matemáticas, buscó realizarse a través de la implementación de buenas prácticas y de andamiajes. El espacio idóneo para trabajar con ambos es el aula, pero, adicionalmente en este sistema de bachillerato, existe otro espacio académico que brinda oportunidades excelentes para llevarlos a la acción: la asesoría personalizada. En el caso de las matemáticas, al desarrollarse el curriculum en acción, es necesario que la evaluación del proceso completo incluya ciertos andamiajes y buenas prácticas, de modo que la implementación del curriculum produzca aprendizajes sólidos, y realmente se incida en una evaluación formativa.

Seda (2002) indica que es deseable que cada profesor desarrolle sistemas de evaluación que sean multidimensionales, y que conecten a la evaluación directamente con el proceso de enseñanza-aprendizaje, y con el curriculum formal.

Los andamiajes han sido definidos como:

"las interacciones de los adultos con los estudiantes. Estas interacciones se consideran un andamio en el proceso de construcción del conocimiento, y por esta razón (...) se denominan andamiaje (...) Desde el punto de vista de las buenas prácticas en la enseñanza, el andamiaje puede considerarse como una condición necesaria para que tenga lugar una retroalimentación adecuada entre enseñanza y aprendizaje" (Planas \& Alsina, 2009, p. 17).

Dos puntos deben cuidarse: 1) las tareas efectuadas por los estudiantes deben adecuarse a sus características; y 2) debe incluirse la oportunidad de autocorrección, 
para fortalecer las actitudes de perseverancia y autodirección. Puede notarse, entonces, que los andamiajes no sólo contemplan la construcción de "habilidades" o "destrezas", sino que tocan también lo relativo a lo actitudinal y lo valoral, llegando a incidir también en los aspectos metacognitivos. Factores todos, que son importantísimos constituyentes de las competencias en matemáticas.

Las buenas prácticas son las aplicaciones que los docentes utilizan, para movilizar y desplegar sus saberes sobre matemáticas y sobre didáctica, con la finalidad fundamental de que el estudiante y los procesos de construcción de sus aprendizajes se instauren como los protagonistas más importantes de las acciones educativas. Broomes (en Planas \& Alsinas, 2009) ha hecho mención de ciertas características que las buenas prácticas en matemáticas deben presentar: concatenación con el curriculum; establecer conexiones interdisciplinarias; resultar motivadoras para el estudiante; presentar oportunidades de retos graduados, adecuados a las características de los estudiantes; implicar personalmente a éstos; flexibilidad; contemplar la orientación hacia la solución de problemas; invitar al estudiante a formular preguntas y generar dudas pertinentes; impulsar la metacognición, permitiendo que el estudiante reflexione sobre sus propios aprendizajes. Todo ello, con el objetivo primordial de estimular el desarrollo de aprendizajes, y el proceso continuo de concientización del estudiante, en torno a sus procesos de construcción de conocimientos y saberes conceptuales, procedimentales y actitudinales.

Al respecto de la asesoría personalizada, ésta se establece como una serie de momentos didácticos propicios para el trabajo centrado en el estudiante, en el cual es éste quien se asume como sujeto activo de su propio aprendizaje. La asesoría académica personalizada cuenta con una función enfáticamente pedagógica (Sanmartí, 2007), revistiendo una bifuncionalidad: por una parte, es un recurso de evaluación continua; y por otra, es un proceso de enseñanza-aprendizaje que tiene lugar a lo largo de todo el semestre. En el caso de la primera función, de evaluación y regulación, la asesoría incide en la identificación de aspectos del aprendizaje susceptibles de mejorar, y ello conlleva la pertinente toma de decisiones que conduzcan a la implementación de 
las medidas que tiendan hacia la mejora. La asesoría académica en el IEMS, y, de manera específica en Matemáticas, ofrece características de trabajo sui generis:

a) Periódicamente, cada estudiante puede ejercer el derecho a trabajar en asesorías personalizadas, o bien, en grupos reducidos de pares. Sin embargo, no todos los estudiantes muestran disposición a ejercer este derecho. Cuando el docente ha detectado la necesidad de que el estudiante refuerce sus aprendizajes en actividades extra-clase, puede solicitarle al estudiante que tome las asesorías pertinentes. Las asesorías pueden ser personalizadas debido a las condiciones propias que engloban los planteles del IEMS: grupos reducidos, con un máximo de 25 estudiantes; carga docente de 3 grupos por profesor, lo cual representa alrededor de 20 horas por semana frente a grupo. Las asesorías tienen lugar en un cubículo del profesor, equipado con los recursos materiales necesarios para el trabajo académico.

b) El carácter individualizado de las asesorías, o bien, en grupos pequeños, posibilita la detección oportuna y rigurosa de los puntos problemáticos que requieren trabajo remedial oportuno.

c) Las asesorías personalizadas permiten hacerse cargo efectivamente de uno de los rasgos característicos más notables de los estudiantes de este modelo educativo: la diversidad y heterogeneidad, reflejadas en factores tales como la edad, el bagaje cultural, el estrato social, la trayectoria educativa, etc. El trabajo en asesorías permite centrarse diferencialmente en cada estudiante, comprometiendo al docente en una toma de decisiones: la determinación del nivel de exigencia y naturaleza de las tareas, para cada estudiante, de modo que cada uno, desde su individualidad, pueda desarrollar las competencias buscadas.

d) La evaluación de las competencias matemáticas no puede efectuarse simplemente a través de exámenes tradicionales. Las asesorías posibilitan cumplir una función de evaluación formativa más detallada. Las asesorías brindan un espacio adecuado para implementar, redireccionar, adaptar, estrategias de enseñanza-aprendizaje que incidan en el desarrollo de las 
competencias matemáticas, privilegiando la retroalimientación. Esto, mediante la identificación de deficiencias en la construcción de éstas, y a partir de tales datos, sobreviene la toma de decisiones pertinentes sobre las medidas remediales ex profeso diseñadas para el caso en cuestión. "La evaluación formativa debe servir para identificar dónde se encuentran deficiencias en el aprendizaje", con el fin de utilizar la información para elaborar actividades de enseñanza diferentes, y así lograr el aprendizaje propuesto" (López \& Hinojosa, 2010, p. 18).

\section{El plantel Felipe Carrillo Puerto.}

Este plantel recibe a 350 estudiantes en cada generación, y son seleccionados mediante un sorteo certificado por Notario Público. 175 de estos estudiantes se encontrarán en el turno matutino (de 8 a 14 horas, de lunes a viernes); y los restantes 175 estarán en el turno vespertino (de 14 a 20 horas, los mismos días). La población estudiantil está conformada por alrededor de 750 estudiantes. Esta población es sumamente heterogénea y diversa, y en ella se pueden encontrar desde estudiantes recién egresados de secundaria; otros más que ya han tenido una o varias experiencias en otros bachilleratos; hasta adultos jóvenes o mayores, que nunca concluyeron la educación media superior oportunamente.

Un gran porcentaje de los estudiantes presenta problemas personales que interfieren en los procesos de aprendizaje: desintegración familiar, violencia intrafamiliar, embarazos en adolescentes, adicciones, necesidad de desempeñar un empleo remunerado, baja autoestima, previos fracasos escolares, etc. Debido a que el ingreso a este sistema se hace por medio de un sorteo, algunos de los seleccionados han sido personas con déficits de aprendizaje, que no podrían haber tenido oportunidad en ningún otro sistema. Incluso, se han atendido a estudiantes que, por provenir de una comunidad en alguna provincia del país, no tienen dominio completo del idioma español; sin embargo, los docentes-tutores no están preparados para enfrentar el trabajo con estos estudiantes, que presentan necesidades especiales. 
Como resultado de las anteriormente referidas condiciones personales del estudiantado, los docentes-tutores eventualmente deben enfrentar problemas tales como hurtos dentro del plantel, agresividad o violencia (enfrentamientos entre estudiantes), amenazas, grupos apáticos, estudiantes con reiteradas inasistencias o incumplimiento académico, etc. Este sistema de bachillerato presenta un índice mayor que el nacional en cuanto a deserción escolar.

El plantel se encuentra en la delegación Iztacalco (Oriente 237, núm 21, casi esquina con calzada Ignacio Zaragoza, colonia Agrícola Oriental). La población estudiantil debe residir en las colonias aledañas al plantel. La escuela se encuentra en un área de bodegas de empresas como Coca Cola y Kimberly Clark, o de centros de producción como la panificadora El Globo. La colonia Agrícola Oriental es una de las más problemáticas de la delegación Iztacalco, ya que tiene un alto índice de inseguridad, y existen numerosos puntos de venta de estupefacientes.

Contando con los ya presentados marco teórico y marco contextual, se llevó a cabo una investigación dirigida a dilucidar si las asesorías académicas, a través del trabajo centrado en los estudiantes, podían provocar el desarrollo y despliegue de competencias matemáticas, contribuyendo a tomar en cuenta la heterogeneidad y diversidad de la población estudiantil.

\section{Metodología}

Sujetos. Los sujetos de investigación fueron 100 estudiantes del plantel Felipe Carrillo Puerto, perteneciente al Sistema de Bachillerato del Instituto de Educación Media Superior del D. F. Estos sujetos se hallaban cursando las materias de Matemáticas III (tercer semestre), o Matemáticas IV (cuarto semestre) durante los semestres 2012-A (que comprendió el período de enero a junio de 2012), y 2012-B (junio a diciembre de 2012).

Estos 100 sujetos fueron elegidos intencionalmente, ya que debían reunir una de dos condiciones: estar dispuestos, o no, a trabajar en asesorías académicas a lo largo del semestre. Se buscó formar dos grupos. El primero, con 50 estudiantes que se 
manifestaron interesados en trabajar en asesorías académicas personalizadas. Estos 50 sujetos constituyeron el grupo experimental. Los restantes 50 estudiantes manifestaron su rechazo a trabajar en asesorías; con ellos se conformó el grupo control.

Instrumentos. Se utilizaron distintos instrumentos, los cuales fueron diseñados ex profeso para esta investigación:

a) Formatos de registro de las estrategias de enseñanza-aprendizaje trabajadas en cada asesoría.

b) Formatos de registro de las actividades realizadas en cada asesoría, y de registro de las competencias matemáticas estimuladas/activadas a través de cada actividad.

c) Formatos de evaluación de los procesos y productos de las asesorías, y de registro de la retroalimentación.

d) Examen elaborado con base en las competencias matemáticas propuestas por Turner (2011).

\section{Diseño de investigación.}

Se llevó a cabo un estudio pretest-postest, con un grupo experimental y otro control, del tipo:

$$
\begin{aligned}
& 0 \times 0 \\
& 0 \quad 0
\end{aligned}
$$

En donde:

O: representa un proceso de medición (o evaluación)

$X$ : exposición del grupo experimental a una variable (trabajo en asesorías), cuyos efectos fueron medidos en la segunda fase $O$.

Se trató entonces de una investigación experimental, comparativa, prolectiva (la información se obtuvo durante el desarrollo del estudio); longitudinal (la medición de las variables fue hecha en dos momentos: previa a la aplicación de la variable experimental 
(trabajo en asesorías), y posterior a la exposición del grupo experimental a la variable) (Mendoza Núñez, et al., 2007).

Procedimiento. Al principio de la investigación, fue aplicado a los grupos experimental y control, el examen elaborado ex profeso para esta investigación, y cuyo contenido contemplaba ejercicios para explorar el despliegue de las competencias matemáticas propuestas por Turner (2011). Esto constituyó la etapa de pretest. Posteriormente, durante los dos semestres, se trabajó en asesorías personalizadas con los sujetos integrantes del grupo experimental. Fueron diseñadas estrategias y actividades tendientes a estimular el desarrollo de las competencias matemáticas propuestas por Turner. De igual manera, se utilizaron andamiajes y buenas prácticas para provocar el mismo objetivo. El uso extensivo de andamiajes incluyó:

- explicación verbal clara y detallada de los procedimientos para resolver las tareas;

- modelación docente sobre estrategias, métodos y procedimientos matemáticos;

- diseño, construcción y adecuación de tareas adaptadas a las características personales de los estudiantes (atención a la heterogeneidad y diversidad), siempre orientándose hacia el desarrollo de aprendizajes y competencias matemáticas;

- fomento del trabajo cooperativo, buscando que los estudiantes con mayores conocimientos apoyaran a otros que precisaban desarrollarlos;

- impulso al papel del estudiante como actor protagónico, activo y autónomo, en el desarrollo y despliegue de las competencias matemáticas.

El desempeño de los estudiantes durante estas sesiones de trabajo proporcionó datos de evaluación, minuciosos, que posibilitaron la retroalimentación, el diseño e implementación de los andamiajes.

Por otra parte, algunas de las buenas prácticas emprendidas durante las asesorías, (aunque en realidad, éstas se extendieron a todo el curriculum en acción, es decir, en el trabajo en aula, en las clases normales de estas materias) fueron:

- Conceder mayor peso a los datos arrojados cotidianamente durante las sesiones de clase y las asesorías, integrándolos a los resultados de la evaluación 
formativa global. Asimismo, asignar a los exámenes un papel fundamentalmente como mecanismos de exploración, que permitieran detectar "áreas de oportunidad", para abordarse en las asesorías académicas personalizadas.

- Construcción de portafolios de trabajo, a lo largo del semestre, que permitieron a los estudiantes percatarse y reflexionar sobre su propio aprendizaje, fomentando las actitudes de responsabilidad y perseverancia, al depositar en ellos el control sobre la colección, sistematización y presentación de las evidencias de los portafolios personales. Los objetivos adicionales: incentivar la metacognición, y fomentar las actitudes favorables y la motivación positiva hacia las matemáticas. Afianzar valores como la responsabilidad y el cumplimiento, así como la autonomía y la autodirección.

- Fortalecimiento de la vinculación interdisciplinaria, por medio del trabajo colegiado con profesores de otras áreas, en el diseño e implementación de actividades que movilizaran diversas competencias transversales en los estudiantes.

- Actividades lúdico-formativas diversas, con el objeto de incrementar el interés de los estudiantes hacia las Matemáticas, de modo que aumentara su motivación hacia su desempeño en estas materias, pues se ha comprobado que una mejor actitud y una motivación más fuerte producen mejores resultados en los aprendizajes (Petriz, et al., 2010; Zarrazaga, 2006; Valdez, 2000).

Al término de los dos semestres que abarcó la investigación, se aplicó nuevamente el mismo examen que había sido administrado al principio de ésta, a ambos grupos, experimental y control. Esto constituyó la etapa de postest.

\section{Resultados}

Al finalizar los dos semestres que cubrió esta investigación, pudo constatarse que el empleo de los anteriormente mencionados andamiajes y buenas prácticas, posibilitaron 
un mejor abordaje del proceso de enseñanza-aprendizaje, ofreciendo resultados positivos, como parte del curriculum en acción.

El examen exploratorio de las competencias matemáticas arrojó resultados similares en los grupos control y experimental durante la primera aplicación (pretest); esto es, antes de la exposición del grupo experimental a la variable (asesorías), mostrando que ninguno de los dos grupos había podido activar, movilizar o desplegar las competencias matemáticas a evaluar. Esto hizo suponer que ninguno de los sujetos había construido o desarrollado dichas competencias previamente, puesto que los ejercicios estaban basados en el curriculum formal del semestre en cuestión (tercero o cuarto).

La aplicación del mismo examen, durante la etapa de postest, permitió entablar una comparación entre los resultados obtenidos por el grupo control y el grupo experimental. Se hizo notorio que este último grupo obtuvo puntajes sensiblemente más altos que los del grupo control, a pesar de que, durante todo el semestre, fueron trabajados ejercicios similares en las clases normales; sin embargo, el trabajo centrado en el estudiante, llevado a cabo durante las asesorías académicas, mostró un incremento importante en el impulso al desarrollo de las competencias matemáticas exploradas.

Estos resultados fueron comparados con los datos de aprobación de las materias en cuestión. Esto indicó que el $85 \%$ de los estudiantes que trabajaron en asesorías personalizadas, consiguieron aprobar satisfactoriamente la materia cursada. El restante $15 \%$ no aprobó, debido a alguna de las siguientes causas: dejó de asistir a clases o a las asesorías; o bien, presentó problemas especiales para la comprensión de los temas/actividades, y requeriría de mayor tiempo para desarrollar las competencias y aprobar. En comparación: el porcentaje de estudiantes que no trabajaron en asesorías, y que aprobaron el curso, alcanzó sólo un $60 \%$.

Estos resultados son una muestra fehaciente de que las asesorías personalizadas, aunadas al fomento de andamiajes adecuados y a las buenas prácticas pertinentes, pueden contribuir considerablemente a aumentar la posibilidad de que los 
estudiantes desarrollen competencias matemáticas, y consecuentemente, tengan una mayor probabilidad de aprobar estas materias.

\section{Conclusiones}

En la actualidad, las sociedades se presentan como cambiantes, interactivas, altamente tecnologizadas y demandantes para los individuos. Es menester que los sistemas educativos contribuyan a que los sujetos desarrollen competencias que posibiliten su integración y participación adecuada en la construcción de estas mismas sociedades. Distintos organismos internacionales han buscado brindar definiciones y clasificaciones de las competencias claves o indispensables que los diversos sistemas educativos deberían estimular para propiciar que los individuos cuenten con las herramientas conceptuales, procedimentales y valoral-actitudinales que fomenten su inclusión exitosa en los procesos sociales, culturales, económicos y productivos de las sociedades modernas. No se ha olvidado que las competencias para la vida deben coadyuvar a que los individuos experimenten su capacidad de acción y decisión en la esfera personal.

Dentro de las competencias clave que la OCDE ha contemplado, se encuentra el manejo de herramientas de forma interactiva, que incluyen la utilización consciente del lenguaje, los símbolos y las operaciones, comprendiéndose aquí lo relativo a las competencias matemáticas. México ha obtenido resultados pobres, consistentemente, en las evaluaciones que el PISA ha llevado a cabo en diferentes ocasiones, sobre las competencias matemáticas. Resulta de capital importancia que los sistemas educativos emprendan un trabajo fuerte y dirigido al desarrollo de dichas competencias, pues tal desarrollo puede brindar una llave de acceso a la educación superior, y a la integración de los individuos a los entornos laborales. Igualmente, los esquemas mentales asociados con las competencias matemáticas pueden ser activados en contextos extraescolares, propiciando la aplicación de herramientas de razonamiento, análisis, lógica y resolución de problemas, en diferentes situaciones de la vida diaria. El nivel de desarrollo de competencias matemáticas exige revisar los alcances y limitaciones del 
trabajo que se ha llevado a cabo en los diferentes sistemas educativos, y que se propongan alternativas viables para mejorar sus resultados.

En el caso de las matemáticas, resulta necesario que el papel de los exámenes se relativice y se brinde una importancia creciente a otros medios para llevar a cabo la evaluación formativa, poniendo especial cuidado en incorporar continuamente los resultados arrojados por ésta, a los procesos de enseñanza-aprendizaje. Los andamiajes y las buenas prácticas en matemáticas constituyen recursos que pueden evidenciar una gran utilidad al trabajar los procesos de evaluación dirigidos a fomentar el desarrollo de competencias matemáticas. La asesoría académica, como un trabajo especialmente centrado en el estudiante, y como una parte indispensable del curriculum en acción, al situar al estudiante en un papel protagónico, posibilita la obtención de datos más exactos sobre las fortalezas y debilidades de los estudiantes. De esta manera, las asesorías se convierten en una oportunidad para el desarrollo de aprendizajes. A través de esta investigación se ha buscado compartir una serie de alternativas útiles en los procesos de enseñanza-aprendizaje, de evaluación y de trabajo con miras al desarrollo de competencias matemáticas. Si bien todo esto ha sido propuesto desde un modelo educativo que ofrece las condiciones idóneas para que estos recursos puedan ser implementados adecuadamente, se cree que sí habría oportunidad de aplicar y/o adaptar éstos a otros sistemas educativos, y a otras materias, sobre todo, a aquellas de alta reprobación.

Sin embargo, en el caso del bachillerato del IEMS, la heterogeneidad y diversidad de la población estudiantil traen consigo problemáticas muy específicas, que abren la posibilidad de realizar ulteriores investigaciones. A manera de cierre, se mencionan algunas de las limitaciones vinculadas con la diversidad del alumnado:

a) La población de las preparatorias del IEMS presenta una heterogeneidad que constituye un desafío inédito, y que en no pocas ocasiones, dificulta el trabajo y el progreso académico de los grupos. Esto se encuentra directamente relacionado con la falta de un dispositivo de selección para el ingreso a este sistema. 
b) La evaluación cualitativa precisa de una mayor inversión de tiempo y esfuerzo, y los estudiantes no se habitúan fácilmente a no recibir una calificación numérica. Para ellos resulta especialmente difícil comprender qué nivel de desarrollo de competencias matemáticas han logrado.

c) No todos los estudiantes aprovechan efectivamente las ventajas de asistir y trabajar de manera personalizada en las asesorías, por lo cual, durante el trabajo en las clases normales, se encuentran niveles marcadamente discordantes en el grado de desarrollo de las competencias matemáticas, entre aquellos estudiantes que han trabajado en asesorías, y aquellos que no lo han hecho.

d) Los prejuicios preconcebidos acerca de la dificultad de las Matemáticas continúan ejerciendo un impacto negativo en la actitud generalizada de los estudiantes hacia esta materia.

El modelo educativo del IEMS no es un documento concluido, ni tampoco negado a la revisión dirigida a introducir mejoras. Una de ellas, seguramente en un futuro próximo, será el énfasis en promover el desarrollo de competencias. Esto deberá reflejarse no sólo en el curriculum formal, sino también, en el curriculum en acción, lo cual supondrá un nuevo reto en el ejercicio de la docencia, y en la calidad y características del trabajo que los estudiantes deberán realizar para poder desarrollar dichas competencias.

\section{Referencias}

Álvarez, J. M (2001). Evaluar para conocer; examinar para excluir. España: Ediciones Morata.

Argudín, Y. (2006). Educación basada en competencias. Nociones y antecedentes. México: Ed. Trillas.

Castañon, R. \& Seco, R. (2000). La educación media superior en México. Una invitación a la reflexión. México: UNAM.

Coll, C. \& Martín, E. (2006). Vigencia del debate curricular. Aprendizajes básicos, competencias y estándares. México: SEP, Serie: Cuadernos de la Reforma.

Gimeno, J. (2007). El curriculum: una reflexión sobre la práctica. España: Ediciones Morata.

Gimeno, J. (2009). Diez tesis sobre la aparente utilidad de las competencias en educación. En J. Gimeno Sacristán (comp.), Educar por competencias, ¿qué hay de nuevo?, (pp. 1558). España: Morata.

González, J. L. (2004). Competencias básicas en educación matemática. España: Universidad de Málaga. 
Gutiérrez, L., Martínez, E. \& Nebreda, T. (2008). Las competencias básicas en el área de Matemáticas. Cantabria: Consejería de Educación de Cantabria.

IEMS / GDF. (2006). Proyecto Educativo. Sistema de Bachillerato del GDF. México: IEMS / GDF.

Jorbá, J. \& Sanmartí, N. (2009). La función pedagógica de la evaluación. En Margarita Ballester et al. Evaluación como ayuda al aprendizaje, (pp. 21-44). España: Graó.

López, B. \& Hinojosa, E. (2010). Evaluación del aprendizaje. Alternativas y nuevos desarrollos. México: Trillas.

Martínez, J. B. (2009). La ciudadanía se convierte en competencia. Avances y retrocesos. En J. Gimeno Sacristán (comp.), Educar por competencias, ¿qué hay de nuevo?, (pp. 103142). España: Morata.

Mendoza, V. M. et al. (2007). Investigación. Introducción a la Metodología. México: UNAM /FES Zaragoza.

OCDE (2005). The definition and selection of key competencies. Executive Summary. Recuperado de http://oecd.org/pisa/35070367.pdf

Planas, N. \& Alsina, A. (2009). Educación matemática y buenas prácticas. España: Graó.

Pérez, A. I. (2007) La naturaleza de las competencias básicas y sus implicaciones pedagógicas. Consejería de Educación de Cantabria, Santander. Recuperado de http://213.0.8.18/portal/Educantabria/Congreso\%20Competencias\%20Basicas/index.htm

Pérez, A. I. (2009) ¿Competencias o pensamiento práctico? La construcción de los significados de representación y de acción. En J. Gimeno Sacristán (comp.), Educar por competencias, ¿qué hay de nuevo? (pp. 59-99). España. Ediciones Morata.

Perrenoud, P. (1998). Construire des compétences dès l'école. París: Éditions ESF.

Perrenoud, P. (2013). Ser competentes para enseñar. En: Educación Futura. El debate continúa. Recuperado de http://www.educacionfutura.org/ser-competentes-para-ensenar

Petriz, M. A. et al. (2010). Niveles de desempeño y actitudes hacia las matemáticas en estudiantes de la Licenciatura en Administración en una universidad estatal mexicana. Revista Mexicana de Investigación Educativa. Octubre-Diciembre, 2010.Vol. 15, núm. 47, 1223-1249.

Pimienta, J. H. (2008). Evaluación de los aprendizajes. Un enfoque basado en competencias. México: Pearson Educación.

Sanmartí, N. (2007). Evaluar para aprender. 10 ideas clave. España: Graó.

Seda, I. (2002). Evaluación por portafolios: un enfoque para la enseñanza. En Revista Latinoamericana de Estudios Educativos. México, vol. XXXII, núm. 1, 105-128.

Torres, J. (2009). Obviando el debate sobre la cultura en el sistema educativo: cómo ser competentes sin conocimientos. En J. Gimeno Sacristán (comp.), Educar por competencias, ¿qué hay de nuevo?, (pp. 15-58). España: Ediciones Morata.

Turner, R. (2011). Exploring mathematical competencies. Developments, Vol. 24 (2011) Art. 5. 2-6.

Recuperado

http://research.acer.edu.au/cgi/viewcontent.cgi?article=1083\&context=resdev

UNESCO (2003). Calidad de la educación y competencias para la vida. Recuperado de: http://www.ibe.unesco.org/International/ICE47/Spanish/Organisation/Workshops/Worksh op3CompSPA.

Valdez, E. (2000). Rendimiento y actitudes. La problemática de las matemáticas en la escuela secundaria. México: Grupo Editorial Iberoamérica.

Zarrazaga, A. I. (2006). La actitud hacia las matemáticas y el rendimiento académico. Memorias 2006, 57-66. Recuperado de http://circule.adventist.org/download/Actitudmat.pdf. 


\title{
LA FORMACIÓN DE DOCENTES DE EDUCACIÓN BÁSICA DESDE EL ENFOQUE POR COMPETENCIAS
}

\section{TEACHER TRAINING BASIC EDUCATION FROM THE COMPETENCE APPROACH}

\author{
José Antonio Fernández Lozano \\ Departamento de Educación Secundaria Técnica SEED \\ Josea_fer@hotmail.com
}

\begin{abstract}
Resumen
La educación es la base del desarrollo de los pueblos; sin embargo México, es visto como un país de reprobados. Las reformas educativas se enfocan en la formación en competencias, pero ¿Cómo se forman los docentes? Este es el centro del presente trabajo, producto de la investigación de mi tesis doctoral. Vivimos tiempos nuevos que requieren innovación de las prácticas docentes. Es necesario formar un nuevo maestro, más comprometido con los intereses del alumno y con su habilidad para generar aprendizajes; se requiere de un facilitador de aprendizajes y no un transmisor de conocimientos; así se va difuminando el "especialista" en la asignatura para dar paso al docente competente. El presente trabajo es producto de una investigación en el enfoque cualitativo, realizada en la Escuela Normal Superior de Durango basada en un estudio de caso. En la formación de docentes para la educación secundaria está vigente el Plan de estudios 1999, que se basa en el Plan de estudios 1993 para la educación secundaria; los docentes son formados con un enfoque que tiene 30 años de desfase y que, según los hallazgos no responde a las necesidades de formación actual del docente del siglo XXI.
\end{abstract}

Palabras clave: normalismo, currículum, docencia, innovación.

\begin{abstract}
Education is the basis for the development of peoples, but México, is seen as a country of reprobate. Educational reforms focus on skills training, but how are the teachers? This is the focus of this study, the product of my $\mathrm{PhD}$ research. We live in times that require innovative new teaching practices. Is necessary to form a new teacher, more committed to the interests of students and their ability to provide learning, requiring just an enabler of learning and not a transmitter of knowledge, so it fades away the "specialist" in the course to make way the competent teacher. This work is the result of an investigation on the qualitative approach, on the Superior Normal School of Durango based on a case study. In teacher training for secondary education is the current curriculum 1999, which is based on the 1993 curriculum for secondary education; teachers are trained with an approach that is 30 years out date and, according to the findings do not meet the needs of current teacher education of XXI century.
\end{abstract}

Keywords: normal school, curriculum, teaching, innovation. 


\section{Introducción}

Se atribuye a Teresa de Calcuta la frase que dice: "A veces sentimos que lo que hacemos es tan sólo una gota en el mar; pero el mar sería menos si le faltara una gota". Haciendo referencia a esta expresión, debo señalar que, ciertamente ya existen tratados completos sobre la formación basada en competencias, pero mi intención es aportar un punto de vista, una gota de agua en la inmensidad del mar, desde mi percepción como educador, basado en los resultados del proceso de investigación de mi tesis para obtener el grado de doctor en ciencias de la educación en el Instituto Universitario Anglo Español, con el tema "La Formación Docente en el Enfoque por Competencias".

Las recientes reformas educativas en México, hablan de la formación docente centrada en el enfoque por competencias; es decir, formar docentes competentes para la formación de alumnos competentes; así, el artículo doce, de la ley del servicio profesional docente, publicado en el Diario Oficial de la Federación con fecha 11 de septiembre de 2013, establece claramente el tipo de personal para ejercer la docencia:

Las funciones docentes, de dirección de una escuela o de supervisión de la Educación Básica y Media Superior impartida por el Estado y sus organismos descentralizados deberán orientarse a brindar educación de calidad y al cumplimiento de sus fines. Quienes desempeñen dichas tareas deben reunir las cualidades personales y competencias profesionales para que dentro de los distintos contextos sociales y culturales promuevan el máximo logro de aprendizaje de los educandos (DOF, 2013, p. 10).

Y el acuerdo 649, publicado en el Diario Oficial de la Federación el 20 de agosto de 2012, puntualiza la intensión de formar a los docentes del mañana en el enfoque por competencias:

La formación de los docentes de educación básica debe responder a la transformación social, cultural, científica y tecnológica que se vive en nuestro país y en el mundo. Ante los retos que ésta supone, el sistema educativo nacional ha puesto en marcha desde la primera década de este siglo un conjunto 
de medidas para hacer de la educación, en sus diversos tipos y modalidades, una de las piezas clave para atenderlos con mayores niveles de eficacia y eficiencia. (DOF, 2012, p. 1).

Las Escuelas Normales, como ha quedado asentado a lo largo de su historia, han cumplido con la tarea trascendental de formar a los docentes de la educación básica de nuestro país. Las políticas y acciones emprendidas para mejorar la calidad de la educación buscan favorecer su transformación, para convertirlas en espacios de generación y aplicación de nuevos conocimientos, de producción de cultura pedagógica y de democracia institucional, de manera que los futuros docentes de educación básica logren la formación necesaria para desarrollar una práctica docente más pertinente y efectiva. Si se trata en el sistema educativo nacional de formar en el enfoque por competencias, se deberá formar a los formadores en este mismo enfoque.

¿Qué sucede en la Escuela Normal Superior, cuando el plan de estudios 1999, vigente, busca cumplir con los requisitos de formación del docente de la escuela secundaria; tal y como lo especificaba el plan de estudios 1993 para la educación secundaria, que a casi 20 años, ha sufrido dos grandes y trascendentales reformas, la del año 2006 y la reciente en 2011?

Existe una problemática fuerte en el normalismo; subyacen problemáticas variadas en la Escuela Normal Superior, que conducen a inercias que detienen el crecimiento académico. La Escuela Normal Superior de Durango tiene prestigio y tradición, sin embargo no responde a las exigencias de formación docente de nuestro tiempo.

Todo esto nos lleva a problematizar acerca de la necesidad de transformar la propuesta curricular del plan de estudios 1999, aún vigente.

Este es el punto central de la investigación realizada en la Escuela Normal Superior de Durango, donde se buscó indagar acerca del impacto de la formación docente que se oferta de cara a los retos del docente del siglo XXI. EI planteamiento fue documentar el desfase en el que se forman docentes en un enfoque que no corresponde a la propuesta por competencias que desde el Plan de estudios 2011 se 
debe trabajar en la Educación Básica. ¿Cómo se puede formar en competencias, cuando la formación del propio docente no corresponde a este mismo criterio?

En el presente análisis de la investigación realizada, el objetivo general fue: propiciar que la formación docente en la Escuela Normal Superior de Durango, responda a las exigencias de la sociedad del siglo XXI, a través de un proceso la investigación acción participativa.

La maestra Alba Martínez Olivé, subsecretaria de Educación Básica, en su discurso en la cuarta reunión de supervisores en León Guanajuato, realizada el 5 y 6 de noviembre de 2014, enfatizaba en que el sistema educativo necesita cambiar, pero el vino nuevo debe estar en odres nuevos, y se refería precisamente a que para formar en un enfoque nuevo, se requiere cambiar de odres, de recipientes, de vasijas, formar en consecuencia docentes competentes que enfrenten los retos la formación en competencias.

\section{Desarrollo}

\section{Conceptualización.}

Definamos claramente lo que se entiende por formar, desde este enfoque de la formación por competencias. Barraza lo define de la siguiente manera:

Formar es algo que tiene que ver con la forma, por lo tanto formarse tiene que ver con adquirir una forma, la cual, a su vez, posibilita actuar y reflexionar para perfeccionar esa forma. Esa forma, si está enfocada al campo profesional, consistiría en una forma que tendría, como intencionalidad central, cumplir con las tareas requeridas para ejercer esa profesión. Adquirir esa forma implica la adquisición de conocimientos, habilidades, ciertas representaciones del trabajo a desarrollar o de la profesión que se va a ejercer, la concepción del propio rol profesional. (Barraza, 2007, p. 36).

Esta concepción de formar, no se refiere a trabajar sobre un molde en el que todos debemos caber; no es tan sólo una currícula básica, única para moldear al ser 
humano. La formación debería de responder a las necesidades de la sociedad del siglo $X X I$, incluso debería ser personalizada, desde el enfoque que formarse es transformarse, es decir, ir más allá de sí mismo, en lo que se quiere y en lo que se desea.

El formador, debe asumir los retos de la formación, debe si pretende formar en competencias, ser competente en su quehacer educativo; no es válido decir que la materia humana tiene deficiencias, que el nivel educativo anterior no cubrió con el perfil de egreso, porque se habla entonces, de las incompetencias para formar del propio formador; más delicado aún, si para ingresar a la institución se dio un proceso de selección de aspirantes. Ese es su trabajo. "Si el educando ya estuviera formado, no requeriría la acción del educador".

La formación en las instituciones debe sustentarse en el propio valor humano del formador, en la competencia misma del educador. Si el formador no posee un alto sentido humano y de su propia competencia, difícilmente podrá tener éxito en su trabajo. "Un ciego difícilmente puede guiar a otro ciego". Los rasgos de la formación y la currícula, son aspectos, que si bien es cierto establecen parámetros comunes que se deben inducir en los formados, son los educandos quienes con libertad deberán aceptarlos y aplicarlos. Pero existe en las instituciones aspectos formativos más allá de la currícula, acciones que deberían ser abordadas para la formación integral de los educandos. Toda actividad docente deberá ser cuestionada acerca de si contribuye o no a la formación del alumno.

Afirmar que el concepto formación debe convertirse en criterio para enjuiciar las actividades escolares como pedagógicas implica que todo modelo, estrategia, proyecto y acción educativa serán válidos y potentes pedagógicamente, si contribuyen a la formación humana del alumno... incluso, consideramos que la reflexión del día a día sobre el quehacer docente debe estar orientada por el interrogante:¿Cuánto de lo que hicimos hoy contribuye, verdaderamente, en forma significativa a la formación? (Flórez, 2007, p. 166).

$\mathrm{Si}$ se habla de formar al docente en competencias primero se debe definir lo que se entiende por competencia docente. EI maestro Justo Sierra, ya desde el siglo XIX 
decía: "Un maestro no es solamente un hombre que sabe, sino que sabe enseñar; necesita, pues, no solamente la ciencia, sino el método... lo que hace al maestro".

Según esta idea es el método lo que hace al docente y este pensamiento está vigente ciento veinte años después, puesto que, ser un profesional de la educación implica lograr ser competente en el quehacer docente.

Un docente competente será aquel que es capaz de desarrollar con lo que sabe su competencia didáctica y que, por lo tanto logrará aprendizajes significativos en sus educandos. Pero, ¿Dónde se forman los docentes en el enfoque por competencias? La formación docente en el enfoque por competencias implica mejorar las prácticas docentes, la metodología de enseñanza - aprendizaje y los criterios de evaluación; "lo que hace al maestro" y esa es la tarea que la institución deberá ofrecer: formar docentes competentes.

El acuerdo secretarial 284 del Diario Oficial de Federación por el que se establece el plan de estudio 1999 vigente para la licenciatura en educación secundaria, puntualiza los siguientes cinco rasgos del perfil de egreso del estudiante normalista (Habilidades intelectuales específicas, dominio de propósitos y contenidos, competencias didácticas, identidad profesional y ética, capacidad de percepción y respuesta a las condiciones sociales del entorno de la escuela). Estos rasgos y el plan de estudios, fueron diseñados para formar docente que trabajarían en la escuela secundaria, donde la normatividad dependía del Plan de Estudios 1993.

Si recuperamos los cinco rasgos del perfil de egreso del estudiante normalista en el Plan 1999 descubrimos que se centran primeramente en formar al profesionista con habilidades específicas (no con competencias) y con el dominio de propósitos y contenidos, (no con la idea de alcanzar los aprendizajes esperados, como se puntualiza actualmente). Y si comparamos estos rasgos, con la propuesta de nuevas competencias docentes, que Perrenoud (2004) presenta en sus diez nuevas competencias para enseñar, encontramos un inquietante desfase en el plan de estudios 1999. 
El perfil de egreso y las nuevas competencias para enseñar, parecen a la vez, antagónicas y complementarias. Estas dos propuestas para la formación docente en un cuadro comparativo quedarían así:

Tabla 1

Cuadro comparativo perfil de egreso - competencias.

\begin{tabular}{|c|c|}
\hline Campos del perfil de egreso 1999 & 10 NUEVAS COMPETENCIAS \\
\hline 1. Habilidades intelectuales específicas & 1. Organizar la propia formación continua \\
\hline $\begin{array}{l}\text { 2. Dominio de los propósitos y los } \\
\text { contenidos de la educación secundaria }\end{array}$ & \\
\hline Competencias didácticas & $\begin{array}{l}\text { 2. Organizar y animar situaciones de aprendizaje } \\
\text { 3. Gestionar la progresión de los aprendizajes } \\
\text { 4. Implicar a los alumnos en sus aprendizajes y } \\
\text { su trabajo } \\
\text { 5. Trabajar en equipo } \\
\text { 6. Utilizar las nuevas tecnologías }\end{array}$ \\
\hline 4. Identidad profesional y ética & $\begin{array}{l}\text { 7. Elaborar y hacer evolucionar dispositivos de } \\
\text { diferenciación } \\
\text { 8. Afrontar los deberes y los dilemas éticos de la } \\
\text { profesión }\end{array}$ \\
\hline $\begin{array}{l}\text { 5. Capacidad de percepción y respuesta } \\
\text { a las condiciones sociales del entorno } \\
\text { de la escuela }\end{array}$ & $\begin{array}{l}\text { 9. Participar en la gestión de la escuela } \\
\text { 10. Informar e implicar a los padres }\end{array}$ \\
\hline
\end{tabular}

¿Dónde quedó el dominio de propósitos y contenidos de la educación básica? ¿será que el paradigma ha cambiado?

En el acuerdo secretarial 592, por el que se establece la articulación de la Educación Básica, publicado el 15 de agosto de 2011, se dice que la articulación es el inicio de una transformación que generará una escuela centrada en el logro educativo al atender las necesidades específicas de aprendizaje de cada uno de sus estudiantes, para que adquieran las competencias que permitan su desarrollo personal; una escuela, que al recibir la asesoría y el acompañamiento pertinentes, genere acciones para atender y prevenir el rezago; organicen redes académicas de aprendizaje donde todos los integrantes de la comunidad escolar participen del desarrollo de competencias que permiten la autonomía en el aprendizaje y la participación en los procesos sociales. Se 
habla del desarrollo de competencias y se pretende que el maestro sea capaz de lograr los aprendizajes esperados y la formación en competencias en los alumnos.

Resulta interesante reflexionar cómo se modifica el proceso de formación del docente. Se busca un nuevo rol del maestro en el aula, más comprometido con los intereses del alumno y con su habilidad para generar aprendizajes; un docente competente, capaz de formar alumnos competentes. Pero, se ha comprendido a la formación docente desde un enfoque tradicional en el que se da clase, transmitiendo conocimientos, pero no formando en competencias; es decir buscando ser competente para lograr aprendizajes en sus alumnos. ¿Cómo transformar al docente "transmisor de conocimientos" en un docente "facilitador de aprendizajes"?

Miranda (2007) establece que las competencias profesionales se forman básicamente en el proceso de aprendizaje profesional, a través de procesos culturales vividos por los docentes, ya sea de modo personal o colectivo, y por lo tanto sugiere que en las escuelas formadoras de docentes se debería trabajar en la formación de competencias genéricas y específicas, por tal razón la observación y práctica docente se enfocaría a desarrollar:

1. Lo genérico: Procesos de práctica, diagnóstico de necesidades de los alumnos y las alumnas, aprendizajes esperados y contenidos a abordar, metodología de la enseñanza y del aprendizaje, procesos de evaluación y vinculación de los aprendizajes con la práctica.

2. Lo específico: critica, valoración y reflexión sobre la práctica, áreas de oportunidad para la investigación educativa.

Estos pasos ya se están dando; desde el mes de enero de 2011 se da una propuesta para reformar la educación normal y entre otras cosas reafirma la necesidad de formar docentes en competencias. En este mismo proyecto se aclara que las competencias específicas exigen una mayor puntualización de las acciones diferenciadas del quehacer docente referidas al nivel educativo de que se trate. En la propuesta para la reforma a la educación normalista se reafirma la necesidad de formar en situaciones reales de aprendizaje, es decir, en la práctica: 
La labor docente requiere de una toma de decisiones constante en el campo didáctico del profesor en situaciones reales y específicas para lograr el aprendizaje de sus alumnos; por ello, la propuesta en competencias, al estar centrada en la actuación del maestro en el aula, contribuye a formar un profesionista que pueda resolver problemas de manera autónoma y crítica, con una postura reflexiva permanente sobre su práctica. Por otro lado, las reformas realizadas en la educación básica, preescolar, primaria y secundaria, hacen énfasis en la formación de competencias en los alumnos, por lo que un diseño curricular con este enfoque, resulta conveniente para dar congruencia y estructura entre la formación de los alumnos y el trabajo docente (SEP, 2011, p. 15).

Leonard Mertens (1996, como se citó en Pavié, 2011) clasifica en cuatro enfoques, o "niveles de aplicación" esta idea de competencias:

1. En el enfoque conductista, se hace referencia a las competencias como atributos, es decir, la competencia como conductas asociadas a tareas concretas.

2. En el enfoque funcionalista, las competencias son un conjunto de habilidades y conocimientos que se aplican en el desempeño de una función ocupacional a partir de los requerimientos de institución.

3. En el enfoque constructivista, la competencia se da a partir de la construcción propia del individuo, a través de un conjunto de acciones de carácter educativo que le permitan apropiarse progresivamente de estructuras de conocimiento.

4. En el enfoque holístico o integrado, competente es la persona que posee los atributos necesarios (conocimientos, habilidades, actitudes y valores), para el desempeño del trabajo de acuerdo con la norma apropiada.

Para reconocer, desde esta propuesta el enfoque por competencias, en la siguiente tabla se muestra un análisis de los 5 rasgos del perfil de egreso estudiante normalista que plantea el Plan de Estudios 1999 y su relación con el nivel de aplicación. 
Tabla 2

Cuadro comparativo perfil de egreso - nivel de aplicación.

\begin{tabular}{|c|c|}
\hline PERFIL DE EGRESO 1999 & NIVEL DE APLICACIÓN \\
\hline Habilidades intelectuales específicas & Funcionalista \\
\hline $\begin{array}{l}\text { - Dominio de los propósitos y los contenidos de la } \\
\text { educación secundaria }\end{array}$ & Funcionalista \\
\hline - Competencias didácticas & Constructivista \\
\hline - Identidad profesional y ética & Holístico \\
\hline $\begin{array}{l}\text { - Capacidad de percepción y respuesta a las condiciones } \\
\text { sociales del entorno de la escuela }\end{array}$ & Funcionalista \\
\hline
\end{tabular}

Por separado, cada uno de los rasgos del perfil de egreso no responde al enfoque por competencias; sin embargo, si se trabajara de manera conjunta los 5 rasgos, se logra un nivel de aplicación de la competencia holístico o integral; la tarea es definir cada rasgo desde la propuesta actual de enseñanza, en atención al Plan de estudios vigente y los programas de estudios correspondientes.

Para la formación docente de las licenciaturas en educación preescolar y en educación primaria ya existen los Planes de Estudio 2012; no así para las licenciaturas en educación secundaria donde, aunque parezca increíble todavía es vigente el Plan de Estudios 1999, basado en el Plan de Estudios 1993 para la educación básica en secundaria, con un desfase real de veinte años.

Los acuerdos secretariales 649 y 650 , publicados en el Diario oficial de la Federación, por los que se establecen nuevos planes de estudios para la formación de maestros de educación primaria y de educación preescolar, definen a las competencias con un carácter holístico e integrado. Rechazan la pretensión sumativa y mecánica de las concepciones conductistas; establecen que las competencias se componen e integran de manera interactiva con conocimientos explícitos y tácitos, actitudes, valores y emociones, en contextos concretos de actuación de acuerdo con procesos históricos y culturales específicos. Además aclara que las competencias se encuentran en permanente desarrollo.

En esta perspectiva de la formación docente en el enfoque por competencias, se enfatiza tanto en el proceso como los resultados del aprendizaje, es decir, lo que el estudiante de docencia deberá ser capaz de hacer al término de su proceso formativo. 
En este mismo plan se establece el nuevo perfil de egreso del docente del siglo XXI, en donde se distingue entre dos tipos de competencias: genéricas y profesionales. Las competencias genéricas expresan desempeños comunes que deben demostrar los egresados, tienen un carácter transversal y se desarrollan a través de la experiencia personal y la formación de cada sujeto. Estas competencias se enuncian a continuación:

1. Usa su pensamiento crítico y creativo para la solución de problemas y la toma de decisiones.

2. Aprende de manera permanente.

3. Colabora con otros para generar proyectos innovadores y de impacto social.

4. Actúa con sentido ético.

5. Aplica sus habilidades comunicativas en diversos contextos.

6. Emplea las tecnologías de la información y la comunicación.

De igual forma, en el mismo documento se hace mención de que las competencias profesionales expresan desempeños que deben demostrar los futuros docentes de educación básica; tienen un carácter específico y se forman al integrar conocimientos, habilidades, actitudes y valores necesarios para ejercer la profesión docente y desarrollar prácticas en escenarios reales. Estas competencias permitirán al egresado atender situaciones y resolver problemas del contexto escolar; colaborar activamente en su entorno educativo y en la organización del trabajo institucional. Las competencias profesionales que se definieron son las siguientes:

1. Diseña planeaciones didácticas, aplicando sus conocimientos pedagógicos y disciplinares para responder a las necesidades del contexto en el marco del plan y programas de educación básica.

2. Genera ambientes formativos para propiciar la autonomía y promover el desarrollo de las competencias en los alumnos de educación básica.

3. Aplica críticamente el plan y programas de estudio de la educación básica para alcanzar los propósitos educativos y contribuir al pleno desenvolvimiento de las capacidades de los alumnos del nivel escolar.

4. Usa las TIC como herramienta de enseñanza y aprendizaje. 
5. Emplea la evaluación para intervenir en los diferentes ámbitos y momentos de la tarea educativa.

6. Propicia y regula espacios de aprendizaje incluyentes para todos los alumnos, con el fin de promover la convivencia, el respeto y la aceptación.

7. Actúa de manera ética ante la diversidad de situaciones que se presentan en la práctica profesional.

8. Utiliza recursos de la investigación educativa para enriquecer la práctica docente, expresando su interés por la ciencia y la propia investigación.

9. Interviene de manera colaborativa con la comunidad escolar, padres de familia, autoridades y docentes, en la toma de decisiones y en el desarrollo de alternativas de solución a problemáticas socioeducativas.

Las competencias genéricas y las competencias profesionales se articulan en un conjunto de cursos orientados al logro del perfil de egreso de la licenciatura en educación primaria integrados en una malla curricular, en la que se concibe cada curso como nodos que articulan saberes, propósitos, metodologías y prácticas que le dan sentido a los trayectos formativos. En este perfil de egreso se ve claramente el enfoque por competencias y la propuesta de las nuevas competencias para enseñar.

\section{El problema de estudio.}

Día 2 del mes de enero de 2012. Primer día de labores del año en la Escuela Normal Superior de Durango, iniciaba mi trabajo cuando uno de mis alumnos pregunta:

- Maestro, ¿Qué opina de la reforma educativa que recientemente se aprobó en el senado? ¿Está de acuerdo con la propuesta de evaluación al docente? ¿Es la educación producto de una política de estado? ¿Habrá cambios en los planes de estudio para la Escuela Normal?

- Son demasiadas preguntas- le contesté. - Vamos con calma y esperemos que se publique, para opinar con certeza.

Y guardé silencio; afortunadamente la sesión de trabajo había concluido, pero yo me fui pensando en las respuestas... 
Es indudable que ha sido la política educativa factor determinante en el desarrollo histórico de la educación y también la formación docente es producto de una política de estado...

¿Cómo saber si la política educativa es la correcta? ¿Cómo saber si la propuesta de reforma es correcta?...

¿Cuál será la propuesta de reforma a la Escuela Normal?

Para dar respuesta a estas interrogantes, lo primero fue establecer que se ha escrito sobre el tema en el ámbito académico; en la indagación se trabajó con más de treinta artículos de revistas de la comunidad educativa; entre otras: Revista Mexicana de Investigación Educativa. Revista Iberoamericana de Educación. Revista Educación y pedagogía. Revista Visión Educativa IUNAES. Todas editadas en los cinco años.

Un ejemplo de cómo la política educativa marca los rumbos de las instituciones es la historia de la Escuela Normal Rural de Roque, Guanajuato. Aguilar (2011), en la Memoria de Veranos de la Investigación Científica de la Universidad de Guanajuato aborda este tema:

Al término de las funciones de la Escuela Normal Rural de Roque, en 1970, se instaló la Escuela Nacional de Maestros para la Capacitación del Trabajo Agropecuario: (E. Na. Ma. C. T. A), que funcionó durante el periodo 1970-1978. Esta "nueva" institución se creó por iniciativa de la SEP, que necesitaba incrementar el número de maestros técnicos para las escuelas secundarias tecnológicas agropecuarias. La institución ofrecía al maestro normalista tres especialidades: agricultura, ganadería, manejo y mantenimiento de equipo e instalaciones rurales" (Aguilar, 2011, p. 1106).

El trabajo de investigación de Brumat (2011), aborda las condiciones de trabajo de los maestros rurales de la provincia de Córdova en Argentina; se desarrolla en tres escuelas primarias rurales, es un acercamiento a la vida cotidiana de estas escuelas donde se identifican y describen características de la organización institucional, en política educativa que excede el trabajo del maestro en el aula y donde se denota el sentido de responsabilidad y competencia que permiten comprender las estrategias utilizadas por los maestros en sus intervenciones pedagógicas. Así, en cada trabajo 
analizado se reconoce un esfuerzo valioso por tratar la formación docente, como una necesidad. En este análisis encontramos que, como lo señala Galván (2010), ciertamente se habla del normalismo, en un contraste dialéctica entre la tradición, de la Escuela Normal y la modernidad de propuesta por la Universidad Pedagógica Nacional:

Hoy en día podemos afirmar que en la formación de los maestros mexicanos se juntan dos sistemas; uno con una larga tradición histórica que se materializa en las Escuelas Normales de todo el país; y otro que aparece hace 18 años, y que está representado por la Universidad Pedagógica Nacional (Galván, 2010, p. 11).

Así en los trabajos analizados, se habla de la lucha gremial, de las transformaciones de la escuela formadora de docentes; pero poco se aporta al campo curricular y los procesos de formación al interior de la escuela normal y menos aún se trabaja sobre la perspectiva educativa de las escuelas normales superiores de modalidad mixta.

En los últimos años las Instituciones formadoras de docentes enfrentan serios problemas ante la política educativa actual; pareciera que la docencia deja de ser una profesión de Estado para integrarse al libre mercado y entrar en un proceso de competencia, de oposición. Así lo señala Barraza, cuando se refiere a las Instituciones formadoras y actualizadoras de docentes:

Ante este panorama, parece más atractivo el debilitamiento de estas instituciones para, ante la supuesta deficiente formación académica, fomentar el traslado de la formación docente a las universidades y otras modalidades de la educación superior, públicas y particulares, rompiendo el compromiso laboral con sus egresados, involucrándolos en una competencia laboral con otras profesiones. Así, la docencia deja de ser una profesión de Estado para integrarse al libre mercado (Barraza, 2010, p. 51).

El 21 de marzo de 2013, el subsecretario de Educación Superior, Fernando Serrano, sostuvo que las escuelas normales no desaparecen sino que se transforman, por lo que se modificará su sistema Zavala (2013): "No se habla de que desaparezcan sino de que se transformen. Llevan funcionando igual durante muchísimo tiempo y 
estamos en un momento de reconsideración del sistema educativo nacional y entre ellas están las Normales".

¿Cómo será la transformación de las Escuelas Normales? $\mathrm{Y}$ en particular, ¿Cómo será la transformación hacia el desarrollo de competencias? Resulta complicado entender que para el diseño del Plan de Estudios 1999 de la licenciatura en educación secundaria, vigente aún, se siga considerando el plan de estudios para la educación secundaria 1993. Si la transformación será en el enfoque de campos temáticos, de estándares curriculares y de competencias se deberá considerar lo que el Acuerdo Secretarial 592 establece para la Educación Básica:

La Educación Básica favorece el desarrollo de competencias, el logro de los Estándares Curriculares y los aprendizajes esperados, porque: Una competencia es la capacidad de responder a diferentes situaciones, e implica un saber hacer (habilidades) con saber (conocimiento), así como la valoración de las consecuencias de ese hacer (valores y actitudes) (DOF, 2011, p. 22).

\section{Metodología.}

El método de investigación a desarrollar aborda el paradigma de la investigación cualitativa. César A. Bernal, citando a Bonilla y Rodríguez (2000) acerca del método cualitativo escribe:

Se orienta a profundizar casos específicos y no a generalizar. Su preocupación no es prioritariamente medir, sino cualificar y describir el fenómeno social a partir de rasgos determinantes, según sean percibidos por los elementos mismos que están dentro de la situación estudiada (Bernal, 2010, p. 60).

Según Taylor y Bogdan (1988) la frase "metodología cualitativa" se refiere en su más amplio sentido a la investigación que produce datos descriptivos: las propias palabras de las personas, habladas o escritas, y la conducta observable, es un modo de encarar el mundo empírico.

La investigación se desarrolló mediante el método de estudio de caso, que de acuerdo con Rosado (2010), un es una descripción escrita de una organización, 
cubriendo un cierto periodo; en la mayoría de los casos contienen información sobre la historia de la organización, sus operaciones internas y su entorno, este es el caso de la investigación realizada en la Escuela Normal Superior de Durango.

Para el presente trabajo, se emplearon como técnicas de registro de datos: la entrevista a profundidad, la observación participante y los grupos de enfoque. La entrevista es una situación cara a cara entre dos personas, en la que una, el entrevistador, formula preguntas precisas a fin de obtener respuestas pertinentes al problema de investigación. En la presente investigación, se utilizó una entrevista de tipo no estructurada, abierta, dirigida al director de la Institución.

En la metodología del estudio de caso, se trabajó en el análisis de debilidades, oportunidades, amenazas y fortalezas, (WOTS: weaknesses, opportunities, threats and strengths); metodología, que también se conoce por sus siglas en español FODA. Las fortalezas y las oportunidades son aspectos positivos que conviene afianzar y las resistencias y amenazas son áreas que se deberán combatir para mejorar la organización. Las fortalezas y resistencias son de origen interno; mientras que las oportunidades y las amenazas corresponden a factores externos a la organización.

La técnica del grupo focal se realiza en un ambiente de confianza y permite, escuchar los discursos ideológicos en el grupo y entre pares, permitiendo recuperar las relaciones complejas de los sujetos con el tema estudiado, que pueden escapar a las preguntas concretas. Para el caso de la presente investigación se trabajó en los siguientes grupos focales: Alumnos de nuevo ingreso, alumnos de los semestres superiores y personal docente.

Una vez iniciados los procesos, se buscaron las categorías provisionales de análisis, que surgen de las preguntas planteadas trasformadas en temas; por lo tanto, en torno a la formación docente se definieron las siguientes tres categorías provisionales:

- El perfil de egreso del estudiante normalista.

- La observación y práctica docente en la Escuela Normal. 
- Modificaciones curriculares académicas para la mejora de los procesos de formación docente.

Para el trabajo con el grupo focal de exalumnos, se creó el espacio virtual www.creadocencia,com. En esta página existe una plataforma definida como "grupo de enfoque", en la que los exalumnos, tuvieron la oportunidad de opinar acerca de la investigación en línea.

\section{Discusión de resultados.}

El avance de la investigación es sustancial. Con los resultados de la entrevista, los cuestionarios y los instrumentos FODA, se trabajó un proceso de triangulación por extractos que nos permitió establecer relaciones de comparación entre los sujetos, en función de los diversos tópicos interrogados. Cisterna $(2005$, p.62) expresa que, "Cuando se ha realizado esta integración de toda la información triangulada, es posible sostener entonces que se cuenta con un corpus coherente, que refleja de modo orgánico aquello que denominamos resultados de la investigación".

Al realizar el trabajo de triangulación, encontré en este proceso una Meta categoría, que he definido como "Formación y currículum" puesto que integra las categorías de análisis. En la siguiente figura ejemplifico el hallazgo:

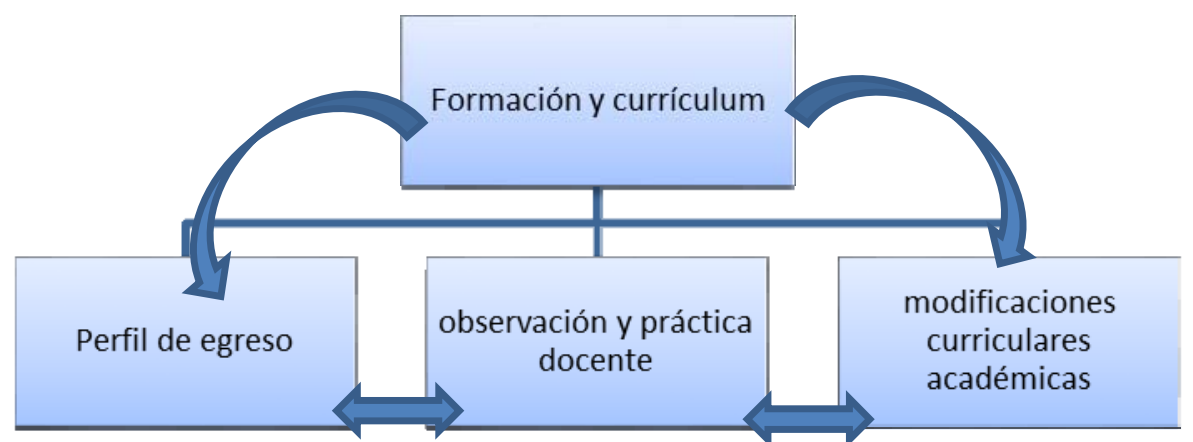

Figura 1: Meta categoría

Esta Meta categoría cobra importancia desde la idea misma de los procesos de formación docente, en ella se integran las categorías trabajadas, en atención a que el 
perfil de egreso del estudiante normalista tiene estrecha relación con la observación y práctica docente en el acercamiento a la práctica educativa y por supuesto con lo referente a las modificaciones curriculares académicas para la mejora de los procesos de formación docente.

Se ha denominado a esta meta categoría como "formación y currículum", pretendiendo conceptualizar la necesidad urgente de innovar en los procesos de la práctica educativa, desde el enfoque mismo de la modificación curricular.

Las ideas de currículum, según Stenhouse (1987), deben ser entendidas y han de serlo en relación con la práctica; por esta razón al hablar de formación docente y currículum, hblamos tambien del ejercicio de la práctica docente. Es necesario establecer con claridad que la práctica del currículum debe hallarse sometida a juicio crítico constantemente, a la luz de la comprensión de ideas. Pero, que se entiende por currículum? Para definirlo tomaré las palabras de Stenhouse:

¿Qué es un curriculum tal como entendemos ahora el término? Ha cambiado su significado como consecuencia del movimiento curricular. No es un sumario simple lista del contenido que ha de ser abarcado- ni siquiera lo que en alemán se diría un Lehrerpnan, una prescripción de objetivos, métodos y conte nido. $\mathrm{Ni}$ en nuestro concepto figura una lista de objetivos. Permítame decir que es un objeto simbólico y significativo, como la primera página de Shakespeare, no como una cortadora de césped; como las piezas y el tablero del ajedrez, no como un manzano. Posee una existencia física, pero también un significado encarnado en palabras, imágnenes, sonidos, juegos o lo que fuere. (Stenhouse, 1987, p. 102)

De la misma manera, el currículum y la formación docente, en la Escuela Normal Superior de Durango, entretejen imágenes, palabras, sonidos, juegos, cultura, ideas que generan conceptos sobre la práctica docente, sobre el perfil de egreso del estudiante y sobre las modificaciones e innovaciones curriculares en la propuesta de enseñanza y de aprendizaje que ha constituido el quehacer de la propia institución a lo largo de cuatro décadas de formación docente. 
La formación del docente en la Escuela Normal Superior de Durango, debería de responder a las necesidades de la sociedad del siglo XXI, incluso debería ser personalizada, desde el enfoque que formarse es transformarse, ir más allá de sí mismo, en lo que se quiere y en lo que se desea.

Se trata sin duda alguna de formar al formador que prestará sus servicios en la escuela secundaria. El formador, en cualquier espacio que se dé la formación, debe asumir los retos de la formación misma, debe si pretende formar en competencias, ser competente en su quehacer educativo; no es válido decir que la materia humana tiene deficiencias, que el nivel educativo anterior no cubrió con el perfil de egreso, porque se habla entonces, de las incompetencias para formar del propio formador; más delicado aún, si para ingresar a la institución se dio un proceso de selección de aspirantes. Ese es su trabajo. "Si el educando ya estuviera formado, no requeriría la acción del educador".

La formación en las instituciones debe sustentarse en el propio valor humano del formador, en la competencia misma del educador. Si el formador no posee un alto sentido de su propia formación humana y de su competencia, difícilmente podrá tener éxito en su trabajo. "Un ciego difícilmente puede guiar a otro ciego". Los rasgos de la formación, la currícula, son aspectos, que si bien es cierto establecen parámetros comunes que se deben inducir en los formados, son los educandos quienes con libertad deberán aceptarlos y aplicarlos. Pero existe en las instituciones aspectos formativos más allá de la currícula, acciones que deberían ser abordadas para la formación integral de los educandos. Toda actividad docente deberá ser cuestionada acerca de si contribuye o no a la formación del alumno.

Afirmar que el concepto formación debe convertirse en criterio para enjuiciar las actividades escolares como pedagógicas implica que todo modelo, estrategia, proyecto y acción educativa serán válidos y potentes pedagógicamente, si contribuyen a la formación humana del alumno... incluso, consideramos que la reflexión del día a día sobre el quehacer docente debe estar orientada por el interrogante:¿Cuánto de lo que hicimos hoy contribuye, verdaderamente, en forma significativa a la formación? (Flórez, 2007, p. 166). 
Se establecieron procesos de triangulación, en dos etapas, considerando tres categorías de análisis, en las que se trabajaron las aportaciones de la parte directiva, de los docentes y de los alumnos.

En la primera etapa, se triangularon los resultados de la entrevista y el cuestionario. Las inferencias fueron las siguientes:

- Para el director, la formación docente en la Institución es excelente.

- Alumnos y docentes señalan que se requiere una actualización y capacitación de la planta docente

- Es común la idea de que es necesario ofertar capacitación y actualización y trabajar proyectos transversales de lectura y escritura.

En la segunda etapa se triangularon los resultados de los grupos focales y el instrumento WOTS.

La Matriz FODA, se capturó por medio de dos matrices de evaluación: una externa y otra de carácter interno, denominadas por Fred (2003) "Matriz de Evaluación Externa" (EFE) y "Matriz de Evaluación Interna" (EFI).

En los resultados, es evidente que son más fuertes las amenazas que las oportunidades y lo mismo sucede en lo interno, son más fuertes las debilidades que las fortalezas. En cada área de la matriz FODA, se establecieron estrategias que responden a las inferencias de la categoría trabajada; estas estrategias nos muestran las posibles pautas para la mejora de la formación docente.

Las inferencias de la segunda etapa fueron:

- Para cubrir el perfil de egreso del estudiante normalista, ante un nuevo plan de estudios para la educación básica enfocado a la formación por competencias, se debe buscar la capacitación y la actualización permanente.

- Se debe trabajar conforme a la normatividad, actualizando las propuestas didácticas en atención al plan de estudios 2011. No se hace un adecuado análisis de la experiencia ni se supervisa la práctica; ante la reforma educativa se podrían dificultar las prácticas docentes en los centros de trabajo e incluso los cursos de verano de inducción y regularización. 
- En lo externo son mayores las amenazas que las oportunidades, esto es una señal de alarma al normalismo. En lo interno son más fuertes las debilidades que las fortalezas, lo que nos da un panorama más complicado en esta categoría, porque, pensar en la problemática, buscar solución y enfrentar la resistencia al cambio nos dificulta el crecimiento en torno a la formación docente.

Al triangular los instrumentos en sus dos etapas, se buscó encontrar en cada una de estas etapas evidencias de resultados para cada categoría.

Primera categoría: El perfil de egreso del estudiante normalista

- Para cumplirlo, es necesario vincular teoría y práctica en un enfoque por competencias, con cierta flexibilidad curricular al plan de estudios 1999, buscando la actualización permanente del personal docente.

Segunda categoría: La observación y la práctica docente en la Escuela Normal. Acercamiento a la práctica educativa

- Se debe cumplir la normatividad de horas de práctica docente; ante la falta de supervisión, se hace necesario establecer requerimientos comunes para la práctica docente. Se pudiera dificultar la práctica en los cursos de verano de inducción y regularización, que, además no cumplen con lo que establece la normatividad.

Tercera categoría: Modificaciones curriculares para la mejora de los procesos de formación docente.

- Es necesario ofertar proyectos de capacitación y actualización docente, como: diplomados y estudios de posgrado (recuperar la maestría en pedagogía). Trabajar proyectos transversales de Lectura y escritura.

\section{Conclusión}

La ley del servicio profesional docente, en el transitorio vigésimo segundo, señala que la secretaría formulará un plan integral para iniciar a la brevedad los trabajos formales, a nivel nacional, de diagnóstico, rediseño y fortalecimiento para el sistema de Normales Públicas a efecto de asegurar la calidad en la educación que imparta y la competencia 
académica de sus egresados, así como su congruencia con las necesidades del sistema educativo nacional.

El 15 de enero de 2014, la Secretaría de Educación Pública convocó a participar en los foros de consulta nacional para la revisión del modelo educativo que se llevarán a cabo de febrero a junio de 2014; se trata de construir el nuevo modelo de Educación Básica, de Media Superior y de Educación Normal. Así las normales "no desaparecen" "se transforman", en la convocatoria se establece que:

El proceso legal para poner en marcha la reforma educativa en México concluyó luego de que el Gobierno Federal promulgara tres leyes secundarias: Ley General del Servicio Profesional Docente, la Ley del Instituto Nacional para la Evaluación de la Educación, así como las reformas a la Ley General de Educación. En cumplimiento de los mandatos legales se requirió seguir adelante con la instrumentación de la reforma educativa, revisar el modelo educativo en su conjunto a través de consultas regionales y nacionales, e iniciar de inmediato el "Plan integral de diagnóstico, rediseño y fortalecimiento del sistema de normales públicas" (SEP, 2014, p. 1).

En el documento de la convocatoria se establece que las escuelas normales nacieron y se han interpretado bajo el signo de la diversidad. No respondieron a un solo proyecto ni se fundaron en un mismo momento histórico. Además se proporciona un dato interesante, cuando se afirma que del $100 \%$ de las escuelas que imparten programas autorizados para la formación de maestros para la educación básica, el 58\% son públicas (por su tipo de sostenimiento en federales, federalizadas y estatales) y el $42 \%$ son particulares; del total de instituciones públicas existe una diversidad entre las que se encuentran las escuelas normales experimentales, rurales, indígenas, beneméritas estatales y nacionales y que decir de las de "modalidad mixta" como es el caso de la Escuela Normal Superior de Durango. Aquí cabe la pregunta acerca de si el perfil de egreso del estudiante normalista cumple con los requerimientos de la sociedad el siglo XXI y por el sentido de la misma convocatoria y la búsqueda de un nuevo modelo queda claro que no se cubre con las exigencias formativas de los docentes ante los retos del presente siglo; esta misma realidad es conclusión en nuestra investigación 
cualitativa, la Escuela Normal Superior de Durango cumple con el perfil de egreso, pero este perfil no basta para la formación de los docentes del siglo XXI. Entonces, ¿Cómo cubrir el perfil de egreso del estudiante normalista, cumpliendo con las exigencias formativas actuales del docente del siglo XXI?

La respuesta es transformando la observación y práctica docente de fondo, recuperando en enfoque por competencias; dejando el enciclopedismo para alcanzar calidad en la los procesos de enseñanza y de aprendizaje partiendo del logro de los aprendizajes esperados y no del manejo de contenidos.

Docentes y alumnos tienen una opinión favorable de la Escuela Normal Superior de Durango, consideran que no solo es una Institución "acreditadora" de docentes, sino que ha formado, por lo menos en el Estado de Durango a más del $80 \%$ de los docentes en servicio; dado que cumple y ha cumplido desde su fundación con la misión de "aprender para guiar a la juventud" como lo dice el lema de la Institución.

Finalmente, quienes trabajamos en los procesos de formación docente tenemos clara la idea de que se requieren cambios sustanciales y que la formación de los docentes de educación secundaria tendrá en un futuro muy cercano su nuevo Plan der Estudios y deberá ser muy similar al que se ha citado sobre la formación para la docencia en la escuela primaria; pero, ¿Qué tipo de formación requieren los docentes? Al respecto, Gutiérrez señala lo siguiente:

La necesidad de formación que requiere el profesor es en el sentir de que le falta algo, las autoridades educativas dan por hecho que el docente está preparado para cualquier cambio, pero en realidad no es así, y eso se confirma en las discusiones que se generan en círculos de estudio, en los cursos que se les dan a los profesores, en grupos de posgrados, el sentir de la gran mayoría es verse implicados en tanto cambios, sin tener las herramientas necesarias para hacerles frente, entonces se requiere entender la formación no como un mero instrumento correctivo que supla ciertas carencias sino como una oportunidad de encontrar respuestas a tantas inquietudes (Gutiérrez, 2007, p. 45).

Sólo formando educadores competentes se puede garantizar el desarrollo de competencias en los educandos. Formar en competencias es una tarea que debe partir 
desde la comprensión básica de que la competencia no es una condición con la que las personas nacen y tampoco es algo que se adquiera a lo largo de la vida; la competencia no es tan sólo experiencia; pero tampoco es algo ajeno a la persona misma, se nace y se crece con ella; es decir se nace con las condiciones necesarias para ser competente, pero, si no se va construyendo la competencia a lo largo de la formación, pudiera nunca manifestarse.

Se debe formar formadores competentes, así lo escribe Cruz García (2011) en su publicación en el siglo de Torreón: "Cuando se habla de la formación en competencias profesionales y tratamos de contextualizarlas en el ámbito docente, suele repetirse con frecuencia que necesitamos formar profesionales competentes a partir de profesores competentes".

Esta es mi visión sobre el futuro cercano de la formación de los docentes de educación básica y en particular en la licenciatura en reducación secundaria. Es mi gota de agua lanzada en la inmensidad del mar; y el mar sigue en calma... o bien, en aparente calma, pero seguramente en el futuro cercano han de venir tempestades que transformen la realidad de los procesos educativos en las Instituciones Formadoras de Docentes. Queda claro que los procesos deben cambiar y deberán hacerlo lo antes posible. Antes de que "el futuro nos alcance".

\section{Referencias}

Aguilar, M. (2011), Las escuelas normales rurales, orígenes, desarrollo e Impacto social. Memoria de Veranos de investigación científica. Universidad de Guanajuato.

Barraza, A. (2007). Formación docente en una conceptualización comprehensiva y un enfoque por competencias. Revista Innovación Educativa, 7(40). pp. 27-47.

Barraza, I. (2010) El Sistema Estatal de formación docente en Durango: sus implicaciones Revista de Ciencias Sociales, XVI(1).

Bernal, C. A. (2010). Metodología de la investigación. (Tercera edición). Colombia: Pearson educación.

Brumat, R. M. (2011), Maestros rurales: condiciones de trabajo, formación docente y práctica cotidiana, Revista Iberoamericana de Educación, 55(4).

Cisterna, C. F. (2005). Categorización y triangulación como procesos de validación del conocimiento en investigación cualitativa. Theoria, 14 (1): 61-71. Chile.

Cruz, G. R. (2011) Las competencias básicas de la profesión docente. El siglo de Torreón. Recuperado de http:// www. elsiglodetorreón.com.mx. 
DOF (2011). Acuerdo número 592 por el que se establece la Articulación de la Educación Básica. Recuperado de: http//:www.dof.gob.mx.

DOF (2012). Acuerdo 649, por el que se establece el Plan de estudios para la formación de Maestros de educación primaria. Recuperado de: http//:www.dof.gob.mx.

DOF (2013). Decreto por el que se expide la Ley General del Servicio Profesional Docente del 11 de septiembre de 2013. Recuperado de http:// www.dof.gob.mx.

Flórez, O. R. (2007). La formación como principio y fin de la acción pedagógica. Revista Educación y Pedagogía, Medellín, Universidad de Antioquia. Facultad de Educación, $\mathrm{XIX}(47)$.

Fred, R. D. (2003). Conceptos de administración estratégica. México: Pearson educación.

Galván, L. L. E. (2010). La formación docente en México, entre la tradición y la modernidad. Centro de investigaciones y estudios superiores de antropología.

Gutiérrez, R. D. (2007). Reforma educativa y necesidades de formación de los docentes. Revista Visión Educativa IUNAES, 1 (1).

Miranda, J. C. (2007). Formación permanente e innovación en las prácticas pedagógicas en docentes de educación básica. Universidad Austral de Chile. Revista Iberoamericana de Educación, p. 3.

Pavié, A. (2011). Formación docente: hacia una definición del concepto de competencia profesional docente. REIFOP, 14 (1), 67-80. Recuperado de: http//www.aufop.com.

Perrenoud P. (2004). Diez nuevas competencias para enseñar. Editorial Grao.

Rosado, M. Á. (2010). Metodología de la investigación y evaluación. México: Editorial trillas.

SEP. (2000). Acuerdo número 284 por el que se establece el plan de estudios de la licenciatura en educación secundaria en modalidad mixta. Recuperado de http://www.dgespe.sep.gob.mx.

SEP. (2011). Convocatoria nacional para el otorgamiento de plazas docentes. Alianza por la calidad de la educación. Recuperado de: http://concursonacionalalianza.sep.gob.mx.

SEP. (2012). Plan de estudios para la licenciatura en educación primaria. Recuperado de: http://www.dgespe.sep.gob.mx.

SEP. (2014). Foro de consulta nacional para la revisión del modelo educativo. Recuperado de: http://modeloeducativo.sep.gob.mx.

Stenhouse, L. (1987). La Investigación como base de la enseñanza. Editorial Morata. Colección La pedagogía hoy.

Taylor, S. J. \& Bogdan, R. (1988). Introducción a los métodos cualitativos de Investigación: La búsqueda de significados. Editorial Paidós básica.

Zavala L. (2013), El sistema de normales de fin del siglo XIX: SEP. Telediario. Recuperado de http:// www.telediario.mx. 


\title{
LAS COMPETENCIAS Y SU RELACIÓN CON EL DOCENTE DE MATEMÁTICAS DE SECUNDARIA
}

\author{
COMPETENCES AND THEIR RELATIONSHIP WITH THE \\ MATHEMATICS SECONDARY SCHOOLTEACHER
}

\author{
Edith J. Cisneros-Cohernour \\ Universidad Autónoma de Yucatán \\ cchacon@uady.mx \\ Yazbeth Alejandra López Mézquita \\ Universidad Autónoma de Yucatán \\ tebzay@hotmail.com \\ Pedro J. Canto Herrera \\ Universidad Autónoma de Yucatán \\ pcanto1962@gmail.com
}

\begin{abstract}
Resumen
Este trabajo describe los resultados de un estudio que se centró en evaluar la efectividad de un programa de mejora de conocimientos y competencias en el área de matemáticas. Asimismo, el estudio determinó si existen diferencias significativas entre las competencias de los docentes participantes antes y después de que formen parte en el programa de actualización en relación con sus años de experiencia docente. Participaron en el estudio quince profesores de matemáticas de secundaria y la recolección de datos involucró observaciones, auto-evaluación docente, pruebas de dominio de contenido y grupos focales. Los resultados, indican que sí existe diferencia significativa en las competencias de los docentes antes y después de participar en el programa. No se encontraron diferencias significativas en los puntajes de los docentes en relación con sus años de experiencia docente.
\end{abstract}

Palabras clave: evaluación, competencias docentes, matemáticas.

\begin{abstract}
This work presents the findings of the evaluation of the effectiveness of a program oriented to improve knowledge and competences in mathematics. The study also examined if there were differences among the participants in relation to their teacher experience. Fifteen Math secondary school teachers participated in the study, and data collection involved participant observation, teacher self-evaluation, knowledge-based assessment tests and focus groups. Findings of the study indicate that teachers' improvement before and after the participation in the program significantly increased. No significant differences were found in the improvement of novice and experienced teachers who participated in the program.
\end{abstract}

Keywords: evaluation, teacher competences, mathematics. 


\section{Introducción}

Las evaluaciones internacionales en los últimos años han revelado el pobre desempeño de los estudiantes en matemática. En el Tercer Estudio Internacional de Matemáticas y Ciencias, llevado a cabo por la Internacional Association for Student Assessment en 1999, se encontró que los estudiantes de primaria y secundaria obtuvieron los puntajes más bajos de aprovechamiento en matemáticas y ciencias al ser comparados con estudiantes de otros países; Asimismo en la evaluación del Programa Internacional de Evaluación de Estudiantes (Programme for Internacional Student Assessment, PISA) realizada en el 2000, se obtuvieron similares resultados, pues los estudiantes de México ocuparon el lugar 37 en matemáticas y 38 en conocimiento científico de 41 países participantes. Con base en lo anterior, es evidente que son pocos los estudiantes mexicanos de educación básica que están alcanzando los resultados esperados en el área de las ciencias.

A nivel nacional, los resultados de las evaluaciones a estudiantes de educación básica han confirmado los resultados internacionales. De acuerdo con las pruebas aplicadas en el 2003 por el Instituto Nacional para la Evaluación de la Educación (INEE), en el área de matemáticas en secundaria, solo el 17 por ciento de los alumnos de todas las secundarias del país logra el nivel más alto. En las secundarias públicas, generales y técnicas, solo alcanzan el nivel IV entre el 16 y 17 por ciento de los alumnos, y el nivel III, lo alcanzan alrededor del 48 por ciento de los estudiantes. En esta prueba las telesecundarias obtuvieron los resultados más bajos, al alcanzar el nivel IV solo el 8.9 por ciento, y el nivel III, sólo el 42 por ciento de los estudiantes. De entre todos, los estudiantes del estado de Yucatán ocuparon el lugar 27 a nivel nacional, de los 31 estados participantes en el estudio.

De acuerdo con la literatura de investigación, las matemáticas en cualquier currículo son consideradas como una disciplina indispensable, esencial para poder desarrollar diferentes habilidades en el desarrollo tecnológico y en la continuidad de los estudios en todos los niveles. Pero a pesar de su importancia, esta es una asignatura que se hace difícil para muchos estudiantes en todos los niveles (Gómez \& Calatayud, 
2002; Furió \& Carnicer, 2002). Entre las múltiples causas que tiene esta situación se encuentran la naturaleza abstracta de la disciplina la inadecuación o escasa pertinencia de los contenidos y métodos de enseñanza-aprendizaje, la insuficiencia de infraestructura, de los recursos y materiales auxiliares de educación, y la debilidad en la gestión administración y la formación de los docentes, principalmente si el docente no cuenta con el dominio de los contenidos y las estrategias necesarias para su enseñanza (Rodríguez, 2003).

De acuerdo con Ponce (2004), el bajo desempeño de los estudiantes puede estar relacionado con la falta de profesionalización del docente de matemáticas de secundaria. Debido a que éste no posee las competencias formativas suficientes y necesarias para llevar a cabo la profesión docente, además de no contar con prácticas de enseñanza propicias para la educación de sus alumnos. Como afirma Schulmeyer (2002), el desarrollo profesional del docente es un factor influyente en la mejora de la calidad de la educación.

El desarrollo profesional de profesorado es un proceso formativo, integrado por una serie de etapas a través de las cuales el sujeto va adquiriendo conocimientos, desarrollando competencias y actitudes en su labor docente, e incrementando su nivel de seguridad y de responsabilidad laboral; todos estos elementos en conjunto, le permiten reflexionar sobre su práctica docente, así como comprender la importancia de su labor educativa y mejorarla (Manteca, 2003). De allí que Climent y Carrillo (2003) consideren al desarrollo profesional como el eventual punto de partida de un cambio elegido por el profesor.

En un esfuerzo por mejorar la calidad de la docencia de matemáticas en secundaria, investigadores de la Universidad Autónoma de Yucatán llevaron a cabo el proyecto Fortalecimiento de Recursos Humanos para Mejorar la Calidad y promover la Innovación en la Enseñanza de las Ciencias en Yucatán (Cisneros-Cohernour, 2007), con financiamiento de CONACYT-SEP-SEBYN, de la Secretaria de Educación Pública, la Facultad de Educación, y el Centro de Investigación y Estudios Avanzados de Yucatán. Este proyecto de investigación involucró la creación de un programa de desarrollo profesional denominado: Diplomado de Enseñanza Innovadora de las 
Ciencias para profesores de secundaria y estuvo dirigido a profesores de secundaria en cuatro áreas: matemáticas, física, química y biología.

El objetivo del programa fue preparar a los profesores para mejorar sus competencias en cada una de estas áreas tomando en cuenta el contexto en el que se desenvuelven. Para poder detectar si se cumplió el objetivo del mismo y se logró un impacto en la mejora de la calidad educativa, se utilizó el modelo de evaluación de Wholey, et al. (2010), que percibe a la evaluación como un medio para saber si los programas responden eficazmente a las necesidades de sus participantes. Para estos autores, la evaluación es la comparación de la actuación del programa con alguna norma de actuación esperada, para después arribar a conclusiones sobre su efectividad y valor. Al realizar la evaluación bajo este enfoque teórico se obtiene información de su calidad y de sus consecuencias, éxitos y fracasos. Además la evaluación proporciona información crítica con relación a si el programa se encuentra cumpliendo sus metas.

\section{Objetivo del estudio}

El objetivo del estudio fue evaluar la calidad y la efectividad del programa de formación en competencias el área de matemáticas. Asimismo, el estudio permitió determinar si existían diferencias significativas entre las competencias de los docentes antes y después de participar en el programa de actualización con relación a sus años de experiencia docente.

El contar programas de desarrollo profesional y evaluar la calidad de los mismos es una prioridad nacional, ya que de acuerdo con los objetivos del Programa Nacional de Educación 2007-2012, esto es esencial para brindar una educación de calidad de acuerdo a las necesidades de todos los mexicanos.

El trabajo contribuye a la literatura del cuerpo de conocimientos de la evaluación de programas de desarrollo profesional de docentes de matemáticas y ciencias, un área que es todavía incipiente, porque muchas de las investigaciones para evaluarlos solo se limitan a determinar la satisfacción de los sujetos; y es casi inexistente el número de evaluaciones para saber si el programa contribuye verdaderamente a una mejora en el 
desarrollo de competencias del docente y cumple con las expectativas y necesidades de desarrollo detectadas.

La evaluación permitió comprobar si efectivamente el Diplomado cumplió con sus propósitos y objetivos planteados, y si los cumplió hasta qué grado. Con base en los resultados de la evaluación se podrán realizar mejoras al diplomado para que, posteriormente, cuando sea puesto en práctica de nuevo, pueda obtener mejores resultados y contribuir a mejorar la calidad de la educación.

\section{Preguntas de investigación}

- ¿Qué tan efectivo fue el programa en la mejora de competencias en el área de matemáticas en los profesores de secundaria?

- ¿Existen diferencias significativas en los conocimientos y las competencias de los docentes de matemáticas que participaron en un programa de mejora antes y después de concluir el programa?

- ¿Existen diferencias significativas en los conocimientos y las competencias de los docentes de matemáticas que participaron en un programa de mejora en relación con sus años de experiencia docente?

\section{Metodología}

Este es un estudio de investigación evaluativa que se llevó a cabo utilizando el modelo de evaluación de programas de Wholey, et al. (2010) enfocado al mejoramiento de programas.

Este modelo fue seleccionado porque permite obtener información valiosa del programa para saber si esté respondió eficazmente a las necesidades requeridas por los participantes, es decir, si los sujetos pueden demostrar que adquirieron las competencias proporcionadas por el programa a corto, mediano o largo plazo. En este caso, la medición se centró en resultados a corto y mediano plazo. 


\section{Participantes.}

En un principio se inscribieron al programa Diplomado de Enseñanza innovadora de las Ciencias con la especialidad de Matemáticas 27 docentes de matemáticas de secundaria del estado de Yucatán, de éstos, 15 completaron el programa, quienes fueron los participantes en el estudio. La tabla 1 presenta las características de los participantes.

Tabla 1.

Datos demográficos de los docentes participantes.

\begin{tabular}{ccccc}
\hline Individuo & Género & Edad & $\begin{array}{c}\text { Años de experiencia } \\
\text { docente }\end{array}$ & $\begin{array}{c}\text { Máximo grado de } \\
\text { estudios }\end{array}$ \\
\hline 1 & Masculino & 25 & 2 & Licenciatura \\
2 & Masculino & 42 & 21 & Licenciatura \\
3 & Femenino & 44 & 29 & Maestría \\
4 & Masculino & 26 & 5 & Licenciatura \\
5 & Masculino & 59 & 24 & Licenciatura \\
6 & Masculino & 47 & 19 & Licenciatura \\
7 & Femenino & 27 & 5 & Licenciatura \\
8 & Masculino & 43 & 20 & Licenciatura \\
9 & Masculino & 50 & 19 & Licenciatura \\
10 & Masculino & 48 & 10 & Licenciatura \\
11 & Masculino & 34 & 6 & Licenciatura \\
12 & Masculino & 36 & 7 & Licenciatura \\
13 & Masculino & 29 & 7 & Licenciatura \\
14 & Masculino & 32 & 10 & Maestría \\
15 & Masculino & 36 & 13 & Licenciatura \\
\hline
\end{tabular}

Se observa en dicha tabla, que la mayoría de los participantes fueron hombres (13 hombres y 2 mujeres), con edades entre 25 y 36 años (53.3\% entre 25 y 36 años y el restante $46.7 \%$ tiene entre 37 y 59 años), con una experiencia docente entre 19 y 30 años ( $40 \%$ con experiencia entre 1 a 7 años y el $60 \%$ poseen experiencia de 19 a 30 años) y con sólo estudios de licenciatura $(86.7 \%$ de los profesores cuenta con estudios de licenciatura y sólo el $13.3 \%$ cuenta con un estudio de postgrado). 


\section{Métodos de recolección de datos.}

En el estudio se utilizaron múltiples métodos de recolección de datos, tales como observaciones, pruebas de conocimientos, cuestionarios de auto-evaluación de competencias al inicio y final de cada módulo y entrevistas de enfoque.

En la evaluación se respetaron las decisiones de las personas que participaron en el estudio, teniendo en cuenta las siguientes consideraciones:

a) La recolección de datos se llevó a cabo únicamente durante las sesiones del Diplomado Enseñanza Innovadora de las Ciencias, en las instalaciones de la Facultad de Educación de la Universidad Autónoma de Yucatán.

b) Se les informaron, verbalmente y por escrito, los objetivos de la investigación.

c) Se les indicó que su participación sería voluntaria.

d) Se garantizó la confidencialidad de los datos.

\section{Técnicas de análisis de los datos.}

Se utilizaron porcentajes de respuesta para identificar los aprendizajes y estrategias más importantes adquiridos en cada módulo, así como para determinar las fortalezas y debilidades del programa. También, con base en las autoevaluaciones realizada por los docentes se calcularon los porcentajes de conocimientos y habilidades antes y después de cursar los módulos II, III y IV para determinar la ganancia obtenida como resultado del diplomado.Se utilizó la prueba Kolmogorov-Smirnov para comprobar que los puntajes obtenidos por los docentes en las pruebas de conocimientos siguen una distribución normal. Esta prueba no paramétrica se utiliza para determinar la bondad de ajuste de dos distribuciones de probabilidad entre sí, así como para determinar la normalidad de una distribución. Con base en estos resultados de esta prueba, se procedió a administrar la prueba t para datos relacionados.

Como afirma Cachi (2012), "con la prueba t se comparan las medias y las desviaciones estándar de grupo de datos y se determina si entre esos parámetros las diferencias son estadísticamente significativas o si sólo son diferencias aleatorias" (p.1). 


\section{Resultados}

\section{Efectividad del programa.}

Se evaluó la efectividad en lo referente a los aprendizajes y estrategias que los docentes adquirieron durante el programa. Se encontró que todos los docentes manifestaron haber mejorado en cuanto a sus conocimientos como en sus estrategias docentes (tabla 2).

Tabla 2.

Aprendizajes y estrategias más importantes, adquiridos en cada módulo.

\begin{tabular}{|c|c|c|}
\hline Módulo & Aprendizajes más importantes & $\begin{array}{c}\text { Estrategias que incorporaron a su práctica } \\
\text { docente }\end{array}$ \\
\hline I & $\begin{array}{l}\text { La aplicación del método científico en el } \\
\text { aula para lograr aprendizajes significativos } \\
(80 \%) \text {. } \\
\text { La necesidad de reflexión acerca de su } \\
\text { práctica docente y de su enseñanza no } \\
\text { solo se centre en la transmisión de } \\
\text { conocimientos }(90 \%) \text {. } \\
\text { La importancia de diseñar material } \\
\text { didáctico que promueve el involucramiento } \\
\text { de los estudiantes en su propio aprendizaje } \\
(70 \%) \text {. }\end{array}$ & $\begin{array}{l}\text { Demostrar los principios matemáticos por medio } \\
\text { del método científico }(90 \%) \text {. } \\
\text { Realizar experimentos cuando los temas así lo } \\
\text { requieran }(20 \%) \text {. } \\
\text { Utilizar la tecnología para apoyar las clases } \\
(50 \%) \text {. }\end{array}$ \\
\hline II & $\begin{array}{l}\text { La planeación apropiada de sus clases } \\
(80 \%) \text {. } \\
\text { La importancia del trabajar en equipo, } \\
\text { intercambio de experiencias con otros } \\
\text { profesores }(100 \%) \text {. } \\
\text { La necesidad de modificar la metodología } \\
\text { de enseñanza, el diseño de materiales } \\
\text { didácticos }\end{array}$ & $\begin{array}{l}\text { Organización a los alumnos en grupos de } \\
\text { trabajo para que realicen investigaciones (80\%) } \\
\text { Uso de la actividad lúdica en la resolución de } \\
\text { problemas (60\%). } \\
\text { Fomento de la participación activa de los } \\
\text { alumnos. }\end{array}$ \\
\hline III & $\begin{array}{l}\text { Uso de la computadora en la enseñanza de } \\
\text { las matemáticas (70\%). } \\
\text { Como utilizar el programa Descartes }(80 \%)\end{array}$ & $\begin{array}{l}\text { Uso del programa descartes para poder } \\
\text { enseñar con mayor detalle los temas de las } \\
\text { ecuaciones y pendientes ( } 40 \%)\end{array}$ \\
\hline IV & $\begin{array}{l}\text { Aprender a compartir estrategias entre } \\
\text { colegas, así como experiencias de } \\
\text { aprendizaje con sus compañeros }(100 \%)\end{array}$ & $\begin{array}{l}\text { Fomento de la participación de los estudiantes } \\
\text { por medio de proyectos de investigación ( } 80 \%) \\
\text { Como utilizar problemas de la vida diaria para } \\
\text { ejemplificar el tema a enseñar ( } 70 \%) \text {. }\end{array}$ \\
\hline
\end{tabular}


De la misma manera los profesores hicieron sugerencias para mejorar el módulo, siendo la más recomendada la de incluir actividades prácticas para la enseñanza de las matemáticas.

Por módulo los profesores recomendaron lo siguiente:

- En relación con el primer módulo, que fue introductorio, recomendaron que éste se rediseñe, en caso de que el programa se imparta de nuevo, y que se enfoque en el desarrollo de competencias para las matemáticas.

- Respecto al módulo II, la principal sugerencia de los docentes fue que el instructor utilice más estrategias novedosas, ya que los temas se prestaban para enseñarlos utilizando estrategias activas de enseñanza.

- En lo referente al módulo III, los docentes expresaron que sería de mucha utilidad incrementar la duración del módulo e incluir más tiempo al uso de la Internet, pues la mayoría de los docentes carecen de esas habilidades.

- En el cuarto módulo, los docentes indicaron haber adquirido aprendizajes y estrategias vinculadas con el trabajo en equipo y la colaboración entre colegas. La única sugerencia para este módulo fue organizar mejor el tiempo dedicado a las actividades de tal manera que se adecuara a las necesidades de los participantes.

En lo referente a las fortalezas y debilidades del programa, los profesores manifestaron las siguientes fortalezas:

- El $100 \%$ expresó que hubo un ambiente de compañerismo de todos los que participaron, pues cada uno aportaba ideas diferentes que complementaba el tema visto en cada una de las sesiones.

- El $80 \%$ manifestó que las experiencias de cada uno de los participantes, fue de gran utilidad, pues la mayoría tiene similares problemáticas en el salón de clases, lo que hizo enriquecedor de nuevas alternativas para resolverlas.

- De la misma manera el $90 \%$ de los docentes expresaron que hubo una gran motivación por la investigación, pues realizaban búsquedas de más información y profundizaban en los temas vistos en cada sesión. 
En cuanto a las debilidades:

- El $20 \%$ de los docentes manifestaron que el primer módulo no tuvo mucho enfoque en cuanto a la enseñanza de las matemáticas.

- Otra debilidad manifestada por el $30 \%$ de los docentes fue la falta de estrategias innovadoras, ya que consideraban que el programa no aportó mucho en la parte de innovación.

Se hizo un análisis de las autoevaluaciones realizada por los docentes antes y después de cada uno de los módulos específicos del área de Matemáticas. A continuación se detalla los conocimientos y habilidades de los docentes en las autoevaluaciones realizadas en los módulos II, III y IV.

Tabla 3.

Porcentaje de conocimientos antes y después de cursar los módulos II, III y IV.

\begin{tabular}{cccc}
\hline \multirow{2}{*}{ Módulo } & \multicolumn{2}{c}{ Porcentaje de conocimientos } & \multirow{2}{*}{ Diferencia } \\
\cline { 2 - 3 } & Antes & Después & 10.00 \\
II & 80.66 & 90.66 & 12.00 \\
III & 76.00 & 88.00 & 16.00 \\
IV & 73.33 & 89.33 & \\
\hline
\end{tabular}

Se observa que, en los módulos II, III y IV los docentes tuvieron mayor porcentaje de conocimientos después del obtenido con anterioridad, lo que nos permite concluir que el diplomado fue efectivo en cuanto a la ganancia de conocimientos obtenidos por los profesores. En el módulo III los profesores mostraron menor porcentaje de conocimiento antes de cursarlo, y en el módulo II mostraron un mayor porcentaje antes; en el módulo III los profesores mostraron menor porcentaje de conocimientos una vez concluido el módulo, y en módulo I mostraron un mayor porcentaje. Adicionalmente, en el módulo IV los profesores tuvieron un mayor incremento (diferencia $=16.00$ ).

La tabla 4 presenta los porcentajes de habilidades, tanto antes como después, relacionadas con el módulo II del diplomado.

En cuanto a las competencias de los docentes, se obtuvo, al principio del módulo II, un porcentaje medio de 65.99 ( $D S=5.0678$ ) y al final un porcentaje medio de 84.00 
(DS= 3.0316). Por lo anterior se concluye que el módulo Il fue efectivo en el desarrollo de competencias por parte de los profesores. Antes de cursar el módulo II, los docentes tuvieron el menor porcentaje de dominio en la competencia Usa diagramas de árbol en la enumeración de experimentos aleatorios, mientras que tuvieron el mayor porcentaje de dominio en la competencia Mide y calcula áreas y perímetros.

Después de cursar el módulo II, los docentes tuvieron el menor porcentaje de dominio en la competencia Grafica funciones; estudio en casos sencillos del comportamiento local de la función, y tuvieron el mayor porcentaje de dominio en las competencias Mide y calcula áreas y perímetros y Usa en la medición de decimales y ubicación en la recta numérica fracciones decimales. Finalmente, los profesores tuvieron mayor desarrollo en la competencia Realiza actividades que favorecen el registro y el tratamiento en situaciones sencillas, de los resultados de un mismo experimento aleatorio que se repite varias veces.

Tabla 4.

Porcentaje de competencias antes y después de cursar el módulo II.

\begin{tabular}{|c|c|c|c|}
\hline \multirow{2}{*}{ Competencias } & \multicolumn{2}{|c|}{$\begin{array}{l}\text { Porcentaje de } \\
\text { habilidades }\end{array}$} & \multirow[t]{2}{*}{ Diferencia } \\
\hline & Antes & Después & \\
\hline $\begin{array}{l}\text { - Usa en la medición de decimales y ubicación en la recta } \\
\text { numérica fracciones decimales. }\end{array}$ & 65.33 & 89.33 & 24.00 \\
\hline $\begin{array}{l}\text { - Hace operaciones con decimales (suma, resta, multiplicación y } \\
\text { división de fracciones). }\end{array}$ & 68.00 & 84.00 & 16.00 \\
\hline - Realiza despeje y sustitución algebraica... & 64.00 & 81.33 & 17.33 \\
\hline - Resuelve razones y proporciones (directa e inversa). & 66.66 & 85.33 & 18.67 \\
\hline - Calcula porcentajes y su aplicación a la vida diaria. & 69.33 & 88.00 & 18.67 \\
\hline - Usa números con signo. Usa la calculadora (teclas +, -, M+, M-) & 69.33 & 81.33 & 12.00 \\
\hline $\begin{array}{l}\text { - Aplica nociones de función (funciones dadas por formulas, por } \\
\text { tablas, por gráficas, por teclas de la calculadora y funciones } \\
\text { extraídas de la geometría, la física, la economía, etc.) }\end{array}$ & 58.66 & 80.00 & 21.34 \\
\hline $\begin{array}{l}\text { - Grafica funciones; estudio en casos sencillos del } \\
\text { comportamiento local de la función. }\end{array}$ & 68.00 & 84.00 & 16.00 \\
\hline - Jerarquiza operaciones y usa paréntesis en la aritmética. & 69.33 & 88.00 & 18.67 \\
\hline - Mide y calcula áreas y perímetros. & 72.00 & 89.33 & 17.33 \\
\hline - Lee y elabora tablas y gráficas. & 64.00 & 86.66 & 22.66 \\
\hline
\end{tabular}




\begin{tabular}{|c|c|c|c|}
\hline \multirow{2}{*}{ Competencias } & \multicolumn{2}{|c|}{$\begin{array}{c}\text { Porcentaje de } \\
\text { habilidades }\end{array}$} & \multirow[t]{2}{*}{ Diferencia } \\
\hline & Antes & Después & \\
\hline $\begin{array}{l}\text { - Realiza actividades que favorecen el registro y el tratamiento en } \\
\text { situaciones sencillas, de los resultados de un mismo experimento } \\
\text { aleatorio que se repite varias veces. }\end{array}$ & 57.33 & 84.00 & 26.67 \\
\hline $\begin{array}{l}\text { - Está familiarizado con situaciones de probabilidad } \\
\text { (lanzamientos, dados, rifas, etc.). }\end{array}$ & 65.33 & 82.66 & 17.33 \\
\hline $\begin{array}{l}\text { - Usa diagramas de árbol en la enumeración de experimentos } \\
\text { aleatorios. }\end{array}$ & 54.66 & 84.00 & 29.34 \\
\hline
\end{tabular}

La tabla 5 presenta el porcentaje de dominio por competencia a lograr en el módulo III, antes y después de que se impartió dicho módulo.

Tabla 5.

Porcentaje de competencias antes y después de cursar el módulo III.

\begin{tabular}{|c|c|c|c|}
\hline \multirow{2}{*}{ Competencias } & \multicolumn{2}{|c|}{ Porcentaje de habilidades } & \multirow{2}{*}{ Diferencia } \\
\hline & Antes & Después & \\
\hline $\begin{array}{l}\text { - Resuelve problemas relacionados con técnicas de } \\
\text { conteo. }\end{array}$ & 69.33 & 78.66 & 9.33 \\
\hline - Usa números con signo. & 73.33 & 86.66 & 13.33 \\
\hline $\begin{array}{l}\text { - Se introduce en el lenguaje algebraico, uso de } \\
\text { incógnitas. }\end{array}$ & 65.33 & 82.66 & 17.33 \\
\hline $\begin{array}{l}\text { - Revisa y expresa fracciones algebraicas (operaciones } \\
\text { con fracciones comunes; multiplicación, división, suma y } \\
\text { resta). }\end{array}$ & 69.33 & 84.00 & 14.67 \\
\hline - Usa métodos de solución de ecuaciones lineales. & 77.33 & 85.33 & 8.00 \\
\hline $\begin{array}{l}\text { - Resuelve problemas que conducen a sistemas de dos } \\
\text { ecuaciones lineales con dos incógnitas. }\end{array}$ & 68.00 & 84.00 & 16.00 \\
\hline $\begin{array}{l}\text { - Aplica las propiedades de las figuras básicas en la } \\
\text { solución de problemas y trazos geométricos. }\end{array}$ & 70.66 & 81.33 & 10.67 \\
\hline $\begin{array}{l}\text { - Determina la simetría axial (reflexión respecto a una } \\
\text { recta de un punto) y central (reflexión respecto a un } \\
\text { punto de una figura y centro de simetría de una figura). }\end{array}$ & 64.00 & 88.33 & 24.33 \\
\hline $\begin{array}{l}\text { - Calcula la equivalencia de figuras y de áreas } \\
\text { (demostración(es) del teorema de Pitágoras). }\end{array}$ & 74.66 & 86.66 & 12.00 \\
\hline $\begin{array}{l}\text { - Demuestra el teorema de Pitágoras por diversos } \\
\text { temas. }\end{array}$ & 65.33 & 74.66 & 9.33 \\
\hline
\end{tabular}




\begin{tabular}{llcc}
\hline \multicolumn{1}{c}{ Competencias } & \multicolumn{2}{c}{ Porcentaje de habilidades } & Diferencia \\
\cline { 2 - 3 } & Antes & Después & 12.00 \\
\hline - Calcula promedios y densidades. & 70.66 & 82.66 & 6.67 \\
- Resuelve problemas para introducir la noción de & 69.33 & 76.00 & 14.67 \\
$\begin{array}{l}\text { función como una regla entre dos cantidades. } \\
\text { - Usa la noción frecuencial de la probabilidad. }\end{array}$ & 66.66 & 81.33 & 6.66 \\
$\begin{array}{l}\text { - Usa experiencias aleatorias y formulas clásicas } \\
\text { (resultados equiprobables y no equiprobables). }\end{array}$ & 72.00 & 78.66 & \\
$\begin{array}{l}\text { - Resuelve problemas sencillos que pueden resolverse } \\
\text { por simulación. }\end{array}$ & 68.00 & 77.33 & 9.33 \\
\hline
\end{tabular}

En el módulo III, los profesores consideraron tener un porcentaje medio de 69.33 ( $D S=3.675$ ), y al final un porcentaje medio de 82.66 ( $D S=4.124)$, al igual que en el módulo anterior los profesores expresaron una mejoría en cuanto a las competencias a desarrollar.

Antes de iniciar el módulo III, los profesores tuvieron el menor porcentaje de desarrollo en la competencia Determina la simetría axial (reflexión respecto a una recta de un punto) y central (reflexión respecto a un punto de una figura y centro de simetría de una figura), mientras que tuvieron el mayor porcentaje de desarrollo en la competencia Usa métodos de solución de ecuaciones lineales.

Después de concluir el módulo III, los profesores tuvieron el menor porcentaje de desarrollo en la competencia Demuestra el Teorema de Pitágoras, mientras que tuvieron el mayor porcentaje de desarrollo en la competencia Calcula la equivalencia de figuras y de áreas (demostración(es) del teorema de Pitágoras).

Finalmente, los profesores mostraron una mayor ganancia en el desarrollo de la competencia Determina la simetría axial (reflexión respecto a una recta de un punto) y central (reflexión respecto a un punto de una figura y centro de simetría de una figura).

La tabla 6 presenta los porcentajes de habilidades antes y después de cursar el módulo IV. 
Tabla 6.

Porcentaje de habilidades antes y después de cursar el módulo IV.

\begin{tabular}{|c|c|c|c|}
\hline \multirow{2}{*}{ Competencias } & \multicolumn{2}{|c|}{ Porcentaje de habilidades } & \multirow{2}{*}{ Diferencia } \\
\hline & Antes & Después & \\
\hline $\begin{array}{l}\text { - Representa en el plano cartesiano de conjuntos de } \\
\text { puntos y regiones que satisfacen ecuaciones y } \\
\text { desigualdades lineales en dos variables (casos sencillos). }\end{array}$ & 68.00 & 85.33 & 17.33 \\
\hline $\begin{array}{l}\text { - Usa métodos de solución de sistemas } 2 \text { x } 2 \text { de } \\
\text { ecuaciones lineales (sustitución, igualación, suma, y } \\
\text { resta; método gráfico, y número de soluciones de un } \\
\text { sistema } 2 \text { x 2.) }\end{array}$ & 70.66 & 89.33 & 18.67 \\
\hline - Resuelve sistemas de 3 ecuaciones lineales con 3 & & & \\
\hline $\begin{array}{l}\text { incógnitas ( } \text { istema de } 3 \times 3 \text { ) por el método de } \\
\text { eliminaciones sucesivas. }\end{array}$ & 70.66 & 86.66 & 16.00 \\
\hline $\begin{array}{l}\text { - Usa los productos notables y sus aplicaciones al cálculo } \\
\text { numérico y a la factorización de polinomios de segundo } \\
\text { grado. }\end{array}$ & 77.33 & 88.00 & 10.67 \\
\hline - Soluciona ecuaciones incompletas $(a \times 5+c=0$, ax 5 & & & \\
\hline $\begin{array}{l}\text { +bx }=0 \text { ); ecuaciones completas por factorización y } \\
\text { completando cuadrados. }\end{array}$ & 70.66 & 85.33 & 14.67 \\
\hline $\begin{array}{l}\text { - Usa la fórmula general discriminante y obtiene un } \\
\text { número de soluciones de una ecuación cuadrática. }\end{array}$ & 66.66 & 84.00 & 17.34 \\
\hline $\begin{array}{l}\text { - Aplica los criterios de congruencia en la justificación de } \\
\text { construcciones geométricas y algunas de las propiedades } \\
\text { de los triángulos y los paralelogramos. }\end{array}$ & 62.66 & 88.00 & 25.34 \\
\hline $\begin{array}{l}\text { - Usa el Teorema de Tales en el triángulo y su reciproco; } \\
\text { criterios de semejanza de triángulo }\end{array}$ & 65.33 & 86.66 & 21.33 \\
\hline $\begin{array}{l}\text { - Calcula distancias inaccesibles en construcciones con } \\
\text { regla y compás. }\end{array}$ & 66.66 & 88.00 & 21.34 \\
\hline $\begin{array}{l}\text { - Aplica la semejanza el estudio de las homotecias al } \\
\text { dibujo escala. }\end{array}$ & 64.00 & 84.00 & 20.00 \\
\hline $\begin{array}{l}\text { - Aplica el efecto de una reducción o ampliación sobre las } \\
\text { magnitudes lineales, el área y el volumen de una figura o } \\
\text { sólido geométrico. }\end{array}$ & 61.33 & 82.66 & 21.33 \\
\hline $\begin{array}{l}\text { - Calcula longitudes y distancias. } \\
\text { - Utiliza la representación plana de cubos y }\end{array}$ & 70.66 & 81.33 & 10.67 \\
\hline $\begin{array}{l}\text { paralelepípedos como auxiliar en el dibujo de otros } \\
\text { cuerpos espaciales. } \\
\text { - Observa y estudia las secciones que se forman al cortar } \\
\text { un prisma o una pirámide recta por una familia de planos }\end{array}$ & 64.00 & 81.33 & 17.33 \\
\hline
\end{tabular}
paralelos. 


\begin{tabular}{|c|c|c|c|}
\hline \multirow{2}{*}{ Competencias } & \multicolumn{2}{|c|}{ Porcentaje de habilidades } & \multirow{2}{*}{ Diferencia } \\
\hline & Antes & Después & \\
\hline $\begin{array}{l}\text { - Aplica las fórmulas para calcular el volumen de } \\
\text { pirámides, conos, esferas y la superficie de la esfera. }\end{array}$ & 65.33 & 86.66 & 21.33 \\
\hline $\begin{array}{l}\text { - Calcula la diagonal de cubos y paralelepípedos; de la } \\
\text { altura, la arista o la apotema de pirámides rectas y conos } \\
\text { de revolución. }\end{array}$ & 66.66 & 78.66 & 12.00 \\
\hline $\begin{array}{l}\text { - Usa razones trigonométricas de un ángulo agudo: seno, } \\
\text { coseno y tangente. }\end{array}$ & 70.66 & 88.00 & 17.34 \\
\hline $\begin{array}{l}\text { - Calcula valores del seno, coseno y la tangente para los } \\
\text { ángulos de } 30^{\circ}, 45^{\circ} \text { y } 60^{\circ} .\end{array}$ & 70.66 & 88.00 & 17.34 \\
\hline $\begin{array}{l}\text { - Resuelve problemas de triángulos rectángulos y su } \\
\text { aplicación a la solución de problemas: cálculo de } \\
\text { distancias inaccesibles; del lado y la apotema de } \\
\text { polígonos regulares. }\end{array}$ & 69.33 & 89.33 & 20.00 \\
\hline $\begin{array}{l}\text { - Usa y aplica tasas (estudio de fenómenos que varían a } \\
\text { tasa constante y crecimiento aritmético vs. Crecimiento } \\
\text { exponencial o geométrico.). }\end{array}$ & 70.66 & 88.00 & 17.34 \\
\hline $\begin{array}{l}\text { - Describe una lista de datos (moda, media y mediana; } \\
\text { usos y limitaciones; formas de indicar los datos de una } \\
\text { lista). }\end{array}$ & 74.66 & 88.00 & 13.34 \\
\hline $\begin{array}{l}\text { - Usa los conceptos de población y muestra; de censos y } \\
\text { encuesta. }\end{array}$ & 64.00 & 81.33 & 17.33 \\
\hline $\begin{array}{l}\text { - Usa nociones de probabilidad (enriquecimiento y } \\
\text { explotación de la noción frecuencia en la solución de } \\
\text { problemas de probabilidad, aplicaciones diversas de la } \\
\text { formula clásica de probabilidad). }\end{array}$ & 68.00 & 85.33 & 17.33 \\
\hline $\begin{array}{l}\text { - Calcula probabilidades (probabilidad de que un evento } \\
\text { no ocurra, de que ocurra no de dos eventos, aplicabilidad } \\
\text { del principio de una suma, uso de diagramas de árbol en } \\
\text { la enumeración y descripción de los posibles resultados } \\
\text { de un experimento aleatorio; probabilidades de transición } \\
\text { y regla del producto. }\end{array}$ & 69.33 & 84.00 & 14.67 \\
\hline $\begin{array}{l}\text { - Soluciona problemas por simulación mediante el } \\
\text { esquema de urnas de Bernoulli. }\end{array}$ & 57.33 & 72.00 & 14.67 \\
\hline
\end{tabular}

Al iniciar el módulo IV al realizar la auto-evaluación los docentes manifestaron un porcentaje medio de $73.33(S D=5.7919)$ en habilidades, mientras que al terminar el módulo los profesores manifestaron un porcentaje medio de 89.33 (DS=3.83112). 
Antes de iniciar el módulo IV, los profesores tuvieron el menor porcentaje de desarrollo en la competencia Soluciona problemas por simulación mediante el esquema de urnas de Bernoulli, y el mayor porcentaje de desarrollo en la competencia Usa los productos notables y sus aplicaciones al cálculo numérico y a la factorización de polinomios de segundo grado.

Después de finalizar el módulo IV, los profesores tuvieron el menor porcentaje de desarrollo en la competencia Soluciona problemas por simulación mediante el esquema de urnas de Bernoulli, y el mayor porcentaje de desarrollo en las competencias Resuelve problemas de triángulos rectángulos y su aplicación a la solución de problemas: cálculo de distancias inaccesibles; del lado y la apotema de polígonos regulares y Usa métodos de solución de sistemas $2 \times 2$ de ecuaciones lineales (sustitución, igualación, suma, y resta; método gráfico, y número de soluciones de un sistema $2 \times 2$ ). Finalmente, tuvo la mayor ganancia de desarrollo en la competencia Aplica los criterios de congruencia en la justificación de construcciones geométricas y algunas de las propiedades de los triángulos y los paralelogramos.

A continuación se presentan los resultados de las pruebas de contenido que avalan los avances manifestados por los docentes.

Tabla 7.

Calificaciones de los profesores en la prueba de conocimientos antes y después de cursar el diplomado.

\begin{tabular}{cccc}
\hline \multirow{2}{*}{ Sujetos } & \multicolumn{2}{c}{ Resultados de la prueba de conocimientos } & \multirow{2}{*}{ Diferencia } \\
\cline { 2 - 3 } & Antes & Después & -10 \\
\hline 1 & 100 & 90 & 15 \\
2 & 77 & 92 & 14 \\
3 & 81 & 95 & 11 \\
4 & 84 & 95 & 17 \\
5 & 43 & 60 & 12 \\
6 & 81 & 93 & 8 \\
7 & 83 & 91 & 10 \\
8 & 90 & 100 & 10 \\
9 & 73 & 83 & 15 \\
10 & 80 & 95 & 15 \\
11 & 70 & 85 & 2 \\
12 & 85 & 87 & 8 \\
13 & 82 & 90 & 12 \\
14 & 75 & 87 & 2 \\
15 & 91 & 93 & \\
\hline
\end{tabular}


Los docentes antes de tomar el diplomado obtuvieron un promedio de calificación de 79.67 ( $S D=12.61$ ), y después de concluir el diplomado y presentar la prueba tuvieron un promedio de $89.07(S D=9.17)$, por lo que se puede decir que hubo una mejoría por parte de los profesores después de haber concluido el diplomado (ganancia promedio de 9.4 puntos).

\section{Comparaciones entre grupos.}

Se encontró diferencia significativa entre los puntajes obtenidos por los docentes en la primera y segunda prueba de conocimientos $(\mathrm{t}=-5.225$ con un $\mathrm{P}<.05)$, lo que permite concluir que existe evidencia suficiente para decir que el rendimiento de los profesores fue mayor después de concluir el Diplomado, por lo que se puede afirmar que el diplomado cumplió con el objetivo de lograr una mejora en los conocimientos de los profesores.

Para determinar diferencias entre los profesores según sus años de experiencia docente se clasificó a los docentes según sus años de experiencia docente en nóveles y veteranos.

La tabla 8 presenta los porcentajes de habilidades antes y después por módulo y tipo de docente.

Tabla 8.

Porcentaje de habilidades antes y después por módulo y tipo de docente.

\begin{tabular}{cccc}
\hline \multirow{2}{*}{ Módulo } & \multirow{2}{*}{ Docentes } & \multicolumn{2}{c}{ Porcentaje de habilidades } \\
\cline { 3 - 4 } & & Antes & Después \\
\hline \multirow{2}{*}{ II } & Nóveles & 80.17 & 88.21 \\
& Veteranos & 79.38 & 92.24 \\
III & Nóveles & 77.49 & 87.00 \\
& Veteranos & 75.61 & 86.66 \\
& Nóveles & 68.90 & 84.62 \\
& Veteranos & 76.87 & 92.91 \\
\hline
\end{tabular}


Con respecto a los conocimientos de los docentes antes de iniciar el módulo 2, los docentes noveles manifestaron que dominaban el $80.17 \%$, de la misma manera los docentes veteranos manifestaron que dominaban el $79.38 \%$. Como se puede observar tanto los docentes noveles como los veteranos tenían un porcentaje de dominio similar. Pero al concluir el módulo II, los noveles manifestaron haber incrementado su dominio en un $8.04 \%$ más y los veteranos un $12.36 \%$ más.

Tabla 9.

Porcentaje de competencias antes y después, por módulo y tipo de docente.

\begin{tabular}{cccc}
\hline \multirow{2}{*}{ Módulo } & Docentes & \multicolumn{2}{c}{ Porcentaje de habilidades } \\
\cline { 3 - 4 } & & Antes & Después \\
\hline \multirow{2}{*}{ II } & Nóveles & 64.1 & 83.45 \\
& Veteranos & 66.52 & 85.91 \\
III & Nóveles & 69.49 & 83.33 \\
& Veteranos & 70.85 & 79.23 \\
IV & Nóveles & 65.40 & 81.61 \\
& Veteranos & 69.94 & 89.60 \\
\hline
\end{tabular}

En cuanto habilidades como se aprecia en la Tabla 9, los veteranos manifestaron contar con $66.52 \%$ de las habilidades requeridas en el módulo II, mientras que los noveles manifestaron contar con el 64.1\%; sin embargo el incremento (noveles 19.35\%, veteranos $19.39 \%$ ) de las habilidades al concluir el módulo fue casi en mismo para los dos. También se puede observar que al inicio del módulo III los docentes noveles manifestaron un dominio de contenido del $77.49 \%$ de los temas; los docentes veteranos dijeron que contaban con el $75.61 \%$ de los conocimientos de los temas. Al concluir el módulo III ambos grupos de docentes manifestaron haber obtenido similar incremente. No obstante fue mayor el incremento de los veteranos pues ellos habían manifestado al principio menos conocimientos que los novatos, por lo que su aumento fue mayor.

Como podemos ver, en las habilidades antes de iniciar el módulo III, los docentes noveles dijeron tener el $69.49 \%$ al principio de módulo y el 83.33 al concluir, teniendo 
un aumento de $13.84 \%$., mientras que los profesores veteranos dijeron tener el 70.85 . $\%$ al principio de módulo y el 79.23 al concluir, teniendo un aumento de $8.65 \%$. Con lo que se puede afirmar que en el módulo III los noveles fueron los que más incrementaron sus habilidades docentes.

En el módulo IV, como puede observarse en la Tabla 9, fueron los docentes veteranos quienes manifestaron tanto al inicio del módulo como al final mayor porcentaje de conocimientos, pues dijeron tener al principio del módulo el $76.87 \%$ de los conocimientos que abarco y al finalizar el $92.91 \%$, mientras que los noveles dijeron contar con el $68.90 \%$ al principio y el 84.62 al final de los conocimientos de los temas del módulo. No obstante el aprovechamiento fue similar, ya que los profesores noveles tuvieron un incremento de 15.72 y los veteranos del $16.04 \%$.

En cuanto al módulo IV, se puede observar que el nivel de habilidades que los docentes tenían antes de iniciar, fue por parte de los noveles de un $65.40 \%$, y por parte de los veteranos un porcentaje de $69.94 \%$. Al terminar el curso se obtuvo un $81.61 \%$ por parte de los noveles y de un $\mathbf{8 9 . 6 \%}$ por parte de los veteranos. La diferencia que se obtuvo al final del módulo VI fue la siguiente: de acuerdo con los resultados obtenidos hubo un incremento de $16.21 \%$ al finalizar el diplomado por parte de los noveles; $y$ un incremento de $19.66 \%$ al finalizar el curso por parte de los veteranos.

En lo que respecta a la calificación obtenida en la prueba de conocimientos administrado al inicio y al final del Diplomado los resultados se describen en la tabla 10.

Tabla 10.

Promedio de los docentes por años de experiencia en el test de conocimientos antes de cursar el Diplomado.

\begin{tabular}{cccc}
\hline Momento & Docentes & $\begin{array}{c}\text { Promedio de } \\
\text { calificaciones }\end{array}$ & $\begin{array}{c}\text { Desviación } \\
\text { Estándar }\end{array}$ \\
\hline \multirow{2}{*}{ Antes } & Nóveles & 82.37 & 8.73 \\
& Veteranos & 76.57 & 16.16 \\
Después & Nóveles & 90.00 & 3.66 \\
& Veteranos & 88.00 & $13 . .34$ \\
\hline
\end{tabular}


Como se puede observar los docentes noveles obtuvieron en el test de conocimientos administrado al principio del diplomado un promedio mayor por 5.8 puntos, que el obtenido por los docentes veteranos.

Sin embargo como se muestra en la tabla 10, al finalizar el diplomado ambos grupos terminaron casi a la par, ya que el promedio de los profesores noveles fue de 90 , mientras que el de los veteranos de 88 , por lo que se puede afirmar que al final lograron obtener los dos grupos el mismo incremento en sus conocimientos. No obstante se puede inferir que los veteranos obtuvieron un mejor aprovechamiento del Diplomado ya que lograron incrementar su promedio inicial 11.44 puntos, mientras que los novatos solo 7.63 puntos.

\section{Conclusiones}

Esta investigación tuvo como objetivo evaluar si efectivamente el Diplomado que se ofreció a los profesores de matemáticas de secundaria cumplió con sus propósitos y objetivos planteados, y si los cumplió hasta qué grado.

Por lo anterior, dado que se encontró diferencia significativa, tanto en la autoevaluación como en la prueba de conocimientos, en los resultados de antes y después del diplomado, se concluye que sí hubo una mejoría por parte de los profesores después de haber concluido el diplomado, en cuanto a su dominio de contenido en matemáticas.

Además, en la autoevaluación se encontró diferencia significativa en los módulos II, III y IV en las habilidades matemáticas en los resultados de antes y después del diplomado, lo que permite concluir que los profesores de matemáticas mejoraron sus habilidades matemáticas como resultado de su participación en el diplomado.

Estos resultados son consistentes con los resultados de otros estudios de evaluación realizados acerca de otras especializaciones del diplomado tanto Atoche (2007) como Castillo y Dorantes (2007), quienes encontraron docentes que en física y química también reportaron haber mejorado sus habilidades y conocimientos después de haber concluido el diplomado. Atoche (2007) reporta que hubo un aprendizaje 
significativo por partes de los docentes del diplomado de Física., de la misma manera Castillo y Dorantes (2007) encontraron que los docentes manifestaron que adquirieron conocimientos y habilidades que le serán de utilidad en su desempeño docente.

No se encontraron diferencias significativas entre la experiencia de los profesores en la docencia y sus resultados en las pruebas administradas, sin embargo, los profesores más experimentados, en comparación con los profesores noveles mostraron una ligera diferencia en la ganancia obtenida en conocimientos y habilidades. Estos resultados son contradictorios con los resultados encontrados por Castillo y Dorantes (2007), en donde se encontró que si existían diferencias significativas entre profesores de acuerdo a sus años de experiencia docente.

Los resultados de este estudio presentan similitudes con investigaciones previas realizadas en la misma línea de investigación. En lo concerniente a programas de desarrollo profesional, este estudio y los realizados por Climent y Carrillo (2003) y el estudio realizado por Barak y Waks (1997) coinciden que deben estar enfocados a las necesidades de los profesores. De igual manera estos programas brindan una motivación a los profesores para llevar a la práctica docente los conocimientos y habilidades adquiridos, así como espacios de reflexión sobre el propio conocimiento (Climent \& Carrillo, 2003).

Futuros estudios pueden evaluar la puesta en práctica de conocimientos y habilidades adquiridos por los docentes, por medios de observaciones dentro del aula de clases, así como realizar entrevistas con los alumnos de los profesores. Esto permitirá identificar cuáles son los conocimientos y habilidades que el docente implementó a su práctica docente, y detectar nuevas necesidades de desarrollo profesional que podrán dar lugar a nuevos programas de desarrollo.

Por último se recomienda que debido a la nueva reforma Integral de educación segundaria realizar nuevos estudios de detección de necesidades de desarrollo profesional manifestadas a partir de esta reforma., Para con ello crear programas enfocados a los retos y necesidades de los docentes y lograr una mejora de mayor impacto en la práctica docentes. 
Los resultados de este estudió pueden ser utilizados para mejorar los programas de desarrollo profesional de docentes, en este caso el Diplomado de Enseñanza Innovadora de la ciencias especialidad Matemáticas. Pues brinda datos útiles para futuras implementación del programa.

\section{Referencias}

Atoche, K. (2007). Evaluación de la implementación y beneficios de un programa de fortalecimiento de recursos humanos en el área de la física. Tesis de Licenciatura no publicada. Universidad Autónoma de Yucatán. Mérida, Yucatán, México.

Barak, M. \& Waks, S. (1997). An Israeli study of longitudinal in-service training of mathematics, science and technology teachers. Journal of Education for Teaching, 23(2), 179-190.

Cachi, N. (2012). Prueba T de Student para datos relacionados (muestras dependientes). Recuperado de: http://www.slideshare.net/niko54-sagitario/prueba-t-de-student-paradatos-relacionados

Castillo, N. \& Dorantes, W. (2007). Experiencia docente y efectividad de un programa de desarrollo profesional en química .Tesis de Licenciatura no publicada. Universidad Autónoma de Yucatán. Mérida, Yucatán, México.

Climent, N. \& Carrillo, J., (2003). El dominio compartido de la investigación y el desarrollo profesional. Una experiencia en matemáticas con maestras. Enseñanza de las Ciencias, 21 (3), 387-404 [en red]. Recuperado de http://www.bib.uab.es/pub/ensenanzadelasciencias/02124521v21n3p387.pdf

Furió, C. \& Carnicer, J. (2002). El desarrollo Profesional del profesor de ciencias mediante tutorías de grupos cooperativos: Estudio de ocho casos. Enseñanza de las ciencias 20 (1), 47- 73.

Gómez, C. \& Calatayud, M. (2002). La evaluación de la formación permanente del profesorado como variable de calidad educativa. Revista Electrónica Interuniversitaria de Formación del Profesorado, 5(1) [en red]. Recuperado de http://www.aufop.com/aufop/uploaded files/articulos/1227717552.pdf

INEE. (2003). La calidad de la educación Básica en México. Primer informe anual. Instituto Nacional para la Evaluación de la Educación. (2003). La calidad de la educación Básica en México. Primer informe anual INEE.

Manteca, E. (2003) Hacia una política integral para la formación y el desarrollo profesional de los maestros de educación básica. Cuadernos de discusión 1. Secretaría de Educación Pública.

Ponce, V. (2004) Reprobación y fracaso en secundaria. Hacia una reforma integral. Revista de Educación y Desarrollo, 1, pp. 60-70.

Programa Nacional de Educación 2007-2012, Secretaría de Educación Pública.

Rodríguez, J. (2003) Conceptuaciones de los profesores de matemáticas acerca de la enseñanza y el aprendizaje. Tesis de Maestría no publicada. Universidad Autónoma de Yucatán. Mérida, Yucatán, México.

Schulmeyer, A. (2002) Estado actual de la evaluación docente en trece países de América Latina. Maestros en América Latina 25-64. [En red]. Recuperado de 


\section{REDIED}

http://www.google.com.mx/search?hl=es\&q=Estado+actual+de+la+evaluaci\%C3\%B3n+doce nte\&btnG=Buscar\&meta.

Wholey, J., Hatry, H., \& Newcomer, K. A. (2010). Handbook of practical program evaluation. Jossey-Bass, Third Edition. 


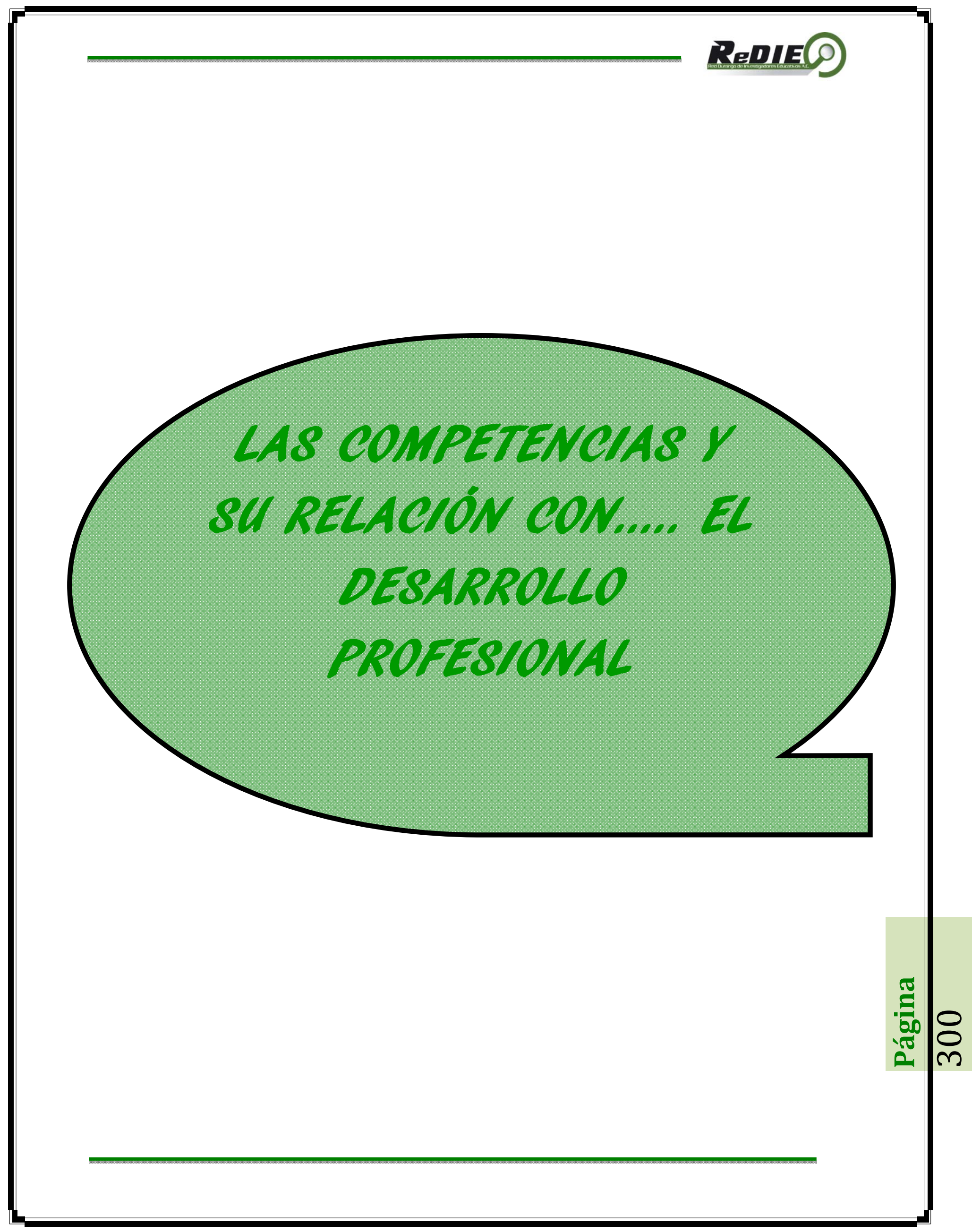




\title{
EL NIVEL DE DESEMPEÑO DE COMPETENCIAS PROFESIONALES EN RELACIÓN CON LA AUTOEFICACIA
}

\section{PERFORMANCE LEVEL OF PROFESSIONAL COMPETENCE IN RELATION TO SELF-EFFICACY}

\author{
Luis Fernando Hernández Jácquez \\ Profesor Investigador de la Universidad Pedagógica de Durango \\ Ifhi1@hotmail.com; Ifhi1@yahoo.com
}

\begin{abstract}
Resumen
La formación basada en competencias profesionales ha sido adoptada por la educación superior tecnológica en México a partir del año 2008, como el enfoque de trabajo para su sistema educativo. Dentro de él, se encuentra el Instituto Tecnológico Superior de Santa María de El Oro como una organización en la cual se desea investigar acerca de la relación que puede existir entre el nivel de desempeño que los estudiantes alcanzan respecto de las competencias descritas en los programas de estudio, y la autoeficacia académica que perciben de ellos mismos, como fuente de autorregulación para el logro o fracaso de las metas propuestas. En este sentido la idea central de la investigación es describir el nivel de autoeficacia presente en los estudiantes, el nivel de desempeño que han alcanzado respecto a las competencias profesionales definidas e indagar acerca de la relación entre ambas variables.
\end{abstract}

Palabras clave: autorregulación, evaluación, educación superior.

\begin{abstract}
The skills-based training has been adopted by the technological higher education in Mexico since 2008; as the focus of work for its education system. Within it, there is the Instituto Tecnológico Superior de Santa María de el Oro as an organization in which you want to investigate the relationship may exist between the level of performance that students achieve regarding the competencies described in the programs study, academic self-efficacy and perceived themselves as a source of self-regulation for the success or failure of the goals. Thus the thrust of the research is to describe the present level of selfefficacy in students, to describe the level of performance reached regarding the defined skills, and inquire about the relationship between the two variables.
\end{abstract}

Keywords: self - regulation, evaluation, higher education.

\section{Introducción}

El esquema educativo de la formación basada en competencias ha sido adoptado a partir del año 2008 por la Dirección General de Educación Superior Tecnológica como 
elemento central para el diseño, rediseño y puesta en marcha de sus planes y programas de estudio.

En este sentido, fue el enfoque socioformativo propuesto por Sergio Tobón, el que ha marcado la pauta dentro de este enorme sistema educativo que alberga a más de 270 institutos tecnológicos en todo el territorio Mexicano y del que es parte el Instituto Tecnológico Superior de Santa María de El Oro (ITSSMO), institución en la cual se enmarca la presente investigación, y que muestra como característica principal su reciente creación (año 2008) y su ubicación dentro del medio semi urbano del noreste del estado de Durango, atendiendo a una población que abarca a seis municipios de la zona.

Por otra parte, los factores motivacionales de autorregulación suelen ser considerados como elementos fundamentales dentro del éxito o fracaso de las tareas que desarrollan los individuos y es justamente la Teoría de la Autoeficacia desarrollada por Albert Bandura en 1977, una de las más aceptadas para el estudio de los mecanismos que pueden contribuir a la consecución o no, de las metas propuestas por las personas.

Con la finalidad de indagar si la autoeficacia académica percibida de los estudiantes del mencionado tecnológico se relaciona con el nivel de desempeño que alcanzan en las competencias profesionales, se desarrolló una investigación durante el periodo semestral Enero - Junio 2012 bajo las preguntas de investigación: ¿cómo se presenta el nivel de autoeficacia académica percibida en los estudiantes del ITSSMO? ¿Cómo se presenta el nivel de desempeño alcanzado de las competencias profesionales en los estudiantes del ITSSMO? y ¿cuál es la relación que existe entre la autoeficacia académica percibida por los estudiantes del ITSSMO y su desempeño alcanzado en las competencias profesionales?

De manera adicional, se buscará indagar acerca si el mencionado nivel alcanzado en las competencias tiene alguna relación con el género, la edad y el semestre cursado por los estudiantes. 


\section{La Formación Basada en Competencias Profesionales en la Dirección General de}

\section{Educación Superior Tecnológica}

Desde su ingreso al sector educativo, el término de "competencias profesionales" se ha visto envuelto en una serie de discusiones polémicas, ya sea por su fundamentación, su definición, y desde luego, por su integración al medio educativo.

Una de las primeras dificultades con este enfoque (asintiendo que es un enfoque, y no un modelo o un paradigma), es el concepto en sí, ya que presenta múltiples definiciones. En ello, originalmente el término se estructura en los años setentas con base en las aportaciones de la lingüística de Chomsky y la psicología conductual de Skinner. Chomsky (1970) propuso el concepto de competencia lingüística como una estructura mental implícita y genéticamente determinada que se ponía en acción mediante el desempeño comunicativo.

Dentro de las aportaciones de esta línea, la psicolingüística y la psicología cultural, están las elaboraciones de Hymes (1996), quien plantea el concepto de competencia comunicativa como el empleo efectivo del lenguaje y de la lingüística en situaciones específicas de comunicación, teniendo en cuenta las demandas del entorno.

En la línea contextual básicamente se ha propuesto que las competencias "son acciones situadas que se definen en relación con determinados instrumentos mediadores" (Hernández, Rocha \& Verano, 1998, p. 14). En la psicología cognitiva se tienen las contribuciones de Sternberg (1997) en torno a la inteligencia práctica, la cual se refiere a la capacidad que han de tener las personas para desenvolverse con inteligencia en las situaciones de la vida.

Por su parte, Sergio Tobón (2006, p. 5) asiente que "las competencias son procesos complejos de desempeño con idoneidad en un determinado contexto, con responsabilidad".

Justamente atendiendo a lo determinado por Tobón, dentro de la Dirección General de Educación Superior Tecnológica se ha tomado al enfoque socioformativo 
como el fundamento para el diseño y operación de los planes y programas de estudio pertenecientes a esta Dirección.

De acuerdo con Tobón, Pimienta y García (2010, p. 08), a finales de la década de 1990 y comienzos de 2000:

Empezó a estructurarse el enfoque socioformativo, al cual también se le suele denominar enfoque sistémico - complejo o enfoque complejo, ya que concibe la formación de las competencias como parte de la formación humana integral, a partir del proyecto ético de vida de cada persona, dentro de escenarios educativos, colaborativos y articulados con lo social, lo económico, lo político, lo cultural, el arte, la ciencia y la tecnología.

En este enfoque "se enfatiza la formación del compromiso ético ante uno mismo, la especie humana, las otras especies, el ambiente ecológico, la Tierra y el cosmos" (Tobón, Pimienta \& García, 2010; p. 10).

De esta manera, Tobón, Pimienta \& García (2010, p. 11) definen que "las competencias son actuaciones integrales ante actividades y problemas del contexto, con idoneidad y compromiso ético, integrando el saber ser, el saber hacer y el saber conocer en una perspectiva de mejora continua" y con esta definición como fundamento, dentro de la Dirección General de Educación Superior Tecnológica (DGEST), queda entonces definida la competencia profesional como:

La capacidad profesional que implica una construcción intelectual culturalmente diseñada, desarrollada en un proceso formativo. Es la capacidad de articular un conjunto de esquemas mentales permitiendo movilizar distintos saberes en determinados contextos con el fin de resolver situaciones de carácter profesional (DGEST, 2010, p. 14).

Lo anterior conlleva a tomar en cuenta la condición en la cual el estudiante debe ser considerado como competente y es cuando éste demuestra haber cubierto el $100 \%$ de la(s) evidencia(s) conceptual(es), procedimental(es) y actitudinal(es) propuesta(s) para la(s) actividad(es) del curso. Esta condición es necesaria ya que los programas de estudios diseñados en competencias profesionales unen varias competencias 
genéricas, específicas y emergentes, en donde una 0 varias de ellas pueden presentarse durante toda la asignatura.

Ahora bien, dentro de la propia DGEST, la acreditación de una asignatura es la forma en la que se confirma que el estudiante posee las competencias que están definidas en una asignatura o programa de estudio y que son necesarias para el desarrollo del perfil de egreso.

Es por esto que la evaluación de las competencias debe ser un proceso integral, permanente, sistemático y objetivo, en el que son corresponsables el estudiante y el docente. Para ésta evaluación se debe considerar la integración de información cuantitativa y cualitativa, así como los diferentes tipos y formas de la evaluación y la diversidad de instrumentos.

Por tal motivo, la evaluación de las competencias profesionales dentro de este sistema educativo (DGEST, 2010, p. 1) se considera "un proceso que permite generar, recabar, analizar, integrar y presentar evidencias, para valorar la medida en que se han alcanzado los objetivos propuestos,... y entonces las evidencias son el resultado de la actividad de aprendizaje realizada por el estudiante". Además:

El alcance de una competencia, corresponde con el logro de objetivos por parte del estudiante de una serie de indicadores que determina su nivel de desempeño como excelente, notable, bueno, suficiente o insuficiente, dicho nivel de desempeño se traduce en la asignación de una valoración numérica, que es la que finalmente expresa dicho alcance, esto significa que las valoraciones numéricas indican el nivel de desempeño con que el estudiante alcanzó la competencia específica (DGEST, 2010, p. 1).

Los indicadores del alcance de la competencia (en torno al estudiante) se definen de la siguiente manera (DGEST, 2010):

a) Se adapta a situaciones y contextos complejos. Puede trabajar en equipo, reflejar sus conocimientos en la interpretación de la realidad. Inferir comportamientos o consecuencias de los fenómenos o problemas en estudio. 
b) Hace aportaciones a las actividades académicas desarrolladas. Pregunta ligando conocimientos de otras asignaturas o de casos anteriores de la misma asignatura. Presenta otros puntos de vista que complementan al presentado en la clase. Presenta fuentes de información adicionales (Internet, documentales), usa más bibliografía, consulta fuentes en un segundo idioma, entre otras.

c) Propone y/o explica soluciones o procedimientos no vistos en clase (creatividad). Ante problemas o casos de estudio propone perspectivas diferentes para abordarlos correctamente sustentados. Aplica procedimientos aprendidos en otra asignatura o contexto para el problema que se está resolviendo.

d) Introduce recursos y experiencias que promueven un pensamiento crítico; (por ejemplo el uso de las tecnologías de la información estableciendo previamente un criterio). Ante temas de una asignatura, introduce cuestionamientos de tipo ético, ecológico, histórico, político, económico, etc., que deben tomarse en cuenta para comprender mejor, o a futuro dicho tema. Se apoya en foros, autores, bibliografía, documentales, etc., para apoyar su punto de vista.

e) Incorpora conocimientos y actividades interdisciplinarias en su aprendizaje. En el desarrollo de los temas de la asignatura, incorpora conocimientos y actividades desarrollados en otras asignaturas para lograr la competencia propuesta sobrepasando la calidad o prestaciones del producto o evidencia requerida.

f) Realiza su trabajo de manera autónoma y autorregulada. Es capaz de organizar su tiempo y trabajar sin necesidad de una supervisión estrecha y/o coercitiva. Aprovecha la dosificación de la asignatura presentada por el docente (avance programático) para llegar a las clases con dudas o comentarios de la temática a ver. Investiga o lee y en consecuencia es capaz de participar activamente en clase.

Con lo anterior, en la tabla 1 se puede visualizar la correspondencia entre el nivel desempeño alcanzado en la competencia, los indicadores de su alcance y la valoración numérica correspondiente. 
Tabla 1.

Correspondencia entre el nivel de desempeño alcanzado en la competencia, su alcance y valoración numérica.

\begin{tabular}{|c|c|c|c|}
\hline Desempeño & Nivel de Desempeño & Indicadores del Alcance & Valoración Numérica \\
\hline \multirow{12}{*}{ 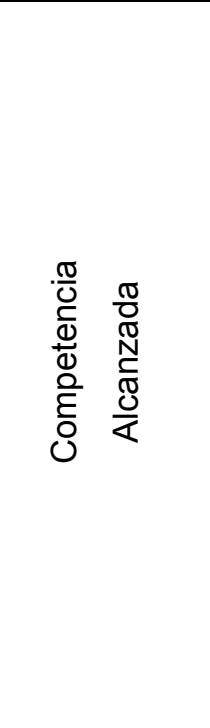 } & \multirow{3}{*}{ Excelente } & Cumple al menos cinco de los & \multirow{3}{*}{$95-100$} \\
\hline & & indicadores mencionados & \\
\hline & & anteriormente (incisos $a-f$ ) & \\
\hline & \multirow{3}{*}{ Notable } & Cumple cuatro de los & \multirow{3}{*}{$85-94$} \\
\hline & & indicadores mencionados & \\
\hline & & anteriormente (incisos $a-f$ ) & \\
\hline & \multirow{3}{*}{ Bueno } & Cumple tres de los indicadores & \multirow{3}{*}{$75-84$} \\
\hline & & definidos anteriormente & \\
\hline & & (incisos $a-f$ ) & \\
\hline & \multirow{3}{*}{ Suficiente } & Cumple dos de los indicadores & \multirow{3}{*}{$70-74$} \\
\hline & & definidos anteriormente & \\
\hline & & (incisos $a-f$ ) & \\
\hline \multirow{6}{*}{ 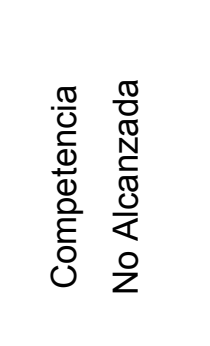 } & \multirow{6}{*}{ Insuficiente } & No se cumple con el $100 \%$ de & \multirow{6}{*}{ NA (No Alcanzada) } \\
\hline & & las evidencias conceptuales, & \\
\hline & & procedimentales y & \\
\hline & & actitudinales de los & \\
\hline & & indicadores definidos & \\
\hline & & anteriormente & \\
\hline
\end{tabular}

De manera global, la evaluación de las competencias profesionales se considera que es integral porque toma en cuenta los aspectos conceptuales, procedimentales y actitudinales del estudiante; es permanente, ya que es continua y constante de los aspectos que integran una competencia hasta la acreditación de las asignaturas; es procedimental, porque lleva una secuencia que va dando cuenta del progreso en el desarrollo o el alcance de la (s) competencia (s); es objetiva, dado que integra un conjunto de evidencias que pueden confirmar la existencia o no de la competencia en el estudiante; y es sistemática, por ser un proceso que permite identificar la evolución del 
estudiante en la adquisición de la competencia y valorarla, así como registrar cuantitativa y cualitativamente su avance académico.

\section{La Autoeficacia Percibida}

En esencia la motivación es un constructo teórico utilizado dentro de las distintas áreas de la psicología y la educación como en el caso de la pedagogía o la orientación vocacional y sirve para otorgar explicaciones a las conductas de los individuos, mismas que responden a la condición de satisfacer alguna necesidad o alcanzar algún objetivo (Chacón, 2006).

Interiorizando en el ámbito educativo, Chacón (2006; p. 1) menciona que:

La motivación académica no es otra cosa que un tipo de motivación que viene dada por el esfuerzo o la intensidad del compromiso en el estudiante hacia el aprendizaje, y se evidencia a través del deseo de querer crecer... además de que se constituye en sí en un deseo que se refleja mediante conductas voluntarias y que eventualmente llevan a un resultado favorable o desfavorable...

Dentro de la motivación, diversas formas de auto creencias, especialmente aquellas referidas a las ideas subjetivas sobre competencia han recibido una importante atención en las últimas décadas de investigación sobre el aprendizaje y la motivación humanos (Blog \& Clark, 1999, como se citó en Blanco, 2010). Entre ellas destaca por su amplio desarrollo teórico y empírico el constructo "autoeficacia", elemento central de la teoría social cognoscitiva.

La teoría sociocognitiva integra la cognición, metacognición y los mecanismos motivadores de autorregulación. La motivación incluye factores afectivos en términos de metas personales, juicios de autoeficacia, resultados de expectativas y monitoreo, componentes que afectan el desempeño de los individuos y la auto percepción que tiene de sus capacidades (Chacón, 2006). Por lo tanto se considera que la motivación guarda una relación notable con los procesos de auto percepción de las personas, 
misma que se explica de manera amplia en la teoría de la autoeficacia que se describe en seguida.

\section{Teoría de la Autoeficacia de Bandura.}

Aunque la teorización de la autoeficacia se originó de la teoría del aprendizaje social de Rotter, fue Albert Bandura en 1977 quien la desarrolló de manera amplia a través de su teoría sociocognitiva o cognitiva social.

De acuerdo con Peralbo, Sánchez y Simón (1986), el concepto de autoeficacia surge como un intento de conceptualizar la mayor parte del comportamiento humano desde una perspectiva integradora. Esta implicaba necesariamente (en la psicología científica contemporánea) el recurso a una explicación de los determinantes de la conducta humana, que toma su origen en posturas centralistas derivadas del auge de la psicología cognitiva, en clara oposición a las posturas periferialistas que sitúan los determinantes de la conducta en el ambiente externo.

Fue precisamente esta situación lo que dio lugar a la ruptura con aquellas visiones unidireccionales de la génesis de la conducta, en las cuales la respuesta del organismo aparece siempre como resultado de la acción aislada o bidireccional de los componentes personales o situacionales, para dar lugar a una visión más compleja del funcionamiento humano que integra a la propia conducta como agente que participa en su propia determinación, a través de la interacción recíproca con los factores personales y ambientales. Esta perspectiva dio lugar al denominado "determinismo recíproco" en cuyo marco cobraría sentido la formulación sobre el papel de las expectativas de autoeficacia como agente motivador del comportamiento humano (Bandura, 1978, como se citó en Peralbo, Sánchez \& Simón, 1986).

Blanco (2010, p. 2) asienta que de manera general, de la Teoría Cognitiva Social se desprenden dos preposiciones:

a) Las creencias de autoeficacia son específicas de un ámbito de funcionamiento dado. 
b) El constructo de autoeficacia puede ser distinguido de otros constructos autorreferentes cuando se evalúa en relación con un dominio específico.

Las creencias de la autoeficacia se refieren a los juicios que cada individuo hace acerca de sus capacidades para llevar a cabo una tarea. Bandura (1997, como se citó en Chacón, 2006) plantea que los individuos poseen un sistema interno que les permite ejercer control sobre sus propias acciones, conductas y pensamientos, siendo este sistema un componente fundamental de influencia en el logro de las metas que cada quien se propone.

Bandura (1997, como se citó en Chacón, 2006, p. 2) señala que "las creencias de autoeficacia constituyen un factor decisivo en el logro de metas y tareas de un individuo. Si las personas creen que no tienen poder para producir resultados, no harán el intento para hacer que esto suceda".

Atendiendo a Bandura (1977, como se citó en Blanco, 2010, p. 2), "la autoeficacia en sí, se define como el conjunto de juicios de cada individuo sobre las capacidades propias para organizar y ejecutar las acciones requeridas en el manejo de posibles situaciones específicas". Tales juicios se entiende que tienen importantes efectos sobre la elección de conductas o actividades, sobre el esfuerzo empleado y la persistencia, y sobre los patrones de pensamiento y las reacciones emocionales ante las tareas.

De ello se desprende que si el sujeto se juzga capaz y confía en sus habilidades de ejecución de una tarea específica, esta auto percepción contribuirá al éxito de su desempeño, por lo tanto podría decirse que el éxito esperado en el logro de una meta se relaciona de manera directa con las expectativas de resultado que el sujeto anticipa.

Este sistema interno de creencias proporciona un marco referencial determinante de la percepción, regulación y evaluación de la conducta del individuo. De allí la importancia de considerar las creencias de autoeficacia como el juicio personal sobre las capacidades o autoconfianza en la ejecución de tareas propuestas en el momento de llevar a cabo lo que se intenta hacer. Las preconcepciones o juicios que la persona establece acerca del éxito o fracaso de su desempeño proporcionan información que a 
su vez, alteran las creencias de autoeficacia percibida que se reflejarán en desempeños posteriores.

Siguiendo a Bandura (1977, como se citó en Blanco, 2010, p. 2):

La autoeficacia no es un rasgo global sino un conjunto de auto creencias ligadas a ámbitos de desempeño diferenciados. La teoría mantiene que los sujetos no solo emiten juicios de autoeficacia diferenciados y diferenciables para dominios diversos, sino que la autoeficacia puede y debe definirse con distintos niveles de especificidad en relación con un ámbito dado, de acuerdo con la conducta y criterio de interés.

Así, los individuos evalúan sus propias experiencias mediante la autorreflexión, de manera que el juicio o creencias personales sobre las capacidades y logros previos ejercen una fuerte influencia en las actuaciones futuras. De esta manera, las creencias de autoeficacia pueden anticipar mejor el comportamiento futuro del sujeto que la actuación previa; sin embargo, es importante aclarar que en la fundamentación de esta teoría las tareas que una persona es capaz de ejecutar no pueden ir más allá de sus capacidades, ya que no basta sólo con creer en las capacidades que se poseen, sino que se requiere de las propias habilidades y conocimientos necesarios para el logro de una competencia adecuada.

\section{Fuentes de Autoeficacia.}

Tanto el aumento como la disminución progresiva de las expectativas de autoeficacia puede lograrse a través de un procedimiento que incluya a alguna de las fuentes de información sobre eficacia o la combinación de ellas, ya que representan la información necesaria para el desarrollo del autoconocimiento y explican la conducta en términos de procesamiento central de fuentes de información, ya sean directas, vicarias, o simbólicas (Bandura, 1977, como se citó en Peralbo, Sánchez \& Simón, 1986).

Dichas fuentes se conceptualizan como sigue: 
1. Experiencias directas. Las creencias de autoeficacia se generan a partir del éxito o fracaso en la ejecución de una tarea (Bandura, 1997, como se citó en Chacón, 2006). El éxito tiende a fortalecer las creencias en la autoeficacia personal percibida, mientras que el fracaso tiende a debilitar dichas creencias. Las consecuencias directas de la respuesta representan la más influyente fuente de información (Bandura, Adams \& Beyer, 1977, como se citó en Chacón, 2006).

2. Experiencias vicarias - modelling - o aprendizaje por observación. El aprendizaje por observación permite al individuo evaluar en términos de observación, sus habilidades para llevar a cabo la tarea prevista. Bandura (1997, como se citó en Chacón, 2006) sostiene que mediante la observación de los logros de otras personas el individuo se compara y se ve a sí mismo desempeñándose en la misma situación. Por lo tanto, la observación de cómo los demás realizan con éxito determinadas actividades puede producir expectativas de eficacia en observadores que también poseen las capacidades para dominar actividades comparables.

3. Persuasión verbal (simbólica). Cuando las personas reciben apreciaciones basadas en "juicios valorativos o evaluativos" de personas cercanas en torno a sus capacidades para alcanzar el éxito, esta persuasión verbal parece fortalecer el sentido de autoeficacia (Bandura, 1997, como se citó en Chacón, 2006). Es por esto que las personas pueden incrementar sus expectativas de eficacia para una tarea dada e iniciar en consecuencia un determinado curso de acción cuando por sugestión o persuasión se establece el convencimiento de que poseen ciertas capacidades y pueden superarse los obstáculos y dificultades de la misma.

4. Activación fisiológica. Los estados emocionales de una persona ejercen influencia sobre el sentido de eficacia desde la perspectiva de que la activación fisiológica evidenciada en ansiedad, estrés, estado de ánimo, y temores, afectan el desempeño del individuo. Así, quienes se consideran altamente eficaces 
suelen beneficiarse de dicha activación fisiológica debido a que perciben tal activación como facilitadora para la realización de la tarea.

En resumen, con base en todas estas fuentes que originan las creencias de eficacia percibida, Bandura (1999, como se citó en Chacón, 2006, p. 8) afirma que:

La medida en que los logros derivados de la ejecución alteran la eficacia percibida dependerá de las preconcepciones de la persona en relación a sus capacidades, dificultad percibida de las tareas, cantidad de esfuerzo destinado, su estado físico y emocional en el momento, la cantidad de ayuda externa que reciba, y las circunstancias situacionales bajo las que ejecute su acción.

\section{La Autoeficacia en el Rendimiento Escolar.}

La aplicación al rendimiento escolar de la teoría general sobre la autoeficacia se desprende desde la realización óptima de una tarea educativa, que no depende únicamente de las capacidades propias del sujeto, sino de la evaluación subjetiva que realiza a partir de la información proporcionada por cualquiera de las fuentes de información sobre eficacia acerca de la efectividad de sus anteriores realizaciones en esa misma área de rendimiento (Peralbo, Sánchez \& Simón, 1986).

El grado de congruencia existente entre sus capacidades reales y el nivel de capacidad percibida a través de la información de ejecución y de sus consecuencias, determinará el que se generen altas o bajas expectativas de éxito ante la tarea. De aquí se derivará la movilización o no de todas sus capacidades potenciales objetivas para la realización del trabajo escolar, con la anticipación de que sus resultados serán satisfactorios intrínseca o extrínsecamente.

Explicado por Blanco (2010, p. 3):

Puesto que se asume que las creencias de autoeficacia de los estudiantes son específicas de un ámbito determinado, los juicios que emiten sobre su capacidad para movilizar sus recursos propios deberían ser diferenciados con nitidez en razón del área sobre el que se solicita la autoevaluación. 
Según lo explican Peralbo, Sánchez y Simón (1986, p. 4), para los estudiantes, las fuentes de autoeficacia se presentan de la siguiente manera:

a) La información que proviene de la experiencia directa viene dada por las propias ejecuciones de ellos mismos, es decir por su propio rendimiento y que es evaluado en tanto se acompaña por consecuencias positivas (éxito) o negativas (fracaso), formando una primera base sobre la que se asienta el nivel de autoeficacia del sujeto.

b) La experiencia vicaria proviene fundamentalmente de la observación del rendimiento de los compañeros, hermanos, familiares, etc.; y del nivel de comunicación social que es proporcionado por determinadas experiencias de modelamiento, que normalmente provienen de los medios de comunicación, ya que estos presentan abundantes modelos (de éxito y de fracaso) que pueden ser utilizados por los sujetos como guías para la acción.

c) La persuasión verbal es proporcionada básicamente por los maestros, padres y agentes de socialización más cercanos al estudiante, jugando un importante papel los propios compañeros.

d) En cuanto a la excitación emocional, ésta puede provenir de diversos factores relacionados tanto con situaciones extraescolares, situaciones meramente escolares, como también las relacionadas con la dificultad de las metas a alcanzar; en el sentido de que la excesiva discrepancia entre la dificultad de las tareas y la propia capacidad percibida por el estudiante genera insatisfacciones al producir fracasos consecutivos en la ejecución.

\section{Metodología}

El presente estudio se realiza bajo el enfoque cuantitativo de investigación, se medirán variables tal como se presentan en su estado natural para encontrar la existencia o no de una relación estadística entre ellas, por lo tanto el alcance del estudio es correlacional bajo el esquema no experimental y transeccional. 


\section{Objetivos de investigación.}

1. Determinar cuál es el nivel de autoeficacia académica percibida en los estudiantes del ITSSMO.

2. Identificar cuál es el nivel de desempeño alcanzado de las competencias profesionales en los estudiantes del ITSSMO.

3. Analizar cuál es la relación que existe entre la autoeficacia académica percibida por los estudiantes del ITSSMO y su desempeño alcanzado en las competencias profesionales.

La hipótesis que guía el estudio, está definida de la siguiente manera:

$\mathrm{Hi}$ : "Existe una relación positiva entre la autoeficacia académica y el nivel de desempeño de competencias alcanzado por los estudiantes del Instituto Tecnológico Superior de Santa María de El Oro".

\section{Definición operacional de variables centrales.}

a) Autoeficacia percibida: Inventario de Expectativas de Autoeficacia Académica (IEAA, Barraza, 2010).

b) Nivel de desempeño de competencias alcanzado: Promedio obtenido en el semestre inmediato anterior.

Al respecto del Inventario de Expectativas de Autoeficacia Académica (IEAA), se tiene que fue validado en el Estado de Durango para estudiantes de educación media superior y superior por su autor (Barraza, 2010a), y dentro de las propiedades psicométricas del instrumento, presenta un nivel de confiabilidad de .91 en alfa de Cronbach y de 0.88 en confiablidad por mitades. Los ítems lograron una escala de 1.5 (en escala de 0 a 3 ) en cuando a validez de contenido. Además, por medio del análisis de grupos contrastados se comprobó la direccionalidad única del instrumento, bajo un nivel de significación de .00 . 
El IEAA consta de 20 ítems con cuatro opciones de respuesta con escala tipo Likert, más un ítem que pregunta sobre el promedio obtenido en el semestre inmediato anterior, y se aplicará de manera auto administrada.

\section{Sujetos de investigación.}

Los participantes de la investigación son todos los estudiantes del instituto que estudian planes bajo el modelo de competencias profesionales y que se encuentran inscritos del segundo semestre en adelante, ya que a partir de éste semestre se puede contar con el dato del promedio del semestre anterior. Por la facilidad y economía para la administración del instrumento, la aplicación consistirá en un censo, siendo un total de 121 estudiantes, cuyas características principales son las siguientes:

a) $44 \%$ son varones, mientras que el $56 \%$ damas.

b) $71 \%$ se encuentra inscrito en el tercer semestre, mientras que el $29 \%$ restante cursa el quinto semestre. Cabe mencionar que el quinto es el semestre más avanzado en los planes de estudio bajo el modelo de competencias profesionales.

c) La mayor cantidad de los estudiantes se encuentra entre los 19 y 21 años $(83 \%)$.

d) En cuanto a la carrera que estudian, el $46 \%$ lo hace en Ingeniería Industrial, el $23 \%$ en Ingeniería en Sistemas Computacionales, y el 31\% en Ingeniería en Administración.

\section{Resultados}

Los resultados se presentan en dos momentos, el primero que hace referencia y explica distribución de frecuencias para las variables principales consideradas en la investigación (tabla 2 y tabla 3 ), mientras que en el segundo momento se describen los 
resultados para los estadísticos de diferencia de grupos y correlacional al respecto de las variables.

Tabla 2.

Distribución de frecuencias y media aritmética para el IEAA.

\begin{tabular}{|c|c|c|c|c|c|c|c|}
\hline No. & $\begin{array}{c}\text { Ítem: } \\
\text { ¿Qué tan seguro estoy de }\end{array}$ & $\begin{array}{l}\text { Nada } \\
\text { seguro }\end{array}$ & $\begin{array}{l}\text { Poco } \\
\text { Seguro }\end{array}$ & & & $\begin{array}{l}\text { Muy } \\
\text { Seguro }\end{array}$ & $\begin{array}{l}\text { Media } \\
(0-3)\end{array}$ \\
\hline & poder...? & f $\%$ & f $\%$ & f & $\%$ & f $\%$ & \\
\hline
\end{tabular}

Trabajar eficazmente en cualquier

1 equipo sin importar quienes sean los $\quad \begin{array}{llllllllll}3 & 3 & 18 & 15 & 68 & 57 & 31 & 26 & 2.06\end{array}$ compañeros

Competir académicamente cuando

2 así se requiera, con cualquiera de los compañeros de grupo

3

Realizar cualquier trabajo académico que encargue el maestro

Organizarme adecuadamente para

4 entregar a tiempo los trabajos que encargue el maestro

5

Adaptarme al estilo de enseñanza de cualquiera de los maestros Aprobar cualquier proceso de

6 evaluación, sin importar el maestro o seminario

Participar activamente aportando

7 comentarios o sustentos teóricos que requiera la clase o seminario Realizar una buena exposición de

8 un tema referente a alguno de los contenidos del seminario

Entender los diferentes temas que

9 abordan los maestros durante las clases

Prestarle atención a la clase que

10 imparte el maestro sin importar sin tengo otras preocupaciones

Preguntar al maestro cuando

11 entiendo algo de lo que se está abordando

12 Comprometer más tiempo para

$\begin{array}{lllllllll}4 & 3 & 29 & 25 & 45 & 38 & 40 & 34 & 2.03 \\ 4 & 3 & 28 & 23 & 65 & 54 & 23 & 19 & 1.89\end{array}$


realizar mis labores escolares o

para estudiar cuando así se requiera

13

Concentrarme a la hora de estudiar

sin que me distraigan otras cosas

Buscar la información necesaria

14 para elaborar un ensayo o un artículo académico

Tomar notas de los aspectos más

15 importantes que se abordan durante las clases

16

Cuestionar al maestro cuando no estoy de acuerdo con lo que expone

17 Construir argumentos propios en los trabajos escritos que se solicitan

18 Utilizar distintas estrategias para lograr un mejor aprendizaje

Analizar y apropiarme

19 adecuadamente de los diversos conceptos teorías que se abordan en los seminarios

Comprender la idea central de un

20 texto o los aspectos medulares de la exposición del maestro o compañero

$$
7
$$

6

54

1

18

18

15

61

51

5140

33

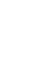

0

17

9

17

14

58

49

44

37

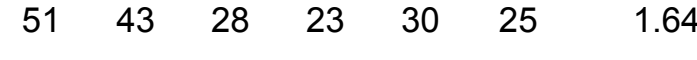

$\begin{array}{lllllllll}2 & 2 & 30 & 25 & 63 & 53 & 24 & 20 & 1.92\end{array}$

33

$\begin{array}{llllll}28 & 53 & 44 & 34 & 28 & 2.01\end{array}$

$\begin{array}{lllllllll}1 & 1 & 31 & 26 & 70 & 58 & 18 & 15 & 1.88 \\ 3 & 3 & 16 & 13 & 72 & 60 & 29 & 24 & 2.06\end{array}$

Como puede observarse, el $83 \%$ de los estudiantes dice sentirse seguro o muy seguro para poder trabajar eficazmente en cualquier equipo. El $46 \%$ asegura estar seguro de poder competir académicamente con cualquiera de los compañeros de grupo, pero el $25 \%$ del total se siente poco seguro de realizar esta actividad.

En cuanto a la confianza para realizar cualquier trabajo académico, el $87 \%$ de los alumnos se considera seguro o muy seguro de ello. Por su parte, el $88 \%$ de los alumnos, se siente capaz de organizarse adecuadamente para entregar a tiempo los trabajos, mientras que el $42 \%$ del total se dice confiado en adaptarse al estilo de enseñanza de cualquier maestro: sin embargo, en esta misa actividad, el 39\% dice estar poco seguro de poder adaptarse. 
La seguridad para poder aprobar cualquier proceso de evaluación es alta en el $47 \%$ de los alumnos, pero el $32 \%$ se siento poco seguro de ello. Un poco más de la mitad de la población (54\%) se dice sentir con la confianza para participar activamente en la clase mientras que el $47 \%$ del total se concibe seguro de poder realizar una buena exposición. Cabe mencionar que en estas dos últimas actividades, cerca de un cuarto de los estudiantes se concibe como poco seguros de llevarlas a cabo.

Aunque el $58 \%$ de los estudiantes se considera capaz (seguro) de entender los diferentes temas que se abordan, el $28 \%$ se considera poco seguro de esto. Además, el $38 \%$ asegura estar poco seguro de poder prestarle atención a la clase que imparte el maestro. De manera contraria, la gran mayoría de los alumnos dice sentirse seguro o muy seguro de preguntar al maestro cuando no se entiende algo y de comprometer más tiempo para realizar las labores escolares ( $72 \%$ y $73 \%$ respectivamente).

Más de la mitad de los encuestados afirma sentirse poco o nada seguros de poder concentrarse al momento de estudiar y de cuestionar al maestro cuando no se está de acuerdo con lo que expone (51\% y $52 \%$ respectivamente). Por otra parte, el $51 \%$ y $49 \%$ afirma estar seguros de poder buscar la información necesaria para elaborar un ensayo, y de poder tomar notas de los aspectos más importantes que se abordan en las clases.

Por último, aunque la mayor parte de los estudiantes se sienten seguros de poder construir argumentos propios en los trabajos (53\%), utilizar distintas estrategias para lograr un mejor aprendizaje $(44 \%)$, y analizar y apropiarse de los distintos conceptos $(58 \%)$, se debe hacer notar que al menos un cuarto de los alumnos dice sentirse poco seguro de realizar estas tres actividades $(25 \%, 28 \%$ y $26 \%$ respectivamente). En cuanto a la seguridad de comprender la idea central de un texto, el $84 \%$ de los encuestados afirma estar seguro o muy seguro.

De manera general, el promedio (en una escala de 0 a 3 puntos) para la autoeficacia percibida es de 1.94 puntos, que de acuerdo con la clave de corrección diseñada por Barraza (2010, p. 66) corresponde a un $64.66 \%$, lo que significa un nivel medio de autoeficacia (académica) percibida. 
Respecto a la distribución de frecuencias y su correspondiente significado para la variable "nivel de desempeño alcanzado por los estudiantes", se detalla lo que se muestra en la tabla 3.

Tabla 3.

Distribución de frecuencias para el nivel de desempeño alcanzado por los estudiantes.

\begin{tabular}{ccccc}
\hline Promedio & F & \% & Nivel de Desempeño & Desempeño \\
\hline $\mathbf{9 5 - 1 0 0}$ & 8 & 7 & Excelente & \\
$\mathbf{8 5 - 9 4}$ & 54 & 45 & Notable & Competencia alcanzada \\
$\mathbf{7 5 - 8 4}$ & 29 & 24 & Bueno & \\
$\mathbf{7 0 - 7 4}$ & 9 & 7 & Suficiente & \\
Menor a $\mathbf{7 0}$ & 21 & 17 & Insuficiente & Competencia no alcanzada \\
\hline
\end{tabular}

Como se observa, el $17 \%$ de los estudiantes obtuvo un desempeño insuficiente, mientras que el restante $83 \%$ alcanzó la competencia, estando el $45 \%$ (del total) en un nivel notable de desempeño de la competencia, mientras que el $24 \%$ se ubica en el nivel de desempeño bueno; y el restante $14 \%$ se divide en partes iguales ( $7 \%$ para cada una) en los niveles de desempeño excelente y suficiente.

De manera particular, a excepción del elemento de autoeficacia percibida "seguridad para poder trabajar eficazmente en cualquier equipo, sin importar quienes sean los compañeros", el resto mostró una correlación positiva con el nivel de desempeño alcanzado de la competencia (promedio).

Al nivel de significancia de 0.01 , el nivel de desempeño alcanzado de la competencia mostró una relación positiva con la seguridad para poder: competir académicamente con cualquiera de los compañeros de grupo (.294), realizar cualquier trabajo académico que encargue el maestro (.362), organizarse adecuadamente para entregar a tiempo los trabajos (.525), adaptarse al estilo de enseñanza de cualquiera de los maestros (.270), aprobar cualquier proceso de evaluación (.325); participar activamente aportando comentarios a la clase (.279), realizar una buena exposición (.247), entender los diferentes temas (.243), preguntar al maestro cuando no se entiende algo de lo que está abordando (.379), comprometer más tiempo para realizar 
las labores escolares (.296); buscar información para elaborar un ensayo (.268), tomar notas de los aspectos más importantes de la clase (.351), utilizar distintas estrategias para lograr un mejor aprendizaje (.392) y, analizar y apropiarse adecuadamente de los diversos conceptos y teorías (.316).

Al nivel de significancia de .05 , el nivel de desempeño alcanzado de la competencia mostró una relación positiva con la seguridad para poder: prestare atención a la clase sin importar que se tengan otras preocupaciones (.217), concentrarse al momento de estudiar (.217), cuestionar al maestro cuando no se está de acuerdo con lo que se expone (.209); construir argumentos propios en los trabajos escritos (.211), y comprender la idea central de un texto o exposición (.229).

En cuanto a la correlación general entre el nivel de desempeño alcanzado de la competencia y la autoeficacia percibida, ésta alcanzó un nivel de .449 (significancia de .01). Como análisis adicionales se encontró que existe diferencia significativa (estadística) entre el nivel de desempeño alcanzado en la competencia, y el género de los estudiantes, resultando que son las mujeres quienes muestran un mayor nivel alcanzado.

Se encontró además, que la edad del estudiante no muestra correlación alguna con el nivel de desempeño alcanzado de la competencia; y que este nivel alcanzado se diferencia entre los semestres, siendo los estudiantes de quinto semestre los que muestran un mayor nivel de desempeño.

\section{Conclusiones}

Los resultados anteriores han permitido constatar que el nivel de autoeficacia académica percibida por los estudiantes es medio, lo que significa que en lo general no muestran una gran seguridad para poder desempeñar sus labores académicas, pero tampoco muestran una gran desconfianza para ello, lo que da respuesta a la primera pregunta de investigación. 
En cuanto al cómo se presenta le nivel de desempeño alcanzado de las competencias profesionales, se concluye (basado en la normatividad de la DGEST, 2010), que el nivel de la mayoría de los estudiantes es "notable".

El indicador de correlación de Pearson para las variables en cuestión se situó en un nivel de .449 , que significa que existe una relación positiva entre ambas variables, es decir, que entre mayor sea el nivel de autoeficacia percibida, mayor será el nivel de desempeño alcanzado de la competencia, y viceversa. Con esto, se da respuesta a la tercera pregunta de investigación, así como es posible asentar que se acepta la hipótesis del estudio: "Existe una relación positiva entre la autoeficacia académica y el nivel de desempeño de competencias alcanzado por los estudiantes del Instituto Tecnológico Superior de Santa María de El Oro".

\section{Referencias}

Barraza, A. (2010). Inventario de Expectativas de Autoeficacia Académica. Praxis Investigativa ReDIE, 2 (2). Red Durango de Investigadores Educativos A. C.

Barraza, A. (2010a). Validación del Inventario de Expectativas de Autoeficacia Académica en Tres Muestras Secuenciales e Independientes. CPU - e, Revista de Investigación Educativa, 10, 2 - 30. Recuperado de: http://www.uv.mx/cpue/num10/inves/barraza validacion.html

Blanco, B. (2010). Creencias de Autoeficacia de Estudiantes Universitarios: un Estudio Empírico sobre la Especificidad del Constructo. Revista Electrónica de Investigación y Evaluación Educativa (RELIEVE), $16 \quad$ (1), 1 - 28. Recuperado de: http://www.uv.es/RELIEVE/v16n1/RELIEVEv16n1 2.htm

Chacón, C. (2006). Las Creencias de Autoeficacia: un Aporte para la Formación del Docente de Inglés. Acción Pedagógica, 15, 44 - 54. Venezuela. Recuperado de:

http://www.saber.ula.ve/bitstream/123456789/17262/2/articulo5.pdf

Chomsky, N. (1970). Aspectos de la Teoría de la Sintaxis. Madrid: Editorial Aguilar.

Dirección General de Educación Superior Tecnológica (DGEST). (2010). Lineamiento para la Evaluación y Acreditación de Asignaturas, Versión 1.0 para Planes de Estudio 2009 2010. México.

Hernández, C., Rocha, A. \& Verano, L. (1998). Exámenes de un Estado. Una propuesta de Evaluación por Competencias. Colombia: ICFES.

Hymes, D. (1996). Acerca de la Competencia Comunicativa. Forma y Función, 9. Colombia.

Peralbo, M., Sánchez, J. \& Simón, M. (1986). Motivación y Aprendizaje Escolar: una Aproximación desde la Teoría de la Autoeficacia. Infancia y Aprendizaje, 35 (36), 37 - 45. Chile. Recuperado de: dialnet.unirioja.es/descarga/articulo/662383.pdf

Sternberg, R. (1997). Successful Intelligence. EUA: Simon and Shuster. 


\section{REDIED}

Tobón, S. (2006). Aspectos Básicos de la Formación Basada en Competencias.

Tobón, S., Pimienta, J. \& García, J. (2010). Secuencias Didácticas. Aprendizaje y Evaluación de Competencias. Primera Edición. México: Pearson. 


\title{
COMPETENCIAS DE DESARROLLO PROFESIONAL EN LOS CURSOS DE SALUD COMUNITARIA
}

\author{
COMPETENCES PROFESSIONAL DEVELOPMENT COURSES \\ COMMUNITY HEALTH
}

\author{
María Elena Martínez Tapia \\ Escuela de Medicina Instituto Tecnológico de Monterrey, Campus Chihuahua \\ maelmata@prodigy.net.mx
}

\begin{abstract}
Resumen
A partir de la integración de la Metodología de Aprendizaje-Servicio en el Modelo de Trabajo Comunitario, se ha observado en los estudiantes un mejor desarrollo de las competencias de desarrollo profesional, particularmente en las competencias de desarrollo personal a lo largo de los semestres donde se realiza su proyecto de comunidad. Se plantea si esta metodología permite el desarrollo de las competencias actitud ante nuevas experiencias, actitud ante el cambio, confianza para asumir riesgos, actitud ante la autoridad. Se realizó un estudio longitudinal, con 31 alumnos que cursaron el primer y segundo semestres de Comunidad, se aplicó una rúbrica para evaluar el desarrollo de competencias, se realizaron cuatro mediciones. Para cada competencia se compararon los resultados obtenidos en cuatro mediciones. En la Competencia "actitud ante nuevas experiencias" se obtuvo valor de $p=0.13$, en "actitud ante el cambio" $p=0.0002$, "confianza para asumir riesgos" $p=0.0000$, "Actitud ante la Autoridad" $p=0.004$. Por medio de la implementación de nuevas metodología en el proceso de Enseñanza-Aprendizaje, al declarar conocimientos, habilidades, actitudes y valores integrados a manera de competencias se continúa con el compromiso de reforzar el profesionalismo del alumno de la carrera de medicina.
\end{abstract}

Palabras clave: Competencias, Aprendizaje-Servicio, desarrollo personal.

\begin{abstract}
Based on the integration of the Service-Learning Methodology in the Community Service Model, it has been observed in students a better evolution in the personal development competences throughout the semesters in which their community project has taken place. It is planted if this methodology allows the development of the competences of attitude towards new experiences, attitude towards change, confidence to assume risks, and attitude towards authority. A longitudinal study was performed, with 31 students who coursed the first, and second semesters of Community. A rubric was applied to evaluate the development of competences. Four measurements were performed. For each competence, the results obtained in four measurements were compared. In the "attitude towards new experiences" competence, a $p=.13$ value was obtained. In "attitude towards change" a $p=.0002$. In "trust to assume risks", $p=.0000$, and in "attitude towards authority", $p=.004$. By means of the implementation of new methodologies in the process of Service-Learning, in the declaring of knowledge, skill, attitudes, and integrated values in the means of competences, a commitment to strengthen the professionalism of the alumni in the career of medicine is being enforced.
\end{abstract}

Key-Words: Competences, Service-Learning, personal development. 


\section{Introducción}

En la carrera de Medicina del Tecnológico de Monterrey, la formación de alumnos con habilidades, actitudes y valores relacionados con estos aspectos ha sido un elemento fundamental del perfil del egresado y es distintivo de nuestros graduados. En el Currículo 2001, las competencias relacionadas con profesionalismo se desarrollan longitudinalmente y por niveles durante todos los cursos de la carrera de Medicina.

La definición de profesionalismo en Medicina comprende lo que el médico hace y el "cómo lo hace", es decir, integra las habilidades, actitudes y valores con los cuales el profesional de la Medicina demuestra que merece la confianza que el paciente y la comunidad le otorgan bajo la premisa de que antepondrá siempre la búsqueda del bienestar del paciente y de la comunidad como primer objetivo. El Modelo de Trabajo Comunitario, de la Escuela de Medicina del Tecnológico de Monterrey, está basado en la experiencia de actividades de campo e intervenciones comunitarias y acciones preventivas, el cual es un buen ejemplo del aprendizaje activo, con la aplicación de la Metodología de Aprendizaje-Servicio, se ha logrado la sensibilización y motivación de los estudiantiles de medicina, para realizar de manera independiente distintas acciones educativas y preventivas bajo una planeación supervisada en diversas comunidades, gozando de autonomía y respaldo de los profesores. Este modelo permite medir el impacto de las actividades comunitarias en cada una de las localidades para el trabajo de campo, se han establecido etapas que se deben cumplir en cada uno de los semestres de la carrera, dejando evidencias a través de estudios, diagnósticos y trabajos de investigación realizados por alumnos y profesores (Mora, 2008). El Aprendizaje-Servicio es un enfoque pedagógico basado en una experiencia de servicio solidario, en la cual los estudiantes, docentes y miembros de la comunidad aprenden, se forman y trabajan juntos para satisfacer necesidades comunitarias, potenciándose mutuamente los objetivos curriculares de un curso con los objetivos del servicio. El Aprendizaje - Servicio permite experiencias que ofrecen simultáneamente una alta calidad del servicio y un alto nivel de aprendizaje; por lo tanto, podemos caracterizarlo a 
partir de la integración de la Metodología de Aprendizaje-Servicio en el Modelo de Trabajo Comunitario, se ha observado en los estudiantes un mejor desarrollo de las competencias de desarrollo personal a lo largo de los semestres donde se realiza su proyecto de comunidad implementado con la Metodología de Aprendizaje-Servicio (Tapia, 2002).

Se plantea la pregunta de estudio: ¿la Metodología de Aprendizaje-Servicio permite que los alumnos de la Escuela de medicina del Tecnológico de Monterrey desarrollen las competencias de Desarrollo personal: actitud ante nuevas experiencias, actitud ante el cambio, confianza para asumir riesgos, actitud ante la autoridad, a lo largo de los Cursos de Salud Comunitaria en el primer y segundo semestre de la carrera de medicina? La realización del presente proyecto pretende seguir los objetivos del proyecto de profesionalismo de la Escuela de Medicina y realizar una contribución al desarrollo de este.

Como hipótesis se plantea: La Metodología de Aprendizaje-Servicio que los alumnos de la Escuela de Medicina del Instituto Tecnológico y de Estudios Superiores Monterrey permite desarrollen las competencias de Desarrollo personal: actitud ante nuevas experiencias, actitud ante el cambio, confianza para asumir riesgos actitud ante la autoridad, al menos a un nivel 3 - 4 durante los Cursos de Salud Comunitaria en el primer y segundo semestres de la carrera.

\section{Marco Teórico}

Los estudiantes de medicina inician su formación requiriendo desarrollar ampliamente sus conocimientos y destrezas, pero con actitudes y valores tan bien sustentados que tal vez no requerirían de mayor atención. Tradicionalmente el énfasis en la educación médica se otorgó a los conocimientos y destrezas, hoy y para la medicina del futuro la atención otorgada a enseñar y evaluar aspectos de profesionalismo es vital. Las competencias relacionadas con el profesionalismo médico sólo pueden ser establecidas a través del ejemplo de lo que el médico realiza día con día: enfrentar su 
responsabilidad ante el paciente en lo individual y ante la comunidad en general. Las competencias con las que el médico es capaz de interactuar y responder a las demandas diarias del paciente y sus familiares, así como de otros colegas y miembros del personal de atención a la salud, son aquellas que sustentan el profesionalismo médico y deben ser desarrolladas desde la formación misma del futuro graduado. En la actualidad, la patente necesidad de enseñar los valores y elementos del profesionalismo ha ido acompañada del rediseño de los métodos tradicionales de enseñanza-aprendizaje que garanticen que los nuevos médicos reflejen y practiquen dichos valores (Luijk, 2000).

En el Currículo 2001 de la Carrera de Médico Cirujano las competencias relacionadas con profesionalismo se desarrollan gradualmente a lo largo de todos los cursos de la carrera y adquieren su mayor grado en los cursos en los cuales el alumno, en estrecha relación con su profesor, tiene la oportunidad de participar directamente en la atención a pacientes.

El modelo educativo del Tecnológico de Monterrey es utilizar técnicas didácticas, con las que los alumnos analizan y resuelven problemas complejos relacionados con su carrera profesional. En los últimos años el modelo educativo, incorporó al AprendizajeServicio como una metodología didáctica a utilizar en las actividades académicas.

La metodología de Aprendizaje-Servicio ofrece a los estudiantes la oportunidad de aplicar los conocimientos y las habilidades adquiridas en el aula para responder a algunas necesidades de la propia comunidad mediante la participación activa de experiencias de servicio, lo que los lleva a tomar conciencia de la realidad de su entorno y a comprender la responsabilidad de su profesión en el servicio a los demás. Esta técnica puede utilizarse como apoyo al servicio social comunitario que realizan los alumnos y en los cursos vinculados al mismo (Tecnológico de Monterrey Dirección de Formación Social del Sistema, 2006).

Lograr que una propuesta basada en Aprendizaje-Servicio, requiere un esfuerzo consciente, sistemático y planificado, pensado para desarrollar, junto a las actividades de servicio, procesos de enseñanza y de aprendizaje que abarquen diferentes aspectos 
de la formación humana. Quizás lo más relevante del Aprendizaje-Servicio es que sus aprendizajes permiten el desarrollo de competencias, integrando capacidades, habilidades, conocimientos y valores que se movilizan para resolver situaciones reales de manera eficaz.

Es importante resaltar que para definir y comprender el término, se deben desechar ideas simplistas de explicación de la realidad; y considerar al pensamiento complejo, como una nueva racionalidad en la forma de abordar al mundo y al ser humano. El pensamiento complejo consiste en la integración de las partes en el todo, mediante el establecimiento de relaciones entre ellas, considerando sus respectivas diferencias (Tóbón, 2008). Por lo tanto se tiene que analizar el término competencias desde el pensamiento complejo para poder integrar un concepto, dado que es de suma importancia manifestar que es un enfoque inacabado, y en constante construccióndestrucción-recostrucción, demandando de forma continua el análisis crítico para comprenderlo y usarlo (Tóbón, 2006). De acuerdo a Tobón, se puede abordar la definición de las competencias considerando a un individuo de manera integral, incorporado a una sociedad con necesidades específicas de autorealización, y con una perspectiva de incorporarse al mercado laboral en un futuro inmediato.

El Curriculo MC 2001 tiene establecido 11 competencias profesionales generales que incorporan actitudes, bases éticas y entendimiento de la responsabilidad legal dentro de las competencias directamente relacionadas con el profesionalismo. El conjunto de competencias se agrupó en tres grandes rubros:

I. Relacionadas con las tareas esperadas de un médico

II. Relacionadas con la manera adoptada por el médico para realizar la tarea

III. Relacionadas con el Profesionalismo Médico

Los sub-componentes que se determinaron para el Currículo MC 2001 relacionados con las competencias de Profesionalismo Médico son:

1. Desempeño del médico dentro del sistema de salud:

Código de conducta profesional y reglamento de la institución.

Conciencia de aspectos psicosociales y económicos de la práctica médica. 
Respeto a pacientes, colegas y personal de salud.

Responsabilidad legal.

Participación en los sistemas de salud.

Responsabilidad del médico.

Apreciación del médico como: investigador, administrador y miembro de un equipo multiprofesional.

Pertenencia a la institución de salud.

Apreciación del médico en el proceso del control de calidad. Internacionalización.

2. Desarrollo personal, incorporación de actitudes y bases éticas:

Autoaprendizaje.

Conciencia de sí mismo: De la propia competencia; emocional; confianza en sí mismo.

Auto-regulación, autocuidado, autocontrol, adaptabilidad al cambio y administración del tiempo personal.

Motivación: espíritu de superación (búsqueda de la excelencia, emprendedor); arte y cultura, iniciativa, innovación y creatividad.

Trabajo colaborativo.

Principios Éticos.

Liderazgo.

Desarrollo Sustentable.

\section{Pregunta de investigación}

¿Cómo la Metodología de Aprendizaje y Servicio permite que los alumnos de la Escuela de Medicina del Tecnológico de Monterrey desarrollen las competencias de desarrollo personal: actitud ante nuevas experiencias, actitud ante el cambio, confianza para asumir riesgos actitud ante la autoridad, a lo largo de los Cursos de Salud Comunitaria en el primer y segundo semestre de la carrera? 


\section{Hipótesis}

La Metodología de Aprendizaje y Servicio permite que los alumnos de la Escuela de Medicina del Tecnológico de Monterrey desarrollen la competencia de desarrollo personal, al menos a un nivel intermedio (3-4) durante los Cursos de Salud Comunitaria en el primer y segundo semestre de la carrera.

\section{Objetivo}

Demostrar que La Metodología de Aprendizaje y Servicio permite que los alumnos de la Escuela de Medicina del Instituto Tecnológico y de Estudios Superiores de Monterrey desarrollen la competencia de desarrollo personal: actitud ante nuevas experiencias, actitud ante el cambio, confianza para asumir riesgos actitud 2 autoridad, al menos a un nivel 3 - 4 durante los Cursos de Salud Comunitaria en el primer y segundo semestre de la carrera.

\section{Justificación}

El "Proyecto de Profesionalismo en la Escuela de Medicina del Tecnológico de Monterrey" establece explícitamente un currículo basado en competencias con énfasis en los aspectos de profesionalismo, manifestando así el compromiso con su relevancia en la formación médica. Por medio de un proceso de investigación educativa se pretende demostrar que los egresados no sólo son médicos expertos, sino que a través del intencionado desarrollo de sus competencias de profesionalismo son médicos de excelencia con compromiso social, es decir profesionales de la medicina actuando y colaborando para retribuir a ésta su vocación.

Dentro del Proyecto de Profesionalismo, en la fase de revisión y rediseño de las competencias de Profesionalismo del currículo MC 2001 y con la experiencia del proceso de implantación de las competencias se ha establecido un proceso de mejora 
continua de las competencias de profesionalismo señaladas para el currículo MC 2002, a través de la revisión y el rediseño de éstas por el Comité Académico de la Escuela y la participación del Comité de Profesionalismo. Se han realizado agrupaciones de competencias que deban ser desarrolladas y planteadas a manera de acciones observables de manera conjunta en los cursos en donde se han establecido. Se ha visto que es necesario establecer adecuaciones a las competencias y sus componentes que faciliten el desarrollo de las competencias de profesionalismo al interior de cada uno de los cursos de la carrera de Medicina. Es necesario el rediseño de las acciones observables buscando facilitar su seguimiento y evaluación a través de un sistema estandarizado y longitudinal para todos los cursos de la carrera de Medicina (Comité de Profesionalismo de la Escuela de Medicina del ITESM, 2001).

\section{Metodología}

La valoración de las competencias se debe de llevar a cabo en tres momentos: al inicio, durante el proceso formativo y al final de esté. Por lo que se decidió la realización de un estudio longitudinal de tipo observacional, por cuestión de los tiempos de desarrollo este fue ambipectivo: una primera medición realizada de manera retrospectiva y tres valoraciones realizadas prospectivamente.

Para el análisis de la parte cuantitativa del estudio, se realizó un análisis simple de datos, que constó de medidas de frecuencia absolutas y relativas, y medidas de resumen para las variables cuantitativas (media y desviación estándar), para el análisis del desarrollo de la competencia estudiada, se realizó una comparación de grupos dependientes, por tratarse de variables cualitativas ordinales se utilizó Chi Cuadrada para la comparación de datos en los diferentes momentos de medición: al inicio (de manera retrospectiva), al final del primer semestre, al inicio de la fase de implementación del proyecto en el segundo semestre. Se consideró un valor de $p<$ 0.05 para significancia estadística. Los datos fueron capturados en una base de datos en EXCEL 2003 y se utilizó el programa EPI INFO ver 3.4.1 para la realización del 
análisis estadístico. Como variables de control se utilizaron la edad, sexo y escuela de procedencia del nivel medio superior.

Se incluyó en este estudio a la generación de estudiantes de medicina del Campus Chihuahua que ingresó en agosto del 2009, la cual estaba conformada por 35 alumnos, los cuales cursaron la materia de Salud Comunitaria en el Semestre Agosto - Diciembre 2009 y Desarrollo Comunitario en el semestre Enero- Mayo 2010. Se excluyeron a los alumnos que desertaron de la carrera en el primer semestre y aquellos de nuevo ingreso en segundo semestre que no cursaron Salud Comunitaria. Participaron los dos profesores responsables de los Cursos, quienes fueron los mismos en ambos semestres.

Para la evaluación del desarrollo de las competencias, se diseñó un instrumento basado en una escala de valoración, es un instrumento que nos permite realizar una estimación cualitativa del desarrollo de una competencia en el periodo de tiempo establecido. Para este instrumento se seleccionaron las características por medir de acuerdo con los criterios de valoración y evidencias requeridas, cada atributo fue medido en base a una escala cualitativa ordinal ya que indica el grado en el cual cada atributo está presente en la persona.

Para cada Competencias de Desarrollo Personal se realizó una pregunta, con 6 o 7 posibles respuestas, cada respuesta representa un nivel de desarrollo de las competencias: del Nivel 1 básico al nivel 6 ó 7 que representa un nivel avanzado.

Durante el curso de Salud Comunitaria se revisó la Metodología de Aprendizaje en Servicio como parte de los contenidos en programa, en base a la metodología se planeó y se realizó un estudio de comunidad, durante el segundo semestre se realizó la implementación de los proyectos desarrollados por los alumnos en la Colonia Vistas de Cerro Grande.

El primer instrumento de Valoración de Competencias de los alumnos de aplicó al finalizar el primer semestre, durante la última clase del curso se entregó a cada alumno la encuesta, la cual respondieron de manera individual y sin límite de tiempo, después de explicarles el objetivo de la encuesta y las instrucciones para su correcto 
llenado. En este primer tiempo se hicieron dos mediciones: de manera retrospectiva el nivel de competencia que tenía el alumno al iniciar el curso y la segunda medición. El nivel de competencia que tenía al término del semestre. Durante el segundo semestre, en el Curso de Desarrollo comunitario y Propedéutica se realizó la tercera medición, con el mismo instrumento, el cuestionario se aplicó al inicio de la fase de implementación del proyecto, está se realizó al inicio del segundo parcial del semestre, una cuarta medición se realizó durante el desarrollo de la implementación del proyecto en comunidad, mediante el mismo instrumento de valoración de competencias.

\section{Resultados}

Primeramente se estableció si la Metodología de Aprendizaje-Servicio fue implementada de manera correcta y posteriormente se define si existió un desarrollo de las competencias estudiadas en los alumnos.

Para la realización de este proyecto se incluyeron 31 alumnos que cumplieron el requisito de haber cursado el primer semestre de Comunidad e iniciaron el Segundo semestre de Desarrollo Comunitario, los cuales le dieron continuidad al proyecto que se elaboró mediante la metodología de Aprendizaje-Servicio.

\section{Valoración de la Implementación de la Metodología}

El instrumento aplicado a los tres profesores que implementaron el curso, es el utilizado en el ITESM para evaluar la metodología de aprendizaje en servicio en un curso. Se valoran dos aspectos: los relacionados con el proceso del proyecto y los resultados obtenidos. En todos los aspectos evaluados por los profesores, hubo coincidencia en las respuestas.

Aspectos relacionados con el proceso del proyecto:

a) Trato con los integrantes de la comunidad, organización o entidad de desarrollo social: Los estudiantes fueron conscientes de la diversidad, fueron cordiales con 
los habitantes de la colonia visitada, su comportamiento fue siempre respetuoso. (4 puntos)

b) Estilos de trabajo y tiempos: Los estudiantes no consideraron la disponibilidad de tiempos y estilo de trabajo de la comunidad. La sobrecarga de tareas y horas de estudio de los estudiantes de la carrera de medicina es una de las principales limitantes para la disponibilidad de tiempo de los alumnos, el tiempo destinado a las visitas a la comunidad fue planificado, no fue posible disponer de tiempo extra para otras visitas. (1 punto)

c) Compromiso: Los estudiantes siempre respetaron los acuerdos pactados originalmente con la comunidad. (4 puntos)

Aspectos relacionados con el resultado

a) Pertinencia: Se logró que los estudiantes consideraran el contexto en el que desarrollaron el proyecto (experiencia de A-S) acorde a la realidad de la comunidad (4 puntos)

b) Utilidad. La Los proyectos desarrollados son de utilidad para la comunidad (3 puntos)

c) Calidad del producto o servicio Diagnóstico y planificación El producto responde a necesidad de la comunidad y podrá ser para utilizado por esta (4 puntos)

d) Presentación del reporte final. El reporte está estructurado lógicamente, con material de apoyo gráfico que respalda la información presentada (4 puntos)

Lograr que una propuesta basada en Aprendizaje-Servicio requiere un esfuerzo consciente, sistemático y planificado, pensado para desarrollar, junto a las actividades de servicio, procesos de enseñanza y de aprendizaje que abarquen diferentes aspectos de la formación Humana. Quizás lo más relevante del Aprendizaje-Servicio es que sus aprendizajes permiten el desarrollo de competencias, integrando capacidades, habilidades, conocimientos y valores que se movilizan para resolver situaciones reales de manera eficaz.

Además de esto, el impacto en el entorno de aplicación y de los proyectos, promueven cambios positivos en los alumnos, principales protagonistas, en las familias 
de la comunidad, dentro las competencias más desarrolladas se encuentran son la competencia social y ciudadana, la autonomía e identidad personal.

\section{Reflexión de los alumnos}

Como en todo proceso educativo, la evaluación es un aspecto central en un proyecto de Aprendizaje-Servicio, evaluar significa reflexionar sobre los logros e impactos de las acciones realizadas para poder corregir errores, valorar los aciertos y eventualmente, hacer las modificaciones que se consideren necesarias.

Los alumnos presentaron una reflexión al finalizar el curso, referente a la Implementación de la metodología Aprendizaje-Servicio, lo que nos permite valorar cualitativamente cual fue el resultado del trabajo realizado desde el punto de vista de los alumnos.

El alumno no se percata del beneficio que obtienen, por lo que el realizar los ejercicios de reflexión, el cual se encuentra incluido en la metodología de AprendizajeServicio, permite que el alumno sea consciente del cambio. Como resultados se puede observar un porcentaje de alumnos que reaccionan ante el cambio trabajando esmeradamente, pero en ocasiones de maneras antiguas, a menudo incorrectas y con pocos resultados para de solucionar los problemas, por lo que es importante que el profesor, un su rol de facilitador este muy al pendiente del desarrollo del proyecto antes y durante la implementación para poder guiar al alumno de la forma más correcta posible. Un cambio que produce una situación más insegura pero que ofrece más oportunidades, podrá ser percibido negativamente por parte de una persona que estima sobre todo la seguridad. Pero para otra más abierta a la novedad y más ambiciosa, ese mismo cambio puede aparecer como un reto positivo y estimulante. La velocidad con que se desencadena el cambio también contribuye a dar forma al cambio de actitud. Para unos, un cambio determinado puede resultar demasiado lento, mientras que para otros parecerá excesivamente rápido. 


\section{Desarrollo de Competencias}

En cuanto a la medición del desarrollo de las competencias: en relación a la Competencia "actitud ante nuevas experiencias" la $\mathrm{X}^{2}$ obtenida fue de 17.4 y el valor de $p$ de .13 , en este caso no se encontró una diferencia estadísticamente significativa entre las tres primeras mediciones, pero para la cuarta medición se encontró que ya existía una diferencia entre los resultados obtenidos, $X^{2}$ de 43.5 y el valor de $p$ de .0007 . Observando que en las primeras tres mediciones la mayoría de los alumnos se mantienen en un nivel 2 de desarrollo de la competencia, pero para la cuarta medición el $80 \%$ se encontraban ya en un nivel 3 y 4 de desarrollo de la competencia.

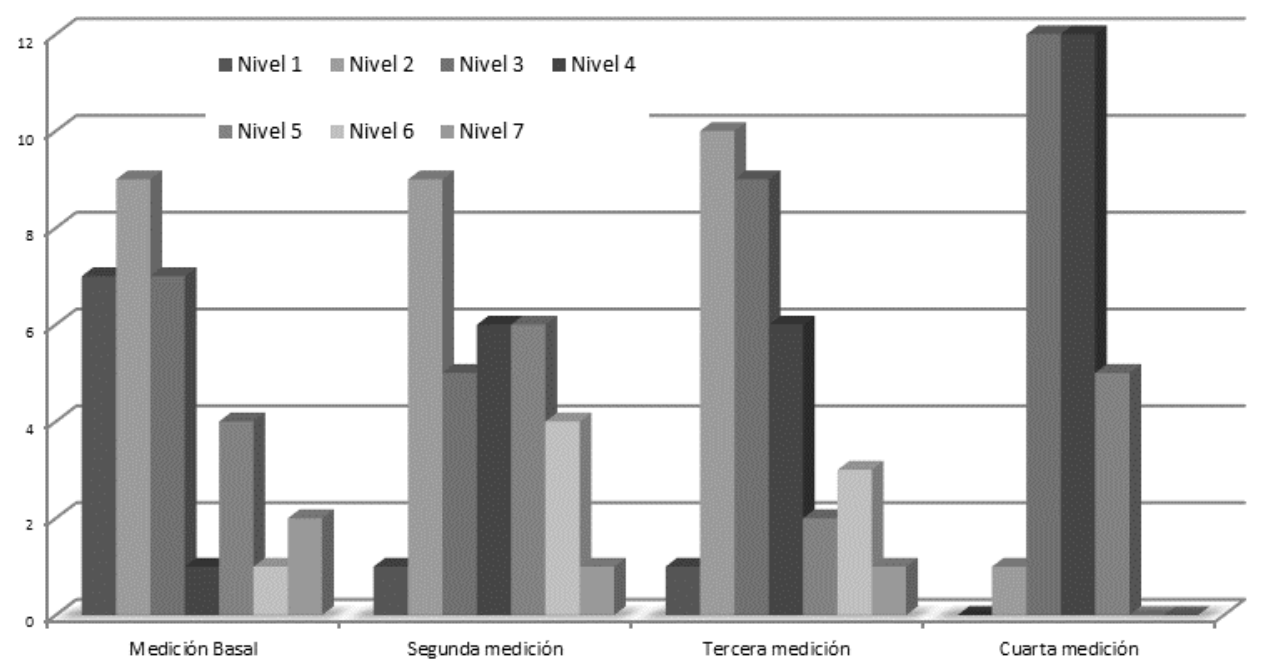

Figura 1 Datos estadísticos descriptivos comparativos de los niveles de competencia "Actitud ante Nuevas experiencias" en las cuatro mediciones

En relación a la Competencia "actitud ante el cambio" la $X^{2}$ obtenida fue de 37.5 y el valor de $p$ de .0002 , en esta competencia sí se encontró una diferencia estadísticamente significativa ya para la tercera medición, para la última valoración, se continuó observando esa diferencia, $\mathrm{X}^{2}$ de 51.6 y el valor de $p$ de .0000 . Se ve un importante desarrollo de la competencia, estando en un nivel 1 al inicio, hasta un nivel 4 en la última medición en el $50 \%$ y un $23 \%$ en el nivel 6 de los alumnos evaluados. 


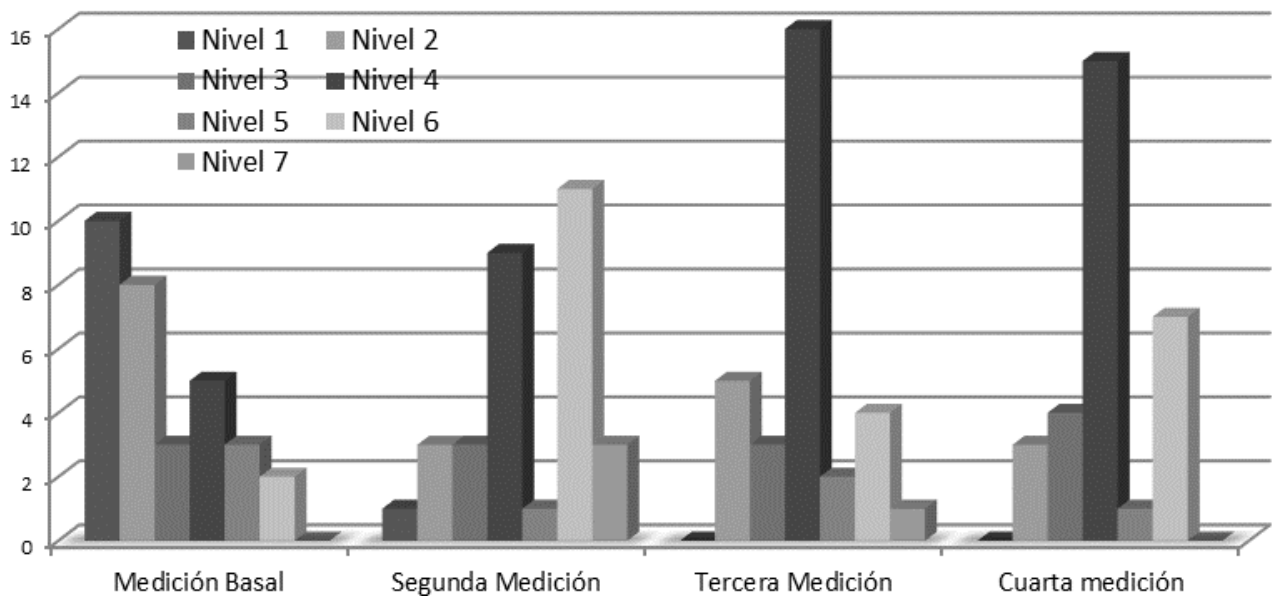

Figura 2 Datos estadísticos descriptivos comparativos de los niveles de competencia "Actitud ante el cambio" en las cuatro mediciones.

Para la Competencia "confianza para asumir riesgos" la $X^{2}$ obtenida fue de 52.2 y el valor de $p$ de .0000 , en esta competencia también se encontró una diferencia estadísticamente significativa entre las cuatro mediciones. Observando un importante desarrollo de la competencia, estando en un nivel 1 al inicio, hasta un nivel 5 y 6 en la última medición.

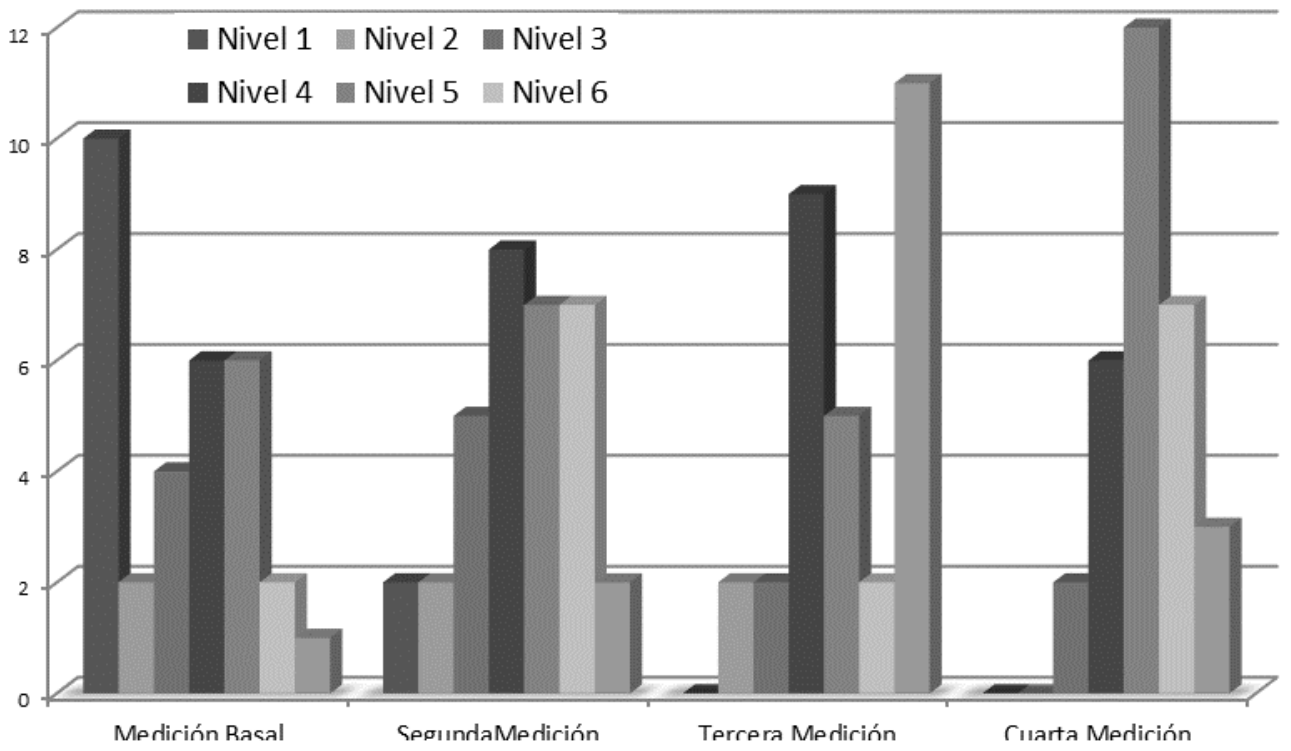

Figura 3. Datos estadísticos descriptivos comparativos de los niveles de competencia "confianza para asumir riesgos" en las cuatro mediciones. 
Finalmente en la Competencia "Actitud ante la Autoridad" la $\mathrm{X}^{2}$ obtenida fue de 12.2 y el valor de $p$ de .2687 , en esta competencia no se encontró una diferencia estadísticamente significativa entre las primeras tres mediciones, pero para la cuarta medición si se encontró una diferencia estadísticamente significativa $X^{2}$ de 33.4 y el valor de p de .004 . Observando que el $53 \%$ de los alumnos desarrollaron hasta un nivel 4 de la competencia.

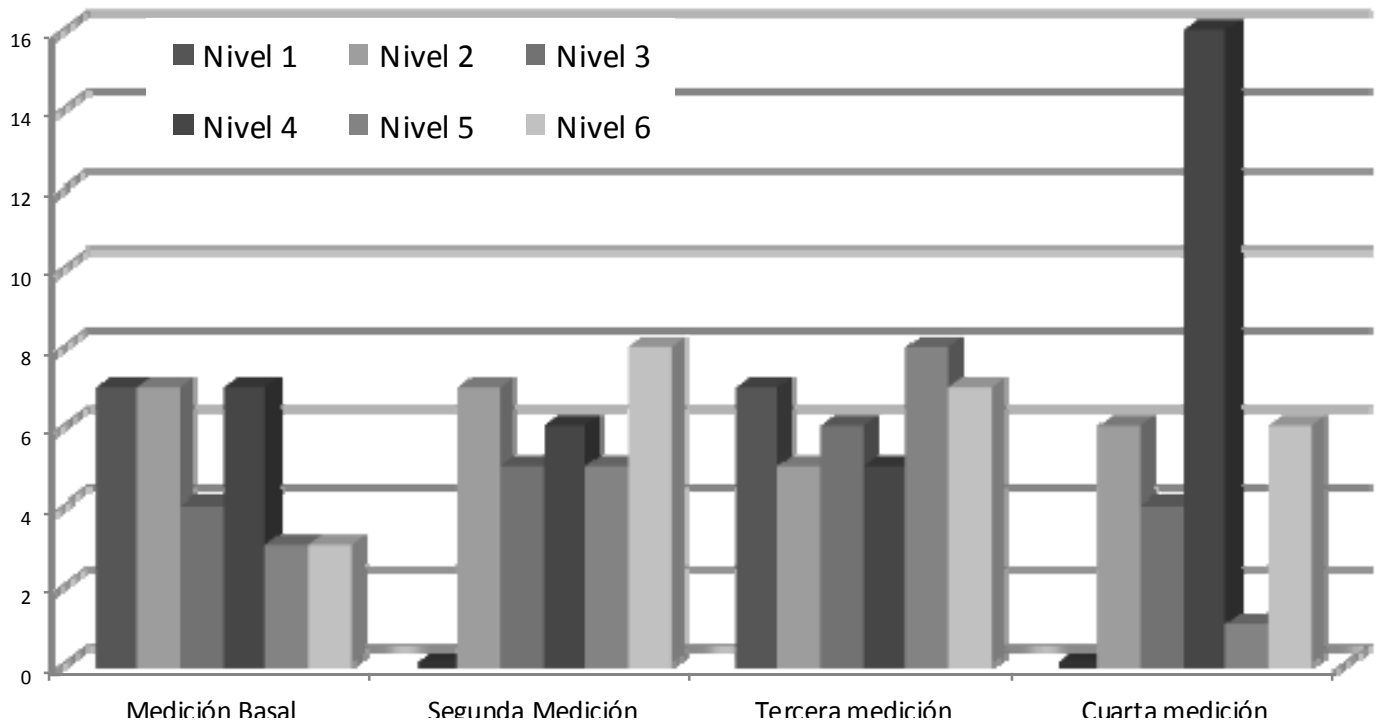

Figura 4. Datos estadísticos descriptivos comparativos de los niveles de competencia "actitud ante la autoridad" en la cuatro mediciones.

Con los resultados obtenidos se confirman las hipótesis presentadas en este trabajo.

\section{Conclusión}

En el presente estudio se ha evaluado el desarrollo de algunas de las competencias de Desarrollo Personal con la implementación de la metodología de Aprendizaje-Servicio en los alumnos del primer año de medicina. Entre otras características del currículo de la Escuela de Medicina del Tecnológico de Monterrey es que está basado en competencias. Tener un modelo de enseñanza, como el de las competencias, requiere 
también de la propuesta de un sistema de evaluación adecuado a él, una evaluación que cumplan con las nuevas necesidades educativas del saber saber, el saber ser y el saber hacer, según Mcdonald (1995) la evaluación es el estímulo más importante del aprendizaje, pues es el acto que da un mensaje a los estudiantes acerca de lo que deberían estar aprendiendo y cómo deberían hacerlo.

Una evaluación basada en competencias se refiere a los juicios reunidos de una variedad de fuentes, que definen si un individuo satisface los requisitos planteados por un estándar o conjunto de criterios. Para lograr lo anterior, se reúnen evidencias, las cuales son documentos utilizados para evaluar y realizar predicciones de largo plazo acerca de la habilidad de una persona para satisfacer las necesidades futuras de una ocupación o profesión (Mcdonald, 1995 ).

Por otro lado, el Aprendizaje-Servicio se ha convertido en una estrategia educativa con utilidad social que aporta un método para la educación ciudadana en contextos formales y no formales donde se desarrollan acciones solidarias y aprendizajes en una corriente de solidaridad y de reciprocidad, donde todas las partes involucradas reciben algo valioso (Rodríguez, 2006).

\section{Capitalización}

La Metodología de Aprendizaje-Servicio permite que los alumnos de la Escuela de Medicina del Tecnológico de Monterrey desarrollen las competencias de Actitud ante nuevas experiencias, actitud ante el cambio, confianza para asumir riesgos, actitud ante la autoridad, componentes todas ellas de la competencias al menos a un nivel 3 - 4 durante los Cursos de Salud Comunitaria en el primer y segundo semestre de la carrera.

A través del desarrollo de la competencia la competencia desarrollo personal: conciencia de sí mismo, se pretende continuar con el establecimiento del modelo mediante la cual los alumnos de la escuela de medicina del Tecnológico de Monterrey adquieran durante su formación académica las habilidades que van más allá del 
conocimiento científico y técnico que favorezcan que el médico cumpla del compromiso que, sólo por la profesión que desempeña, ha adquirido tanto con su paciente como individuo, como con la comunidad en la que se desenvuelve.

Por medio de la implementación de nuevas metodología en el proceso de Enseñanza-Aprendizaje, al declarar conocimientos, habilidades, actitudes y valores integrados a manera de competencias en nuestro currículo 2001 se continúa con el compromiso de reforzar el profesionalismo del alumno de la carrera de medicina. Con lo anterior, nuestro objetivo es ser congruentes con la misión del Sistema ITESM, la misión de la Escuela de Medicina y el perfil del egresado y se pretende contribuir en devolver a la medicina su vocación distintiva (Comité de Profesionalismo de la Escuela de Medicina del ITESM, 2001).

\section{Referencias}

Comité de Profesionalismo de la Escuela de Medicina del ITESM. (2001). Profesionalismo. Recuperado de http://dcs.mty.itesm.mx/educacion/profesionalismo/proyectos.php

Luijk, V. (2000). Assesing profesional bahaviour and the role of academic advice at the Maastricht Medical School. Med Teach, 168-172.

Mcdonald, R. (1995). Nuevas perspectivas sobre la evaluación. Sección para la Educación Técnica y Profesional. Boletín Cinterfor, 149, 21-72.

Mora, C. (2008). Modelo de Trabajo Comunitario de la Escuela de Medicina del TEC de Monterrey. Recuperado de

http://www.itesm.mx/vds/dfs/congreso/memorias/pdfs/C01_16.pdf

Rodríguez, J. (2006). Cuadernos de Pedagogía. Recuperado de http://roserbatlle.files.wordpress.com/2009/03/rasgos-pedagogicos.pdf

Tapia, M. (2002). El aprendizaje en servicio en America latina. Recuperado de CLAYSS: http://clayss.org.ar/biblioteca.htm

Tecnológico de Monterrey Dirección de Formación Social del Sistema. (2006). Manual operativo de Aprendizaje-Servicio. Recuperado de

http://www.itesm.mx/vds/S_Formacion_cl_pdf/02_profesores/info_esp/03_Aprendizaje_Se rvicio/manual_operativo_AS.pdf

Tobón, S. (2006). Formación b̆asada en competencias. Bogota, Colombia: Ecoe.

Tóbón, S. (2008). Pensamiento Complejo y formación humana en el sistema educativo colombiano. Recuperado de tp://www.scribd.com/doc/5512752/Principios-pensamientoComplejo. 


\title{
ESTUDIOS DE EGRESADOS: ESTRATEGIA DE MEJORA A LA CALIDAD DE LA EDUCACIÓN SUPERIOR
}

\section{STUDIES OF GRADUATES, STRATEGY TO IMPROVE THE QUALITY OF HIGHER EDUCATION}

\author{
Judith Francisca Silvia Avelino Huerta \\ Facultad de Medicina. B.U.A.P. \\ avelinohh@yahoo.com.mx \\ José Gaspar Rodolfo Cortés Riveroll \\ Facultad de Medicina. B.U.A.P. \\ jgrcr2002@yahoo.com.mx \\ Jaime Meneses Guerra \\ Facultad de Medicina B.U.A.P. \\ clmed1@live.com.mx
}

\section{Resumen}

La calidad de la educación superior requiere evaluar la pertinencia de los programas educativos, para lograrlo necesitamos estudios de seguimiento de egresados. Este reporte tiene como objetivo sistematizar los resultados obtenidos en un primer momento, para saber cómo se realiza la inserción laboral de los egresados de la Facultad de Medicina de la Benemérita Universidad Autónoma de Puebla (BUAP). Esta investigación se realizó con la metodología y el cuestionario de la Asociación Nacional de Universidades e Instituciones de Educación Superior (ANUIES), adaptado a las necesidades de nuestra Universidad y aplicado a las generaciones de egresados de la licenciatura en medicina y así también efectuar estudios comparativos con otras instituciones educativas. También se realizó un análisis de pertinencia del programa educativo de medicina, que nos permite implementar estrategias para mejorar la formación integral de los egresados. A partir de las respuestas, se pueden identificar los problemas que están enfrentando los egresados al insertarse al mercado laboral, en particular los médicos.

Palabras Clave: Seguimiento de egresados, Conocimiento, Evaluación.

\begin{abstract}
The quality of higher studies requires assessing the relevance of educational programs, to achieve this we need graduate's tracing studies. The objective of this research is systematize the results obtained initially, to learn how the graduates employment from the Faculty of Medicine of the Benemérita Universidad Autónoma de Puebla (BUAP) is done. This work was conducted with methodology and questionnaire from the National Association of Universities and Institutions of Higher Education (ANUIES), adapted to requierements for our University and applied to the graduate students from all degree programs, to accomplish comparative studies with other educational institutions. There was also an analysis of relevance of the medicine educational program, and implement strategies to improve the graduates integral formation. From the answers, we can identify problems the graduates are confronting to be inserted into the laboral market, particularly doctors.
\end{abstract}

Key words: Graduate Study, Evaluation, Quality. 


\section{Introducción}

En las últimas décadas del siglo $X X$, sucedieron cambios sociales y políticos que impactaron directamente a las Instituciones de Educación Superior (IES), en este contexto surgieron los estudios de egresados, que se empezaron a realizar a partir de los años setenta en diferentes IES con diversos objetivos; pero será hasta la última década del siglo cuando empiezan a formar parte de los procesos de evaluación es necesario robustecer los procesos de evaluación, como lo es la acción del autoanálisis, ya que con ello se identifican logros pero también estados problemáticos, propiciando estimular a la organización educativa el diseño de estrategias y/o acciones que corrijan o minimicen la problemática detectada, Valenti y Varela (2003) evitando en lo posible los proyectos carentes de una cimentación adecuada, con lo que se ampliaría la brecha para alcanzar un mejor nivel educativo. Finalidad y misión de las instituciones de educación superior, el de responder a las necesidades sociales del entorno. A partir de los años noventa en México, se empiezan a observar cambios importantes en la educación superior, ocasionando una transformación en la estructura de las IES, orientada desde luego, a formar nuevos profesionales altamente competitivos y comprometidos con el momento social de su entorno, colocando a la evaluación como un elemento central en la educación ANUIES (2003).

De manera general en este trabajo se hace referencia a la Benemérita Universidad Autónoma de Puebla (BUAP), y particularmente a los egresados de la licenciatura en medicina; se eligió esta carrera por pertenecer a una Facultad de Medicina (FM) de mucha tradición en la ciudad de Puebla desde el siglo XIX, que además cuenta con una de las matrículas más elevadas en esta institución (Agüera, Vázquez \& Vries, 2005).

La BUAP a fines de los años noventa, inició con iniciativas parciales; en 1999 se formó una comisión institucional para abarcar el conjunto de la Universidad con una metodología común de estudios de egresados, aplicando parcialmente el "Esquema 
básico" de la Asociación Nacional de Universidades e Instituciones de Educación Superior (ANUIES) (ANUIES, 2003).

En este reporte se plantea la necesidad de realizar estudios sobre el seguimiento de los egresados, pues si son desarrollados de manera sistemática, serán una fuente de valiosa de información que puede ser utilizada para: la actualización de los programas educativos; conocer en qué condiciones los egresados de medicina se insertan al mercado laboral (Sánchez, Gutiérrez, Valdez, Sánchez \& Reyna, 2010). Se busca fortalecer el vínculo entre egresados, la institución (BUAP) y los empleadores. Por lo que, el objetivo general de este trabajo es presentar algunos de los resultados del primer estudio sistemático de egresados de la licenciatura de medicina de la BUAP, y en forma específica conocer el tiempo y dificultades en conseguir empleo, así como aspectos vinculados con la formación académica.

Los resultados de esta investigación, manifiestan el sentir de los egresados, a partir de su experiencia en lo que llamaremos la primera inserción al mercado laboral, sus exigencias y la satisfacción para con la Facultad de Medicina. Se pretende presentar información y datos básicos a las Comisiones de Planeación, Diseño, Evaluación, y Seguimiento Curricular, y a las autoridades de la Facultad, para permitir una adecuada toma de decisiones basadas en la autoevaluación, que responda a sus necesidades y a transitar hacia la calidad educativa. Como lo menciona Gago (2002) la educación de calidad es el verdadero capital con el que cuentan los jóvenes, pues la mayoría de las veces no cuentan con más recursos sus propias capacidades, sus conocimientos, destrezas y habilidades.

La información con la que se realiza este trabajo, es el resultado del compromiso institucional y el arduo trabajo de los docentes que conforman el Nodo Institucional de Egresados (NIE), en dependencia directa de la Vicerrectoría de Docencia. Fue a través de este nodo, que se generó y se procesó la información vertida por los egresados de nuestra Institución; correspondió a cada representante de cada Unidad Académica (UA), analizar las respuestas con tratamiento estadístico y proporcionar los resultados a las autoridades e instancias correspondientes, para ser punto de partida en la 
generación de estrategias y planteamiento de metas a corto y mediano plazo, para conservar y/o adecuar la pertinencia de cada programa educativo, y a las exigencias del contexto laboral no solo regional, sino también nacional e internacional.

Por otra parte, los estudios de seguimiento de egresados también son solicitados por evaluadores internos y externos para medir el cumplimiento de estándares de calidad, considerados para la evaluación de la institución y propuestos por la Secretaría de Educación Pública (SEP). De igual forma son estudios requeridos por los organismos acreditadores como los Comités Interinstitucionales para la Evaluación de la Educación Superior (CIEES), o en el caso específico de la licenciatura en medicina por el Consejo Mexicano para la Acreditación de la Educación Médica (COMAEM). Las recomendaciones sugeridas por los CIEES, han propiciado que la administración central de la BUAP, considere a los estudios de seguimiento de egresados como uno de los programas estratégicos de la planeación institucional (Gago, 2002).

Consideramos necesario, recabar más resultados de investigaciones realizadas en torno al seguimiento de egresados, que proporcionen información de su ubicación en el mercado laboral, su opinión en cuanto a cómo vivieron su proceso de formación profesional, pero sobre todo considerar que este tipo de estudios constituyen un vínculo entre el egresado, la institución y los empleadores, información que fortalecerá sin duda la pertinencia de cada programa educativo ofertado por las instituciones educativas. La evaluación aportará tanto el grado de éxito alcanzado como las modificaciones a imprimirán la estructura normativa y las directrices políticas para incidir sobre la eficacia y la eficiencia (Valenti, Varela, González \& Zurita, 1997).

Si los resultados obtenidos del análisis de los estudios de egresados son fuente de información para la reestructuración curricular y de los procesos de enseñanzaaprendizaje, estaremos en condiciones de lograr que en las decisiones tomadas para la transformación de las IES, se contará con dos elementos muy importantes para consolidar su fortalecimiento: tomar en cuenta el contexto de la institución y los requerimientos del mercado laboral. Con ello sin duda se podrá alcanzar de una mejor manera la pertinencia de la educación superior en México, "se recuerda el discurso de 
Luis Echeverría en 1971 citado por Nigel Brooke: ...La contribución de la educación al desarrollo es evidente. La educación también repercute en la movilidad económica y social y contribuye a fomentar el genio creativo de la población..." (Didou, 1992, p. 8).

\section{Sustento}

El nuevo escenario global obliga a evaluar lo que se hace para mejorar la calidad de los procesos educativos, concibiendo entonces a la evaluación educativa como un proceso continuo, que genera información a las instituciones para la correcta toma de decisiones. Los cambios observados en las sociedades del mundo, llevan a asumir la necesidad de una nueva práctica profesional que sustente y propicie un proceso social más equitativo y más independiente. En México, durante los últimos veinte años se ha conformado la etapa inicial de la evaluación de la Educación Superior y al mismo tiempo la necesidad de transparentar los recursos públicos asignados a las IES, ante el problema de la restricción presupuestal (Díaz Barriga, et al. 2008).

La pertinencia como factor de la calidad de la educación, se define como el grado en que la educación responde a los problemas, demandas y expectativas de la sociedad. Esto es, la educación será más pertinente cuanto mejor satisfaga los reclamos de la sociedad, a saber: preservar y fortalecer la cultura y los valores; formar recursos humanos calificados para los procesos económico, político y social; desarrollar el conocimiento científico y las aplicaciones tecnológicas (Gago Huguet, 2002).

En la mayoría de las universidades estatales se observa la tendencia a reproducir esquemas laborales sin planeación previa ni evaluación posterior motivados por decisiones burocráticas. En este sentido, los estudios de egresados generalmente buscan describir características sobre su inserción y desempeño laboral por una parte, y por otra inquirir sobre la formación obtenida, con el fin de evaluar y planificar los procesos de mejora y con ello su consolidación (ANUIES, 2003). Si bien, las IES en cumplimiento de las funciones que les son propias deben ser sensibles a todos los sectores de la sociedad -incluyendo al sector productivo-, no pueden ser dependientes 
de la dinámica propia de este sector; el conocimiento del desempeño de sus egresados sólo constituye una vía de aproximación a la realidad de los campos profesionales, que en conjunto con estudios de las tendencias económicas y sociales, son de gran utilidad para redimensionar la labor educativa que, día a día coadyuva en dilucidar con claridad y precisión un escenario deseable del sistema de educación superior, para aproximarnos a mejores niveles de pertinencia, cobertura, de calidad y de desarrollo académico e incluso pensar en acercar la oferta educativa los sectores sociales históricamente marginados de las oportunidades de la educación superior (ANUIES, 2006).

\section{Metodología}

Este trabajo forma parte del primer estudio sistemático que se realiza en la Facultad de Medicina, se trabajó con un estudio mixto, descriptivo, transversal y de campo para dar respuesta al objetivo propuesto. La muestra poblacional está conformada por las encuestas aplicadas y contestadas vía web a partir de marzo de 2004 a marzo de 2009, sumando las que lograron captarse durante el "I Encuentro de Egresados y Empleadores con la BUAP", realizado del 16 al 18 de octubre de 2007, en el Centro de Convenciones de la ciudad de Puebla. Es de tipo determinístico por generación, en la que los datos de la misma fueron validados por el Departamento de Administración Escolar (DAE) de la BUAP, logrando captar en total 2,238 encuestas; el diseño se realizó como un estudio mixto donde se aplicaron análisis cualitativos y cuantitativos.

El estudio es también descriptivo por su objetivo, ya que se describen los fenómenos tal cual se encontraron, se decidió también realizar un corte estratificado de un periodo de tiempo determinado; para el acopio de datos, se tomaron las encuestas ingresadas y contestadas vía web en el sitio: www.egresado.buap.mx y las tomadas por consulta directa en el encuentro mencionado (BUAP, 2012).

Por ser el primer estudio de este tipo, se decidió que la población fuera conformada por egresados de todas las generaciones captadas de 2004 a 2009 y que 
cumplieron los criterios de inclusión, realizando una ponderación generacional. Por lo tanto, se trata de una muestra intencional o administrativa, dado que la referencia de la población a estudiar consiste en un padrón o censo de los egresados, se esperaba alcanzar el cien por ciento de los encuestados; es decir, todos los elementos tenían la misma posibilidad de ser elegidos para esta investigación. Las variables son politómicas, con escalas de medición ordinal, con ponderación.

El instrumento que se utilizó en la investigación es el instrumento ANUIES BUAP, del esquema básico para el estudio de egresados elaborado por ANUIES pero modificado y validado en la BUAP (ANUIES, 2003). La información se organizó por programa de egreso, utilizando el programa ACCESS; se conjuntaron las encuestas obtenidas por medio electrónico y una vez elaborada la fuente básica de datos, se transfirió a formato del programa Excel.

La fase siguiente consistió en el planteamiento de resultados a partir de la interpretación de datos, utilizando la matriz de datos generada en un primer momento, utilizando como herramienta la estadística descriptiva, y en un segundo momento se utilizó el programa (SPSS) para realizar correlaciones entre grupos con inferencia estadística; en nuestro caso, se utilizó el análisis de varianza (ANOVA) de un factor para comparar varios grupos en una variable cuantitativa. En cuanto al manejo de variables, la variable categórica (nominal $u$ ordinal) que define los grupos que comparamos la llamamos independiente o factor y la representamos por VI. A la variable cuantitativa (de intervalo o razón) en la que deseamos comparar los grupos la llamamos dependiente y se representa por VD.

\section{Resultados}

El estudio realizado contó con un total de 2,238 respuestas de encuestas aplicadas a los graduados, con las cuales se conformó la muestra de la presente investigación. Las generaciones participantes en la muestra poblacional la conforman generaciones de 1962 al 2002. En la tabla 1 se puede observar a detalle la distribución de frecuencia por 
generación, resaltando los mayores porcentajes encontrados y a qué generación pertenecen.

Tabla I.

Distribución de frecuencia por generación.

\begin{tabular}{|c|c|c|c|c|c|}
\hline Generación & Cantidad & Porcentaje & Generación & Cantidad & Porcentaje \\
\hline 1962 & 1 & $0 \%$ & 1993 & 32 & $1 \%$ \\
\hline 1964 & 1 & $0 \%$ & 1994 & 37 & $2 \%$ \\
\hline 1971 & 2 & $0 \%$ & 1995 & 97 & $4 \%$ \\
\hline 1975 & 1 & $0 \%$ & 1996 & 114 & $5 \%$ \\
\hline 1980 & 6 & $0 \%$ & 1997 & 264 & $12 \%$ \\
\hline 1981 & 4 & $0 \%$ & 1998 & 346 & $15 \%$ \\
\hline 1982 & 5 & $0 \%$ & 1999 & 421 & $19 \%$ \\
\hline 1983 & 5 & $0 \%$ & 2000 & 296 & $13 \%$ \\
\hline 1984 & 8 & $0 \%$ & 2001 & 261 & $12 \%$ \\
\hline 1985 & 6 & $0 \%$ & 2002 & 47 & $2 \%$ \\
\hline 1986 & 9 & $0 \%$ & --- & --- & $\begin{array}{ll}-- \\
\end{array}$ \\
\hline 1987 & 16 & $1 \%$ & --- & --- & --- \\
\hline 1988 & 12 & $1 \%$ & --- & --- & --- \\
\hline 1989 & 27 & $1 \%$ & --- & --- & --- \\
\hline 1990 & 35 & $2 \%$ & --- & --- & --- \\
\hline 1991 & 44 & $2 \%$ & Seleccione & 87 & $5 \%$ \\
\hline 1992 & 55 & $2 \%$ & Total general & 2238 & $100 \%$ \\
\hline
\end{tabular}

Fuente: Base de datos institucional BUAP

Consideramos importante mencionar que de esta población 1,132 pertenecen al género femenino (51\%) y 1,093 al masculino (49\%). La edad que predominó de la muestra se ubicó en un rango de 21 a 30 (84\%); en cuanto al estado civil el $74 \%$ son solteros. Por lugar de origen el $80 \%$ pertenecen al Estado de Puebla; en cuanto a la situación académica el $49 \%$ de la población son pasantes; el $41 \%$ están titulados en licenciatura, con maestría sólo se contaron 21 casos y 63 con doctorado. Otro dato importante es que el $74 \%$ de la muestra refiere que no trabajó durante el último año de la carrera y sólo el $26 \%$ de los encuestados si trabajaron durante el último año de estudio. 
En cuanto a la coincidencia de su trabajo con la profesión durante los estudios de licenciatura; resulta ser nula en un $44 \%$ de la muestra, el $30 \%$ el trabajo que desempeñaban si coincidía con la profesión médica, mientras que el $26 \%$ no respondió a la pregunta. Un indicador importante es el tiempo que tardó el egresado en emplearse después de egresar de la carrera, los datos se muestran en la tabla 2.

Tabla 2.

Tiempo que tardó en conseguir empleo.

\begin{tabular}{|l|c|c|}
\hline Tiempo & No. & $\%$ \\
\hline De 1 a 2 años & 056 & 06 \\
\hline De 6 meses a 1 año & 141 & 14 \\
\hline Más de 2 años & 032 & 03 \\
\hline Menos de 6 meses & 501 & 49 \\
\hline No encontré empleo & 168 & 16 \\
\hline No Contestó & 092 & 09 \\
\hline Mismo empleo que mis estudios & 034 & 03 \\
\hline \multicolumn{1}{|r|}{ Total } & 2238 & $100 \%$ \\
\hline
\end{tabular}

Fuente. Base de datos institucional BUAP.

Es muy interesante encontrar que al preguntar sobre la aceptación de la carrera en el mercado laboral, los egresados de medicina refieren en un $78 \%$, que fue difícil encontrar empleo, y también el $81 \%$ de las respuestas coinciden en la falta de experiencia laboral previa, mostrando que este es un componente que dificulta su inserción al mercado laboral.

Otro factor que obstaculiza la inserción al mercado laboral es la edad, quienes reportan este dato son en su mayoría jóvenes de 23 a 27 años, y se encontró que el género es también un elemento que obstaculiza el conseguir empleo; un factor más que obstaculiza la aceptación en el mercado laboral son las responsabilidades familiares, al igual que no contar con el título que acredite su profesión.

También resulta importante la respuesta respecto a cuánto se requiere de sólidos conocimientos generales, la percepción es en general mucho, pero además requieren 
de conocimientos especializados y habilidad en el manejo de paquetes computacionales. Esta información se esquematiza en la figura 1.

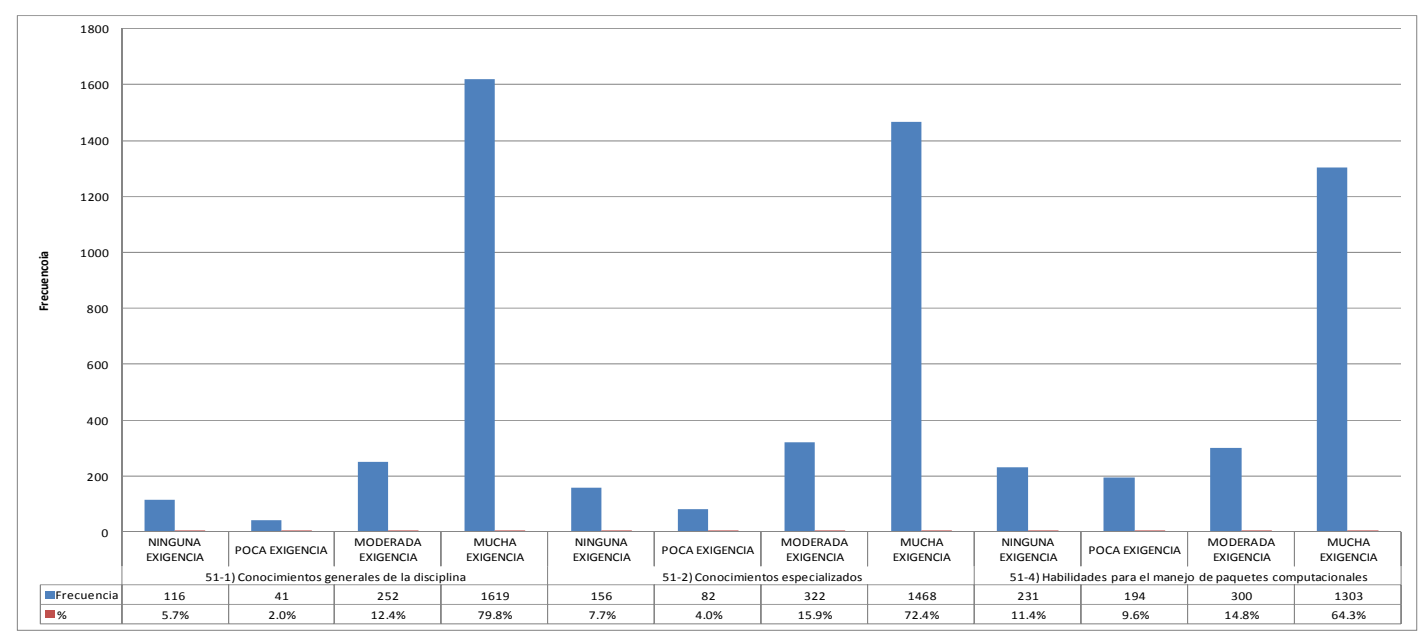

Figura 1. Requerimientos del mercado laboral.

La pregunta respecto a la exigencia del razonamiento lógico y analítico, el $78 \%$ de los encuestados refieren que es de mucha exigencia durante su práctica médica, se encontró un alto porcentaje de respuestas positivas en cuanto a la necesidad de contar con habilidad para la aplicación del conocimiento en el desarrollo de su profesión $(86 \%)$, estos resultados se muestran en la tabla 3.

Tabla 3.

Habilidad en la aplicación de conocimiento.

\begin{tabular}{|c|c|c|}
\hline Exigencia & No. & $\%$ \\
\hline Moderada & 195 & $9 \%$ \\
\hline Mucha & 1934 & $86 \%$ \\
\hline Ninguna & 76 & $3 \%$ \\
\hline Poca & 33 & $2 \%$ \\
\hline
\end{tabular}

Fuente: Base de datos institucional BUAP

La toma de decisiones en la profesión médica es fundamental y los egresados confirman que en esta profesión es muy importante, los que confirman la necesidad de 
haber desarrollado esta habilidad sumaron un $89 \%$. En cuanto a la exigencia de contar con habilidades desarrolladas para encontrar soluciones, la respuesta positiva fue también $89 \%$. Otro aspecto fundamental para esta profesión es la capacidad para buscar información y actualizarse, un $79 \%$ de las respuestas lo confirman. La habilidad para trabajar en equipo también es muy importante en esta profesión, así lo consideraron el $80 \%$ de los encuestados; otro porcentaje alto de respuestas positivas es el que se refiere a contar con habilidades para dirigir y coordinar la práctica médica (78\%), de igual manera se requiere de habilidad para el manejo administrativo dentro de la profesión médica y el $70 \%$ lo confirmaron. Existen otros factores que son muy importantes para el desarrollo de la profesión médica, éstos se esquematizan en la tabla 4.

Tabla 4.

Habilidades requeridas por la profesión.

\begin{tabular}{|l|c|}
\hline \multicolumn{1}{|c|}{ Exigencias del mercado laboral. } & $\%$ \\
\hline Actualización constante & 80 \\
\hline Habilidad para generar relaciones públicas & 80 \\
\hline Habilidades en comunicación oral escrita y gráfica. & 81 \\
\hline Puntualidad y formalidad & 88 \\
\hline Buena presentación & 89 \\
\hline Asumir responsabilidades & 91 \\
\hline Creatividad para el desarrollo de la profesión & 80 \\
\hline
\end{tabular}

Fuente: Base de datos institucional BUAP

Es importante conocer el grado de coincidencia entre la actividad laboral y los contenidos de la licenciatura, teniendo presente que no basta contar con conocimientos teóricos, pues éstos por sí solos no aseguran al egresado poder lograr la aplicación práctica de la profesión con éxito. El resultado de este estudio se muestra en la figura 2. 


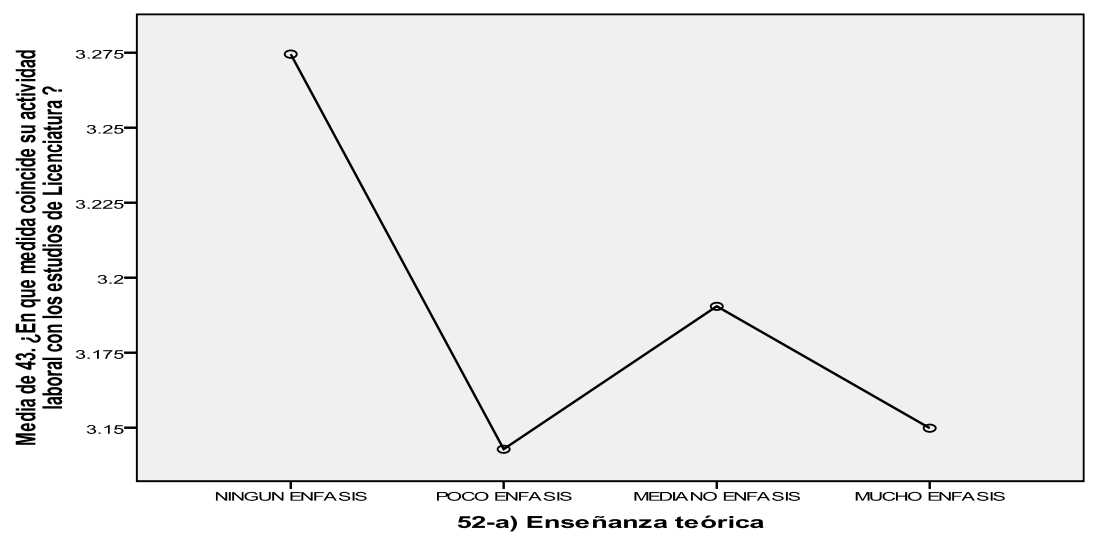

Figura 2. Actividad laboral vs. Enseñanza teórica.

El resultado del análisis utilizando el programa SPSS para el cálculo de la ANOVA para relacionar el énfasis en la necesidad de prácticas profesionales durante la carrera con la satisfacción del desarrollo de la profesión, muestra que para la licenciatura en medicina es muy importante realizar durante la carrera dichas prácticas, pues en gran medida de ello depende una buena inserción del profesionista en el campo laboral. La figura 3 muestra este resultado.

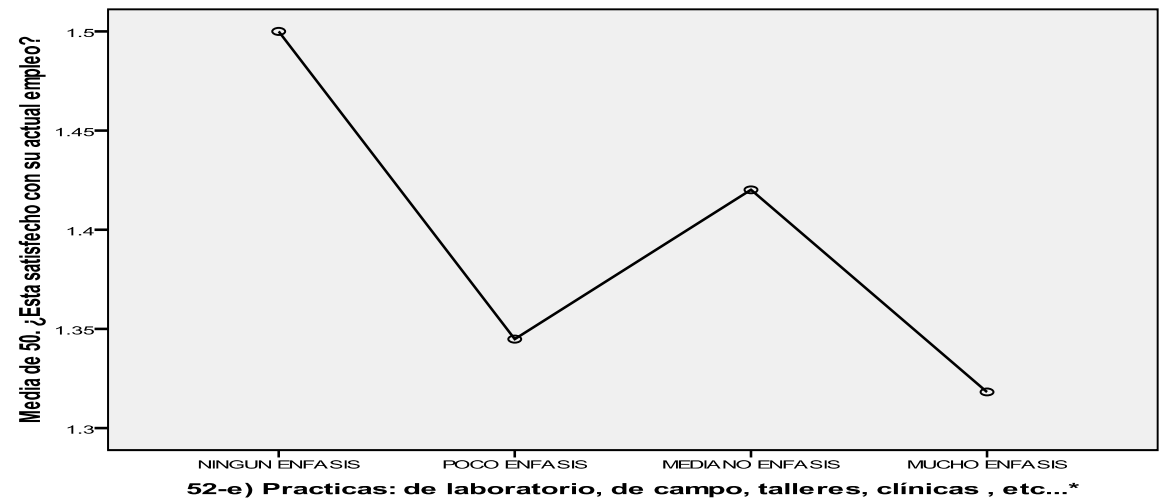

Figura 3. Satisfacción profesional vs. Práctica durante su formación.

El resultado que se muestra en la figura 4 es muy interesante, pues podemos observar que algunos egresados no están laborando en su área de formación, que puede ser resultado de la saturación del campo laboral o bien porque pudiera haber 
fallas importantes en el currículum de la profesión, cosa que desde nuestro punto de vista es poco probable.

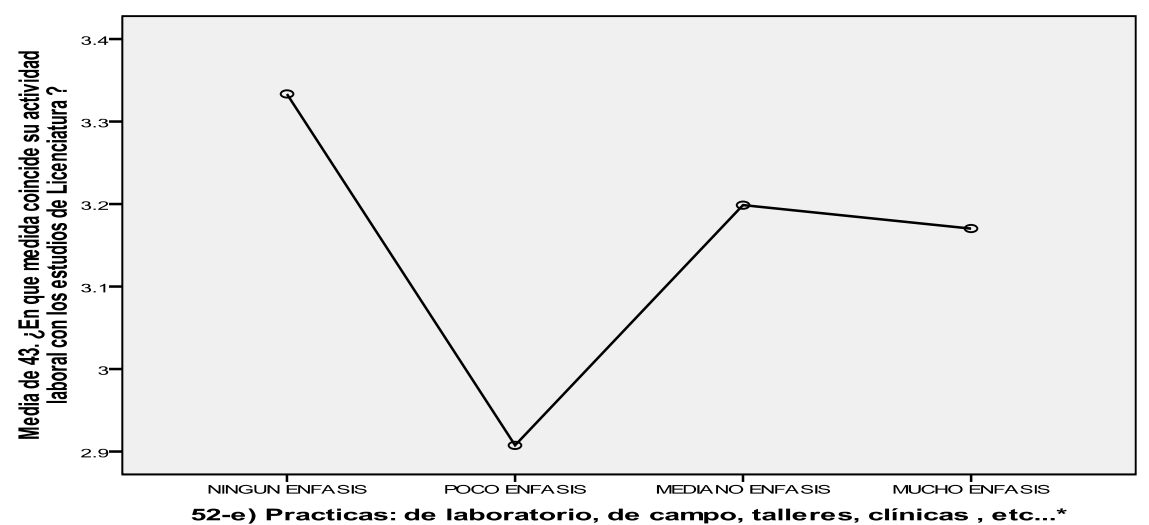

Figura 4. Coincidencia de actividad laboral vs. Estudios de licenciatura

Por último, es importante conocer si los egresados de la carrera de medicina de la BUAP, están satisfechos con la formación que les proporcionó esta institución o si consideran que los resultados serían diferentes si hubieran egresado de otra institución, este análisis se realizó también calculando la ANOVA, relacionando la satisfacción con la carrera y la institución, con los contenidos teóricos y prácticos, esto se muestra en la figura 5 .

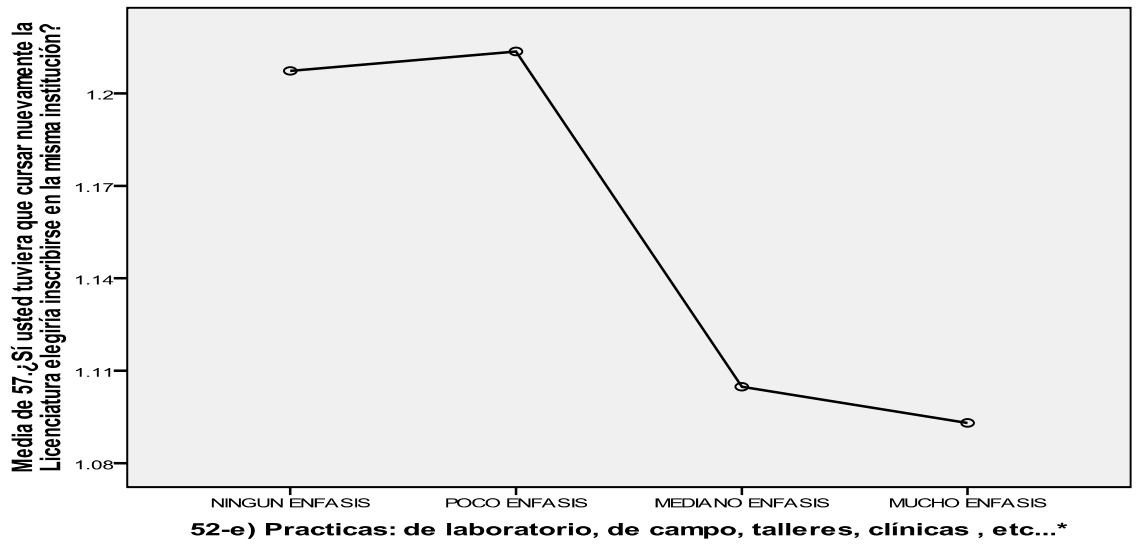




\section{Aportes y Conclusiones}

Esta investigación forma parte del trabajo que se realiza en el Nodo Institucional de Egresados de la BUAP, esta instancia empezó a trabajar de manera formal y coordinada a partir de 2007 , sin que ello signifique que antes no se realizaba trabajo al respecto, anteriormente se realizaban los estudios de egresados de manera desarticulada para cada programa de estudio, de acuerdo a criterios particulares, ahora el trabajo es coordinado bajo una sola metodología y medición de indicadores de acuerdo a las políticas institucionales.

El número de encuestados para esta investigación es pequeño si tomamos en cuenta todas las generaciones que conforman la población; sin embargo, contar con esta base de datos institucional ha implicado enormes esfuerzos de autoridades y cada uno de los integrantes del Nodo Institucional de Egresados.

Por otra parte es importante tomar en cuenta que los estudiantes de medicina no pueden ejercer su carrera mientras no obtengan el título, situación que de alguna manera afecta la práctica profesional fuera de la formación profesional generada por la institución. En estos resultados se puede apreciar que la población encuestada, reporta demora y dificultades para conseguir empleo al concluir sus estudios por diversos factores, destacando la falta de experiencia de práctica profesional suficiente previa a la inserción al mercado laboral, dificultando la obtención de un empleo en el área médica, además de otros factores que influyen en su inserción laboral, algunos factores se reportan en este trabajo y han servido para tener información a partir de los egresados, acerca de la importancia de implementar los campos clínicos como obligatorios para las nuevas generaciones, lo cual nos dará pie para generar una investigación sobre su impacto en los futuros egresados.

Autoridades y docentes debemos estar conscientes de la importancia que representa al momento de reestructurar los programas de estudio, tomando en cuenta estas evidencias para mejorar la formación integral de los estudiantes, ya que no basta egresar alguna cantidad importante de profesionales, si finalmente terminarán 
desarrollándose en algún empleo que no tiene nada que ver con su profesión. La sociedad no debe permitir que sigamos encontrando por ejemplo, profesionales de la medicina que terminan detrás de un mostrador, de una ventanilla de banco o ganándose la vida detrás de un volante en un vehículo de servicio público.

La competitividad que genera la globalización, exige egresados no sólo con conocimientos teóricos, se requiere desarrollar habilidades, aptitudes y actitudes que permitan que la institución educativa, cumpla con la pertinencia social. Reconocemos que en ésta temática hay mucho por trabajar y que incrementar, sistemáticamente los estudios de egresados son una alternativa para ocuparnos en la autoevaluación como práctica cotidiana en nuestro quehacer docente, pues en la medida en que lo logremos, estaremos refrendando el compromiso con la institución pero sobre todo el compromiso por lograr la calidad de la educación superior que nos requiere la población.

\section{Referencias}

Agüera Ibáñez, E., Vázquez López, J. \& Vries Meijer, W. (2005). Retos y perspectivas de la educación superior. México: Plaza y Valdéz editores.

ANUIES. (2006). Consolidación y avance de la educación superior en México. Elementos de Diagnóstico y propuestas. México: ANUIES.

ANUIES. (2003). Esquema Básico para Estudios de Egresados en Educación Superior. México: ANUIES.

Base Institucional de Egresados BUAP. Recuperado de https://facmed.buap.mx/egresados/?page=introduccion

Díaz Barriga, A., Barrón Tirado, C., \& Díaz Barriga Arceo, F. (2008). Impacto de la evaluación en la Educación Superior Mexicana. Un estudio en la universidades públicas estatales. México: UNAM, ANUIES, Plaza y Valdés Editores.

Didou, A. (1992). Los profesionistas Egresados de la UAEM y su zona de Primer Empleo. México: Centro de Estudios estratégicos UAEM.

Gago, H. (2002). Apuntes acerca de la Evaluación Educativa. México: Secretaría de Educación Pública.

Sánchez, D., Gutiérrez, G., Valdez, G., Sánchez, D. \& Reyna, C. (2010) Sistema de Información para el seguimiento de egresados de las maestrías del Instituto Tecnológico de Aguascalientes. (Versión electrónica), Conciencia Tecnológica, (40), 20-22.

Valenti Nigrini, G., Varela Petito, G., González Robles, R. O., \& Zurita Rivera, U. (1997). Los egresados de la UAM en el mercado de trabajo. México: Universidad Autónoma Metropolitana.

Valenti Nigrini, G. \& Varela Petito, G. (2003): Diagnóstico sobre el estado actual de los estudios de egresados. México: ANUIES. 


\section{ACERCA DE LOS COORDINADORES}

\section{DRA. ADLA JAIK DIPP}

La Dra. Adla Jaik Dipp cuenta con formación de Ingeniera en Tecnología de Alimentos por la Facultad de Ciencias Químicas de la Universidad Juárez del Estado de Durango. Tiene un Diplomado en Formación y actualización docente para un nuevo modelo educativo por el Instituto Politécnico Nacional. De igual forma es Maestra en Educación por el Centro de Estudios Superiores de Baja California y Doctora en Ciencias de la Educación por el Instituto Universitario Anglo Español.

Actualmente la Dra. Adla es Investigadora en el área educativa en el Instituto Politécnico Nacional CIIDIR Durango y Directora Académica de Posgrado en el Instituto Universitario Anglo Español. Asimismo es Integrante del Comité Editorial de la Revista Investigación Educativa Duranguense; de la Revista Estudios Clínicos e Investigación Psicológica (Campeche); y de la Revista Horizontes Pedagógicos (Colombia). De igual forma, es Coordinadora Editorial de la Revista Electrónica VISIÓN EDUCATIVA IUNAES y Coordinadora General del Programa Editorial de la Red Durango de Investigadores Educativos (ReDIE).

Recientemente coordinó el libro Experiencias de aplicación de las competencias en la educación y el mundo organizacional, con el Dr. Sergio Tobón. Su más reciente publicación es Competencias Investigativas: Una mirada a la Educación Superior.

\section{MTRO. SERGIO GERARDO MALAGA VILLEGAS}

El Mtro. Sergio Gerardo Malaga Villegas cuenta con formación de Licenciado en Educación Secundaria con especialidad en Telesecundaria por la Benemérita Escuela Normal Veracruzana "Enrique C. Rébsamen". Tiene un Diplomado en Elaboración de anteproyectos de investigación y otro en Educación basada en competencias, ambos por la Dirección de Educación Normal del estado de Veracruz; De igual forma es Maestro en Educación por la Universidad Pedagógica Veracruzana.

Actualmente el Mtro. Sergio Malaga estudia el Doctorado en Ciencias con especialidad en Investigaciones Educativas por el Departamento de Investigaciones Educativas del CINVESTAVIPN, tesis: Discursividad del significante interculturalidad en las Políticas de Educación Básica en México, de Ernesto Zedillo (1994-2000) a Vicente Fox (2000-2006).

Asímismo, es Profesor del Área de Posgrado de la Universidad Pedagógica Veracruzana y del Área de investigación de la Universidad Central de Veracruz. Es miembro permanente del Programa de Análisis Político de Discurso e Investigación Social en el DIE-CINVESTAV-IPN y la FFyL de la UNAM; de la International Association for Intercultural Education (IAIE) y la Society for Latin American Studies, UK (SLAS). 


\section{EVALUADORES DE LAS PROPUESTAS, PARA CAPÍTULO DE LIBRO, PRESENTADAS A LA CONVOCATORIA EMITIDA}

Los trabajos presentados en este libro, previa convocatoria, fueron seleccionados tras ser evaluados por pares mediante el procedimiento denominado "doble ciego".

En el proceso de evaluación participaron los siguientes investigadores:

- Isidro Barraza Soto

- Octavio González Vázquez

- Adla Jaik Dipp

- Sergio Gerardo Malaga Villegas

- Manuel de Jesús Mejía Carrillo

- Alejandra Méndez Zúñiga

- Heriberto Monárrez Vásquez

- Enrique Ortega Rocha

Se agradece a todos ellos el trabajo realizado y el profesionalismo mostrado en el proceso de valuación 